Serviço de Pus-Gradução EESC/USP

Data de entrada no Serviço:........................ EXEMPLAR REVISADO

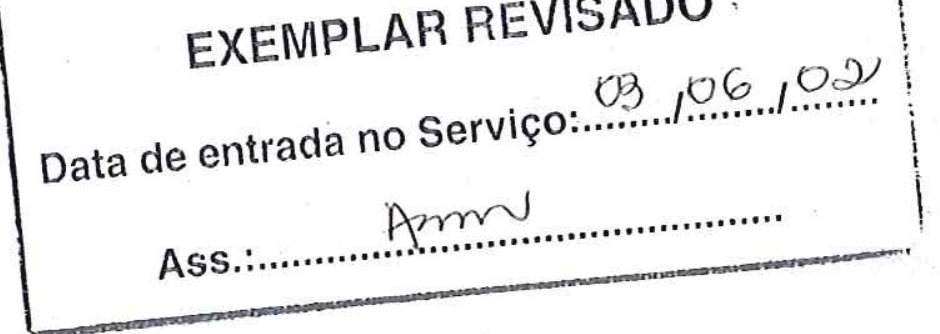

\title{
UM ESTUDO EXPERIMENTAL DA EBULIÇÃO CONVECTIVA DE REFRIGERANTES NO INTERIOR DE TUBOS LISOS E INTERNAMENTE RANHURADOS
}

\section{ENIO PEDONE BANDARRA FILHO}

Tese apresentada à Escola de Engenharia de São Carlos, da Universidade de São Paulo, como parte dos requisitos para obtenção do título de Doutor em Engenharia Mecânica

ORIENTADOR: Prof. Dr. José M. Saiz Jabardo

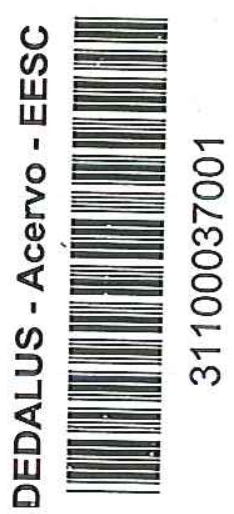

São Carlos

2002 
Bandarra Filho, Enio Pedone Um estudo experimental da ebulição convectiva de refrigerantes no interior de tubos lisos e internamente ranhurados / Enio Pedone Bandarra Filho. -- São Carlos, 2002.

Tese (Doutorado) -- Escola de Engenharia de São Carlos-Universidade de São Paulo, 2002.

Área: Engenharia Mecânica.

Orientador: Prof. Dr. José M. Saiz Jabardo.

1. Ebulição convectiva. 2. Transferência de calor. 3. Refrigerantes. 4. Intensificação. 5. Perda de carga. 6. Tubos microaletados. I. Título. 
Candidato: Engenheiro ENIO PEDONE BANDARRA FILHO

Tese defendida e julgada em 29-04-2002 perante a Comissão Julgadora:
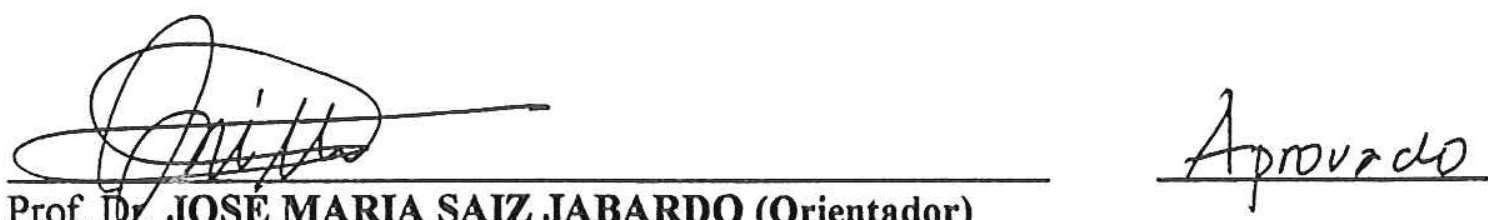

(Escola de Engenharia de São Carlos/USP)

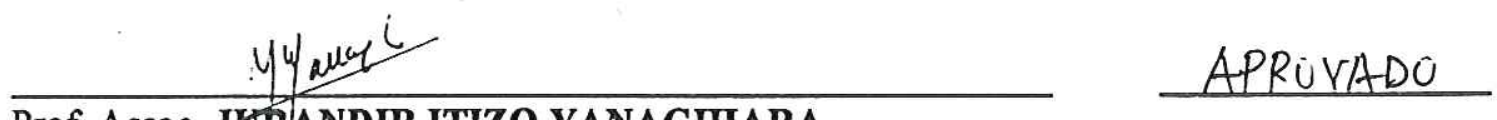

Prof. Assoc. JURANDIR ITIZO YANAGIHARA

(Escola Politécriica/USP)

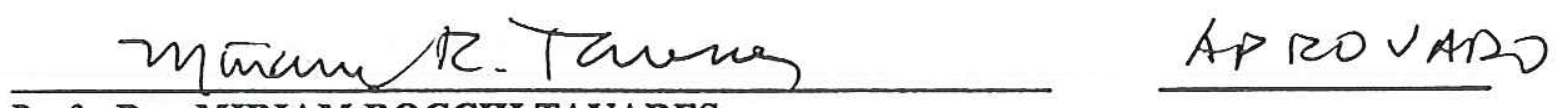

Profa. Dra. MIRIAM ROCCHI TAVARES

(Escola Politécnica/USP)

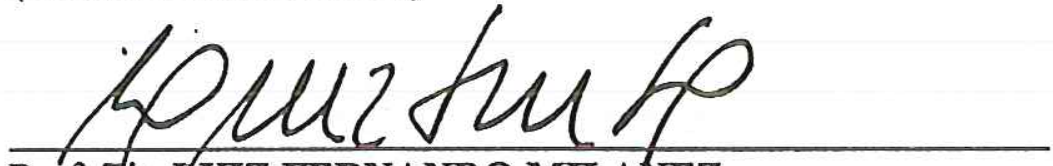

Prof. it. LUIZ FERNANDO MILANEZ

(Universidade Estadual de Campinas/JNICAMP)
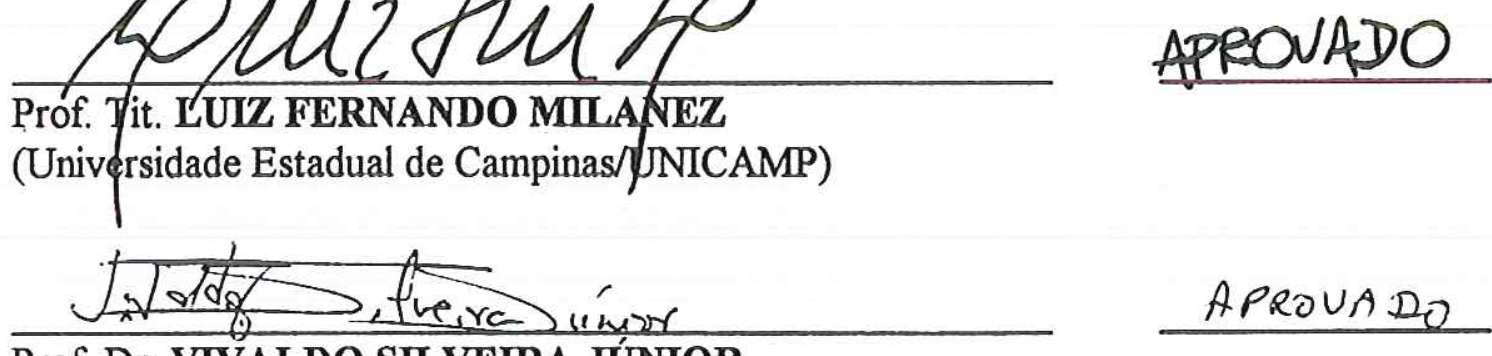

Prof. Dr. VIVALDO SILVEIRA JÚNIOR

(Universidade Estadual de Campinas/UNICAMP)

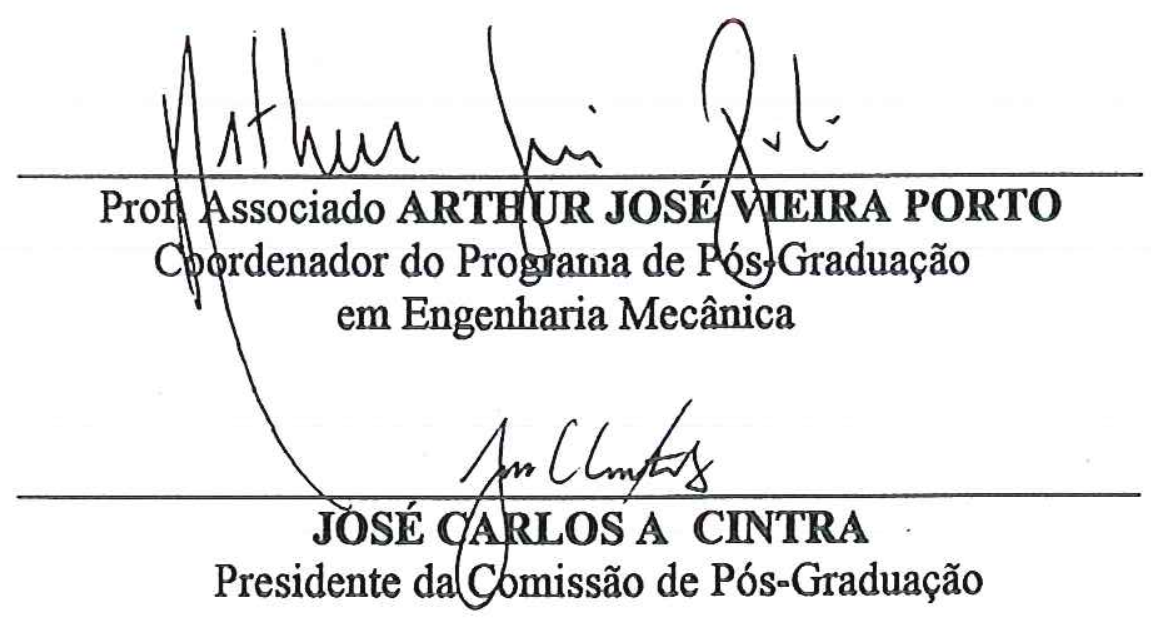


Dedico este trabalho a toda minha família, em especial as pessoas sempre presentes em minha vida, minha amada esposa Ana Cristina e meus filhos queridos Vítor e Vinícius. Não poderia esquecer dos incentivos permanentes e apoio constante de meus pais Enio e Sandra e meus sogros Moacyr e Wilma. 


\section{AGRADECIMENTOS}

Inicialmente, gostaria de expressar meu profundo agradecimento $\mathrm{e}$ reconhecimento ao Mestre e Amigo Prof. Jabardo pela sua excelente orientação e constante preocupação com a qualidade de ensino e formação pessoal. Reconheço, ainda, que jamais alcançaria este nível sem sua ilimitada paciência, inúmeras broncas e palavras de incentivo.

À Fundação de Amparo a Pesquisa do Estado de São Paulo, FAPESP, pela bolsa de estudos concedida, extensivo ao assessor do projeto pelos valiosos conselhos.

A meus irmãos Sílvio, Patrícia, Márcio e Paula, meus cunhados Ique, Paula, Ronaldo e Cláudia por seu apoio durante o desenvolvimento do trabalho.

Um agradecimento em especial ao Eng ${ }^{\circ}$. MSc. Paulo Eduardo Lopes Barbieri, pelo auxílio na correção da tese.

Um reconhecimento especial ao Técnico de Laboratório José Roberto Bogni pelo imprescindível auxílio na construção da bancada e pelo constante apoio durante a pesquisa, além é claro pela sua amizade.

Aos amigos do Laboratório de Refrigeração da EESC-USP, que estão presentes e aqueles que passaram, mas a amizade permanece sempre, Artur A. Jarhmann, Carlos U. da Silva Lima, Elton F. Higino de Cuba, Evandro F. da Silva, Gherhardt Ribatski, João R. Zoghbi Filho, Marcelo R. Ianella, Paulo E. L. Barbieri, Richard G. A Mello, Samuel F. de Barros, Elvio B. Stelute, Ricardo Masini, Rodrigo de Macedo.

Aos demais professores e funcionários da EESC-USP, pela formação e colaboração no trabalho e pelas horas de descontração.

Ao Sr. Edivaldo Cardoso, da Vidraria do Instituto de Física da EESC-USP, pelo fornecimento dos visores de vidro tipo "pirex", que possibilitaram a visualização e registro dos padrões de escoamento.

À empresa Termomecânica São Paulo S/A pela doação dos tubos microaletados para os ensaios.

À empresa DUPONT do Brasil S/A, em especial ao Eng ${ }^{\circ}$ José Antônio, pela doação dos fluidos refrigerantes utilizados nos ensaios. 


\section{SUMÁRIO}

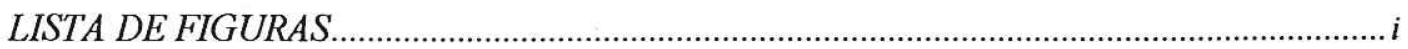

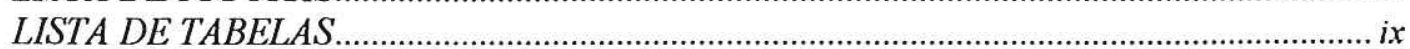

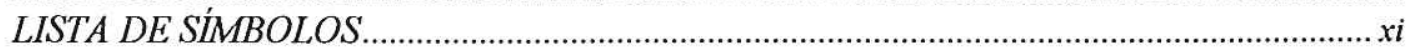

RESUMO

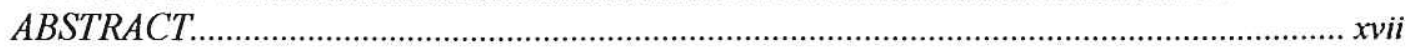

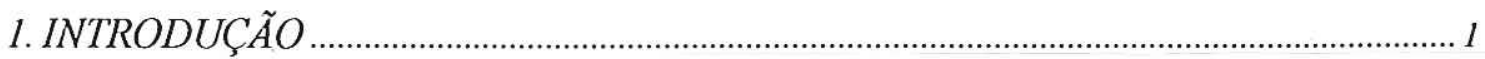

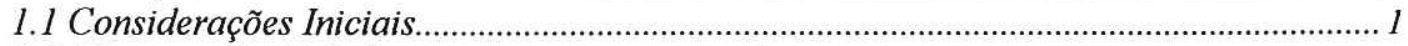

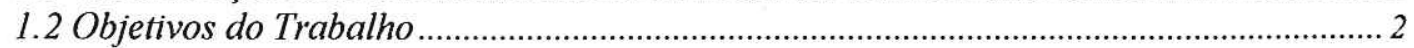

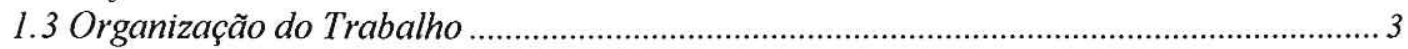

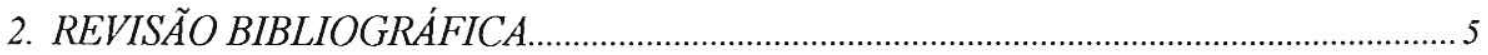

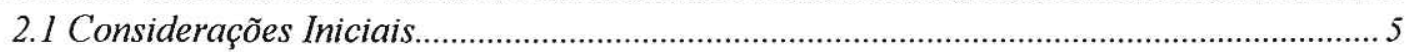

2.2 Padrões de Escoamento......................................................................................................... 5

2.2.1 Mapas de Padrões de Escoamento................................................................................. 8

2.3 Transferência de calor em Ebulição Convectiva ............................................................. 12

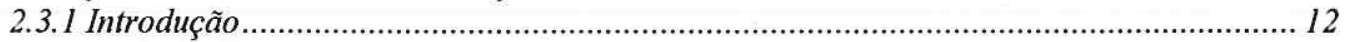

2.3.2 Correlações para o Coeficiente de Transferência de Calor............................................. 15

2.3.2.1 Correlações Estritamente Convectivas ............................................................. 16

2.3.2.1.1 Introdução à Analise das Correlações Estritamente Convectivas........ 16

2.3.2.1.2 Analise Comparativa das Correlações do Grupo 1............................ 25

2.3.2.2 Correlações Baseadas na Superposição dos Efeitos ......................................... 28

2.3.2.2.1 Analise Comparativa das Correlações do Grupo 2.............................41

2.3.2.3 Correlações Estritamente Empíricas ............................................................ 45

2.3.2.3.1 Analise Comparativa das Correlações do Grupo 3............................. 53

2.3.2.4 Comparação entre as Correlações dos Grupos 1, 2 e 3.................................... 55

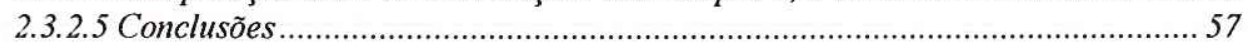

2.4 Intensificação da Transferência de Calor ...................................................................... 58

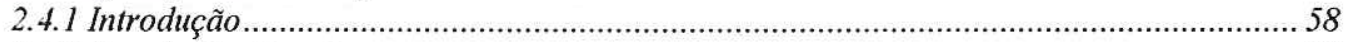

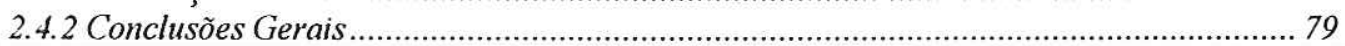

2.5 Transferência de Calor na Região de Secagem de Parede .................................................8 80

2.5.1 Conclusões ............................................................................................................... 93

3. ANÁLISE DE RESULTADOS EXPERIMENTAIS ……………………………………....95

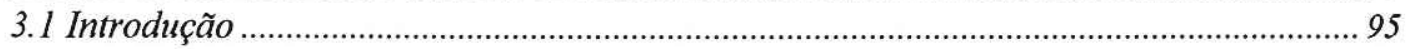

3.2 Levantamento na Literatura de Equipamentos Existentes ............................................. 95

3.3 Equipamento Experimental ....................................................................................... 98

3.3.1 Descrição do Equipamento Experimental ..................................................................... 98

3.3.1.1 Considerações Iniciais................................................................................... 98

3.3.1.2 Circuito Principal ou de Ensaios....................................................................... 98

3.3.1.3 Circuito de Solução Anti-Congelante ......................................................... 100

3.3.1.4 Resfriador de Liquido ........................................................................ 100

3.3.1.5 Água de Condensação................................................................................... 101

3.3.3 Seção de Testes............................................................................................................ 102

3.4 Metodologia de Ensaios .................................................................................................. 114

3.4.1 Preparação e Operação do Equipamento Experimental .............................................. 114

3.4.2Verificação dos Resultados ..................................................................................... 115

3.5 Tratamento dos Resultados Experimentais ...................................................................... 117

3.5.1 Avaliação do Título na Entrada e Saída da Seção de Testes........................................ 117

3.5.2 Determinação do Coeficiente de Transferência de Calor ............................................ 119 
3.5.3 Cálculo da Perda de Carga .............................................................................. 120

3. 6 Matriz de Experimentos.................................................................................................. 120

3. 7 Análise de Incertezas ............................................................................................. 122

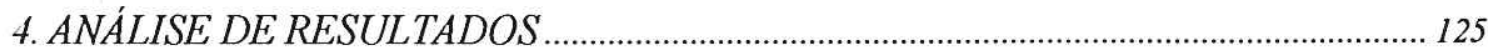

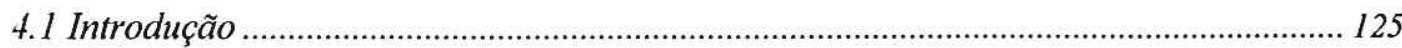

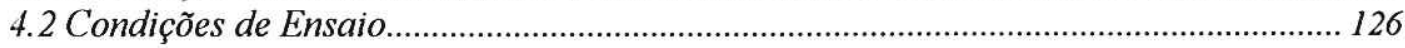

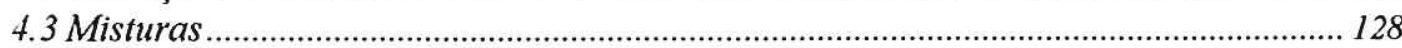

4.4 Escoamento Monofásico de Líquido................................................................................. 131

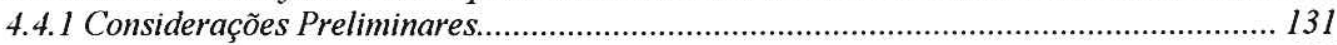

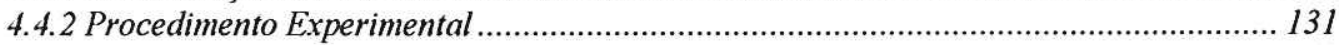

4.4.3 Resultados Experimentais - Escoamento Monofásico............................................... 132

4.5 Escoamento com Mudança de Fase (Ebulição Convectiva) .......................................... 143

4.5.1 Considerações Preliminares.................................................................................... 143

4.5.2 Procedimento Experimental - Mudança de Fase ....................................................... 143

4.5.3 Resultados Experimentais ............................................................................................. 144

4.5.3.1 Padrões de Escoamento em Tubos Horizontais........................................... 145

4.5.3.2 Transferência de Calor em Tubos Lisos....................................................... 153

4.5.3.2.1 Efeito da Velocidade Mássica ....................................................... 153

4.5.3.2.2 Efeito do Refrigerante.............................................................. 157

4.5.3.2.3 Efeito do Fluxo de Calor Especifico............................................... 161

4.5.3.2.4 Efeito da Temperatura de Evaporação............................................... 164

4.5.3.2.5 Efeito do Diâmetro do Tubo............................................................ 166

4.5.3.3 Perda de Carga em Tubos Lisos................................................................. 169

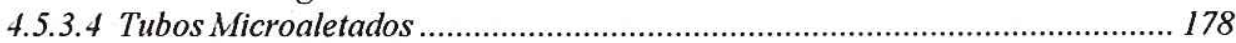

4.5.3.5 Perda de Carga em Tubos Microaletados...................................................... 186

4.5.3.6 Secagem de Parede ............................................................................... 192

5. CORRELAÇÃO DE RESULTADOS EXPERIMENTAIS ..................................................... 199

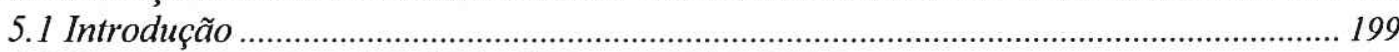

5.2 Correlação para a Perda de Carga em Tubos Lisos....................................................... 200

5.2.1 Correlação para Perda de Carga em Tubos Lisos para Vazões Elevadas..................... 202

5.2.2 Correlação para Perda de Carga em Tubos Lisos para Vazões Reduzidas ................... 204

5.3 Correlação para a Perda de Carga em Tubos Microaletados ...................................... 206

5. 4 Correlação para o Coeficiente de Transferência de Calor em Tubos Lisos................. 213

5.4.1 Comparação dos Resultados Experimentais para o Coeficiente de Transferência de Calor com as Principais Correlações ....................................................................... 213

5.4.2 Desenvolvimento de um Modelo para o Coeficiente de Transferência de Calor em Tubos Lisos para Vazões Elevadas $\left(G \geq 200 \mathrm{~kg} / \mathrm{s.m}^{2}\right)$............................................ 215

5.4.3 Desenvolvimento de um Modelo para o Coeficiente de Transferência de Calor em Tubos Lisos para Vazões Reduzidas $\left(G<200 \mathrm{~kg} / \mathrm{s} . \mathrm{m}^{2}\right)$............................................ 217

5.3 Correlação para o Coeficiente de Transferência de Calor em Tubos Microaletados 226

5.4 Sumário das Correlações Propostas ............................................................................. 228

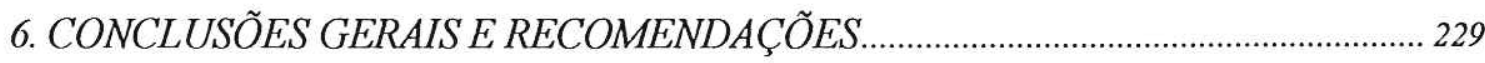

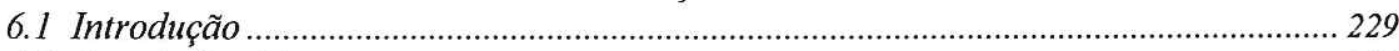

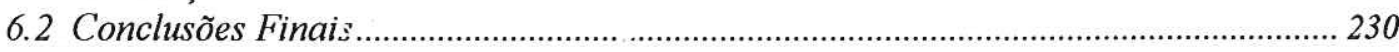

6.3 Recomendações a Trabalhos Futuros............................................................................. 233

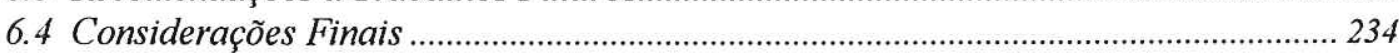

REFERÊECIAS BIBLIOGRÁFICAS ................................................................... 235

APÊEDICE I - Calibração dos Instrumentos ......................................................................... 248

APÊNDICE II - Fotos dos Padrões de Escoamento............................................................... 254 


\section{LISTA DE FIGURAS}

Figura 2.1 Padrões de escoamento em tubos horizontais. ........................................................... 6

Figura 2.2 Principais padrões de escoamento encontrados em evaporação......................................... 7

Figura 2.3 Mapa de padrão de escoamento proposto por BAKER (1954).........................................

Figura 2.4 Mapa de KATTAN et al (1998), para o $R-134 a, T_{\text {sat }}=4,4^{\circ} \mathrm{C}$ e $D_{i}=10,9 \mathrm{~mm} \ldots \ldots \ldots \ldots \ldots \ldots \ldots$

Figura 2.5 Comportamento típico do coeficiente de transferência de calor bifásico. ............................13

Figura 2.6 Efeito da velocidade mássica, $G$, no coeficiente de transferência de calor bifásico............... 14

Figura 2.7 Efeito do fluxo de calor, $\phi$, no coeficiente de transferência de calor bifásico........................ 15

Figura 2.8 Caracterização do padrão anular de escoamento no interior de um duto. 16

Figura 2.9 Comparação entre correlações estritamente convectivas para $R-134 a$, com $T_{\text {sat }}=-5^{\circ} \mathrm{C} e$ $G=300 \mathrm{~kg} / \mathrm{m}^{2} . \mathrm{s}$.

Figura 2.10 Comparação das correlações de Murata-Hashizume para tubos lisos e Microaletados. R$134 \mathrm{a}, \mathrm{com} T_{\mathrm{sat}}=5^{\circ} \mathrm{C}, \mathrm{G}=300 \mathrm{~kg} / \mathrm{m}^{2}$.s e $\phi=5 \mathrm{~kW} / \mathrm{m}^{2}$

Figura 2.11 Comparação dos coeficientes de transferência de calor das correlações do grupo 2, para as condições: $T_{\text {sat }}=-5^{\circ} \mathrm{C}, G=200 \mathrm{~kg} / \mathrm{m}^{2}$. s e $\phi=15 \mathrm{~kW} / \mathrm{m}^{2}$.

Figura 2.12 Gráfico para o cálculo do coeficiente de transferência de calor de SHAH (1976).

Figura 2.13 Comparação entre as correlações baseadas em banco de dados para R-134a com $T_{\text {sat }}=-5^{\circ} \mathrm{C}, G=200 \mathrm{~kg} / \mathrm{m}^{2} . \mathrm{s}$ e $\phi=15 \mathrm{~kW} / \mathrm{m}^{2}$

Figura 2.14 Comparação entre as correlações dos grupos 1,2 e 3 para $R-134$ a com $T_{\text {sat }}=-5^{\circ} \mathrm{C}$, $G=200 \mathrm{~kg} / \mathrm{m}^{2}$.s e $\phi=15 \mathrm{~kW} / \mathrm{m}^{2}$ superpostos os dados experimentais.

Figura 2.15 Representação esquemática e parâmetros geométricos de um tubo internamente ranhurado.

Figura 2.16 Ilustração das características geométricas de cada tubo descrito acima. REID et al. (1991).

Figura 2.17 Geometria dos tubos microaletados utilizados por ECKELS et al. (1992).

Figura 2.18 Comparação das correlações de Murata \& Hashizume para tubos lisos e microaletados para as condições: $R-134 a T_{\text {sat }}=5^{\circ} \mathrm{C}, G=100 \mathrm{~kg} / \mathrm{s} \cdot \mathrm{m}^{2}, \phi=5 \mathrm{~kW} / \mathrm{m}^{2}$ e $D=9,52 \mathrm{~mm}$.

Figura 2.19 Variação do ângulo de hélice pelo coeficiente de transferência de calor em tubos microaletados. ITO \& KIMURA (1979)..

Fïgura 2.20 Comparação do coeficiente de transferência de calor e perda de carga entre tubos lisos $e$ microaletados. WEBB (1994) 
Figura 2.21 Medida do coeficiente de transferência de calor em três posições do tubo, para tubos microaletado e liso. (a) para $G=100 \mathrm{~kg} / \mathrm{s}^{2} \mathrm{~m}^{2}$; (b) $G=300 \mathrm{~kg} / \mathrm{s.m} \mathrm{m}^{2}$. YOSHIDA et al. (1987).

Figura 2.22 Perfis dos tubos microaletados utilizados por MUZZIO et al. (1998)

Figura 2.23 Variação da temperatura com o comprimento da região de deficiencia de líquido. COLLIER \& THOME (1994)

Figura 2.24 Efeitos de suspensão e deposição de líquido. COLLIER \& THOME (1994).

Figura 2.25 Comportamento tipico do coeficiente de transferência de calor em função do título. LAVIN (1963)..

Figura 2.26 Variação do coeficiente com o título, medido no topo, na lateral e na aresta inferior do tubo. $R-22 \mathrm{com} G=570 \mathrm{~kg} / \mathrm{m}^{2} . \mathrm{s}$ e $\phi=18,7 \mathrm{~kW} / \mathrm{m}^{2}$. VARMA (1970).....

Figura 2.27 Comparação da variação do comprimento do tubo com o título. RHEE (1972)..

Figura 2.28 Configuração do tipo de tubo utilizado por BERTHOUD \& JAYANTI (1990)......

Figura 3.1 Diagrama esquemático do circuito experimental ou de ensaios

Figura 3.2 Esquema do circuito da solução anti-congelante : Etileno glicol/água.....

Figura 3.3 Representação esquemática do resfriador de líquido - "chiller" 101

Figura 3.4 Detalhe da seção de testes e localização dos termopares na seção de testes.

Figura 3.5 Detalhes da fixação dos termopares para a medida da temperatura da parede do tubo. 104

Figura 3.6 Fotografia ilustrando o eixo e as engrenagens da microbomba. (a) Teflon, (b) Ryton. 105

Figura 3.7 Fotografia ilustrando o primeiro pré-aquecedor do circuito

Figura 3.8 Fotografia ilustrando o segundo pré-aquecedor da bancada .

Figura 3.9 Esquema de instalação dos termopares blindados para a medida da temperatura do fluido (a) e do termopar para a determinação da temperatura da solução anti-congelante.

Figura 3.10 Exemplo da tela de aquisição de dados que foi utilizada no presente trabalho.

Figura 3.11 Resultados experimentais relacionando a potência elétrica, $Q_{S T}$, aplicada na seção de testes com a potência avaliada pelo balanço de energia, $Q_{B E}$, tubo liso de 9,52mmde diâmetro externo.

Figura 3.12 Comparação entre o coeficiente de transferência de calor avaliado experimentalmente $e$ aquele calculado pela correlação de Gnielinski. Tubo de cobre de 7,0 mm de diâmetro externo..... 117

Figura 3.13 Diagrama esquemático ilustrando como o título na saída do pré-aquecedor é detrminado através do balanço de energia.

Figura 3.14 Exemplo de uma Matriz de Experimentos para as seguintes condições: Tubo de latão, $T_{\text {Evap }}=5^{\circ} \mathrm{C}, \mathrm{R}-134 \mathrm{a}$ e fluxo de calor especifico de $5 \mathrm{~kW} / \mathrm{m}^{2}$

Figura 3.15 Exemplo de uma Matriz de Experimentos para o tubo de latão em escoamento monofásico de refrigerante $R-134 a$. 
Figura 4.1 Corte, representação esquemática e microfotografias - tubo microaletado.

Figura 4.2 Microfotografias e uma representação esquemática do tubo Duplo-V.

Figura 4.3 Diagramas de equilibrio: (a) misturas azeotrópicas e (b) não azeotrópicas, SAIZ JABARDO (2001).

Figura 4.4 Exemplo de banda de temperatura dos fluidos $R-404 A, R-410 A$ e $R-407 C$.

Figura 4.5 Comparação dos resultados experimentais com a correlação de Gnielinski (Eq. 4.1) para tubo liso de 7,0mm de diâmetro.

Figura 4.6 Comparação dos resultados experimentais com a correlação de Dittus-Boelter (Eq. 2.15) para tubo liso de $9,52 \mathrm{~mm}$ de diâmetro......

Figura 4.7 Resultados obtidos para o tubo liso de latão em função do grupo adimensional $\mathrm{NuPr}{ }^{0.4}$ superpostos com os dados para tubo liso de 9,52mm e a correlação de Dittus-Boelter, Eq. (2.15).......

Figura 4.8 Nusselt local obtido de soluções para o comprimento de entrada em tubos..

Figura 4.9 Comparação dos resultados experimentais para transferência de calor dos tubos da empresa Termomecânica (TM) de 7,93mm e 9,52mm de diâmetro, superpostos com os de Khanpara et al $(1987)\left(R-22, D_{i}=8,83 \mathrm{~mm}\right.$, dimensão da aleta $=0,22 \mathrm{~mm}$ e $\left.\beta=17^{\circ}\right)$..

Figura 4.10 Comparação dos resultados experimentais para transferência de calor em escoamento monofásico dos tubos Liso, Microaletado (TM) e Duplo-V de 9,52mm de diâmetro.

Figura 4.11 Comparação do h em escoamento monofásico dos refrigerantes $R-22$ e R134a para o tubo microaletado da empresa Furukawa. $D=9,52 \mathrm{~mm}, T_{\text {ent }}=-2,5^{\circ} \mathrm{C}$ e G variando entre 70 e 1270 $\mathrm{kg} / \mathrm{s} . \mathrm{m}^{2}$

Figura 4.12 Comparação do h para os tubos: liso, microaletado (TM) 82 ranhuras e microaletado (TMI) 76 ranhuras. $R-134 a, D=9,52 \mathrm{~mm}$ e $T_{\text {ent }}=-2,5^{\circ} \mathrm{C}$..

Figura 4.13 Comparação da perda de carga para os tubos: liso, microaletado (TM) 82 ranhuras $e$ microaletado (TM1) 76 ranhuras. $R-134 a$. $D=9,52 \mathrm{~mm}$ e $T_{\text {ent }}=-2,5^{\circ} \mathrm{C}$

Figura 4.14 Comparação da perda de carga em função da velocidade mássica, G, para os tubos: liso, microaletado (TM) e Duplo-V. R-134a, $T_{\text {ent }}=-2,5^{\circ} \mathrm{C}$ e $D=9,52 \mathrm{~mm}$.

Figura 4.15 Padrão de escoamento em Bolhas, obtido para as condições: $R 134 a, T_{E v a p}=8^{\circ} \mathrm{C}, \phi=5$ $\mathrm{kW} / \mathrm{m}^{2}, G=300 \mathrm{~kg} / \mathrm{s} . \mathrm{m}^{2}$ e $D=7,93 \mathrm{~mm}$.

Figura 4.16 Padrão de escoamento Pistonado, obtido para as condições: $R 134 a, T_{E \text { घap }}=5^{\circ} \mathrm{C}, \phi=5$ $\mathrm{kW} / \mathrm{m}^{2}, G=100 \mathrm{~kg} / \mathrm{s} . \mathrm{m}^{2}$ e $D=9,52 \mathrm{~mm}$.

Figura 4.17 Padrão de escoamento Intermitente (Slug), obtido para as condições: R134a, $T_{\text {Evap }}=5^{\circ} \mathrm{C}, \phi=5 \mathrm{~kW} / \mathrm{m}^{2}, G=200 \mathrm{~kg} / \mathrm{s} . \mathrm{m}^{2}$ e $\mathrm{D}=17,4 \mathrm{~mm}$..

Figura 4.18 Padrão de escoamento Anular, obtido para as condições: $R 134 a, T_{\text {Eюp }}=8^{\circ} \mathrm{C}, \phi=5$ $\mathrm{kW} / \mathrm{m}^{2}, G=300 \mathrm{~kg} / \mathrm{s}^{2} \mathrm{~m}^{2}$ e $D=17,4 \mathrm{~mm}$.

Figura 4.19 Padrão de escoamento Estratificado Liso, obtido para as condições: $R 134 a, T_{E v a p}=5^{\circ} \mathrm{C}$, $\phi=5 \mathrm{~kW} / \mathrm{m}^{2}, G=50 \mathrm{~kg} / \mathrm{s} . \mathrm{m}^{2}$ e $D=12,7 \mathrm{~mm}$. 
Figura 4.20 Padrão de escoamento Estratificado Ondulado, obtido para as condições: R134a, $T_{\text {Evap }}=5^{\circ} \mathrm{C}, \phi=5 \mathrm{~kW} / \mathrm{m}^{2}, \mathrm{G}=100 \mathrm{~kg} / \mathrm{s} . \mathrm{m}^{2}$ e $D=17,4 \mathrm{~mm}$.

Figura 4.21 Padrão de escoamento em Névoa, obtido para as condições: $R 134 a, T_{E ı p}=5^{\circ} \mathrm{C}, \phi=5$ $\mathrm{kW} / \mathrm{m}^{2}, G=500 \mathrm{~kg} / \mathrm{s} . \mathrm{m}^{2}$ e $D=9,52 \mathrm{~mm}$.

Figura 4.22 Figura ilustrado a Secagem da Parede, obtida para as condições: $R 134 a, T_{\text {Eıap }}=5^{\circ} \mathrm{C}$, $\phi=10 \mathrm{~kW} / \mathrm{m}^{2}, G=100 \mathrm{~kg} / \mathrm{s} . \mathrm{m}^{2}$ e $D=9,52 \mathrm{~mm}$.

Figura 4.23 Resultados experimentais inseridos no mapa de KATTAN et al (1998), obtidos para as condições: $R 134 a, T_{\text {Evap }}=5^{\circ} \mathrm{C}, \phi=5 \mathrm{~kW} / \mathrm{m}^{2}$ e $D=9,52 \mathrm{~mm}$..

Figura 4.24 Resultados experimentais inseridos no mapa de KATTAN et al (1998), obtidos para as condições: $R-134 a, T_{\text {Evap }}=5^{\circ} \mathrm{C}, \phi=5$ e $10 \mathrm{~kW} / \mathrm{m}^{2}$ e $D=17,4 \mathrm{~mm}$.

Figura 4.25 Mapa de padrão de escoamento válido para tubos microaletados.

Figura 4.26 Mapa de padrão de escoamento para tubos microaletados, incluindo os pontos experimentais obtidos no presente trabalho.

Figura 4.27 Resultados experimentais para o $R-22$ nas condições: $T_{E \unlhd a p}=15^{\circ} \mathrm{C}, \phi=5 \mathrm{~kW} / \mathrm{m}^{2}$ e $D=12,7 \mathrm{~mm}$.

Figura 4.28 Resultados experimentais para o $R-22$ nas condições: $T_{E v a p}=8^{\circ} \mathrm{C}, D=12,7 \mathrm{~mm}$ e $G=100$ $\mathrm{kg} / \mathrm{s} . \mathrm{m}^{2}$. (a) $\phi=5 \mathrm{~kW} / \mathrm{m}^{2}$ e (b) $\phi=20 \mathrm{~kW} / \mathrm{m}^{2}$.

Figura 4.29 Resultados experimentais para o $R-134$ a nas condições: $T_{E v a p}=5^{\circ} \mathrm{C}, \phi=5 \mathrm{~kW} / \mathrm{m}^{2} e$ $D=9,52 \mathrm{~mm}$.

Figura 4.30 Resultados experimentais para os fluidos $R-22, R-134 a, R-404 A$ e R-407C para as condições: $T_{\text {Evap }}=8^{\circ} \mathrm{C}, \phi=5 \mathrm{~kW} / \mathrm{m}^{2}, G=300 \mathrm{~kg} / \mathrm{s.m} \mathrm{m}^{2}$ e $D=12,7 \mathrm{~mm}$.

Figura 4.31 Resultados experimentais para os fluidos $R-22, R-134 a, R-404 A$ e R-407C para as condições: $T_{\text {Eup }}=8^{\circ} \mathrm{C}, \phi=5 \mathrm{~kW} / \mathrm{m}^{2}, G=200 \mathrm{~kg} / \mathrm{s.m} \mathrm{m}^{2}$ e $D=12,7 \mathrm{~mm}$.

Figura 4.32 Resultados experimentais para os fluidos $R-22$ e R-134a para as condições: $T_{E ı a p}=5^{\circ} \mathrm{C}, \phi$ entre 5 e $10 \mathrm{~kW} / \mathrm{m}^{2}, G=50 \mathrm{~kg} / \mathrm{s} . \mathrm{m}^{2}$ e $D=17,4 \mathrm{~mm}$.

Figura 4.33 Resultados experimentais para o R-407C nas condições: $T_{\text {Evap }}=8^{\circ} \mathrm{C}, G=200 \mathrm{~kg} / \mathrm{s} . \mathrm{m}^{2} e$ $D=12,7 \mathrm{~mm}$

Figura 4.34 Resultados experimentais para o R-134a nas condições: $T_{E v a p}=8^{\circ} \mathrm{C}, G=300 \mathrm{~kg} / \mathrm{s} \cdot \mathrm{m}^{2} e$ $D=12,7 \mathrm{~mm}$.

Figura 4.35 Resultados experimentais para o $R-22$ nas condiçães: $T_{E \unlhd a p}=5^{\circ} \mathrm{C}, G=50 \mathrm{~kg} / \mathrm{s} \cdot \mathrm{m}^{2} e$ $D=17,4 \mathrm{~mm}$.

Figura 4.36 Resultados experimentais para o R-22 nas condições: $\phi=5,10$ e $20 \mathrm{~kW} / \mathrm{m}^{2}$, $G=100 \mathrm{~kg} / \mathrm{s} . \mathrm{m}^{2}$ e $D=12,7 \mathrm{~mm}$.

Figura 4.37 Resultados experimentais para o $R-404 \mathrm{~A}$ nas condições: $\phi=5 \mathrm{~kW} / \mathrm{m}^{2}, G=300 \mathrm{~kg} / \mathrm{s} . \mathrm{m}^{2} e$ $D=12,7 \mathrm{~mm}$.

Figura 4.38 Resultados experimentais para o $R-134$ a nas condições: $\phi=5 \mathrm{~kW} / \mathrm{m}^{2}, G=300 \mathrm{~kg} / \mathrm{s} . \mathrm{m}^{2}$ e Diâmetro de 8,76, 10,92 e 12,7 $\mathrm{mm}$. 
Figura 4.39 Resultados experimentais para o $R-134$ a nas condições: $\phi=5 \mathrm{~kW} / \mathrm{m}^{2}, G=100 \mathrm{~kg} / \mathrm{s} . \mathrm{m}^{2} e$ Diâmetro de 7,2, e 17,4mm.

Figura 4.40 Multiplicador bifásico em função do parâmetro de Martinelli. Refrigerante: $404 \mathrm{~A}$. Temperatura de evaporação: $15^{\circ} \mathrm{C}$, diâmetro do tubo: $12,7 \mathrm{~mm}$.

Figura 4.41 Multiplicador bifásico em função do parâmetro de Martinelli. Refrigerante R-22. Escoamento adiabático na seção de testes, diâmetro interno de $12,7 \mathrm{~mm}$.

Figura 4.42 Multiplicador bifásico em função do parâmetro de Martinelli, para velocidades mássicas superiores a $100 \mathrm{~kg} / \mathrm{s} . \mathrm{m}^{2}$, diâmetro do tubo de $12,7 \mathrm{~mm}$..

Figura 4.43 Multiplicador bifásico em função do parâmetro de Martinelli, para velocidades mássicas inferiores a $100 \mathrm{~kg} / \mathrm{s} \cdot \mathrm{m}^{2}$, diâmetro do tubo de $12,7 \mathrm{~mm}$.

Figura 4.44 Perda de carga em função do título para diversas velocidades mássicas para escoamento em tubo liso de 8,76 de diâmetro interno.

Figura 4.45 Multiplicador bifásico em função do paràmetro de Martinelli. Tubo liso, refrigerante R$134 a$, temperatura de saturação: $5^{\circ} \mathrm{C}$; fluxo de calor variando entre 5 e $10 \mathrm{~kW} / \mathrm{m}^{2}$..

Figura 4.46 Multiplicador bifásico em função do parâmetro de Martinelli. Tubo liso, refrigerante R$134 a, D_{i}=8,76 \mathrm{~mm}$, escoamento adiabático.

Figura 4.47 Comparação do multiplicador bifásico em função do $X_{t t}$ para escoamento com troca de calor e adiabático. $G=100 \mathrm{~kg} /{\mathrm{s} . \mathrm{m}^{2}}_{\text {e }} D_{i}=8,76 \mathrm{~mm}$.

Figura 4.48 Comparação do multiplicador bifásico em função do $X_{t t}$ para escoamento com troca de calor e adiabático. $G=500 \mathrm{~kg} / \mathrm{s.m}^{2}$ e $D_{i}=8,76 \mathrm{~mm}$.

Figura 4.49 Variação do coeficiente de transferência de calor em função do título para tubos liso e ranhurado. $D_{e}=7,93 \mathrm{~mm}, T_{E v a p}=5^{\circ} \mathrm{C}, \phi=5 \mathrm{~kW} / \mathrm{m}^{2}$ e $G=130 \mathrm{~kg} / \mathrm{s} . \mathrm{m}^{2}$.

Figura 4.50 Variação do coeficiente de transferência de calor em função do título para tubos liso $e$ ranhurado. $D_{e}=9,52 \mathrm{~mm}, T_{\text {Evap }}=5^{\circ} \mathrm{C}, \phi=5 \mathrm{~kW} / \mathrm{m}^{2}$ e $G=100 \mathrm{~kg} / \mathrm{s} . \mathrm{m}^{2}$.

Figura 4.51 Variação do coeficiente de transferência de calor em função do título para tubos liso $e$ ranhurado. $D_{e}=9,52 \mathrm{~mm}, T_{E v a p}=5^{\circ} \mathrm{C}, \phi=5 \mathrm{~kW} / \mathrm{m}^{2}$ e $G=200 \mathrm{~kg} / \mathrm{s} . \mathrm{m}^{2}$.

Figura 4.52 Variação do coeficiente de transferência de calor em função do título para tubos liso $e$ ranhurado. $D_{e}=9,52 \mathrm{~mm}, T_{\text {Exap }}=5^{\circ} \mathrm{C}, \phi=5 \mathrm{~kW} / \mathrm{m}^{2}$ e $G=300 \mathrm{~kg} / \mathrm{s} . \mathrm{m}^{2}$.

Figura 4.53 Variação do coeficiente de transferência de calor em função do título para tubos liso e ranhurado ( 82 ranhuras), $T_{\text {Evap }}=5^{\circ} \mathrm{C}, \phi=5 \mathrm{~kW} / \mathrm{m}^{2}$ e $G=500 \mathrm{~kg} / \mathrm{s.m}$..

Figura 4.54 Variação do coeficiente de transferência de calor em função do título para tubos liso e ranhurado (76 ranhuras), $T_{\text {Eıap }}=5^{\circ} \mathrm{C}, \phi=5 \mathrm{~kW} / \mathrm{m}^{2}$ e $G=500 \mathrm{~kg} / \mathrm{s.m}$.

Figura 4.55 Variação do Fator de Intensificạ̣ão de transferência cle calor, $F_{b}$ em função do título para tubos liso e microaletado (TM) (82 ranhuras).

Figura 4.56 Variação do coeficiente de transferência de calor em função do título para tubos liso, microaletado e Duplo- $V, T_{\text {Evap }}=5^{\circ} \mathrm{C}, \phi=5 \mathrm{~kW} / \mathrm{m}^{2}$ e $G=100 \mathrm{~kg} / \mathrm{s} . \mathrm{m}^{2}$.

Figura 4.57 Variação do coeficiente de transferência de calor em função do título para tubos liso, microaletado e Duplo- $V, T_{\text {Evap }}=5^{\circ} \mathrm{C}, \phi=5 \mathrm{~kW} / \mathrm{m}^{2}$ e $G=200 \mathrm{~kg} / \mathrm{s} . \mathrm{m}^{2}$. 
Figura 4.58 Comparação da perda de carga em função do título entre os tubos: liso e microaletado (TM), com $T_{\text {Evap }}=5^{\circ} \mathrm{C}, \phi=5 \mathrm{~kW} / \mathrm{m}^{2}$ e $D_{e}=9,52 \mathrm{~mm}$.....

Figura 4.59 Variação da perda de carga em função do título para os seguintes tubos: liso, microaletado (TM) 82 ranhuras, microaletado (TM1) 76 ranhuras, microaletado (Trefi-Metaux.) e Duplo-V. Diâmetro externo dos tubos de $9,52 \mathrm{~mm}$, fluxo de calor de $5 \mathrm{~kW} / \mathrm{m}^{2}$ e $\mathrm{G}=500 \mathrm{~kg} / \mathrm{s} . \mathrm{m}^{2} \ldots 188$

Figura 4.60 Comparação do multiplicador bifásico em função do $X_{\text {tt }}$ para os tubos: liso $e$ microaletado. (a) $G=200 \mathrm{~kg} / \mathrm{s} \cdot \mathrm{m}^{2}$ e (b) $G=300 \mathrm{~kg} / \mathrm{s} \cdot \mathrm{m}^{2}$. $D=9,52 \mathrm{~mm}$

Figura 4.61 Variação do Fator de Intensificação Global, $F I_{G l o b a l}$ em função do titulo para o tubo microaletado (TM) (82 ranhuras).

Figura 4.62 Variação do Fator de Intensificação Global, $\mathrm{FI}_{\text {Global }}$ em função do título para o tubo Duplo- $V$.

Figura 4.63 Distribuição de temperatura superficial na seção de testes em função do tempo. Refrigerante R-134a; $T_{\text {Evap }}=6,2^{\circ} \mathrm{C} ; G=175 \mathrm{~kg} / \mathrm{s.m}^{2} ; \phi=25 \mathrm{~kW} / \mathrm{m}^{2}$.

Figura 4.64 Variação temporal da temperatura superficial nas arestas superior, lateral e inferior da seção 4 para as condições da Fig. 4.63..

Figura 4.65 Variação temporal da temperatura média superficial nas seções de medida do tubo de testes. $R-134 a ; T_{\text {Evap }}=6,5^{\circ} \mathrm{C} ; G=170 \mathrm{~kg} / \mathrm{s}^{2} \mathrm{~m}^{2} ; \phi=35 \mathrm{~kW} / \mathrm{m}^{2}$.

Figura 4.66 Distribuição da temperatura média da parede ao longo da seção de testes. R-22, $T_{\text {Evap }}=10^{\circ} \mathrm{C}$ e $\phi=5 \mathrm{~kW} / \mathrm{m}^{2}$.

Figura 4.67 Distribuição do coeficiente de transferência de calor ao longo da seção de testes. R-22, $T_{\text {Evap }}=10^{\circ} \mathrm{C}, G=130 \mathrm{~kg} / \mathrm{s} . \mathrm{m}^{2}$ e $\phi=5 \mathrm{~kW} / \mathrm{m}^{2}$

Figura 4.68 Variação do coeficiente de transferência de calor em função do fluxo específico de calor para o tubo microaletado TM de 9,52 $\mathrm{mm}$. Refrigerante $R-134 \mathrm{a} ; T_{\mathrm{sat}}=2,5^{\circ} \mathrm{C} ; G=100 \mathrm{~kg} / \mathrm{s.m} \mathrm{m}^{2} e$ $x_{e n t}=74 \%$.

Figura 5.1 Ilustração dos modelos Homogêneo e de Fases Separadas.

Figura 5.2 Resultados experimentais para tubos lisos do multiplicador bifásico em função do Parâmetro de Martinelli. R-134a, $T_{\text {Evap }}=5^{\circ} \mathrm{C}$ e G entre 25 e $500 \mathrm{~kg} / \mathrm{s.m}^{2}$.

Figura 5.3 Correlação dos resultados experimentais para tubos lisos. $R-134 a, T_{E v a p}=5^{\circ} \mathrm{C}$ e $G$ variando entre 200 e $500 \mathrm{~kg} / \mathrm{s.m}$...

Figura 5.4 Correlação dos resultados experimentais para tubos lisos para vazões reduzidas. $R-134 a$, $T_{\text {Evap }}=5^{\circ} \mathrm{C}$ e $G$ variando entre 25 e $100 \mathrm{~kg} / \mathrm{s}_{\mathrm{m}} \mathrm{m}^{2}$..

Figura 5.5 Correlação dos resultados experimentais para o tubo microaletado (TM) de 9,52mm diametro, $T_{\text {Evap }}=5^{\circ} \mathrm{C}$ e $G$ variando entre 100 e $500 \mathrm{~kg} / \mathrm{s.m}{ }^{2}$..

Figura 5.6 Comparação dos resultados experimentais para tubo Duplo-V com a correlação proposta, Eq. 5.5. $D=9,52 \mathrm{~mm}, R-134 \mathrm{a}, T_{\text {Evap }}=5^{\circ} \mathrm{C}$ e $G$ entre 100 e $500 \mathrm{~kg} / \mathrm{s} . \mathrm{m}^{2}$.

Figura 5.7 Comparação dos resultados experimentais envolvendo tubos microaletados de distintos diâmetros e geometrias com a correlação proposta, Eq. (5.6). $R-134 a, T_{\text {Evap }}=5^{\circ} \mathrm{C} e$ G entre $100 e$ $500 \mathrm{~kg} / \mathrm{s} . \mathrm{m}^{2}$. 
Figura 5.8 Comparação dos resultados de KATTAN (1996) para tubos microaletados com o modelo proposto, $R-134 \mathrm{a}, D_{i}=11,9 \mathrm{~mm}, T_{E v a p}=3,8^{\circ} \mathrm{Ce} \phi$ entre 4 e $14 \mathrm{~kW} / \mathrm{m}^{2}$

Figura 5.9 Comparação dos resultados de CHIOU et al (1999) para tubos microaletados com a correlação proposta, $R-134 \mathrm{a}, D_{i}=8,9 \mathrm{~mm}, T_{\text {Evap }}=5^{\circ} \mathrm{C}$ e $P_{\text {sat }}=350 \mathrm{kPa}$...

Figura 5.10 Comparação dos resultados de CHIOU et al (1999) para tubos microaletados com a correlação proposta, $R-22, D_{i}=8,9 \mathrm{~mm}, T_{\text {Eıap }}=5^{\circ} \mathrm{C}$ e $P_{\text {sat }}=585 \mathrm{kPa}$.

Figura 5.11 Comparação da correlação proposta, Eq. (5.9) com resultados experimentais. Condições: $R-134$ a e R-22, $T_{E v a p}$ variando entre 5 e $15^{\circ} \mathrm{C}$, G entre 200 e $500 \mathrm{~kg} / \mathrm{s.m} \mathrm{m}^{2}$, $\phi$ entre 5 e $20 \mathrm{~kW} / \mathrm{m}^{2}$ e $D_{i}$ entre 6,24 e $17,4 \mathrm{~mm}$.

Figura 5.12 Comparação da correlação proposta, Eq. (5.10) com resultados experimentais.

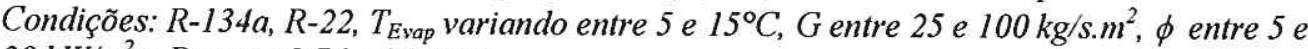
$20 \mathrm{~kW} / \mathrm{m}^{2}$ e $D_{i}$ entre 8,76 e $17,4 \mathrm{~mm}$.

Figura 5.13 Comparação dos resultados experimentais com as correlações de Jung-Radermacher, Wattelet e Kandlikar, superposta a correlação proposta, Eq. (5.10). R-134a com $T_{E v a p}=5^{\circ} C$, $G=50 \mathrm{~kg} / \mathrm{s} . \mathrm{m}^{2}, \phi=5 \mathrm{~kW} / \mathrm{m}^{2}$ e $D_{i}=17,4 \mathrm{~mm}$.

Figura 5.14 Comparação dos resultados experimentais com as correlações de Jung-Radermacher, Wattelet e Kandlikar, superposta a correlação proposta, Eq. (5.10). R-134a com $T_{E v a p}=5^{\circ} \mathrm{C}$, $G=25 \mathrm{~kg} / \mathrm{s} \cdot \mathrm{m}^{2}, \phi=10 \mathrm{~kW} / \mathrm{m}^{2}$ e $D_{i}=17,4 \mathrm{~mm}$.

Figura 5.15 Comparação dos resultados experimentais com as correlações de Jung-Radermacher, Wattelet e Kandlikar, superposta a correlação proposta, Eq. (5.10). R-22 com $T_{\text {Evap }}=5^{\circ} \mathrm{C}$, $G=50 \mathrm{~kg} / \mathrm{s} \cdot \mathrm{m}^{2}, \phi=10 \mathrm{~kW} / \mathrm{m}^{2}$ e $D_{i}=17,4 \mathrm{~mm}$.

Figura 5.16 Comparação dos resultados experimentais com as correlações de Jung-Radermacher, Wattelet e Kandlikar, superposta a correlação proposta, Eq. (5.10). R-22 com $T_{E v a p}=5^{\circ} \mathrm{C}$, $G=100 \mathrm{~kg} / \mathrm{s} . \mathrm{m}^{2}, \phi=5 \mathrm{~kW} / \mathrm{m}^{2}$ e $D_{i}=17,4 \mathrm{~mm}$.

Figura 5.17 Comparação dos resultados experimentais de KATTAN (1996) com a correlação proposta e as correlações de Jung-Radermacher, Wattelet e Kandlikar, Eq. (5.10). Condições: $R-134 \mathrm{a}$ com $T_{\text {Evap }}=10^{\circ} \mathrm{C}, \mathrm{G}=100 \mathrm{~kg} / \mathrm{s} \cdot \mathrm{m}^{2}$, $\phi$ entre 4 e $6 \mathrm{~kW} / \mathrm{m}^{2}$ e $D_{i}=10,9 \mathrm{~mm}$.

Figura 5.18 Comparação dos resultados experimentais de KATTAN (1996) com a correlação proposta e as correlações de Jung-Radermacher, Wattelet e Kandlikar, Eq. (5.10). Condições: $R-134 \mathrm{a}$ com $T_{E v p}=10^{\circ} \mathrm{C}, G=100 \mathrm{~kg} / \mathrm{s} . \mathrm{m}^{2}, \phi$ entre 6 e $8 \mathrm{~kW} / \mathrm{m}^{2}$ e $D_{i}=10,9 \mathrm{~mm} .$.

Figura 5.19 Comparação dos resultados experimentais obtidos experimentalmente com o calculado pela correlação proposta no presente estudo. Condições: $R-134 a, T_{E v a p}=5^{\circ} \mathrm{C}, \mathrm{G}$ variando entre 100 e $500 \mathrm{~kg} / \mathrm{s} . \mathrm{m}^{2}$, $\phi$ entre 5 e $10 \mathrm{~kW} / \mathrm{m}^{2}$ e $D_{i}$ entre 6,4 e $8,96 \mathrm{~mm}$.

Figura AI.1 Curva de calibração dos termopares

Figura AI.2 Curva de calibração dos transdutores de pressão

Figura AI.3 Curva de calibração do transdutor diferencial de pressão.

Figura AI.4 Curva de calibração do medidor de vazão

Figura AII.1 Padrão de escoamento em Ondulado. Detalhe de uma onda sendo rompida pelo vapor.

$R-134$ a e $D_{i}=17,4 \mathrm{~mm}$. 
Figura AII.2 Padrão de escoamento Ondulado. Detalhe de uma onda sendo rompida pelo vapor na entrada do visor. $R-134$ a e $D_{i}=17,4 m m$.

Figura AII.3 Padrão de escoamento Ondulado. $R 134$ a e $D_{i}=12,7 \mathrm{~mm}$.

Figura AII. 4 Padrão de escoamento Anular. R134a e $D_{i}=8,76 \mathrm{~mm}$.

Figura AII.5 Padrão de escoamento Intermitente. Detalhe do rompimento de uma onda de grande amplitude. R134a e $D_{i}=12,7 \mathrm{~mm}$..

Figura AII.6 Padrão de escoamento Estratificado Ondulado. Detalhe de um pistão de líquido: $R 134 a$ e $D_{i}=8,76 \mathrm{~mm}$.

Figura AII. 7 Padrão de escoamento Intermitente, ilustrando uma onda de grande amplitude. RI34a e $D_{i}=12,7 \mathrm{~mm}$.

Figura AII.8 Padrão de escoamento Intermitente, ilustrando uma onda de grande amplitude. R134a e $D_{i}=17,4 \mathrm{~mm}$.

Figura AII.9 Padrão de escoamento Intermitente, ilustrando uma onda de grande amplitude na entrada do visor. R134a e $D_{i}=17,4 \mathrm{~mm}$.

Figura AII.10 Padrão de escoamento Intermitente, ilustrando o momento que uma onda de grande amplitude atinge a região superior do tubo. $R 134$ a e $D_{i}=17,4 \mathrm{~mm}$.

Figura AII.11 Padrão de escoamento Ondulado, ilustrando as instabilidades hidrodinâmicas do escoamento. R134a e $D_{i}=17,4 \mathrm{~mm}$.

Figura AII.12 Padrão de escoamento Ondulado, ilustrando o momento da passagem de um pistão de liquido. R134a e $D_{i}=17,4 \mathrm{~mm}$.

Figura AII.13 Padrão de escoamento Anular, com a espessura do filme de líquido maior na região inferior do tubo. R134a e $D_{i}=17,4 \mathrm{~mm}$.

Figura AII.14 Padrão de escoamento Intermitente, ilustrando as instabilidades hidrodinâmicas do escoamento. R134a e $D_{i}=17,4 \mathrm{~mm}$.

Figura AII.15 Transição do padrão em Bolhas para o Pistonado. R134a e $D_{i}=12,7 \mathrm{~mm}$.

Figura AII.16 Padrão de escoamento Ondulado, Detalhe do rompimento de uma onda de grande amplitude. R134a e $D_{i}=12,7 \mathrm{~mm}$.

Figura AII.17 Padrão de escoamento Anular, com a espessura do filme de líquido maior na região inferior do tubo. R134a e $D_{i}=12,7 \mathrm{~mm}$.

Figura AII.18 Padrão de escoamento Anular, com menor espessura do filme de líquido que a Fig. AII.17. R134a e $D_{i}=12,7 \mathrm{~mm}$.

Figura AII.19 Transição do padrão de escoamento Anular para Névoa. Detalhe da espessura do filme de liquido a região inferior du tubo. $R 134$ a e $D_{i}=1 \ddot{2}, 7 \mathrm{~mm}$ 


\section{LISTA DE TABELAS}

Tabela 2.1 Sumário das correlações estritamente convectivas......................................................... 26

Tabela 2.2 Exemplos da aplicação do modelo assintótico, com n=2,5....................................... 42

Tabela 2.3 Sumário das correlações baseadas na superposição de efeitos........................................... 43

Tabela 2.4 Valores das constantes para ebulição convectiva e nucleada. .......................................... 50

Tabela 2.5 Valores de $F f_{L}$ para distintos fluidos......................................................................... 51

Tabela 2.6 Sumário das correlações baseadas em banco de dados................................................. 54

Tabela 2.7 Pesquisas envolvendo a intensificação da transferência de calor em tubos microaletados. SCHLAGER et al. (1988)............................................................................................. 61

Tabela 2.8 Parâmetros geométricos de tubos lisos e com aletamento interno. SCHLAGER (1988)......... 62

Tabela 2.9 Características geométricas dos tubos ensaiados. REID et al. (1991)..............................63

Tabela 2.10 Valores das constantes para ebulição convectiva e nucleada.. ...................................... 72

Tabela 2.11 Desvio médio da correlação de KANDLIKAR \& RAYKOFF (1997) com os dados experimentais de diversos autores incluindo os valores de $F_{E C}, F_{E N}$ e n.................................... 73

Tabela 2.12 Parâmetros geométricos dos tubos ensaiados por MUZZIO et al (1998)......................... 74

Tabela 2.13 Sumário dos estudos relacionados no presente trabalho ............................................... 76

Tabela 2.14 Relação de algumas das geometrias de microaleta mais representativas......................... 78

Tabela 3.1 Relação de trabalhos envolvendo levantamentos experimentais da Ebulição Convectiva e suas principais características. ......................................................................................... 97

Tabela 3.2 Precisão e incertezas dos distintos parâmetros envolvidos nos ensaios............................ 123

Tabela 4.1 Caracteristicas geométricas dos tubos utilizados no presente trabalho........................... 127

Tabela 4.2 Variação dos principais parâmetros fisicos utilizados no presente trabalho...................... 128

Tabela 4.3 Sumário dos fluidos refrigerantes ensaiados no presente trabalho................................. 130

Tabela 4.4 Propriedades de transporte dos refrigerantes à temperatura de saturação de $5^{\circ} \mathrm{C}$.............. 158

Tabela 4.5 Resistência térmica do filme de liquido de refrigerantes para o padrão anular.................... 158

Tabela 5.1 Desvio médio absoluto e relativo proporcionados pelas correlações em relação aos resultados experimentais. $R-134 \mathrm{a}, R-22, T_{\text {Evap }}$ variando entre 5 e $15^{\circ} \mathrm{C}$, G entre 25 e $500 \mathrm{~kg} / \mathrm{s} . \mathrm{m}^{2}$, фentre 5 e $20 \mathrm{~kW} / \mathrm{m}^{2}$ e $D_{i}$ entre 6,24 e $17,4 \mathrm{~mm}$.. 
Tabela 5.2 Desvio médio absoluto e relativo proporcionado pela correlação (5.9) em relação aos resultados experimentais. $R-134$ a e $R-22, T_{\text {Evap }}$ variando entre 5 e $15^{\circ} \mathrm{C}$, G entre 25 e 500 $\mathrm{kg} / \mathrm{s} \cdot \mathrm{m}^{2}, \phi$ entre 5 e $20 \mathrm{~kW} / \mathrm{m}^{2}$ e $D_{i}$ entre 6,24 e $17,4 \mathrm{~mm}$.

Tabela 5.3 Desvio médio absoluto e relativo proporcionado pela correlação (5.10) em relação aos resultados experimentais. $R-134 a, R-22, T_{E \rightsquigarrow p}$ variando entre 5 e $15^{\circ} \mathrm{C}$, G entre 25 e $100 \mathrm{~kg} / \mathrm{s} \cdot \mathrm{m}^{2}$, $\phi$ entre 5 e $20 \mathrm{~kW} / \mathrm{m}^{2}$ e $D_{i}$ entre 8,76 e $17,4 \mathrm{~mm}$.......

Tabela 5.4 Desvio médio absoluto e relativo proporcionados pelas correlações em relação aos resultados experimentais. $R-134 a, T_{E v a p}=5^{\circ} \mathrm{C}$, G variando entre 100 e $500 \mathrm{~kg} / \mathrm{s} \cdot \mathrm{m}^{2}$, $\phi$ entre 5 e $10 \mathrm{~kW} / \mathrm{m}^{2}$ e $D_{i}$ entre 6,4 e $8,96 \mathrm{~mm}$.

Tabela 5.5 Sumário das correlações propostas no presente trabalho.

Tabela AI.1 Dados medidos pelos termopares e termômetro de precisão.

Tabela AI.2 Dados medidos pelos transdutores de pressão e multimetro.

Tabela AI.3 Dados medidos pelo transdutor diferencial de pressão e multimetro...

Tabela AI.4 Dados medidos pelo medidor de Vazão e o erro proporcionado 


\section{LISTA DE SIMBOLOS}

A $\rightarrow$ Área. $\left(\mathrm{m}^{2}\right)$

$\mathrm{C} \rightarrow$ Constante.

cp $\rightarrow$ Calor específico. $\left(\mathrm{J} / \mathrm{kg} .{ }^{\circ} \mathrm{C}\right)$

$\mathrm{C}_{f} \rightarrow$ Coeficiente de atrito tipo Fanning.

D $\rightarrow$ Diâmetro. (m)

$\mathrm{D}_{\mathrm{b}} \rightarrow$ Diâmetro da bolha. (m)

$\mathrm{e} \rightarrow$ Espessura da ranhura do tubo. (mm)

$\mathrm{E} \rightarrow$ Desvio médio.

$f \rightarrow$ Coeficiente de atrito de Darcy.

F $\rightarrow$ Fator intensificador de convecção.

$\mathbf{F I}_{\mathbf{h}} \rightarrow$ Fator de intensificador da transferência de calor.

$\mathrm{FI}_{\text {Global }} \rightarrow$ Fator de intensificador global.

$\mathrm{F} f_{\mathrm{L}} \rightarrow$ Valor tabelado para refrigerantes da correlação de Kandlikar.

$\mathrm{G} \rightarrow$ Velocidade mássica. $\left(\mathrm{kg} / \mathrm{s} \cdot \mathrm{m}^{2}\right)$

$\mathrm{g} \rightarrow$ Constante gravitacional. $\left(9,81 \mathrm{~m} / \mathrm{s}^{2}\right)$

$\mathrm{h} \rightarrow$ Coeficiente de transferência de Calor local. $\left(\mathrm{W} / \mathrm{m}^{2}{ }^{\circ} \mathrm{C}\right)$.

$\mathrm{i} \rightarrow$ Entalpia de evaporação. (J/kg)

$j_{H} \rightarrow$ Fator de Colburn para transferência de calor.

$\mathrm{k} \rightarrow$ Condutividade térmica. $\left(\mathrm{W} / \mathrm{m} .{ }^{\circ} \mathrm{C}\right)$

$\mathrm{K} \rightarrow$ Constante.

$\mathrm{L} \rightarrow$ Comprimento. (m)

$\dot{m} \rightarrow$ Vazão mássica. $(\mathrm{kg} / \mathrm{s})$

$\mathrm{M} \rightarrow$ Massa molecular. (kg/kmol); Expoente de equação.

$\mathrm{n} \rightarrow$ número de rarthuras do tubo.

$\mathrm{N} \rightarrow$ Fator especificado por SHAH (1982).; Expoente de equação.

$P \rightarrow$ Pressão. $\left(\mathrm{N} / \mathrm{m}^{2}\right)$

Q $\rightarrow$ Potência Elétrica. (W)

$\mathbf{R} \rightarrow$ Parâmetro de redução, função do número de Froude. 
$\mathbf{R a} \rightarrow$ Rugosidade aritmética. (m)

$\mathrm{S} \rightarrow$ Fator de supressão de bolhas.

$\mathrm{t} \rightarrow$ Altura da ranhura do tubo. (mm)

$\mathrm{T} \rightarrow$ Temperatura. $\left({ }^{\circ} \mathrm{C}\right)$

$\mathrm{V} \rightarrow$ Velocidade. $(\mathrm{m} / \mathrm{s})$

X $\rightarrow$ Parâmetro de Martinelli.

$\mathbf{X}_{\mathbf{t t}} \rightarrow$ Parâmetro de Martinelli, fases turbulento, turbulento.

$\mathbf{X}_{\mathrm{T}} \rightarrow$ Comprimento de entrada térmico.

$\mathrm{x} \rightarrow$ Título.

$\mathrm{z} \rightarrow$ Coordenada axial do tubo. (m)

\section{Números Adimensionais}

Bo $\rightarrow$ Número de ebulição.

$B o=\frac{\phi}{G \cdot i_{L V}}$

Bj $\rightarrow$ Número adimensional.

$B j=\frac{\phi \cdot D}{k_{L} \cdot T_{\text {sat }}}$

Co $\rightarrow$ Número de convecção.

Co $=\left(\frac{1-x}{x}\right)^{0,8} \cdot\left(\frac{\rho_{L}}{\rho_{V}}\right)^{0,5}$

Fr $\rightarrow$ Número de Froude.

$F r=\frac{G^{2}}{\rho_{L}^{2} \cdot g \cdot D}$

$\mathrm{Fr}_{\mathrm{L}} \rightarrow$ Número de Froude Local.

$F r_{L}=\frac{G^{2} \cdot(1-x)^{2}}{\rho_{L}{ }^{2} \cdot g \cdot D}$

$\mathbf{K}_{f} \rightarrow$ Adimensional de Pierre.

$K f=\frac{\Delta x \cdot i_{L V}}{L \cdot g}$

$\mathrm{Nu} \rightarrow$ Número de Nusselt.

$N u_{D}=\frac{h \cdot D}{k}$

Pr $\rightarrow$ Número de Prandtl.

$\operatorname{Pr}=\frac{c p \cdot \mu}{k}$

$\operatorname{Pr}_{\mathrm{L}} \rightarrow$ Número de Prandtl, fase líquida.

$\operatorname{Pr}_{L}=\frac{c p_{L} \cdot \mu_{L}}{k_{L}}$

Re $\rightarrow$ Número de Reynolds.

$\operatorname{Re}_{D}=\frac{G \cdot D}{\mu_{L}}$ 


$$
\begin{array}{ll}
\mathbf{R e}_{\mathbf{L}} \rightarrow \text { Número de Reynolds, fase líquida. } & \operatorname{Re}_{L}=\frac{G \cdot(1-x) \cdot D}{\mu_{L}} \\
\mathbf{R e}_{\mathrm{LO}} \rightarrow \text { Número de Reynolds. } & \operatorname{Re}_{L O}=\frac{G \cdot D}{\mu_{L}} \\
\mathbf{R e}_{\mathbf{V}} \rightarrow \text { Número de Reynolds. } & \operatorname{Re}_{V}=\frac{G \cdot(x) \cdot D}{\mu_{V}} \\
\mathbf{S t} \rightarrow \text { Número de Stanton. } & S t=\frac{N u}{\operatorname{Re} \operatorname{Pr}} \\
\text { We } \rightarrow \text { Número de Weber. } & W e=\frac{G^{2} \cdot D}{\sigma \cdot \rho}
\end{array}
$$

\section{Letras Gregas}

$\alpha \rightarrow$ Fração de vazio.

$\beta \rightarrow$ Ângulo de contato $\left({ }^{\circ}\right)$; Ângulo de hélice $\left({ }^{\circ}\right)$

$\rho \rightarrow$ Densidade. $\left(\mathrm{kg} / \mathrm{m}^{3}\right)$

$\delta \rightarrow$ Espessura do filme de líquido (Regime Anular). (m)

$\delta_{\mathrm{c}} \rightarrow$ Dimensão característica. (m)

$\varepsilon \rightarrow$ Rugosidade. (m)

$\lambda \rightarrow$ Parâmetro adimensional utilizado por BAKER (1954).

$\wp \rightarrow$ Perimetro. (m)

$\sigma \rightarrow$ Tensão superficial. ( $\mathrm{N} / \mathrm{m})$

$\mu \rightarrow$ Viscosidade dinâmica. (N.s $/ \mathrm{m}^{2}$ )

$\Delta \mathbf{T} \rightarrow$ Diferença de Temperatura. $\left({ }^{\circ} \mathrm{C}\right)$

$\Delta \mathbf{P} \rightarrow$ Diferença de Pressão. $\left(\mathrm{N} / \mathrm{m}^{2}\right)$

$\Delta \mathbf{x} \rightarrow$ Diferença entre o título de saída com o de entrada.

$\theta \rightarrow$ Ângulo de cunha. $\left({ }^{\circ}\right)$

$\phi \rightarrow$ Fluxo de Calor. $\left(\mathrm{W} / \mathrm{m}^{2}\right)$ e Multiplicador bifásico.

$\psi \rightarrow$ Parâmetro adimensional de SHAH (1982).

$\Lambda \rightarrow$ Parâmetro adimensional utilizado por BAKER (1954).

\section{Subscrito :}

$\mathrm{a} \rightarrow$ água de aquecimento.

$\mathrm{A} \rightarrow$ propriedades do ar. 
acel $\rightarrow$ aceleração.

b $\rightarrow$ bifásico.

$\mathrm{BE} \rightarrow$ balanço de energia.

cal $\rightarrow$ calculado.

$\mathrm{C} \rightarrow$ convectivo.

$\mathrm{CH} \rightarrow$ relativo à Chen.

correl $\rightarrow$ correlação.

cr $\rightarrow$ crítica.

D $\rightarrow$ diâmetro.

e $\rightarrow$ entrada; externo.

ef $\rightarrow$ efetivo.

en $\rightarrow$ entrada.

evap $\rightarrow$ evaporação.

Exp $\rightarrow$ experimental.

$\mathrm{EC} \rightarrow$ ebulição convectiva.

$\mathrm{EN} \rightarrow$ ebulição nucleada.

ENF $\rightarrow$ ebulição nucleada de Foster \& Zuber.

ENN $\rightarrow$ ebulição nucleada de Nishikawa.

ENS $\rightarrow$ ebulição nucleada de Stephan \& Abdelsalam.

ENC $\rightarrow$ ebulição nucleada de Copper.

EPA $\rightarrow$ entrada do pré-aquecedor.

EST $\rightarrow$ entrada da seção de testes.

$\mathrm{GH} \rightarrow$ relativo à Groothius \& Hendal.

$\mathrm{GW} \rightarrow$ relativo à Gungor $\&$ Winterton.

$\mathbf{h} \rightarrow$ hidráulico.

$\mathrm{i} \rightarrow$ interno.

$\mathrm{JR} \rightarrow$ relativo à Jung \& Radermacher.

$\mathrm{L} \rightarrow$ relativo à fase líquida no tubo.

$\mathrm{LA} \rightarrow$ relativo à Lavin.

$\mathrm{LI} \rightarrow$ relativo à Lima.

LO $\rightarrow$ mistura bifásica escoando como líquido no tubo.

$\mathrm{LV} \rightarrow$ líquido e vapor.

$\mathrm{LW} \rightarrow$ relativo à Liu \& Winterton. 
med $\rightarrow$ médio.

$\mathbf{M H} \rightarrow$ relativo à Murata \& Hashizume.

MS $\rightarrow$ médio na seção.

$0 \rightarrow$ condições normalizadas de fluxo de calor e pressão reduzida.

$\mathrm{p} \rightarrow$ parede.

$\mathrm{PI} \rightarrow$ posição inferior do tubo.

$\mathrm{PF} \rightarrow$ fator de correção da pressão.

$\mathrm{PL} \rightarrow$ posição lateral do tubo.

$\mathrm{PR} \rightarrow$ pré-aquecedor.

PS $\rightarrow$ posição superior do tubo.

$\mathrm{R} \rightarrow$ refrigerante.

red $\rightarrow$ reduzida

$\mathbf{R h} \rightarrow$ relativo à Rhee.

$\mathrm{s} \rightarrow$ saida.

sa $\rightarrow$ saída.

sat $\rightarrow$ saturação.

SB $\rightarrow$ supressão de Bolhas.

$\mathrm{SPA} \rightarrow$ saída do pré-aquecedor.

SST $\rightarrow$ saída da seção de testes.

$\mathrm{ST} \rightarrow$ seção de testes.

$\mathrm{S} 1 \rightarrow$ seção de medida de temperatura superficial 1 .

S2 $\rightarrow$ seção de medida de temperatura superficial 2.

S3 $\rightarrow$ seção de medida de temperatura superficial 3 .

S4 $\rightarrow$ seção de medida de temperatura superficial 4 .

$\mathrm{T} \rightarrow$ térmico.

$\mathrm{V} \rightarrow$ vapor.

$\mathrm{W} \rightarrow$ relativo à Wattelet; propriedades da água.

WA $\rightarrow$ interface ar/água. 


\section{RESUMO}

BANDARRA FILHO, E.P. (2002). Um Estudo Experimental da Ebulição Convectiva de Refrigerantes no Interior de Tubos Lisos e Internamente Ranhurados. São Carlos, 2002, 258p. Tese (Doutorado) - Escola de Engenharia de São Carlos, Universidade de São Paulo.

A presente pesquisa trata de um estudo experimental da transferência de calor e da perda de carga de fluidos refrigerantes puros e suas misturas em mudança de fase convectiva no interior de tubos lisos e aqueles dotados de ranhuras internas. Para tanto, foi desenvolvido um equipamento experimental cujo componente básico é composto por um tubo horizontal, aquecido por intermédio de uma resistência elétrica do tipo fita, aderida à superfície externa do tubo. As condições de ensaio variaram numa ampla faixa, permitindo cobrir as condições verificadas na maioria das instalações frigoríficas. Os resultados experimentais foram agrupados em duas faixas de velocidades mássicas: elevadas $\left(\mathrm{G} \geq 200 \mathrm{~kg} / \mathrm{s} . \mathrm{m}^{2}\right)$, onde prepondera o padrão anular de escoamento, e reduzidas $\left(\mathrm{G}<200 \mathrm{~kg} / \mathrm{s} . \mathrm{m}^{2}\right)$, predominando o padrão estratificado. Os principais parâmetros que afetam o coeficiente de transferência de calor, tais como, velocidade mássica, fluxo de calor, tipo de refrigerante, temperatura de evaporação e diâmetro do tubo foram analisados. O desempenho termohidráulico, relativo ao efeito combinado da transferência de calor e da perda de carga, dos tubos ranhurados foi sensivelmente superior quando comparados aos tubos lisos. A análise dos resultados experimentais permitiu a proposição de correlações para a perda de carga, avaliada através do multiplicador bifásico, $\phi_{\mathrm{L}}$, e para $\mathrm{o}$ coeficiente de transferência de calor, em tubos lisos e ranhurados. As correlações propostas se mostraram adequadas para aplicações práticas, proporcionando desvios reduzidos em relação aos resultados experimentais. Destacam-se as correlações obtidas para o multiplicador bifásico para tubos microaletados e para o coeficiente de transferência de calor para vazões reduzidas em tubos lisos. Diversos registros fotográficos dos principais padrões de escoamento foram levantados, tendo sido importante na análise e entendimento da mudança de fase.

Palavras Chave: Ebulição convectiva, Transferência de calor, Refrigerantes, Intensificação, Perda de carga, Tubos microaletados. 


\begin{abstract}
BANDARRA FILHO, E.P. (2002). An Experimental Study of Convective Flow Boiling of Refrigerants Inside Smooth and Microfin Tubes. São Carlos, 2002, 258p. Tese (Doutorado) - Escola de Engenharia de São Carlos, Universidade de São Paulo.
\end{abstract}

Present research deals with an experimental study of the heat transfer and pressure drop of pure and mixtures of refrigerants undergoing convective boiling inside horizontal smooth and microfin tubes. An experimental apparatus has been developed and constructed whose main component is a horizontal tube electrically heated. Experimental results have been grouped into two mass velocity ranges: the one corresponding to mass velocities lower than $200 \mathrm{~kg} / \mathrm{s} . \mathrm{m}^{2}$, where the stratified flow pattern is dominant, and that for mass velocities higher than $200 \mathrm{~kg} / \mathrm{s} . \mathrm{m}^{2}$, where typically the annular flow pattern can be found. Effects over the heat transfer coefficient of physical parameters such as mass velocity, heat flux, diameter, saturation temperature, and refrigerant have been investigated and analyzed. It has been found out that the thermo-hydraulic performance of microfin tubes is better than that of the smooth ones. Empirical correlations have been proposed for both the two-phase flow multiplier and the heat transfer coefficient for different ranges of operating conditions as well as for smooth and microfin tubes. Results from the proposed correlations can be deemed adequate for practical applications given the limited dispersion obtained with respect to their experimental counterpart. Noteworthy are the results obtained from correlations for both the two phase flow multiplier for microfin tubes and the heat transfer coefficient for the lower range of mass velocities in smooth tubes. Finally, worth mentioning is the photographic essay developed in present research involving the flow patterns that occur under convective boiling of refrigerants in horizontal tubes.

Keywords: Convective flow boiling, Heat transfer, Refrigerants, Enhancement, Pressure Drop, Microfin tube. 


\section{CAPÍTULO 1 - INTRODUÇÃO}

\subsection{Considerações Iniciais}

$\left\{\begin{array}{l}\text { transferência de calor e perda de carga de refrigerantes em mudança de fase } \\ \text { (líquido/vapor) no interior de tubos (ou Ebulição Convectiva) tem passado por } \\ \text { uma minuciosa investigação por parte da comunidade científica com o objetivo }\end{array}\right.$ de cobrir lacunas deixadas no passado ou como apoio às novas tecnologias que vem sendo introduzidas. A introdução de novos compostos halogenados em substituição àqueles cuja eliminação foi determinada pelo Protocolo de Montreal em 1987 e a problemática do aquecimento global ou efeito estufa, Protocolo de Kyoto em 1997, regulamentando a diminuição progressiva de emissão de gases na atmosfera, colaboraram para impulsionar novas pesquisas. Infelizmente, no Brasil ainda são raras as pesquisas sobre o tema, o que contribui para que a indústria nacional se torne ainda mais dependente de informações provenientes do exterior.

Apesar do relativo conhecimento adquirido ao longo dos anos a respeito da ebulição convectiva de refrigerantes, a necessidade de substituição daqueles da família dos CFC's suscitou um renovado esforço de pesquisa desse mecanismo de transferência de calor. Como resultado, recentes estudos têm abordado, com ferramental mais adequado tecnologicamente, algumas lacunas deixadas por pesquisas anteriores. Estas, como regra geral, se restringiram a correlacionar resultados experimentais, sendo limitadas as tentativas de um melhor entendimento do fenômeno físico. Assim, a crise dos CFC's constituiu umz oportunidade para a retomada das pesquisas desse tema, abandonadas, por assim dizer, no final da década de 60 .

Com a crescente preocupação com a conservação de energia e a preservação do meio ambiente, é importante que os trocadores de calor sejam projetados de forma otimizada, tendo como objetivo principal a diminuição de custos e operação eficiente, sem, 
entretanto, agredir o meio ambiente. Nesse sentido, as pesquisas estão sendo direcionadas para a intensificação da transferência de calor, visando obter geometrias eficientes que incrementem a transferência de calor sem, entretanto, penalizar excessivamente o consumo de energia no "bombeamento".

O desenvolvimento de superfícies intensificadoras (da taxa de transferência de calor) tem sido objeto de estudos intensivos nos últimos 20 anos. Tais superfícies permitem a obtenção de trocadores de calor mais compactos - envolvendo considerações econômicas relacionadas ao custo inicial ou condições que permitam uma redução do custo operacional. Infelizmente, a obtenção de altas taxas de transferência de calor está intimamente relacionada a uma elevação da resistência hidráulica (perda de carga) do fluido do processo. No evaporador, a perda de carga do refrigerante afeta diretamente o desempenho da instalação, uma vez que reduz a pressão de aspiração do compressor, acarretando um aumento no consumo de energia. Nesse sentido, alguns pesquisadores têm introduzido parâmetros de avaliação (ou de "intensificação"), definidos em termos da relação entre as intensificações da taxa de transferência de calor e da perda de carga. A utilização de uma superficie intensificadora se justificaria, assim, caso proporcionasse um parâmetro de intensificação elevado.

Dentro deste contexto, o presente trabalho procurou abordar a Ebulição Convectiva no interior de tubos sobre os aspectos tais como, ebulição convectiva de refrigerantes puros e suas misturas, intensificação da transferência de calor, perda de carga, secagem de parede ou "Dryout" e visualização dos padrões de escoamento.

\subsection{Objetivos do Trabalho}

Com o intuito de fornecer uma visão geral sobre a mudança de fase de refrigerantes no interior de tubos, por intermédio de uma revisão bibliográfica abrangente e de resultados experimentais consistentes, para que sirva de subsídio na avaliação dos mecanismos físicos que regem a Ebulição Convectiva, a presente pesquisa teve por principais objetivos:

* Apresentar um panorama geral do estado da arte na área de mudança de fase de refrigerantes no interior de tubos.

* Avaliação dos efeitos dos principais parâmetros físicos sobre o coeficiente de transferência de calor, tais como, velocidade mássica, fluido refrigerante, fluxo de calor, temperatura de evaporação e diâmetro de tubo. 
* Verificar, analisar e comparar a transferência de calor e perda de carga de tubos lisos em relação aos microaletados.

Identificar, através de registros fotográficos, os principais padrões de escoamento em tubos horizontais.

* Atestar a potencialidade dos tubos microaletados como uma técnica de intensificação eficaz.

* Verificar as instabilidades da região final de evaporação ou secagem de parede.

Propor correlações baseadas em resultados experimentais para transferência de calor e perda de carga.

\subsection{Organização do Trabalho}

O presente trabalho procurou fornecer um panorama global da Ebulição Convectiva no interior de tubos. Nesse sentido, tendo em vista a extensão da pesquisa foram dedicados quatro sub-capítulos à pesquisa bibliográfica (padrões de escoamento, ebulição convectiva, intensificação da transferência de calor e secagem de parede), um à bancada experimental, outro contendo a análise dos resultados experimentais, divididos de maneira organizada, uma seção dedicada à correlação dos resultados para transferência de calor e perda de carga e, finalmente, as conclusões e recomendações a futuros trabalhos.

Assim, o trabalho foi organizado nos seguintes capitulos:

(G) Capítulo 2: A primeira seção, aborda uma revisão bibliográfica sobre os padrões de escoamento em tubos horizontais. Posteriormente, é apresentado o estado da arte das correlações existentes para o coeficiente de transferência de calor em escoamento com mudança de fase de refrigerantes no interior de tubos. Na seqüência, são apresentadas as principais pesquisas sobre intensificação da transferência de calor no interior de tubos, dando uma visão geral do estágio atual dessa técnica. Finalmente, a última seção é dedicada à pesquisa bibliográfica sobre a região final de evaporação (secagem de parede).

Capítulo 3: Mostra, em uma descrição detalhada, da bancada experimental e sua instrumentação.

Capítulo 4: Apresenta os resultados experimentais, avaliando os principais parâmetros físicos sobre o coeficiente de transferência de calor em tubos lisos, tais como, efeito da vazão, fluxo de calor, diâmetro de tubo, temperatura de evaporação, 
título e efeito do refrigerante. Na seqüência, é realizada uma análise dos resultados para intensificação da transferência de calor e perda de carga e, finalmente, avaliar os resultados da transferência de calor na região de secagem de parede, além da proposição de um mapa de padrão de escoamento para tubos microaletados.

( Capítulo 5: É dedicado à correlação dos resultados experimentais, apresentando modelos para perda de carga em tubos lisos e microaletados, correlações para a avaliação do coeficiente de transferência de calor para duas faixas de vazões especificadas, e, por fim, uma correlação para tubos microaletados em termos da transferência de calor.

$\leftrightarrow$ Capítulo 6: Traz as principais conclusões do presente trabalho e recomendações para os próximos passos em trabalhos futuros. 


\section{CAPÍTULO 2 - REVISÃO BIBLIOGRÁFICA}

\subsection{Considerações Iniciais}

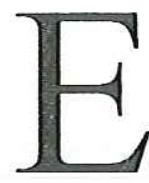

ᄀste capítulo contempla a extensa pesquisa bibliográfica realizada ao longo do presente trabalho. Inicialmente, será abordada, de forma objetiva, uma seção dedicada aos padrões de escoamento encontrados em ebulição convectiva, mormente aqueles associados ao escoamento em tubos horizontais, objeto da presente pesquisa. Na seqüência, aparece uma seção dedicada à transferência de calor no interior de tubos, discutindo, analisando e comparando as principais correlações para avaliação do coeficiente de transferência de calor que foram encontradas na literatura. A seção seguinte, trata da intensificação da transferência de calor, abordando a maioria das pesquisas relacionadas ao tema e as principais técnicas utilizadas para intensificação. A última parte deste capítulo é dedicada à região final de evaporação, denominada de secagem de parede, ou ainda, região de deficiência de líquido. É nessa região que ocorre a evaporação completa do fluido refrigerante, estando associada a baixos coeficientes de transferência de calor (vapor em contato com a parede do tubo), do que resulta uma significativa elevação da temperatura da parede.

\subsection{Padrões de Escoamento}

Escoamento com mudança de fase envolvendo líquido e vapor em um tubo pode assumir diversas configurações geométricas entre as fases, as quais são comumente denominadas de padrões de escoamento ou regimes de escoamento. A denominação das distintas configurações pode variar de acordo com cada referência encontrada na literatura. A Fig. 2.1 ilustra a classificação dos diversos padrões de escoamento encontrados em tubos horizontais. As configurações dos padrões de escoamento em tubos horizontais são mais complexas que aquelas verificadas em tubos verticais. Em tubos verticais, o padrão anular de 
escoamento, apresenta uma simetria no filme de líquido em toda a circunferência do tubo. Já para tubos horizontais, os efeitos gravitacionais, na direção normal ao escoamento, causam uma distribuição assimétrica da película de líquido aderida à circunferência do tubo. Nessas condições, a região inferior do tubo apresenta uma espessura maior do filme de líquido, ao passo que na parte superior do tubo esse filme é delgado. Neste estudo será dada ênfase aos mecanismos físicos encontrados nos escoamentos horizontais.

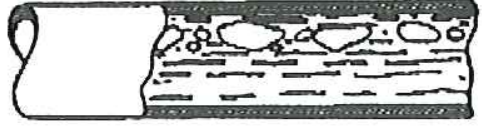

Bolhas

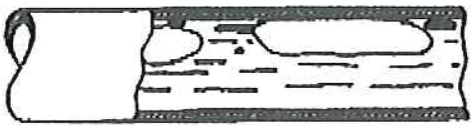

Pistonado

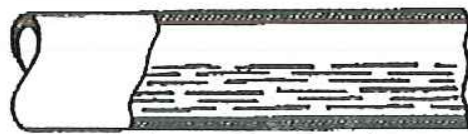

Estratificado Liso

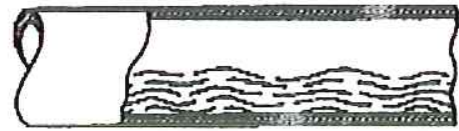

Estratificado Ondulado

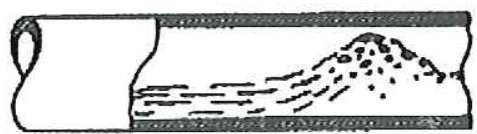

Intermitente

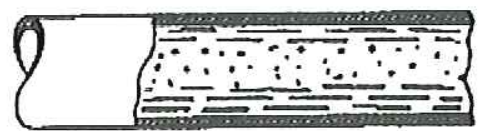

Anular

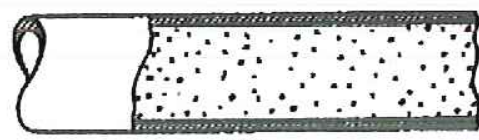

Névoa

Escoamento

Figura. 2.1 Padrões de Escoamento em tubos horizontais.

$\mathrm{O}$ escoamento em evaporadores ocorre predominantemente em tubos horizontais e os padrões geralmente encontrados são: padrão estratificado, ondulado, intermitente, o anular e, finalmente, o escoamento em névoa. Podem, ainda, ser encontrados em tubos horizontais os padrões em bolhas e pistonado, para títulos reduzidos. A transição do escoamento anular para o névoa ocorre de maneira gradual, com secagem de parede na parte superior do tubo e mais a montante da parte inferior, devido à assimetria gerada pela gravidade. A Fig. 2.2 apresenta uma ilustração dos principais padrões de escoamento encontrados em ebulição convectiva. 


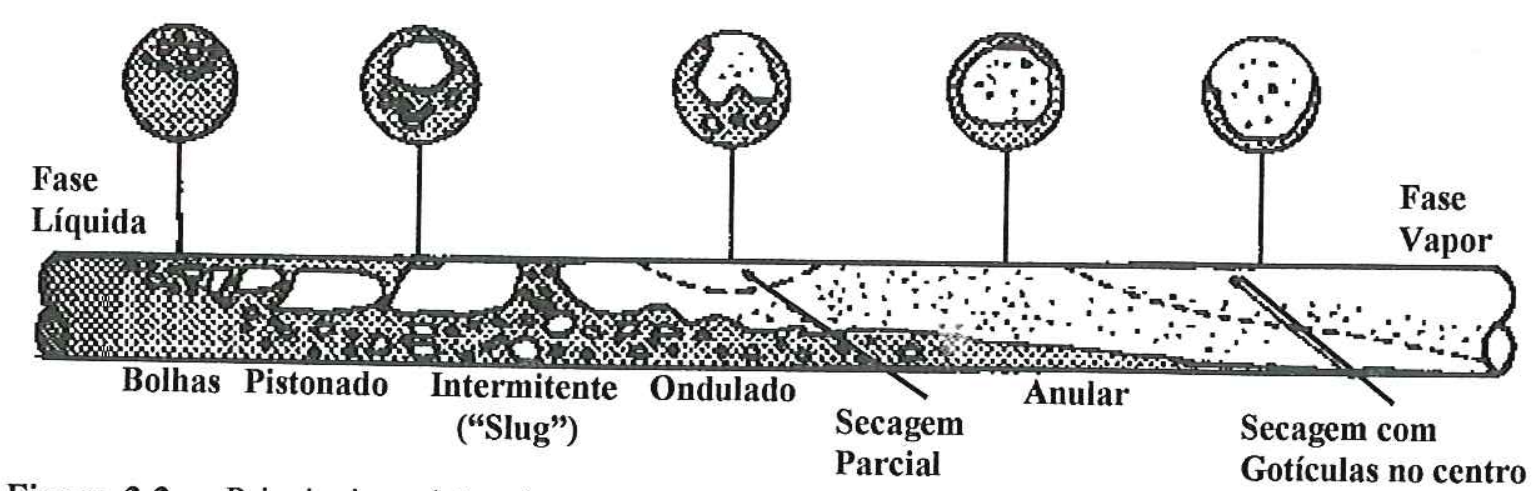

Figura 2.2 Principais padrões de escoamento encontrados em evaporação.

A definição dos padrões de escoamento em tubos horizontais pode ser descrita como segue, respeitando a ordem apresentada na Fig. 2.2.

Escoamento em Bolhas: é caracterizado pela formação de bolhas na periferia do tubo, sendo as mesmas deslocadas para parte superior do tubo.

Escoamento Pistonado: este escoamento é formado pela aglomeração de bolhas que coalescem entre si originando bolhas de razoável dimensão, verdadeiros pistões de vapor, que escoam de modo intermitente, porém com uma freqüência regular.

Escoamento Estratificado: tal regime é caracterizado pela segregação da fase líquida na parte inferior do tubo. Ocorre para vazões reduzidas, geralmente para valores de $\mathrm{G}<100$ $\left(\mathrm{kg} / \mathrm{s} \cdot \mathrm{m}^{2}\right)$.

Escoamento Estratificado Ondulado: o padrão ondulado ocorre quando há um aumento na velocidade da fase vapor em relação à fase liquida, gerando distúrbios na interface ocasionando a formação de ondas. Geralmente as vazões encontradas para este regime são da ordem de $\mathrm{G}<150\left(\mathrm{~kg} / \mathrm{s} . \mathrm{m}^{2}\right)$.

Escoamento Anular: o padrão anular é caracterizado pela presença de uma película de líquido ao longo da superfície interna do tubo. Para tubos horizontais essa película é assimétrica, com o filme de líquido mais espesso na parte inferior do tubo. As vazões geralmente associadas a este regime são elevadas, da ordem de $\mathrm{G}>200\left(\mathrm{~kg} / \mathrm{s} \cdot \mathrm{m}^{2}\right)$.

Escoamento em Névoa: neste regime o líquido é evaporado da superficie do tubo e, devido à elevada velocidade da fase vapor, gotículas de líquido são carregadas para o centro do tubo.

De um modo geral, a interface líquido-vapor pode, ainda, ser caracterizada por três regimes distintos: 
(1) Regime de fase dispersa: ocorre quando num meio liquido ou vapor surgem bolhas, no caso de um meio líquido, ou no caso de vapor, gotículas de líquido. Os principais padrões associados a este regime são o padrão em bolhas e em névoa.

(2) Regime de fases separadas: como o próprio nome enfatiza, a interface líquido-vapor é bem definida. $\mathrm{O}$ escoamento apresenta uma distinção entre as fases. Tais escoamentos são típicos do padrão anular e o estratificado, que incluem a maioria das aplicações frigoríficas.

(3) Regime misto: há uma mescla dos regimes mencionados anteriormente. Inclui-se o padrão pistonado, onde bolhas de razoável dimensão escoam de modo intermitente, como mencionado anteriormente.

Outro fenômeno importante a ser elucidado é a transição entre os padrões de escoamento. Com o passar dos anos, diversos autores têm sugerido correlações para prever a transição de um padrão para outro. Na maioria dos casos, a estratégia utilizada pelos pesquisadores é a visualização do escoamento, o que envolve um certo grau de subjetivismo. Isso, possibilitou a muitos, propor correlações baseadas, principalmente, em observações visuais, deixando de lado o fenômeno físico. Um recurso, de última geração, que está sendo utilizado em recentes pesquisas é a câmara de vídeo-tape de alta velocidade, onde é possível verificar detalhes que a olho nu seria impossível, devido à alta velocidade do escoamento. Desde meados da década de 50, inúmeros autores vêm propondo mapas para identificação dos padrões de escoamento em tubos. Apesar desse esforço, pode-se afirmar que ainda inexiste um mapa generalizado para identificar os padrões de escoamento. A seguir serão apresentados, de forma sumária, alguns dos principais mapas propostos para identificação dos padrões de escoamento em tubos horizontais.

\subsubsection{Mapas de Padrões de Escoamento}

Um dos primeiros pesquiisadores a publicar um mapa de padrão de escoamento para tubos horizontais foi BAKER (1954), o qual foi baseado em termos dimensionais, velocidades mássicas sı:perficiais da fase líquido e vapor $\left(\mathrm{G}_{\mathrm{L}}\right.$ e $\left.\mathrm{G}_{\mathrm{V}}\right)$, com alguns parâmetros adimensionais denominados de $\Lambda$ e $\lambda$, que envolvem os efeitos relativos entre as fases, apresentados a seguir. A Fig. 2.3 ilustra o mapa desenvolvido por BAKER (1954), baseado nos escoamentos ar-água e óleo-água. 


$$
G_{V^{\prime}} / \lambda \quad \text { e } G_{L} \cdot \Lambda
$$

onde,

$$
\lambda=\left(\left(\frac{\rho_{V}}{\rho_{A}}\right) \cdot\left(\frac{\rho_{L}}{\rho_{W}}\right)\right)^{1 / 2} \quad \text { e } \quad \Lambda=\left(\frac{\sigma_{W A}}{\sigma}\right) \cdot\left(\left(\frac{\mu_{L}}{\mu_{W}}\right) \cdot\left(\frac{\rho_{W}}{\rho_{L}}\right)^{2}\right)^{1 / 3}
$$

Os subscritos $\mathrm{A} \mathrm{e} \mathrm{W}$ referem-se às propriedades do ar e água à pressão atmosférica $\mathrm{e}$ temperatura de $20^{\circ} \mathrm{C}$, já o subscrito WA refere-se à interface ar-água para as mesmas condições de pressão e temperatura.

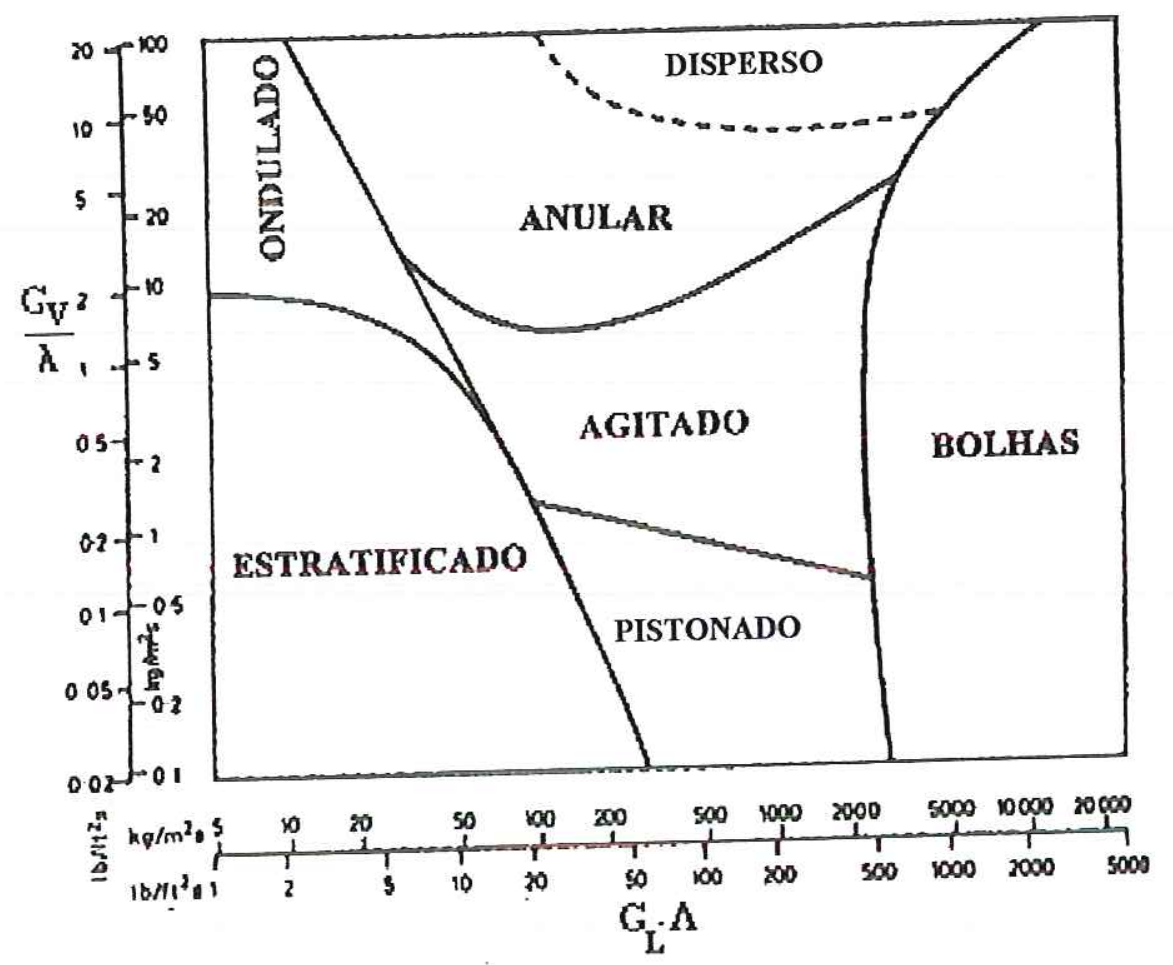

Figura 2.3 Mapa de padrão de escoamento proposto por BAKER (1954).

TAITEL \& DUKLER (1976) desenvolveram um modelo mais refinado para escoamento horizontal, apresentado em termos adimensionais, considerando os regimes de escoamento intermitente, que pode ser definido como um padrão estratificado ondulado com grande amplitude de onda, o estratificado ondulado, bolhas dispersas e anular disperso. $\mathrm{O}$ mapa desenvolvido foi baseado no parâmetro de Martinelli, $X_{\mathfrak{t t}}$, e no número de Froude modificado. 
O estudo mais recente publicado sobre mapas de padrões de escoamento foi realizado por KATTAN et al (1998). O objetivo principal deste trabalho foi desenvolver um mapa de regime de escoamento para refrigerantes sobre diversas condições de evaporação. Utilizaram cerca de 700 pontos experimentais, onde os principais padrões observados foram o estratificado, estratificado ondulado, intermitente, o anular e em névoa. Os autores transformaram o mapa de Steiner, proposto em 1993, o qual era função de diversas variáveis, para um mapa somente função da velocidade mássica, $\mathrm{G}$, e do título, $\mathrm{x}$, porém com variação da temperatura de saturação. É interessante destacar que, com a utilização da velocidade mássica e do título, a interpretação dos pontos experimentais tornou-se mais simplificada. $\mathrm{O}$ novo mapa correlacionou $96,2 \%$ dos pontos experimentais para cinco fluidos refrigerantes distintos, ensaiados sobre uma faixa limitada de condições operacionais. A Fig. 2.4 ilustra o mapa proposto por KATTAN et al (1998).

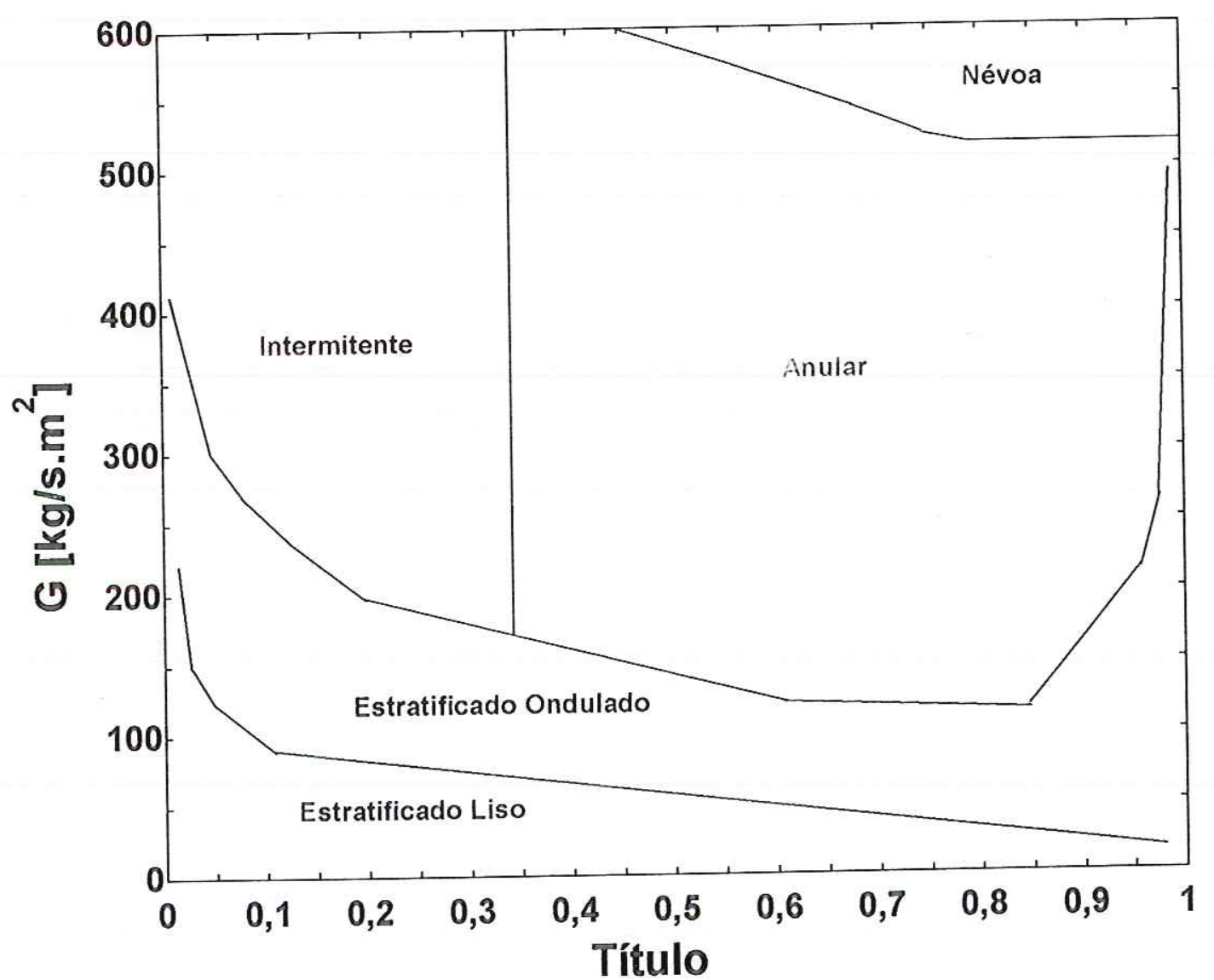

Figura. 2.4 Mapa de KATTAN et al (1998), para o R-134a, $T_{\text {sat }}=4,4^{\circ} \mathrm{C}$ e $D_{i}=10,9 \mathrm{~mm}$. 
É interessante destacar que, apesar de uma relativa gama de trabalhos publicados sobre padrões de escoamento, ainda há diversas lacunas sobre o fenômeno fisico que rege cada padrão de escoamento. Nesse sentido, houve um aumento significativo nas pesquisas realizadas nesta última década envolvendo padrões de escoamento, com o objetivo de se obter resultados mais consistentes auxiliados por uma instrumentação avançada, podendo-se destacar câmera de vídeo-tape de alta velocidade. Por intermédio de uma câmera de vídeotape deste tipo, é possivel identificar a transição dos padrões de escoamento, bem como verificar as instabilidades hidrodinâmicas do escoamento. 


\subsection{Transferência de Calor em Ebulição Convectiva}

\subsubsection{Introdução}

A mudança de fase convectiva (ou ebulição estritamente convectiva) designa a vaporização do líquido sem a presença de bolhas, ocorrendo simplesmente como resultado da evaporação na interface líquido-vapor. O termo "convectiva", utilizado neste trabalho, foi introduzido com o objetivo de designar a condição em que ocorre escoamento de ambas as fases. A mudança de fase estritamente convectiva é caracterizada pelos regimes de fase não dispersa, como os padrões de escoamento anular e o estratificado, como observado na seção anterior. No entanto, em condições especiais de operação, mesmo com a ocorrência destes padrões, poderá haver a formação de bolhas junto à parede do tubo, ocorrendo os dois regimes simultaneamente.

Os evaporadores frigoríficos podem ser divididos basicamente em três categorias, os de expansão direta ou seca, os inundados e os de recirculação. A ebulição convectiva ocorre especialmente nos evaporadores de expansão seca, geralmente alimentados por uma válvula de expansão termostática ou um tubo capilar. Em evaporadores de expansão seca predominam os padrões de escoamento anular, para vazões elevadas, e estratificado, para vazões relativamente baixas. $O$ coeficiente de transferência de calor está intimamente relacionado ao padrão de escoamento. Uma análise qualitativa superficial do coeficiente de transferência de calor bifásico permite estabelecer que, entre os parâmetros que mais o afetam se incluem o fluxo de calor, $\phi$, e velocidade mássica, G. Os efeitos desses parâmetros serão considerados a seguir numa análise superficial introdutória à revisão bibliográfica.

A Fig. 2.5 ilustra, qualitativamente, o comportamento típico do coeficiente de transferência de calor bifásico, $h_{b}$, ao longo do evaporador, para velocidades mássicas significativamente elevadas. Para títulos reduzidos (geralmente inferiores a 20\%), a formação de bolhas se intensifica, isolando, por sua vez, o líquido da parede, o que acaba por afetar o coeficiente de transferência de calor no sentido de reduzi-lo. Para títulos maiores (entre $20 \%$ e $80 \%$ ), os efeitos convectivos tornam-se mais acentuados, pois ocorre a formação de uma película de líquido assimétrica, em tubos horizontais, típico do padrão anular de escoamento. Nesta fase, a espessura da película de líquido diminui progressivamente pela intensa evaporação na interface líquido-vapor, resultando numa redução da resistência térmica, o que determina a elevação do coeficiente de transferência de calor no sentido do escoamento, como observado na Fig. 2.5. Tal situação perdura até uma 
condição onde ocorre secagem da parede, títulos da ordem de $80 \%$, situação esta, associada a uma significativa redução do coeficiente de transferência de calor, em virtude da presença de vapor na superfície do tubo, resultando numa drástica elevação da temperatura da superfície. A partir desta seção, o coeficiente de transferência de calor permanece nos níveis de escoamento monofásico de vapor.

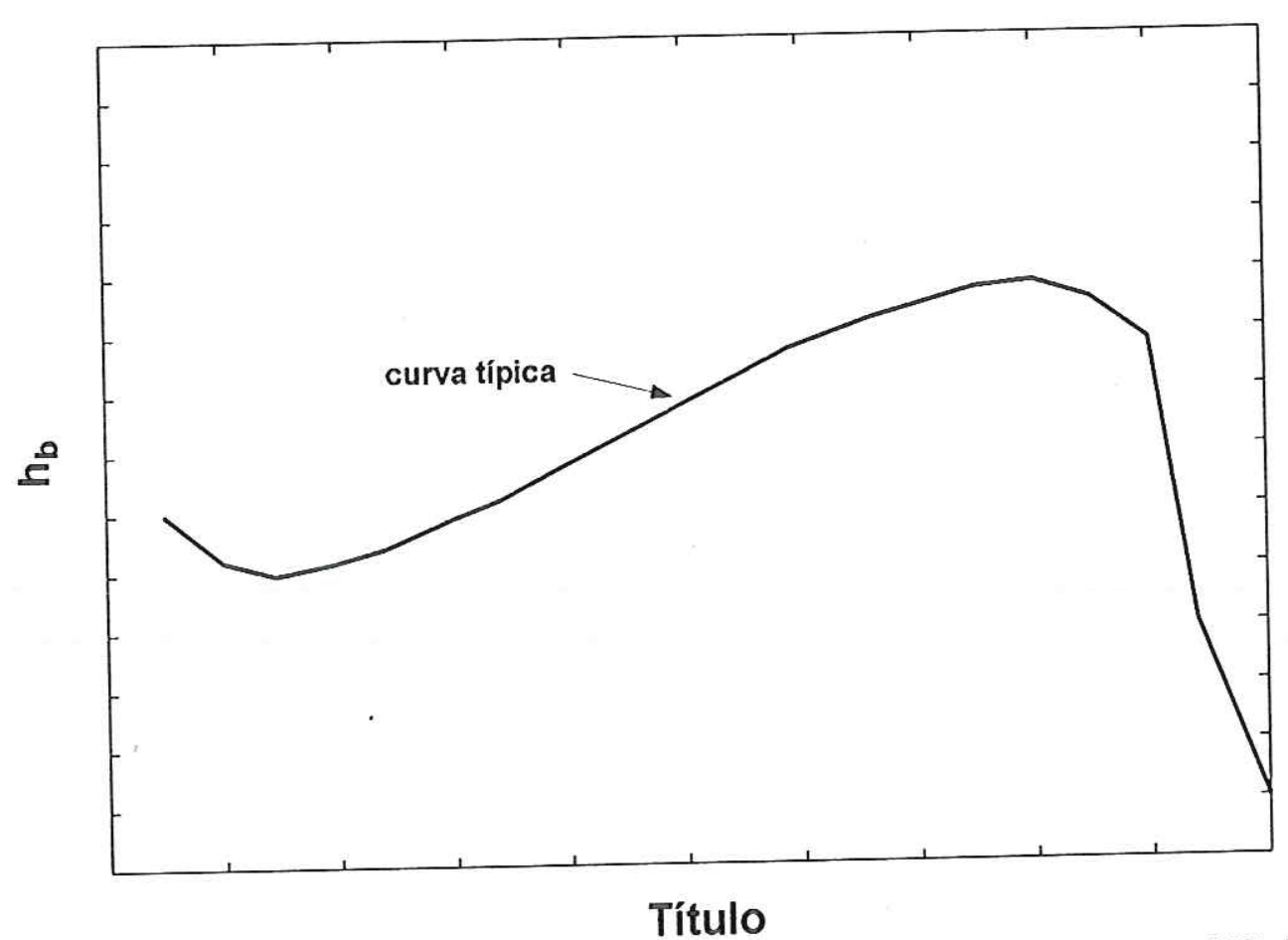

Figura 2.5 Comportamento típico do coeficiente de transferência de calor bifásico.

Os efeitos da velocidade mássica, G, são ilustrados na Fig. 2.6. À medida que G aumenta, a partir de um padrão de escoamento intermitente, verifica-se uma tendência à formação de uma película aderida à superficie do tubo, caracterizando o escoamento anular. Como observado anteriormente, a redução da espessura dessa película está associada a uma elevação do coeficiente de transferência de calor, nessas condições, os efeitos convectivos predominam sobre os efeitos de ebulição nucleada. Na Fig. 2.6, é, ainda, ilustrado o caso em que a velocidade mássica, $\mathrm{G}$, é reduzida. O comportamento típico dessa condição é um valor de $h_{b}$ constante ao longo do evaporador até a secagem da parede, onde se verifica uma queda do miesmo. O padrão de escoamento associado a esta condição é o estratificado. É interessante destacar, ainda, que o coeficiente de transferência de calor é incrementado à medida que a vazão aumenta. 


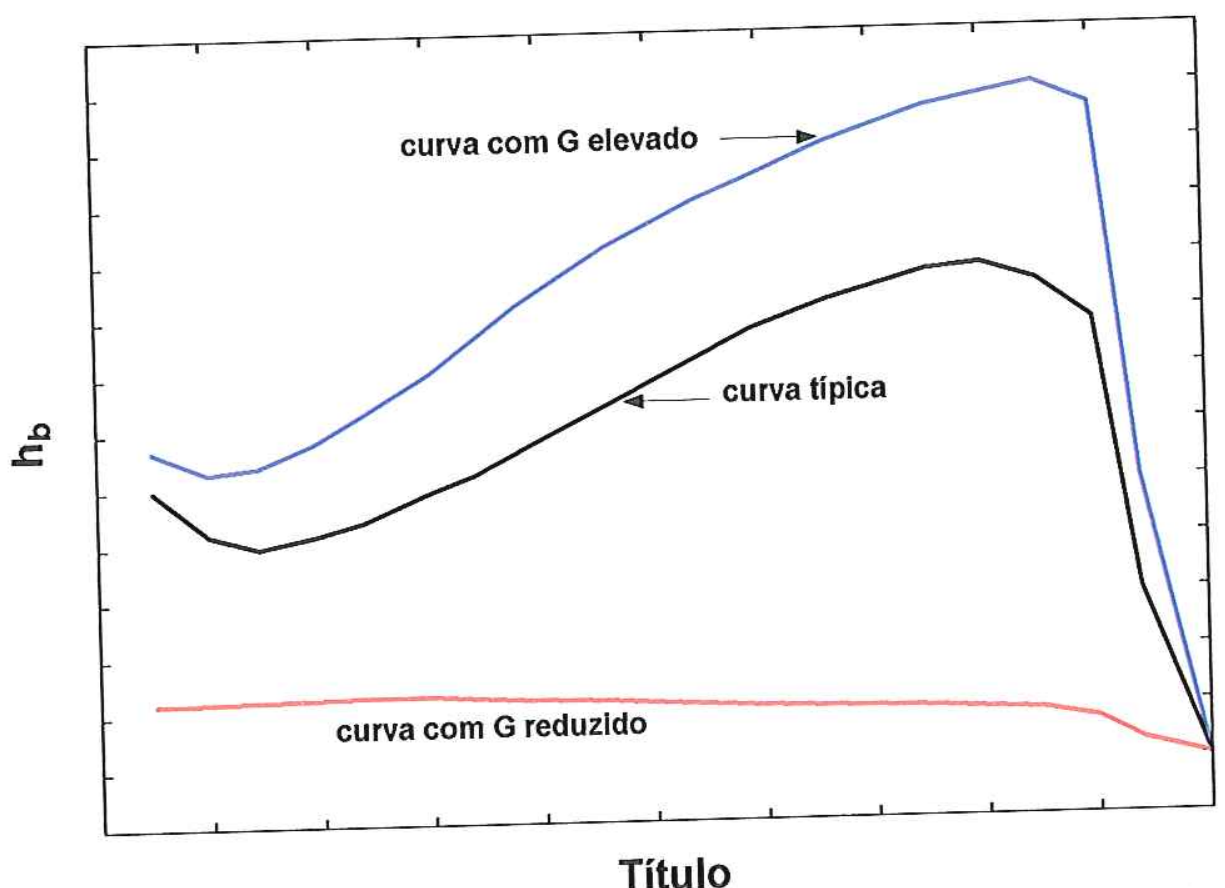

Figura 2.6 Efeito da velocidade mássica, G, no coeficiente de transferência de calor bifásico.

A Fig. 2.7, exibe os efeitos do fluxo de calor, $\phi$. Em condições de títulos relativamente reduzidos, os efeitos de ebulição nucleada são predominantes. Este aspecto é demonstrado pela significativa dependência de $h_{b}$ no fluxo de calor, elevando-se com este. Com o aumento do título, o valor de $h_{b}$ sofre uma progressiva redução, associada a um curto isolamento da superfície do tubo por partes das bolhas. Essa região é tipicamente de transição entre os padrões associados à ebulição nucleada e os padrões tipicamente convectivos especialmente o anular. À medida que o título é incrementado o coeficiente de transferência de calor torna-se independente do fluxo de calor. Isso é um claro sinal que os efeitos convectivos estão predominando, em outras palavras, esse comportamento é típico do padrão anular de escoamento. 


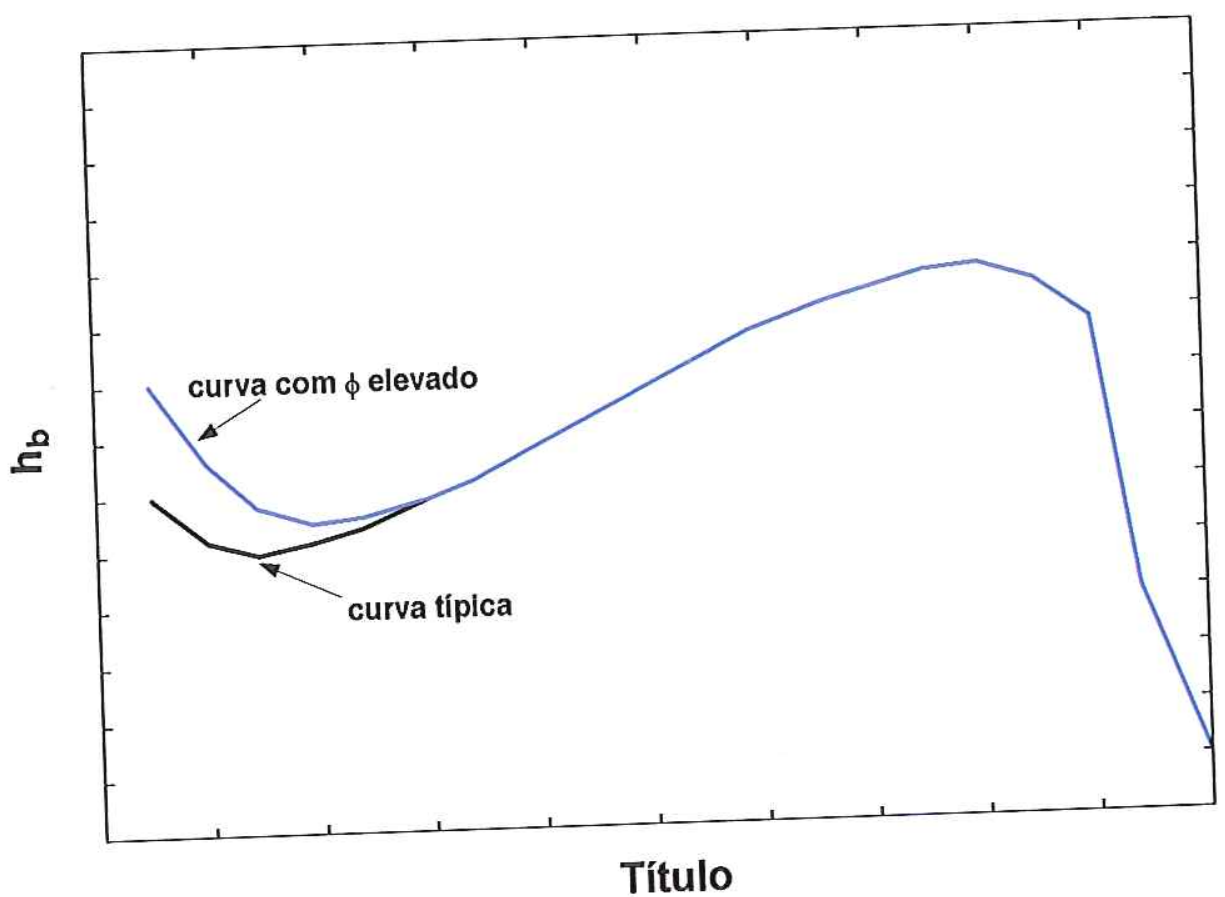

Figura 2.7 Efeito do fluxo de calor, $\phi$, no coeficiente de transferência de calor bifásico.

\subsubsection{Correlações para o Coeficiente de Transferência de Calor}

Uma extensa busca bibliográfica permitiu levantar as principais correlações existentes para o coeficiente de transferência de calor. Para melhor identificação destas correlações, as mesmas foram classificadas, conforme SAIZ JABARDO et al (1999), nos seguintes grupos:

1. Correlações estritamente convectivas

2. Correlações baseadas na superposição de efeitos

3. Correlações estritamente empíricas

As correlações estritamente convectivas foram desenvolvidas a partir do modelo de McADAMS (1954), segundo o qual a transferência de calor entre a superfície do tubo e a mistura bifásica ocorre através de um filme de líquido junto à parede. Tal hipótese assume implicitamente o padrão anular de escoamento. As correlações para o coeficiente de transferência de calor são apresentadas em termos adimensionais, com o coeficiente bifásico referido àquele que ocorreria caso o líquido da mistura escoasse isoladamente no tubo. Mais adiante será demonstrado que o coefíciente, assim adimensionalizado, é uma função do Parâmetro de Martinelli, $\mathrm{X}_{\mathrm{tt}}$. Em sistemas frigoríficos, os efeitos convectivos predominam 
sobre os efeitos da ebulição nucleada, pois, geralmente, o título na entrada do evaporador é superior a $20 \%$.

As correlações do segundo grupo são caracterizadas pela superposição dos efeitos convectivos e os de ebulição nucleada. Esta superposição pode ser simplesmente linear, como o modelo de CHEN (1966), ou pode adotar estratégias como a sugerida por KUTATELADZE (1961), que assumiu uma superposição não linear.

As correlações do grupo 3 correspondem àquelas obtidas por ajustes de banco de dados experimentais, envolvendo uma gama relativamente ampla de fluidos e condições operacionais. Este grupo de correlações utiliza constantes e alguns adimensionais para a avaliação do coeficiente de transferência de calor bifásico.

\subsubsection{Correlações Estritamente Convectivas}

\subsection{Introdução à Análise das Correlações Estritamente Convectivas}

A finalidade desta introdução é detalhar, a título de demonstração, o procedimento desenvolvido para a obtenção da forma geral das correlações estritamente convectivas, objetivando esclarecer o leitor quanto a sua forma. Deve-se notar que o modelo proposto por McADAMS (1954), segundo SAIZ JABARDO (1988), foi desenvolvido para o padrão de escoamento anular, embora tenha sido aplicado a outros padrões. As hipóteses básicas em que se fundamenta são as seguintes:

- padrão de escoamento anular, simétrico.

- fases liquido e vapor constituídas de fluidos incompressíveis

- regime permanente

A Fig. 2.8 apresenta uma representação esquemática do modelo de McAdams, base para o desenvolvimento apresentado a seguir.

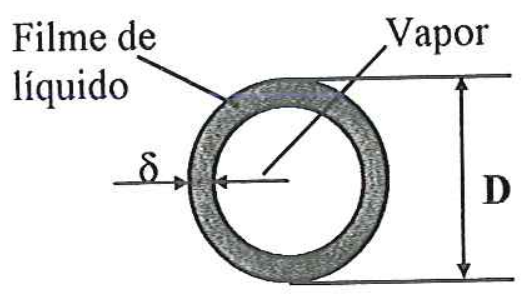

Figura 2.8 Caracterização do padrão anular de escoamento no interior de um tubo. 
Uma vez caracterizado o modelo físico, não é difícil obter algumas conclusões importantes, como será apresentado a seguir. É interessante, entretanto, enfatizar que o índice L será utilizado para designar o líquido ou parâmetros de escoamento associados ao líquido da mistura quando este escoa isoladamente no tubo. Nessas condições é possível escrever:

$$
\begin{aligned}
& N u=C \cdot \operatorname{Re}_{L}{ }^{M} \cdot \operatorname{Pr}_{L}{ }^{N} \text { (Monofásico) } \\
& N u_{b}=C \cdot \operatorname{Re}_{b}{ }^{M} \cdot \operatorname{Pr}_{L}{ }^{N} \text { (Bifásico) }
\end{aligned}
$$

O número de Prandtl do escoamento bifásico é referido ao líquido, uma vez que este é o agente de transferência de calor na parede, de acordo com o padrão de escoamento estabelecido nas hipóteses. Dividindo a Eq. (2.2) pela Eq. (2.1), resulta:

$$
\frac{N u_{b}}{N u}=\left(\frac{\mathrm{Re}_{b}}{\mathrm{Re}_{L}}\right)^{M}
$$

onde:

$$
\begin{aligned}
& { }^{*} N u_{b}=\frac{h_{b} \cdot D_{h}}{k_{L}} \text { e } N u=\frac{h_{L} \cdot D}{k_{L}} \\
& \operatorname{Re}_{L}=\frac{G_{L} \cdot D}{\mu_{L}}=\frac{\left(\dot{m}_{L} / A\right) \cdot D}{\mu_{L}}
\end{aligned}
$$

e

$$
\operatorname{Re}_{b}=\frac{\dot{m}_{L} \cdot D_{h}}{A_{L} \cdot \mu_{L}}=\frac{\left(G_{L} \cdot A\right) \cdot D_{h}}{A_{L} \cdot \mu_{L}}
$$

onde o diâmetro hidráulico, $\mathrm{D}_{\mathrm{h}}$, pode ser avaliado como:

$$
\begin{gathered}
D_{h}=\frac{4 \cdot A_{L}}{\wp}=\frac{4 \cdot(\pi \cdot D \cdot \delta)}{\pi \cdot D}=4 \delta \quad \therefore \\
\left(\frac{h_{b}}{h_{L}}\right) \cdot\left(\frac{4 \cdot \delta}{D}\right)=\left(\frac{\mathrm{Re}_{b}}{\mathrm{Re}_{L}}\right)^{M}
\end{gathered}
$$

Como,

$$
\frac{A}{A_{L}}=\frac{1}{(1-\alpha)}=\frac{D}{4 \delta}
$$

e,

* $\mathrm{D}_{\mathrm{h}}$ se refere ao diâmetro hidráulico do filme de líquido junto à superfície do tubo 


$$
\frac{\mathrm{Re}_{b}}{\mathrm{Re}_{L}}=1
$$

a Eq. (2.4) pode ser reduzida a:

$$
\frac{h_{b}}{h_{L}}=\frac{1}{(1-\alpha)}
$$

A fração de vazio, $\alpha$, é de difícil determinação experimental, razão pela qual, a seguir, far-se-á uma tentativa de relacioná-la com o título, x. Para tanto será utilizado o modelo de Martinelli e colaboradores. Este consiste em definir os multiplicadores bifásicos, $\phi_{\mathrm{v}}^{2}$ e $\phi_{\mathrm{L}}^{2}$, de acordo com as seguintes relações:

$$
\phi_{V}{ }^{2}=\frac{(d P / d z)_{b}}{(d P / d z)_{V}} \text { e } \quad \phi_{L}{ }^{2}=\frac{(d P / d z)_{b}}{(d P / d z)_{L}}
$$

Os subscritos V e L referem-se aos gradientes de pressão que se verificariam caso o vapor ou o líquido da mistura bifásica escoassem isoladamente no mesmo duto. LOCKHART \& MARTINELLI (1949) introduziram o parâmetro X, tal que:

$$
X^{2}=\frac{\phi_{V}{ }^{2}}{{\phi_{L}}^{2}}=\frac{(d P / d z)_{L}}{(d P / d z)_{V}}
$$

O termo $(d P / d z)$ representa o gradiente de pressão no escoamento, resultante apenas do efeito do atrito, pois os trabalhos de Martinelli foram desenvolvidos para tubos horizontais, sem mudança de fase. Nessas condições, o gradiente de pressão resulta exclusivamente do atrito, uma vez que os efeitos da aceleração e da gravidade são nulos.

Inicialmente foi considerada uma expressão para o gradiente de pressão a partir de uma relação do tipo de Blasius para o coeficiente de atrito: $\mathrm{C}_{f}=\mathrm{C} \cdot \mathrm{Re}^{-\mathrm{n}}$, , resultando:

$$
\left(-\frac{d P}{d z}\right)=2 \cdot C_{f} \cdot\left(\frac{\rho \cdot V_{m e d}^{2}}{D}\right)=2 \cdot C \cdot \operatorname{Re}^{-n} \cdot \frac{\rho \cdot V_{m e d}^{2}}{D}=2 \cdot C \cdot\left(\frac{\rho \cdot V_{m e d} \cdot D}{\mu}\right)^{-n} \cdot\left(\frac{\rho}{D}\right) \cdot V_{\text {med }}^{2}
$$

A velocidade média do escoamento, $\mathrm{V}_{\text {med, }}$, dada por:

$$
V_{\text {med }}=\frac{G}{\rho}
$$

então,

\footnotetext{
* $n=1$ para escoamento laminar e $n=0,25$ ou 0,2 para escoamento turbulento em tubos lisos, dependendo do autor.
} 


$$
\left(-\frac{d P}{d z}\right)=\frac{2 \cdot C}{\rho} \cdot \frac{G^{2-n}}{D^{n+1} \cdot \mu^{-n}}
$$

Pode ser facilmente demonstrado, conforme SAIZ JABARDO (1995), que a relação entre o parâmetro $\mathrm{X}$ e a fração de vazio $\alpha$, pode ser obtida pelo seguinte procedimento:

$$
\phi_{L}^{2}=\left(\frac{A}{A_{L}}\right)^{2-n} \cdot\left(\frac{D}{D_{L}}\right)^{n+1}
$$

do que resulta:

$$
\phi_{L}^{2}=\left(\frac{1}{1-\alpha}\right)^{m}
$$

onde,

$$
m=\frac{(5-n)}{2}
$$

Analogamente,

$$
\phi_{V}^{2}=\left(\frac{1}{\alpha}\right)^{m}
$$

Assim,

$$
X^{2}=\frac{\phi_{V}^{2}}{\phi_{L}^{2}}=\left(\frac{1-\alpha}{\alpha}\right)^{m}
$$

Percebe-se, assim, que $\alpha$ depende do parâmetro X. É interessante observar que tal parâmetro, conhecido como parâmetro de Martinelli, independe das características do escoamento, sendo função das propriedades das fases e do título. Utilizando a forma de Blasius para o coeficiente de atrito, no caso em que o regime é turbulento quando as fases escoam isoladamente no tubo, condição em que $\mathrm{X}$ é afetado do índice $\mathrm{tt}$, resulta:

$$
X^{2}{ }_{t t}=\frac{\phi^{2}{ }_{V}}{\phi^{2}{ }_{L}}=\left(\frac{G_{L}}{G_{V}}\right)^{2-n} \cdot\left(\frac{\rho_{V}}{\rho_{L}}\right) \cdot\left(\frac{\mu_{L}}{\mu_{V}}\right)^{n}
$$

como: $\frac{G_{L}}{G_{V}}=\left(\frac{1-x}{x}\right) \quad e \quad n=0,25$ (escoamento turbulento)

fazendo a substituição,

$$
X_{n}=\left(\frac{1-x}{x}\right)^{0,875} \cdot\left(\frac{\rho_{V}}{\rho_{L}}\right)^{0,5} \cdot\left(\frac{\mu_{L}}{\mu_{V}}\right)^{0,125}
$$

$\mathrm{Na}$ literatura é comum encontrar uma expressão parecida, correspondendo a um valor de $\mathrm{n}=$ 0,2 , do que resulta: 


$$
X_{t}=\left(\frac{1-x}{x}\right)^{0,9} \cdot\left(\frac{\rho_{V}}{\rho_{L}}\right)^{0,5} \cdot\left(\frac{\mu_{L}}{\mu_{V}}\right)^{0,1}
$$

Do exposto nos parágrafos precedentes e da Eq. (2.5), é possível concluir que:

$$
\frac{h_{b}}{h_{L}}=f\left(X_{t t}\right)
$$

Os primeiros estudos envolvendo o coeficiente de transferência de calor em ebulição foram baseados no mesmo princípio de cálculo do coefíciente de transferência de calor monofásico, através da Analogia de Colburn,

$$
j_{H}=\frac{f}{8}
$$

onde, o fator de Colburn, $j_{H}$, é definido como:

$$
\begin{aligned}
& j_{H}=S t \cdot \operatorname{Pr}^{\frac{2}{3}} \quad \therefore \\
& j_{H}=N u \cdot \operatorname{Re}_{D}{ }^{-1} \cdot \operatorname{Pr}^{-\frac{1}{3}}
\end{aligned}
$$

Com relação ao coeficiente de atrito, $f$, (de Darcy), para $\mathrm{Re}_{D}>2 \cdot 10^{4}$ e superfícies lisas, uma correlação relativamente generalizada na literatura é a seguinte:

$$
f=0,184 \cdot \operatorname{Re}_{D}{ }^{-\frac{1}{5}}
$$

Combinando as Eqs. (2.10), (2.12) e (2.13), resulta:

$$
N u=0,023 \cdot \operatorname{Re}^{4 / 5} \cdot \operatorname{Pr}{ }^{1 / 3}
$$

DITTUS \& BOELTER (1930) alteraram o expoente do número de Prandtl da Eq. (2.14) para ajustá-la a resultados empiricamente obtidos. Nessas condições, propuseram um expoente igual a 0,3 , no caso de resfriamento do fluido, e 0,4 , no caso de aquecimento. A correlação de Dittus-Boelter, dada abaixo pela Eq. (2.15), para aquecimento, é uma das correlações mais aceitas e utilizadas, fato este provavelmente devido à sua simplicidade.

$$
N u=0,023 \cdot \mathrm{Re}_{D}^{0,8} \cdot \mathrm{Pr}^{0,4}
$$

Segundo INCROPERA \& De WITT (1990), a correlação de Dittus-Boelter pode levar, entretanto, a erros relativamente elevados, caso seja aplicada em condições distintas para as que foi proposta, quais sejam:

$$
\begin{aligned}
& 0,7 \leq \operatorname{Pr} \leq 120 \\
& \operatorname{Re}_{D} \geq 10^{4}
\end{aligned}
$$


Outras correlações para o cálculo do coeficiente de transferência de calor em escoamento monofásico foram desenvolvidas, onde se destacam a de PETHUKOV (1970) e a de GNIELINSKI (1976). Um resumo de excelente nível pode ser encontrado em KAKAÇ et al (1986). A opção pela correlação de Dittus-Boelter deve-se à sua simplicidade e adequabilidade. Esta (a adequabilidade) está associada a números de Reynolds relativamente reduzidos $\left(10000<\operatorname{Re}_{\mathrm{D}}<100000\right)$, típicos daqueles resultantes das condições operacionais comumente encontradas.

Com relação ao coeficiente de transferência de calor monofásico, deve-se notar que alguns autores utilizam $h_{L O}$ ao invés de $h_{L}$. A diferença entre os índices está relacionada à definição do coeficiente monofásico. LO é utilizado para a condição em que a mistura escoa como líquido no tubo, ao passo que $\mathrm{L}$, como observado anteriormente, designa o caso em que o líquido da mistura bifásica escoa isoladamente no tubo. $\mathrm{O}$ coeficiente de transferência de calor monofásico, $h_{\mathrm{LO}}$, pode ser avaliado pela correlação de Dittus-Boelter. O número de Prandtl, Pr, e a condutividade térmica, $\mathrm{k}_{\mathrm{L}}$ não são afetados, uma vez que constituem propriedades de transporte associadas ao líquido. Assim:

$$
\operatorname{Re}_{L O}=\frac{G \cdot D}{\mu_{L}}
$$

Portanto,

$$
h_{L O}=0,023 \cdot \frac{k_{L}}{D} \cdot \operatorname{Re}_{L O} O^{0,8} \cdot \operatorname{Pr}_{L}{ }^{0,4}
$$

Analogamente,

$$
h_{L}=0,023 \cdot \frac{k_{L}}{D} \cdot \operatorname{Re}_{L}^{0,8} \cdot \operatorname{Pr}_{L}^{0,4}
$$

A seguir será realizada uma análise detalhada das correlações, encontradas na literatura, mais representativas deste grupo.

A correlação de DENGLER \& ADDOMS (1956) foi desenvolvida para água escoando num tubo vertical de $25,4 \mathrm{~mm}$ de diâmetro. A vazão variou de 100 a $2000 \mathrm{~kg} / \mathrm{h}$, o título entre 0 e $70 \%$ e a pressão entre 50 e $270 \mathrm{kPa}$. Os autores correlacionaram os resultados experimentais em termos de $h_{\mathrm{LO}}$, ao invés de $\mathrm{h}_{\mathrm{L}}$, como ilustrado anteriormente. Esta correlação é considerada uma das clássicas, mesmo tendo sido desenvolvida para água em tubo vertical. Os resultados proporcionados pela correlação resultaram em desvios na ordem de $30 \%$ em relação aos seus resultados experimentais. A correlação proposta foi a seguinte:

$$
\frac{h_{b}}{h_{L O}}=3,5 \cdot\left(X_{t t}\right)^{-0,5}
$$


GUERRIERI \& TALTY (1956) propuseram a correlação (2.20) a partir de resultados experimentais envolvendo fluidos como metanol, benzeno, pentano, hexano cíclico e heptano, escoando em tubo de latão de 3/4" a 1" de diâmetro. A pressão utilizada nos ensaios foi de $100 \mathrm{kPa}$ e os títulos na entrada da seção de testes variaram de 1 a $12 \%$. 0 coeficiente de transferência de calor utilizado foi o $\mathrm{h}_{\mathrm{L}}$, Eq. (2.18), referido à fase líquida escoando isoladamente no tubo. A diferença para a correlação de Dengler-Addoms está no coeficiente de transferência de calor monofásico, já que na Eq. (2.19), adotou-se o $h_{\text {LO }}$.

$$
\frac{h_{b}}{h_{L}}=3,4 \cdot\left(X_{n}\right)^{-0,45}
$$

A correlação de Guerrieri-Talty proporcionou desvios médios da ordem de $12 \% \mathrm{em}$ relação aos próprios resultados experimentais.

CHADDOCK \& NOERAGER (1966) desenvolveram sua correlação para a determinação do coeficiente de transferência de calor utilizando a média dos coeficientes locais de transferência de calor, medidos em quatro posições da seção transversal da superficie do tubo: no topo, dos lados e no fundo. Para o desenvolvimento da correlação foram utilizados 20 pontos experimentais, sendo que os resultados envolvendo possível secagem da parede foram descartados.

Um tubo de aço inox foi usado como seção de testes, apresentando diâmetro interno de $12,7 \mathrm{~mm}$. O fluxo de calor, $\phi$, variou entre $2200 \mathrm{~W} / \mathrm{m}^{2}$ e $11000 \mathrm{~W} / \mathrm{m}^{2}$ e a velocidade mássica $\mathrm{G}$, entre 100 e $433 \mathrm{~kg} / \mathrm{m}^{2}$.s. O título na entrada da seção de testes foi mantido constante e igual a $20 \%$, o mesmo acontecendo com a temperatura de evaporação, mantida igual a $8,3^{\circ} \mathrm{C}$. Como fluido de trabalho utilizou-se o CFC-12. Os autores correlacionaram os dados experimentais de dois modos distintos. Inicialmente, adotaram o coeficiente de transferência de calor monofásico, $\mathrm{h}_{\mathrm{LO}}$, como parâmetro de referência e, posteriormente, utilizaram $h_{L}$. As correlações obtidas foram as seguintes:

$$
\begin{aligned}
& \frac{h_{b}}{h_{L O}}=3,0 \cdot\left(X_{t t}\right)^{-(2 / 3)} \\
& \frac{h_{b}}{h_{L}}=3,0 \cdot\left(X_{t t}\right)^{-(1,0)}
\end{aligned}
$$


Como foram utilizados poucos resultados experimentais os desvios máximos proporcionados pela correlação foram da ordem de $20 \%$. É importante ressaltar que as correlações acima devem ser utilizadas com certa reserva, dado o reduzido número de pontos experimentais utilizados no seu desenvolvimento, além de envolverem um único fluido, $\mathrm{R}^{*}$ 12.

As correlações que serão apresentadas a seguir foram desenvolvidas no ACRC, Centro de Refrigeração e Ar Condicionado da University of Illinois. A primeira Eq. (2.23), proposta por WATTELET et al (1991), foi desenvolvida a partir de dados obtidos com o refrigerante R-12. Em todos os testes, o título na entrada foi mantido constante e igual a $20 \%$ e a temperatura de evaporação da ordem de $4,4{ }^{\circ} \mathrm{C}$. Os resultados obtidos devem ser aceitos, também, com certa reserva, pois os ensaios foram realizados com certa precariedade de instrumentação, especialmente para a medida da temperatura superficial. A correlação proposta foi a seguinte:

$$
\frac{h_{b}}{h_{L}}=2,30 \cdot\left(X_{t t}\right)^{-(0,666)}
$$

Em fase posterior, a bancada de testes passou por reformas no sentido de melhorar a aquisição de dados, tendo proporcionado resultados que foram tratados por PANEK (1992). Os padrões observados nos ensaios foram o anular e estratificado ondulado. Alguns resultados envolvendo secagem de parede foram omitidos da análise. Os fluidos refrigerantes ensaiados foram o R-12 e o R-134a. O comprimento da seção testes era de, aproximadamente, $2,44 \mathrm{~m}$. O título na entrada variou entre 20 e $60 \%$, o fluxo de calor entre 5 e $30 \mathrm{~kW} / \mathrm{m}^{2}$ e a velocidade mássica, G, entre 100 e $500 \mathrm{~kg} / \mathrm{m}^{2}$.s. A visualização do escoamento foi possível pela instalação de visores a montante e a jusante da seção de testes.

A regressão dos resultados experimentais obtidos proporcionou a seguinte correlação:

$$
\frac{h_{b}}{h_{L}}=3,686 \cdot\left(X_{t \prime}\right)^{-(0,563)}
$$

A correlação acima está afetada de desvios médios da ordem de 11,7\% para o R-12 e $8,7 \%$ para o R-134a, relativamente aos resultados experimentais.

\footnotetext{
* A nomenclatura R é utilizada para designar Refrigerante, no caso R-12 refere-se ao CFC-12.
} 
CHADDOCK \& BUZARD (1986) propuseram a correlação (2.25) para o refrigerante R-502. Na seção de testes foi utilizado tubo de cobre de aproximadamente 2 metros de comprimento, aquecido eletricamente. Através de um variador de voltagem foi aplicado um fluxo de calor máximo de $23,6 \mathrm{~kW} / \mathrm{m}^{2}$, e um mínimo de $1,9 \mathrm{~kW} / \mathrm{m}^{2}$. A velocidade mássica variou entre 45 e $358 \mathrm{~kg} / \mathrm{m}^{2}$.s. Foram usados três visores na seção de testes, a montante, no meio e a jusante com o objetivo de observar os padrões de escoamento. Alguns ensaios incluíram a presença de óleo para verificar seu efeito na taxa de transferência de calor. $\mathrm{O}$ fluxo de calor e a vazão foram adequadamente ajustados para garantir uma completa evaporação do líquido na seção. A correlação apresentou a seguinte forma:

$$
\frac{h_{b}}{h_{L}}=\left(\frac{0,785}{X_{t t}}\right) \cdot\left(1+3,83 \cdot X_{t t}{ }^{0,81}\right)
$$

Essa correlação apresenta desvios máximos na faixa de $35 \%$ e foi desenvolvida a partir de 40 pontos experimentais para o R-502, novamente, devido ao reduzido números de pontos, deve ser aceita com certa reserva.

Com o objetivo de propor uma configuração fisicamente mais adequada, BANDARRA FILHO et al (1997) desenvolveram um modelo baseado em cerca de 600 pontos experimentais para o refrigerante HFC-134a, levantados no ACRC, Centro de Refrigeração e Ar Condicionado da University of Illinois. As condições de teste foram: velocidade mássica variou entre 50 e $500 \mathrm{~kg} / \mathrm{m}^{2}$.s; o fluxo de calor entre 3 e $30 \mathrm{~kW} / \mathrm{m}^{2}$; título na entrada da seção de testes entre 5 e $90 \%$ e temperatura de entrada no evaporador entre -20 e $15^{\circ} \mathrm{C}$. Estas condições representam adequadamente aquelas observadas em sistemas frigoríficos convencionais. As correlações estritamente convectivas propostas na literatura envolvem resultados empíricos, onde predomina o padrão anular de escoamento. Assim, pela sua característica de aplicação, tais correlações se apresentam numa forma que não permite a extrapolação para títulos reduzidos, tendo como limite a condição de escoamento monofásico na fase líquida $(\mathrm{x}=0)$. No estudo empírico apresentado no referido trabalho foi incorporada tal possibilidade, razão pela qual a correlação desenvolvida é dada da seguinte forma: 


$$
\frac{h_{b}}{h_{L}}=1+3,0 \cdot\left(X_{t t}\right)^{-(0,65)}
$$

Esta correlação apresentou um desvio médio da ordem de 14\%, razoável para ampla faixa de condições operacionais para o qual os resultados experimentais foram obtidos.

\subsection{Análise Comparativa das Correlações do Grupo 1}

As correlações estritamente convectivas são muito semelhantes entre si, no sentido em que todas são apresentadas numa forma adimensional, função do parâmetro de Martinelli, $X_{\mathrm{tt}}$, diferenciando no fator numérico. Estas correlações aparentemente podem ser extensivas a distintos fluidos pela incorporação do parâmetro adimensional de Martinelli, $\mathrm{X}_{\mathrm{tt}}$. Outra característica favorável é a sua simplicidade, o que facilita sua aplicação.

Como observado nas seções precedentes, as correlações estritamente convectivas foram obtidas de forma empírica, através da correlação de resultados experimentais. Nessas condições, como os resultados experimentais tratavam de condições para as quais os títulos, em sua maioria, eram relativamente elevados, não houve preocupação com as condições limite. Assim, a condição para $X_{t t} \rightarrow \infty$, não é geralmente satisfeita, uma vez que tal condição deveria corresponder ao escoamento de líquido na seção do tubo, o que implicaria num valor

de $\frac{h_{b}}{h_{L}}$ igual a 1 . Nessas condições, uma configuração mais adequada para estas correlações deveria apresentar a forma da correlação proposta por BANDARRA FILHO et al (1997), ou seja:

$$
\frac{h_{b}}{h_{L}}=1+C_{1} \cdot X_{t t}^{-C_{2}}
$$

Ao analisar esta última equação, quando o $X_{\mathrm{tt}}$ tende a infinito, o membro da esquerda tende a um., em outras palavras, $o h_{b}$ tende $a h_{L}$, o que é fisicamente consistente.

A seguir, na Tabela 2.1, será apresentado um sumário das correlações estritamente convectivas. 
Tabela 2.1 Sumário das correlações estritamente convectivas.

\begin{tabular}{|c|c|c|c|}
\hline Autor & Correlação & Fluidos & Condições \\
\hline $\begin{array}{l}\text { Dengler \& } \\
\text { Addoms } \\
(1956)\end{array}$ & $\frac{h_{b}}{h_{L O}}=3,5 \cdot\left(X_{t u}\right)^{-0.5}$ & Água & $\begin{array}{c}\text { D: } 25,4 \mathrm{~mm} \\
\text { G: } 55 \text { a } 1100 \\
\mathrm{~kg} / \mathrm{m}^{2} . \mathrm{s} \\
\mathrm{x}_{\mathrm{en}}: 0 \text { a } 70 \%\end{array}$ \\
\hline $\begin{array}{l}\text { Guerrieri \& Talty } \\
(1956)\end{array}$ & $\frac{h_{b}}{h_{L}}=3,4 \cdot\left(X_{n}\right)^{-0,45}$ & $\begin{array}{c}\text { Metanol, } \\
\text { Benzeno, Hexano. }\end{array}$ & $\begin{array}{c}\text { D: } 19 \text { e } 25,4 \mathrm{~mm} \\
\mathrm{P}_{\mathrm{sat}}=100 \mathrm{kPa} \\
\mathrm{x}_{\mathrm{en}}: 1 \text { a } 12 \% \\
\end{array}$ \\
\hline $\begin{array}{c}\text { Chaddock \& } \\
\text { Noerager } \\
\text { (1966) }\end{array}$ & $\begin{array}{l}\frac{h_{b}}{h_{L O}}=3,0 \cdot\left(X_{t}\right)^{-(2 / 3)} \\
\frac{h_{b}}{h_{L}}=3,0 \cdot\left(X_{t t}\right)^{-(1,0)}\end{array}$ & $\mathrm{R}-12$ & $\begin{array}{c}\text { D: } 12,7 \mathrm{~mm} \\
\text { G: } 100 \text { a } 433 \\
\mathrm{~kg} / \mathrm{m}^{2} . \mathrm{s} \\
\phi: 2,2 \text { a } 11 \mathrm{~kW} / \mathrm{m}^{2} \\
\mathrm{x}_{\mathrm{en}}: 20 \% \\
\end{array}$ \\
\hline $\begin{array}{c}\text { ACRC-1 } \\
\text { Wattelet et al } \\
(1991)\end{array}$ & $\frac{h_{b}}{h_{L}}=2,30 \cdot\left(X_{n}\right)^{-(0,666)}$ & $R-12$ & $\begin{array}{c}\mathrm{D}: 12,7 \mathrm{~mm} \\
\mathrm{x}_{\mathrm{en}}: 20 \% \\
\mathrm{~T}_{\text {sat }}=4,4^{\circ} \mathrm{C} \\
\end{array}$ \\
\hline $\begin{array}{c}\text { ACRC-2 } \\
\text { Panek (1992) }\end{array}$ & $\frac{h_{b}}{h_{L}}=3,686 \cdot\left(X_{H}\right)^{-(0,563)}$ & $\begin{array}{c}\mathrm{e} \\
\mathrm{R}-134 \mathrm{a}\end{array}$ & $\begin{array}{c}\text { D: } 10,2 \text { e } 12,7 \mathrm{~mm} \\
\text { G: } 100 \text { a } 500 \\
\mathrm{~kg} / \mathrm{m}^{2} . \mathrm{s} \\
\phi: 5 \text { a } 30 \mathrm{~kW} / \mathrm{m}^{2} \\
\mathrm{x}_{\mathrm{en}}: 20 \text { a } 60 \% \\
\end{array}$ \\
\hline $\begin{array}{l}\text { Chaddock \& } \\
\text { Buzard } \\
\text { (1986) }\end{array}$ & $\frac{h_{b}}{h_{L}}=\left(\frac{0,785}{X_{t}}\right) \cdot\left(1+3,83 \cdot X_{t}{ }^{0,81}\right)$ & $\mathrm{R}-502$ & $\begin{array}{c}\text { D: } 12,7 \mathrm{~mm} \\
\text { G: } 45 \text { a } 358 \mathrm{~kg} / \mathrm{m}^{2} . \mathrm{s} \\
\phi: 1,9 \text { a } 23,6 \\
\mathrm{~kW} / \mathrm{m}^{2}\end{array}$ \\
\hline $\begin{array}{c}\text { Bandarra Filho et } \\
\text { al (1997) }\end{array}$ & $\frac{h_{b}}{h_{L}}=1+3,0 \cdot\left(X_{t t}\right)^{-(0,65)}$ & R-134a & $\begin{array}{c}\text { G: } 50 \text { a } 500 \mathrm{~kg} / \mathrm{m}^{2} \cdot \mathrm{s} \\
\phi: 3 \text { a } 30 \mathrm{~kW} / \mathrm{m}^{2} \\
x_{\text {en }}: 5 \text { a } 90 \%\end{array}$ \\
\hline
\end{tabular}

A seguir será apresentado um gráfico comparativo entre as correlações estritamente convectivas, mostrando a relação dos coefícientes de transferência de calor bifásico, $\mathrm{h}_{\mathrm{b}}$, em função do título, x, para condições operacionais típicas. 


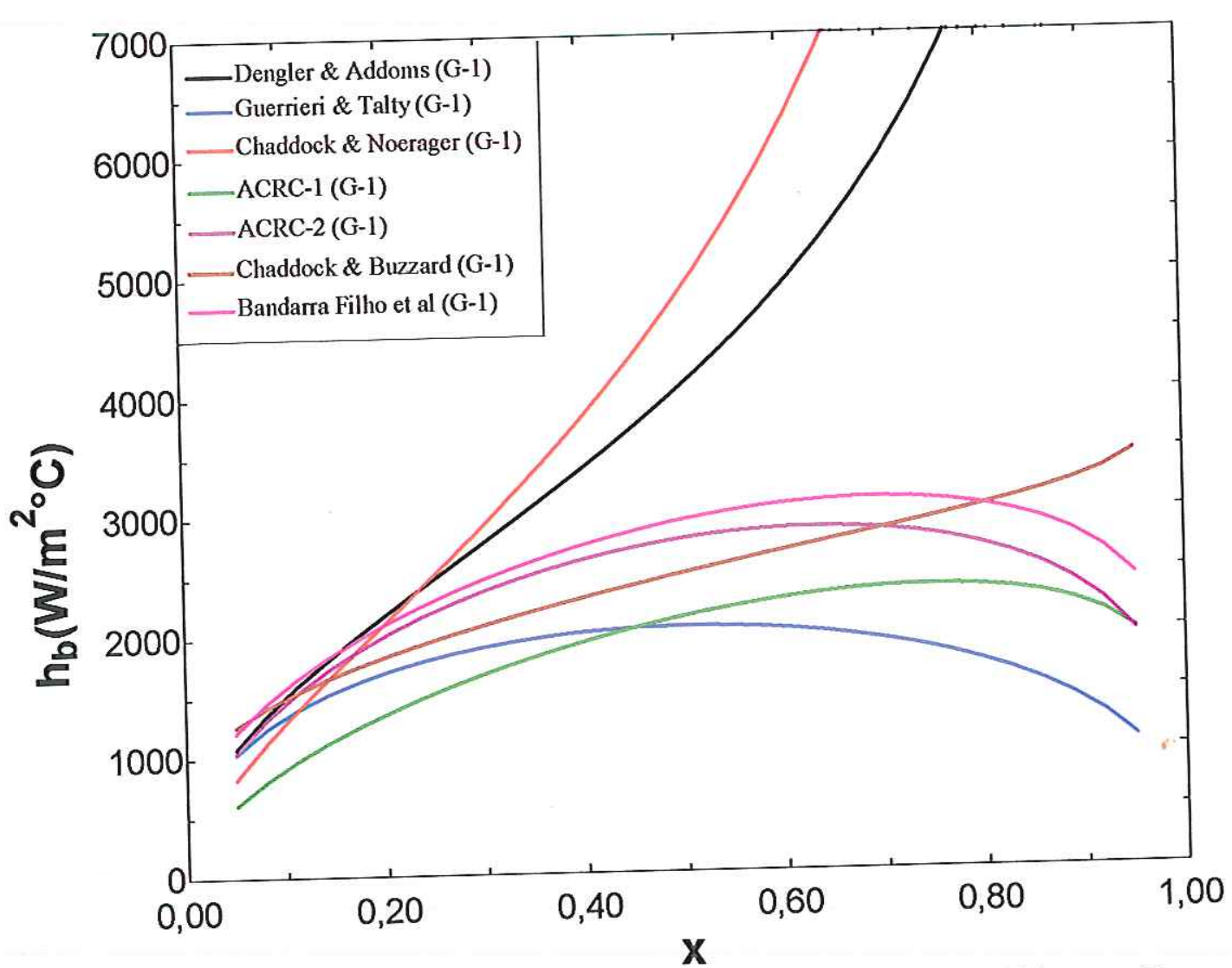

Figura 2.9 Comparação entre correlações estritamente convectivas para $\mathrm{R}-134 \mathrm{a}, \mathrm{com}_{\mathrm{sat}}=-$ $5^{\circ} \mathrm{C} \mathrm{e} \mathrm{G}=300 \mathrm{~kg} / \mathrm{m}^{2} . \mathrm{s}$.

É notável a discrepância entre os resultados proporcionados pelas distintas correlações, como pode ser observado no gráfico da Fig. 2.9. Observa-se que as correlações de Dengler-Addoms e de Chaddock-Noerager apresentam valores do coeficiente de transferência de calor superiores às demais. No caso da correlação de Dengler-Addoms, tal comportamento pode resultar do fato de tratar-se de água que, de forma geral, deve apresentar coeficientes superiores aos demais fluidos. No caso da correlação de ChaddockNoerager, poderia ser argumentado que o elevado valor do coeficiente de transferência de calor foi resultado da presença de óleo (em concentrações da ordem de $0,1 \%$ ), o que, no entanto, não justificaria a elevação observada. Deve-se notar que o número de pontos experimentais com que esses autores trabalharam foi relativamente reduzido para que se possam extrair conclusões definitivas.

Apesar do caráter pretensamente generalizado deste grupo de correlações, pela incorporação do parâmetro de Martinelli, $X_{\mathrm{tt}}$, verifica-se que alguns efeitos não são adequadamente correlacionados, qual seja o fluido e, por que não o título, velocidade mássica, $\mathrm{G}$, ou mesmo o fluxo de calor, $\phi$. É interessante destacar, ainda, as diferenças entre as correlações quanto às condições operacionais, como observado na Tabela 2.1. 


\subsubsection{Correlações Baseadas na Superposição de Efeitos}

O mecanismo da superposição de efeitos foi introduzido para levar em consideração a possibilidade de ocorrência simultânea dos efeitos convectivos e de ebulição nucleada. Os padrões de escoamento que potencialmente apresentariam as condições fisicas para a superposição de efeitos são: bolhas e pistonado e sua transição para os padrões anular e estratificado. Em certos casos, embora as correlações que envolvem a superposição de efeitos sejam aplicadas, é possível que não se verifique a presença de bolhas. Deve-se reconhecer, no entanto, que as correlações foram propostas ou desenvolvidas para ajustar resultados experimentais. Por outro lado, a ocorrência da ebulição nucleada têm sido constatada ou proposta, não como resultado de observações físicas diretas, mas da análise de dados experimentais em que se verifica uma dependência do fluxo de calor por parte do coeficiente de transferência de calor, o que efetivamente, se observa na ebulição nucleada. Assim, resultaram diversas correlações que serão discutidas a seguir. Destacam-se entre elas, a correlação de CHEN (1966), por tratar-se da primeira, e as que utilizam o método de KUTATELADZE (1961), ou modelo assintótico, que propõe uma superposição não linear de efeitos.

Em evaporadores para aplicações frigoríficas com expansão seca, aqueles alimentados por uma válvula de expansão termostática ou tubo capilar, a possibilidade de ocorrência simultânea dos dois mecanismos é questionável. Tal não é o caso em evaporadores com recirculação, onde o mecanismo predominante deve ser o da ebulição nucleada, com possivel ocorrência dos efeitos convectivos nos estágios finais. A seguir serão apresentadas as principais correlações pertencentes ao grupo 2 .

A correlação de CHEN (1966) foi a primeira proposta para o cálculo do coeficiente de transferência de calor na região bifásica, que introduziu a superposição de efeitos, incorporando os fatores de correção, $\mathrm{F} \mathrm{e} \mathrm{S}^{*}$. Essa correlação foi baseada num banco de dados de 594 pontos experimentais. Todos os resultados estavam associados a escoamento vertical, utilizando como fluido a água e alguns fluidos orgânicos. $\mathrm{O}$ desvio médio encontrado por Chen entre os coefícientes medido e calculado foi de $12 \%$. A correlação obtida é a seguinte:

$$
h_{b}=h_{L} \cdot F_{C H}+h_{E N F} \cdot S_{C H}
$$

\footnotetext{
* $F$ corresponderia aproximadamente ao parâmetro corretivo $f\left(X_{t t}\right)$ das correlações do grupo 1, ao passo que $\mathrm{S}$ foi denominado de fator de supressão de bolhas, associado a efeitos de ebulição nucleada.
} 
Inicialmente, CHEN (1966) admitiu que o termo $h_{L}$ poderia ser determinado pela correlação de Dittus-Boelter, Eq. (2.18), porém aplicado ao escoamento bifásico, de acordo com a seguinte relação:

$$
h_{b}=\frac{k_{b}}{D} \cdot 0,023 \cdot \operatorname{Re}_{b}^{0,8} \cdot \operatorname{Pr}_{b}{ }^{0,4}
$$

$\mathrm{O}$ índice $\mathrm{b}$ refere-se ao escoamento bifásico. Como em mudança de fase convectiva o líquido se encontra em contato com a parede do tubo, os parâmetros $\operatorname{Pr}_{b}$ e $k_{b}$ estão associados à fase líquido, ou seja: $\operatorname{Pr}_{\mathrm{L}}$ e $\mathrm{k}_{\mathrm{L}}$. Para a avaliação de $\mathrm{Re}_{\mathrm{b}}$, CHEN (1966) introduziu uma relação entre $\operatorname{Re}_{b}$ e $\operatorname{Re}_{\mathrm{L}}$, dada na equação abaixo:

$$
F=\left(\frac{\mathrm{Re}_{s}}{\mathrm{Re}_{L}}\right)^{0.8}
$$

Através dos resultados experimentais foram levantadas curvas para a determinação gráfica do parâmetro F. Mais tarde COLLIER (1981) ajustou uma curva àqueles resultados de Chen, propondo a seguinte relação para o cálculo de $\mathrm{F}_{\mathrm{CH}}$ :

$$
\begin{aligned}
& F_{C H}=1 \quad \text { para } \frac{1}{X_{t t}} \leq 0,1 \\
& F_{C H}=2,35 \cdot\left(\frac{1}{X_{t}}+0,213\right)^{0,736} \quad \text { para } \frac{1}{X_{t}}>0,1
\end{aligned}
$$

De acordo com o que foi apresentado anteriormente, $\mathrm{F}_{\mathrm{CH}}$ corresponde à relação $h_{b} / h_{L}$ das correlações estritamente convectivas, o que justificaria o fato de ter sido relacionado ao parâmetro de Martinelli, $X_{\mathrm{tt}}$.

CHEN (1966) escolheu uma das correlações disponíveis na literatura para ebulição nucleada, a equação de FOSTER \& ZUBER (1955), apresentada abaixo:

$$
h_{E N F}=0,00122 \cdot\left[\frac{k_{L}^{0,79} \cdot c p_{L}^{0,45} \cdot \rho_{L}^{0,49}}{\sigma^{0,5} \cdot \mu_{L}^{0,29} \cdot i_{L V}{ }^{0,24} \cdot p_{V}}\right] \cdot \Delta T_{\text {sat }}{ }^{0,24} \cdot \Delta P_{\text {sat }}{ }^{0,75}
$$

$\mathrm{O}$ fator $\mathrm{S}$ depende diretamente da velocidade do escoamento, através do número de Reynolds. Quanto maior a velocidade mássica, G, menor é a espessura da subcamada limite laminar, inibindo a formação e nucleação de bolhas. Se esta camada é espessa, oferece condições para o crescimento e o desprendimento da bolha. Por outro lado, se a subcamada atingir o valor do diâmetro de desprendimento de bolha, a nucleação pode ser comprometida. Utilizando esta argumentação física, CHEN (1966) introduziu um fator para levar em 
consideração este fenômeno, denominando-o de "Fator de Supressão de Bolhas", S, definido como:

$$
S=\left(\frac{\Delta T_{\text {sat }}}{\Delta T_{\text {ef }}}\right)^{0,99}
$$

S apresenta um valor máximo quando a vazão tende a zero, ou seja, ebulição em piscina, condição para a qual $\mathrm{S}$ tende a um valor unitário. $\mathrm{O}$ menor valor ocorre para vazões elevadas, para as quais o gradiente de temperatura junto à parede é mais pronunciado. Nessas condições, S deverá tender a zero. CHEN (1966) avaliou o fator de supressão S na forma gráfica. COLLIER (1981) sugeriu uma correlação para seu cálculo em termos de $\mathrm{Re}_{\mathrm{L}}$, como seria de esperar, resultando:

$$
S_{C H}=\frac{1}{\left(1+2,53 \cdot 10^{6} \cdot \operatorname{Re}_{L}^{1,17}\right)}
$$

É interessante notar que $\mathrm{S}_{\mathrm{CH}}$ é inversamente proporcional a $\mathrm{Re}_{\mathrm{L}}$, evidenciando o efeito da vazão anteriormente discutido.

GUNGOR \& WINTERTON (1986) propuseram um refinamento para o modelo de Chen, utilizando um banco de dados de mais de 4300 pontos experimentais, com resultados para fluidos como a água, refrigerantes e etileno glicol. Partiram do mesmo princípio de Chen, propondo uma correlação com a seguinte forma:

$$
h_{b}=h_{L} \cdot F_{G W}+h_{E N C} \cdot S_{G W}
$$

Algumas modificações, em relação ao modelo de Chen, foram propostas para os efeitos convectivos e de ebulição nucleada. Alguns modelos, que utilizam o fator $\mathrm{F}$ como função do parâmetro de Martinelli, foram obtidos a vazões relativamente elevadas, para as quais o efeito do fluxo de calor é praticamente desprezível. Entretanto, para vazões menores, resultados experimentais demonstraram que o fluxo de calor afeta o coeficiente de transferência de calor na mudança de fase convectiva. Nessas condições, GUNGOR \& WINTERTON (1986) sugeriram que o fator $\mathrm{F}_{\mathrm{GW}}$ incorporasse, além do parâmetro de Martinelli, $\mathrm{X}_{\mathrm{tt}}$, o número de ebulição, Bo. Em outras palavras, através do adimensional Bo, 
os efeitos do fluxo de calor são levados em consideração. A terceira parcela da equação abaixo, corresponde àquela das correlações estritamente convectivas. $\mathrm{O}$ parâmetro $\mathrm{F}_{\mathrm{GW}}$ foi assim definido:

$$
F_{G W}=1+24000 \cdot B o^{1,16}+1,37 \cdot\left(\frac{1}{X_{n}}\right)^{0,86}
$$

$\mathrm{Na}$ avaliação do coeficiente de transferência de calor, $h_{L}$, os autores sugerem a correlação de Dittus-Boelter, Eq. (2.18). Caso o escoamento em questão for horizontal e o número de Froude $\mathrm{Fr}$, for inferior a 0,05 , o valor do parâmetro $\mathrm{F}_{\mathrm{GW}}$ deve ser corrigido por outro fator $F_{1}$, devido aos efeitos de gravidade:

$$
F_{1}=F r^{(0,1-2 \cdot F r)}
$$

Para o efeito da ebulição nucleada, a exemplo do modelo de Chen, os autores utilizaram um fator de supressão, $\mathrm{S}_{\mathrm{GW}}$, distinguido apenas pela introdução do fator intensificador $\mathrm{F}_{\mathrm{GW}}$, que incorpora o número de ebulição, Bo, para caracterizar a ebulição nucleada. $\mathrm{S}_{\mathrm{GW}}$, como no caso do modelo de Chen, é inversamente proporcional ao número de Reynolds, $\mathrm{Re}_{\mathrm{L}}$. Assim, o fator de supressão da correlação de Gungor-Winterton assumiu a seguinte forma:

$$
S_{G W}=\frac{1}{1+1,15 \cdot 10^{-6} \cdot F_{G W}^{2} \cdot \mathrm{Re}_{L}^{1,17}}
$$

Para o termo do coeficiente de transferência de calor na ebulição nucleada, $\mathrm{h}_{\mathrm{ENC}}$, GUNGOR \& WINTERTON (1986) usaram a correlação de Cooper, que associa simplicidade e precisão, sendo função da pressão reduzida, $\mathrm{P}_{\text {red, }}$ fluxo de calor, $\phi$, e massa molecular, M. A correlação é definida abaixo:

$$
h_{E N C}=55 \cdot P_{r e d}^{0,12} \cdot\left(-\log _{10} P_{r e d}\right)^{0,55} \cdot M^{-0,5} \cdot \phi^{0,67}
$$

Em escoamentos horizontais, em que o número de Froude Fr, é inferior a 0,05, o valor de $\mathrm{S}_{\mathrm{GW}}$ deve ser corrigido pelo fator $\mathrm{S}_{1}$ : 


$$
S_{1}=\sqrt{F r}
$$

JUNG \& RADERMACHER (1989) seguiram o mesmo princípio de Chen, porém, com algumas alterações mais evidentes na parcela da ebulição nucleada. Utilizaram um banco de dados de mais de 3000 pontos experimentais, empregando como fluido uma gama de treze tipos de refrigerantes halogenados. A correlação resultante tem a forma análoga à de Chen,

$$
h_{b}=h_{L} \cdot F_{J R}+S_{J R} \cdot h_{E N S}
$$

$\mathrm{O}$ fator intensificador de convecção, $\mathrm{F}_{\mathrm{JR}}$, também função do parâmetro de Martinelli, apresenta a mesma configuração das correlações estritamente convectivas. Baseado em evidências experimentais e observações de outros trabalhos, os autores revisaram o fator de intensificação que, através de uma análise de regressão de dados resultou na correlação (2.41), que apresentou um desvio na faixa de $5 \%$ para a região de ebulição estritamente convectiva. $\mathrm{O}$ coeficiente de transferência de calor para escoamento monofásico, $\mathrm{h}_{\mathrm{L}}$, é o mesmo das correlações anteriores, Eq. (2.18), de Dittus-Boelter. O fator intensificador proposto tem a seguinte forma:

$$
F_{R}=2,37 \cdot\left(0,29+\frac{1}{X_{t t}}\right)^{0,85}
$$

O efeito de ebulição nucleada foi significativamente alterado por JUNG \& RADERMACHER (1989) em relação à correlação de Chen. O coeficiente de transferência de calor para ebulição nucleada, $h_{\mathrm{ENS}}$, é calculado através da correlação de STEPHAN \& ABDELSALAM (1980), válida para refrigerantes, cuja a forma simplificada é a seguinte:

$$
h_{E N S}=207 \cdot \frac{k_{L}}{D_{b}} \cdot\left(\frac{\phi \cdot D_{b}}{k_{L} \cdot T_{\text {sat }}}\right)^{0,745} \cdot\left(\frac{\rho_{V}}{\rho_{L}}\right)^{0,581} \cdot\left(\operatorname{Pr}_{L}\right)^{0,533}
$$

onde,

$$
D_{b}=0,0146 \cdot \beta \cdot\left[\frac{2 \cdot \sigma}{g \cdot\left(\rho_{L}-\rho_{v}\right)}\right]^{0,5} \quad \text { e } \quad \beta=35^{\circ}
$$


O fator de supressão proposto por JUNG \& RADERMACHER (1989), $S_{\mathrm{R}}$, foi definido inicialmente, utilizando uma forma semelhante a do modelo de Chen, porém resultou em desvios da ordem de $70 \%$ em relação aos dados experimentais. Nessas condições, incorporaram um fator dependente do fluxo de calor, o número de ebulição, Bo, que é uma função explícita do $\phi$. Desenvolveram, através de uma regressão de dados, um modelo para o fator de supressão de bolhas, o que proporcionou desvios da ordem de $3 \%$. Os autores propuseram o fator $\mathrm{S}_{\mathrm{R}}$ para duas faixas de valores do parâmetro de Martinelli.

$$
\begin{aligned}
& S_{J R}=4048 \cdot X_{t t}^{1,22} \cdot B o^{1,13} \quad \text { para } X_{t t} \leq 1 \\
& S_{J R}=2,0-0,1 \cdot X_{u}^{-0,28} \cdot B o^{-0,33} \quad \text { para } 1<X_{t} \leq 5
\end{aligned}
$$

LIU \& WINTERTON (1991) propuseram seu modelo baseado no modelo assintótico, método de Kutateladze, o qual introduz uma superposição não linear de efeitos. No caso eleva-se os termos à potência de ordem dois. Nesses termos, o método enfatiza os fatores de intensificação, F, e de supressão de bolhas, S. Exemplificando, como F é sempre maior que a unidade, ao elevá-lo a uma potência maior que um, resultará um valor superior. Nessas condições, os efeitos convectivos são enfatizados relativamente aos de ebulição nucleada.

Os autores utilizaram um banco de dados com mais de 4200 pontos experimentais na região de saturação e 991 pontos experimentais para a região de subresfriamento a fim de propor um modelo de aplicação geral. Estes resultados foram reunidos a partir de 30 fontes disponíveis na literatura aberta, envolvendo nove fluidos diferentes. A correlação proposta é a seguinte:

$$
h_{b}^{2}=\left(F_{L W} \cdot h_{L O}\right)^{2}+\left(S_{L W} \cdot h_{E N C}\right)^{2}
$$

Os autores modificaram o fator intensificador de convecção, $\mathrm{F}_{\mathrm{LW}}$, introduzindo neste termo o número de Prandtl, $\mathrm{Pr}_{\mathrm{L}}$, o título, $\mathrm{x}$, e a razão entre as densidades do líquido e do vapor. O coefíciente de transferência de calor monofásico, $h_{\mathrm{LO}}$, é avaliado através da correlação de Dittus-Boelter, porém aplicado à mistura bifásica escoando como líquido no duto, Eq. (2.17). $O$ fator intensificador de convecção $F_{L W}$, foi, assim, defínido:

$$
F_{L W}=\left[1+x \cdot \operatorname{Pr}_{L} \cdot\left(\frac{\rho_{L}}{\rho_{V}}-1\right)\right]^{0,35}
$$


Os autores utilizam um modelo para o fator intensificador de convecção distinto dos apresentados anteriormente, através da incorporação explícita do número de $\mathrm{Prandtl} \mathrm{Pr}_{\mathrm{L}}$, título, $\mathrm{x}$, e relação entre densidades. Esse modelo é fisicamente consistente, pois para números de Prandtl maiores que um, a espessura da subcamada limite laminar diminui, aumentando o coeficiente de transferência de calor. Nessas condições, os efeitos convectivos se sobressaem em relação aos de ebulição nucleada. A incorporação do título nessa correlação enfatiza os efeitos convectivos, pois, como observado anteriormente, quanto maior o título maior o coeficiente de transferência de calor para regiões estritamente convectivas. No caso da relação entre densidades observa-se que, quanto mais distintos, para um mesmo título, maior a velocidade da fase vapor, resultando num maior efeito de vaporização na interface líquido-vapor.

$\mathrm{O}$ termo relativo à ebulição nucleada segue o mesmo princípio daquele de GUNGOR \& WINTERTON (1986), introduzindo-se mudanças somente nas constantes do fator de supressão S. Na avaliação do coeficiente de transferência de calor para ebulição nucleada, os autores propuseram a correlação de Cooper, definida anteriormente pela Eq. (2.38). A expressão proposta para o fator de supressão, $\mathrm{S}_{\mathrm{LW}}$, é a seguinte:

$$
S_{L W}=\frac{1}{\left(1+0,055 \cdot F_{L W}^{0,1} \cdot \operatorname{Re}_{L O}^{0,16}\right)}
$$

É interessante observar que o fator de supressão apresenta uma forma semelhante àquela proposta por GUNGOR \& WINTERTON (1986), somente modificando o número de Reynolds, no caso, $\mathrm{Re}_{\mathrm{LO}}$, aplicado à mistura bifásica escoando como líquido no tubo. Os autores incorporaram o número de Froude, Fr, a fim de corrigir os possíveis efeitos gravitacionais resultantes de condições operacionais associadas a vazões reduzidas. Nessas condições, os fatores $F_{L W}$ e $S_{L W}$ devem ser multiplicados pelos fatores $F_{1}$ e $S_{1}$, anteriormente definidos pelas Eqs. (2.36) e (2.39), caso o número de Froude seja inferior a 0,05.

STEINER \& TABOREK (1992) propuseram um novo modelo baseado no princípio de adição assintótica das duas componentes da ebulição, nucleada e convectiva. Conforme BANDARRA FILHO (1997), quando comparado com as correlações baseadas na superposição linear, proporcionam melhores resultados. A correlação apresenta a seguinte forma: 


$$
h_{B}=\left[\left(h_{E N}\right)^{n}+\left(h_{E C}\right)^{n}\right]^{1 / n}
$$

onde,

$$
\mathrm{n}=3,0, \quad h_{E N}=h_{E N, o} \cdot F_{E N} \quad \text { e } \quad h_{E C}=h_{L O} \cdot F_{B}
$$

$\Rightarrow h_{E N, o}$ é o coeficiente de transferência de calor na ebulição nucleada, baseado em condições normalizadas de fluxo de calor e pressão reduzida.

$\Rightarrow F_{E N}$ é um fator de correção para o coefíciente de transferência de calor na ebulição nucleada que compensa as diferenças entre as condições do fluido estagnado e em movimento. Estão inclusos parâmetros de pressão, fluxo de calor, diâmetro de tubo e rugosidade da superficie bem como um fator de correção residual, expresso em função da massa molecular.

$\Rightarrow h_{L O}$ é o coeficiente de transferência de calor, assumindo que toda a mistura bifásica escoa como líquido no tubo. É normalmente determinado através da correlação de DITTUSBOELTER (1930).

$\Rightarrow F_{B}$ é um multiplicador bifásico para o coefíciente $h_{L O}$, considerando a intensificação do coeficiente na mistura líquido-vapor. Ele é uma função do título e da relação entre as densidades do líquido e do vapor. É interessante observar que o coeficiente $h_{L O}$ é baseado na mistura bifásica escoando como líquido no tubo, com $\operatorname{Re}_{L O}=\frac{G \cdot D}{\mu}$; isto é, não leva em consideração o título. O título é introduzido em $F_{B}$, conforme indicado a seguir:

$$
F_{B}=\left[(1-x)^{1,5}+1,9 \cdot x^{0,6} \cdot\left(\frac{\rho_{L}}{\rho_{V}}\right)^{0,35}\right]^{1,1}
$$

É interessante observar que a correlação (2.49) satisfaz os limites fisicos, quais sejam: $F_{B} \rightarrow 1$ quando $x \rightarrow 0$, ou seja, fisicamente evidencia o predomínio dos efeitos da ebulição nucleada sobre os convectivos. O termo ræferente à contrituição da ebulição nucleada na Eq. (2.48), é baseado em $h_{E N, o}$ que é um coeficiente de transferência de calor na ebulição nucleada relativo à valores normalizados de fluxo de calor e pressão reduzida. Esse termo é corrigido pelo fator $F_{E N}$, que considerara os efeitos do escoamento e geometria do fluido. Os parâmetros normalizados e seus respectivos valores são dados a seguir: 
- $\quad P_{\text {red }, \mathrm{O}}=0,1$ (Pressão reduzida)

- $R_{\mathrm{a}}, \mathrm{O}=1 \mathrm{~mm}$ (Rugosidade)

- $\phi_{\mathrm{o}}=$ Fluxo de calor; valores tabelados para diferentes fluidos.

Para a obtenção do valor de $h_{E N, o}$ é suficiente, nesse caso, apenas identificar o fluido. Os parâmetros que afetam $F_{E N}$ foram determinados da literatura e detalhados a partir do banco de dados disponível; são eles: título, x, velocidade mássica, G, pressão, P, diâmetro do tubo, $D$, rugosidade, $\mathrm{R}_{\mathrm{a}}$, e o fator de correção residual, que é função da massa molecular do fluido, $f(M)$. A equação para determinação de $F_{E N}$ é dada por:

$$
F_{E N}=F_{P F} \cdot\left[\frac{\phi}{\phi_{o}}\right]^{n f\left(P_{r d d}\right)}\left[\frac{D}{D_{o}}\right]^{-0,4}\left[\frac{R_{a}}{R_{a}, o}\right]^{0,133} \cdot f(M)
$$

Esta correlação apresenta a desvantagem de possuir os valores para o coeficiente de transferência de calor na ebulição nucleada tabelados, pois depende de cada fluido e no caso de novos refrigerantes esse valor ainda não foi proposto. Entre tais fluidos pode-se citar o refrigerante R-404A, que está sendo empregado como substituto do R-502, além do R-407C, R-410A, entre outros.

MURATA \& HASHIZUME (1993) desenvolveram dois tipos de correlação: uma para tubos lisos e outra para tubos microaletados, este segundo tipo será analisado mais adiante. Neste estudo, foi utilizado como fluido, o refrigerante R-123. A vazão variou entre 100 e $300 \mathrm{~kg} / \mathrm{m}^{2} . \mathrm{s}$, para tubos lisos, o fluxo de calor entre 0 e $30 \mathrm{~kW} / \mathrm{m}^{2}$ e o título entre $0,1 \mathrm{a}$ 1,0. A correlação proposta, semelhante a de CHEN (1966), é a seguinte:

$$
h_{b}=h_{L} \cdot F_{M H}+h_{E N N} \cdot S_{M H}
$$

A parcela convectiva segue o mesmo principio da correlação de Chen. O coeficiente de transferência de calor para escoamento monofásico, $\mathrm{h}_{\mathrm{L}}$, é o de Dittus-Boelter Eq. (2.18), para tubo liso. No caso de tubos com ranhuras, o coeficiente, $\mathrm{h}_{\mathrm{L}}$, é alterado de acordo com a Eq. (2.52), abaixo. $\mathrm{O}$ fator intensificador de convecção, $\mathrm{F}_{\mathrm{MH}}$, segue o mesmo princípio das correlações estritamente convectivas, diferenciando-se os valores para tubos lisos e tubos com ranhuras. As correlações propostas foram as seguintes: 


$$
\begin{array}{ll}
h_{L}=\frac{k_{L}}{D} \cdot 0,036 \cdot \operatorname{Re}_{L}{ }^{0,8} \cdot \operatorname{Pr}_{L}{ }^{0,4} & \text { (tubos microaletados) } \\
F=2,44 \cdot X_{t}{ }^{-0,863} & \text { (tubos liso) } \\
F=2,2 \cdot X_{t}{ }^{-1} & \text { (tubos microaletados) }
\end{array}
$$

Observa-se que os tubos com ranhuras apresentam $u m h_{L}$ superior, da ordem de $56 \%$, em relação aos tubos lisos, como seria de esperar, uma vez que as ranhuras introduzem certa intensificação.

Os autores utilizaram para o cálculo do coeficiente de transferência de calor para ebulição nucleada $h_{\mathrm{ENN}}$, a correlação de NISHIKAWA et al (1982). O fator de supressão de bolhas, $\mathrm{S}_{\mathrm{MH}}$, dado pela Eq. (2.58), abaixo, leva em consideração a velocidade mássica, $\mathrm{G}$, através do coeficiente de transferência monofásico, $h_{L}$. No caso, quanto maior o valor de $G$, maior o valor de $h_{\mathrm{L}}$ e, portanto, menor o valor de $\mathrm{S}_{\mathrm{MH}}$. É interessante notar na Eq. (2.58) que a dimensão característica, $\delta_{\mathrm{C}}$, está relacionada com diâmetro de desprendimento de bolhas. As distintas correlações adotadas pelos autores são apresentadas a seguir:

$$
\begin{aligned}
& h_{E N N}=31,4 \cdot\left[\frac{P_{c r}^{0,2} \cdot F_{p}}{\left(M^{0,1} \cdot T_{c r}^{0,9}\right)}\right] \cdot \phi^{0,8} \quad \text { (tubos liso) } \\
& h_{E N N}=48 \cdot\left[\frac{P_{c r}^{0,2} \cdot F_{p}}{\left(M^{0,1} \cdot T_{c r}^{0,9}\right)}\right] \cdot \phi^{0,8} \quad \text { (tubos microaletados) }
\end{aligned}
$$

onde,

$$
F_{p}=\frac{P_{r e d}^{0,23}}{\left[1-0,99 \cdot P_{r e d}\right]^{0,9}}
$$

Para o fator de Supressão $\mathrm{S}_{\mathrm{MH}}$ :

$$
S_{M H}=\frac{\left[1-\exp \left(\frac{\left(-h_{L} \cdot F\right) \cdot \delta_{C}}{k_{L}}\right)\right]}{\left[\frac{\left(h_{L} \cdot F\right) \cdot \delta_{C}}{k_{L}}\right]}
$$

onde, $\quad \delta_{C}=0,08 \cdot\left[\frac{\sigma}{g \cdot\left(\rho_{L}-\rho_{v}\right)}\right]^{0,5}$

Uma comparação, ilustrada pela Fig. 2.10, foi realizada para avaliar o coeficiente de transferência de calor para tubos lisos e com ranhuras, utilizando o R-134a para $\mathrm{T}_{\text {sat }}=5^{\circ} \mathrm{C}$; 
$\mathrm{G}=300 \mathrm{~kg} / \mathrm{m}^{2} . \mathrm{s} ; \phi=5 \mathrm{~kW} / \mathrm{m}^{2}$ e $\mathrm{D}=9,52 \mathrm{~mm}$. É interessante observar que as diferenças vão se acentuando a medida em que o título se eleva, essa diferença é da ordem de $35 \%$ no início e atinge $140 \%$ para títulos elevados. No início, onde a ebulição nucleada é predominante, a diferença é menor devido principalmente ao fator de supressão de bolhas, que para tubos microaletados é menor, fazendo com que essa diferença seja menor. Para títulos elevados essa diferença se acentua, pois como predominam os efeitos convectivos, o primeiro membro da Eq. (2.51), para tubos microaletados, é consideravelmente maior que para tubos lisos.

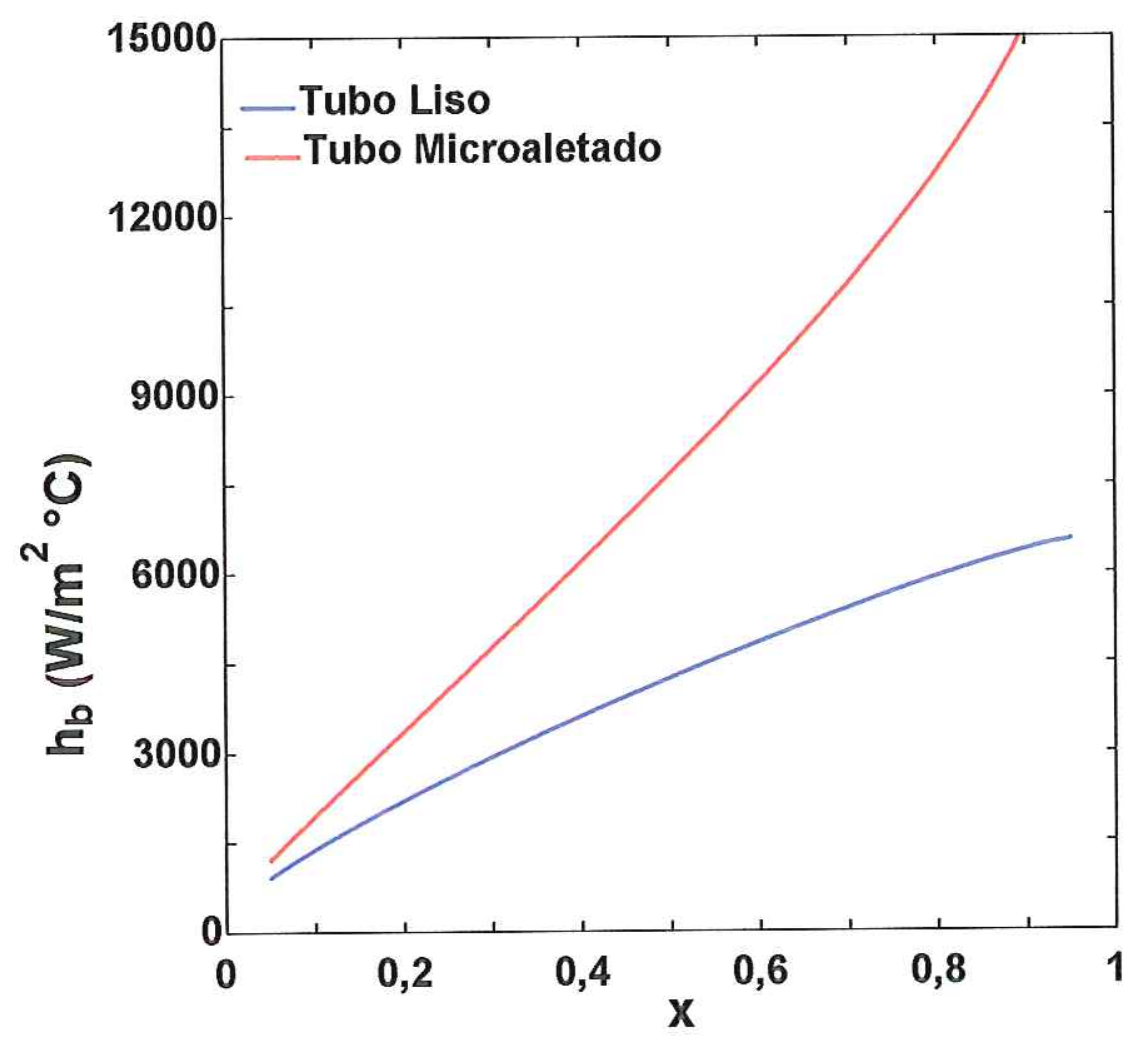

Figura 2.10 Comparação das correlações de Murata-Hashizume para tubos lisos e tubos microaletados. R-134a, $\mathrm{T}_{\text {sat }}=5^{\circ} \mathrm{C}, \mathrm{G}=300 \mathrm{~kg} / \mathrm{s} \cdot \mathrm{m}^{2}, \phi=5 \mathrm{~kW} / \mathrm{m}^{2}$ e D=9,52mm.

WATTELET (1994) desenvolveu uma correlação utilizando o modelo assintótico. Através de uma análise de regressão entre potências de ordem 1 e 3 , foi encontrada a potência 2,5. Esta foi a que melhor correlacionou seus resultados experimentais. Ele utilizou um banco de dados de mais de 1000 pontos experimentais, com vazões variando entre $25 \mathrm{e}$ $500 \mathrm{~kg} / \mathrm{m}^{2}$.s, fluxos de calor entre 2 e $30 \mathrm{~kW} / \mathrm{m}^{2}$ e títulos na entrada entre 10 e $90 \%$. Seus resultados experimentais envolveram, basicamente, dois padrões de escoamento: o anular e o estratificado. Os fluidos utilizados foram o R-12 e o R-134a. A correlação proposta foi a seguinte: 


$$
\left(h_{b}\right)^{2,5}=\left(h_{E C}\right)^{2,5}+\left(h_{E N C}\right)^{2,5}
$$

Os efeitos convectivos, $\mathrm{h}_{\mathrm{EC}}$, incorporam três fatores, incluindo o coeficiente de transferência de calor monofásico, $\mathrm{h}_{\mathrm{L}}$, o fator intensificador de convecção, $\mathrm{F}_{\mathrm{W}}$, e um fator designado por $\mathrm{R}$, que incorpora os efeitos de gravidade, associados ao número de Froude, Fr. $\mathrm{O}$ coeficiente de transferência de calor monofásico, $\mathrm{h}_{\mathrm{L}}$, é o avaliado pela Eq. (2.18), de Dittus-Boelter. $\mathrm{O}$ fator intensificador de convecção, $\mathrm{F}_{\mathrm{W}}$, apresenta características semelhantes àquelas das correlações estritamente convectivas. Nessas condições, o "termo" convectivo, $\mathrm{h}_{\mathrm{EC}}$, apresenta as seguintes características:

$$
h_{E C}=h_{L} \cdot F_{W} \cdot R
$$

onde,

$$
F_{W}=1+1,925 \cdot X_{t}^{-0,83}
$$

e,

$$
\begin{array}{ll}
R=1,32 \cdot F^{0,2} & \text { para } F r<0,25 \\
R=1 & \text { para } F r \geq 0,25
\end{array}
$$

É interessante observar que o autor incorporou o número de Froude ao fator R para levar em consideração as condições correspondentes às baixas vazões. Nessas condições, o escoamento assume a configuração de padrão estratificado e, conseqüentemente, os efeitos de gravidade tornam-se importantes. Dessa forma, através da incorporação do $\mathrm{Fr}$, os resultados experimentais foram melhor correlacionados.

Ao contrário dos outros modelos, WATTELET (1994) não utilizou um fator de supressão. Para o cálculo do coefíciente de transferência de calor para ebulição nucleada utilizou a correlação de Cooper, Eq. (2.38). É interessante observar que o fator FW cresce aproximadamente com o quadrado de $\mathrm{x}$, ao passo que $\mathrm{o}$ fator de ebuiição nucleada permanece constante. Em outras palavras, os efeitos convectivos crescem com o quadrado do título relativamente aos de ebulição nucleada. $\mathrm{O}$ argumento adverso quanto a este modclo está relacionado ao fato do nível dos efeitos de ebulição nucleada se manter constante ao longo do evaporador, o que não seria consistente fisicamente. A correlação, no entanto, efetivamente visa ajustar resultados experimentais. 
LIMA (2000) investigou a ebulição convectiva de refrigerantes halogenados (R-22, $\mathrm{R} 134 \mathrm{a}$ e R-404A) em tubos horizontais, levantando cerca de 960 pontos experimentais para as seguintes condições de ensaio:

- Diâmetro interno do tubo: $12,7 \mathrm{~mm}$

- Temperatura de evaporação: 8 e $15^{\circ} \mathrm{C}$

- Fluxo de calor entre: 5 e $20 \mathrm{~kW} / \mathrm{m}^{2}$

- Velocidade mássica entre: 50 e $500 \mathrm{~kg} / \mathrm{s} \cdot \mathrm{m}^{2}$

- Título médio na seção de testes entre: 5 e 98\%.

Nessas condições, LIMA (2000) propôs um modelo baseado na superposição dos efeitos do tipo assintótico para correlacionar os resultados experimentais, que apresenta a seguinte forma:

$$
h_{b}=(16 \cdot F r)^{C 7}\left[\left(F_{L I} \cdot h_{L}\right)^{3,07}+\left(S_{L I} \cdot h_{E N C}\right)^{3,07}\right]^{1 / 3,07}
$$

É interessante destacar que a correlação é dependente do número de Froude, Fr, pois os ensaios foram realizados com vazões reduzidas (G inferior a $100 \mathrm{~kg} / \mathrm{s} . \mathrm{m}^{2}$ ), onde tal parâmetro físico torna-se importante. Para tanto, encontrou a condição limite de Fr, no caso, para $\mathrm{Fr}<0,06$ a constante $\mathrm{C} 7$ assume o valor de 1,8 e para números de Froude superior a 0,06 essa constante é nula. Para a determinação dos coeficientes de transferência de calor monofásico e de ebulição nucleada, o autor sugere as correlações de Dittus-Boelter e de Cooper, respectivamente.

LIMA (2000) seguiu o modelo de Wattelet que apresenta a forma semelhante para o fator intensificador de conveç̧ão alterando apenas a constante e o expoente, o qual assume a seguinte configuração:

$$
F_{L I}=1+1,893 \cdot X_{t t}^{-0,77}
$$

Já para o fator de supressão de bolhas, o autor partiu da premissa de CHEN (1966), onde esse fator era inversamente proporcional ao número de Reynolds. No entanto, os desvios encontrados foram elevados e, de acordo com BANDARRA FILHO (1997), o número de ebulição, Bo, deve ser incorporado ao modelo para evidenciar os efeitos da ebulição nucleada. Nesse sentido, LIMA (2000) incorporou o número de ebulição no fator de 
supressão de bolhas, correlacionando melhor os resultados experimentais. A expressão para a determinação do fator de supressão tem a forma:

$$
S_{L I}=\frac{1}{\left(1+5,35 \cdot 10^{-6} \cdot \mathrm{Re}_{L}^{1,25} \cdot B o^{0,22}\right)}
$$

O desvio médio proporcionado pela correlação de LIMA (2000) foi de 13,5\% em relação aos próprios resultados experimentais.

\subsection{Análise Comparativa das Correlações do Grupo 2}

A característica básica das correlações pertencentes ao segundo grupo é a superposição de efeitos convectivos e de ebulição nucleada. Estes são, de forma geral, relacionados pelos fatores de intensificação, F, e de supressão, S. Observa-se, claramente, que cada correlação é muito particular ao trabalho desenvolvido. No caso dos fatores $\mathrm{S}$ e $\mathrm{F}$ os mesmos apresentam características físicas semelhantes, embora apresentam certas nuances. Estas estão relacionadas ao modelo físico proposto e, eventualmente, a uma necessidade de correlacionar resultados experimentais. De forma geral, envolvem parâmetros adimensionais como o $\mathrm{X}_{\mathrm{tt}}$, Bo ou mesmo Fr. A seguir será realizada uma análise comparativa para cada um dos aspectos, tais como, critérios de superposição, forma do fator intensificador, $\mathrm{F}$, e forma do fator de supressão, $\mathrm{S}$.

\section{- Critérios de superposição}

As correlações analisadas se apresentam basicamente de duas formas: as que propõem uma superposição linear de efeitos e aquelas que sugerem uma superposição não linear. As correlações que apresentam uma superposição linear de efeitos envolvem uma simples soma dos fatores convectivos e de ebulição nucleada. Neste grupo se encontram as correlações de Chen, Gungor-Winterton, Jung-Radermacher e Murata-Hashizume. Pertencem ao segundo grupo, em que se elevam a uma potência os componentes convectivo e de ebulição nuc'eada, as correlaçôes de Liu-Wintertcin (potência de ordem 2,0), Wattelet (de ordem 2,5), Steiner-Taborek (de ordem 3,0) e Lima (de ordem 3,07). O método assintótico, ou modelo de Kutateladze, se aproxima do maior dos dois componentes para potências elevadas e assume a forma de Chen, superposição linear, para potência de ordem 1,0. A Tabela 2.2 exemplifica esse modelo para uma potência de ordem 2,5. Para um efeito convectivo maior e um efeito de ebulição nucleada menor, o coeficiente de transferência de 
calor bifásico resulta de uma parcela significativamente maior dos efeitos convectivos. Como seria de esperar, o inverso se dá quando o efeito dominante corresponde ao da ebulição nucleada.

Tabela 2.2 Exemplos da aplicação do modelo assintótico, com $n=2,5$.

\begin{tabular}{|c|c|c|}
\hline $\begin{array}{c}\text { h para Efeitos Convectivos } \\
\left(\mathbf{W} / \mathbf{m}^{2} \cdot{ }^{\circ} \mathbf{C}\right)\end{array}$ & $\begin{array}{c}\text { h para Efeitos de Ebulição } \\
\text { Nucleada }\left(\mathbf{W} / \mathbf{m}^{2} \cdot{ }^{\circ} \mathbf{C}\right)\end{array}$ & $\begin{array}{c}\text { Coeficiente Bifásico } \\
\text { Total }\left(\mathbf{W} / \mathbf{m}^{2} \cdot{ }^{\circ} \mathbf{C}\right)\end{array}$ \\
\hline 4000 & 1000 & 4050 \\
\hline 1000 & 4000 & 4050 \\
\hline 2500 & 2500 & 3300 \\
\hline
\end{tabular}

- Fator intensificador de convecção, F.

$\mathrm{O}$ fator intensificador de conveç̧ão, $\mathrm{F}$, corresponde à relação $\mathrm{h}_{b} / \mathrm{h}_{\mathrm{L}}$, das correlações estritamente convectivas, pois, basicamente, é função de $X_{\text {tt }}$. As correlações de Chen, JungRadermacher, Murata-Hashizume, Wattelet e Lima, assumem esta configuração. O modelo de Gungor-Winterton acrescentou o número de ebulição, Bo, na correlação, para representar a possível presença dos efeitos da ebulição nucleada no escoamento. A correlação de LiuWinterton introduz explicitamente o número de Prandtl. Para valores de Prandtl maiores que um a espessura da subcamada limite laminar diminui, incrementando o coeficiente de transferência de calor.

- Fator de supressão de bolhas, $\mathrm{S}$.

O fator de supressão de bolhas aparece inversamente proporcional ao número de Reynolds, isso demonstra que com o aumento da vazão o fator de supressão tende a diminuir, como seria de esperar. Os fatores de supressão apresentam comportamento semelhante, qual seja, o de diminuir com o título. Tal comportamento é fisicamente consistente, pois, no caso de padrão anular, devido a espessura da película de filme diminuir no sentido do escoamento, a tendência é de inibir a nucleação na medida em que o título cresce.

O coeficiente de transferência de calor bifásico foi avaliado para as correlações desse grupo, como ilustrado pela Fig. 2.11, válido para condições especificadas na legenda. É interessante observar, como comentário geral, o distinto comportamento de cada curva, caracterizando a peculiaridade de cada correlação com o respectivo trabalho. Isso demonstra que as correlações apresentadas são inadequadas a generalizações. 


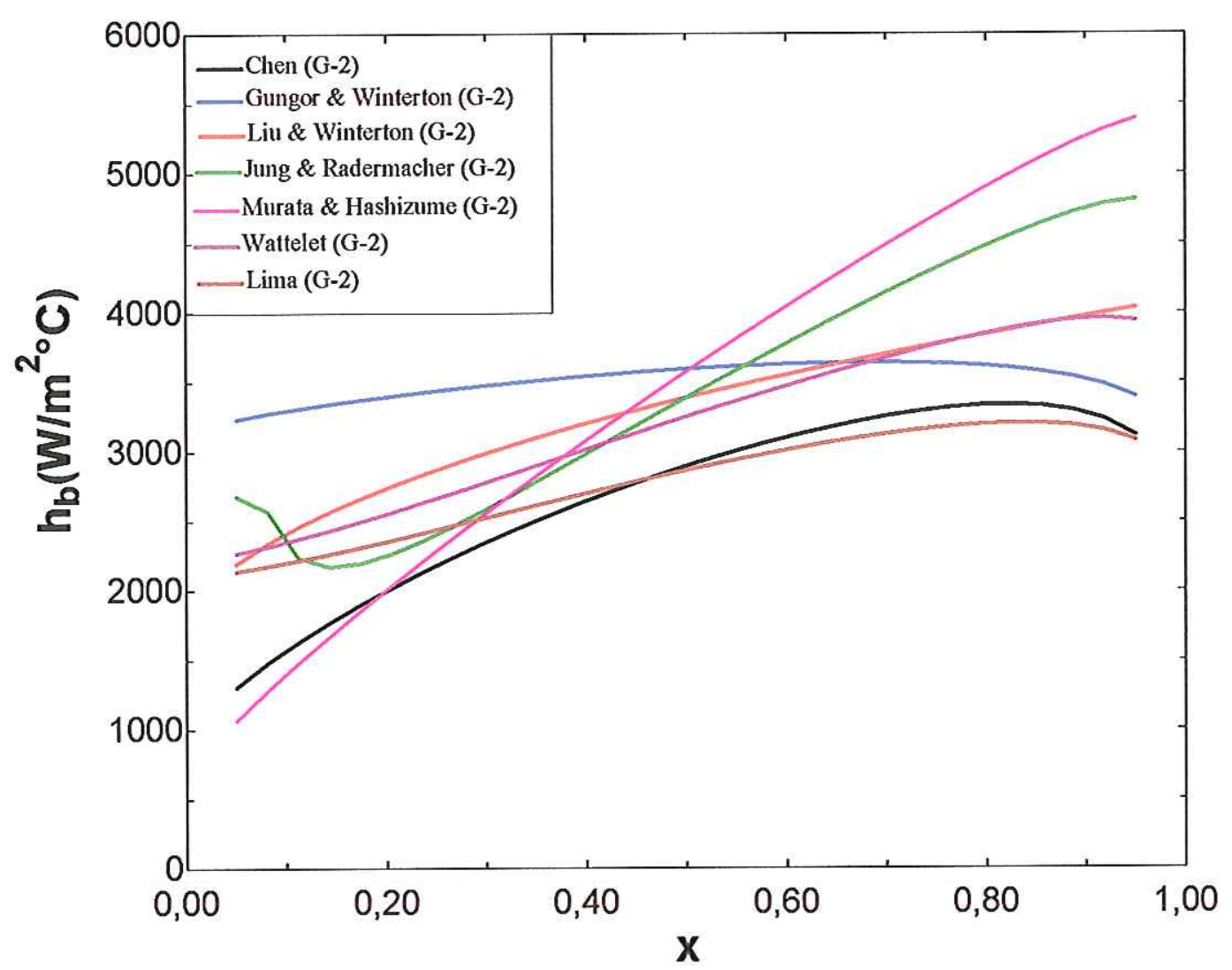

Figura 2.11 Comparação dos coeficientes de transferência de calor das correlações do grupo 2, para as condições: $\mathrm{T}_{\text {sat }}=-5^{\circ} \mathrm{C}, \mathrm{G}=200 \mathrm{~kg} / \mathrm{m}^{2} . \mathrm{s}$ e $\phi=15 \mathrm{~kW} / \mathrm{m}^{2}$.

Tabela 2.3 Sumário das correlações baseadas na superposição de efeitos.

\begin{tabular}{|c|c|c|c|}
\hline Autor & Correlação & Fluidos & Condições \\
\hline $\begin{array}{l}\text { Chen } \\
(1966)\end{array}$ & 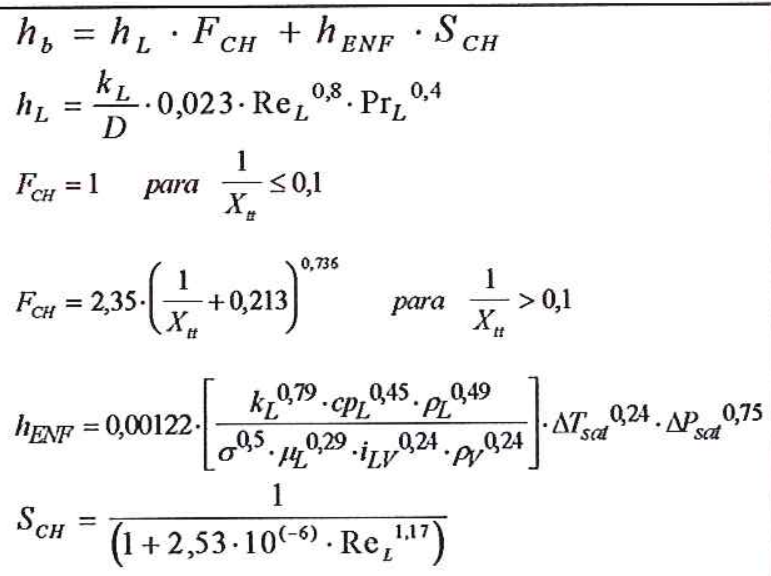 & $\begin{array}{c}\text { Água } \\
\text { Metanol } \\
\text { Benzeno } \\
\text { Pentano } \\
\text { Hexano } \\
\text { Heptano }\end{array}$ & $\begin{array}{l}\text { Tubo: Vertical } \\
\begin{array}{c}\mathrm{P}_{\text {sat }}: \begin{array}{l}55 \text { a } 3500 \\
\mathrm{kPa}\end{array} \\
\text { G: } \begin{array}{c}500 \text { a } 3600 \\
\mathrm{~kg} / \mathrm{m}^{2} . \mathrm{s}\end{array} \\
\text { x: } 1 \text { a } 71 \%\end{array}\end{array}$ \\
\hline
\end{tabular}




\begin{tabular}{|c|c|c|c|}
\hline $\begin{array}{c}\text { Gungor } \\
\& \\
\text { Winterton } \\
(1986)\end{array}$ & $\begin{array}{l}h_{b}=h_{L} \cdot F_{G W}+h_{E N P} \cdot S_{G W} \\
F_{G W}=1+24000 \cdot B o^{1,16}+1,37 \cdot\left(\frac{1}{X_{n}}\right)^{0,86} \\
h_{E N C}=55 \cdot P_{r e d}^{0,12} \cdot\left(-\log _{10} P_{r e d}\right)^{0,55} \cdot M^{-0,5} \cdot \phi^{0,67} \\
S_{G W}=\frac{1}{1+1,15 \cdot 10^{-6} \cdot F_{G W}{ }^{2} \cdot \mathrm{Re}_{L}^{1,17}} \\
\text { Para Fr for menor que } 0,05, \text { os fatores } \mathrm{F}_{G W} \mathrm{e} \mathrm{S}_{\mathrm{GW}} \text { deverão } \\
\text { ser multiplicados por: } F_{1}=F r(0,1-2 \cdot F r) \mathrm{e} \\
S_{1}=\sqrt{F r}\end{array}$ & $\begin{array}{l}\text { Água } \\
\text { R-11 } \\
\text { R-12 } \\
\text { R-113 } \\
\text { R-114 } \\
\text { R-22 }\end{array}$ & $\begin{array}{c}\text { G: } 60 \text { a } 8180 \\
\mathrm{~kg} / \mathrm{m}^{2} . \mathrm{s} \\
\phi: 1 \text { a } 2600 \\
\mathrm{~kW} / \mathrm{m}^{2}\end{array}$ \\
\hline $\begin{array}{c}\text { Jung } \\
\& \\
\text { Raderma- } \\
\text { cher (1989) }\end{array}$ & $\begin{array}{l}h_{b}=h_{L} \cdot F_{J R}+S_{J R} \cdot h_{E N S} \\
F_{J R}=2,37 \cdot\left(0,29+\frac{1}{X_{t}}\right)^{0,85} \\
h_{E N S}=207 \cdot \frac{k_{L}}{D_{b}} \cdot\left(\frac{\phi \cdot D_{b}}{k_{L} \cdot T_{s a t}}\right)^{0,745} \cdot\left(\frac{\rho_{V}}{\rho_{L}}\right)^{0,581} \cdot\left(\mathrm{Pr}_{L}\right)^{0,533} \\
D_{b}=0,0146 \cdot \beta \cdot\left[\frac{2 \cdot \sigma}{g \cdot\left(\rho_{L}-\rho_{v}\right)}\right]^{0,5} \quad \text { com: } \beta=35^{\circ} \\
S_{J R}=4048 \cdot X_{t t}{ }^{1,22} \cdot B o^{1,13} \quad \text { para } \quad X_{t t} \leq 1 \\
S_{J R}=2,0-0,1 \cdot X_{t}^{-0,28} \cdot B o^{-0,33} \quad \text { para } \quad 1<X_{t} \leq 5\end{array}$ & $\begin{array}{l}\text { R-11 } \\
\text { R-12 } \\
\text { R-13 } \\
\text { R-22 } \\
\text { R-32 } \\
\text { R-114 } \\
\text { R-123 } \\
\text { R-124 } \\
\text { R-134a } \\
\text { R-141b } \\
\text { R-142b } \\
\text { R-143a } \\
\text { R-152a }\end{array}$ & $\begin{array}{c}\mathrm{T}_{\text {sat }}:-10 \text { a } 10^{\circ} \mathrm{C} \\
\text { G: } 100 \text { a } 700 \\
\mathrm{~kg} / \mathrm{m}^{2} . \mathrm{s} \\
\phi: 5 \text { a } 40 \mathrm{~kW} / \mathrm{m}^{2} \\
\mathrm{x}: 10 \text { a } 90 \% \\
\mathrm{D}=8 \mathrm{~mm}\end{array}$ \\
\hline $\begin{array}{c}\text { Liu } \\
\& \\
\text { Winterton } \\
(1991)\end{array}$ & $\begin{array}{l}h_{b}^{2}=\left(F_{L W} \cdot h_{L O}\right)^{2}+\left(s_{L W} \cdot h_{E N C}\right)^{2} \\
h_{L O}=\frac{k_{L}}{D} \cdot 0,023 \cdot \operatorname{Re}_{L O}{ }^{0,8} \cdot \operatorname{Pr}_{L}{ }^{0,4} \\
F_{L W}=\left[1+x \cdot \operatorname{Pr}_{L} \cdot\left(\frac{\rho_{L}}{\rho_{V}}-1\right)\right]^{0,35} \\
S_{L W}=\frac{1}{\left(1+0,055 \cdot F_{L W}{ }^{0,1} \cdot \operatorname{Re}_{L O}{ }^{0,16}\right)} \\
\text { Para Fr for menor que } 0,05, \text { os fatores } \mathrm{F}_{\mathrm{GW}} \mathrm{e} \mathrm{S}_{\mathrm{GW}} \text { deverão } \\
\text { ser multiplicados pelos fatores } \mathrm{F}_{1} \mathrm{e} \mathrm{S}_{1} \text { de Gungor- } \\
\text { Winterton. }\end{array}$ & $\begin{array}{l}\text { Água } \\
\text { R-11 } \\
\text { R-12 } \\
\text { R-113 } \\
\text { R-114 } \\
\text { R-22 } \\
\text { Etileno- } \\
\text { glicol }\end{array}$ & $\begin{array}{c}\text { G: } \begin{array}{c}12,4 \text { a } 8180 \\
\mathrm{~kg} / \mathrm{m}^{2} \cdot \mathrm{s}\end{array} \\
\begin{array}{c}\phi: \\
0,4 \text { a } 2600 \\
\mathrm{~kW} / \mathrm{m}^{2}\end{array} \\
\text { x: } 0 \text { a } 94,8 \% \\
\text { D: } 3 \text { a } 32 \mathrm{~mm}\end{array}$ \\
\hline $\begin{array}{c}\text { Steiner } \\
\& \\
\text { Taborek } \\
(1992)\end{array}$ & $\begin{array}{l}h_{B}=\left[\left(h_{E N}\right)^{n}+\left(h_{E C}\right)^{n}\right]^{1 / n} \\
h_{E N}=h_{E N . o} \cdot F_{E N} \text { e } h_{E C}=h_{L O} \cdot F_{B} \\
F_{B}=\left[(1-x)^{1.5}+1,9 \cdot x^{0.6} \cdot\left(\frac{\rho_{L}}{\rho_{V}}\right)^{0.35}\right]^{1,1} \\
F_{E N}=F_{P F}\left[\frac{\phi}{\phi_{o}}\right]^{r(f r)} \cdot\left[\frac{D}{D_{o}}\right]^{-0.4}\left[\frac{R_{a}}{R_{a}, o}\right]^{0.133} \cdot f(M) \\
F_{P F}=2,816 \cdot P_{r e d}^{0,45}+\left(3,4+\frac{1,7}{1-P_{r e d}^{7}}\right) \cdot P_{r e d}^{3.7}\end{array}$ & $\begin{array}{c}\text { Agua } \\
\text { Hidro- } \\
\text { carbonetos } \\
\text { R-11 } \\
\text { R-12 } \\
\text { R-22 } \\
\text { R-113 } \\
\text { Amônia }\end{array}$ & $\begin{array}{c}\text { G: } 59 \text { a } 4850 \\
\mathrm{~kg} / \mathrm{m}^{2} . \mathrm{s} \\
\phi: 1,9 \text { a } 4600 \\
\mathrm{~kW} / \mathrm{m}^{2}\end{array}$ \\
\hline
\end{tabular}




\begin{tabular}{|c|c|c|c|}
\hline $\begin{array}{c}\text { Murata } \\
\& \\
\text { Hashizume } \\
(1993)\end{array}$ & $\begin{array}{l}h_{b}=h_{L} \cdot F_{M H}+h_{E N N} \cdot S_{M H} \\
F_{M H}=2,44 \cdot X_{t t^{-0,863}} \\
h_{E N N}=31,4 \cdot\left[\frac{P_{c r}^{0,2} \cdot F_{p}}{\left(M^{0,1} \cdot T_{c r}^{0,9}\right)}\right] \cdot \phi^{0,8} \\
S_{S H}=\frac{\left[1-\exp \left(\frac{\left(-h_{L} \cdot F_{M H}\right) \cdot \delta_{C}}{k_{L}}\right)\right]}{\left[\frac{\left(h_{L} \cdot F_{M H}\right) \cdot \delta_{C}}{k_{L}}\right]} \\
F_{P}=\frac{P_{r e d}{ }^{0.23}}{\left[1-0,99 \cdot P_{r e d}\right]^{0,9}} \delta_{C}=0,08 \cdot\left[\frac{\sigma}{g \cdot\left(\rho_{L}-\rho_{v}\right)}\right]^{0.5}\end{array}$ & R-123 & $\begin{array}{c}\text { G: } 100 \text { a } 300 \\
\mathrm{~kg} / \mathrm{m}^{2} . \mathrm{s}\end{array}$ \\
\hline $\begin{array}{c}\text { Wattelet } \\
\text { (1994) }\end{array}$ & 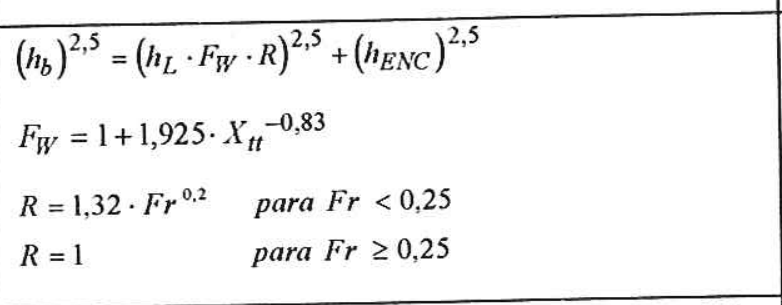 & $\begin{array}{c}R-12 \\
R-134 a\end{array}$ & $\begin{array}{c}\text { G: } 25 \text { a } 500 \\
\mathrm{~kg} / \mathrm{m}^{2} . \mathrm{s} \\
\phi: 2 \text { a } 30 \mathrm{~kW} / \mathrm{m}^{2} \\
\text { x: } 10 \text { a } 90 \% \\
\mathrm{~T}_{\text {sat }}:-15 \text { a } 5^{\circ} \mathrm{C}\end{array}$ \\
\hline $\begin{array}{l}\text { Lima } \\
(2000)\end{array}$ & $\begin{array}{l}h_{b}=(16 \cdot F r)^{C 7}\left[\left(F_{L L} \cdot h_{L}\right)^{3,07}+\left(S_{L} \cdot h_{E N C}\right)^{3,07}\right]^{1 / 3,07} \\
F_{L I}=1+1,893 \cdot X_{t t}^{-0,77} \\
S_{L I}=\frac{1}{\left(1+3,45 \cdot 10^{-6} \cdot \operatorname{Re}_{L}^{1,25} \cdot 1,55 \cdot B o^{0,22}\right)}\end{array}$ & $\begin{array}{l}\mathrm{R}-22 \\
\mathrm{R}-134 \mathrm{a} \\
\mathrm{R}-404 \mathrm{~A}\end{array}$ & $\begin{array}{c}\mathrm{D}=12,7 \mathrm{~mm} \\
\mathrm{G}: 50 \text { a } 500 \\
\mathrm{~kg} / \mathrm{m}^{2} . \mathrm{s} \\
\phi: 5 \text { a } 20 \mathrm{~kW} / \mathrm{m}^{2} \\
\text { x: } 5 \text { a } 98 \% \\
\mathrm{~T}_{\text {evap }}: 8 \text { e } 15^{\circ} \mathrm{C}\end{array}$ \\
\hline
\end{tabular}

\subsubsection{Correlações Estritamente Empíricas}

As correlações estritamente empíricas ou baseadas em banco de dados experimentais envolvem uma gama relativamente ampla de fluidos refrigerantes e condições operacionais. Serão apresentadas as correlações mais representativas, como a de SHAH (1982) e a de KANDLIKAR (1990). Neste grupo foram incluídas as seguintes correlações: a de PIERRE (1956), que não segue a regra geral das apresentadas neste trabalho e outras duas correlações que diferem das citadas; a de SCHROCK \& GROSSMAN (1962) e a de BANDARRA FILHO (1997). Deve-se destacar que as mais signifícativas e de maior alcance são as de Shah, Kandlikar e Bandarra Filho, por envolverem parâmetros adimensionais. As duas primeiras são resultados de regressão de dados experimentais de distintas fontes, envolvendo uma gama relativamente extensa de fluidos e condições operacionais, ao passo que a de Bandarra Filho foi baseada em cerca de 600 pontos e sua principal característica é a simplicidade na aplicação. A seguir as referidas correlações serão discutidas com detalhe. 
PIERRE (1956) desenvolveu uma correlação empírica para o coeficiente de transferência de calor bifásico médio ao longo do evaporador, válida para os refrigerantes $\mathrm{R}$ 12 e R-22, em termos de parâmetros adimensionais. Um desses parâmetros, denominado de $\mathrm{K}_{f}$, é função da diferença entre os valores do título de entrada e saída, do calor latente de vaporização e do comprimento do evaporador. É importante salientar que a constante gravitacional, $\mathrm{g}$, foi introduzida para adimensionalização do grupo $\mathrm{K}_{f}$. $\mathrm{O}$ grupo adimensional introduzido por PIERRE (1956) é o número de Reynolds bifásico, $\mathrm{Re}_{\mathrm{LO}}$. Duas versões foram propostas.

- Evaporação Completa

$$
h_{b}=\frac{k_{L}}{D} \cdot 0,0082 \cdot\left[\operatorname{Re}_{L O}{ }^{2} \cdot K_{f}\right]^{0,4}
$$

para $6^{\circ} \mathrm{C}$ de superaquecimento na saída e $10^{9}<\mathrm{Re}_{\mathrm{LO}}{ }^{2} \cdot \mathrm{K}_{f}<0,7 \cdot 10^{12}$

- Evaporação Incompleta

$$
\begin{aligned}
h_{b}= & \frac{k_{L}}{D} \cdot 0,0009 \cdot\left[\operatorname{Re}_{L O}{ }^{2} \cdot K_{f}\right]^{0,5} \\
& \quad \text { para } \mathrm{x}_{\text {saida }}<0,9 \text { e } 10^{9}<\operatorname{Re}_{\mathrm{LO}}{ }^{2} \cdot \mathrm{K}_{f}<0,7 \cdot 10^{12}
\end{aligned}
$$

onde,

$$
K_{f}=\left(\frac{i_{L V} \cdot \Delta x}{L \cdot g}\right)
$$

Deve-se observar que PIERRE (1956) utilizou $\mathrm{Re}_{\mathrm{LO}}$, referido à toda mistura escoando como líquido no tubo. Concluindo, é interessante observar que o adimensional $\mathrm{K}_{f}$, fisicamente pode ser considerado como uma espécie de número de ebulição modificado, uma vez que de certa forma incorpora o fluxo de calor e velocidade mássica (através da relação $\left.\frac{i_{L V} \cdot \Delta x}{L}\right)$

SCHROCK \& GROSSMAN (1962) elatoraram um modelo para a deternninaş̃o do coeficiente de transferência de calor utilizando água escoando num tubo vertical com diâmetros variando entre 2,95 e 10,97 mm. O fluxo de calor variou entre 190 e $4570 \mathrm{~kW} / \mathrm{m}^{2}$, a velocidade mássica entre 240 e $4450 \mathrm{~kg} / \mathrm{m}^{2}$.s, título de saída entre 5 e $57 \%$ e a faixa de pressão entre 289 e $3500 \mathrm{kPa}$. A correlação foi proposta em termos adimensionais, onde o coeficiente de transferência de calor foi avaliado em função do número de Nusselt, Nu. Os 
autores perceberam que com a introdução do número de ebulição, Bo, e do parâmetro de Martinelli, $\mathrm{X}_{\mathrm{tt}}$, os resultados experimentais eram melhor correlacionados. Embasados nesta observação, propuseram a seguinte correlação:

$$
N u=170 \cdot \operatorname{Re}^{0,8} \cdot \operatorname{Pr}_{L}^{1 / 3} \cdot\left(B o+1,5 \cdot 10^{-4} \cdot X_{t}{ }^{-2 / 3}\right)
$$

É interessante observar que esta correlação leva em consideração os efeitos de ebulição nucleada através do número de ebulição, Bo, e os efeitos convectivos através do parâmetro $X_{\mathrm{tt}}$. Em outras palavras, pode ser considerada uma correlação baseada na superposição de efeitos através da soma dos efeitos convectivos e de ebulição nucleada. A correlação apresentou desvios da ordem de $\pm 35 \%$, possivelmente devido às incertezas quanto à confiabilidade do equipamento experimental.

SHAH (1982) propôs, inicialmente, em 1976, um método para o cálculo do coeficiente de transferência de calor baseado nos resultados de cerca de 800 pontos experimentais, para escoamentos tanto verticais como horizontais. $\mathrm{O}$ autor dividiu a ebulição convectiva (no sentido amplo) em três regimes: de ebulição estritamente convectiva; de ebulição nucleada; e de supressão de bolhas. Estabeleceram-se, de antemão, os parâmetros adimensionais que regem o fenômeno da mudança de fase no interior de tubos: número de ebulição, Bo, correspondente à ebulição nucleada, número de Froude, Fr, e um parâmetro de Martinelli, $X_{\mathrm{tt}}$, modificado, o número de convecção, Co, referido à ebulição estritamente convectiva. Shah denominou o método de cálculo do coeficiente de transferência de calor bifásico de "Chart", provavelmente em virtude do procedimento envolver o uso de um ábaco, apresentado na Fig. 2.12. 


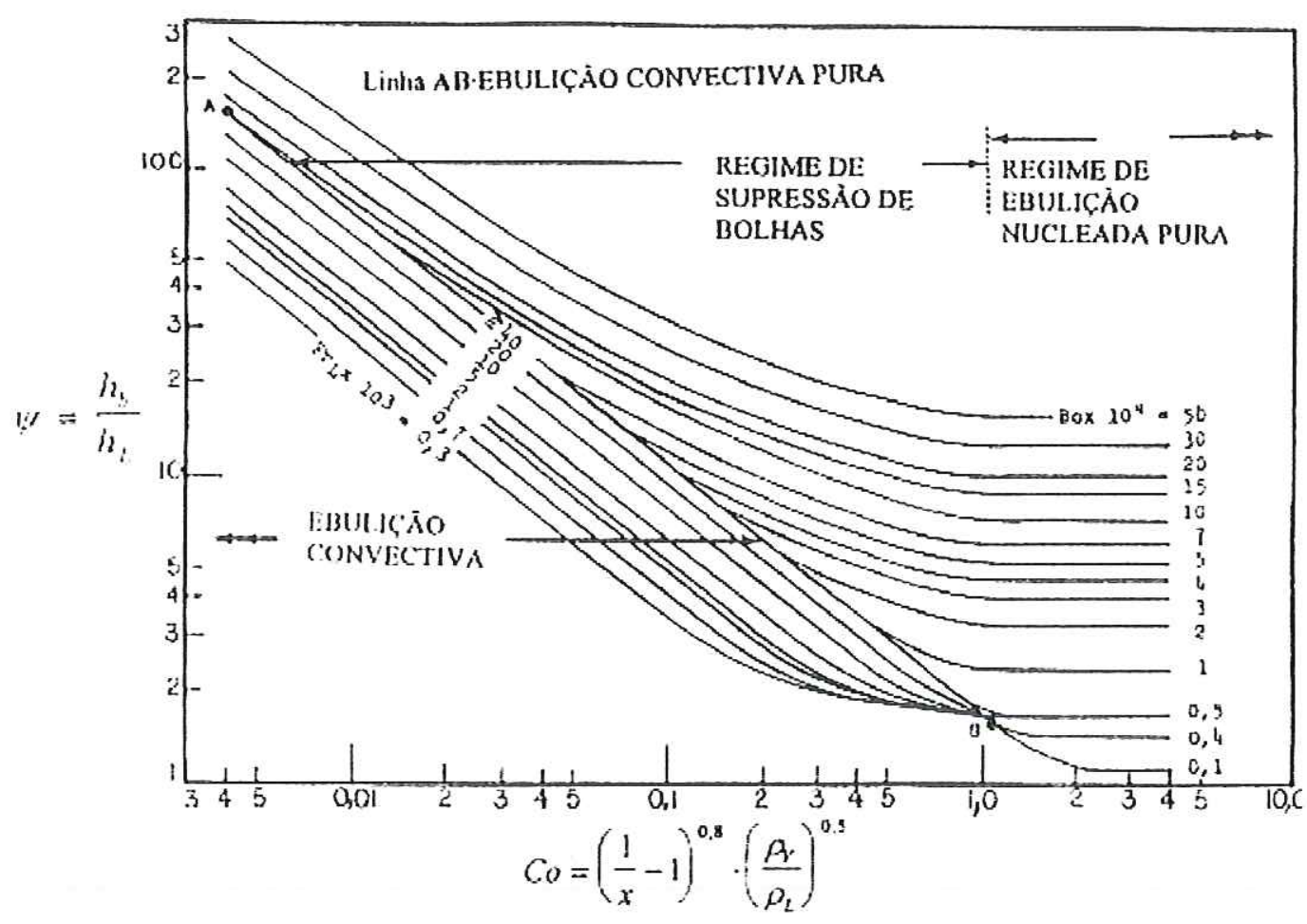

Figura 2.12 Gráfico para o cálculo do coeficiente de transferência de calor de SHAH (1976).

Mais tarde, em 1982 o autor desenvolveu correlações representativas do ábaco da Fig. 2.12. Inicialmente, é interessante observar que o parâmetro adimensional $\psi$, definido como:

$$
\psi=\frac{h_{b}}{h_{L}}
$$

A eq. (2.68) corresponde à relação entre coeficientes já introduzida na análise das correlações do grupo 1. A seguir serão discutidas as correlações correspondentes ao ajuste das curvas da Fig. 2.12.

- Para dutos verticais ou dutos horizontais, com número de Froude, Fr, superior a 0,04 :

$$
N=C o
$$

- Para dutos horizontais, com número de Froude, Fr, inferior a 0,04:

$N=0,38 \cdot \mathrm{Fr}^{-0,3} \cdot \mathrm{Co}$

Para o cálculo do $h_{b}$, Shah sugeriu o seguinte procedimento: 


$$
\begin{aligned}
& \text { - Para } \mathrm{N}>1,0 \text {, têm-se: } \\
\psi_{E N} & =230 \cdot B o^{0,5} \quad \text { para } \text { Bo }>0,3 \cdot 10^{-4} \\
\psi_{E N} & =1+46 \cdot B 0^{0,5} \quad \text { para } \quad B o \leq 0,3 \cdot 10^{-4} \\
\psi_{C} & =\frac{1,8}{N^{0,8}}
\end{aligned}
$$

Portanto, o valor final de $\psi$ é o maior entre $\psi_{\mathrm{EN}}$ e $\psi_{\mathrm{C}}$.

- Para $0,1<\mathrm{N}<1,0$ :

$$
\psi_{S B}=F \cdot B o^{0,5} \cdot \exp \left(2,74 \cdot N^{-0,1}\right)
$$

- Para $\mathrm{N}<0,1$, têm-se:

$$
\psi_{S B}=F \cdot B o^{0,5} \cdot \exp \left(2,47 \cdot N^{-0,15}\right)
$$

onde,

$$
\begin{array}{lll}
F=14,7 & \text { para } & B o \geq 11 \cdot 10^{-4} \\
F=15,4 & \text { para } & B o<11 \cdot 10^{-4}
\end{array}
$$

Portanto o valor de $\psi$, é o maior entre $\psi_{\mathrm{SB}}$ e $\psi_{\mathrm{C}}$.

O coeficiente de transferência de calor bifásico de Shah pode ser interpretado como sendo o maior valor resultante das correlações para os três regimes. Para regime de supressão de bolhas os efeitos convectivos e de ebulição nucleada são importantes. COLLIER \& THOME (1996) propõem o expoente para o número de ebulição, Bo, para o regime de ebulição nucleada, 0,7 ao invés de 0,5 , nas Eqs. (2.71) e (2.72).

A correlação de SHAH (1982) apresenta um desvio médio de $14 \%$ em relação aos próprios resultados experimentais.

KANDLIKAR (1990) desenvolveu a correlação (2.78), a partir de um banco de dados com mais de 5000 pontos experimentais de distintas fontes, envolvendo uma extensa gama de fluidos e condições experimentais. Ao contrário da correlação de Shah, esta 
correlação foi desenvolvida utilizando diversas constantes, associadas aos adimensionais: número de ebulição, Bo, número de convecção, Co, e o número de Froude, Fr. A forma geral da correlação de Kandlikar é a seguinte:

$$
h_{b}=\left[A \cdot C o^{B} \cdot(25 \cdot F r)^{E}\right] \cdot h_{L}+\left(C \cdot B o^{D} \cdot F f_{L}\right) \cdot h_{L}
$$

onde $h_{L}$ é avaliado pela correlação de Dittus-Boelter, Eq. (2.18).

Os valores das constantes A, B, C, D, e E são apresentados na Tabela 2.4. Esses valores são válidos para ebulição convectiva e para ebulição nucleada. No caso, calcula-se $h_{b}$ separadamente para os efeitos convectivo e de ebulição nucleada, escolhendo-se o maior valor entre os dois.

Tabela 2.4 Valores das constantes para ebulição convectiva e nucleada.

\begin{tabular}{|c|c|c|}
\hline Constante & Ebulição Convectiva & Ebulição Nucleada \\
\hline A & 1,1360 & 0,6683 \\
\hline B & $-0,9$ & $-0,2$ \\
\hline C & 667,2 & 1058,0 \\
\hline D & 0,7 & 0,7 \\
\hline E & 0,3 & 0,3 \\
\hline
\end{tabular}

Para valores de $\mathrm{Fr}>0,04$, adota-se $\mathrm{E}=0$, indicando que $\mathrm{Fr}$ não apresenta um efeito significativo. Para Fr $<0,04, \mathrm{E}=0,3$, de acordo com a Tabela 2.4, sugerindo um efeito mais significativo do número de Froude, Fr, no coeficiente de transferência de calor.

Na Tabela 2.5 são apresentados os valores de $F f_{\mathrm{L}}$, que incorporam o efeito do fluido refrigerante. Segundo ECKELS \& PATE (1990) o valor de $\mathrm{Ff}_{\mathrm{L}}$ para o refrigerante R-134a é 1,63. Observa-se uma significativa disparidade entre os coeficientes $\mathrm{F} f_{\mathrm{L}}$ dos distintos fluidos, uma vez que constitui um dos aspectos negativos desta correlação, já que sua aplicação a um dado fluido exige conhecimento do referido fator. Este, entretanto, não está disponível para a maioria dos fluidos refrigerantes em uso na atualidade. Em vista disso, BANDARRA FILHO et al (2000) propuseram, baseados nos próprios resultados experimentais, outros valores para o fator dependente do fluido, $F f_{\mathrm{L}}$, para novos refrigerantes (R-404A e R-407C). Os valores de $\mathrm{F} f_{\mathrm{L}}$ para os refrigerantes $\mathrm{R}-404 \mathrm{~A}$ e R-407C são 1,55 e 1,50, respectivamente. 
Tabela 2.5 Valores de $\mathrm{F}_{\mathrm{L}}$ para distintos fluidos.

\begin{tabular}{|c|c|}
\hline Fluido Refrigerante & Valor de $\mathrm{F}_{\mathrm{L}}$ \\
\hline Água & 1,00 \\
\hline $\mathrm{R}-11$ & 1,30 \\
\hline $\mathrm{R}-12$ & 1,50 \\
\hline $\mathrm{R}-13 \mathrm{BI}$ & 1,31 \\
\hline $\mathrm{R}-22$ & 2,20 \\
\hline R-113 & 1,30 \\
\hline R-114 & 1,24 \\
\hline R-152a & 1,10 \\
\hline Nitrogênio & 4,70 \\
\hline Neônio & 3,50 \\
\hline R-134a & 1,63 \\
\hline R-404A & 1,55 \\
\hline R-407C & 1,50 \\
\hline
\end{tabular}

A correlação desenvolvida por Kandlikar é similar a de Shah, no sentido em que ambas avaliam o coeficiente de transferência de calor bifásico como maior entre os efeitos convectivos e de ebulição nucleada.

BANDARRA FILHO (1997) elaborou um modelo simplificado para a determinação do coeficiente de transferência de calor bifásico, baseado nos parâmetros adimensionais comumente associados à mudança de fase em ebulição convectiva. Para o desenvolvimento do modelo foram utilizados resultados experimentais levantados por intermédio do aparato experimental, junto ao ACRC, Air Conditioning and Refrigeration Center da University of Illinois at Champaign-Urbana, USA. A seção de testes era composta de um evaporador de tubo simples, utilizado para representar as características operacionais de um evaporador frigorífico. Os tubos utilizados na seção de testes foram de cobre, com diâmetro interno variando entre 7,04 e 10,92 mm, medindo cerca de 2 metros de comprimento. Com o fim de, adequadamente, reproduzir as condições operacionais típicas de sistemas frigoríficos, alguns parâmetros variaram em faixas relativamente amplas nos experimentos. Assim, a temperatura de saturação variou entre -20 e $20^{\circ} \mathrm{C}$, a velocidade mássica, $\mathrm{G}$, entre 25 e 500 $\mathrm{kg} / \mathrm{m}^{2} . \mathrm{s}$, o fluxo de calor entre $1,9 \mathrm{e} 40 \mathrm{~kW} / \mathrm{m}^{2}$ e o título na entrada da seção de testes entre 1 
e $95 \%$. Os refrigerantes utilizados nos testes foram o R-12, o R-22 e o R-134a. Na entrada e saída da seção de testes foram instalados tubos de vidro de mesmo diâmetro interno, com o objetivo de permitir a visualização do escoamento.

A correlação foi desenvolvida a fim de corrigir uma forma das correlações estritamente convectivas, através da introdução do número de ebulição, Bo, que incorpora os efeitos de ebulição nucleada, e o número de Froude, $\mathrm{Fr}$, que incorpora os efeitos de superficie livre. $\mathrm{O}$ modelo, inicialmente, foi proposto da seguinte maneira:

$$
\frac{h_{b}}{h_{L}}=1+C_{1} \cdot X_{t t}^{-C_{2}} \cdot B o^{C_{3}} \cdot F_{r}{ }^{C_{4}}
$$

O parâmetro de Martinelli, $X_{\mathrm{tt}}$, foi introduzido com o objetivo de correlacionar os efeitos do tipo de refrigerante e de pressão, pois incorpora as propriedades do refrigerante, através das densidades e viscosidades. O número de ebulição, Bo, foi incorporado ao modelo a fim de representar a presença de bolhas no escoamento, ou seja, os efeitos de ebulição nucleada, associados, em geral, a elevados fluxos de calor na parede do tubo e a títulos reduzidos. A incorporação do número de Froude, Fr, foi introduzida para correlacionar aqueles resultados obtidos sob condições de baixas vazões, para os quais se verifica o padrão estratificado e ondulado de escoamento, que se caracterizam por valores relativamente reduzidos do coeficiente, visto que uma significativa porção da superfície aquecida fíca exposta ao vapor. Assim, foi determinada uma condição limite onde o número de Froude era significativo, o que proporcionou a forma final da respectiva correlação:

- Para: $\mathrm{Fr}<0,1$ :

$\frac{h_{b}}{h_{L}}=1+125 \cdot X_{t t}^{-0,65} \cdot B o^{0,3} \cdot F^{0,5}$

- Para: $\operatorname{Fr} \geq 0,1$ :

$\frac{h_{b}}{h_{L}}=1+40 \cdot X_{t}^{-0,65} \cdot B o^{0,3}$

As correlações (2.80) e (2.81) são de rápida e fácil aplicação, além de proporcionar resultados bastante significativos. $\mathrm{O}$ desvio médio encontrado em relação aos resultados experimentais foi da ordem de $12 \%$. 


\subsection{Análise Comparativa das Correlações do Grupo 3}

As correlações baseadas em banco de dados são resultados de regressão de dados experimentais, envolvendo uma extensiva gama de fluidos e condições operacionais. A Fig. 2.13 ilustra uma comparação entre as correlações de Shah e Kandlikar, válidas para as condições especificadas na legenda. O objetivo dessa comparação é mostrar as distintas regiões que os referidos autores incorporam nos seus modelos. A correlação de Kandlikar é caracterizada por dois efeitos. $\mathrm{O}$ primeiro, da ebulição nucleada, apresenta uma redução de $\mathrm{h}_{\mathrm{b}}$ até títulos da ordem de $17 \%$, dependendo do fluido e das condições operacionais. Este efeito é fisicamente consistente com o comportamento qualitativo descrito na introdução deste capítulo. $\mathrm{O}$ segundo efeito, de ebulição convectiva, se caracteriza pela elevação de $h_{b}$ até títulos da ordem de $80 \%$, de acordo com as condições especificadas na Fig. 2.13, típico do padrão anular de escoamento. Com títulos superiores a $80 \%$, a superficie interior do tubo se encontra parcialmente seca, do que resulta uma redução do coeficiente de transferência de calor. A correlação de Shah se caracteriza por três regimes, ilustrados no gráfico da Fig. 2.13. Na primeira região predomina a ebulição nucleada, onde o coeficiente de transferência de calor decresce, como observado anteriormente. A segunda, denominada de supressão de bolhas, ambos os efeitos convectivo e de ebulição nucleada são importantes, caracterizando a influência do número de Conveç̧ão, Co, e do número de ebulição, Bo, respectivamente. Nesta região, ocorre a formação de bolhas concomitantemente com a evaporação na interface. A terceira é de domínio da ebulição estritamente convectiva, seguindo os mesmos princípios da correlação de Kandlikar, descrito anteriormente. 


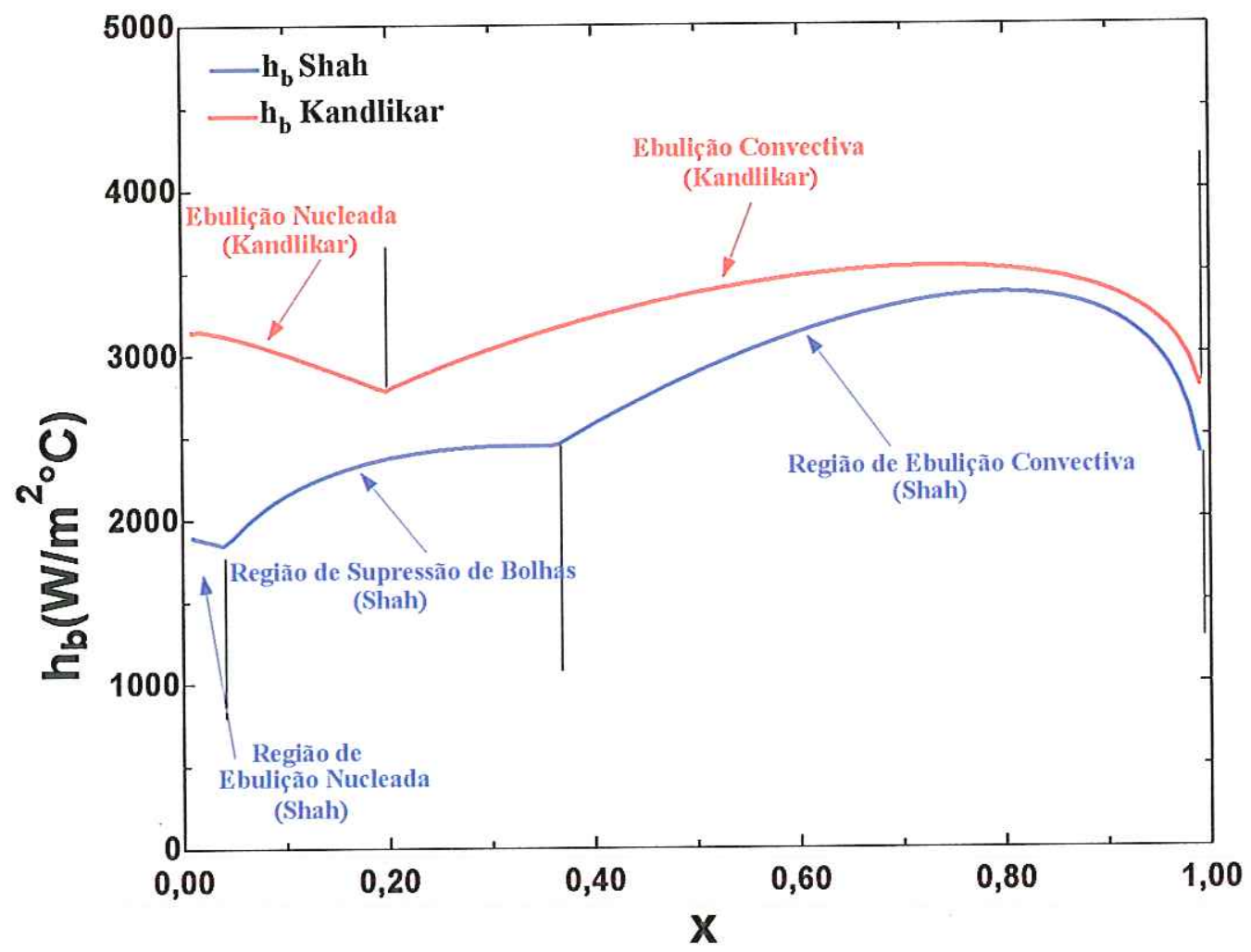

Figura 2.13 Comparação entre as correlações baseadas em banco de dados para R-134a com $\mathrm{T}_{\text {sat }}=-5^{\circ} \mathrm{C}, \mathrm{G}=200 \mathrm{~kg} / \mathrm{m}^{2}$.s e $\phi=15 \mathrm{~kW} / \mathrm{m}^{2}$.

Tabela 2.6 Sumário das correlações baseadas em banco de dados

\begin{tabular}{|c|c|c|c|}
\hline Autor & Correlação & Fluidos & Condições \\
\hline $\begin{array}{l}\text { Pierre } \\
\text { (1956) }\end{array}$ & $\begin{array}{l}\text { Evaporação Completa } \\
\text { para } 6^{\circ} \mathrm{C} \text { de superaquecimento na saída } \\
\text { e } 10^{9}<\operatorname{Re}_{\mathrm{LO}}{ }^{2} \cdot \mathrm{K}_{\mathrm{f}}<0,7 \cdot 10^{12} \\
h_{b}=\frac{k_{L}}{D} \cdot 0,0082 \cdot\left[\operatorname{Re}_{I O}{ }^{2} \cdot K_{f}\right]^{0,4} \\
\text { onde, } \quad K_{f}=\left(\frac{i_{L V} \cdot \Delta x}{L \cdot g}\right) \\
\text { Evaporação Incompleta } \\
\text { para } \mathrm{X}_{\text {saida }}<0,9 \text { e } 10^{9}<\operatorname{Re}_{\mathrm{LO}}{ }^{2} \cdot \mathrm{K}_{\mathrm{f}}<0,7 \cdot 10^{12} \\
h_{b}=\frac{k_{L}}{D} \cdot 0,0009 \cdot\left[\operatorname{Re}_{L O}{ }^{2} \cdot K_{f}\right]^{p, 5}\end{array}$ & R-12 & $\begin{array}{c}\mathrm{D}: 12 \mathrm{a} \\
18 \mathrm{~mm} \\
\mathrm{x}: 15 \% \text { a } 6^{\circ} \mathrm{C} \\
\text { de } \\
\text { superaque- } \\
\text { cimento }\end{array}$ \\
\hline $\begin{array}{c}\text { Schrock } \\
\& \\
\text { Grossman } \\
(1962)\end{array}$ & $\begin{array}{l}\qquad N u=170 \cdot \operatorname{Re}^{0,8} \cdot \operatorname{Pr}_{L}^{1 / 3} \cdot\left(B o+1,5 \cdot 10^{-4} \cdot X_{t}^{-2 / 3}\right) \\
\text { onde, } \\
\qquad N u=\frac{h_{b} \cdot D}{k_{L}}\end{array}$ & Água & $\begin{array}{c}\text { G: } 240 \mathrm{a} \\
4450 \mathrm{~kg} / \mathrm{m}^{2} \cdot \mathrm{s} \\
\phi: 190 \mathrm{a} \\
4570 \mathrm{~kW} / \mathrm{m}^{2} \\
\mathrm{x}: 5 \text { a } 57 \%\end{array}$ \\
\hline
\end{tabular}




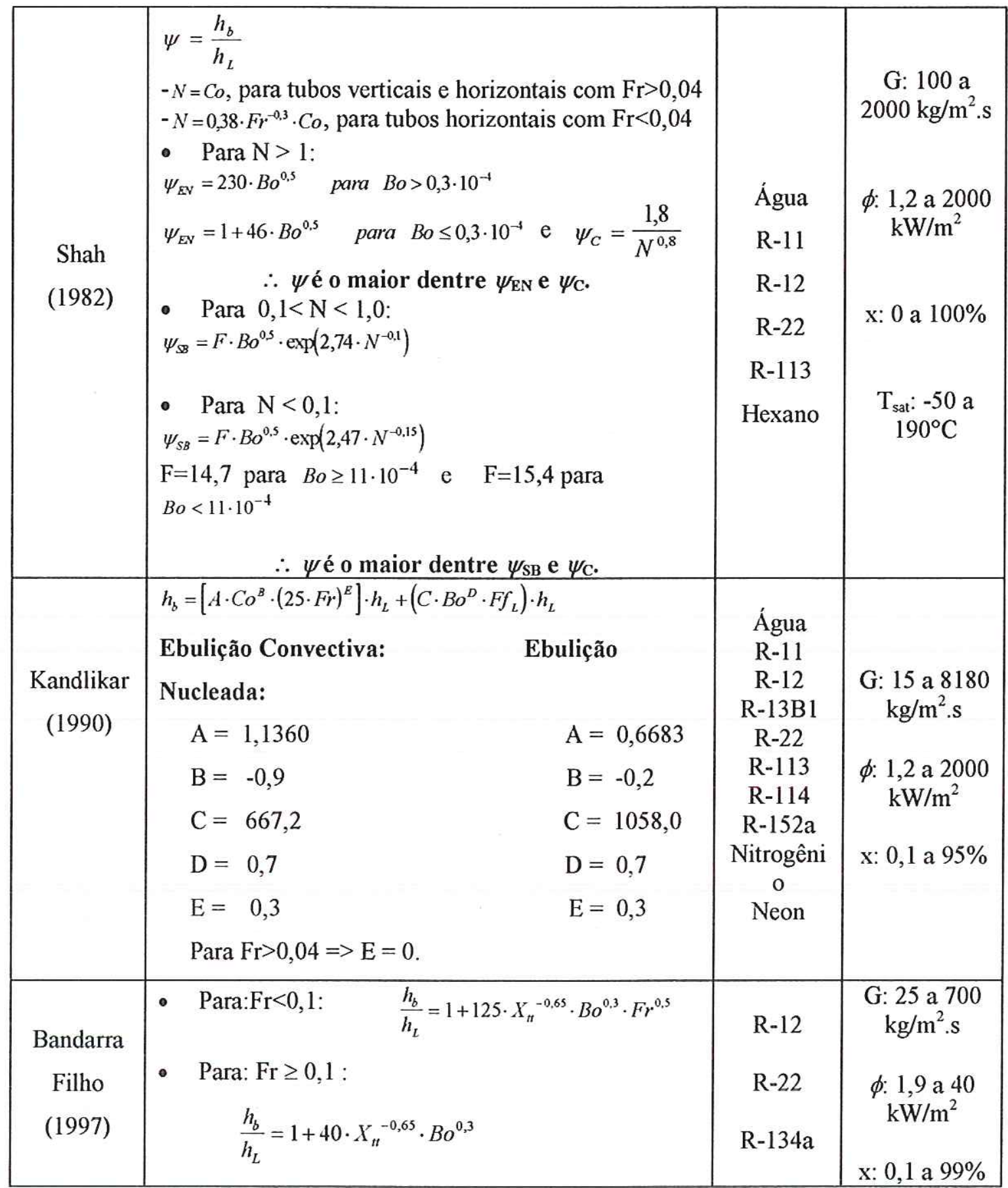

\subsubsection{Comparação entre as Correlações dos Grupos 1, 2 e 3.}

Como pode ser observado na Fig. 2.15, foram selecionadas as correlações mais representativas de cada grupo para efeito de comparação, já que as mesmas proporcionavam resultados significativamente distintos. Foi possível verificar desvios da ordem de $133 \%$, em média entre elas. Isso demonstra a peculiaridade das distintas correlações às próprias 
condições operacionais para as quais foram desenvolvidas, evidenciando que ainda inexiste um padrão de correlação ideal para o cálculo do coeficiente de transferência de calor bifásico. Nesse sentido, destacam-se aquelas que aliam simplicidade e rapidez na aplicação, além, é claro, de proporcionar resultados consistentes. A Fig. 2.14 ilustra a comparação gráfica entre as correlações dos grupos 1, 2 e 3, para as condições especificadas na legenda. Foram incorporados à figura dados experimentais levantados para o R-134a com velocidade mássica de $300 \mathrm{~kg} / \mathrm{s} . \mathrm{m}^{2}$, fluxo de calor de $5 \mathrm{~kW} / \mathrm{m}^{2}$, temperatura de saturação da ordem de $8^{\circ} \mathrm{C}$ e diâmetro interno do tubo de $12,7 \mathrm{~mm}$. Vale destacar que, entre as correlações pertencentes ao grupo 1, somente a BANDARRA FILHO et al (1997) se aproximou dos resultados experimentais. Em relação ao grupo 2, destacam-se as correlações de WATTELET (1994) e a de LIMA (2000). Já para o grupo 3, as correlações que melhor representam os resultados experimentais são as de SHAH (1982), KANDLIKAR (1990) e BANDARRA FILHO (1997).

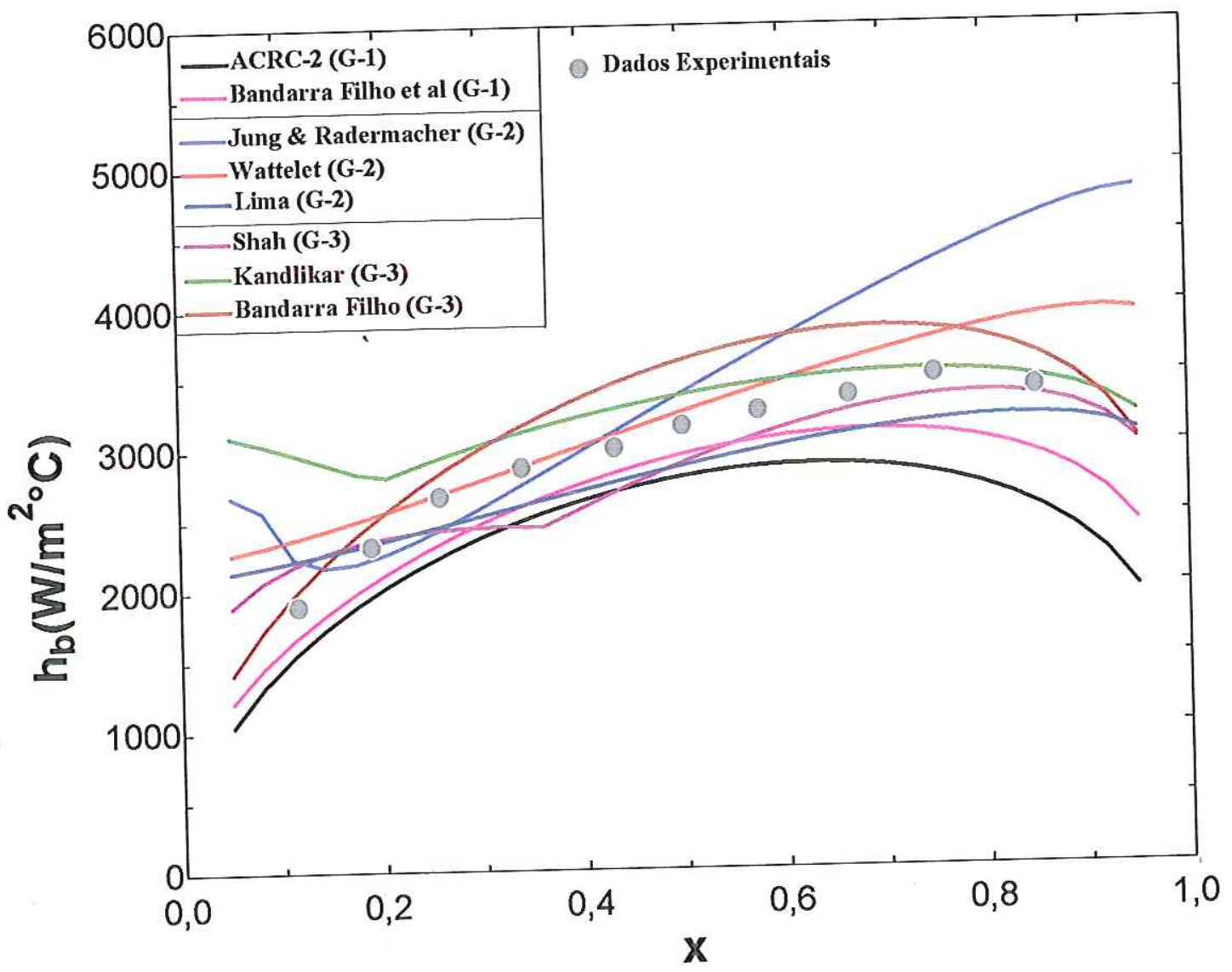

Figura 2.14 Comparação entre as correlações dos grupos 1, 2 e 3 para $\mathrm{R}-134 \mathrm{a}$ com $\mathrm{T}_{\text {sat }}=-$ $5^{\circ} \mathrm{C}, \mathrm{G}=200 \mathrm{~kg} / \mathrm{m}^{2}$.s e $\phi=15 \mathrm{~kW} / \mathrm{m}^{2}$, superpostos os dados experimentais. 


\subsubsection{Conclusões}

Após a apresentação deste capítulo relativo à pesquisa bibliográfica sobre ebulição convectiva, foi possível extrair às seguintes conclusões a respeito das correlações apresentadas:

- As correlações estritamente convectivas proporcionam bons resultados para aplicações que apresentem elevada vazão e títulos na entrada superiores que $20 \%$, como é o caso de algumas aplicações frigoríficas.

- As correlações apresentadas são, de maneira geral, particulares às condições operacionais que foram submetidas, portanto, não podem ser generalizadas.

- As correlações apresentadas nos parágrafos precedentes se aplicam a condições locais, isto é, para uma seção transversal no tubo, exceto a correlação de Pierre, que prevê o coeficiente de transferência de calor médio.

- Os parâmetros que mais interferem nas correlações são a velocidade mássica, G, e o fluxo de calor, $\phi$.

- A seção onde ocorre a secagem da parede não foi adequadamente abordada na literatura, evidenciando que a faixa de aplicação dessas correlações não se aplica para região de títulos elevados. 


\subsection{Intensificação da Transferência de Calor}

\subsubsection{Introdução}

Inúmeras técnicas de intensificação da transferência de calor têm sido sugeridas durante a última década, podendo-se citar tubos corrugados, tubos aletados integralmente, com inserção de fitas torcidas em espiral ou aletas, tubos estriados, tubos microaletados e outros. Essas técnicas de intensificação proporcionam equipamentos compactos e mais eficientes. A indústria frigorífica não tem ficado à margem desse desenvolvimento. Em nosso país, os trocadores de calor de alto desempenho fazem parte da linguagem comum de projetistas e técnicos.

A principal motivação para tal esforço de desenvolvimento é a econômica, através de dois aspectos ou pontos de vista:

(1) Redução do custo inicial. Trocadores de calor mais eficientes proporcionam o mesmo desempenho utilizando uma área de troca de calor inferior, o que implica numa redução de material e, portanto, do custo.

(2) Para uma mesma área de troca de calor, os trocadores de alto desempenho proporcionam condições operacionais vantajosas que podem redundar numa significativa redução do consumo de energia. Na indústria frigorífica, o potencial para redução do consumo de energia através da utilização de trocadores de calor de melhor desempenho térmico é evidente. Considerando o ciclo ideal de Carnot de compressão a vapor, não é difícil perceber que a elevação da temperatura de evaporação e/ou a redução da de condensação proporcionam coeficientes de efícácia, COP, mais elevados.

O uso de dispositivos de intensificação da transferência de calor não é novo na indústria frigorífica, especialmente nos evaporadores resfriadores de líquidos do tipo expansão seca, entre outros, em que se utilizam inserções no interior dos tubos para incrementar o coeficiente de transferência de calor. Infelizmente, todos os dispositivos de intensificação acarretam incrementos de perda de carga. No evaporador, a perda de carga do refrigerante afeta diretamente o desempenho da instalação, uma vez que reduz a pressão de aspiração do compressor, acarretando um incremento no consumo de energia.

Diversos estudos da literatura aberta demonstraram um melinor desempenho :a transferência de calor e, por conseqüência, um aumento indesejável na perda de carga de tubos microaletados em evaporação.

O tubo microaletado distingue-se das demais formas de intensificação no interior de tubos pelas aletas, que apresentam altura da ordem de $0,2 \mathrm{~mm}$, e são mais numerosas, 
tipicamente 60 ao longo do perímetro do tubo. A Fig. 2.15 apresenta um corte esquemático de um tubo internamente ranhurado e um detalhe com os principais parâmetros geométricos.

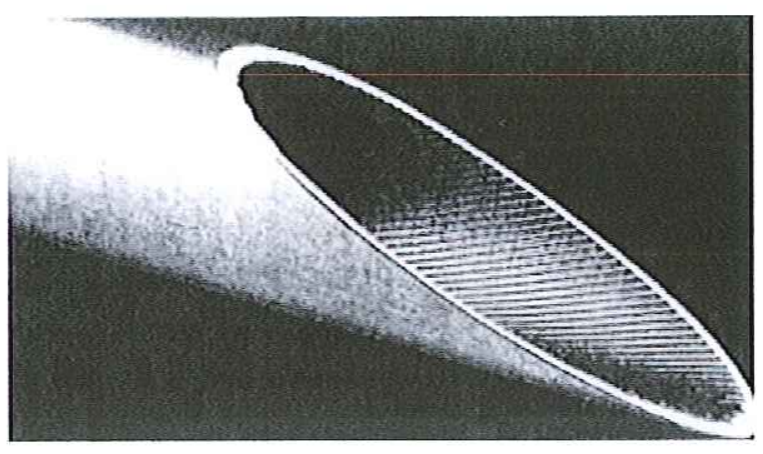

Figura 2.15 Representação esquemática e parâmetros geométricos de um tubo internamente ranhurado.

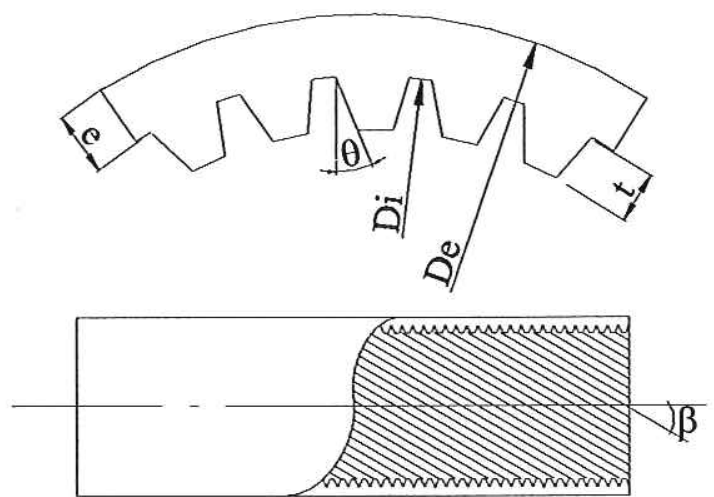

Observações visuais tem mostrado que o melhor desempenho dos tubos microaletados em relação aos lisos se deve à alteração no padrão de escoamento, principalmente para vazões reduzidas. Essa alteração ocorre, principalmente, para o caso do padrão de escoamento estratificado, que para tubos microaletados, assume uma configuração semelhante ao padrão anular, pois o líquido se desloca para a região superior do tubo através das ranhuras espirais.

DARABI et al. (1995) e MUZZIO et al (1997) afirmam que os tubos microaletados estão sendo utilizados por cerca de $30 \%$ das indústrias de refrigeração do mundo, principalmente, devido à sua eficácia, obtendo-se, em certos casos, uma intensificação da ordem de 5 vezes. Algumas indústrias e pesquisadores não têm medido esforços em projetar e desenvolver novas geometrias de microaletas que poderiam melhorar ainda mais seu desempenho.

Um dos primeiros estudos relacionados à mudança de fase de refrigerantes em tubos aletados internamente foi publicado em 1953 por BOLING apud WEBB (1994). LAVIN (1963) realizou o primeiro estudo envolvendo distintas geometrias de aletas internas. Já em relação aos tubos microaletados, as pesquisas iniciaram-se no final da década de 70, com o primeiro estudo registrado na literatura tendo sido desenvolvido em 1977 por FUJIE apud WEBB (1994), para a Hitachi Cable Ltda.

A seguir será apresentada uma revisão de estudos realizados sobre intensificação no interior de tubos, enfatizando as pesquisas envolvendo tubos microaletados.

KHANPARA et al. (1986) pesquisaram a intensificação da transferência de calor do R-113 em mudança de fase de tubos microaletados. A seção de testes era composta por um 
tubo de $9,52 \mathrm{~mm}$ de diâmetro por $1 \mathrm{~m}$ de comprimento. As condições operacionais dos ensaios foram as seguintes: velocidade mássica, G, de 197 a $594 \mathrm{~kg} / \mathrm{s} \cdot \mathrm{m}^{2}$, título médio na

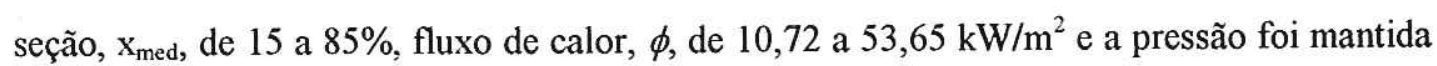
em torno de $241 \mathrm{kPa}$. O tubo da seção de testes era aquecido por água que circulava entre dois tubos concêntricos. As características geométricas do tubo microaletado, utilizadas por KHANPARA et al. (1986), foram: altura da aleta: 0,15 mm; números de aletas de 60 a $70 \mathrm{e}$ ângulo de hélice de $20^{\circ}$. Foram ensaiados oito tubos microaletados, com geometria distinta, $\mathrm{e}$ um tubo liso, utilizado para efeito de comparação. Realizaram testes para escoamento com mudança de fase e monofásico.

Os resultados apresentaram uma intensificação da ordem de 30 a $80 \%$ do tubo microaletado em relação ao tubo liso para escoamento monofásico. Já para escoamento com mudança de fase, a intensificação da transferência de calor foi de 30 a $100 \%$ em relação ao tubo liso. Para o caso da perda de carga, os resultados apresentaram um aumento de até $80 \%$ do tubo microaletado em relação ao tubo liso, porém houve um caso em que a perda de carga para o tubo liso foi superior ao tubo microaletado. Isso, possivelmente, ocorreu devido a erros de leitura ou tais valores estavam dentro da faixa de incertezas. Os autores concluíram, ainda, que a perda de carga aumenta com o incremento do título e velocidade mássica, ao passo que o número de aletas influencia o coeficiente de transferência de calor. No caso, observaram que tubos com maior número de microaletas apresentaram melhores resultados, especialmente por indicar a melhor relação entre o coeficiente de transferência de calor e perda de carga.

SCHLAGER et al. (1988) estudaram a evaporação de misturas refrigerante-óleo em tubos lisos e microaletados. Em circuitos frigoríficos, o óleo lubrificante do compressor está presente na maioria dos componentes do sistema. Nesse estudo, é apresentado um sumário das pesquisas anteriores, como ilustrado na Tabela 2.7, envolvendo a evaporação de refrigerantes. $\mathrm{O}$ fator de intensificação em termos da transferência de calor, $\mathrm{FI}_{\mathrm{h}}$, indica a razão entre o coeficiente de transferência de calor obtido para tubo microaletado e tubo liso. 
Tabela 2.7 Pesquisas envolvendo a intensificação da transferência de calor em tubos microaletados. SCHLAGER et al. (1988).

\begin{tabular}{|l|c|c|c|c|}
\hline Autor & Diâmetro & Refrigerante & Título & $\mathbf{F I}_{\mathbf{h}}$ \\
\hline Ito et al. (1977) & $-\cdots-------$ & $\mathrm{R}-22$ & $-\cdots------$ & 2,0 \\
\hline Ito \& Kimura (1979) & $12,7 \mathrm{~mm}$ & $\mathrm{R}-22$ & 25 a $90 \%$ & 2,0 \\
\hline Kimura \& Ito (1981) & $6,35 \mathrm{~mm}$ & $\mathrm{R}-12$ & $\mathrm{x}_{\text {med }}=55 \%$ & 2,0 \\
\hline Tatsumi et al. (1982) & $9,52 \mathrm{~mm}$ & $\mathrm{R}-22$ & 25 a 95\% & 2,1 \\
\hline Tojo et al. (1982) & $9,52 \mathrm{~mm}$ & $\mathrm{R}-22$ & $-\cdots------$ & 2,0 \\
\hline Shinohara \& Tobe (1985) & $9,52 \mathrm{~mm}$ & $\mathrm{R}-22$ & $\mathrm{x}_{\text {med }}=60 \%$ & 2,5 \\
\hline Khanpara et al. (1986) & $9,52 \mathrm{~mm}$ & $\mathrm{R}-113$ & 15 a $85 \%$ & 2,0 \\
\hline Khanpara et al. (1987) & $9,52 \mathrm{~mm}$ & $\mathrm{R}-113$ & 10 a $90 \%$ & 2,7 \\
\hline
\end{tabular}

$\mathrm{FI}_{\mathrm{h}}$ : fator de intensificação em termos da transferência de calor.

O tubo da seção de testes apresentava um diâmetro de $9,52 \mathrm{~mm}$ e comprimento de 3,66 m, sendo aquecido com água, a qual circulava no espaço anular entre tubos concêntricos. A velocidade mássica variou de 125 a $400 \mathrm{~kg} / \mathrm{s} . \mathrm{m}^{2}$, título na entrada da seção

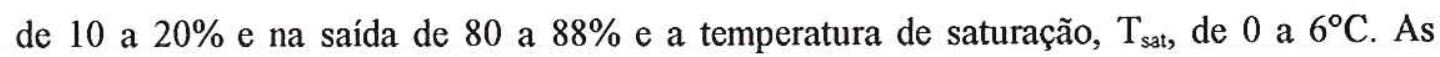
características geométricas dos tubos microaletados utilizados para os testes são: altura da aleta: $0,2 \mathrm{~mm}$, número de aletas: 60 , passo da aleta: $0,44 \mathrm{~mm}$ e ângulo de hélice: $18^{\circ}$. Utilizaram o tubo liso nos ensaios a fim de estabelecer uma referência para a comparação com tubos microaletados, além do uso de refrigerante puro para comparação com misturas refrigerante-óleo. Os testes com tubos microaletados para refrigerantes puros revelaram uma intensificação de $90 \%$ para vazões elevadas, $\mathrm{G}=400 \mathrm{~kg} / \mathrm{s} . \mathrm{m}^{2}$, e $170 \%$ para vazões reduzidas, $\mathrm{G}=125 \mathrm{~kg} / \mathrm{s} \cdot \mathrm{m}^{2}$. Para o caso de misturas refrigerante-óleo, dependendo da concentração de óleo em massa, pode-se elevar o coeficiente de transferência de calor. Os autores concluíram que pequenas quantidades de óleo podem incrementar o coeficiente de transferência de calor para tubos lisos e microaletados e, com o aumento da velocidade mássica, diminui o efeito de intensificação do óleo. No caso de tubos lisos, a intensificação diminuiu de 1,36 para 1,25 a partir do aumento da velocidade mássica, G, de 200 para $400 \mathrm{~kg} / \mathrm{s} \cdot \mathrm{m}^{2}$.

Em 1989, os mesmos autores apresentaram outros resultados experimentais sobre a intensificação da transferência de calcr em tubos micrcaletados de refrigerante R-22 com misturas óleo-refrigerante. Nesse trabalho, apresentaram comparações com tubos lisos e tubos denominados de "aletas baixas", com diferenças na geometria, como ilustrado na Tabela 2.8 , a seguir.

*Aletas baixas: denominação para tubos ranhurados com altura da aleta inferior a $0,4 \mathrm{~mm}$. 
Tabela 2.8 Parâmetros geométricos de tubos lisos e com aletamento interno. SCHLAGER (1988).

\begin{tabular}{|l|c|c|c|}
\hline Geometria & Tubo Liso & Tubo Microaletado & Tubo com aletas baixas \\
\hline Diâmetro externo & $9,52 \mathrm{~mm}$ & $9,52 \mathrm{~mm}$ & $9,52 \mathrm{~mm}$ \\
\hline Diâmetro interno & $8,0 \mathrm{~mm}$ & $8,72 \mathrm{~mm}$ & $8,51 \mathrm{~mm}$ \\
\hline Altura da aleta & ---------- & $0,2 \mathrm{~mm}$ & $0,38 \mathrm{~mm}$ \\
\hline Passo da aleta & $-\cdots-------$ & $0,44 \mathrm{~mm}$ & $1,21 \mathrm{~mm}$ \\
\hline Ângulo da espiral & ---------- & $18^{\circ}$ & $30^{\circ}$ \\
\hline Número de aletas & $----\cdots-----$ & 60 & 21 \\
\hline
\end{tabular}

A conclusão mais significativa deste segundo trabalho foi que o tubo microaletado apresentou um desempenho do fator de intensificação global, relação entre a intensificação no coeficiente de transferência de calor e da perda de carga, de 25 a $35 \%$ superior em relação aos tubos chamados de aletas baixas para refrigerantes puros e misturas com óleo lubrificante.

REID et al. (1991) apresentaram um trabalho onde foram ensaiadas três técnicas de intensificação em escoamento com mudança de fase em tubos com inserção de fita torcida em espiral, altas aletas* e microaletados. Utilizaram o fluido refrigerante R-113 que era aquecido por meio de uma resistência elétrica. $\mathrm{O}$ aparato experimental usado foi o mesmo de KHANPARA et al. (1986), porém com modificações para a inclusão das resistências elétricas. A seção de testes era composta de um tubo com 9,52 mm de diâmetro por 3,66 m de comprimento, com um total de 23 termopares para medida de temperatura superficial ao longo da seção. Os tubos ensaiados são apresentados na Tabela 2.9, concomitantemente com as características geométricas de cada um.

\footnotetext{
* Aletas altas: denominação para tubos microaletados com altura da aleta superior a $0,5 \mathrm{~mm}$.
} 
Tabela 2.9 Características geométricas dos tubos ensaiados. REID et al. (1991).

\begin{tabular}{|c|c|c|c|c|c|c|c|c|}
\hline Geometria & $\begin{array}{l}\text { Tubo } \\
\text { liso } \\
(1)\end{array}$ & $\begin{array}{c}\text { Tubo } \\
\text { micro- } \\
\text { aletado } \\
(2) \\
\end{array}$ & $\begin{array}{c}\text { Aletas } \\
\text { baixas } \\
\text { helicoi- } \\
\text { dais (3) }\end{array}$ & $\begin{array}{l}\text { Tubo } \\
\text { liso } \\
(4)\end{array}$ & $\begin{array}{c}\text { Aletas } \\
\text { altas } \\
\text { helicoidais } \\
\text { (5) }\end{array}$ & $\begin{array}{l}\text { Aletas } \\
\text { altas } \\
\text { helicoi- } \\
\text { dais (6) }\end{array}$ & $\begin{array}{c}\text { Aletas } \\
\text { altas } \\
\text { helicoi- } \\
\text { dais (7) } \\
\end{array}$ & $\begin{array}{c}\text { Fita } \\
\text { retorci- } \\
\text { da }(8)\end{array}$ \\
\hline $\begin{array}{c}\text { Diâmetro } \\
\text { externo }\end{array}$ & $\begin{array}{l}9,52 \\
\mathrm{~mm}\end{array}$ & $\begin{array}{l}9,52 \\
\mathrm{~mm}\end{array}$ & $9,52 \mathrm{~mm}$ & $\begin{array}{l}12,7 \\
\mathrm{~mm}\end{array}$ & $12,58 \mathrm{~mm}$ & $12,55 \mathrm{~mm}$ & $12,7 \mathrm{~mm}$ & $\begin{array}{l}12,7 \\
\mathrm{~mm}\end{array}$ \\
\hline $\begin{array}{c}\text { Diâmetro } \\
\text { interno }\end{array}$ & $\begin{array}{c}8,712 \\
\mathrm{~mm}\end{array}$ & $\begin{array}{c}8,712 \\
\mathrm{~mm}\end{array}$ & $8,509 \mathrm{~mm}$ & $\begin{array}{c}10,92 \\
\mathrm{~mm}\end{array}$ & $10,92 \mathrm{~mm}$ & $10,92 \mathrm{~mm}$ & $11,43 \mathrm{~mm}$ & $\begin{array}{c}10,92 \\
\mathrm{~mm}\end{array}$ \\
\hline $\begin{array}{c}\text { Geometria } \\
\text { da aleta }\end{array}$ & (.......... & $\begin{array}{c}\text { Triangu- } \\
\text { lar }\end{array}$ & $\begin{array}{c}\text { Retangu- } \\
\text { lar }\end{array}$ & -...... & Trapezoidal & $\begin{array}{l}\text { Trapezoi- } \\
\text { dal }\end{array}$ & $\begin{array}{l}\text { Retangu- } \\
\text { lar }\end{array}$ & ............ \\
\hline $\begin{array}{l}\mathrm{N}^{\circ} . \mathrm{de} \\
\text { aletas }\end{array}$ & (n....... & 65 & 21 & (-..--- & 32 & 32 & 26 & - \\
\hline $\begin{array}{c}\text { Altura da } \\
\text { aleta }\end{array}$ & -....-. & 0,211 & 0,381 & --.--- & 0,551 & 0,551 & 0,508 & -........ \\
\hline $\begin{array}{c}\text { Ângulo de } \\
\text { hélice }\end{array}$ & - $\cdots-\cdots-\cdot$ & $17,5^{\circ}$ & $30^{\circ}$ & (-..-..- & $0^{\circ}$ & $16^{\circ}$ & $31^{\circ}$ & - \\
\hline
\end{tabular}

A Fig. 2.16 apresenta as seções que ilustram as características geométricas de cada tubo mencionado acima.

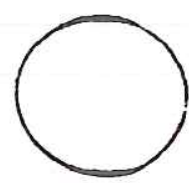

Tubo 1 (Liso)

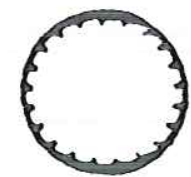

Tubo $3\left(30^{\circ}\right.$ hèlice $)$

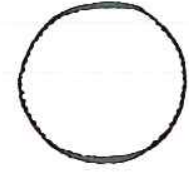

Tubo $2\left(17,5^{\circ}\right.$ hélice $)$

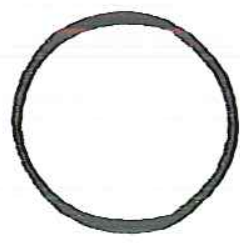

Tubo 4 (Liso)

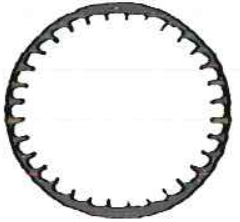

Tubo $5\left(0^{\circ}\right.$ hélice $)$

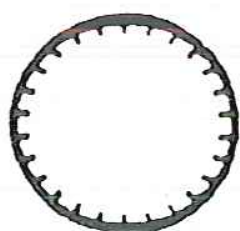

Tubo $7\left(31^{\circ}\right.$ hélice $)$

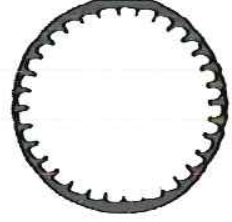

Tubo $6\left(16^{\circ}\right.$ hèlice

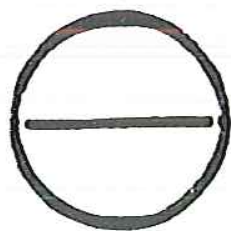

Tubo 8

Figura 2.16 Ilustração das características geométricas de cada tubo descrito acima. REID et al. (1991).

Uma comparação interessante realizada entre os tubos 2 e 3, fabricados pela Hitachi, Inc. e Noranda Metals Industries respectivamente, apresentou o fator de intensificação na região de títulos reduzidos de 1,6 para o tubo 2 e 1,7 para o tubo 3. Para títulos superiores a $40 \%$, correspondendo à região de domínio da ebulição convectiva, o fator de intensificação para ambos os casos diminuiu para valores da ordem de 1,3 .

\footnotetext{
* Aletas altas: denominação para aletas com altura variando entre 0,5 e $0,6 \mathrm{~mm}$.
} 
Para o caso fator de intensificação global, verificou-se que o tubo microaletado (tubo 2) obteve uma vantagem significativa em relação ao tubo com aletas baixas (tubo3). Os tubos com inserção de fita torcida em espiral foram os que apresentaram a maior perda de carga, evidenciando que os tubos microaletados apresentaram os melhores resultados (transferência de calor e perda de carga) quando comparados aos demais tubos ensaiados.

ECKELS et al. (1992) pesquisaram o coeficiente de transferência de calor em evaporação do refrigerante R-22 em tubos microaletados de diferentes configurações. Cinco tubos microaletados diferentes, mas com mesmo diâmetro $(9,52 \mathrm{~mm})$, foram ensaiados e outros três com diâmetros de 7,94 $\mathrm{mm}$. Os testes foram conduzidos à temperatura de evaporação de $2^{\circ} \mathrm{C}$ e $7^{\circ} \mathrm{C}$, variando a velocidade mássica, no caso para diâmetros de 9,52 $\mathrm{mm}, \mathrm{G}$ variou entre 150 e $350 \mathrm{~kg} / \mathrm{s} \cdot \mathrm{m}^{2}$ e para $7,94 \mathrm{~mm}$, entre 135 e $400 \mathrm{~kg} / \mathrm{s} . \mathrm{m}^{2}$, o título na entrada da seção de testes entre 8 e $15 \%$ e na saída entre 80 e $88 \%$. A seção de testes era composta por um tubo de $3,67 \mathrm{~m}$ de comprimento, aquecido por água, que circulava no espaço anular entre dois tubos concêntricos. 0 tubo externo apresentava um diâmetro de 17,2 mm. A pressão foi medida através de transdutores de pressão e a perda de carga através de transdutores de pressão diferencial.

Como pode ser observado na Fig. 2.17, utilizaram distintas geometrias para tubos microaletados, no caso, tubos A e B com ângulo de $53^{\circ}$ e tubos $\mathrm{C}$ e D com $40^{\circ}$. A aleta do tubo A e C é essencialmente triangular, ao passo que para os tubos B e D é trapezoidal. O tubo E apresenta uma configuração assimétrica com ângulo de $25^{\circ}$.

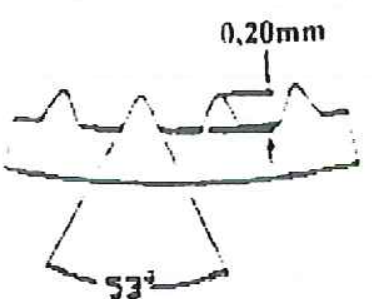

Tubo A

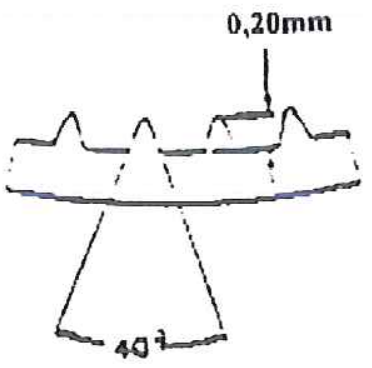

Tubn r.

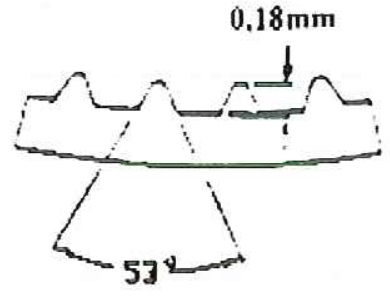

Tubo B

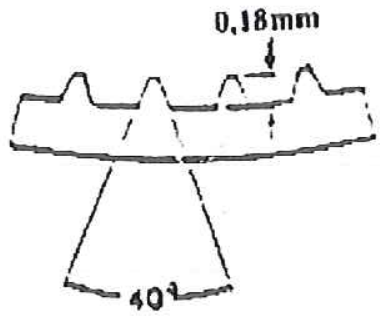

Tubo D

Figura 2.17 Geometria dos tubos microaletados utilizados por ECKELS et al. (1992). 
O coeficiente de transferência de calor para tubos microaletados foi incrementado de 50 a $150 \%$ em relação ao tubo liso, apresentando a vantagem da perda de carga sofrer um aumento significativamente menor, da ordem de 10 a $30 \%$. Um caso especial utilizando velocidades mássicas reduzidas apresentou uma intensificação de $150 \%$ para o coeficiente de transferência de calor e para perda de carga um aumento da ordem de 10 a $20 \%$.

MURATA \& HASHIZUME (1993) desenvolveram dois tipos de correlação, uma para tubos lisos e outra tubos microaletados, como mencionado na seção anterior. As ranhuras apresentaram a seguinte geometria: número de aletas: 60 , altura da aleta: $0,3 \mathrm{~mm}$, ângulo de hélice: $30^{\circ}$ e passo da aleta: $0,56 \mathrm{~mm}$. Nesse trabalho foi utilizado o fluido refrigerante R-123. A velocidade mássica variou entre 100 e $300 \mathrm{~kg} / \mathrm{s} . \mathrm{m}^{2}$, para tubos lisos e entre 93 e $278 \mathrm{~kg} / \mathrm{s}^{2} \mathrm{~m}^{2}$, para microaletados, o fluxo de calor entre 0 e $30 \mathrm{~kW} / \mathrm{m}^{2}$ e o título entre 0,1 e 1,0. A correlação proposta foi apresentada na seção anterior. Uma comparação foi realizada, alterando as condições para verificar se a tendência varia. As condições para efeito de comparação são as seguintes: $\mathrm{T}_{\mathrm{sat}}=5^{\circ} \mathrm{C}, \mathrm{G}=100 \mathrm{~kg} / \mathrm{s} \cdot \mathrm{m}^{2}, \phi=5 \mathrm{~kW} / \mathrm{m}^{2}$ e D=9,52mm, como ilustra a Fig. 2.18.

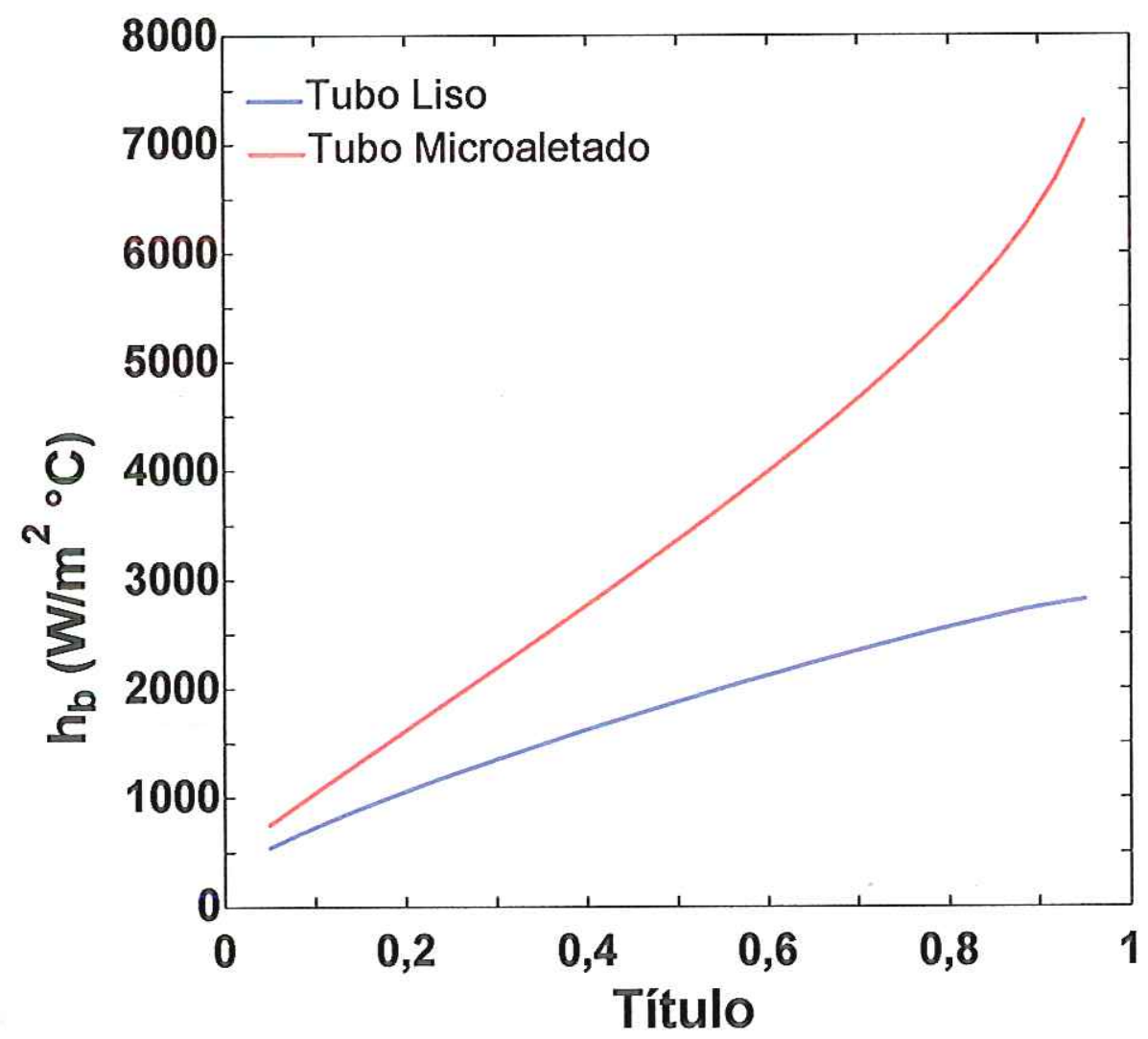

Figura 2.18 Comparação das correlações de Murata-Hashizume para tubos lisos e microaletados para as condições: R-134a $\mathrm{T}_{\mathrm{sat}}=5^{\circ} \mathrm{C}, \mathrm{G}=100 \mathrm{~kg} / \mathrm{s} \cdot \mathrm{m}^{2}, \phi=5 \mathrm{~kW} / \mathrm{m}^{2}$ e $\mathrm{D}=9,52 \mathrm{~mm}$. 
Observa-se a mesma tendência da curva anterior, Fig. 2.10. No entanto, como será visto mais adiante, para velocidades mássicas reduzidas, $G$ inferior a $100 \mathrm{~kg} / \mathrm{s} . \mathrm{m}^{2}$, enquanto o coeficiente de transferência de calor para o tubo liso permanece, praticamente, constante (padrão estratificado), o coeficiente do tubo microaletado apresenta as características do padrão anular, ou seja, se eleva com o título.

WEBB (1994) relacionou diversos estudos envolvendo a variação de alguns parâmetros, como o estudo realizado por ITO \& KIMURA (1979), que variaram o ângulo de hélice da microaleta. Como pode ser observado pela da Fig. 2.19, o ângulo de hélice ótimo para a intensificação do coefíciente de transferência de calor ficou entre 5 e $20^{\circ}$, aproximadamente, e para ângulos de hélice maiores o coeficiente diminui.

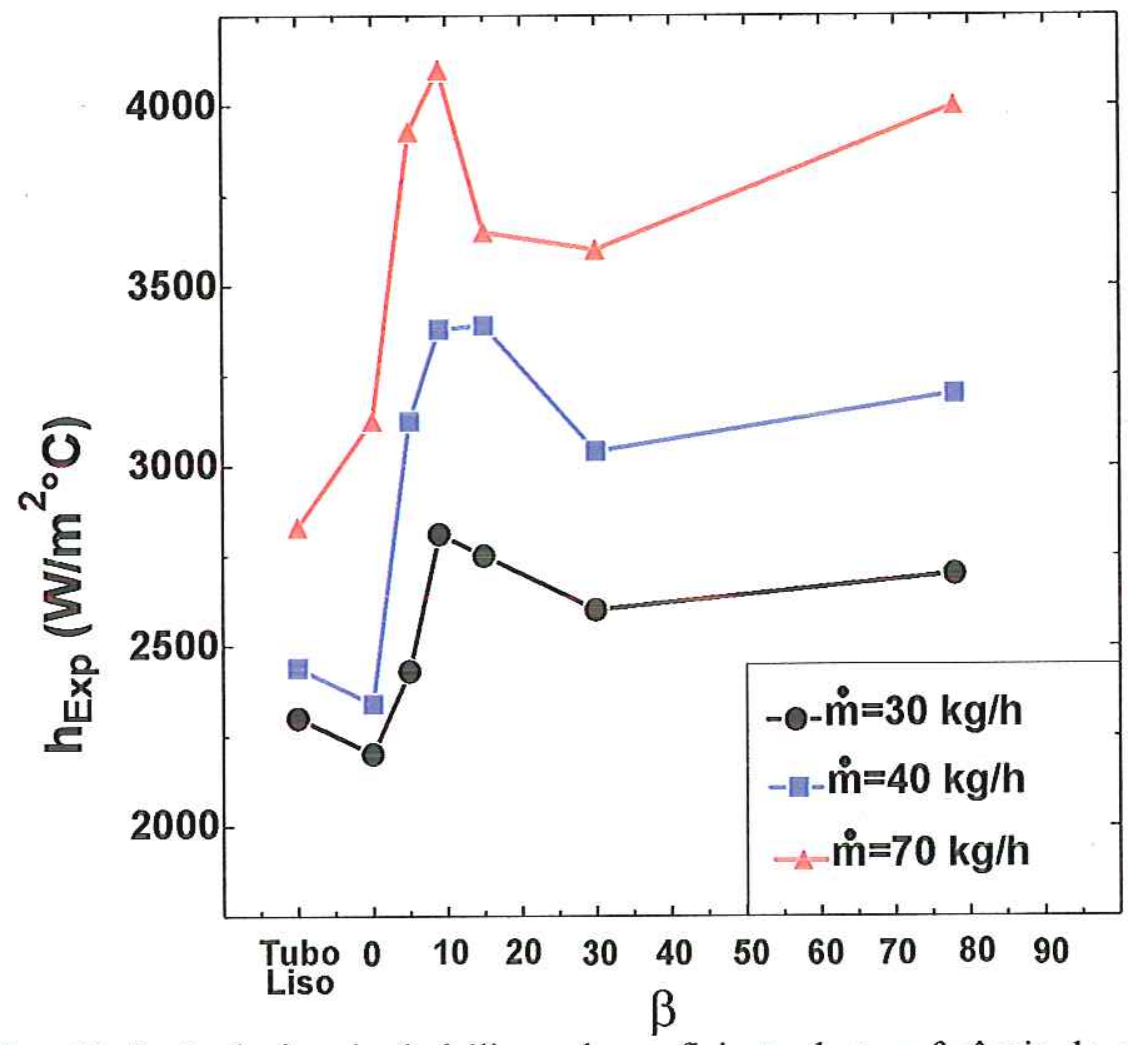

Figura 2.19 Variação do ângulo de hélice pelo coeficiente de transferência de calor em tubos microaletados. ITO \& KIMURA (1979).

WEBB (1994) apresentou, ainda, uma comparação para o escoamento com mudança de fase de refrigerante R-22 em tubo microaletado patenteado pela Hitachi. A Fig. 2.20 apresenta uma comparação do coefíciente de transferência de calor e perda de carga em função da velocidade mássica entre os tubos liso e microaletado. É interessante destacar que houve uma elevação de apenas $10 \%$ da perda de carga em relação ao tubo liso, ao passo que a transferência de calor aumentou de 50 a $100 \%$. 


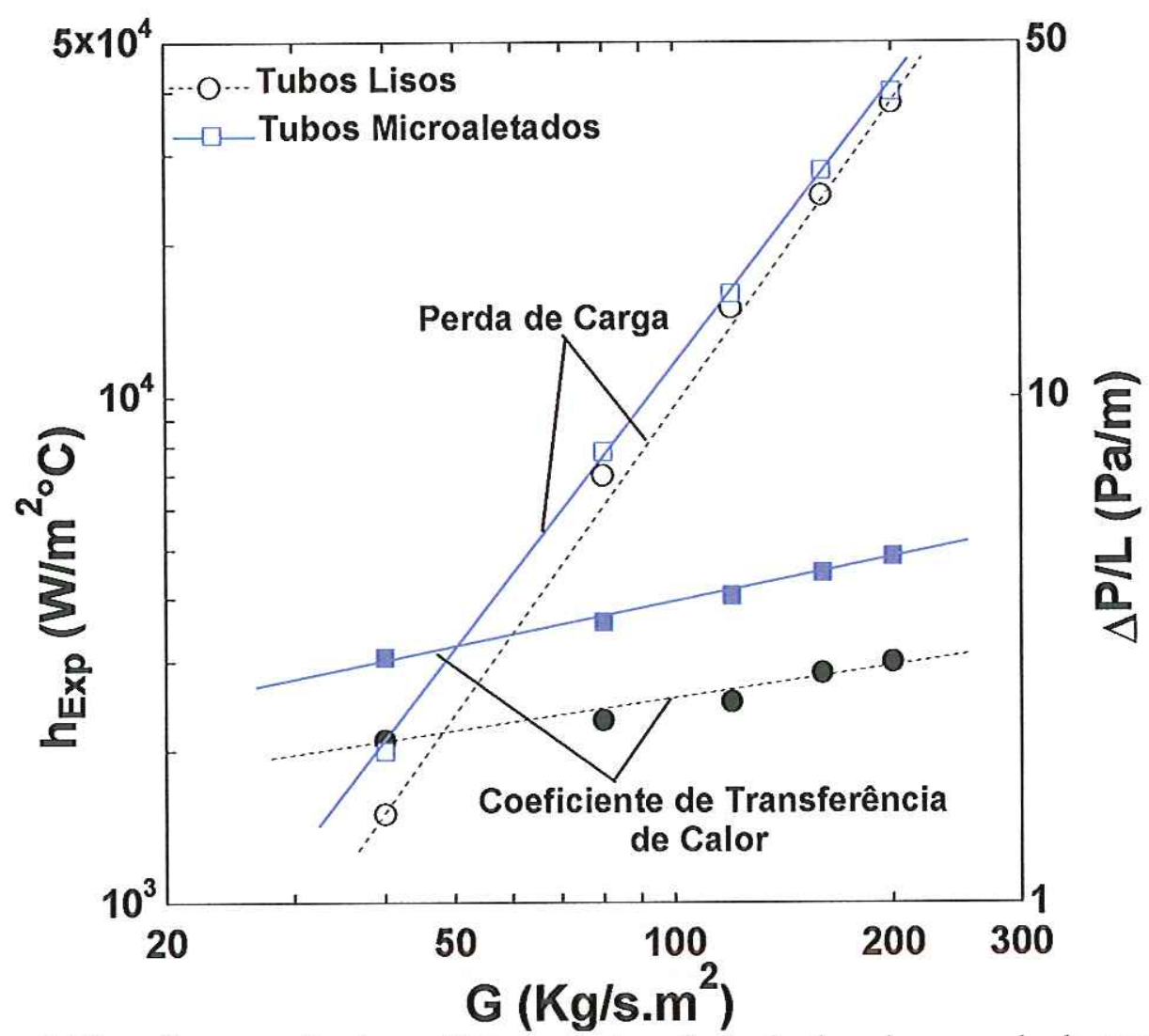

Figura 2.20 Comparação do coeficiente de transferência de calor e perda de carga entre tubos lisos e microaletados. WEBB (1994).

Um estudo interessante foi elaborado por YOSHIDA et al. (1987) apud WEBB (1994) que levantou resultados experimentais para o coeficiente de transferência de calor para o R-22 em três posições na seção transversal do tubo, no topo, na lateral e na região inferior do tubo. $\mathrm{O}$ diâmetro do tubo ensaiado foi de $12 \mathrm{~mm}$. É interessante observar na Fig. 2.21(a) que, para velocidade mássica reduzida, $\mathrm{G}=100 \mathrm{~kg} / \mathrm{s} . \mathrm{m}^{2}$, o coeficiente de transferência de calor para tubo microaletado apresentou um incremento em relação ao tubo liso. Como pode ser observado, o coeficiente local, para tubo liso, do ponto situado no topo da seção apresentava o coeficiente bastante reduzido, ao nível do escoamento monofásico de vapor. Já para o tubo microaletado o líquido se desloca para as regiões superiores do tubo, molhando a superficie que estava previamente seca, fazendo com que o coeficiente de transferência de calor apresentasse um significativo aumento. Como o coeficiente está associado à resistência térmica do líquido, quanto menor a espessura do filme de líquido maior será o valor do coeficiente, o que efetivamente se observa na figura. Já para vazões mais elevadas, no caso $\mathrm{G}=300 \mathrm{~kg} / \mathrm{s} . \mathrm{m}^{2}$, os efeitos observados na Fig. 2.21a não se repetem na Fig. 2.21b, pois o padrão anular de escoamento se verifica também no tubo liso. $\mathrm{O}$ que se observa na Fig. $2.21 \mathrm{~b}$ é uma intensificação da transferência de calor do tubo microaletado em relação ao tubo liso, para um mesmo padrão de escoamento. 

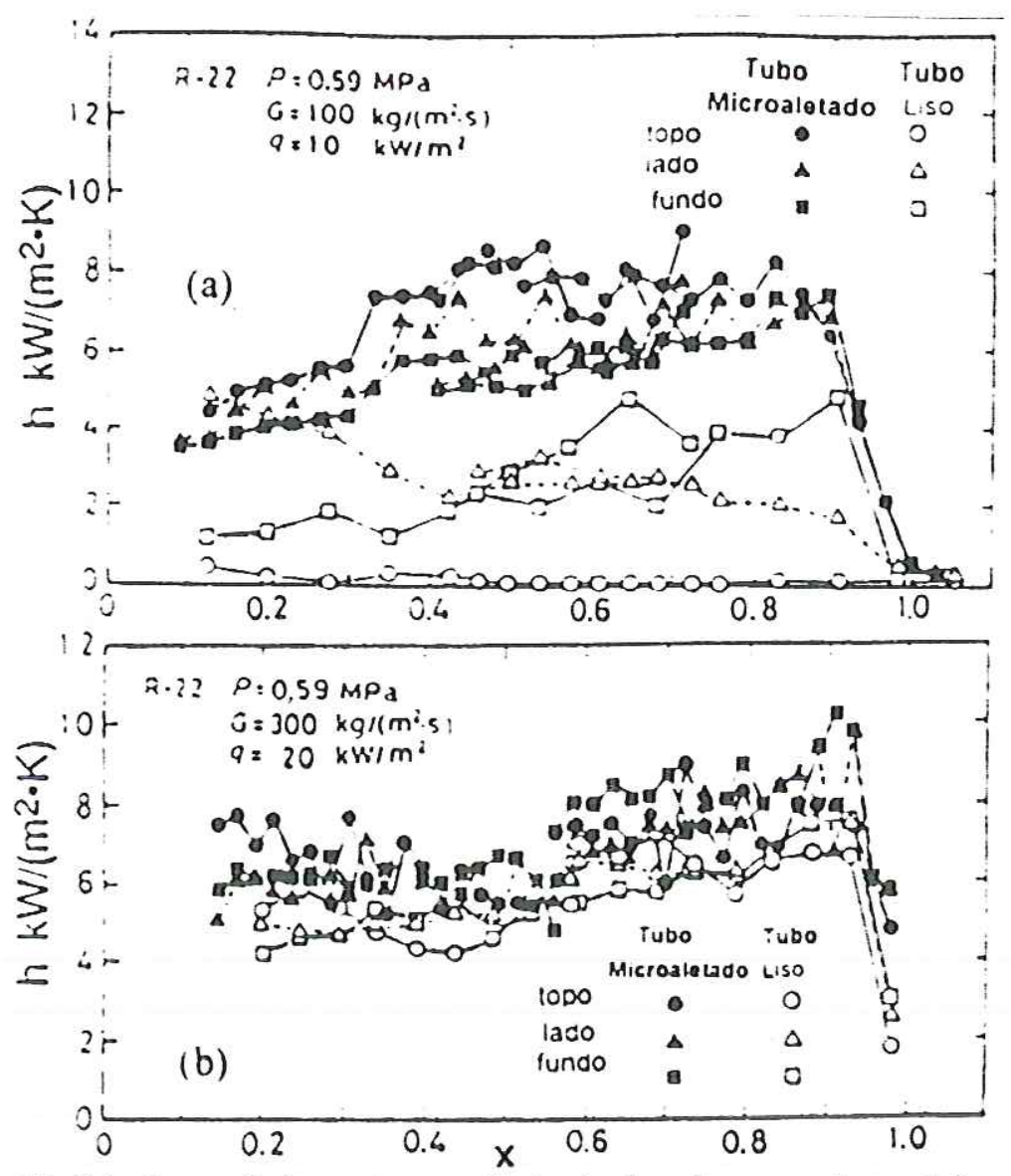

Figura 2.21 Medida do coeficiente de transferência de calor em três posições do tubo, para tubos microaletado e liso. (a) para $\mathrm{G}=100 \mathrm{~kg} / \mathrm{s} \cdot \mathrm{m}^{2}$; (b) $\mathrm{G}=300 \mathrm{~kg} / \mathrm{s} . \mathrm{m}^{2}$. YOSHIDA et al. (1987).

CHIOU et al (1995) pesquisaram as características de transferência de calor e perda de carga de tubos microaletados em escoamento monofásico, utilizando a água como fluido de trabalho. Usaram para os ensaios um tubo liso e dois microaletados, todos com $9,52 \mathrm{~mm}$ de diâmetro externo e $0,95 \mathrm{~m}$ de comprimento. As características geométricas dos dois tubos microaletados ensaiados podem ser assim resumidas: espessura da parede: $0,28 \mathrm{~mm}$ para ambos; altura de aleta, 0,20 e 0,15mm; ângulo de hélice, 18 e $25^{\circ}$ e número de ranhuras, 60 e 65. Os resultados mostraram que, para números de Reynolds inferiores a 7000, o fator de atrito foi praticamente da mesma ordem entre os dois tubos microaletados e para números de Reynolds acima de 10000 o tubo, com altura de aleta maior, ângulo de hélice e números de ranhuras menores, apresentou um coeficiente de atrito maior, como seria de esperar, pois esse tubo apresenta uma altura de aleta maior $(0,2 \mathrm{~mm})$, em outras palavras, quanto maior a rugosidade relativa $(\varepsilon / \mathrm{D})$, maior o coeficiente de atrito, de acordo com o diagrama de Moody. Para comparação da transferência de calor, os autores utilizaram uma relação entre o número de Stanton e o de Reynolds. O tubo microaletado apresentou melhor desempenho do que o tubo B, que apresentava altura de aleta menor $(0,15 \mathrm{~mm})$. 
KUO et al. (1995) estudaram a evaporação do R-22 escoando em tubo microaletado de $7 \mathrm{~mm}$ de diâmetro por $1,2 \mathrm{~m}$ de comprimento. Os testes foram realizados nas seguintes condições: temperatura de evaporação 2,6 e $10^{\circ} \mathrm{C}$, velocidade mássica, $\mathrm{G}$, de 100 a 300 $\mathrm{kg} / \mathrm{s} . \mathrm{m}^{2}$ e fluxo de calor, $\phi$, de 7 a $12,7 \mathrm{~kW} / \mathrm{m}^{2}$. As características geométricas do tubo microaletado eram as seguintes: altura da aleta: $0,15 \mathrm{~mm}$; ângulo de hélice: $18^{\circ}$ e número de aletas: 60. Foram realizados somente testes com tubos microaletados, o que impossibilitou uma comparação da intensificação em relação aos tubos lisos. Eles compararam os dados experimentais para tubos microaletados com uma correlação apresentada na literatura, de KANDLIKAR (1990) Eq. (2.78), válida para tubos lisos, tendo sido constatado uma intensificação de $60 \%$.

KOYAMA et al. (1995) apresentaram um estudo experimental envolvendo os fluidos refrigerantes R-22, R-134a e R-123 escoando horizontalmente num tubo microaletado. A seção de testes era composta de um arranjo de tubos concêntricos, com o fluido refrigerante escoando no interior e, para o aquecimento, água escoava pelo espaço anular. O tubo da seção de testes apresentava $6 \mathrm{~m}$ de comprimento por $10 \mathrm{~mm}$ de diâmetro. As características geométricas do tubo microaletado ensaiado foram: altura da aleta: 0,168 $\mathrm{mm}$, número de aletas: 60 , ângulo de hélice: $18^{\circ}$, passo da aleta: $0,44 \mathrm{~mm}$ e geometria da aleta: trapezoidal. Comparações entre dados experimentais de tubos microaletados e tubos lisos foram apresentadas, indicando uma intensificação variando entre 30 a $150 \%$ na transferência de calor.

CHAMRA et al (1996) realizaram um estudo com duas geometrias distintas para intensificação, uma microaletada, apresentando quatro ângulos diferentes de hélice, $15^{\circ}$; $17,5^{\circ} ; 20^{\circ}$ e $27^{\circ}$, e outra denominada ranhura cruzada, para os mesmos valores do ângulo de hélice. Utilizaram o R-22 como fluido de trabalho e ambos os tubos apresentavam diâmetro externo de $15,88 \mathrm{~mm}$, altura da aleta de $0,35 \mathrm{~mm}$, ângulo de cunha de $30^{\circ}$ e número de aletas variando de 74 a 78 .

Os resultados apresentados confirmaram que, para as duas geometrias (microaletado e ranhuras cruzadas), os tubos com ângulo de hélice igual a $20^{\circ}$ experimentaram valores para o Fator de Intensificação Global, FI $_{\text {Global, (Transferência de calor e Perda de carga) superiores }}$ aos demais tubos. $\mathrm{O}$ tubo dotado de microaletas apresentou melhor desempenho em relação ao de ranhura cruzada para vazões elevadas, ao passo que, para vazões reduzidas, o tubo com ranhuras cruzadas experimentou valores maiores que os microaletados. 
Os autores investigaram, ainda, a influência da profundidade da ranhura cruzada do tubo. Ensaiaram quatro profundidades diferentes, 40;50; 60 e $80 \%$ da altura da primeira ranhura. $\mathrm{O}$ desempenho térmico foi incrementado à medida que a profundidade da ranhura cruzada aumenta até o limite de $60 \%$, condição em que se atinge o máximo, diminuindo a seguir. Vale destacar que os melhores resultados ocorreram para vazões reduzidas, como seria de esperar.

KUO \& WANG (1996) pesquisaram a evaporação do refrigerante R-22 em tubos lisos e microaletados com temperatura de evaporação na faixa de 6 e $10^{\circ} \mathrm{C}$, velocidade mássica, G, variando de 100 a $300 \mathrm{~kg} / \mathrm{s}^{2} \mathrm{~m}^{2}$ e fluxo de calor, $\phi$, de 6 a $14 \mathrm{~kW} / \mathrm{m}^{2}$. A seção de testes era composta por um tubo de $9,52 \mathrm{~mm}$ de diâmetro e aquecida por água, a qual circulava no espaço anular entre dois tubos concêntricos de $1,3 \mathrm{~m}$ de comprimento cada. Utilizaram dois tubos para os ensaios, um liso e outro microaletado, com a seguinte geometria: altura da aleta: $0,3 \mathrm{~mm}$; número de aletas: 60 e ângulo de hélice: $18^{\circ}$. Os autores encontraram um fator de intensificação da ordem de 2,2 , ou seja, o coeficiente de transferência de calor para tubos microaletados foi $120 \%$ superior ao tubo liso. Para o caso da perda de carga, os tubos microaletados apresentaram um incremento da ordem de 15 a $20 \%$ em relação aos tubos lisos.

SINGH et al. (1996) estudaram a transferência de calor do R-134a escoando em tubos microaletados com mudança de fase. A seção de testes apresentava diâmetro de tubo de $12,7 \mathrm{~mm}$ e um reduzido comprimento de $0,5 \mathrm{~m}$, aquecida por meio de resistências elétricas, em que apenas $0,3 \mathrm{~m}$ eram monitorados por meio de termopares. As características geométricas do tubo microaletado em questão podem ser assim resumidas: altura da aleta: 0,3mm; número de aletas: 60 ; ângulo de hélice: $18^{\circ}$ e diâmetro interno de $11,78 \mathrm{~mm}$. A velocidade mássica de refrigerante variou entre 20 e $200 \mathrm{~kg} / \mathrm{s} . \mathrm{m}^{2}$, fluxo de calor entre 5 e 30 $\mathrm{kg} / \mathrm{m}^{2}$, título entre 5 e $90 \%$ e a temperatura de saturação do fluido foi mantida a $20^{\circ} \mathrm{C}$. Não foi verificada a intensificação da transferência de calor, simplesmente compararam-se os dados experimentais variando o fluxo de calor e velocidade mássica. A perda de carga na seção de testes foi desprezível devido ao seu reduzido comprimento, cerca de $0,3 \mathrm{~m}$. Como foram utilizados valores de $G$ reduzidos, $G<200 \mathrm{~kg} / \mathrm{m}^{2}$.s, os padrões de escoamento predominantes nos testes foram o estratificado e o anular, este último proporcionando um aumento significativo no coeficiente de transferência de calor em relação aos tubos lisos. 
BROGNAUX et al (1997) publicaram um trabalho tratando do escoamento monofásico no interior de tubos microaletados e com ranhuras cruzadas. Construíram um circuito para ensaios bastante simples, composto de uma bomba, um medidor de vazão, um tanque de aquecimento de água e a seção de testes. Utilizaram água como o fluido de circulação. Os tubos ensaiados apresentavam diâmetro externo de $15,88 \mathrm{~mm}$, altura da aleta de $0,35 \mathrm{~mm}$, número de aletas igual a 78 e ângulo de hélice $17,5^{\circ}, 20^{\circ}$ e $27^{\circ}$. Os tubos com ranhuras cruzadas apresentavam as mesmas características geométricas daquelas apresentadas anteriormente (CHAMRA et al), variando a profundidade da segunda ranhura $40 ; 60$ e $80 \%$, o que corresponde a 0,$14 ; 0,21$ e $0,28 \mathrm{~mm}$, respectivamente. É interessante destacar que o fator de intensificação, dado pela razão entre a intensificação da transferência de calor pela perda de carga, apresentado pelos tubos com ranhuras cruzadas experimentou valores superiores aos microaletados, merecendo destaque o tubo com ranhura cruzada com ângulo de hélice de $17,7^{\circ}$ e com $80 \%$ de profundidade da segunda ranhura. Em relação ao tubo liso, aquele apresentou um Fator de Intensificação da ordem de $95 \%$.

NIDEGGER et al. (1997) apresentaram um estudo relativo a transferência de calor e perda de carga do refrigerante R-134a e misturas com óleo lubrificante em tubos microaletados em escoamento com mudança de fase. A pressão de entrada da seção de testes foi mantida em $340 \mathrm{kPa}$, a velocidade mássica, G, variou entre 100 e $300 \mathrm{~kg} / \mathrm{s} \cdot \mathrm{m}^{2}$, o fluxo de calor, $\phi$, entre 5 e $10 \mathrm{~kW} / \mathrm{m}^{2}$ e concentrações em massa de óleo lubrificante de 0,$5 ; 1,0 ; 3,0 \mathrm{e}$ $5,0 \%$. Os ensaios foram realizados, como na maioria dos trabalhos apresentados previamente, com água aquecida circulando entre dois tubos concêntricos. $\mathrm{O}$ tubo da seção de testes em questão apresentava diâmetro de $12,7 \mathrm{~mm}$ por $3 \mathrm{~m}$ de comprimento e as características geométricas do tubo microaletado eram: altura da aleta: $0,25 \mathrm{~mm}$; ângulo de hélice: $18^{\circ}$ e número de aletas: 70 . Os ensaios evidenciaram que, para velocidades mássicas elevadas, o óleo incrementa a transferência de calor relativa ao R-134a puro para títulos intermediários e para títulos elevados a transferência de calor diminui. Para velocidades mássicas reduzidas o óleo diminui a transferência de calor para cerca da metade do valor correspondente para refrigerante puro. $\mathrm{O}$ efeito do óleo na perda de caga foi mais evidente para títulos elevados, onde concentrações de óleo lubrificante são superiores a do refrigerante líquido. Nessas condições, para elevadas concenırações de óleo, iesultam, também, elevadas perdas de cargas.

Um dos estudos mais recentes encontrado na literatura aberta foi o de KANDLIKAR \& RAYKOFF (1997) que trata da determinação da transferência de calor em ebulição convectiva de refrigerantes em tubos microaletados. Os autores levantaram na literatura 
resultados experimentais de diversos pesquisadores, para uma extensa gama de parâmetros, propondo uma correlação baseada naquela apresentada na seção anterior, que o próprio autor havia sugerido em 1990 para tubos lisos, alterando alguns coeficientes e introduzindo dois fatores relativos à intensificação para a ebulição nucleada e convectiva. A correlação é apresentada a seguir:

$$
h_{b}=\left[A \cdot C \delta^{B} \cdot(1-x)^{n} \cdot \mathrm{Re}_{L}{ }^{n} \cdot \mathrm{Pr}_{L}^{0,4} \cdot\left(k_{L} / D\right) \cdot(25 \cdot F r)^{E}\right] \cdot F_{E C}+\left(C \cdot B \delta^{D} \cdot F f_{L} \cdot(1-x) \cdot \operatorname{Re}_{L O}{ }^{n} \cdot \mathrm{Pr}_{L}^{0,4} \cdot\left(k_{L} / D\right)\right) \cdot F_{E N}
$$

Os valores das constantes A, B, C, D, e E são apresentados na Tabela 2.10. Esses valores são válidos para ebulição convectiva e para ebulição nucleada. Calcula-se $h_{b}$ do mesmo modo que para tubos lisos, Eq. (2.78), ou seja, separadamente para os efeitos convectivo e nucleado, escolhendo-se o maior valor entre os dois.

Tabela 2.10 Valores das constantes para ebulição convectiva e nucleada.

\begin{tabular}{|l|l|l|}
\hline Constante & Ebulição Convectiva & Ebulição Nucleada \\
\hline A & 1,1360 & 0,6683 \\
\hline B & $-0,9$ & $-0,2$ \\
\hline C & 667,2 & 1058,0 \\
\hline D & 0,7 & 0,7 \\
\hline E & 0,3 & 0,3 \\
\hline
\end{tabular}

Para valores de $\mathrm{Fr}>0,04$, adota-se $\mathrm{E}=0$, indicando que $\mathrm{Fr}$ não apresenta um efeito significativo. Para Fr $<0,04, \mathrm{E}=0,3$, de acordo com a Tabela 2.10 , sugerindo que os efeitos de superficie livre são importantes.

KANDLIKAR \& RAYKOFF (1997) compararam a correlação com os resultados experimentais disponíveis na literatura. Para cada comparação foram levantados os valores de $\mathrm{F}_{\mathrm{EC}}, \mathrm{F}_{\mathrm{EN}}$. Os desvios encontrados para a correlação em relação aos dados experimentais dos diversos autores são apresentados na Tabela 2.11.

Tabela 2.11 Desvio médio da correlação de KANDLIKAR \& RAYKOFF (1997) com os dados experimentais de diversos autores incluindo os valores de $\mathrm{F}_{\mathrm{EC}}, \mathrm{F}_{\mathrm{EN}}$ e n.

\begin{tabular}{|l|l|l|l|l|l|}
\hline Autor & Fluido & $\mathbf{F}_{\mathrm{EC}}$ & $\mathbf{F}_{\mathrm{EN}}$ & $\mathbf{n}$ & Desvio médio \\
\hline Khanpara et al. (1987) & $\mathrm{R}-22$ & 1,04 & 1,8 & 0,4 & $5,6 \%$ \\
\hline Khanpara et al. (1987) & $\mathrm{R}-113$ & 1,04 & 1,8 & 0,4 & $7,9 \%$ \\
\hline Reid et al. (1991) & R-113 & 1,04 & 1,8 & 0,4 & $5,8 \%$ \\
\hline
\end{tabular}




\begin{tabular}{|l|l|l|l|l|l|}
\hline Ha \& Bergles (1993) & R-12 & 1,37 & 0,658 & 0,4 & $10,7 \%$ \\
\hline Murata \& Hashizume (1993) & R-123 & 10,9 & 5,8 & 0,61 & $11 \%$ \\
\hline Chamra \& Webb (1993) & R-22 & 11 & 4,6 & 0,67 & $5,6 \%$ \\
\hline Singh et al. (1996) & R-134a & 0,0241 & 0,00524 & 0,97 & $9,2 \%$ \\
\hline
\end{tabular}

Relacionaram, ainda, a perda de carga que, para tubos microaletados. Geralmente, seus valores permaneceram entre 20 e $60 \%$ superiores ao tubo liso, porém não foi encontrada uma correlação generalizada na literatura, disponível para a avaliação da perda de carga em tubos microaletados. Deve-se tomar certa precaução para a aplicação da correlação proposta por KANDLIKAR \& RAYKOFF (1997), pois é específica para tubos microaletados, restringindo, dessa maneira, a extensão para aplicações em tubos com geometrias distintas. $\mathrm{O}$ desvio médio geral, envolvendo todos os dados experimentais em relação à correlação proposta, ficou em torno de $8 \%$, onde as constantes utilizadas são independentes do fluido, porém dependentes da geometria de cada tubo microaletado.

MUZZIO et al (1998) levantaram, recentemente, resultados experimentais para o coeficiente de transferência de calor e perda de carga durante a evaporação e condensação do refrigerante R-22 no interior de tubos microaletados. Os autores levantaram, ainda, dados experimentais envolvendo tubos lisos para referência. Os principais parâmetros utilizados para os ensaios foram a velocidade mássica, G, que variou entre 90 e $400 \mathrm{~kg} / \mathrm{s} \cdot \mathrm{m}^{2}$ e título na entrada da seção de testes entre 20 e $60 \%$. Utilizaram um parâmetro que serviu como base para comparações que denominaram de variação do título, $\Delta x$, que alternou entre 10 e $50 \%$, o fluxo de calor variou entre 5,2 e $24 \mathrm{~kW} / \mathrm{m}^{2}$ para uma variação de título, $\Delta \mathrm{x}$, de 0,3 . A temperatura de saturação foi mantida a $5^{\circ} \mathrm{C}$.

O equipamento experimental era composto, principalmente, por um Boiler, utilizado para evaporar uma parcela do refrigerante a montante da seção de testes, uma bomba de engrenagens, um vaso de pressão, com função de condensador, e a seção de testes, composta por um tubo com 9,52mm de diâmetro e 2,6 m de comprimento. Os tubos microaletados ensaiados apresentavam o mesmo diâmetro. Os perfis dos tubos microaletados são ilustrados na Fig. 2.22. Os tubos denominados de V (aleta trapezoidal) e $\mathrm{W}$ (aleta triangular) são tradicionalmente encontrados no mercado. No entanto, o tubo VA é caracterizado por apresentar um novo perfil. As características geométricas dos referidos tubos podem ser resumidas como na tabela 2.12 : 
Tabela 2.12 Parâmetros geométricos dos tubos ensaiados por MUZZIO et al (1998).

\begin{tabular}{|c|c|c|c|c|}
\hline Parâmetro & VA & V & W & Liso \\
\hline Diâmetro externo & $9,52 \mathrm{~mm}$ & $9,52 \mathrm{~mm}$ & $9,52 \mathrm{~mm}$ & $9,52 \mathrm{~mm}$ \\
\hline Altura da maior aleta & $0,23 \mathrm{~mm}$ & $0,20 \mathrm{~mm}$ & $0,15 \mathrm{~mm}$ & - \\
\hline Altura da menor aleta & $0,16 \mathrm{~mm}$ & -.------ & -------- & - \\
\hline Ângulo de hélice & $18^{\circ}$ & $18^{\circ}$ & $25^{\circ}$ & - \\
\hline Ângulo de cunha & $40^{\circ}$ & $53^{\circ}$ & $90^{\circ}$ & -.......... \\
\hline Número de aletas & 54 & 60 & 65 & - -...-...- \\
\hline
\end{tabular}

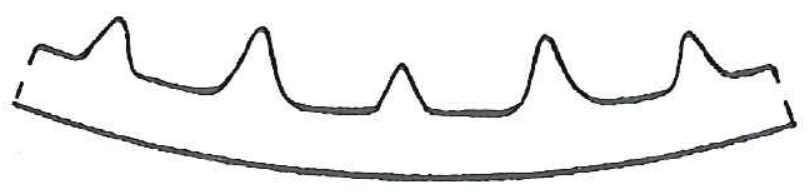

a) VA

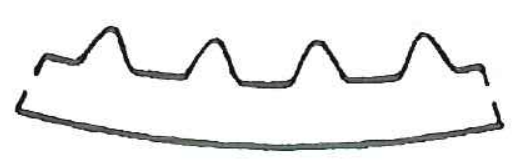

b) $\mathrm{V}$

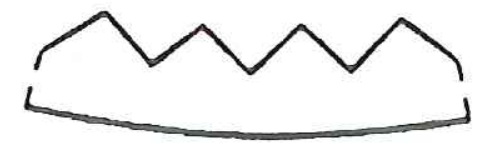

c) $\mathbf{W}$

Figura 2.22 Perfis dos tubos microaletados utilizados por MUZZIO et al. (1997).

Os tubos microaletados proporcionaram uma intensificação significativa na transferência de calor em comparação com tubo liso. Fica claro, ainda, que a maior intensificação ocorreu para velocidade mássica reduzida, da ordem de $100 \mathrm{~kg} / \mathrm{m}^{2} . \mathrm{s}$, onde o padrão predominante é o estratificado para tubos lisos. Com a utilização de tubos microaletados o padrão passa para o anular conferindo uma melhora significativa ao coeficiente.

A perda de carga aumenta significativamente com o aumento da velocidade mássica. Fica, portanto, evidente que, para valores de $\mathrm{G}$ reduzidos, da ordem de $100 \mathrm{~kg} / \mathrm{m}^{2} . \mathrm{s}$, a perda de carga para tubos microaletados apresentou valores próximos dos tubos lisos e para $G$ elevados nota-se que a diferença se acentua.

MUZZIO et al (1997) concluíram que o tubo com configuração VA, ou seja, com variação intercalada na altura da aleta, apresentou o melhor desempenho térmico entre os tubos ensaiados, especialmente em evaporação. Para este caso, o fator de intensificação encontrado foi da ordem de 4 e o coeficiente de transferência de calor foi cerca de $20 \%$, em média, superior àqueles tubos denominados de $\mathrm{V}$ e $\mathrm{W}$, comumente encontrados, ao passo 
que a perda de carga permaneceu praticamente da mesma ordem. Compararam, ainda, os resultados de tubos microaletados com a correlação de KANDLIKAR \& RAYKOFF (1997) proporcionando resultados razoáveis para os tubos de configuração $\mathrm{W}$ e $\mathrm{V}$, pois esses tubos apresentavam características semelhantes àqueles utilizados para o desenvolvimento da correlação. Já para o tubo VA, caracterizado por nova configuração, os resultados foram dispersos, ilustrando que a correlação proposta por KANDLIKAR \& RAYKOFF (1997) deve ser aceita com reservas.

AL-FAHED et al (1999) realizaram um estudo da transferência de calor e perda de carga no interior de tubos microaletados e com inserção de fita torcida em espiral. Os resultados foram levantados para baixos números de Reynolds, preferencialmente na região de escoamento laminar. O fluido de trabalho escolhido foi o óleo. É interessante destacar que o tubo microaletado não apresentou aumento significativo em relação ao tubo liso, o que era de esperar, pois, para escoamento laminar, a tendência é dos tubos apresentarem o mesmo valor para a transferência de calor. Já para o tubo com inserção de fita torcida houve um aumento significativo, porém a perda de carga aumentou na mesma proporção.

Um dos mais recentes trabalhos encontrados na literatura foi realizado por SEO \& KIM (2000), que trata da transferência de calor e perda de carga do refrigerante R-22 em tubos lisos e microaletados. A seção de testes era composta por tubos de diâmetro externo de 7,0 e $9,52 \mathrm{~mm}$ e media cerca de $3,0 \mathrm{~m}$ de comprimento. A temperatura de evaporação variou entre $-15^{\circ} \mathrm{C}$ e $5^{\circ} \mathrm{C}$, a velocidade mássica entre 70 e $211 \mathrm{~kg} / \mathrm{s} \cdot \mathrm{m}^{2}$ e fluxo de calor específico entre 5 e $15 \mathrm{~kW} / \mathrm{m}^{2}$. As características dos tubos microaletados de 7,0 e 9,52mm eram, respectivamente, altura da aleta: 0,15 e $0,12 \mathrm{~mm}$; ângulo de hélice: 18 e $25^{\circ}$; número de aletas: 60 para ambos. $\mathrm{O}$ coeficiente de transferência de calor para tubo liso aumentou com o fluxo de calor e para o tubo microaletado apresentou um pequeno decréscimo. A intensificação da transferência de calor foi mais significativa no tubo de $9,52 \mathrm{~mm}$ comparado com aquele de diâmetro menor, $7,0 \mathrm{~mm}$. O fator de intensificação encontrado para o tubo de $9,52 \mathrm{~mm}$ apresentou valores da ordem de 2,2 a 3,3 e para o tubo de 7,0 $\mathrm{mm}$ experimentou valores da ordem de 1,2 a 1,8. Como seria de esperar, a perda de carga aumentou com o título e a velocidade mássica, numa proporção inferior à da transferência de calor.

A seguir é apresentado um sumário dos estudos relacionados no presente trabalho, que envolveram a aquisição de dados experimentais. 
Tabela 2.13 Sumário dos estudos relacionados no presente trabalho.

\begin{tabular}{|c|c|c|c|}
\hline Autor & Geometria do Tubo & Refrigerante & Aquecimento \\
\hline D’yachkov, F.N. (1978) & Integralmente aletado & R-22 & Elétrico \\
\hline Khanpara et al. (1986) & Microaletado & $\mathrm{R}-113$ & Por Água \\
\hline Schlager et al. (1988) & Microaletado & R-22 com óleo & Por Água \\
\hline Schlager et al. (1989) & $\begin{array}{c}\text { Microaletado e baixas } \\
\text { aletas }\end{array}$ & R-22 com óleo & Por Água \\
\hline Reid et al. (1991) & $\begin{array}{c}\text { Microaletado, aletas } \\
\text { baixas, altas e fita torcida }\end{array}$ & R-113 & Elétrico \\
\hline Eckels \& Pate (1992) & Microaletado & R-22 & Por Água \\
\hline Murata \& Hashizume (1993) & Microaletado & $\mathrm{R}-123$ & Elétrico \\
\hline Chiou et al (1995) & Microaletado & Àgua & Por Água \\
\hline Kuo et al. (1995) & Microaletado & $\mathrm{R}-22$ & Por Água \\
\hline Koyama et al. (1995) & Microaletado & $\begin{array}{l}\mathrm{R}-22, \mathrm{R}-134 \mathrm{a} \text { e } \\
\mathrm{R}-123\end{array}$ & Por Água \\
\hline Chamra et al (1996) & $\begin{array}{c}\text { Microaletado e ranhuras } \\
\text { cruzadas }\end{array}$ & R-22 & Por Água \\
\hline Kuo \& Wang (1996) & Microaletado & $\mathrm{R}-22$ & Por Água \\
\hline Singh et al. (1996) & Microaletado & R-134a & Elétrico \\
\hline Brognaux et al (1997) & $\begin{array}{c}\text { Microaletado e ranhuras } \\
\text { cruzadas }\end{array}$ & Àgua & Por Àgua \\
\hline Nidegger et al. (1997) & Microaletado & R-134a com óleo & Por Água \\
\hline $\begin{array}{c}\text { Kandlikar \& Raykoff (1997) } \\
\text { (Dados de diversos autores) }\end{array}$ & Microaletado & $\begin{array}{c}\mathrm{R}-12, \mathrm{R}-22, \mathrm{R}- \\
113, \\
\mathrm{R}-123 \text { e } 134 \mathrm{a} .\end{array}$ & $\begin{array}{l}\text { Por Água e } \\
\text { Elétrico }\end{array}$ \\
\hline Muzzio et al (1998) & Microaletado & $\mathrm{R}-22$ & Por Água \\
\hline Al-Fahed et al (1999) & $\begin{array}{l}\text { Microaletado e Fita } \\
\text { retorcida }\end{array}$ & Óleo & Por Àgua \\
\hline Seo \& Kim (2000) & Microaletado & $\mathrm{R}-22$ & Elétrico \\
\hline Presente Estudo (2002) & Microalatado & F-134a & Elétrico \\
\hline
\end{tabular}

O presente estudo relacionou, ainda, os principais trabalhos publicados sobre tubos microaletados, que pode ser encontrado na Tabela 2.14. Nela, foram incluídas algumas das geometrias mais representativas de microaletas (ranhuras), ilustrando os esforços 
empreendidos pela comunidade técnico-científica no sentido de melhorar o desempenho termo-hidráulico de trocadores de calor para aplicações frigoríficas. Estas são, sem dúvida, as aplicações mais importantes dos tubos microaletados internamente. Uma rápida análise da Tabela 2.14 permite extrair a seguintes conclusões:

- A maioria dos tubos microaletados foi ensaiada com o refrigerante R-22. Alguns o foram com refrigerantes alternativos da família dos HFCs (R-134a e o R-410A). Um dos trabalhos envolveu ensaios com água ( $\mathrm{R}-718)$.

" O diâmetro mais utilizado foi o de $9,52 \mathrm{~mm}\left(3 / 8^{\prime \prime}\right)$, em virtude do seu potencial nas aplicações.

- A espessura de parede variou entre $0,25 \mathrm{~mm}$ e $0,55 \mathrm{~mm}$, indicando que os tubos ranhurados estão associados a tubos de parede fina.

- A altura da aleta variou entre $0,12 \mathrm{~mm}$ e $0,35 \mathrm{~mm}$, embora as mais utilizadas tenham sido aquelas na faixa entre 0,20 e $0,30 \mathrm{~mm}$.

- O número de aletas depende do diâmetro do tubo, tendo variado entre 50 e 82 para os diâmetros considerados.

- $O$ ângulo $\beta$ da espiral não diferiu muito do considerado ótimo pela maioria dos pesquisadores: $18^{\circ}$.

- $O$ ângulo de cunha da microaleta variou significativamente nos casos em que foi fornecido, sendo o mais comum da ordem de $40^{\circ}$. 
Tabela 2.14 Relação de algumas das geometrias de microaleta mais representativas.

\begin{tabular}{|c|c|c|c|c|c|c|c|c|}
\hline Autor & Refrigerante & $\mathbb{D}_{\mathrm{c}}[\mathrm{mm}]$ & $\mathrm{D}_{\mathrm{i}}[\mathrm{mm}]$ & $\mathrm{e}[\mathrm{mm}]$ & $\mathrm{t}[\mathrm{mm}]$ & $\bar{n}$ & $\beta$ & $\theta$ \\
\hline Tatsumi et al (1982) & $\mathrm{R}-22$ & 9,52 & 8,7 & 0,41 & $0,12-0,15$ & 60 & $7,5^{\circ}$ & \\
\hline Tojo et al (1984) & $\mathrm{R}-22$ & 9,52 & 8,82 & 0,35 & $0,15-0,20$ & 65 & $10^{\circ}-25^{\circ}$ & \\
\hline Khanpara et al (1986) & R-113 & 9,52 & $8,71-8,94$ & $0,38-0,45$ & $0,10-0,19$ & $60-70$ & $10^{\circ}-25^{\circ}$ & \\
\hline Schlager et al (1988) & R-22 & 9,52 & 8,72 & 0,40 & 0,20 & 60 & $18^{\circ}$ & \\
\hline Reid et al (1991) & $\mathrm{R}-113$ & 9,52 & 8,71 & 0,404 & 0,211 & 65 & $17,5^{\circ}$ & \\
\hline Eckels et al (1992) & $\mathrm{R}-22$ & 7,93 e 9,52 & $7,0-8,7$ & $0,41-0,45$ & $0,18-0,20$ & $50-60$ & $18^{\circ}$ & $25^{\circ}-53^{\circ}$ \\
\hline Eckels and Pate (1992) & $\mathrm{R}-12$ e R-134a & 9,52 & 8,0 & 0,55 & 0,2 & 60 & $17^{\circ}$ & \\
\hline Kuo et al (1995) & $\mathrm{R}-22$ & 7,0 & 6,2 & 0,25 & 0,15 & 60 & $18^{\circ}$ & \\
\hline Chiou et al (1995) & R-718 & 9,52 & 8,76 & 0,28 & 0,15 e 0,20 & 60 e 65 & $18^{\circ}$ e $25^{\circ}$ & \\
\hline Koyama et al (1995) & R-22, R-134a e R123 & 10 & 8,8 & 0,40 & 0,168 & 60 & $18^{\circ}$ & \\
\hline Kuo and Wang (1996) & $\mathrm{R}-22$ & 9,52 & 8,92 & 0,30 & 0,2 & 60 & $18^{\circ}$ & \\
\hline Singh et al (1996) & R-134a & 12,7 & 11,78 & 0,46 & 0,3 & 60 & $18^{\circ}$ & \\
\hline Chamra et al (1996) & $\mathrm{R}-22$ & 15,88 & 14,88 & 0,50 & 0,35 & $74-78$ & $15^{\circ}-27^{\circ}$ & \\
\hline Nidegger et al (1997) & R-134a & 12,7 & 11,90 & 0,40 & 0,25 & 70 & $18^{\circ}$ & \\
\hline Muzzio et al (1998) & $\mathrm{R}-22$ & 9,52 & $8,84-8,92$ & $0,30-0,34$ & $0,15-0,23$ & $54-65$ & $18^{\circ}-25^{\circ}$ & $40^{\circ}-90^{\circ}$ \\
\hline Cavallini et al (2000) & $\mathrm{R} 22, \mathrm{R} 134 \mathrm{a}$ e R-410A & 9,52 e 15,88 & $8,52-14,18$ & $0,3-0,5$ & $0,20-0,35$ & $60-80$ & $15^{\circ}-18^{\circ}$ & $30^{\circ}-50^{\circ}$ \\
\hline Miyara et al (2000) & $\mathrm{R}-22$ e $\mathrm{R}-410 \mathrm{~A}$ & 7,0 & 6,36 & 0,25 & 0,21 & 50 & $18^{\circ}$ & $41^{\circ}$ \\
\hline Seo \& Kim (2000) & R-22 & 9,52 & 8,8 & 0,3 & 0,2 & 60 & $18^{\circ}$ & $40^{\circ}$ \\
\hline Presente Estudo (2002) & R-134a & $7,0,7,93$ e 9,52 & $6,04-8,56$ & 0,28 & 0,20 & $60-82$ & $18^{\circ}$ & $23^{\circ}$ \\
\hline
\end{tabular}




\subsubsection{Conclusões Gerais}

No Brasil, são raras as pesquisas relativas ao tema da intensificação da transferência de calor no interior em tubos, o que justifica a dependência da indústria frigorífica de informações provindas do exterior. A seguir foram enumeradas as principais conclusões relativas a bibliografia sobre intensificação da transferência de calor no interior de tubos.

(1) A presente pesquisa levantou os principais trabalhos relacionados à mudança de fase de refrigerantes no interior de tubos microaletados.

(2) Os tubos microaletados apresentaram uma intensificação da ordem de 30 a $170 \% \mathrm{em}$ relação ao tubo liso, ao passo que a perda de carga apresentou um aumento de 20 a $60 \%$. Em certos casos, com o padrão estratificado a intensificação foi da ordem de 4 .

(3) Uma correlação para a determinação do coeficiente de transferência de calor em tubos microaletados foi apresentada, entretanto seus resultados devem ser aceitos com reservas.

(4) A melhor intensificação alcançada em tubos microaletados foi para vazões reduzidas, onde a ranhura helicoidal induz o movimento ascendente do líquido para a parte superior do tubo, acarretando um aumento significativo do coeficiente de transferência de calor. 


\subsection{Transferência de Calor na Região de Secagem de Parede}

A região de secagem de parede é de suma importância em termos da transferência de calor na evaporação. É um tema que, devido sua complexidade, foi pouco explorado exigindo a realização de pesquisas sistemáticas para suprir certas lacunas. Nesse sentido, a presente pesquisa se insere na tentativa de se estudar os mecanismos físicos que regem essa região.

Para área nuclear a região de secagem de parede tem um papel de extrema importância, pois os fluxos de calor são muito elevados, da mesma ordem ou superior ao fluxo crítico de calor, cerca de $1000 \mathrm{~kW} / \mathrm{m}^{2}$. A secagem prematura da parede pode implicar num significativo aumento da temperatura da parede do tubo, que pode atingir a temperatura de fusão do material.

A região que antecede a secagem de parede, para velocidades mássicas elevadas, é dominada pelo padrão anular de escoamento, onde o coeficiente de transferência de calor assume seu maior valor durante a evaporação, devido a espessura do filme de líquido, que diminui progressivamente, como resultado da evaporação na interface líquido-vapor. Como o coeficiente de transferência de calor está associado à resistência térmica proporcionada por essa película, seu valor se eleva no sentido do escoamento. Tal situação perdura até a seção onde se verifica a secagem de parede, ocasião em que, devido à significativa redução do coeficiente de transferência de calor, através do contato direto do vapor com a superficie, a temperatura tende a se elevar. Nessa região, o coeficiente diminui de uma ou duas ordens de magnitude, assumindo valores do escoamento monofásico de vapor. Para velocidades mássicas reduzidas, o padrão estratificado precede a região de secagem de parede, onde o coeficiente, durante esse padrão, praticamente permanece constante até o ponto de secagem de parede, assumindo valores do coefíciente monofásico de vapor.

Em tubos horizontais, a secagem da parede pode ser dividida, basicamente, em duas regiões: a primeira, denominada de secagem parcial da parede, onde, devido aos efeitos gravitacionais a espessura do filme de líquido da região superior do tubo é menor, resultando uma secagem na parte superior do tubo, e a segunda denominada de secagem total da parede. COLLIER \& THOME (1994) denominaram a secagem total da parede de região de deficiência de líquido, sendo caracterizada pela redução do coeficiente de transferência de calor e, consequentemente, pelo aumento da temperatura da parede do tubo. A Fig. 2.23 ilustra a variação da temperatura ao longo do comprimento da região de deficiência de líquido. É interessante observar que no momento da secagem da parede, a temperatura sofre um incremento significativo, depois se eleva gradualmente até que as gotículas de líquido no 
centro do tubo se evaporam, determinando o início da fase de vapor superaquecido. Deve-se ressaltar que COLLIER \& THOME (1994) não consideraram os efeitos gravitacionais e, como pode ser observado na figura, o ponto de secagem da parede ocorre simultaneamente em toda circunferência do tubo. Esta configuração poderia se observar em um tubo vertical.

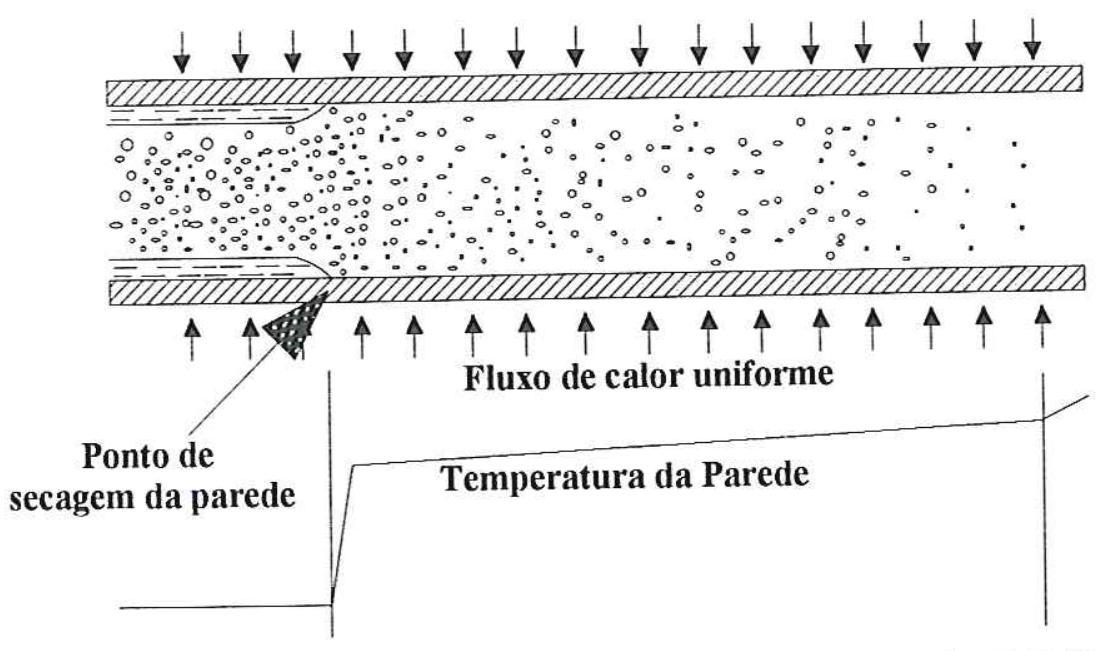

Figura 2.23 Variação da temperatura com o comprimento da região de deficiência de líquido. COLLIER \& THOME (1994).

A complexidade dessa região deve-se à elevada instabilidade em termos do ponto de secagem da parede. Um dos efeitos que colaboram para essa complexidade é a suspensão de gotículas de líquido que circulam com o vapor (Entreinment ${ }^{*}$ ) e que, eventualmente entram em contato com a superfície do tubo, resultando num outro efeito denominado de deposição de líquido. Outro aspecto importante é a instabilidade inerente ao escoamento bifásico, o que torna a secagem de parede um fenômeno não determinístico. A Fig. 2.24 ilustra os efeitos de suspensão e deposição de gotículas de líquido na parede do tubo.

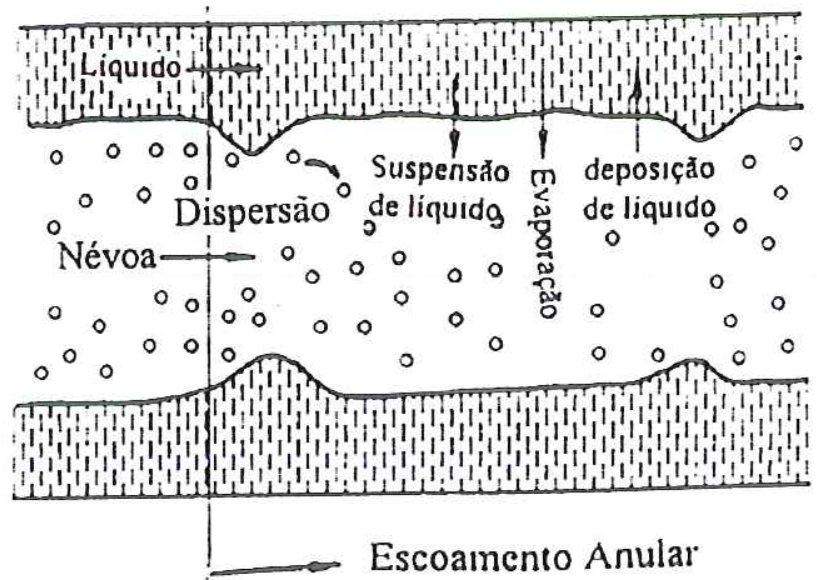

Figura 2.24 Efeitos de suspensão e deposição de líquido. COLLIER \& THOME (1994).

\footnotetext{
* "Entreinment" é o termo comumente encontrado na literatura para o efeito de suspensão de gotículas que circulam com o vapor
} 
GROOTHUIS \& HENDAL (1959) pesquisaram a transferência de calor em escoamento bifásico com especial atenção para a variação da temperatura na parede, a fim de caracterizar o ponto de transição para a secagem. O tubo da seção de testes apresentava diâmetro de $14 \mathrm{~mm}$ e os fluidos utilizados foram ar/àgua e gás-óleo/ar. A temperatura foi medida por termopares inseridos na parede do tubo, através de um furo de $2 \mathrm{~mm}$ de diâmetro e distante $1,5 \mathrm{~mm}$ da parede interna. Os referidos autores propuseram duas correlações para a determinação do coeficiente de transferência de calor, uma para ar/água e outra para gásóleo/ar, do mesmo tipo da correlação de DITTUS-BOELTER (1930), introduzindo uma relação entre viscosidades, às condições da superfície da parede, $\mu_{\mathrm{p}} \mathrm{e} \mu_{\mathrm{b}}$ relativo a mistura.

$$
\begin{aligned}
& N u=0,029 \cdot \operatorname{Re}_{t}^{0,87} \cdot \operatorname{Pr}^{1 / 3} \cdot\left(\frac{\mu_{b}}{\mu_{p}}\right)^{0,14} \quad \text { para ar/água } \\
& N u=2,6 \cdot \operatorname{Re}_{t}^{0,39} \cdot \operatorname{Pr}^{1 / 3} \cdot\left(\frac{\mu_{b}}{\mu_{p}}\right)^{0,14} \quad \text { para gás-óleo/ar }
\end{aligned}
$$

onde,

$$
\mathrm{Re}_{\mathrm{t}}=\mathrm{Re}_{\mathrm{L}}+\mathrm{Re}_{\mathrm{V}}
$$

GROOTHUIS \& HENDAL (1959), possivelmente, foram os primeiros pesquisadores a tentar modelar o ponto de transição para a região de secagem de parede, a qual, segundo eles, ocorria quando o número de Weber, We, excedia um determinado valor. O número de Weber, proposto por Groothius e Hendal, obedece a seguinte relação.

$$
W e_{G H}=\frac{\rho_{V} \cdot V_{V}{ }^{2} \cdot \mu_{L}}{G \cdot \sigma} \cdot\left(\frac{G \cdot D}{\mu_{L}}\right)^{1 / 8}
$$

Deve-se observar que o número de Weber, We, corresponde à relação entre as forças de inércia e as forças de tensão superficial.

LAVIN (1963) pesquisou o coeficiente de transferência de calor para os refrigerantes R-12 e R-22, escoando em tubos verticais e horizontais. Foram ensaiados 5 tubos, entre eles um liso de cobre, três de cobre aletados internamente e um de alumínio aletado integralmente, ou seja, com duas aletas perpendiculares entre si, com largura da mesma dimensão do diâmetro interno. O tubo liso apresentava diâmetro interno de $20,4 \mathrm{~mm}$. 
Termopares foram acoplados em intervalos de $60^{\circ}$ ao longo da circunferência do tubo. LAVIN (1963) propôs diversas correlações para a determinação do coeficiente de transferência de calor, sendo uma para cada padrão de escoamento observado. Para o padrão de escoamento em névoa, propôs a seguinte equação:

$$
h_{b}=0,0162 \cdot \frac{k_{V}}{D} \cdot \operatorname{Re}_{V}^{0,84} \cdot \operatorname{Pr}_{V}^{0,33} \cdot(1-x)^{0,1}
$$

$\mathrm{O}$ referido autor estudou, ainda, a região de transição entre o regime anular e o padrão em névoa. Seguiu o mesmo princípio de GROOTHUIS \& HENDAL (1959), onde o número de Weber, We, foi utilizado para caracterizar a região de transição. Nesse sentido, sugeriu um número de Weber, para tubos lisos, alternativo ao proposto por Groothius e Hendal.

$$
W e_{L A}=3,07 \cdot 10^{-8} \cdot \operatorname{Re}_{V}^{1,0} \cdot B o^{-0,06} \cdot\left(\frac{\rho_{L}}{\rho_{V}}\right)
$$

onde,

$$
\operatorname{Re}_{V}=\frac{G_{V} \cdot D}{\mu_{V}}
$$

A Fig. 2.25 ilustra a variação do comportamento do coeficiente de transferência de calor com o título. Nota-se que a região de títulos reduzidos em que supostamente ocorre o mecanismo de ebulição nucleada, não está totalmente clara. A região de domínio da ebulição convectiva, onde o padrão de escoamento predominante é o anular, para vazões relativamente elevadas, é caracterizada pelo aumento gradual do coeficiente de transferência de calor. Para títulos da ordem de $90 \%$ o início da secagem de parede pode ser caracterizada pelo súbito decréscimo do coeficiente de transferência de calor. 


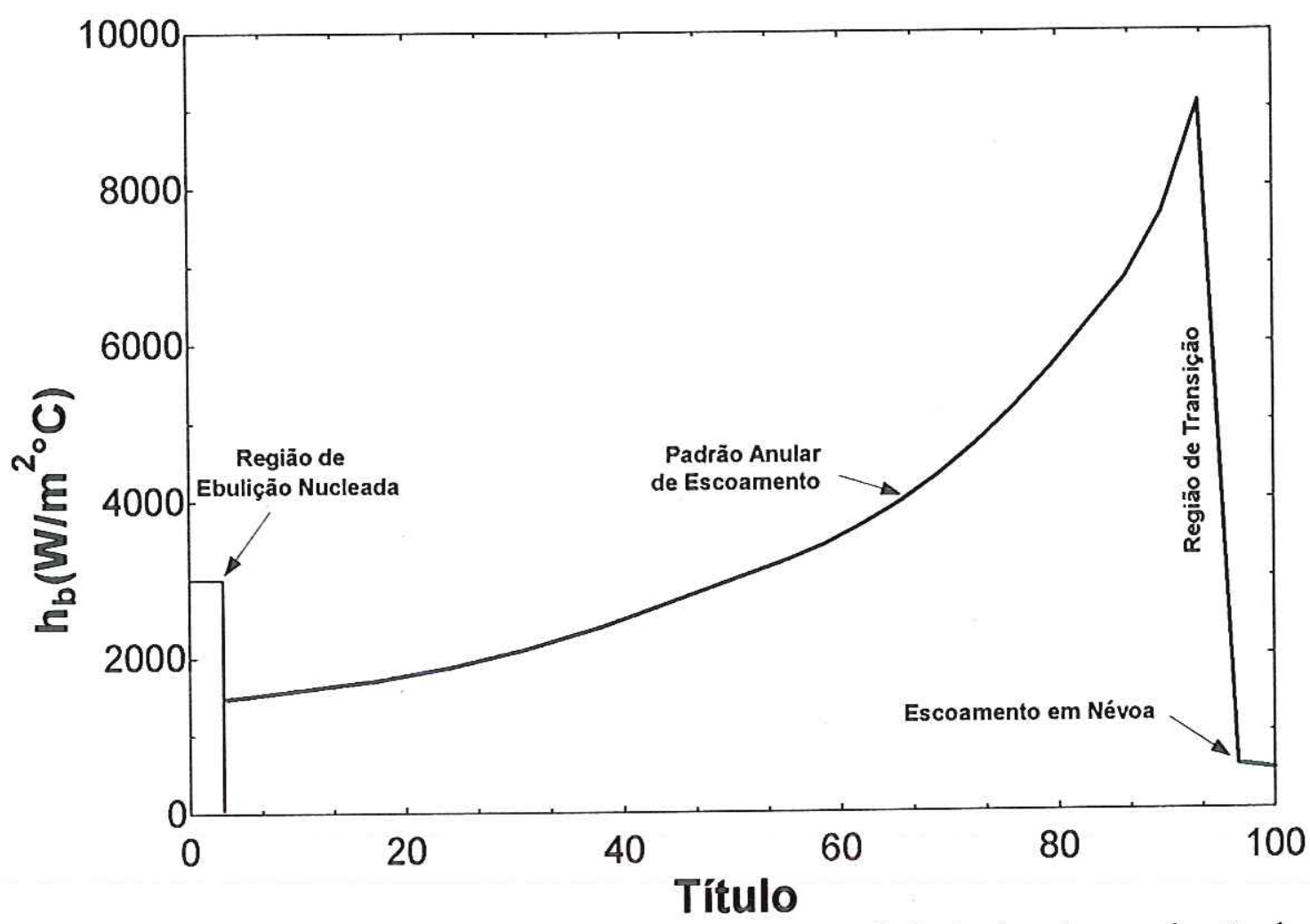

Figura 2.25 Comportamento típico do coeficiente de transferência de calor em função do título. LAVIN (1963).

Este autor, observou, ainda, que a transição da região de ebulição nucleada para o padrão anular de escoamento ocorria para títulos da ordem de $2 \%$, e a transição do regime anular para o padrão em névoa pode ser encontrada através da Eq. (2.87).

Um dos raros estudos, levantados na literatura, sobre a região de secagem de parede na ebulição convectiva foi realizado por VARMA (1970), em sua tese de doutoramento. O enfoque principal desse trabalho foi relativo à parte experimental. A seção de testes, que foi dividida em três partes, cada uma constituída de um tubo, de aço inoxidável de $0,3 \mathrm{~m}$ de comprimento, apresentava diâmetro de $9,52 \mathrm{~mm}$, tendo sido utilizado o refrigerante R-22 como fluido de trabalho. Foram instalados 93 termopares para acompanhar a variação de temperatura em toda a seção de testes, na geratriz superior, na lateral e na geratriz inferior do tubo. As duas primeiras seções apresentavam 18 termopares distribuídos ao longo do comprimento e a terceira, 57 termopares, número superior às demais para acompanhar a secagenı de parede, uma vez que esta ocorria preferencialmente naquela seção. 
VARMA (1970) levantou algumas correlações para ebulição convectiva e concluiu que nenhuma delas levava em consideração o ponto de transição para a região de secagem de parede. A Fig. 2.26 ilustra a variação do coeficiente de transferência de calor com o título, nas regiões superior, lateral e inferior do tubo. As condições operacionais utilizadas estão descritas na legenda. É interessante observar que o coeficiente tem seu valor significativamente reduzido, inicialmente, no topo do tubo. Em outras palavras, a secagem de parede começou pela região superior. Para títulos da ordem de $97 \%$ os coeficientes, relativos às três regiões, se equiparam indicando que a parede do tubo está completamente seca.

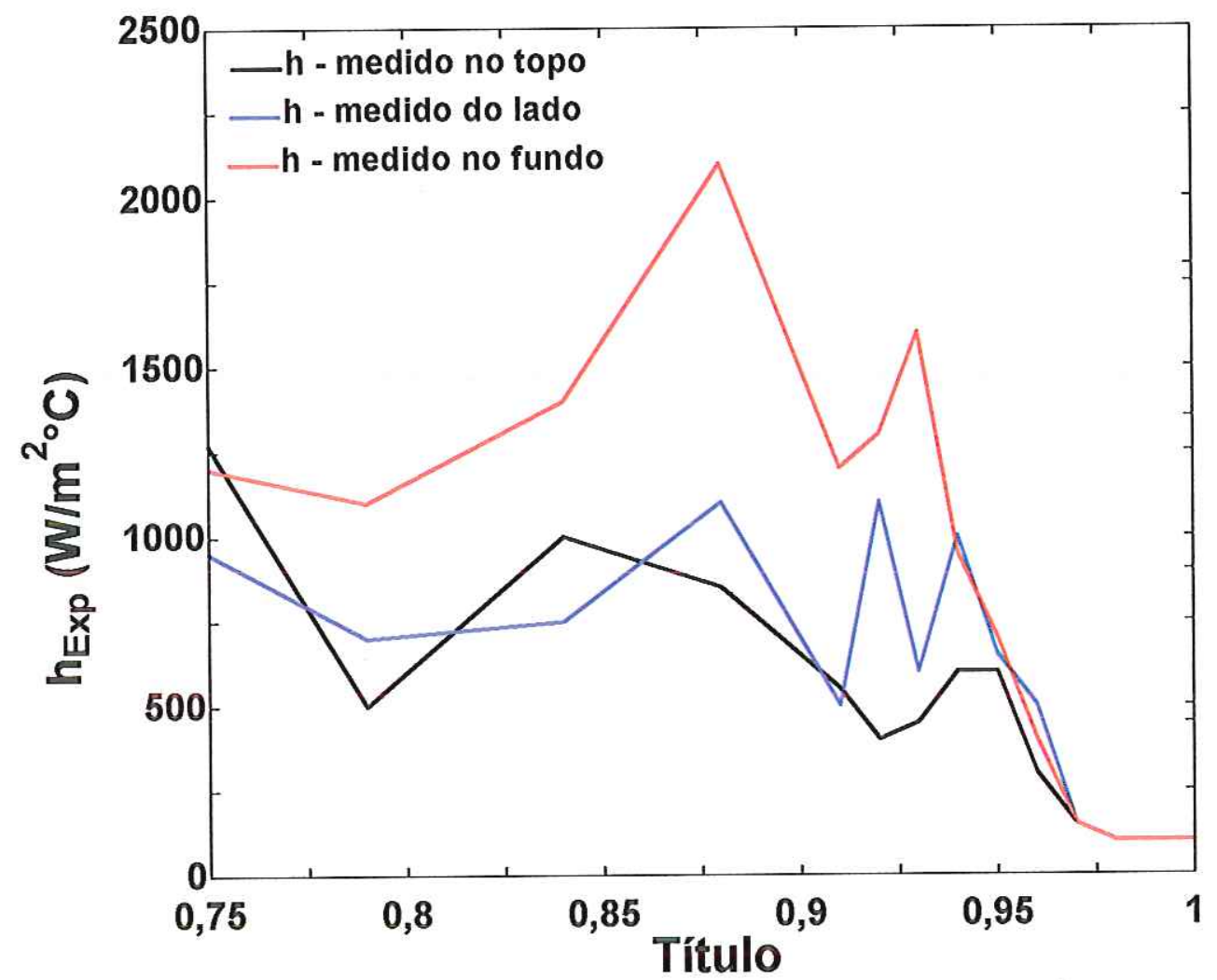

Figura 2.26 Variação do coeficiente com o título, medido no topo, na lateral e na geratriz inferior do tubo. R-22 com G=570 kg/m ${ }^{2}$.s e $\phi=18,7 \mathrm{~kW} / \mathrm{m}^{2}$. VARMA (1970).

VARMA (1970) verificou, ainda, que a presença de óleo no evaporador pode afetar a transição. Os ensaios foram realizados com uma pequena porcentagem de óleo dissolvida no refrigerante. Concentrações moderadas, da ordem de 3 a $5 \%$ em massa, alteram o início da secagem de parede, deslocando essa região para jusante. Entretanto, os principais parâmetros que afetam o coeficiente de transferência de calor bem como o início da secagem de parede são: o fluxo de calor, $\phi$, e a velocidade mássica, G. Para uma velocidade mássica constante, a elevação do fluxo de calor desloca o ponto de transição para montante. Por outro lado, para 
um fluxo de calor constante, a elevação da velocidade mássica, desloca a seção de secagem para jusante, ou seja, para títulos mais elevados.

$\mathrm{O}$ referido autor foi, possivelmente, um dos únicos autores a modelar fisicamente a região de secagem de parede. Assumiu que o padrão anular de escoamento precedia a região de secagem de parede e, para a modelagem, partiu, inicialmente, de um balanço de energia aplicado a um elemento infinitesimal na seção do tubo. Resumidamente, depois de algumas simplificações, encontrou a seguinte correlação:

$$
\frac{h_{b}}{h_{V}}=\frac{1}{1-\left(\frac{Y}{1-x_{C R}}\right) \cdot \frac{d x}{d \eta}+\frac{\pi \cdot D \cdot L \cdot h_{V}}{m \cdot c p_{V}} \cdot\left[\left(x \cdot i \cdot \eta-\frac{x^{\prime}-x_{C R}}{1-x_{C R}}\right)-(\eta-1)\right]}
$$

onde,

$$
\text { x' é definido como: vazão de vapor pela vazão total. } x^{\prime}=\frac{\dot{m_{V^{\prime}}}}{\dot{m}_{V}+\dot{m}_{L}}
$$

Y é uma função de G e $\eta$

$$
\eta=\frac{x-x_{C R}}{1-x_{C R}} \text {, e } \mathrm{x}_{C R} \text { é o título relativo ao início da transição. }
$$

É interessante observar que a relação entre o coeficiente bifásico e o monofásico de vapor é função de variáveis como: velocidade mássica, $\mathrm{G}$, título, $\mathrm{x}$, título relativo ao início da transição para secagem de parede, $\mathrm{x}_{\mathrm{CR}}$, comprimento do tubo, $\mathrm{L}$, e das propriedades dos fluidos.

Algumas conclusões interessantes extraídas desse trabalho podem ser assim resumidas:

1) Na região de domínio do padrão anular o coeficiente de transferência de calor medido na região inferior foi maior ao da região superior do tubo. Em tubos horizontais, isso seria possivel se houvesse uma secagem parcial da parede.

2) A região de secagem de parede ocorre para títulos relativamente elevados, variando entre 89 e 99\%. Na região a jusante daquela em que ocorre secagem de parede, denominada na literatura de "post-dryout", o coeficiente de transferência de calor se caracteriza por valores de uma ordem de magnitude inferior comparados àqueles do padrão anular de escoamento. 
Em seu trabalho de doutoramento, RHEE (1972) apresentou um estudo sobre a transferência de calor na ebulição de refrigerantes no interior de tubos de cobre. Esse trabalho pode ser considerado uma continuação daquele apresentado por LAVIN (1963), tendo sido realizados na Universidade de Michigan sob a coordenação do mesmo orientador. $\mathrm{O}$ autor avaliou o coeficiente de transferência de calor para os fluidos refrigerantes R-12 e R22, escoando num tubo liso horizontal de 19,05 mm de diâmetro e, aproximadamente, $1 \mathrm{~m}$ de comprimento. A região monitorada da seção de testes representava $1 / 3$ do total, cerca de 0,3 $\mathrm{m}$, sendo aquecida por meio de resistências elétricas a fim de obter um fluxo de calor uniforme na seção. Para o R-12, a temperatura de saturação variou entre 28 e $42^{\circ} \mathrm{C}$, e entre 22 e $45^{\circ} \mathrm{C}$ para o R-22. Através de uma janela de visualização foi possível verificar cinco padrões de escoamento predominantes, quais sejam: escoamento em bolhas, estratificado, anular, anular com "Entreinment" e em névoa.

A região de transição entre o anular com névoa e em névoa se caracterizava pelas flutuações da temperatura da parede. RHEE (1972) adotou o mesmo procedimento de GROOTHUIS \& HENDAL (1959), caracterizando a transição pelo número de Weber. Também modificou esse número, introduzindo um parâmetro de correção envolvendo o diâmetro do tubo, com base nas observações de ZAHN (1964). A forma final da correlação para a transição é a seguinte:

$$
W e_{R h}=1,89 \cdot 10^{-7} \cdot \operatorname{Re}_{V} \cdot\left(\frac{\rho_{L}}{\rho_{V}}\right)^{0,6} \cdot\left(\frac{D}{0,0608}\right)^{-0,483}
$$

Os ensaios envolveram condições em que a velocidade mássica variava entre $650 \mathrm{e}$ $1200 \mathrm{~kg} / \mathrm{s} \cdot \mathrm{m}^{2}$ para o R-12, o fluxo de calor entre 15 e $47 \mathrm{~kW} / \mathrm{m}^{2}$ e o título entre 86 e $99 \%$. Para o R-22, a velocidade mássica variou entre 400 e $2000 \mathrm{~kg} / \mathrm{s} . \mathrm{m}^{2}$, o fluxo de calor entre 8,6 e $50 \mathrm{~kW} / \mathrm{m}^{2}$ e o título entre 69 e $96 \%$. Para a região de escoamento em névoa, Rhee sugeriu que a correlação de DITTUS-BOELTER (1930), aplicada à fase vapor, fosse corrigida pela introdução do título. Entretanto, não conseguiu uma correlação gentralizada para refrigerantes, propondo a correlação (2.90) para o R-12 e (2.91) para o R-22.

$$
\begin{aligned}
& N u=0,023 \cdot \operatorname{Re}_{V}{ }^{0,8} \cdot \operatorname{Pr}_{V}{ }^{0,4} \cdot x^{-1,23} \\
& N u=0,038 \cdot \operatorname{Re}_{V}^{0,8} \cdot \operatorname{Pr}_{V}^{0,4} \cdot x^{-1,23}
\end{aligned}
$$


Deve-se ressaltar que os dados relativos às propriedades dos fluidos foram baseados em polinômios levantados pela Dupont em 1956 para o R-12 e em 1964 para o R-22. Nessas condições, dados de outras fontes mais recentes podem produzir resultados distintos. Para essa região, padrão em névoa, a velocidade mássica variou entre 895 e $1300 \mathrm{~kg} / \mathrm{s} . \mathrm{m}^{2}$, o fluxo de calor entre 23 e $40 \mathrm{~kW} / \mathrm{m}^{2}$ e o título entre 96 e 99\%, para o R-12. Para o R-22 a

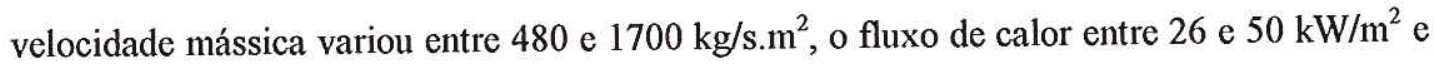
o título entre 74 e $98 \%$.

A Fig. 2.27 ilustra uma comparação da variação do comprimento do tubo com o título, com identificação dos padrões de escoamento associados a cada região. É interessante observar que, para títulos reduzidos, a ebulição nucleada predomina, através do padrão em bolhas e, para títulos da ordem de $90 \%$, a transição para região de secagem de parede ocorre, dando origem ao padrão de escoamento em névoa.

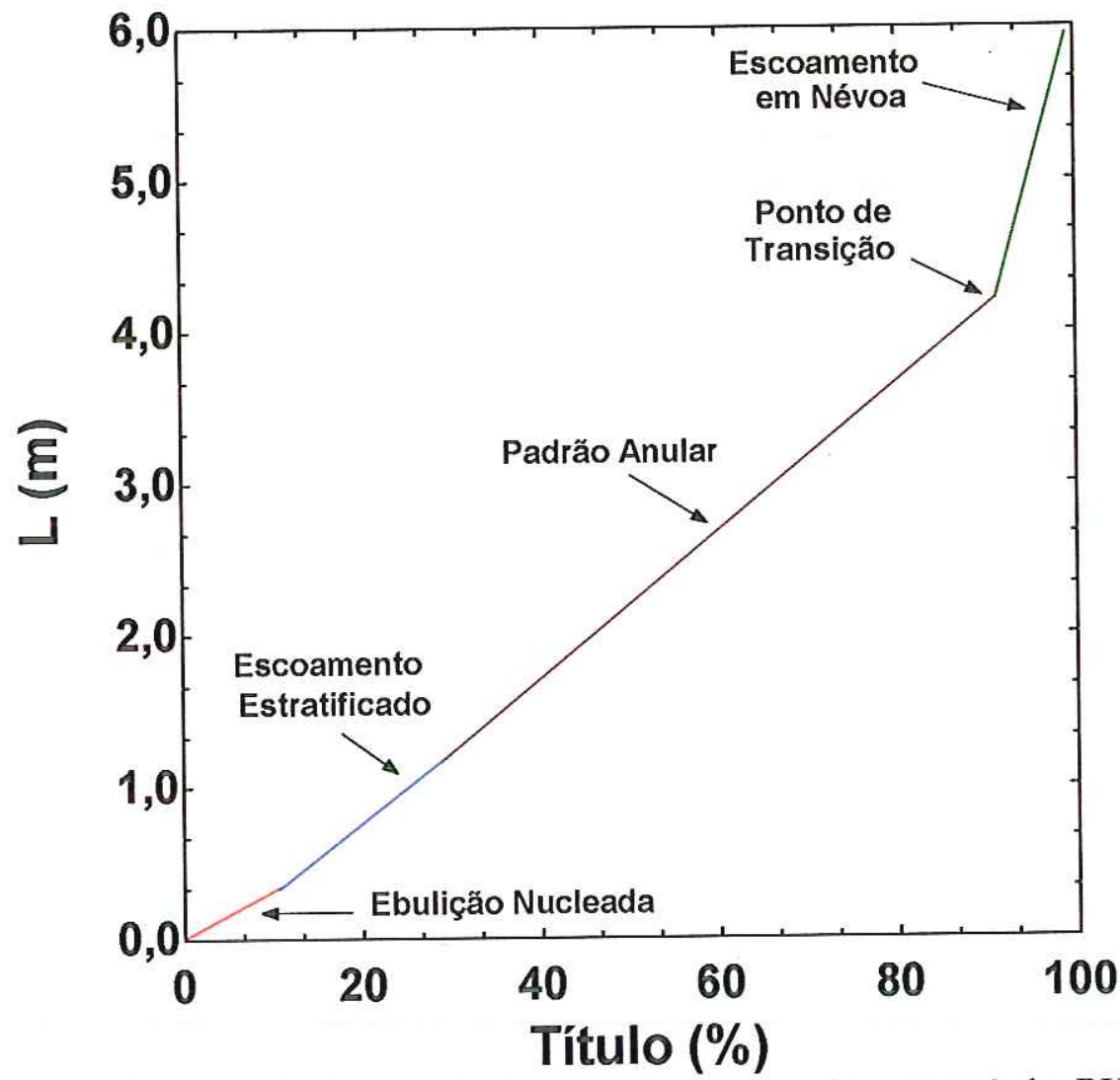

Figura 2.27 Comparação da variação do comprimento do tubo com o título. RHEE (1972).

STHAPAK et al (1976) pesquisaram o coeficiente de transferência de calor na região de secagem para o R-12, escoando num tubo horizontal aquecido com água que circulava no espaço anular entre dois tubos concêntricos. A seção de testes era composta de três tubos de cobre de $6,35 \mathrm{~mm}$ de diâmetro, sendo dois deles com $2,13 \mathrm{~m}$ de comprimento e um com 
3,66m. O tubo exterior, de mesmo comprimento, apresentava o diâmetro de $25,4 \mathrm{~mm}$. As condições de trabalho foram as seguintes: pressão de evaporação variou de 283 a $516 \mathrm{kPa}$, a vazão de refrigerante entre 20 e $90 \mathrm{~kg} / \mathrm{h}$, título de entrada entre 10 e $50 \%$, temperatura de entrada da água de aquecimento entre 20 e $40^{\circ} \mathrm{C}$ e vazão de água entre 143 e $586 \mathrm{~kg} / \mathrm{h}$. A seção de testes foi verificada por 96 termopares.

A correlação foi proposta baseada em termos adimensionais, inicialmente, os autores correlacionaram a relação entre o coefíciente bifásico e monofásico da fase vapor em termos do parâmetro de Martinelli, $X_{t t}$. A introdução desse parâmetro evidenciou que a relação $h_{b} / h_{V}$ aumenta com o $X_{\mathrm{tt}}$, ou seja, quando o título é elevado, o parâmetro de Martinelli é reduzido, implicando num valor, também, reduzido do coeficiente de transferência de calor. Os autores notaram que, para a região de secagem de parede, a introdução de uma relação entre temperaturas, correlacionava melhor os resultados experimentais. Nesse sentido, propuseram uma relação que leva em consideração a temperatura da parede, $T_{p}$, de saturação, $T_{\text {sat, }}$, da água de aquecimento, $\mathrm{T}_{3}$, dada pela Eq. (2.93), abaixo. Finalmente, introduziram o número de Reynolds aplicado a fase vapor, que resultou na correlação (2.92), apresentando um desvio médio de $25 \%$ em relação aos dados experimentais, dada a seguir:

$$
\frac{h_{b}}{h_{V}}=3,138 \cdot 10^{3} \cdot X_{t t}^{0,729} \cdot \Delta T^{0,34} \cdot \operatorname{Re}_{V}^{-0,323}
$$

onde,

$$
\Delta T=\frac{T_{a}-T_{p}}{T_{p}-T_{s a t}}
$$

STHAPAK et al (1976) sugeriram, ainda, a correlação de Chaddock-Brunemann, proposta em 1967, relativa à região de secagem da parede, segundo a qual:

$$
\frac{h_{b}}{h_{L}}=4,24 \cdot\left(\frac{1}{B o}\right)^{0,64} \cdot X_{t}
$$

A correlação não apresenta concordância satisfatória com os resultados experimentais de STHAPAK et al (1976). Essas diferenças podem estar relacionadas à forma de aquecimento, já que Chaddock \& Brunemann utilizaram aquecimento elétrico na seção de testes. 
BERTHOUD \& JAYANTI (1990) pesquisaram um tipo de serpentina helicoidal em geradores de vapor para reatores nucleares. Nesse tipo de configuração, a transição do regime anular para a secagem de parede se estende para uma considerável porção do tubo, como pode ser observado na Fig. 2.28. Os autores apresentaram algumas especificações relativas à região de secagem de parede em serpentina helicoidal: a posição axial, bem como circunferencial, do início da secagem da parede em termos do título; a propagação da secagem da parede na direção circunferencial até a secagem completa; o comprimento da região de secagem parcial.

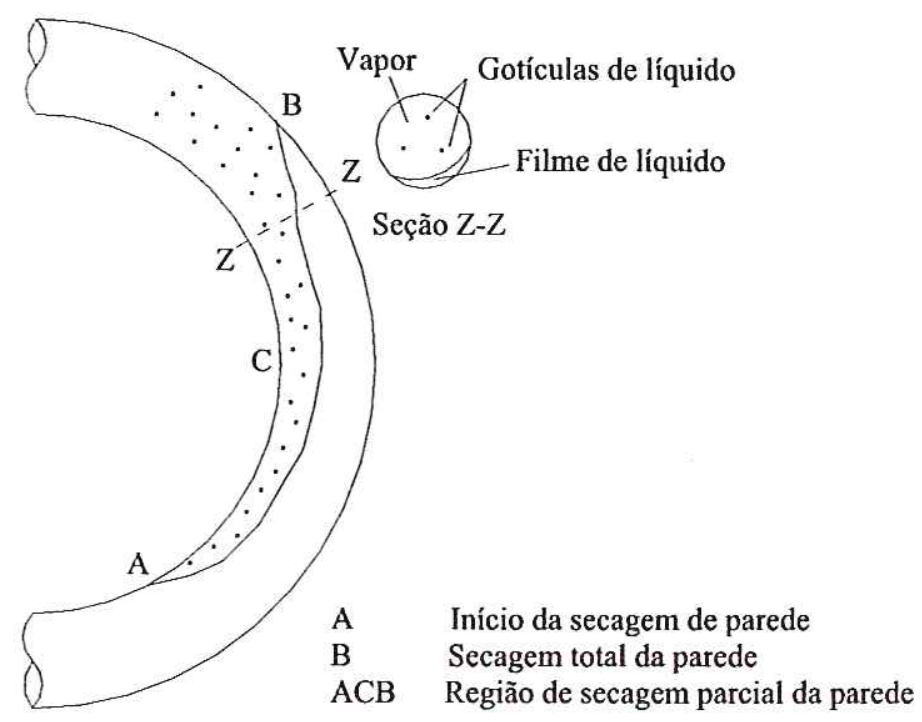

Figura 2.28 Configuração do tipo de tubo utilizado por BERTHOUD \& JAYANTI (1990).

Através de uma análise dos fatores que afetam a secagem de parede, apresentaram quatro mecanismos ligados a mudança na espessura do filme de líquido, quais sejam:

(1) Suspensão de partículas de líquido na forma de gotículas.

(2) Deposição destas gotículas na parede do tubo.

(3) Mudança de fase.

(4) Redistribuição do filme de líquido.

Avaliaram ainda, a influência de cinco parâmetros de operação na região de secagem de parede: grau de subresfriamento na entrada; pressão, diâmetro da serpentina, fluxo de calor e velocidade mássica. Foi verificado que o grau de subresfriamento na entrada não tem efeito direto nos quatro mecanismos enumerados anteriormente. Nessas condições, o título relativo ao ponto de secagem da parede demonstrou ser largamente independente do grau de subresfriamento na entrada. A influência da pressão é sentida, principalmente, pelas 
propriedades físicas e termodinâmicas do fluido. A principal conseqüência de um decréscimo da pressão do sistema implica num aumento da taxa de suspensão e de deposição, contribuindo, ainda, para um aumento do escoamento secundário. $\mathrm{O}$ efeito do diâmetro da serpentina ocorre no processo de deposição de partículas. À medida que o diâmetro diminui, a força centrífuga atuante na suspensão de gotículas de líquido aumenta proporcionalmente à deposição. Nessas condições, para um diâmetro menor a ocorrência de secagem da parede aumenta. O fluxo de calor é um dos parâmetros mais importantes a ser considerado, pois um aumento do fluxo de calor, o título relativo ao início da secagem de parede diminui. Em outras palavras, quanto maior o fluxo de calor a secagem de parede se desloca a montante. A velocidade mássica afeta os quatro mecanismos, mencionados anteriormente. Com um aumento da velocidade mássica, a taxa de suspensão de gotículas de líquido aumenta e há uma elevação da taxa de deposição pelo aumento da força centrífuga. No caso do mecanismo de mudança de fase, o efeito ocorre no sentido de suprimir a ocorrência da ebulição nucleada. Os autores propuseram, ainda, algumas correlações para a determinação do título relativo à secagem da parede. Essas correlações foram classificadas em regiões e propostas em termos de alguns parâmetros adimensionais da seguinte forma:

- Região de domínio da gravidade:

$x_{C R}=10^{7,068} \cdot\left(\frac{\rho_{L}}{\rho_{V}}\right)^{-2,378} \cdot\left(\frac{G \cdot D}{\mu_{L}}\right)^{-1,712} \cdot\left(\frac{G}{\rho_{V} \cdot \sqrt{g \cdot D}}\right)^{0,967} \cdot\left(\frac{\phi}{G \cdot i_{L V}}\right)^{-0,74}$

- Região de domínio de deposição:

$x_{C R}=3,223+\log \left[\left(\frac{\rho_{L}}{\rho_{V}}\right)^{0.101} \cdot\left(\frac{G \cdot D}{\mu_{L}}\right)^{-0,785} \cdot\left(\frac{G}{\rho_{V} \cdot \sqrt{g \cdot D}}\right)^{0.067} \cdot\left(\frac{\phi}{G \cdot i_{L V}}\right)^{-0.43} \cdot\left(\left(\frac{\phi}{\mu_{L} \cdot i_{L V}}\right) \cdot \sqrt{\frac{\sigma}{g \cdot\left(\rho_{L}-\rho_{V}\right)}}\right)^{0,098}\right](2.96)$

- Região de domínio de suspensão de gotículas:

$x_{C R}=10^{32235} \cdot\left[\left(\frac{\rho_{L}}{\rho_{V}}\right)^{-0,267} \cdot\left(\frac{G \cdot D}{\mu_{L}}\right)^{-0,984} \cdot\left(\frac{G}{\rho_{V} \cdot \sqrt{g \cdot D}}\right)^{0,950} \cdot\left(\frac{\phi}{G \cdot i_{L V}}\right)^{-0,428} \cdot\left(\left(\frac{\phi}{\mu_{L} \cdot i_{L V}}\right) \cdot \sqrt{\frac{\sigma}{g \cdot\left(\rho_{L}-\rho_{V}\right)}}\right)^{0,119}\right]$

É interessante observar que as correlações apresentam alguns grupos adimensionais importantes em escoamento com mudança de fase. Deve-se destacar o número de Reynolds, $\operatorname{Re}=\frac{G \cdot D}{\mu}$, o número de Froude, $F r=\frac{G^{2}}{\rho^{2} \cdot g \cdot D}$, associado ao efeitos de superficie livre, o 
número de ebulição, $B o=\frac{\phi}{G \cdot i_{L V}}$, e nas duas últimas aparece um grupo adimensional associado ao diâmetro de desprendimento de bolhas do tipo, $\sqrt{\frac{\sigma}{g \cdot\left(\rho_{L}-\rho_{V}\right)}}$.

KAJI et al (1995) pesquisaram experimentalmente as características da secagem de parede em serpentinas helicoidais, para o refrigerante R-113, através de medidas de temperatura da parede na região da seção de secagem da parede. A seção de testes era composta por um tubo de aço inoxidável com diâmetro interno de $4 \mathrm{~mm}$ e $2,4 \mathrm{~m}$ de comprimento. A seção de testes foi aquecida por água, que circulava entre dois tubos concêntricos. A pressão dos ensaios foi mantida constante e igual a 4,9 $\mathrm{MPa}$, ao passo que a velocidade mássica variou entre 270 e $1000 \mathrm{~kg} / \mathrm{s} . \mathrm{m}^{2}$ e o título de equilíbrio na entrada entre 5 e $30 \%$.

É interessante destacar que, para serpentinas helicoidais, o título de secagem de parede foi superior aos do tubo reto. Nessas condições, é possível afirmar que, para serpentinas helicoidais a taxa de deposição de partículas de líquido na parede é maior e a taxa de suspensão é menor devido ao escoamento secundário causado pela força centrífuga. Deve-se destacar, ainda, a ordem de grandeza dos fluxos de calor utilizados nessa pesquisa, que variou entre 390 e $1500 \mathrm{~kW} / \mathrm{m}^{2}$, o que caracteriza aplicações nucleares, pois se trata de valores da ordem do fluxo crítico de calor.

Um dos trabalhos mais recentes encontrados na literatura foi de HOYER (1998) que trata da determinação do ponto de secagem de parede e da região de pós-secagem. Entretanto, como na maioria dos trabalhos, trata-se de pesquisa voltada à área nuclear. Destaca-se um tópico relacionado à secagem de parede, onde se conclui que o fluxo de calor induz a suspensão de partículas, as quais são desprezíveis a baixas pressões, mas há uma considerável contribuição para pressões elevadas. Os ensaios foram realizados, utilizando água como fluido de circulação, para uma variação de pressão entre 1 e $10 \mathrm{MPa}$, velocidade mássica entre 500 e $1500 \mathrm{~kg} / \mathrm{s} . \mathrm{m}^{2}$ e fluxo de calor entre 300 e $1000 \mathrm{~kW} / \mathrm{m}^{2}$, caracterizando a proximidade com o fluxo crítico de calor.

O trabalho mais recente levantado na literatura foi o de KATTAN et al (i998) que estudaram a ebulição convectiva de cinco fluidos refrigerantes incluindo a região de secagem da parede. Inicialmente, na parte 1 , desenvolveram um mapa de padrão de escoamento, baseado no mapa de STEINER (1993) apud KATTAN et al (1998), incluindo a região de escoamento em névoa. A descrição do aparato experimental é apresentada na parte 2 , onde, 
afirmam que há uma influência definida do fluxo de calor no ponto de secagem da parede e que a utilização de aquecimento elétrico mostrou-se inadequado para ensaios com títulos elevados.

A solução encontrada pelos autores para conduzir os ensaios sem a presença de óleo lubrificante foi a utilização de uma bomba de engrenagem de aço inoxidável com o rotor acionado magneticamente. A seção era aquecida por água que circulava entre dois tubos concêntricos. As condições operacionais dos ensaios variaram da seguinte forma: velocidade mássica entre 100 e $500 \mathrm{~kg} / \mathrm{s} \cdot \mathrm{m}^{2}$, fluxo de calor entre 0,5 e $36 \mathrm{~kW} / \mathrm{m}^{2}$, título entre 1,6 e $100 \%$ e a temperatura de saturação entre $-1,3$ e $30^{\circ} \mathrm{C}$.

Um modelo foi proposto, na parte 3 , baseado, principalmente, na correlação de STEINER \& TABOREK (1992), correlacionando razoavelmente os resultados experimentais. Deve ser destacada a região de títulos elevados, incluindo a secagem da parede. O modelo foi apresentado na forma da seguinte correlação, de aplicação relativamente complexa:

$$
\frac{\left[\left(\frac{2 \cdot \pi \cdot h_{b}-\theta \cdot h_{V}}{2 \cdot \pi-\theta}\right)^{3}-h_{E N}^{3}\right]^{1 / 3}}{\operatorname{Pr}_{L}^{0,4} \cdot \frac{k_{L}}{\delta}}=0,0133 \cdot \operatorname{Re}_{L}^{0,69}
$$

Os autores compararam a Eq. (2.98) com um banco de dados de 1141 pontos experimentais, obtido para cinco fluidos refrigerantes, tendo encontrado um desvio de $13,3 \%$ em relação aos resultados experimentais.

\subsubsection{Conclusões}

Trabalhos relativos à região de secagem de parede na ebulição convectiva são raros, limitando, de certa forma, o acesso às informações referentes ao tema. A seguir serão apresentadas as principais conclusões relativas a regi:̌̃o de secagem da parede.

- A região de secagem de parede apresenta valores do coeficiente de transferência de calor da ordem do coeficiente monofásico de vapor, ou seja, de 1 ou 2 ordens de magnitude inferiores àqueles do padrão anular de escoamento. 
- Os principais parâmetros que interferem na secagem de parede são: fluxo de calor e velocidade mássica.

- No caso de tubos horizontais, foi verificado que houve uma secagem, denominada de parcial, inicialmente no topo do tubo, devido aos efeitos gravitacionais, deslocando-se para a região inferior do tubo, até a secagem total da parede. 


\section{CAPÍTULO 3 - EQUIPAMENTO EXPERIMENTAL}

\subsection{Introdução}

$\mathrm{N}$

este capítulo, será apresentado o equipamento experimental que foi construído no laboratório de refrigeração da EESC-USP. Serão mostrados, em detalhes, todos os dispositivos pertencentes à bancada experimental. Antes, porém, será apresentado, resumidamente, um levantamento de alguns equipamentos experimentais que foram idealizados para a avaliação da transferência de calor e perda de carga em escoamento com ou sem mudança de fase no interior de tubos. O capítulo aborda, ainda, os procedimentos experimentais utilizados nos levantamentos de dados nos escoamentos monofásico e com mudança de fase, além da análise de incertezas dos principais parâmetros, tais como, coeficiente de transferência de calor, título e perda de carga.

\subsection{Levantamento na Literatura de Equipamentos Existentes}

Inicialmente, seria interessante apresentar as principais diferenças existentes entre as diversas bancadas experimentais que foram encontradas na literatura. A maioria dos equipamentos encontrados circulava o refrigerante por intermédio de uma bomba de deslocamento positivo, geralmente, de engrenagens não metálicas. A principal vantagem de se atuar com uma bomba de deslocamento positivo consiste na possibilidade de ensaiar fluidos refrigerantes puros, além de possibilitar a operação em uma larga faixa de vazões, dependendo, é clarc, da vazão máxima da bomba.

Outro dispositivo comumente encontrado para promover a circulação do fluido é o tradicional compressor. Alguns trabalhos, tais como, ANDERSON et al (1966), PALM (1991), HAMBREUS (1995), entre outros, fizeram uso do ciclo de refrigeração por compressão a vapor, onde a principal inconveniência era a presença de óleo para lubrificação do compressor. Este óleo é arrastado até a seção de ensaios, geralmente o evaporador, 
misturado ao fluido refrigerante, retornando, posteriormente ao compressor. Nesse sentido, ensaios com o fluido refrigerante puro ficam comprometidos.

Alguns equipamentos experimentais, tais como aqueles utilizados por JOHNSTON \& CHADDOCK (1966) e MURATA \& HASHIZUME (1993), operavam sem a utilização de dispositivos que promovem a circulação do fluido, tais como, bombas e compressores. Neste caso, a circulação do fluido refrigerante se dá pela diferença de densidades, onde, comumente, o evaporador se encontra num nível inferior e o condensador localiza-se num nível superior. A distância entre ambos resulta em uma diferença de pressão, fazendo com que ocorra a circulação do fluido. Aumentando-se a distância entre os componentes resulta num incremento da vazão, porém há o inconveniente da limitação da altura do equipamento, devido a restrições no pé direito do edifício.

A tabela 3.1 apresenta um sumário das principais características de alguns equipamentos encontrados na literatura, que serviram de referência para a construção da bancada experimental utilizada no presente trabalho. 
Tabela 3.1 Relação de trabalhos envolvendo levantamentos experimentais da Ebulição Convectiva e suas principais caracteristicas.

\begin{tabular}{|c|c|c|c|c|c|c|c|c|c|}
\hline Autor (es) & $\mathrm{T}_{\text {Evap }}\left({ }^{\circ} \mathrm{C}\right)$ & $\phi\left(\mathrm{kW} / \mathrm{m}^{2}\right)$ & $\mathrm{G}\left(\mathrm{kg} / \mathrm{s} \cdot \mathrm{m}^{2}\right)$ & Fluido & $\mathrm{D}(\mathrm{mm})$ & $\mathrm{L}(\mathrm{m})$ & Título (x) & Aquecimento & $\begin{array}{l}\text { Controle } \\
\text { do Óleo }\end{array}$ \\
\hline Altman et al (1960) & 4,4 e 23,8 & 6,5 a 65 & 95 a 635 & $\mathrm{R}-22$ & 8,7 & 1,2 & 0,2 a 0,9 & Água & Não \\
\hline Lavin (1963) & 30 & 3 a 38 & 100 a 500 & $\begin{array}{c}\text { R-12 e R- } \\
22\end{array}$ & 6 a 18 & 6 & 0,1 a 1,0 & Elétrico & Não \\
\hline Anderson et al (1966) & 4,4 & 11 a 33 & 30 a 345 & $\mathrm{R}-22$ & 19 & 2,25 & 0,18 a 1,0 & Água & Não \\
\hline Chaddock et al (1966) & 4,5 & 7 a 39 & 100 a 500 & R-12 & 12,7 & 2,7 & 0,2 a 0,88 & Elétrico & Não \\
\hline $\begin{array}{c}\text { Johnston \& Chaddock } \\
\text { (1966) }\end{array}$ & -15 a 20 & 1,8 a 22 & 15 a 60 & $\begin{array}{c}\text { R-12 e R- } \\
22\end{array}$ & 12,7 & 2 & 0,3 a 0,67 & Elétrico & Não \\
\hline Ross et al (1987) & 4,7 & 10 a 30 & 100 a 500 & $\mathrm{R}-152 \mathrm{a}$ & 9 & 2,7 & 0 a 0,8 & Elétrico & Sim \\
\hline Takamatsu et al (1988) & 10 & 5 a 30 & 75 a 345 & $\mathrm{R}-22$ & 8,3 & 4,8 & 0,5 a 0,27 & Água & Não \\
\hline Takamatsu et al (1991) & 20 & 5 a 50 & 110 a 400 & $\mathrm{R}-134 \mathrm{a}$ & 7,9 & 6 & 0,05 a 0,8 & Água & Sim \\
\hline Reid et al (1991) & 70 & 10 a 40 & 200 a 600 & R-113 & 8,7 & 3,6 & 0 a 1,0 & Elétrico & Não \\
\hline Eckels et al (1992) & 2 e 7 & 5 a 30 & 135 a 400 & $\mathrm{R}-22$ & 7,9 & 3,6 & 0,08 a 0,88 & Água & Sim \\
\hline Palm (1992) & 0 & la 12 & 13 a 162 & $\begin{array}{c}\mathrm{R}-12 \text { e R- } \\
22\end{array}$ & 15 & $\frac{, 0}{10}$ & 0,1 a 0,98 & Elétrico & Sim \\
\hline Ha \&Bergles (1993) & 5 & 5 a 10 & 25 a 100 & $\mathrm{R}-12$ & 9,52 & 1,5 & 0,1 a 0,6 & Elétrico & Sim \\
\hline $\begin{array}{c}\text { Murata \& Hashizume } \\
\text { (1993) }\end{array}$ & 0 & 1 a 30 & 100 a 300 & $\mathrm{R}-134 \mathrm{a}$ & 10,3 & 0,7 & 0,1 a 1 & Elétrico & Sim \\
\hline Hambreus (1993) & -20 a 10 & 2 a 14 & 20 a 255 & R-134a & 12 & 10 & 0,25 a 1 & Elétrico & Sim \\
\hline Wattelet (1994) & -15 a 15 & 5 a 30 & 25 a 500 & $\begin{array}{l}\text { R-22 e R- } \\
134 a\end{array}$ & 10,9 & 2,4 & 0,1 a 0,9 & Elétrico & Sim \\
\hline $\begin{array}{c}\text { Melin \& Vanling } \\
(1994)\end{array}$ & 0 a 30 & 1 a 40 & 120 a 300 & $\mathrm{R}-134 \mathrm{a}$ & 10 & 5 & 0,05 a 0,6 & Água & Sim \\
\hline Kattan et al (1994) & -1 a 10 & 4 a 30 & 100 a 300 & $\mathrm{R}-404 \mathrm{~A}$ & 12 & 3 & 0,02 a 0,9 & Água & Sim \\
\hline $\begin{array}{c}\text { Torikoshi \& Ebisu } \\
(1994)\end{array}$ & 5 & 5 a 20 & 40 a 280 & $\mathrm{R}-134 \mathrm{a}$ & 8,7 & 4 & 0,2 a 0,9 & Agua & Sim \\
\hline Chamra et al (1996) & 2 & 8 a 15 & 70 a 280 & $\mathrm{R}-22$ & 15 & 2,4 & 0,1 a 0,9 & Água & Sim \\
\hline
\end{tabular}




\subsection{Equipamento Experimental}

O projeto inicial da bancada experimental foi idealizado nos moldes de um outro aparato havia sido desenvolvido no ACRC (Air Condictioning and Refrigeration Center) da University of Illinois, Estados Unidos da América. A montagem do aparato experimental teve início no final de 1996, porém, efetivamente, a bancada entrou em operação no primeiro semestre de 1998. A seguir será apresentada uma descrição dos componentes da bancada experimental.

\subsubsection{Descrição do Equipamento Experimental}

\subsubsection{Considerações Iniciais}

O equipamento experimental é composto por quatro circuitos: o principal (de ensaios ou de refrigerante) e outros três circuitos de apoio. O primeiro deles é constituído de uma mistura anti-congelante, composta por uma solução de $60 \%$ de etileno glicol em água, responsável pelo resfriamento do refrigerante do circuito principal. $\mathrm{O}$ outro circuito é o resfriador de líquido ou "chiller" que por sua vez resfria a solução de etileno glicol/água. $\mathrm{O}$ último deles é o da água de condensação do "Chiller". A seguir estes circuitos serão apresentados em detalhes.

\subsubsection{Circuito Principal ou de Ensaios}

O diagrama esquemático do circuito principal se encontra na Fig. 3.1. A circulação do refrigerante é proporcionada por uma bomba de engrenagens de "Ryton", o que evita a contaminação do refrigerante pelo óleo de lubrifícação, que inevitavelmente acompanha o refrigerante em compressores. A vazão de refrigerante é controlada por intermédio de um variador de freqüência, que atua sobre a rotação do motor de acionamento da bomba. $\mathrm{O}$ título do refrigerante na entrada da seção de testes é ajustado pela potência elétrica dissipada no denominado "pró-aquecedor". Este é constituído de uma serpentina de tubos de cobre aquecido por resistências elétricas tipo fita enroladas na superficie exterior, perfazendo um total de $9 \mathrm{~kW}$. A potência elétrica dissipada é controlada por um variador de tensão (VARIAC) de acionamento manual. O pré-aquecedor foi confinado em um envoltório de isolante, lã de vidro e espuma de borracha, para reduzir as perdas para o exterior. Precedendo o pré-aquecedor encontra-se um "subresfriador" do refrigerante líquido proveniente da 
bomba. Este trocador de calor, do tipo tubos concêntricos, foi instalado com o objetivo de prevenir qualquer possibilidade de formação de vapor na entrada do pré-aquecedor em virtude do efeito de coluna, o que tornaria impossível conhecer o estado do refrigerante na entrada do mesmo sem uma determinação experimental do título, o que envolveria um procedimento relativamente complexo. A potência elétrica total dissipada no pré-aquecedor $\mathrm{e}$ na seção de testes é removida pelo condensador. Este é do tipo carcaça/tubos, sendo resfriado pela solução de etileno glicol/água. Outros acessórios foram agregados ao circuito de refrigerante, como o filtro secador e o visor de líquido, indicados na Fig. 3.1. Digno de nota é o depósito de refrigerante que opera como acumulador, constituído de uma garrafa comercial de refrigerante, instalada em um nível superior da bancada, permitindo a carga e descarga de refrigerante do circuito de ensaios de forma relativamente simples.

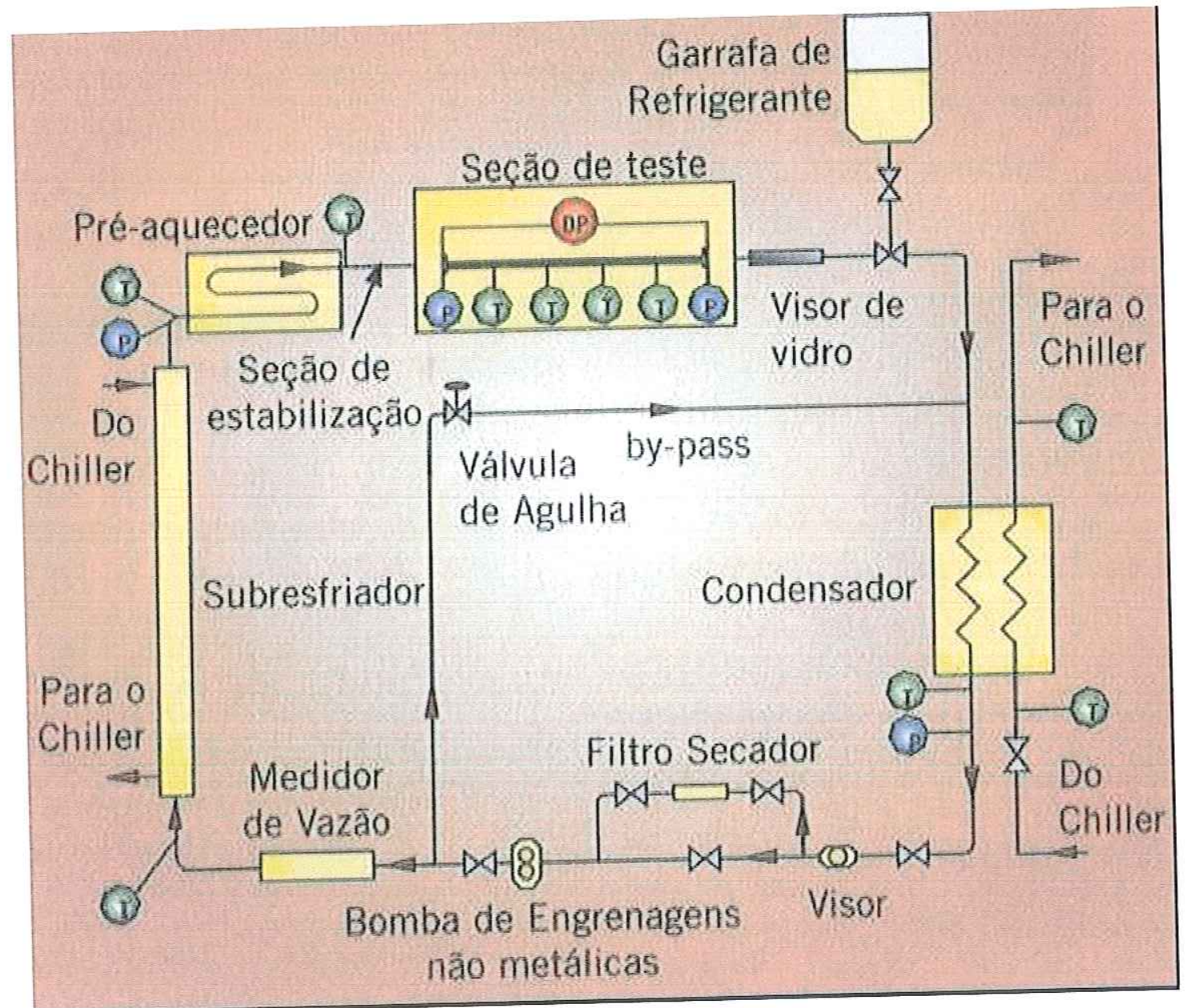

Figura 3.1 Diagrama esquemático do circuito principal ou de ensaios. 


\subsubsection{Circuito de Solução Anti-Congelante}

Este circuito de apoio é responsável pela condensação e subresfriamento do refrigerante no condensador do circuito principal. A solução anti-congelante, se caracteriza por uma temperatura de congelamento da ordem de $-50^{\circ} \mathrm{C}$. A Figura 3.2 ilustra, esquematicamente, o circuito de etileno glicol/água, composto por uma bomba centrífuga de circulação, depósito de 40 litros de volume, devidamente isolado, condensador do circuito principal e medidor de vazão do tipo turbina. Saindo do condensador, a solução passa pelo evaporador do "chiller" onde é resfriada, retornando para o depósito de líquido. Um circuito paralelo permite a circulação da solução pelo subresfriador do circuito principal, conforme ilustrado pela Fig. 3.2.

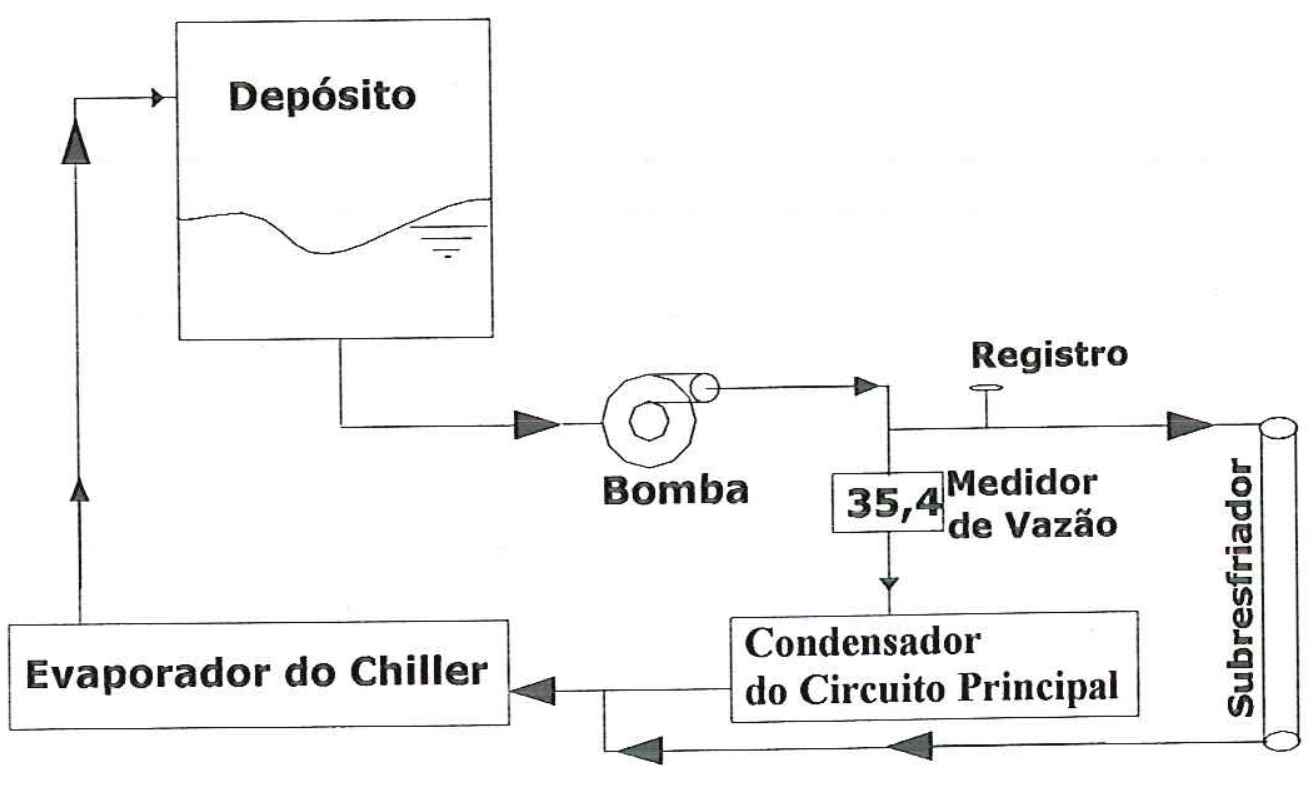

Figura 3.2 Esquema do circuito da solução anti-congelante: etileno glicol/água.

\subsubsection{Resfriador de Líquido}

O resfriador de líquido, "chiller" é responsável pelo resfriamento da solução anticongelante para a condensação do fluido refrigerante de ensaio, como mencionado anteriormente. O "chiller" é constituído de um ciclo de refrigeração por compressão de vapor, utilizando o HCFC 22 (R-22) com condensação a água. Um diagrama esquemático do "chiller" é apresentado na Fig. 3.3. Seguindo o fluxograma da figura é possível observar que 
o vapor deixa o compressor e passa pelo separador de óleo, seguindo para o condensador. Se a válvula de desvio de gás quente estiver aberta, uma parte do vapor superaquecido segue direto para o evaporador. Esta válvula foi adicionada ao sistema com o objetivo de simular uma carga térmica adicional, evitando ciclagens freqüentes do compressor. Deixando o condensador, o fluido refrigerante segue para o dispositivo de expansão. É interessante observar que foram instaladas duas válvulas de expansão termostática, pois cada uma delas é provida de um orifício distinto sendo, assim, utilizadas de acordo com a temperatura de evaporação desejada (ou da carga). Passando pela válvula de expansão, o refrigerante segue para o evaporador, onde muda de fase, dirigindo-se ao acumulador de aspiração (separador de líquido), cujo objetivo é o de evitar que refrigerante na fase líquida entre no compressor, podendo causar sérios danos a este equipamento.

\section{Separador} de óleo

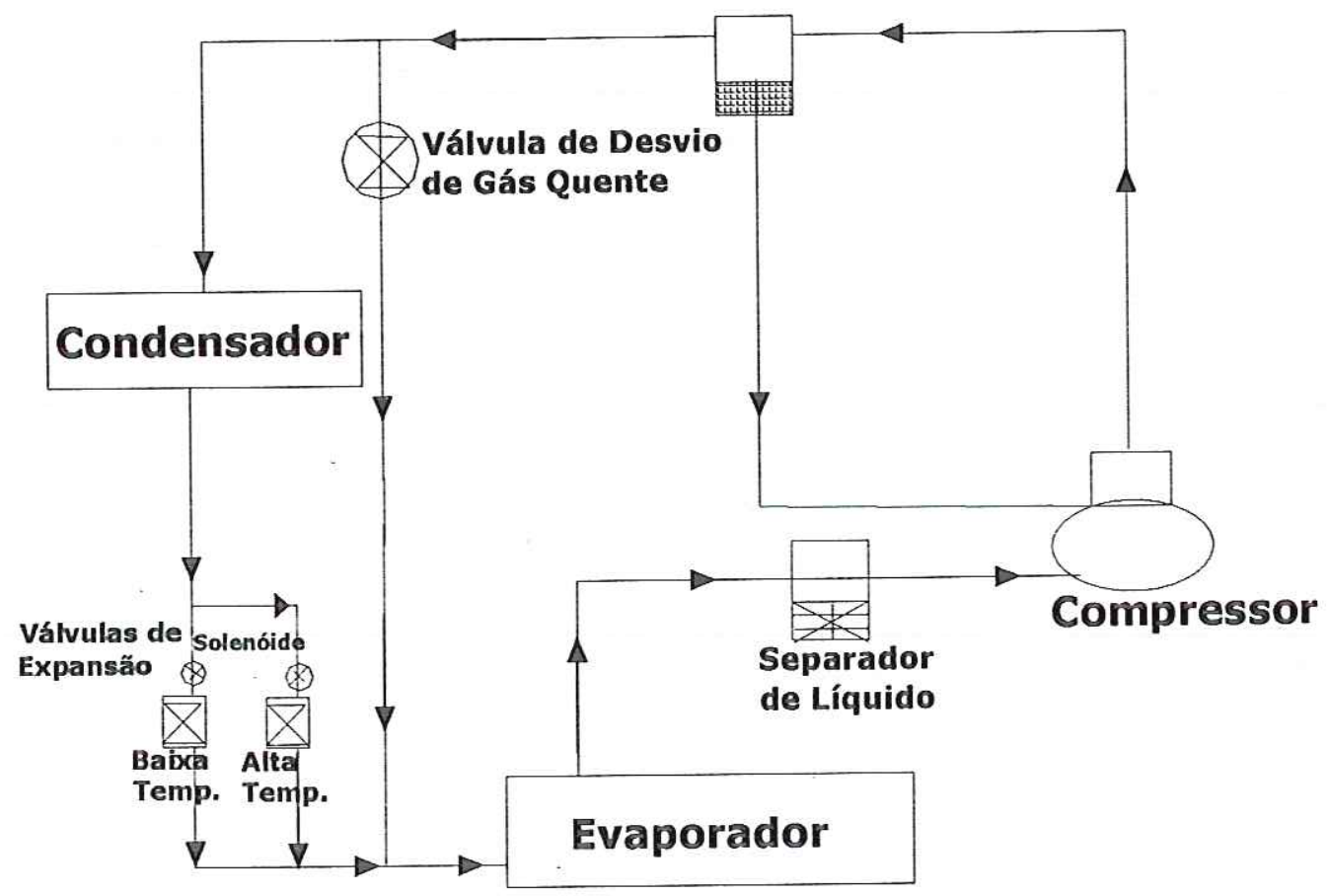

Figura 3.3 Representação esquemática do resfriador de líquido - "chiller".

\subsubsection{5 Água de Condensação}

O quarto circuito de apoio é a torre de resfriamento, conforme mencionado anteriormente. A água de condensação do "chiller" vai para a torre de resfriamento, onde passa por um dispositivo de aspersão. A torre possui, ainda, um ventilador que desloca o ar 
em contra corrente a queda d'água, resfriando por evaporação a água que, posteriormente, irá retornar ao circuito.

\subsubsection{Seção de Testes}

A seção de testes, cuja representação se encontra na Fig. 3.4, basicamente é constituída do tubo em que se realizam os ensaios de ebulição convectiva, podendo este apresentar diâmetros e materiais variáveis, dependendo dos objetivos. Inicialmente os ensaios eram realizados numa seção de $2 \mathrm{~m}$, porém, a partir do segundo tubo ensaiado, o comprimento da seção de testes foi reduzido para $1,5 \mathrm{~m}$. O tubo era aquecido eletricamente por resistências de fita, confeccionadas em "Kapton", e enroladas na superficie exterior, proporcionando um fluxo máximo de calor de $25 \mathrm{~kW} / \mathrm{m}^{2}$. A potência elétrica dissipada é controlada por um variador de tensão (VARIAC) de acionamento manual. Para reduzir ao máximo as perdas de calor para o exterior, o conjunto tubo e resistências foi recoberto sucessivamente por uma camada de lã de vidro de $70 \mathrm{~mm}$ de espessura e outra de espuma de borracha de $25 \mathrm{~mm}$ de espessura. Um visor tubular de vidro "pirex", de $100 \mathrm{~mm}$ de comprimento e diâmetro interno da mesma ordem de grandeza do tubo ensaiado, foi instalado na saída da seção de testes com o objetivo de permitir observações visuais dos padrões de escoamento.
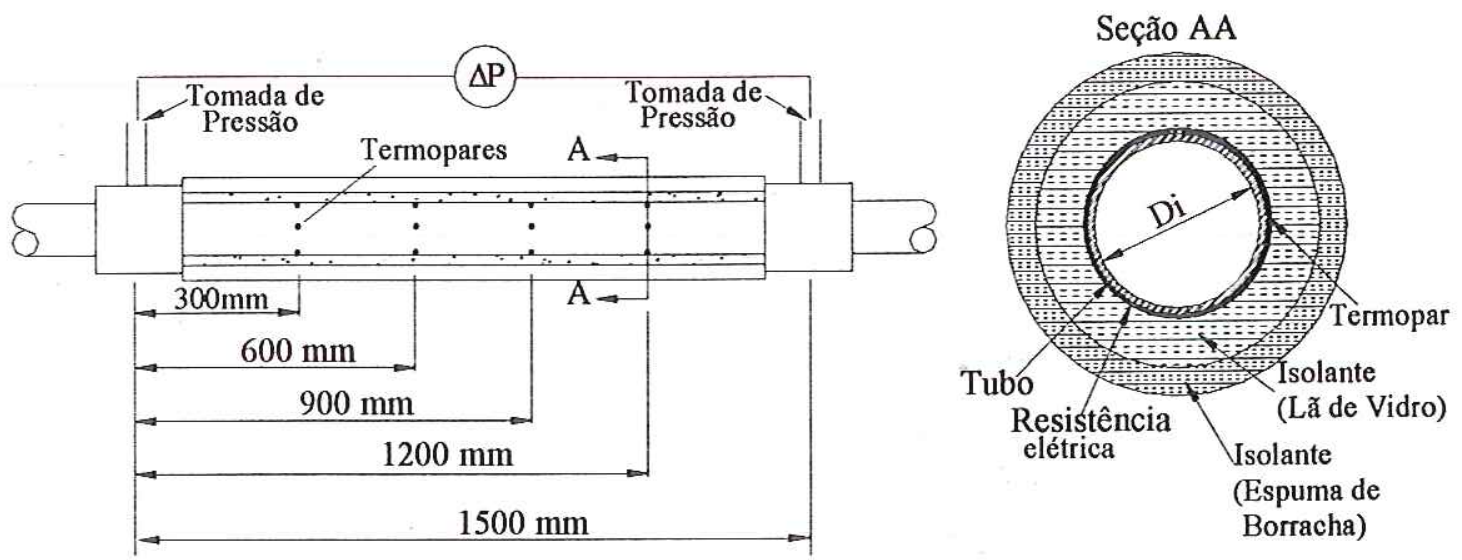

Figura 3.4 Detalhe da seção de testes e localização dos termopares na seção de testes.

U’m doss parâmetros mais importantes, medido nos ensaios do presente estudo, é a temperatura da parede do tubo. Nesse sentido, vários cuidados foram tomados para fixar o termopar na superfície externa do tubo. Seria interessante comentar alguns procedimentos de fixação de termopares utilizados no decorrer do trabalho. Inicialmente, os termopares eram introduzidos em ranhuras abertas na superficie externa do tubo e cobertos por uma fita adesiva de cobre. As ranhuras apresentavam as seguintes dimensões: $50 \mathrm{~mm}$ de comprimento, 
2,5mm de largura, e $0,7 \mathrm{~mm}$ de profundidade. As resistências elétricas eram enroladas cobrindo a fita de cobre. Porém, os resultados revelaram que havia um grande efeito da temperatura da resistência elétrica na medida do termopar. Diagnosticado o problema, optouse por isolar o termopar da resistência elétrica. Nesse sentido, foi utilizada uma cola especial de secagem rápida para a fixação do termopar na ranhura, cobrindo-a com uma fita de Kapton. Sobre a superficie dessa fita era fixada outra fita de cobre coberta pelas resistências elétricas enroladas ao longo da superfície do tubo. Os resultados mostraram que tais modificações surtiram efeito.

Posteriormente, foram ensaiados tubos com três diâmetros distintos, 7,0mm; 7,93mm e $9,52 \mathrm{~mm}$. Os tubos apresentavam espessura de parede da ordem de $0,35 \mathrm{~mm}$, o que impossibilitava a abertura da ranhura como no caso anterior. Neste caso, optou-se pela fixação ilustrada pela Fig. 3.5 (b).

Na última fase de ensaios envolvendo um tubo de latão de $17,4 \mathrm{~mm}$ de diâmetro interno, repetiu-se o procedimento de acomodar os termopares numa ranhura aberta na superficie exterior do tubo. A grande vantagem do tubo de latão era a espessura da parede, cerca de $3 \mathrm{~mm}$. Assim, foi aberta uma ranhura de $2,5 \mathrm{~mm}$ de profundidade, por $1,5 \mathrm{~mm}$ de largura c $40 \mathrm{~mm}$ de comprimento. Os termopares foram confeccionados especialmente para este tubo, pois a junta quente apresentava um diâmetro de aproximadamente $1,4 \mathrm{~mm}$. Nesse sentido, todos termopares foram alojados, pressionando-os de maneira que ficassem presos no fundo da ranhura. Posteriormente, as ranhuras eram recobertas por um cimento condutor com catalisador, fabricado pela OMEGA-USA. Depois que o cimento se solidificava, as resistências eram enroladas na superfície do tubo. Os resultados proporcionados por este tubo foram significativamente adequados, como será observado mais adiante.

As Figs. 3.5 (a), (b) e (c) ilustram as diversas formas de fixação dos termopares superficiais utilizadas no presente trabalho. 


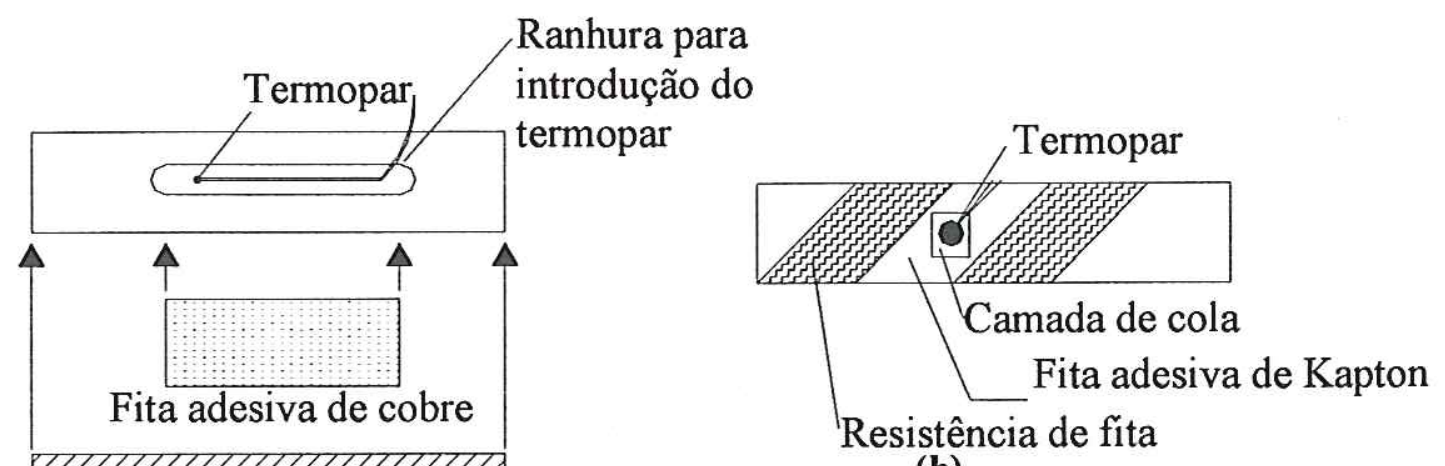

(b)

Resistência de fita

(a)

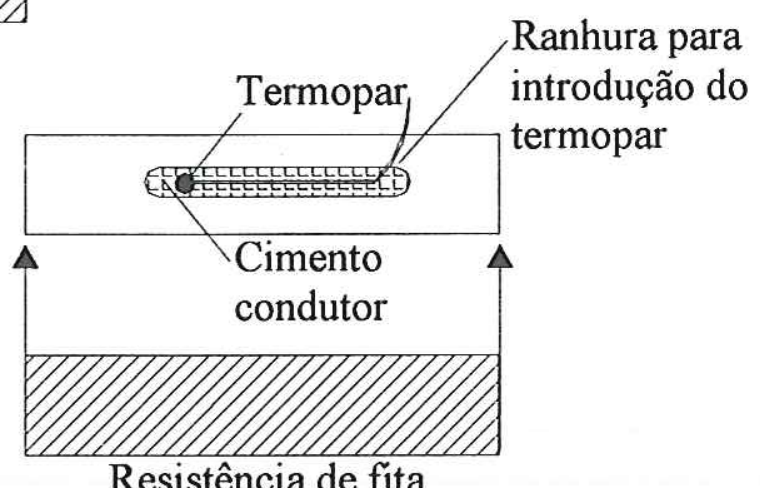

(c)

Figura 3.5 Detalhes da fixação dos termopares para medida da temperatura da parede do tubo.

\subsubsection{Componentes e Instrumentação do Circuito Principal}

Condensador

O condensador utilizado no circuito experimental é do tipo carcaça-tubos, orientado horizontalmente. Trata-se do modelo é CST-7, fabricado pela empresa APEMA, apresentando uma área de troca de calor de $2,64 \mathrm{~m}^{2}$.

Bomba de circulação

Inicialmente, uma bomba de engrenagens de teflon foi utilizada para promover a circulação do refrigerante. Esta bomba, denominada de microbomba, era de fabricação da empresa MICROPUMP, EUA, modelo 114/56C, apresentando uma capacidade máxima de $9,8 \mathrm{l} / \mathrm{min}$. Verificou-se que a microbomba apresentava pequenos vazamentos para temperaturas do fluido refrigerante reduzidas. Decidiu-se, assim, por adquirir outra microbomba, modelo 223/56C, com engrenagem de um material denominado de "Ryton". Segundo o fabricante, este material suporta melhor o contato com fluidos halogenados tais 
como os HFC's e os HCFC's. Os pequenos vazamentos verificados anteriormente foram completamente eliminados após a mudança. A Fig. 3.6 apresenta uma fotografia do eixo e das engrenagens de teflon e de "Ryton".

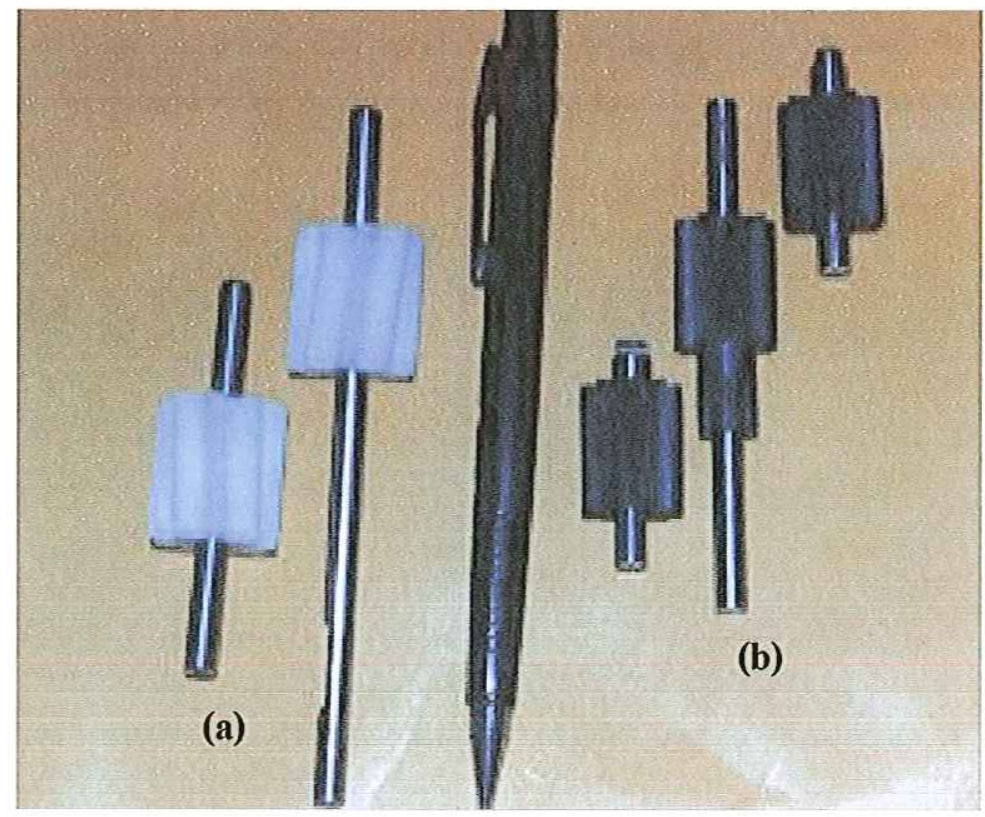

Figura 3.6 Fotografia ilustrando o eixo e as engrenagens da microbomba. (a) Teflon e (b) Ryton.

\section{Inversor de Freqüência}

No primeiro ano de operação, um inversor de freqüência, modelo VLT-210, fabricado pela DANFOSS, foi utilizado para modular a rotação da microbomba e, com isso, variar a vazão de refrigerante do circuito. Em virtude de danos causados por uma descarga elétrica, o inversor foi substituído por outro disponível no laboratório, modelo VLT-3000, também fabricado pela DANFOSS. Posteriormente, foi adquirido um inversor de freqüência dotado de um controlador PID, modelo VLT-2803, de fabricação DANFOSS. Este inversor recebia um sinal do medidor de vazão e, através de programação, era possível fixar a vazão de refrigerante desejada. Assim, o inversor automaticamente corrigia a rotação da microbomba para que a vazão permanecesse constante e igual ao valor pré-determinado.

\section{Medidor de Vazão}

O sensor do medidor de vazão do circuito principal é do tipo efeito de Coriolis, modelo MASS 2100 - DI-6, com fundo de escala de $1000 \mathrm{~kg} / \mathrm{h}$. Este sensor envia um sinal 
para o conversor de sinais, modelo MASS 3000, que, processando-o permite a leitura da vazão em massa, a vazão volumétrica, a densidade e a temperatura do fluido refrigerante que circula pelo sensor. Ambos, sensor e conversor de sinais foram fabricados pela DANFOSS. O conversor envia o sinal para o sistema de aquisição, onde, posteriormente, é armazenado no disco rígido. A precisão fornecida pelo fabricante é de $0,15 \%$, tendo sido confirmada pelo laboratório de vazão do IPT (Instituto de Pesquisas Tecnológicas do Estado de São Paulo), onde foi enviado para calibração, conforme o laudo de calibração. $O$ processo de calibração é ilustrado no Apêndice I.

\section{Subresfriador}

Como mencionado anteriormente, o subresfriador é responsável pelo subresfriamento do fluido refrigerante, consistindo de um trocador de calor do tipo tubos concêntricos. Foi adicionado ao sistema com o objetivo de prevenir qualquer possibilidade de formação de vapor na entrada do pré-aquecedor em virtude do efeito de coluna, o que tornaria impossivel caracterizar o estado do refrigerante na entrada do pré-aquecedor. $\mathrm{O}$ tubo interno é de $12,7 \mathrm{~mm}$ de diâmetro, por onde circula o fluido refrigerante, e o tubo externo apresenta $38,2 \mathrm{~mm}$ de diâmetro, sendo neste espaço anular que é circulada a solução de etileno glicol/água proveniente do "chiller".

\section{Pré-Aquecedor}

Inicialmente, o pré-aquecedor foi construído com tubos de $12,7 \mathrm{~mm}$ de diâmetro interno e, aproximadamente, $4,2 \mathrm{~m}$ de comprimento. Um conjunto de resistências elétricas do tipo fita foram enroladas na superfície externa do tubo, proporcionando uma potência máxima de $5 \mathrm{~kW}$. A Fig. 3.7 apresenta uma foto do primeiro pré-aquecedor. Observou-se, então, que os ensaios ficavam limitados pelo título, sendo que, em certos casos, este não superava o nível de $50 \%$. Foi, então proposta uma nova configuração para o pré-aquecedor, mostrada na fotografia da Fig. 3.8. É possível observar que o comprimento do pré-aquecedor foi incrementado para $8,9 \mathrm{~m}$ com tubos de $15,8 \mathrm{~mm}$ de diâmetro. Um total de 13 resistências elétricas do tipo fita foram enroladas na superficie do tubo, sendo 12 com potência elétrica de $624 \mathrm{~W}$ a $220 \mathrm{~V}$, apresentando $2,4 \mathrm{~m}$ de comprimento por $12 \mathrm{~mm}$ de largura, fabricadas pela empresa AMPTEK-EUA, e 1 com potência de $185 \mathrm{~W}$ a $220 \mathrm{~V}$, apresentando $0,5 \mathrm{~m}$ de comprimento por $12 \mathrm{~mm}$ de largura, fabricada pela empresa RICA-ESPANHA. Vale ressaltar que o isolamento térmico no primeiro caso era de poliuretano expandido e após a 
modificação o pré-aquecedor foi coberto por uma camada de lã de vidro, a qual se superpôs espuma de borracha. Conforme mencionado anteriormente, a potência elétrica dissipada pelas resistências elétricas era controlada por um variador de tensão, comumente denominado de VARIAC, de acionamento manual, modelo VT-290, de 9 kVA de potência máxima, fabricado pela SOCIEDADE TÉCNICA PAULISTA. A potência fornecida é medida através de um transdutor de potência, modelo 2285A fabricado pela YOKOGAWA.

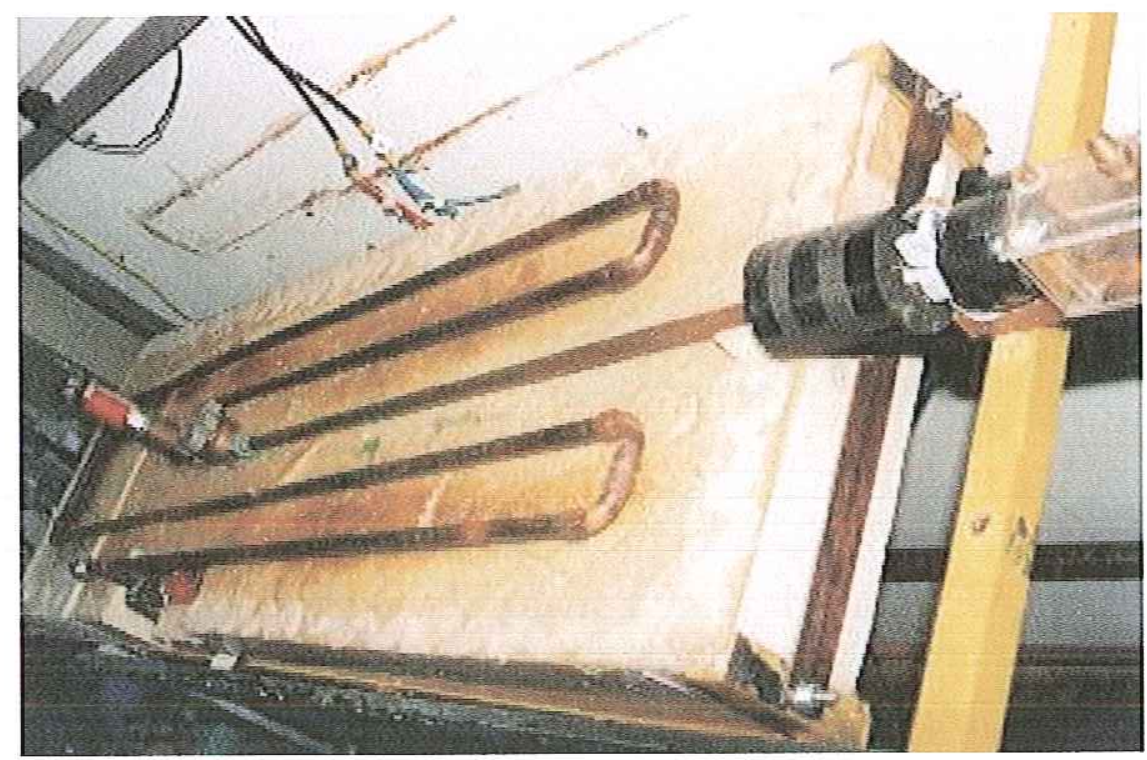

Figura 3.7 Fotografia ilustrando o primeiro pré-aquecedor do circuito.

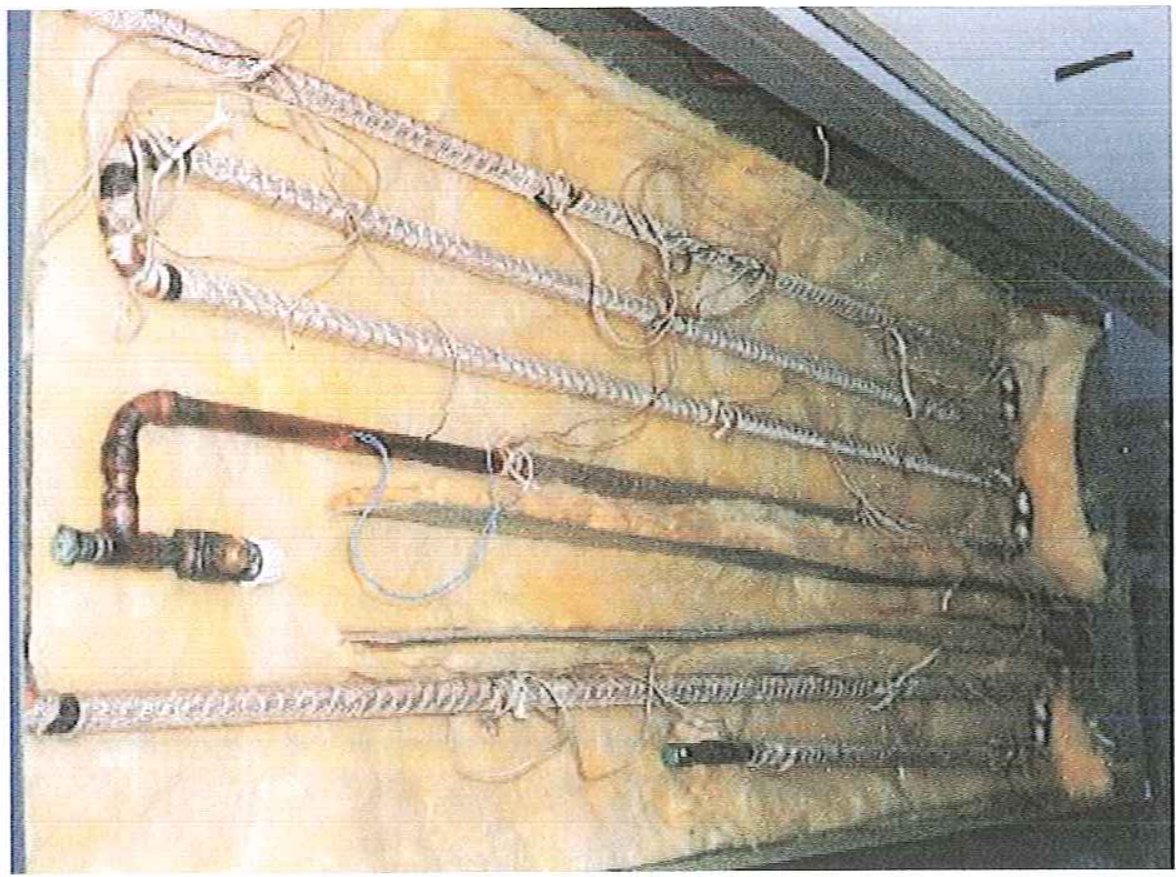

Figura 3.8 Fotografia ilustrando o segundo pré-aquecedor da bancada. 


\section{Seção de Estabilização}

Entre a saída do pré-aquecedor e a entrada na seção de testes existe um trecho de tubo reto, denominado de "seção de estabilização", que é responsável pelo desenvolvimento do escoamento. Nesse sentido, esta seção é constituída de um tubo de mesmo diâmetro interno que o da seção de testes. Inicialmente, essa seção apresentava um comprimento de $1,4 \mathrm{~m}$, porém, após a modificação no pré-aquecedor, aumentou-se o comprimento para $2,1 \mathrm{~m}$. A seção de estabilização é termicamente isolada, de forma a reduzir ao máximo perdas de calor para o meio.

\section{Depósito de Refrigerante}

Na primeira fase de ensaios observou-se que era despendido um tempo considerável, principalmente, na remoção do fluido refrigerante que estava sendo ensaiado. Este procedimento era comum, visto que, para determinadas condições, era necessário adicionar ou extrair fluido refrigerante do circuito, a fim de alcançar a temperatura de evaporação desejada. Foi, então, introduzido um cilindro de refrigerante, denominado de depósito de refrigerante, conectado ao sistema. Nesse sentido, o tempo gasto para a realização desta operação foi reduzido substancialmente, devendo ser ressaltado que, para cada operação anteriormente realizada, uma parcela do fluido era perdida como fuga. Na remoção do fluido refrigerante do sistema era necessário que o depósito de líquido estivesse a uma pressão inferior à do circuito. Assim, foi confeccionada uma serpentina de cobre, enrolada na superficie externa do cilindro, pela qual circulava a solução anti-congelante a baixa temperatura, de forma a reduzir a pressão no interior do depósito.

\section{Seção de Visualização}

A seção de visualização foi idealizada com o objetivo de verificar os padrões de escoamento na mudança de fase. Inicialmente, foram incorporadas ao circuito duas seções de visualização. A primeira na entrada da seção de testes e a outra na saída, porém, por questões de material e montagem, optou-se por manter somente a seção de visualização na saída. Para todos os diâmetros ensaiados $(7,0 ; 7,93 ; 9,52 ; 12,7$ e 17,4mm) utilizaram-se tubos de vidro que apresentavam um diâmetro interno da mesma ordem dos tubos ensaiados na seção de testes. Estes tubos de vidro foram gentilmente cedidos pela Vidraria do Instituto de Física de São Carlos. Através de registros fotográficos, que serão apresentados mais adiante, foi 
possivel verificar a maioria dos padrões de escoamento encontrados no escoamento com mudança de fase no interior de tubos horizontais, tais como os padrões em bolhas, pistonado, intermitente ("slug'), anular, estratificado liso, estratificado ondulado e o em névoa. Estas fotos só foram possíveis graças à velocidade de abertura do diafragma da máquina fotográfica, cujo modelo é o 7SF fabricado pela PENTAX-JAPÃO, de 1/2000s.

\section{Transdutor Diferencial de Pressão}

Para avaliar a perda de carga na seção de testes, optou-se pela aquisição de um transdutor diferencial de pressão. O modelo adquirido, inicialmente, foi o DP-103, fabricado pela empresa VALIDYNE-EUA, constituído de um diafragma modelo 3-30, que suporta uma diferença máxima de pressão de $8,6 \mathrm{kPa}$. Este transdutor mede com precisão escoamentos monofásicos, e para escoamentos com mudança de fase não se mostrou adequado. Nesse sentido, decidiu-se pela aquisição de outro modelo, específico para escoamentos bifásicos e monofásicos, DP-15, produzido pela mesma empresa. Foram adquiridos, ainda, quatro modelos de diafragmas distintos: 3-24, 3-30, 3-34 e 3-38, para as seguintes pressões diferenciais 2,$2 ; 8,6 ; 22$ e $55 \mathrm{kPa}$. Assim, para ensaios em escoamento monofásico de líquido eram utilizados os diafragmas de menor capacidade e para escoamentos bifásicos os de maior fundo de escala. A precisão fornecida pelo fabricante para o transdutor diferencial de pressão é de $0,25 \%$.

\section{Transdutor Pressão}

As tomadas de pressão no circuito experimental de ensaios eram realizadas em cinco pontos distintos: entrada e saída da seção de testes, entrada e saída do pré-aquecedor e na saída do condensador, como pode ser observado na Fig. 3.1. As medidas da pressão na entrada e saída da seção de testes tiveram por finalidade fornecer a pressão de evaporação e por conseqüência as temperaturas de evaporação na entrada e saída da seção de testes, além da perda de carga. Os transdutores instalados na entrada e saída do pré-aquecedor indicavam, juntamente com a temperatura, o estado do refrigerante. Os transdutores de pressão utilizados na bancada pertenciam a dois modelos distintos: AKS-33 apresentando uma faixa de operação de -1 a 12 bar, e o AKS-33, cuja faixa de operação varia entre 0 e 20 bar, ambos fabricados pela DANFOSS.

As tomadas de pressão foram realizadas através de um orificio de $1 \mathrm{~mm}$ de diâmetro. A calibração dos transdutores de pressão foi realizada no Laboratório de Refrigeração da 
EESC-USP, utilizando um manômetro de coluna de mercúrio e um amperímetro de precisão. Levantaram-se diversos pontos e, posteriormente, utilizou-se um polinômio para correlacionar esses pontos.

A precisão fornecida pelo fabricante dos transdutores de pressão é de $0,3 \%$ do fundo de escala e o procedimento de calibração está descrito no Apêndice I.

\section{Medida da Temperatura}

Para as medidas de temperatura foram utilizados termopares do tipo $\mathrm{T}$, de cobreconstantan. Estes termopares foram escolhidos, pois se mostram adequados às aplicações do presente trabalho, por apresentarem uma faixa de utilização $\left(-184^{\circ} \mathrm{C}\right.$ a $\left.270^{\circ} \mathrm{C}\right)$, compatível com os valores típicos dos ensaios.

Os pontos de medida das temperaturas do fluido refrigerante, da superfície ou parede do tubo na seção de teste e da solução anti-congelante podem ser visualizados na Fig. 3.1. Para a determinação da temperatura do fluido foram utilizados termopares blindados, produzidos pela IOPE. No caso das medidas da temperatura da parede do tubo e da solução anti-congelante foram utilizados os termopares, fabricados pela OMEGA-EUA, de bitola AWG-30. As Figuras 3.9 (a) e (b) ilustram como foram introduzidos os termopares blindados para medida da temperatura do fluido refrigerante e do termopar para determinação da temperatura da solução anti-congelante, este último utilizando um tubo capilar de cobre com $1,5 \mathrm{~mm}$ de diâmetro. A fixação deste capilar permitiu introduzir o termopar no seu interior, possibilitando, assim a medida da temperatura da solução de etileno glicol/água.

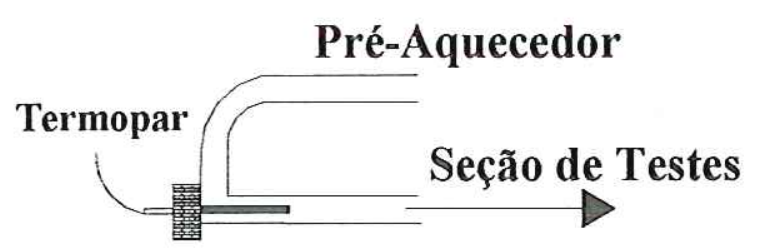

(a)

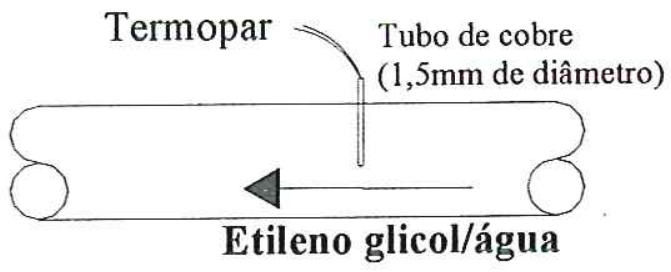

(b)

Figura 3.9 Esquema de instalação dos termopares blindados para medida da temperatura do fluido (a) e do termopar para determinação da temperatura da solução anticongelante (b).

Os termopares foram confeccionados conforme LOMBARDI (1983), recomendando a utilização de luvas para o manuseio e que os fios de cobre e constantan sejam retorcidos para conferir uma maior resistência mecânica. Foi utilizado um gerador de arco voltaico, 
produzido por capacitores, para a confecção da junta quente. Para evitar a oxidação, a união destes metais foi realizada em uma atmosfera não oxidante de nitrogênio.

A medida da temperatura é de suma importância na avaliação do coeficiente de transferência de calor. Nesse sentido, foi realizada a calibração dos termopares utilizando um banho termostático, fabricado pela HAAKE-EUA, cobrindo uma faixa de temperaturas entre $-35^{\circ} \mathrm{C}$ e $200^{\circ} \mathrm{C}$. Utilizou-se uma solução álcool/água e, imersos nesta solução, foram introduzidos cinco termopares com as extremidades conectadas ao sistema de aquisição. Para verificar a temperatura do banho termostático foram utilizados termômetros de precisão de bulbo, fabricados pela OMEGA-USA com rastreabilidade do NIST. O primeiro deles cobria uma faixa de temperatura de $-35^{\circ} \mathrm{C}$ a $25^{\circ} \mathrm{C}$, com escala de $0,1^{\circ} \mathrm{C}$. Já o segundo cobria uma faixa de temperatura de $20^{\circ} \mathrm{C}$ a $60^{\circ} \mathrm{C}$, com escala de $0,1^{\circ} \mathrm{C}$. $\mathrm{O}$ procedimento para a leitura das temperaturas consistia em fixar uma determinada temperatura no banho termostático e, assim que se atingia o regime permanente, ou seja, a temperatura permanecia estável, iniciava a aquisição dos pontos. Tal procedimento foi repetido para a faixa de temperaturas que foi previamente estipulada, $-10^{\circ} \mathrm{C}$ a $50^{\circ} \mathrm{C}$. Este processo de calibração dos termopares permitiu estabelecer a previsão na medida de temperatura, que no caso foi de $0,2^{\circ} \mathrm{C}$. Durante o período de desenvolvimento do presente trabalho houve a necessidade de refazer este processo de calibração diversas vezes. Isso permitiu confirmar que a precisão na medida da temperatura era de $0,2^{\circ} \mathrm{C}$. O Apêndice I ilustra o procedimento de calibração dos termopares.

\section{$\oplus^{\circ}$ Sistema de Aquisição de Dados}

O sistema de aquisição de dados utilizado no presente trabalho tem por finalidade receber os sinais elétricos emitidos pelos distintos transdutores, tratá-los e proceder à digitalização dos mesmos de forma que possam ser armazenados para futuro tratamento. $\mathrm{O}$ sistema é composto por um microcomputador Pentium $133 \mathrm{Mhz}$ com $32 \mathrm{Mb}$ de memória RAM e $120 \mathrm{Mb}$ de disco rígido, por terminais de conexões, placas conversoras analógicodigital e um "software" de controle .

Foram adquiridas duas placas conversoras analógico-digital, modelo DynaRes-16, onde cada uma permite a conexão de dois terminais, sendo três para medida de temperatura, modelo T71-TC, e um para medida de parâmetros elétricos, modelo T71-TG. Cada terminal é composto de 8 canais, totalizando 24 canais de temperatura e 8 canais para os parâmetros elétricos, como pressão, vazão e potência elétrica. O programa utilizado para aquisição, bem como as placas e terminais foram adquiridos da empresa STRAWBERRY TREE-EUA. 
Os terminais de temperatura apresentam uma placa isotérmica incorporada, que possui um circuito eletrônico que serve de referência para os termopares, substituindo, assim, o banho de gelo que é normalmente utilizado para esta finalidade. Para compensar as oscilações da temperatura ambiente, o sistema de aquisição possui uma função que é responsável pela calibração desta placa, evitando alterações na medida da temperatura.

O software do sistema de aquisição, denominado de WorkBench, é constituído de diversos ícones que combinados permitem a leitura de saída desejada. $\mathrm{O}$ software possibilita, ainda, a manipulação dos dados, a execução de gráficos e unidades para uma melhor visualização dos dados.

Um exemplo de uma tela de aquisição utilizada na campanha de ensaios é apresentada pela Fig. 3.10. 


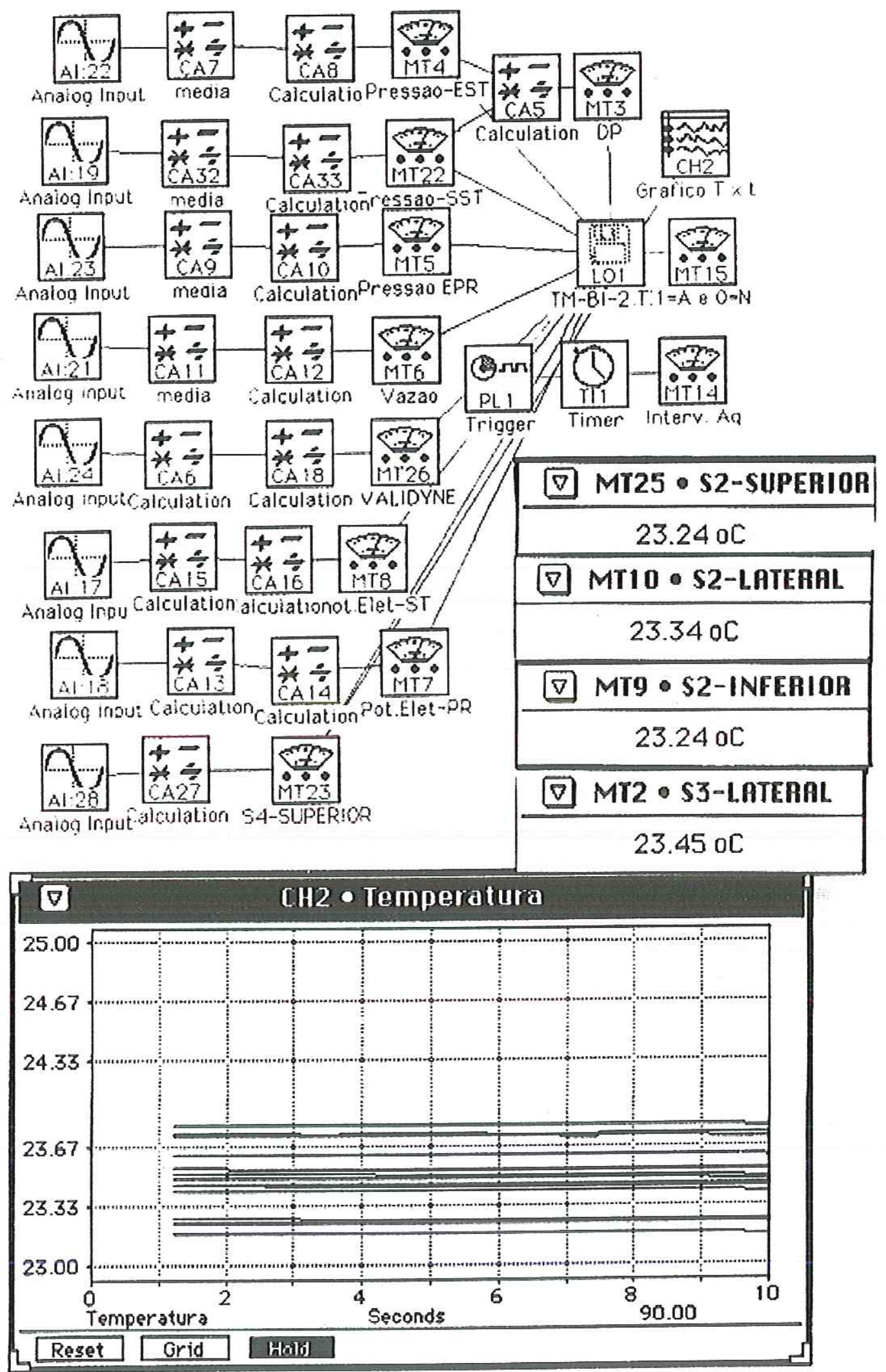

Figura 3.10. Exemplo da tela de aquisição que foi utilizada no presente trabalho. 


\subsection{Metodologia de Ensaios}

Nesta seção serão apresentados alguns procedimentos que foram utilizados nos levantamentos experimentais, tais como: a matriz de ensaios; a preparação do equipamento para os ensaios; a operação propriamente dita; verificação da qualidade dos resultados; técnicas utilizadas para o tratamento dos resultados experimentais e análise de incertezas.

\subsubsection{Preparação e Operação do Equipamento Experimental}

Após a montagem da bancada experimental, tendo sido verificada a estanqueidade, era realizada a limpeza interna do circuito. Inicialmente, era introduzido o fluido refrigerante CFC-11, que apresenta características de solvente, com o objetivo de dissolver ou mesmo carregar algumas impurezas que por ventura estivessem no sistema. Posteriormente, eram realizadas duas evacuações com interregno de duas horas e, então, introduzido, novamente, o R-11 para circulação, porém com o desvio do filtro secador aberto, de forma a obrigar o fluido refrigerante a passar pelo mesmo. A cada meia hora a rotação da bomba era incrementada, até que se atingisse $100 \%$ da rotação estipulada. Assim, eventuais particulados sólidos seriam arrastados até o filtro secador, evitando danos à bomba de circulação. Após a operação de filtragem era realizado um novo vácuo $(5 \mathrm{kPa}) \mathrm{e}$, se a pressão se mantivesse, era introduzido nitrogênio sob pressão. Realizadas todas as etapas, o circuito era carregado com o fluido refrigerante, preferencialmente pela fase vapor, eliminando qualquer possibilidade de introduzir impurezas no equipamento. Procedia-se, então, a verificação da instrumentação, bem como do sistema de aquisição.

Realizadas todas as verificações, o variador de freqüência era programado e, automaticamente, a bomba de circulação do refrigerante era acionada. Com o fluido refrigerante circulando no circuito principal, a bomba de circulação da solução etileno glicol/água era acionada simultaneamente com o resfriador de líquido, "chiller" e a torre de resfriamento. $\mathrm{O}$ passo seguinte consistia em ligar as resistências elétricas do pré-aquecedor e da seção de testes, controlando a potência através dos variadores de tensão. Essa potência era incrementada à medida que a temperatura da schlução da mistıra anti-congelante diminuía, evitando, assim, que todo o fluido refrigerante permanecesse no condensador. Finalmente, com a temperatura da solução constante, a vazão era ajustada para o valor desejado na matriz de experimentos.

Os ensaios com escoamento monofásico de líquido exigiram um procedimento distinto. A válvula de comunicação entre o circuito principal e o depósito de refrigerante 
permanecia aberta durante os ensaios. Isso era necessário para evitar pressões excessivas no circuito resultantes do aquecimento na seção de testes ou mesmo através do isolamento térmico em regiões não aquecidas. Nesses ensaios, o fluido refrigerante era circulado com a máxima vazão estipulada na matriz de experimentos. Uma vez que a temperatura da mistura anti-congelante permanecia constante, as resistências elétricas eram acionadas e, então, ajustados os seguintes parâmetros: vazão, potência elétrica na seção de testes e no préaquecedor, este último responsável pela estabilização da temperatura na entrada da seção de testes, fixada sempre em torno de $-2,5^{\circ} \mathrm{C}$.

\subsubsection{Verificação dos Resultados}

No início de cada ensaio, ou seja, para cada mudança de tubo ou troca do fluido refrigerante, era necessário analisar os resultados experimentais obtidos, com o objetivo de verificar sua consistência. Nesse sentido, a primeira bateria de ensaios com escoamento monofásico era utilizada para verificação das medidas através do cálculo do coeficiente de transferência de calor, comparando-o com correlações amplamente aceitas da literatura, como a de DITTUS \& BOELTER (1930), PETHUKOV (1970) ou GNIELINSKI (1976). A correlação de SIEDER \& TATE (1936) apud INCROPERA e De WITT (1994) foi utilizada, principalmente, quando ocorriam diferenças significativas entre as temperaturas da superficie e a média do fluido, cujo efeito nas propriedades, especialmente a viscosidade, poderia ser importante.

Antes de avaliar o coeficiente de transferência de calor, era necessário verificar as perdas de calor para o ambiente. A Fig. 3.11 apresenta os resultados experimentais obtidos em um dos ensaios realizados, relacionando a potência elétrica aplicada na seção de testes, $\mathrm{Q}_{\mathrm{ST}}$, com aquela resultante do balanço de energia, $\mathrm{Q}_{\mathrm{BE}}$. A Eq. 3.1 ilustra o procedimento para avaliação do $\mathrm{Q}_{\mathrm{BE}}$.

$$
Q_{B E}=\dot{m}\left(i_{S S T}-i_{E S T}\right)
$$




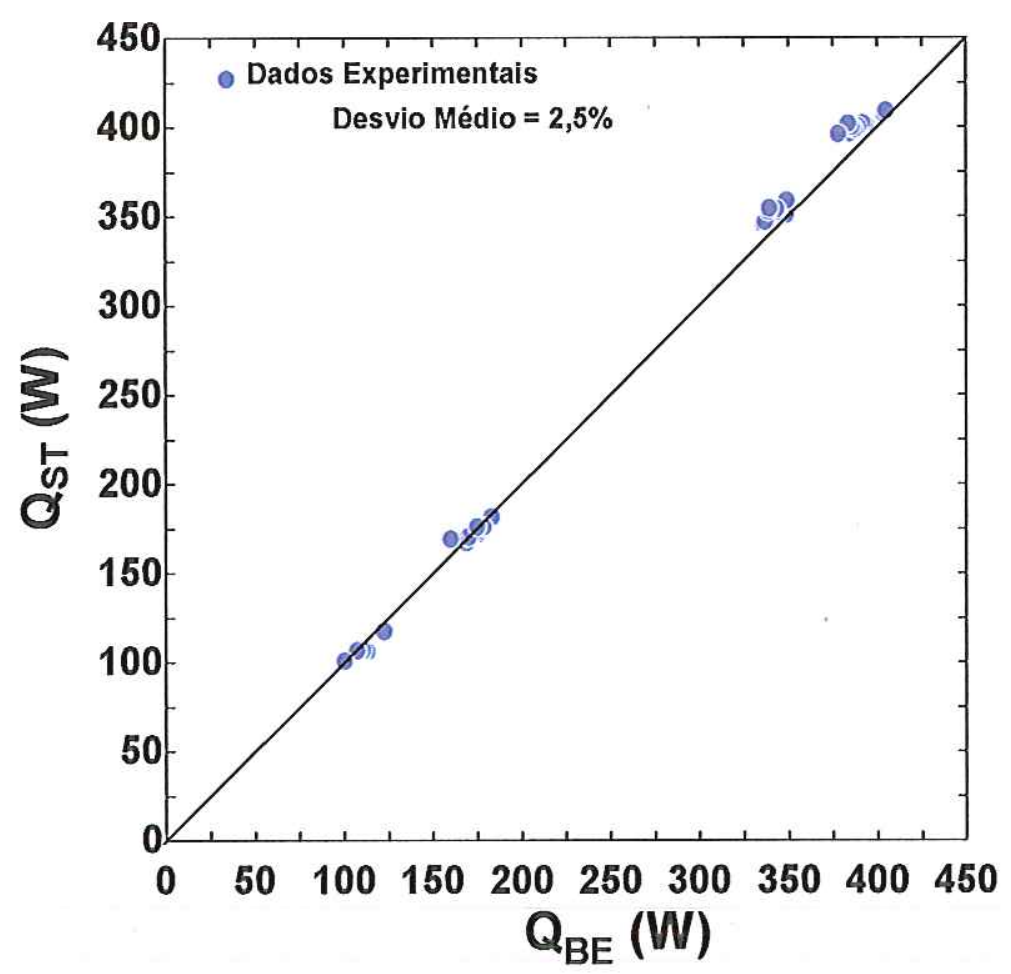

Figura 3.11 Resultados experimentais relacionando a potência elétrica, $\mathrm{Q}_{\mathrm{sT}}$, aplicada na seção de testes com a potência avaliada pelo balanço de energia, $\mathrm{Q}_{\mathrm{BE}}$, tubo liso com 9,52mm de diâmetro externo

Como se observa na Fig. 3.11, o desvio médio da potência elétrica aplicada na seção de testes em relação àquela obtida do balanço de energia, para este tubo, foi de $2,5 \%$ para potências variando entre 100 e $400 \mathrm{~W}$. Vale ressaltar que, caso fossem constatadas perdas significativas para o ambiente, adicionava-se isolante térmico com o objetivo de minimizar tais perdas.

A Fig. 3.12 tem por finalidade ilustrar a boa concordância entre o coeficiente de transferência de calor avaliado experimentalmente e aquele calculado pela correlação de Gnielinski, Eq. 4.1, para o tubo de cobre de 7,0mm de diâmetro externo. Esses resultados revelam que as medidas, principalmente de temperatura, se mostraram bastante confiáveis.

É interessante observar que o desvio médio proporcionado pelos resultados experimentais em relação aqueles obtidos pela correlação de Gnielinski foi de 4,0\%. Vale ressaltar que os resultados foram levantados para uma faixa de velocidade mássica variando entre 200 e $2150 \mathrm{~kg} / \mathrm{s} \cdot \mathrm{m}^{2}$. WATTELET (1994) realizou o mesmo procedimento adotado no presente trabalho e alcançou desvios da ordem de $4,2 \%$ relativamente à correlação de Gnielinski, porém operando numa faixa mais modesta de vazões. 


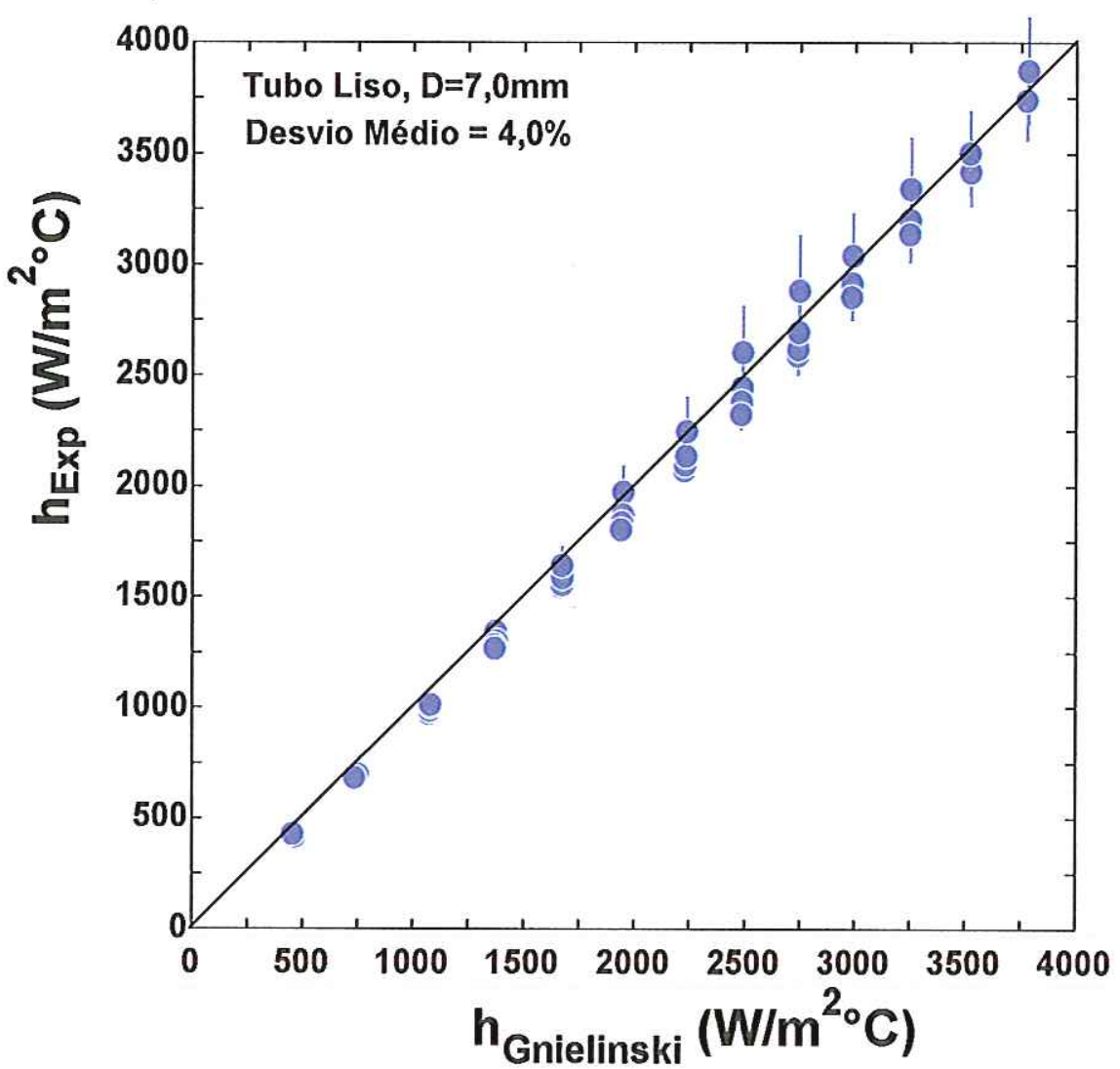

Figura 3.12 Comparação entre o coeficiente de transferência de calor avaliado experimentalmente e aquele calculado pela correlação de Gnielinski. Tubo de cobre de 7,0mm de diâmetro externo.

\subsection{Tratamento dos Resultados Experimentais}

Os resultados experimentais, levantados nas diversas campanhas de ensaios, foram tratados de acordo com o que será exposto a seguir. Inicialmente, será apresentado o procedimento para a avaliação do título na entrada e saída da seção de testes e, posteriormente, o método para determinação do coefíciente de transferência de calor.

\subsubsection{Avaliação do Título na Entrada e Saída da Seção de Testes}

O diagrama esquemático ilustrado na Fig. 3.13 mostra como o título na saída do préaquecedor é determinado. $\mathrm{Na}$ entrada do pré-aquecedor, o fluido refrigerante encontra-se no estado de líquido sub-resfriado, estado que é garantido pela troca de calor no denominado "sub-resfriador". A pressão, P, e a temperatura do fluido, T, são conhecidas, além da vazão, $\dot{m}$. Assim, um fluxo de calor pré-estabelecido é imposto no pré-aquecedor para que o fluido refrigerante, que entra sub-resfriado, deixe o pré-aquecedor com um dado título, obtido por 
um balanço de energia. Como na seção de estabilização as trocas de calor com o ambiente são praticamente nulas, considera-se que o título de saída do pré-aquecedor é o mesmo da entrada da seção de testes.

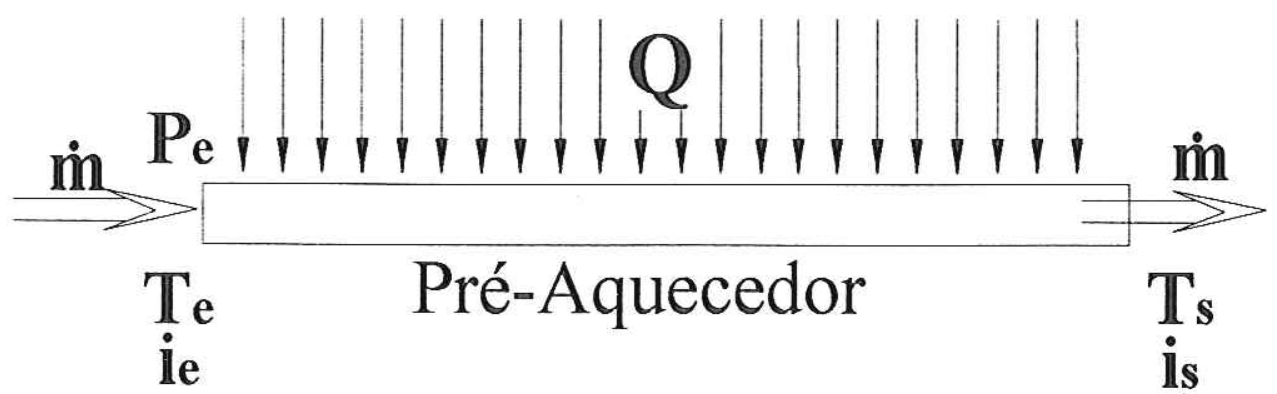

Figura 3.13 Diagrama esquemático ilustrando como o título na saída do pré-aquecedor é determinado através do balanço de energia

Como mencionado anteriormente, conhecido o estado do fluido refrigerante na entrada do pré-aquecedor, uma vez que a temperatura e pressão são medidas, as propriedades de transporte podem ser facilmente determinadas. Garantindo que na saída do pré-aquecedor o estado do refrigerante seja saturado de equilibrio, é possível obter, por meio de tabelas ou um programa de computador, as propriedades nas condições que forem especificadas. Nessas condições, determina-se o título de saída do pré-aquecedor através da seguinte equação:

$$
Q_{P R}=\dot{m}\left[i_{S P A}-i_{E P A}\right]
$$

onde,

$$
i_{S P A}=i_{L}\left(T_{S P A}\right)+x_{S P A} \cdot i_{L V}\left(T_{S P A}\right)
$$

onde, $Q_{\mathrm{PR}}$ é a potência elétrica aplicada no pré-aquecedor; $\dot{m}$ é a vazão mássica de refrigerante; $i_{S P A}$ a entalpia do refrigerante na saída do pré aquecedor; $i_{E P A}$ a entalpia do refrigerante na entrada do pré aquecedor; $\mathrm{x}_{\mathrm{SPA}}$ é o título na saída do pré-aquecedor, $\mathrm{i}_{\mathrm{L}}$ é a entalpia do líquido saturado avaliada à temperatura de saída do pré-aquecedor e $\mathrm{i}_{\mathrm{LV}}$ é o calor latente de vaporização à temperatura de saída do pré-aquecedor.

Do mesmo modo, o título de saída da seção de testes é determinado através de um balanço de energia, onde o volume de controle é a seção de testes. Neste caso, conhecendo o título na entrada da seção de testes (procedimento anterior), as temperaturas do fluido refrigerante na entrada e saída e o fluxo de calor específico, o título na saída da seção de testes é determinado pela seguinte relação: 


$$
Q_{S T}=\dot{m}\left[i_{L V} \cdot\left(x_{S S T}-x_{E S T}\right)\right]
$$

onde, $\mathrm{Q}_{\mathrm{ST}}$ é a potência elétrica aplicada na seção de testes; $\dot{m}$ é a vazão mássica de refrigerante; $i_{\mathrm{LV}}$ é o calor latente de vaporização; $\mathrm{x}_{\mathrm{EST}}$ é o título na entrada e $\mathrm{x}_{\mathrm{SST}}$ é o título na saída da seção de testes.

\subsubsection{Determinação do Coeficiente de Transferência de Calor}

O coeficiente de transferência de calor foi determinado utilizando a Lei de Resfriamento de Newton, segundo a qual:

$$
h=\frac{Q / A}{\Delta T}
$$

onde, o numerador corresponde ao fluxo de calor específico, Q/A, (potência elétrica sobre a área de aquecimento) e o denominador à diferença entre as temperaturas da superficie ou parede do tubo, $T_{P}$, e de saturação ou evaporação do refrigerante, $T_{\text {sat. }}$.

As temperaturas da parede, como mencionado anteriormente, foram medidas em três posições eqüidistantes $90^{\circ}$ na seção transversal e em quatro seções ao longo do tubo. Nesse sentido, foi possível avaliar o coeficiente de transferência de calor em 12 posições ao longo da seção de testes. Em cada seção transversal o coeficiente foi estimado nas seguintes disposições: Superior, Lateral e Inferior do tubo. Assim, foi possível acompanhar as variações de temperatura ao longo de cada seção e, o mais interessante, verificar as diferenças das temperaturas nas posições: superior, lateral e inferior de acordo com cada padrão de escoamento. Mais adiante será possível verificar as variações da temperatura da superfície em cada seção, para cada padrão de escoamento.

Resumidamente, o coeficiente de transferência de calor experimental apresentado na maioria das figuras deste trabalho foi determinado através da seguinte equação:

$$
h_{E X P}=\frac{h_{S 1}+h_{S 2} \div h_{S 3}+h_{S 4}}{4}
$$


$\mathrm{e}, \quad h_{M S}=\frac{\phi}{\left[\left(\frac{T_{P S}+T_{P L}+T_{P I}}{3}\right)-T_{R}\right]}$

onde, $h_{\mathbb{N S}}$ é o coeficiente de transferência de calor médio na seção; $\phi$ é o fluxo de calor específico; $\mathrm{T}_{\mathrm{PS}}$ é a temperatura da parede medida na região superior do tubo; $\mathrm{T}_{\mathrm{PL}}$ é a temperatura na região lateral; $T_{P I}$ na região inferior do tubo e $T_{R}$ é a temperatura do fluido refrigerante.

\subsubsection{Cálculo da Perda de Carga}

A perda de carga experimental foi avaliada por dois caminhos diferentes. $\mathrm{O}$ primeiro consiste na determinação direta através do transdutor diferencial de pressão, lido diretamente na tela. O segundo, servindo como verificação, é obtido pela diferença entre as pressões na entrada da seção de testes e na saída, medidas pelos transdutores de pressão.

\subsection{Matriz de Experimentos}

Desde o início da campanha de ensaios foi necessário construir uma planilha que incorporasse os parâmetros que seriam controlados durante os testes, que foi denominada de Matriz de Experimentos. Para cada condição tornou-se fundamental confeccionar uma matriz de experimentos que envolvia distintas temperaturas de evaporação, fluxos de calor, fluidos refrigerantes e diferentes configurações de tubo. Um exemplo de uma matriz de experimentos utilizada para o tubo de latão de $17,4 \mathrm{~mm}$ de diâmetro interno, utilizando o R134a como fluido de trabalho, temperatura de evaporação de $5^{\circ} \mathrm{C}$ na entrada da seção de testes e fluxo de calor específico de $5 \mathrm{~kW} / \mathrm{m}^{2}$, é ilustrada pela Fig. 3.14. Para o caso do escoamento monofásico de líquido, foi necessário confeccionar uma outra planilha que se adequasse às condições específicas para esse tipo de escoamento. Neste caso, os únicos parâmetros controlados eram: a vazão de refrigerante, a potência elétrica aplicada e temperatura de entrada na seção de testes. A Fig. 3.15 apresenta um exemplo de uma matriz de experimentos válida para o tubo de latão de $17,4 \mathrm{~mm}$ com o R-134a escoando como líquido sub-resfriado.

Deve-se salientar que foram preparadas cerca de 60 matrizes de experimentos distintas ao longo do presente trabalho. 


\begin{tabular}{|c|c|c|c|c|c|c|c|c|c|}
\hline $\mathbf{T}_{\text {Evap }}\left({ }^{\circ} \mathrm{C}\right)$ & P.Aq.(W) & ST (W) & $\phi\left(\mathrm{kW} / \mathrm{m}^{2}\right)$ & m (kg/s) & $\mathbf{G}\left(\mathrm{kg} / \mathrm{m}^{2} . \mathrm{s}\right)$ & $\mathbf{x}_{\mathrm{ENT}}$ & $\mathbf{x}_{\mathrm{SAI}}$ & $\mathbf{x}_{\mathrm{MED}}$ & OK \\
\hline 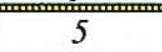 & 1204 & 375 & 5 & 0,048 & 200 & 0,03 & 0,07 & 0,05 & \\
\hline 5 & 1610 & 375 & 5 & 0,048 & 200 & 0,08 & 0,12 & 0,10 & \\
\hline 5 & 2480 & 375 & 5 & 0,048 & 200 & 0,18 & 0,22 & 0,20 & \\
\hline 5 & 3349 & 375 & 5 & 0,048 & 200 & 0,28 & 0,32 & 0,30 & \\
\hline 5 & 4096 & 375 & 5 & 0,048 & 200 & 0,38 & 0,42 & 0,40 & \\
\hline 5 & 5025 & 375 & 5 & 0,048 & 200 & 0,48 & 0,52 & 0,50 & \\
\hline 5 & 5955 & 375 & 5 & 0,048 & 200 & 0,58 & 0,62 & 0,60 & \\
\hline 5 & 6884 & 375 & 5 & 0,048 & 200 & 0,68 & 0,72 & 0,70 & \\
\hline 5 & 7813 & 375 & 5 & 0,048 & 200 & 0,78 & 0,82 & 0,80 & \\
\hline 5 & 8742 & 375 & 5 & 0,048 & 200 & 0,88 & 0,92 & 0,90 & \\
\hline "5 & $\overline{508}$ & 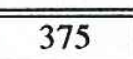 & 5 & 0,024 & 100 & 0,01 & 0,09 & 0,05 & \\
\hline 5 & 711 & 375 & 5 & 0,024 & 100 & 0,06 & 0,14 & 0,10 & \\
\hline 5 & 1146 & 375 & 5 & 0,024 & 100 & 0,16 & 0,24 & 0,20 & \\
\hline 5 & 1581 & 375 & 5 & 0,024 & 100 & 0,26 & 0,34 & 0,30 & \\
\hline 5 & 1954 & 375 & 5 & 0,024 & 100 & 0,36 & 0,44 & 0,40 & \\
\hline 5 & 2419 & 375 & 5 & 0,024 & 100 & 0,46 & 0,54 & 0,50 & \\
\hline 5 & 2884 & 375 & 5 & 0,024 & 100 & 0,56 & 0,64 & 0,60 & \\
\hline 5 & 3348 & 375 & 5 & 0,024 & 100 & 0,66 & 0,74 & 0,70 & \\
\hline 5 & 3813 & 375 & 5 & 0,024 & 100 & 0,76 & 0,84 & 0,80 & \\
\hline 5 & 4277 & 375 & 5 & 0,024 & 100 & 0,86 & 0,94 & 0,90 & \\
\hline $\bar{~} 5$ & 160 & 375 & $\bar{~} 5$ & 0,012 & $\overline{050}$ & $-0,03$ & 0,13 & 0,05 & \\
\hline 5 & 261 & 375 & 5 & 0,012 & 50 & 0,02 & 0,18 & 0,10 & \\
\hline 5 & 479 & 375 & 5 & 0,012 & 50 & 0,12 & 0,28 & 0,20 & \\
\hline 5 & 696 & 375 & 5 & 0,012 & 50 & 0,22 & 0,38 & 0,30 & \\
\hline 5 & 883 & 375 & 5 & 0,012 & 50 & 0,32 & 0,48 & 0,40 & \\
\hline 5 & 1116 & 375 & 5 & 0,012 & 50 & 0,42 & 0,58 & 0,50 & \\
\hline 5 & 1348 & 375 & 5 & 0,012 & 50 & 0,52 & 0,68 & 0,60 & \\
\hline 5 & 1580 & 375 & 5 & 0,012 & 50 & 0,62 & 0,78 & 0,70 & \\
\hline 5 & 1813 & 375 & 5 & 0,012 & 50 & 0,72 & 0,88 & 0,80 & \\
\hline 5 & 2045 & 375 & 5 & 0,012 & 50 & 0,82 & 0,98 & 0,90 & \\
\hline $\bar{~} 5$ & $\bar{~} \overline{50}$ & 375 & $\bar{~} \overline{5}$ & 0,006 & 25 & $-0,01$ & 0,30 & 0,14 & \\
\hline 5 & 85 & 375 & 5 & 0,006 & 25 & 0,01 & 0,28 & 0,15 & \\
\hline 5 & 145 & 375 & 5 & 0,006 & 25 & 0,04 & 0,36 & 0,20 & \\
\hline 5 & 254 & 375 & 5 & 0,006 & 25 & 0,14 & 0,46 & 0,30 & \\
\hline 5 & 348 & 375 & 5 & 0,006 & 25 & 0,24 & 0,56 & 0,40 & \\
\hline 5 & 464 & 375 & 5 & 0,006 & 25 & 0,34 & 0,66 & 0,50 & \\
\hline 5 & 580 & 375 & 5 & 0,006 & 25 & 0,44 & 0,76 & 0,60 & \\
\hline 5 & 696 & 375 & 5 & 0,006 & 25 & 0,54 & 0,86 & 0,70 & \\
\hline 5 & 812 & 375 & 5 & 0,006 & 25 & 0,64 & 0,96 & 0,80 & \\
\hline
\end{tabular}

Figura 3.14 Exemplo de uma Matriz de Experimentos para as seguintes condições: Tubo de Latão, $\mathrm{T}_{\text {Evap }}=5^{\circ} \mathrm{C}, \mathrm{R}-134 \mathrm{a}$ e fluxo de calor específico de $5 \mathrm{~kW} / \mathrm{m}^{2}$. 


\begin{tabular}{|c|c|c|c|c|c|}
\hline Temperatura de Entrada & Vazão / Pot. ST & $\mathbf{1 0 0}$ W & $220 \mathrm{~W}$ & $\mathbf{3 7 5}$ W & $\mathbf{5 0 0}$ W \\
\hline$-2,5^{\circ} \mathrm{C}$ & $0,1 \mathrm{~kg} / \mathrm{s}$ & & & & \\
\hline$-2,5^{\circ} \mathrm{C}$ & $0,09 \mathrm{~kg} / \mathrm{s}$ & & & & \\
\hline$-2,5^{\circ} \mathrm{C}$ & $0,08 \mathrm{~kg} / \mathrm{s}$ & & & & \\
\hline$-2,5^{\circ} \mathrm{C}$ & $0,07 \mathrm{~kg} / \mathrm{s}$ & & & & \\
\hline$-2,5^{\circ} \mathrm{C}$ & $0,06 \mathrm{~kg} / \mathrm{s}$ & & & & \\
\hline$-2,5^{\circ} \mathrm{C}$ & $0,05 \mathrm{~kg} / \mathrm{s}$ & & & & \\
\hline$-2,5^{\circ} \mathrm{C}$ & $0,045 \mathrm{~kg} / \mathrm{s}$ & & & & \\
\hline$-2,5^{\circ} \mathrm{C}$ & $0,04 \mathrm{~kg} / \mathrm{s}$ & & & & \\
\hline$-2,5^{\circ} \mathrm{C}$ & $0,035 \mathrm{~kg} / \mathrm{s}$ & & & & \\
\hline$-2,5^{\circ} \mathrm{C}$ & $0,030 \mathrm{~kg} / \mathrm{s}$ & & & & \\
\hline$-2,5^{\circ} \mathrm{C}$ & $0,025 \mathrm{~kg} / \mathrm{s}$ & & & & \\
\hline$-2,5^{\circ} \mathrm{C}$ & $0,020 \mathrm{~kg} / \mathrm{s}$ & & & & \\
\hline$-2,5^{\circ} \mathrm{C}$ & $0,018 \mathrm{~kg} / \mathrm{s}$ & & & & \\
\hline$-2,5^{\circ} \mathrm{C}$ & $0,016 \mathrm{~kg} / \mathrm{s}$ & & & & \\
\hline$-2,5^{\circ} \mathrm{C}$ & $0,014 \mathrm{~kg} / \mathrm{s}$ & & & & \\
\hline$-2,5^{\circ} \mathrm{C}$ & $0,012 \mathrm{~kg} / \mathrm{s}$ & & & & \\
\hline$-2,5^{\circ} \mathrm{C}$ & $0,010 \mathrm{~kg} / \mathrm{s}$ & & & & \\
\hline$-2,5^{\circ} \mathrm{C}$ & $0,0085 \mathrm{~kg} / \mathrm{s}$ & & & & \\
\hline$-2,5^{\circ} \mathrm{C}$ & $0,0075 \mathrm{~kg} / \mathrm{s}$ & & & & \\
\hline$-2,5^{\circ} \mathrm{C}$ & $0,0065 \mathrm{~kg} / \mathrm{s}$ & & & & \\
\hline$-2,5^{\circ} \mathrm{C}$ & $0,0050 \mathrm{~kg} / \mathrm{s}$ & & & & \\
\hline & & & & & \\
\hline
\end{tabular}

Figura 3.15 Exemplo de uma Matriz de Experimentos para o tubo de latão em escoamento monofásico do refrigerante R-134a.

\subsection{Análise de Incertezas}

A avaliação da incerteza dos parâmetros secundários foi determinada diretamente pelo programa EES (Engineering Equation Solver), que utiliza o método proposto por Kline \& McClintock apud MOFFAT (1988), segundo o qual, se R for um parâmetro secundário função de $\mathrm{N}$ parâmetros primários, isto é,

$$
\mathrm{R}=\mathrm{R}\left(\mathrm{X}_{1}, \mathrm{X}_{2}, \mathrm{X}_{3}, \ldots, \mathrm{X}_{\mathrm{N}}\right)
$$

e

$$
\mathrm{R}=\mathrm{R}_{\mathrm{m}} \pm \delta \mathrm{R}
$$

e, se cada um dos parâmetros $X_{i}$ for escrito como:

$$
\mathrm{X}_{\mathrm{i}}=\mathrm{X}_{\mathrm{mi}} \pm \delta \mathrm{X}_{\mathrm{i}}
$$

onde, $X_{m i}$ é o valor do parâmetro $X_{i}$, e $\delta X_{i}$ é a incerteza de sua medida, a incerteza do parâmetro R é dada por: 


$$
\delta R=\sqrt{\left[\left(S X_{1}\right)\left(\delta X_{1}\right)\right]^{2}+\left[\left(S X_{2}\right)\left(\delta X_{2}\right)\right]^{2}+\ldots+\left[\left(S X_{N}\right)\left(\delta X_{N}\right)\right]^{2}}
$$

onde, $\mathrm{SX}_{\mathrm{i}}$ é a denominada sensibilidade de $\mathrm{R}$ com relação ao parâmetro $\mathrm{X}_{\mathrm{i}}$, dada por:

$$
S X_{i}=\frac{\partial R}{\partial X_{i}}
$$

As incertezas propagadas para a avaliação do coeficiente de transferência de calor, por exemplo, são afetadas pela precisão dos parâmetros medidos. Verificou-se, com base em uma análise dos termos da Eq. (3.9), que a principal componente das incertezas propagadas é a temperatura, sendo o efeito dos demais parâmetros, praticamente, desprezível. É interessante notar que uma melhor precisão na medida da temperatura permitiria a obtenção de uma menor incerteza na avaliação de parâmetros secundários, especialmente o coeficiente de transferência de calor. Entretanto, o uso de termopares limita a precisão medida. Vale ressaltar que o intervalo de confiança adotado para as incertezas nas variáveis independentes foi de $95 \%$ e esse valor será transportado às incertezas dos resultados. A Tabela 3.2 apresenta um sumário das incertezas envolvidas na medida e avaliação dos distintos parâmetros.

\begin{tabular}{|c|c|c|c|}
\hline Parâmetro & Precisão & $\begin{array}{l}\text { Incerteza mínima } \\
\text { observada (valor } \\
\text { absoluto) }\end{array}$ & $\begin{array}{c}\text { Incerteza máxima } \\
\text { observada (valor } \\
\text { absoluto) }\end{array}$ \\
\hline Temperatura & $\pm 0,2^{\circ} \mathrm{C}$ & & \\
\hline Pressão & $\pm 0,3 \%$ & & \\
\hline Vazão & $\pm 0,15 \%$ & & \\
\hline Potência elétrica & $\pm 0,5 \%$ & & \\
\hline $\begin{array}{c}\text { Transdutor Diferencial de } \\
\text { Pressão }\end{array}$ & $\pm 0,25 \%$ & & \\
\hline $\begin{array}{l}\text { Coeficiente de transferência de } \\
\text { calor, } h\left(\mathrm{~W} / \mathrm{m}^{2 \circ} \mathrm{C}\right)\end{array}$ & & 29,4 & 1947 \\
\hline Título na entrada & & 0,00147 & 0,00664 \\
\hline Título na saída & & 0,00162 & 0,00805 \\
\hline
\end{tabular}

Tabela 3.2 Precisão e incertezas dos distintos parâmetros envolvidos nos ensaios. 


\begin{tabular}{|c|c|c|}
\hline$\Delta P-R-22(k P a)$ & 2,70 & 3,38 \\
\hline$\Delta \mathrm{P}-\mathrm{R}-134 \mathrm{a}(\mathrm{kPa})$ & 1,60 & 2,10 \\
\hline$\Delta \mathrm{P}-\mathrm{R}-404 \mathrm{~A}(\mathrm{kPa})$ & 3,21 & 4,09 \\
\hline$\Delta \mathrm{P}-\mathrm{R}-407 \mathrm{C}(\mathrm{kPa})$ & 2,95 & 3,96 \\
\hline
\end{tabular}




\section{CAPÍTULO 4 - ANÁLISE DE RESULTADOS}

\subsection{Introdução}

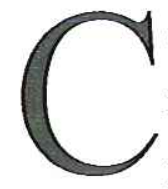

om a finalidade de analisar os mecanismos físicos inerentes à ebulição convectiva no interior de tubos, foram realizados ensaios visando a transferência de calor e perda de carga. A campanha de ensaios durante o programa de doutoramento permitiu levantar, aproximadamente, 4500 pontos experimentais para escoamento monofásico e em ebulição convectiva, envolvendo uma ampla faixa de condições operacionais. Tubos de distintos diâmetros e diversos fluidos refrigerantes foram utilizados para o desenvolvimento do presente trabalho e suas características serão apresentadas mais adiante. Esse extenso banco de dados é suficientemente elevado para fazer de sua análise um verdadeiro quebra-cabeça. Assim, no sentido de organizar os resultados e facilitar comparações e sua interpretação quanto ao mecanismo físico envolvido, a análise será organizada, inicialmente, abordando o escoamento monofásico de líquido e, posteriormente, o escoamento com mudança de fase (líquido-vapor). Em ambas análises serão discutidas a transferência de calor e a perda de carga, bem como os principais parâmetros físicos que intervêm no fenômeno. Além disso, serão apresentados resultados experimentais envolvendo tubos dotados de ranhuras interiores, denominados de "tubos microaletados". Foi incluída, também, uma análise da secagem de parede ou "Dryout" (termo comumente encontrado na literatura em inglês), apresentando a variação da temperatura superficial em função do tempo, bem como a variação do coeficiente de transferência de calor nessa região. Uma discussão sobre os padrões de escoamento em ebulição convectiva foi incorporada neste capítulo, apresentando, ainda, os resultados experimentais inseridos num mapa de escoamento sugerido por KATTAN et al (1998). 


\subsection{Condições de Ensaio}

Para a campanha de levantamento de dados foram utilizados tubos com distintos diâmetros, lisos e com intensificação (ranhuras internas), diversos fluidos refrigerantes e uma ampla gama de condições operacionais. Os tubos de cobre dotados de microaletas na superfície interior, tubos microaletados, começaram a ser desenvolvidos no final da década de 70 pela Hitachi Cable Ltd., com o objetivo de melhorar as características de transferência de calor em evaporadores e condensadores de circuitos frigoríficos. $\mathrm{O}$ corte de um desses tubos é apresentado para efeito de ilustração na Fig. 4.1, que apresenta, ainda, uma representação esquemática e duas microfotografias. Na atualidade, uma série relativamente ampla de configurações alternativas vem sendo desenvolvida pelos fabricantes, tendo por objetivo aplicações específicas, como observado na Tab. 2.14 (capítulo 2).
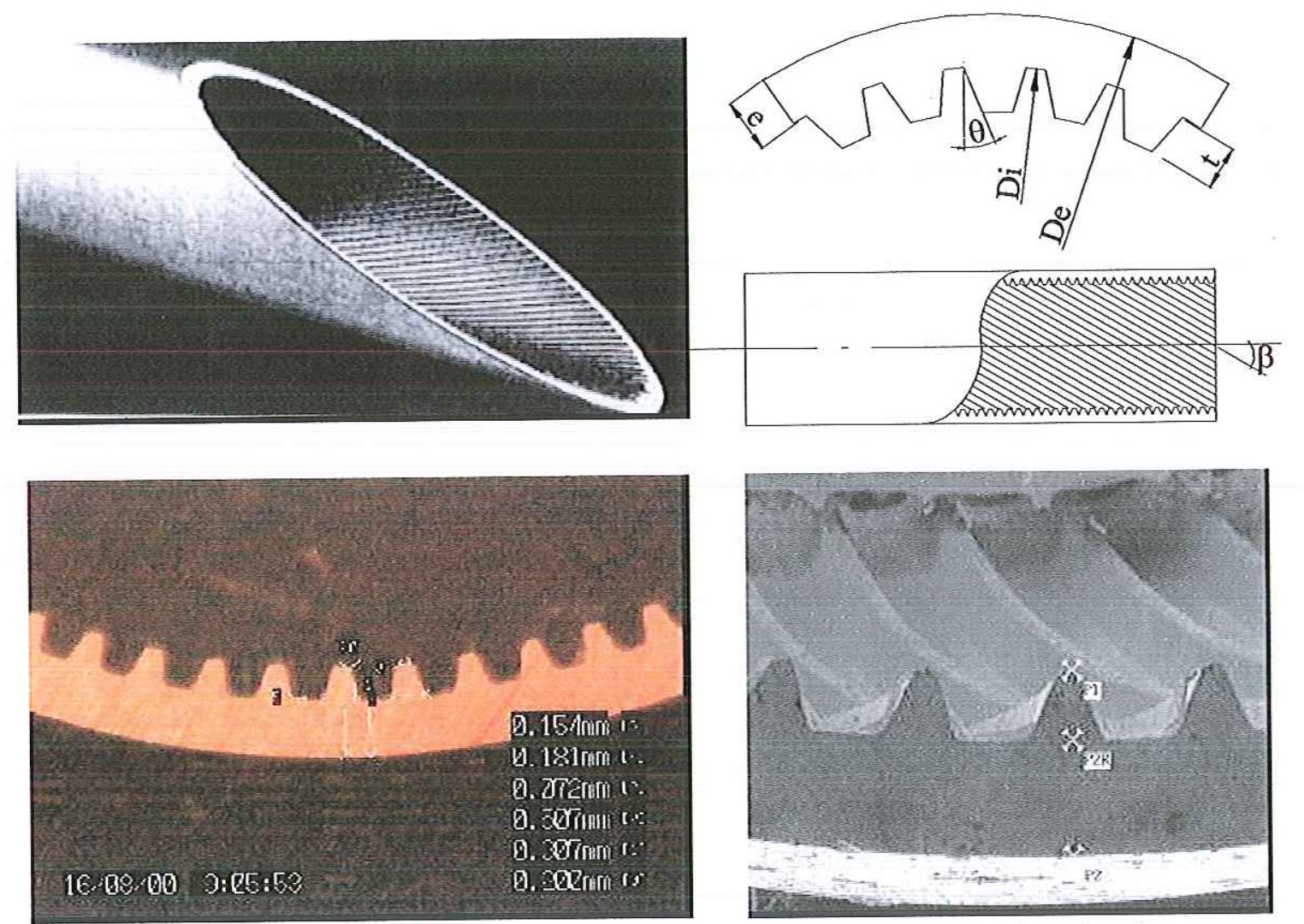

Figura 4.1. Corte, representação esquemática e microfotografias - tubo microaletado.

No final da década de 90 uma nova configuração de tubo microaletado foi lançada, denominada na literatura em inglês de "Herringbone" e, neste trabalho, de Duplo-V. A Fig. 4.2 apresenta uma microfotografia e uma representação esquemática do tubo Duplo-V. 

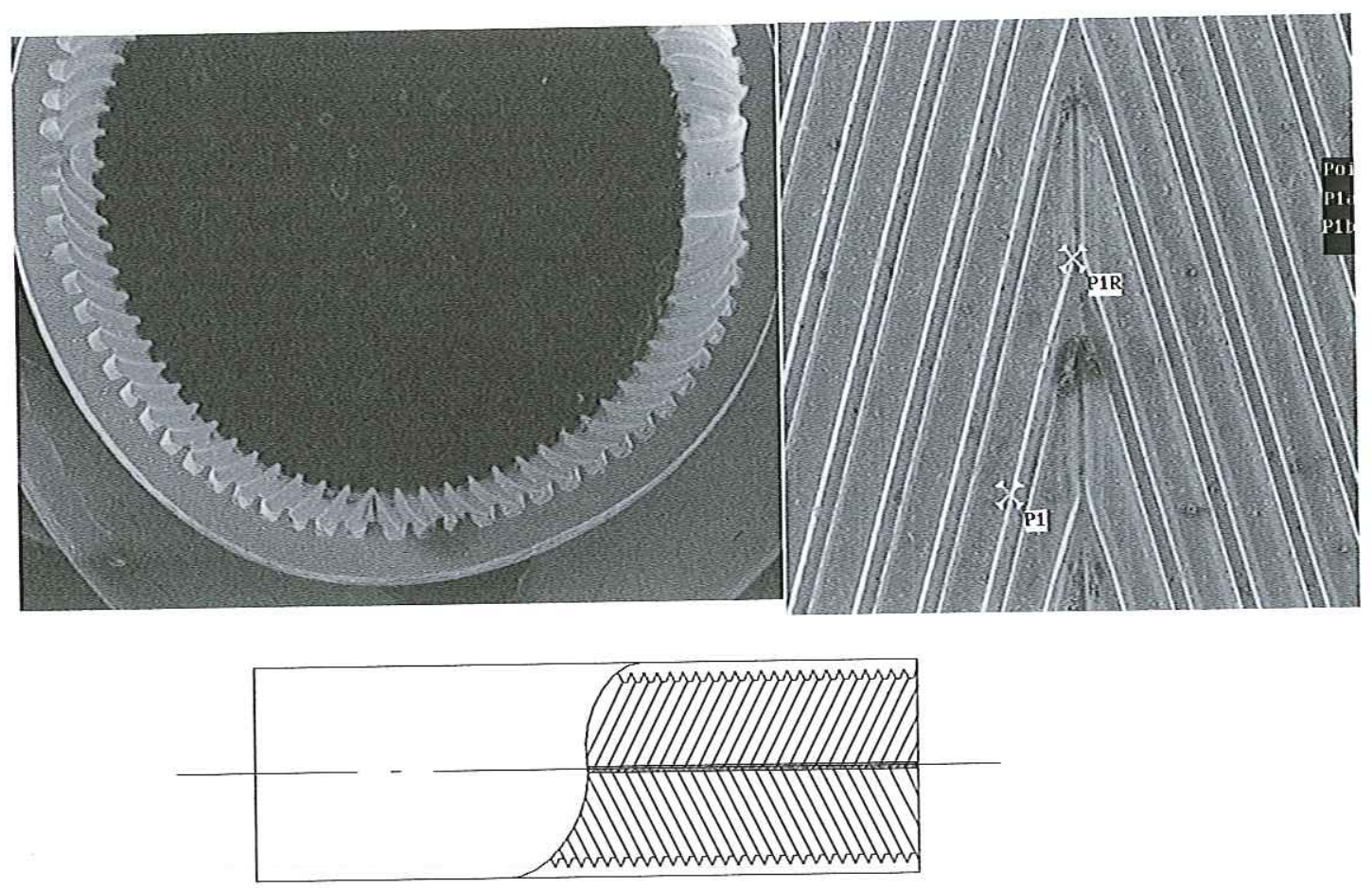

Figura 4.2 Microfotografias e uma representação esquemática do tubo Duplo-V.

A Tabela 4.1 apresenta as características geométricas dos tubos utilizados no presente trabalho.

Tabela 4.1 Características geométricas dos tubos utilizados no presente trabalho.

\begin{tabular}{|c|c|c|c|c|c|c|c|}
\hline Tubo - Fabricante & $\begin{array}{c}\mathrm{D}_{\mathrm{e}} \\
{[\mathrm{mm}]}\end{array}$ & $\begin{array}{c}\mathbf{D}_{\mathbf{i}} \\
{[\mathrm{mm}]}\end{array}$ & $\begin{array}{c}\mathbf{e} \\
{[\mathrm{mm}]}\end{array}$ & $\begin{array}{c}\mathbf{t} \\
{[\mathrm{mm}]}\end{array}$ & $\mathbf{n}$ & $\beta$ & $\theta$ \\
\hline Liso - Termomecânica (TM) & 7,0 & 6,24 & 0,38 & --- & --- & --- & --- \\
\hline Liso - Termomecânica (TM) & 7,93 & 7,17 & 0,38 & --- & $-\cdots$ & $-\cdots$ & $\cdots$ \\
\hline Liso - Termomecânica (TM) & 9,52 & 8,76 & 0,38 & --- & $-\cdots$ & --- & --- \\
\hline Liso - (Comercial) & 15,87 & 12,7 & 1,6 & $-\cdots$ & $-\cdots$ & $-\cdots$ & $-\cdots-$ \\
\hline Liso - Termomecânica (TM) & 23,4 & 17,4 & 3,0 & $\cdots$ & $-\cdots$ & $-\cdots$ & $-\cdots$ \\
\hline Microaletado - Termomecânica (TM) & 7,0 & 6,4 & 0,30 & 0,20 & 60 & $18^{\circ}$ & $33^{\circ}$ \\
\hline Microaletado - Tern & 7,93 & 7,33 & 0,30 & 0,20 & 68 & $18^{\circ}$ & $33^{\circ}$ \\
\hline Microaletado - Hitachi & 7,93 & 7,33 & 0,30 & 0,20 & 62 & $17^{\circ}$ & $44^{\circ}$ \\
\hline Microaletado - Termomecânica (TM) & 9,52 & 8,96 & 0,28 & 0,20 & 82 & $18^{\circ}$ & $33^{\circ}$ \\
\hline Microaletado - Furukawa & 9,52 & 8,92 & 0,30 & 0,15 & 60 & $17^{\circ}$ & $50^{\circ}$ \\
\hline Microaletado - Trefi Metaux & 9,52 & 8,87 & 0,35 & 0,20 & 60 & $18^{\circ}$ & $45^{\circ}$ \\
\hline Microaletado-Termomecânica (TM1) & 9,52 & 8,96 & 0,28 & 0,20 & 76 & $18^{\circ}$ & $33^{\circ}$ \\
\hline Duplo-V - Ter & 9,52 & 8,76 & 0,38 & 0,20 & 72 & $18^{\circ}$ & $28^{\circ}$ \\
\hline
\end{tabular}


A Tab. 4.2 contempla as principais condições de ensaio (variação dos parâmetros físicos) utilizadas no presente trabalho.

Tabela 4.2 Variação dos principais parâmetros físicos utilizados no presente trabalho.

\begin{tabular}{|c|c|}
\hline Parâmetro Físico & Variação \\
\hline Temperatura de Evaporação & $5^{\circ} \mathrm{C} ; 8^{\circ} \mathrm{C}$ e $15^{\circ} \mathrm{C}$ \\
\hline Velocidade Mássica & Entre 25 e $1100 \mathrm{~kg} / \mathrm{s} \cdot \mathrm{m}^{2}$ \\
\hline Fluxo Específico de Calor & Entre 5 e $30 \mathrm{~kW} / \mathrm{m}^{2}$ \\
\hline Título na Entrada da Seção de Testes & Entre 5 e $90 \%$ \\
\hline Título na Saída da Seção de Testes & Entre 8 e $100 \%$ \\
\hline Potência no Pré-Aquecedor & Entre 50 e $7800 \mathrm{~W}$ \\
\hline Grau de Subresfriamento na entrada & Entre 2 e $12^{\circ} \mathrm{C}$ \\
do Pré Aquecedor & \\
\hline
\end{tabular}

Apesar da maioria dos resultados experimentais ter sido levantada para os refrigerantes puros R-22 e R134a, foram, também ensaiadas misturas, como os refrigerantes R-404A, R-407C e R-417A, denominadas de "não azeotrópicas", com o objetivo de compará-las com as substâncias puras. Nesse sentido, se fará, a seguir, um breve comentário sobre misturas, enfatizando as denominadas de não azeotrópicas.

\subsection{Misturas}

As misturas são designadas pelos termos "azeotrópicas" e "não azeotrópicas" ("zeotrópicas"), de acordo com seu comportamento durante a mudança de fase. As misturas azeotrópicas são aquelas compostas de dois ou mais fluidos e se comportam como uma substância pura, ou seja, em mudança de fase não ocorre variação da temperatura de saturação a uma dada pressão. Os exemplos mais comuns são os refrigerantes R-500 (composto por $73,8 \%$ de R-12 e 26,2\% de R-152a) e o R-502 (composto de 51,2\% de R-115 e $48,8 \%$ de R-22). No caso das misturas não azeotrópicas o comportamento durante a mudança de fase é o típico das misturas, verificando-se variações da temperatura para pressão constante, além da mudança de composição das fases líquido e vapor. Esta variação 
da temperatura é denominada de "banda de temperatura" ("temperature glide", termo comumente encontrado na literatura em inglês). Em evaporação, à medida que as misturas não azeotrópicas mudam de fase, a composição do vapor e do líquido se altera. Observando o remanescente da fase líquida, conforme começa a evaporar, ocorre uma porcentagem mais alta de evaporação dos componentes mais voláteis (pressão mais alta). As Figs. 4.3 (a) e (b) ilustram os diagramas de equilíbrio para misturas azeotrópicas (a) e não azeotrópicas (b).

Algumas misturas não azeotrópicas são denominadas de "quase-azeotrópicas". Isto se deve ao fato da banda de temperatura apresentar valores inferiores a $0,7^{\circ} \mathrm{C}$, como é o caso dos refrigerantes R-404A e R-410A. Já o refrigerante R-407C possui uma banda de temperatura na faixa de $3 \mathrm{a} 7^{\circ} \mathrm{C}$, como pode ser observado na Fig. 4.4. Devido à significativa banda de temperatura dessa mistura, deve-se esclarecer que há efeitos de calor sensível, mesmo em mudança de fase.

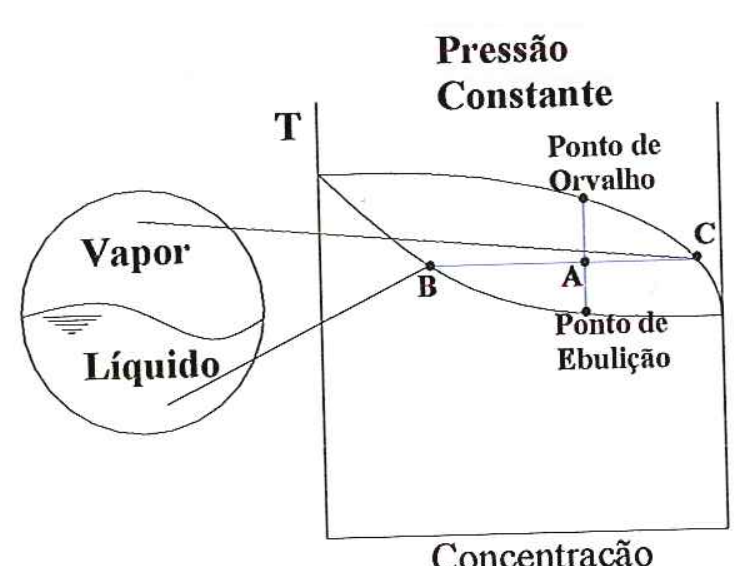

(a)

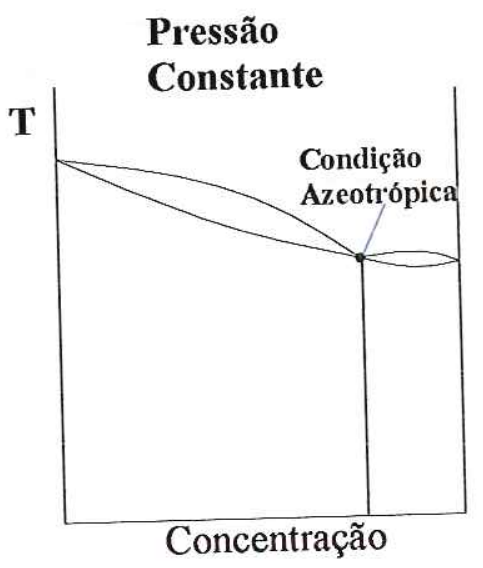

(b)

Figura 4.3 Diagramas de equilíbrio: (a) misturas azeotrópicas e (b) não azeotrópicas. (SAIZ JABARDO (2001) 


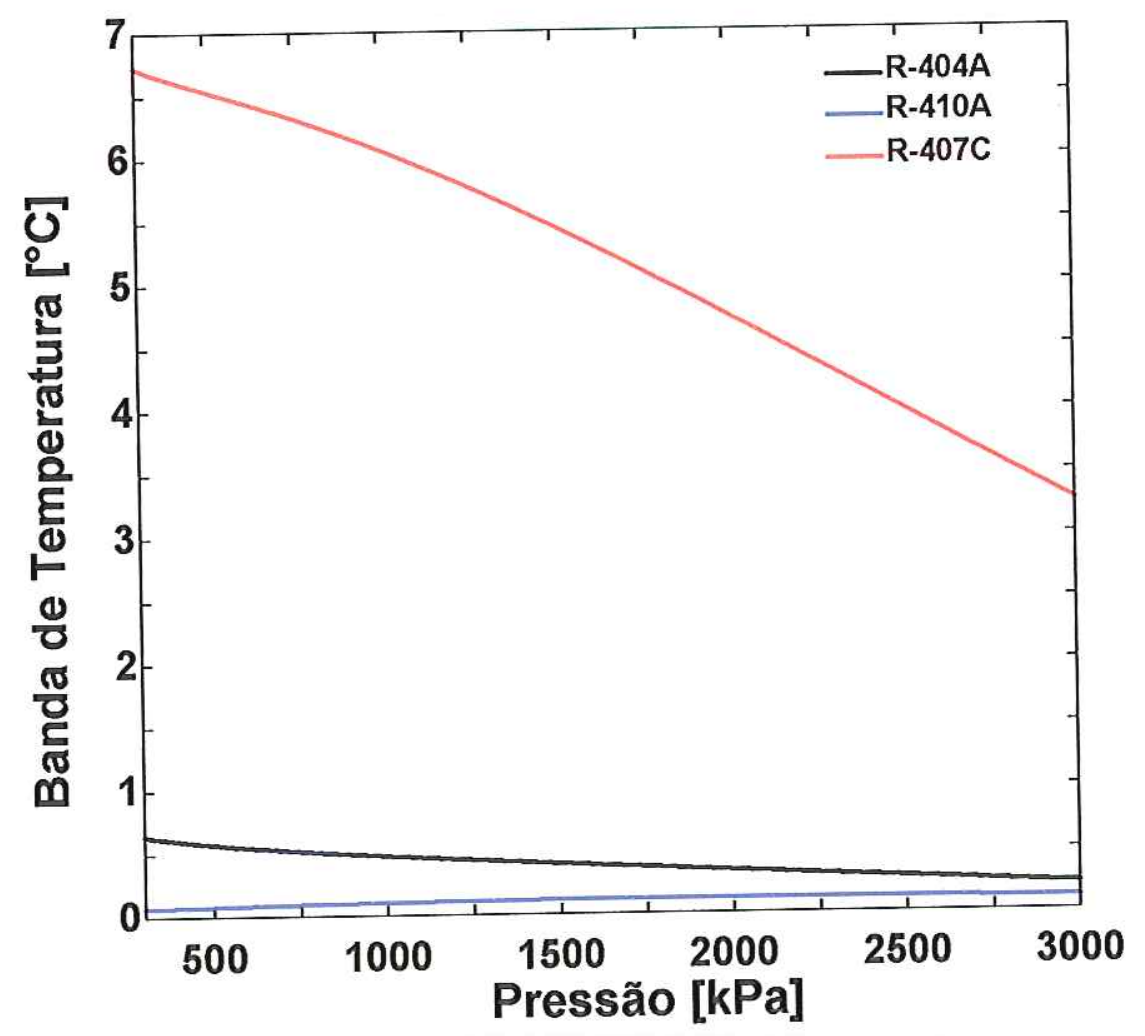

Figura 4.4 Exemplo de banda de temperatura dos fluidos R-404A, R410A e R407C.

A Tab. 4.3 apresenta um sumário dos fluidos refrigerantes ensaiados no presente trabalho, incluindo sua composição (no caso de misturas) e pressão correspondente à temperatura de saturação.

Tabela 4.3 Sumário dos fluidos refrigerantes ensaiados no presente trabalho.

\begin{tabular}{|c|c|c|}
\hline Refrigerante & Composição & Pressão $\left(\mathbf{T}_{\text {sat }}=\mathbf{5}^{\circ} \mathbf{C}\right)$ \\
\hline R-22 & Puro & $584 \mathrm{kPa}$ \\
\hline $\mathrm{R}-134 \mathrm{a}$ & Puro & $350 \mathrm{kPa}$ \\
$\mathrm{R}-404 \mathrm{~A}$ & $4 \% \rightarrow \mathrm{R} 134 \mathrm{a}$ & \\
& $44 \% \rightarrow \mathrm{R} 125$ & $717 \mathrm{kPa}$ \\
& $52 \% \rightarrow \mathrm{R} 143 \mathrm{a}$ & \\
\hline & $52 \% \rightarrow \mathrm{R} 134 \mathrm{a}$ & \\
$\mathrm{R}-407 \mathrm{C}$ & $23 \% \rightarrow \mathrm{R} 32$ & $664 \mathrm{kPa}$ \\
& $25 \% \rightarrow \mathrm{R} 125$ & \\
& $50 \% \rightarrow \mathrm{R} 134 \mathrm{a}$ & \\
& $46,6 \% \rightarrow \mathrm{R} 125$ & $540 \mathrm{kPa}$ \\
$\mathrm{R}-417 \mathrm{~A}$ & $3,4 \% \rightarrow \mathrm{R} 600 \mathrm{a}$ & \\
\hline
\end{tabular}




\subsection{Escoamento Monofásico de Líquido}

\subsubsection{Considerações Preliminares}

Ensaios com escoamento monofásico de refrigerantes na fase líquida eram realizados, preferencialmente, antes dos ensaios com mudança de fase. Com esse procedimento, era possível verificar se as medidas dos termopares superficiais eram consistentes, através de comparações com as principais correlações para a avaliação do coeficiente de transferência de calor no interior de tubos lisos. Antes, porém, de apresentar os resultados, será mostrado o procedimento utilizado para o levantamento dos pontos para escoamento monofásico.

\subsubsection{Procedimento Experimental}

Antes do início dos ensaios, procedia-se uma verificação geral (cabos elétricos conectados, termopares, conexões, etc..) dos equipamentos e instrumentos, o mesmo acontecendo para o sistema de aquisição. Após tais verificações, o variador de freqüência era programado e, então, a bomba de circulação de refrigerante automaticamente entrava em funcionamento. Em seguida, o disjuntor do resfriador de líquido, "chiller", era acionado e, posteriormente, eram ligadas a bomba de circulação de etileno glicol/água e a torre de resfriamento. Após alguns minutos, constatando-se que a temperatura do fluido refrigerante diminuía, as resistências elétricas do pré-aquecedor e da seção de testes eram acionadas, sempre controlando a potência aplicada para que o refrigerante na entrada do pré-aquecedor estivesse, constantemente, no estado de líquido subresfriado. Assim, era possível manter a temperatura na entrada da seção de testes da ordem de $-2,5^{\circ} \mathrm{C}$. Com a vazão ajustada, a temperatura no valor desejado e constatado o regime permanente, o sistema de aquisição era acionado, gravando os parâmetros selecionados no disco rígido. A condição de regime permanente era constatada se, no intervalo entre 10 e 15 minutos, a temperatura na entrada da seção de testes permanecesse inalterada. No início dos ensaios, o tempo para que a temperatura de entrada da seção de testes atingisse o valor desejado era de, aproximadamente, 2 horas.

Normalmente, o ensaio para cada condição era realizado uma única vez, porém houve diversos casos em que, depois de uma análise minuciosa, surgiam algumas dúvidas em relação às medidas. Assim, eram realizados novos ensaios, em que se tentava reproduzir as condições suspeitas, para que as dúvidas levantadas pudessem ser eliminadas. 


\subsubsection{Resultados Experimentais - Escoamento Monofásico}

A campanha de ensaios envolvendo escoamento monofásico de líquido permitiu o levantamento de, aproximadamente, 1000 pontos experimentais, utilizando vários refrigerantes e distintos tubos, inclusive aqueles dotados de microaletas. Inicialmente, serão apresentados resultados para tubos lisos, incluindo comparações com as principais correlações para o coeficiente de transferência de calor no interior de tubos lisos. Posteriormente, apresentar-se-ão os resultados para tubos "ranhurados" ou microaletados, incluindo aqueles do tipo Duplo-V.

A Fig. 4.5 ilustra os resultados obtidos para o tubo liso de 7,0 $\mathrm{mm}$ de diâmetro em comparação com a correlação de Gnielinski, Eq. 4.1, proposta em 1976 e considerada uma das mais precisas para o cálculo do coeficiente de transferência de calor em escoamento monofásico, em regime turbulento, no interior de tubos lisos. É interessante observar que a correlação representa muito bem os resultados experimentais, apresentando um desvio médio absoluto de 2,8\%, para uma faixa de números de Reynolds entre 5000 e 48000 . A referida correlação é representada pela seguinte expressão:

$$
h_{L}=\frac{k_{L}}{D} \cdot\left[\frac{\left(\frac{f}{8}\right) \cdot\left(\operatorname{Re}_{L}-1000\right) \cdot \operatorname{Pr}_{L}}{1,0+12,7 \cdot\left(\frac{f}{8}\right)^{0,5} \cdot\left(\operatorname{Pr}_{L}^{2 / 3}-1\right)}\right]
$$

onde,

$$
f=\left[0,79 \cdot \ln \left(\operatorname{Re}_{L}\right)-1,64\right]^{-2}
$$

A Fig. 4.6 apresenta os resultados experimentais levantados para o tubo liso de 9,52mm de diâmetro em comparação com a correlação de Dittus-Boelter (Eq. 2.15). O desvio médio absoluto verificado foi de $5,5 \%$, sendo que os maiores desvios ocorreram para números de Reynolds, Re, inferiores a 10000, justamente o limite inferior de validade desta correlação. Estes resultados foram obtidos para uma faixa de Re entre 4000 e 52000. 


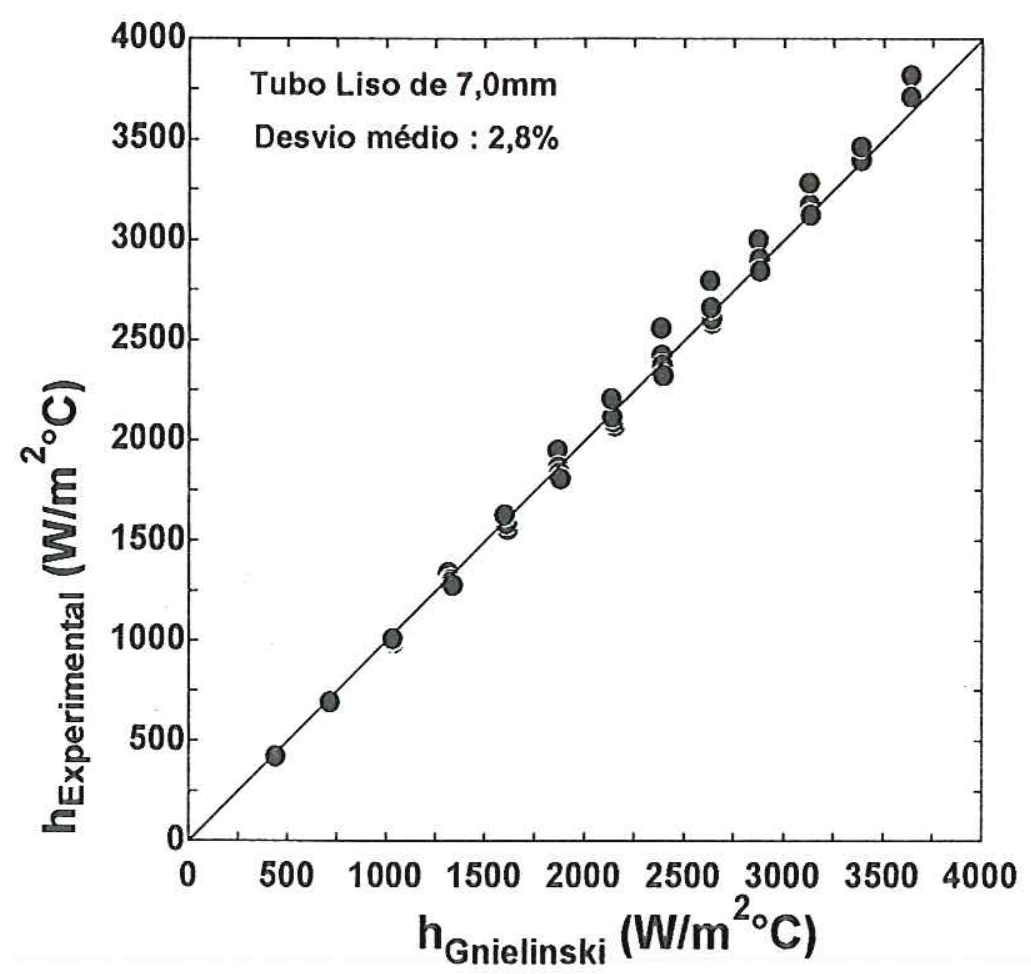

Figura 4.5 Comparação dos resultados experimentais com a correlação de Gnielinski (Eq. 4.1) para tubo liso de 7,0mm de diâmetro.

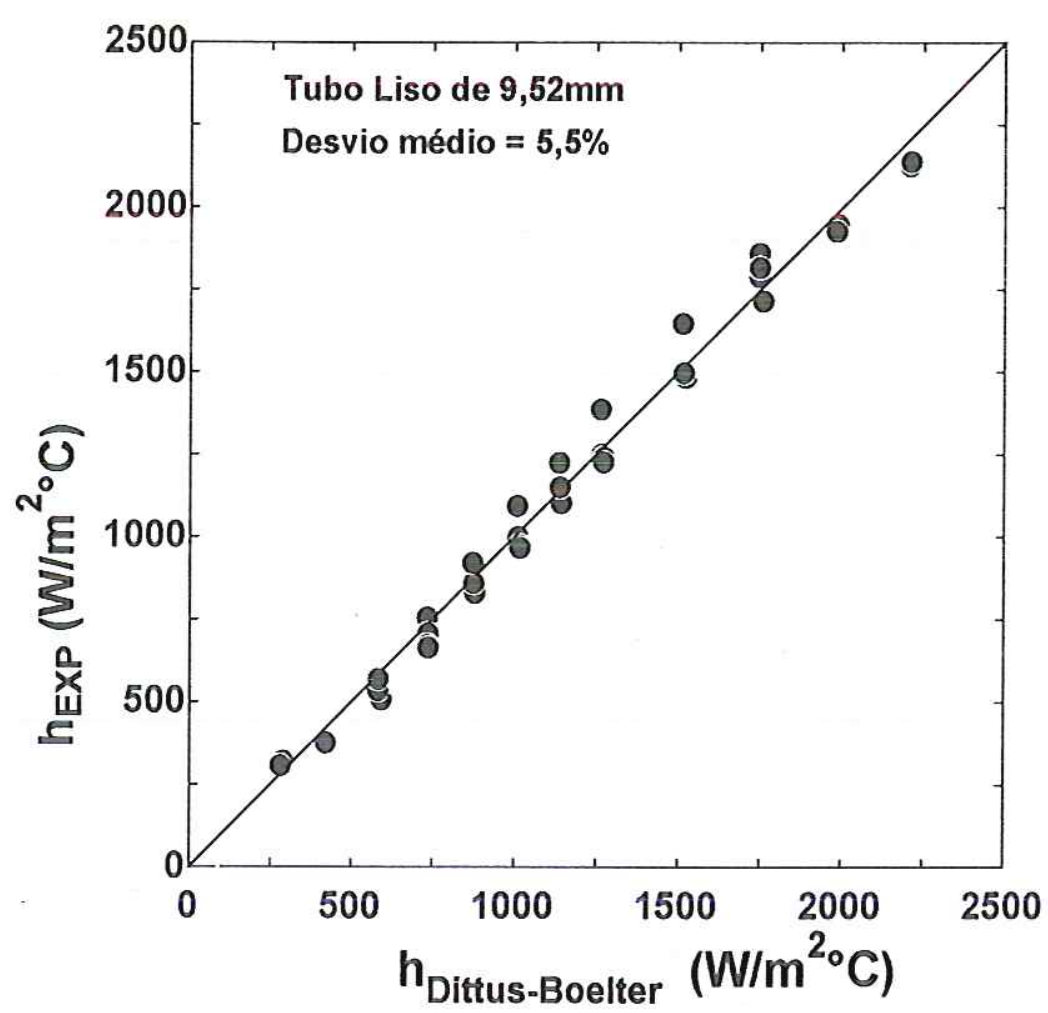

Figura 4.6 Comparação dos resultados experimentais com a correlação de Dittus-Boelter (Eq. 2.15) para tubo liso de 9,52mm de diâmetro. 
A Fig. 4.7 ilustra os resultados experimentais levantados para o tubo de $17,4 \mathrm{~mm}$ de diâmetro interno em termos do grupo adimensional $\mathrm{Nu} / \mathrm{Pr}_{\mathrm{L}}{ }^{0,4}$ em função do $\mathrm{Re}$, superpostos com dados obtidos para tubo liso de $9,52 \mathrm{~mm}$ e a correlação de Dittus-Boelter. Esta figura mostra, ainda, que, para números de Reynolds, Re, superiores a 8000 , os resultados para o tubo de $17,4 \mathrm{~mm}$ concordam com os dados para o tubo de $9,52 \mathrm{~mm}$ e a correlação. Já para Re inferiores a 8000 os resultados divergem daqueles obtidos para outros tubos de menor diâmetro. É importante ressaltar que, no caso de escoamento laminar, o desenvolvimento do perfil de temperatura torna-se importante.

No presente estudo, o perfil de velocidades é desenvolvido, pois, a montante da seção de testes, existe um trecho de tubo reto adiabático, denominado de "seção de estabilização", responsável pelo desenvolvimento do perfil de velocidades. Entretanto, o de temperaturas só começa a se desenvolver quando é iniciado o aquecimento, isto é, na entrada da seção de testes.

O comportamento dos resultados experimentais para Re inferior a 8000 , observado na Fig. 4.7, revela que o perfil de temperatura ainda não está desenvolvido. Isso pode ser justificado através do número de Nusselt que apresenta valores mais elevados na região não desenvolvida termicamente. Um exemplo do comportamento qualitativo do número de Nusselt em função do comprimento de entrada térmico, $\mathrm{X}_{\mathrm{T}}$, sugerido pela Fig. 4.8, demonstra que na região de desenvolvimento do perfil de temperaturas, o coeficiente de transferência de calor experimenta valores superiores aos verificados na região de escoamento termicamente desenvolvida. Observa-se, ainda, na Fig. 4.7, que os resultados para o tubo de $9,52 \mathrm{~mm}$ de diâmetro para $\operatorname{Re}<8000$ não seguem a tendência daqueles obtidos para o tubo de $17,4 \mathrm{~mm}$, como seria de esperar, pois em tubos com menor diâmetro, o perfil de temperatura se desenvolve mais rapidamente.

Este fenômeno foi observado também por BENSLER (1984), em sua dissertação de mestrado, que ensaiou o R-113 no interior de um tubo de aço inoxidável de $8,1 \mathrm{~mm}$ de diâmetro interno na direção vertical. Os dados experimentais foram obtidos para números de Reynolds variando entre 3230 e 49100, região de transição, entre os regimes laminar e turbulento, e o turbulento propriamente dito. Os efeitos de entrada térmicos ocorrem quando o perfil de temperatura na entrada da seção ainda não está completamente desenvolvido e à medida que o número de Reynolds é incrementado, o perfil de temperaturas tende a se desenvolver mais rapidamente. Os resultados obtidos pelo referido autor apresentam a mesma tendência daqueles levantados na presente pesquisa. 


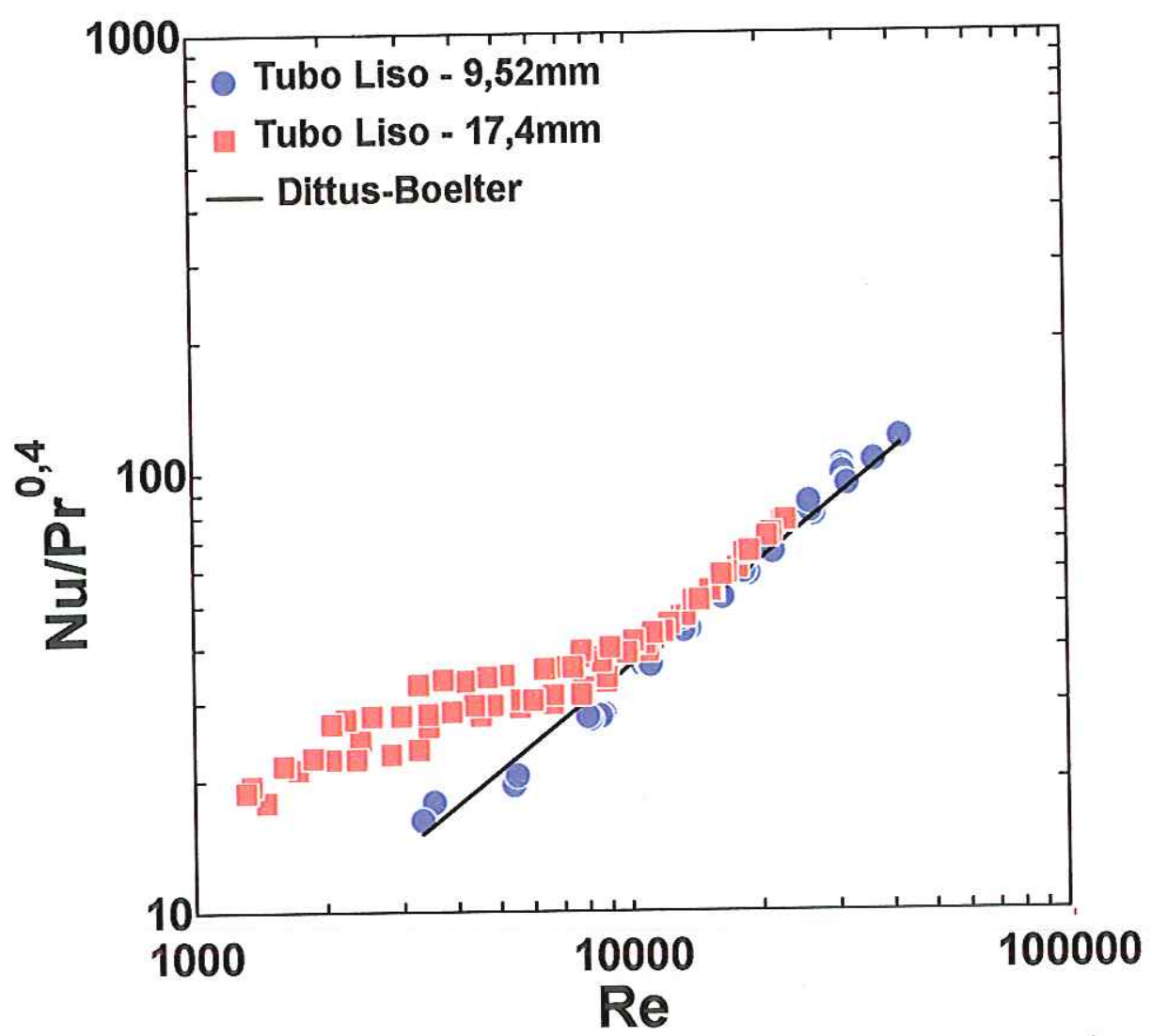

Figura 4.7 Resultados obtidos para o tubo liso de latão em função do grupo adimensional $\mathrm{Nu} / \mathrm{Pr}^{0,4}$ superpostos com os dados para tubo liso de $9,52 \mathrm{~mm}$ e a correlação de Dittus-Boelter, Eq. (2.15).

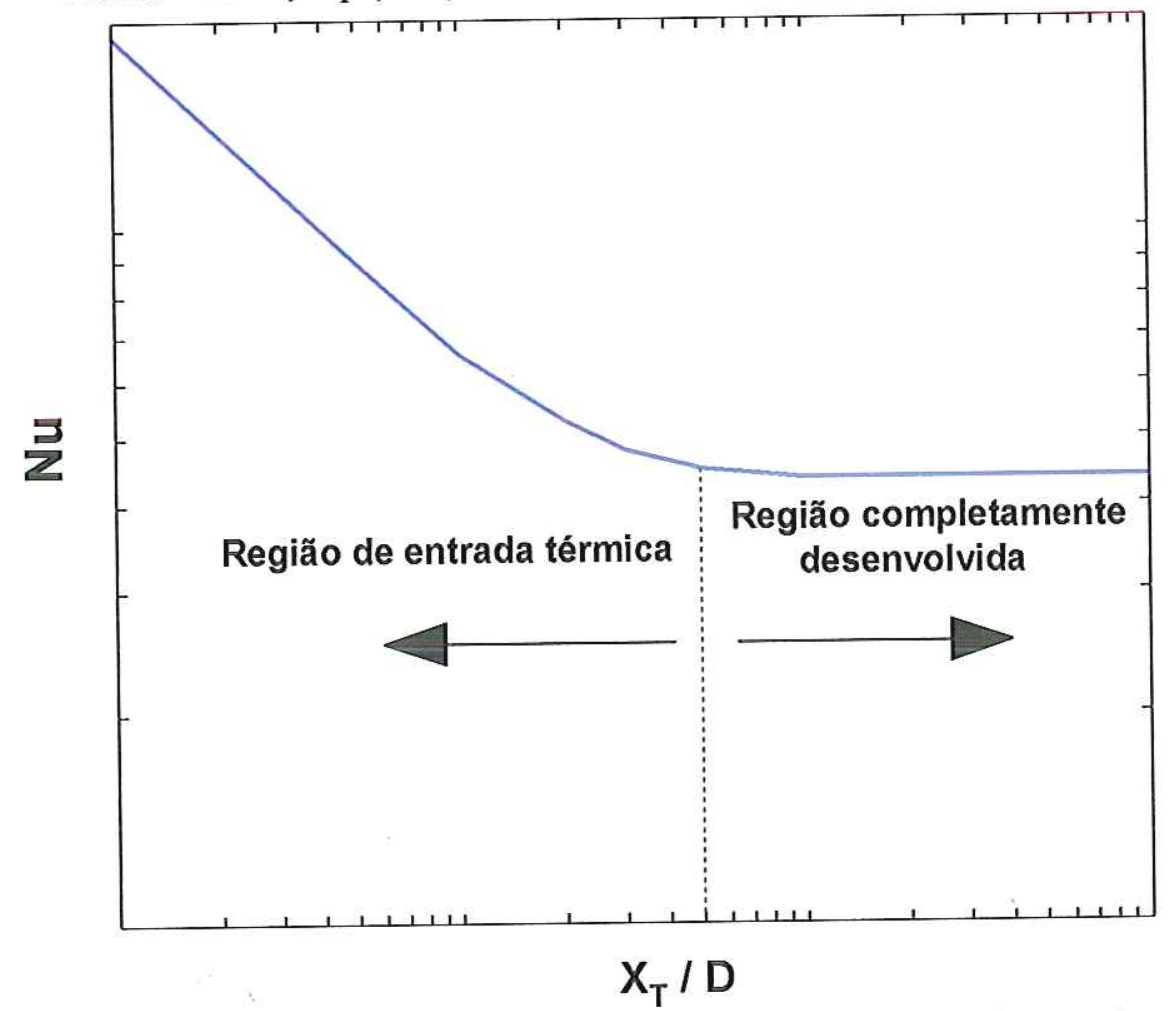

Figura 4.8 Nusselt local obtido de soluções para o comprimento de entrada em tubos. 
Os resultados experimentais envolvendo tubos microaletados em escoamento monofásico de líquido foram obtidos e serão analisados a seguir.

Um dos raros trabalhos digno de nota, citado por WEBB (1994), é o de KHANPARA et al (1987), em que se levanta uma curva do grupo adimensional $\mathrm{Nu}^{2} \mathrm{Pr}^{0,4} \mathrm{em}$ função do número de Reynolds, Re. A Fig. 4.9 apresenta a superposição dos resultados experimentais obtidos para os tubos de $7,93 \mathrm{~mm}$ e $9,52 \mathrm{~mm}$ de diâmetro, da empresa Termomecânica (TM), com os dados de KHANPARA et al (1987), para o R-22 escoando em tubo microaletado de diâmetro interno $8,8 \mathrm{~mm}$, com altura de aleta de $0,22 \mathrm{~mm}$ e ângulo de hélice de $17^{\circ}$. Percebe-se claramente uma significativa elevação do coeficiente de transferência de calor dos tubos microaletados em relação aos lisos. Nota-se, ainda, que o tubo microaletado de $7,93 \mathrm{~mm}$ ensaiado no presente trabalho apresentou valores do parâmetro adimensional superiores àqueles obtidos por KHANPARA et al (1987).

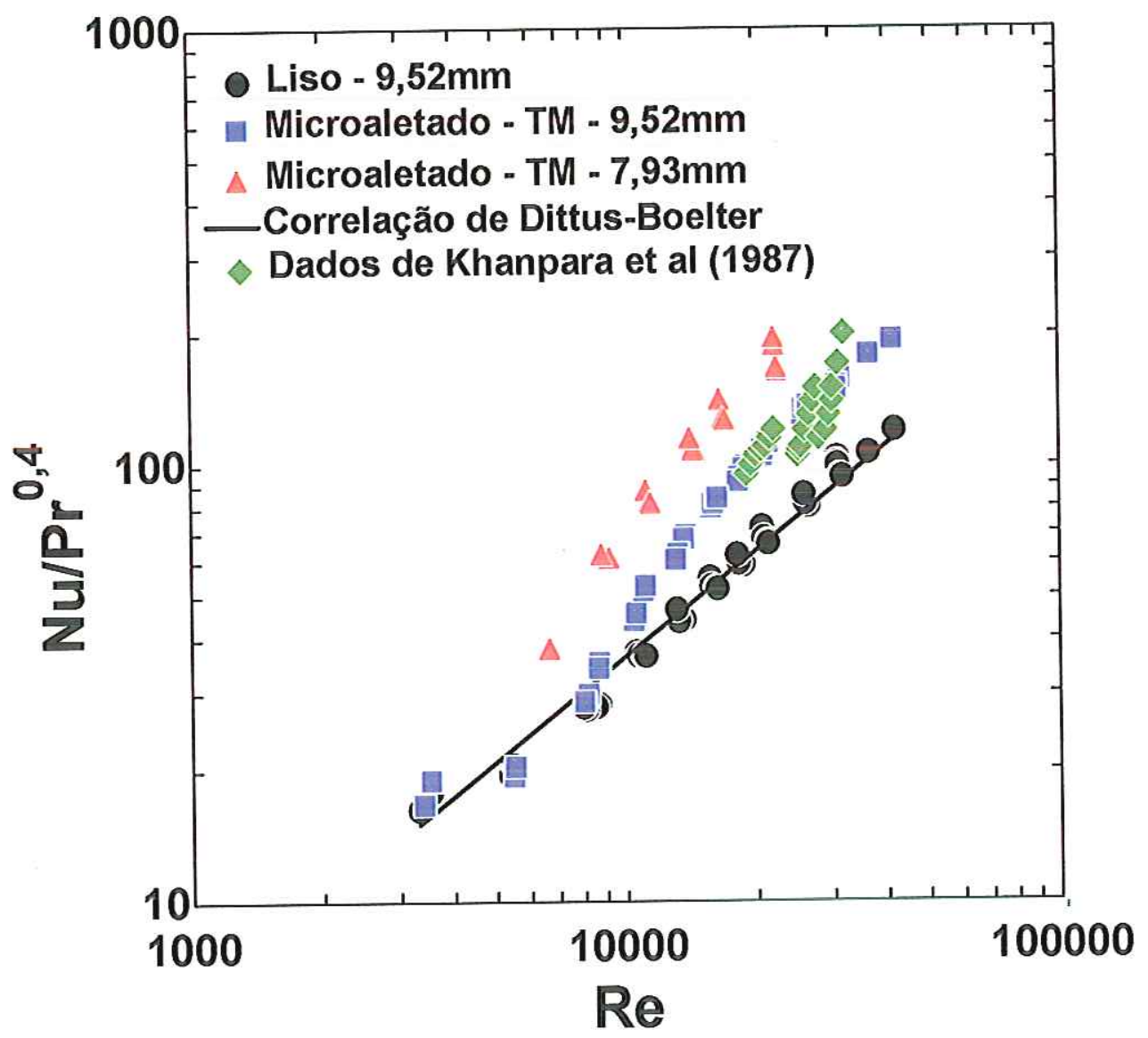

Figura 4.9 Comparação dos resultados experimentais para transferência de calor dos tubos da empresa Termomecânica (TM) de 7,93mm e 9,52mm de diâmetro, superpostos com os de KHANPARA et al (1987), Condições: R-22, $D_{i}=8,83 \mathrm{~mm}$, dimensão da aleta $=0,22 \mathrm{~mm}$ e $\beta=17^{\circ}$. 


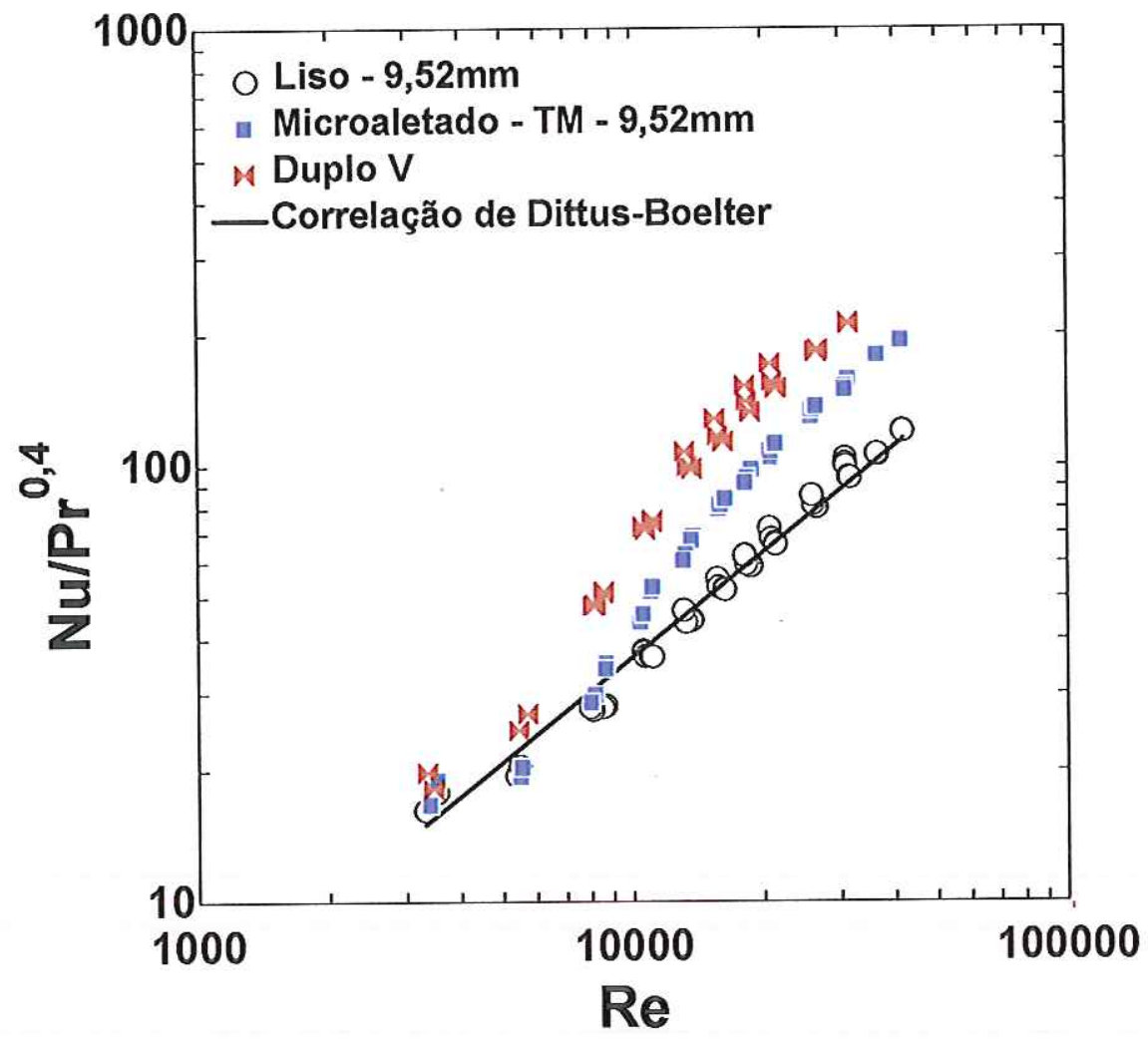

Figura 4.10 Comparação dos resultados experimentais para transferência de calor em escoamento monofásico dos tubos Liso, Microaletado (TM) e Duplo-V de $9,52 \mathrm{~mm}$ de diâmetro.

A Fig. 4.10 ilustra uma comparação semelhante à da Fig. 4.7, porém incorporando os resultados experimentais para o tubo Duplo-V, ou "herringbone", para escoamento do R134a em tubos com diâmetro de 9,52mm. Vale destacar, nesta figura, que os resultados para o tubo Duplo-V apresentaram uma intensificação, do grupo adimensional $\mathrm{Nu} / \mathrm{Pr}^{0,4}$, de $130 \%$ em relação àqueles obtidos para o tubo liso, ao passo que os resultados para o tubo microaletado foram $70 \%$ superiores aos do tubo liso. Deve-se observar, ainda, que, para números de Reynolds inferiores a 8000 , os resultados para os tubos ensaiados tendem a valores semelhantes. Isso se deve ao fato do escoamento estar no regime de transição entre o laminar e o turbulento, pois a espessura da subcamada laminar é maior que a altura da microaleta e, à medida que o número de Reynolds diminui, a espessura da subcamada laminar aumenta, resultando numa supressão da intensificação proporcionada pelas microaletas. No limite, ou seja, escoamento laminar, os resultados devem apresentar os mesmos valores para transferência de calor e perda de carga em tubos lisos e microaletados, já que o regime laminar não se caracteriza pela ocorrência da camada limite. 
Ensaios com o fluido refrigerante R-22, em escoamento monofásico, nas mesmas condições que o refrigerante R-134a foram realizados. Assim, foi possível comparar o desempenho destes fluidos no escoamento de líquido subsresfriado no interior de tubos microaletados. A Fig. 4.11 mostra uma comparação entre os coeficientes de transferência de calor para os refrigerantes R-134a e R-22, escoando no tubo microaletado da empresa Furukawa, com aqueles resultantes da correlação de Dittus-Boelter (tubos lisos), incluindo as respectivas barras de incertezas. É possível verificar que o coeficiente de transferência de calor para o refrigerante R-22 apresentou valores inferiores aos do R-134a. Vale destacar que, para tubos lisos, o coeficiente de transferência de calor, obtido por intermédio de correlações, para o refrigerante R-22 é superior àquele para o refrigerante R-134a. No caso da Fig. 4.11, parece que esse comportamento é devido às configurações das ranhuras, que possivelmente induzem um escoamento secundário, fazendo com que o R-134a experimente valores superiores aos do R-22.

É importante ressaltar, ainda, que as incertezas propagadas para o caso do escoamento monofásico resultaram em valores reduzidos. A incerteza mínima absoluta para o coeficiente de transferência de calor foi de $3,6 \mathrm{~W} / \mathrm{m}^{2 \circ} \mathrm{C}$ e máxima de $248 \mathrm{~W} / \mathrm{m}^{2 \circ} \mathrm{C}$, correspondendo a 1,2 e $8,5 \%$, respectivamente, do valor absoluto.

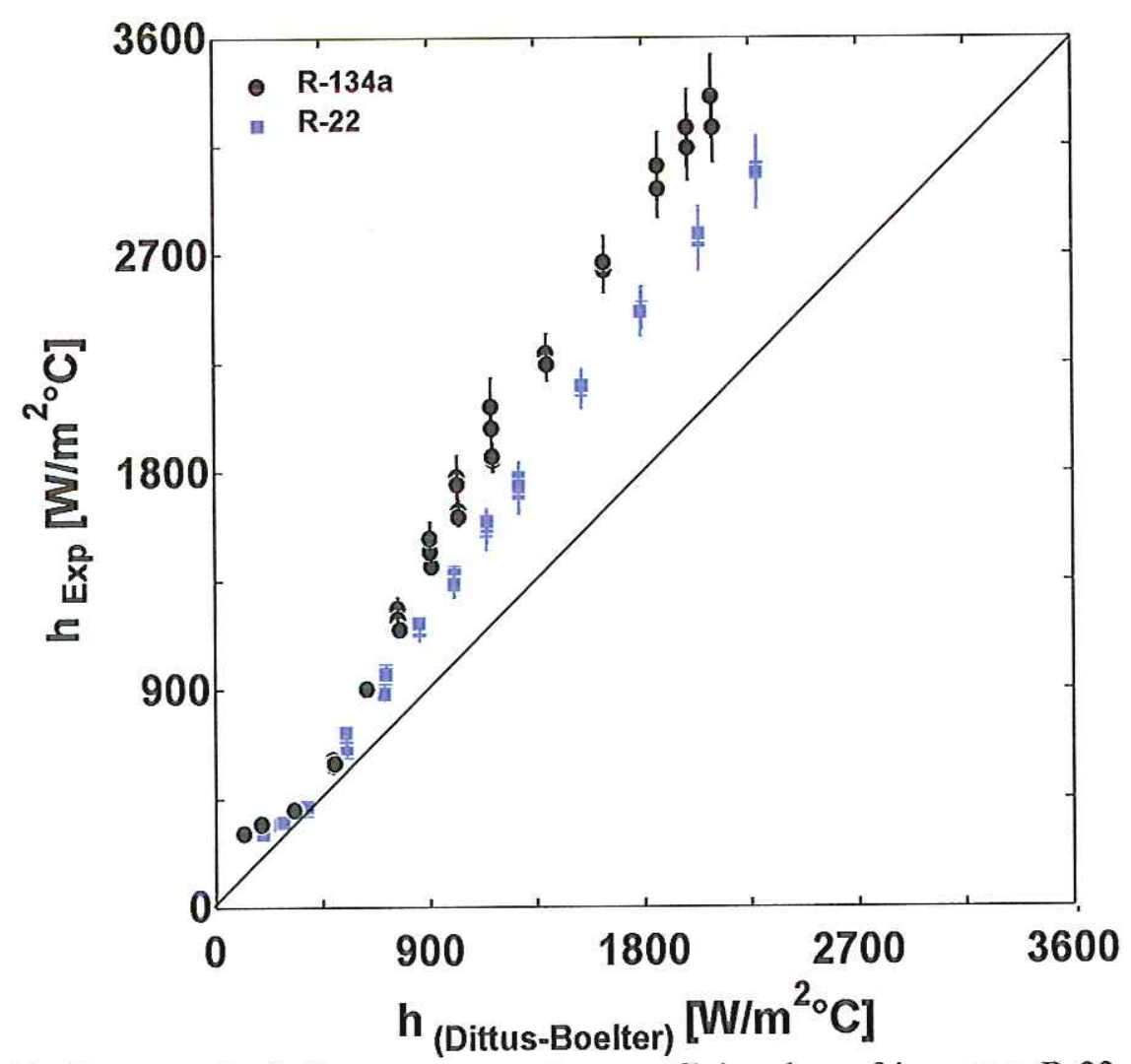

Figura 4.11 Comparação do h em escoamento monofásico dos refrigerantes R-22 e R134a para o tubo microaletado da empresa Furukawa. $D=9,52 \mathrm{~mm}, \mathrm{~T}_{\mathrm{en}}=-2,5^{\circ} \mathrm{C}$ e $\mathrm{G}$ variando entre 70 e $1270 \mathrm{~kg} / \mathrm{s} . \mathrm{m}^{2}$. 


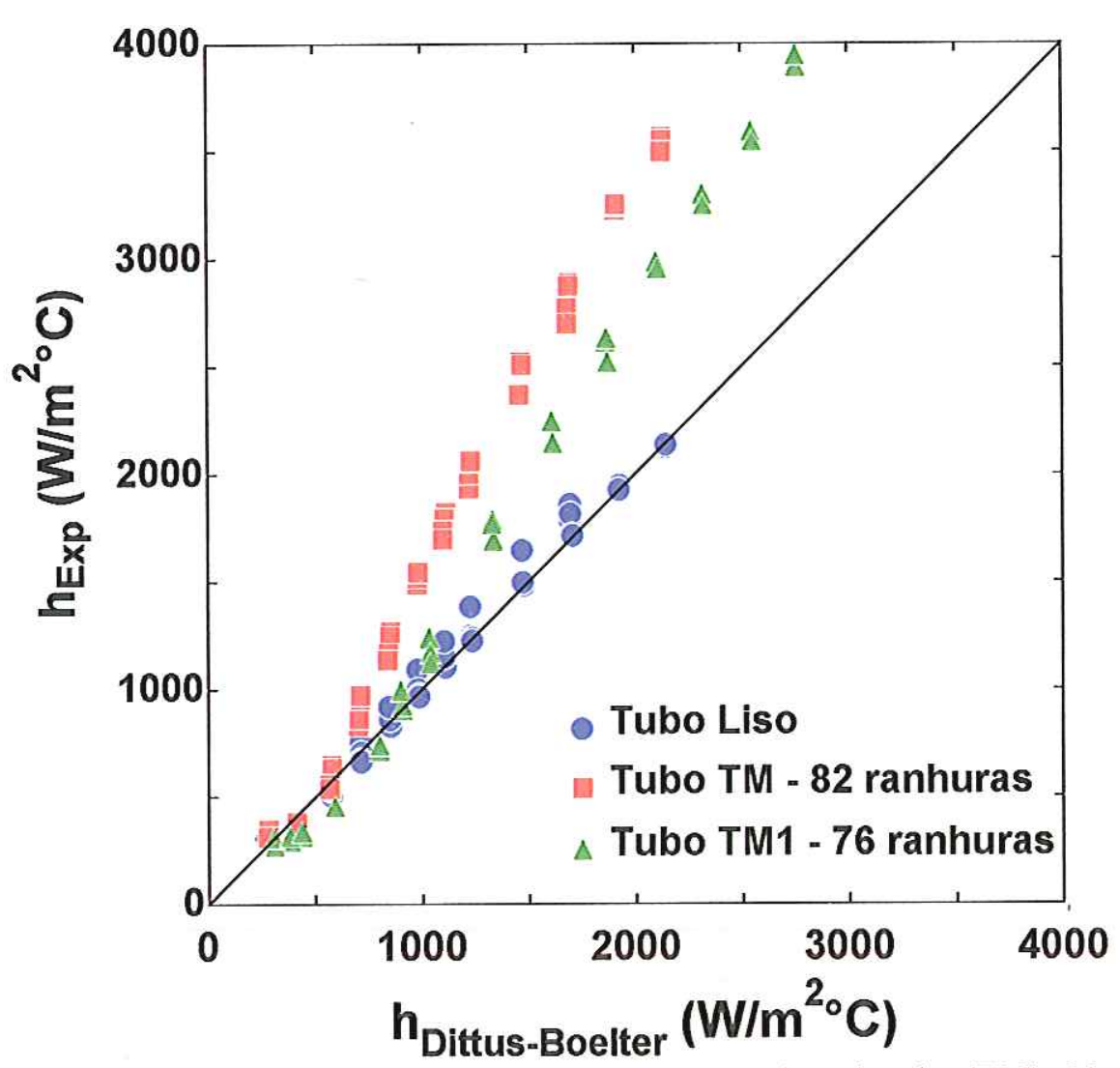

Figura 4.12 Comparação do h para os tubos: liso, microaletado (TM) 82 ranhuras c microaletado (TM1) 76 ranhuras. $\mathrm{R}-134 \mathrm{a}, \mathrm{D}=9,52 \mathrm{~mm} \mathrm{e} \mathrm{T}_{\mathrm{en}}=-2,5^{\circ} \mathrm{C}$.

Ensaios comparativos evidenciando o efeito do número de microaletas no coeficiente de transferência de calor e perda de carga foram realizados. A Fig. 4.12 ilustra os resultados experimentais para o coeficiente de transferência de calor superpostos com a correlação de Dittus-Boelter. Como seria de esperar, o tubo com 82 microaletas apresentou valores para o coeficiente de transferência de calor superiores àqueles obtidos para o tubo com 76 ranhuras (TM1) devido a maior área interna de troca de calor, cerca de $8 \%$ superior. Em contrapartida, a perda de carga apresentou valores mais elevados para o tubo com 82 ranhuras do que o de 76 ranhuras, como pode ser observado na Fig. 4.13. Nesse sentido, numa rápida inspeção nos valores do coeficiente de transferência de calor e na perda de carga dos tubos microaletados em comparação com o liso, é possível verificar que o tubo com 76 ranhuras apresenta um melhor desempenho que o de 82 ranhuras. Isso se deve à relação entre o aumento da transferência de calor e o incremento da perda de carga, denominado de fator de intensificação, que será definido mais adiante, que é superior para o tubo TM1 de 76 ranhuras. 


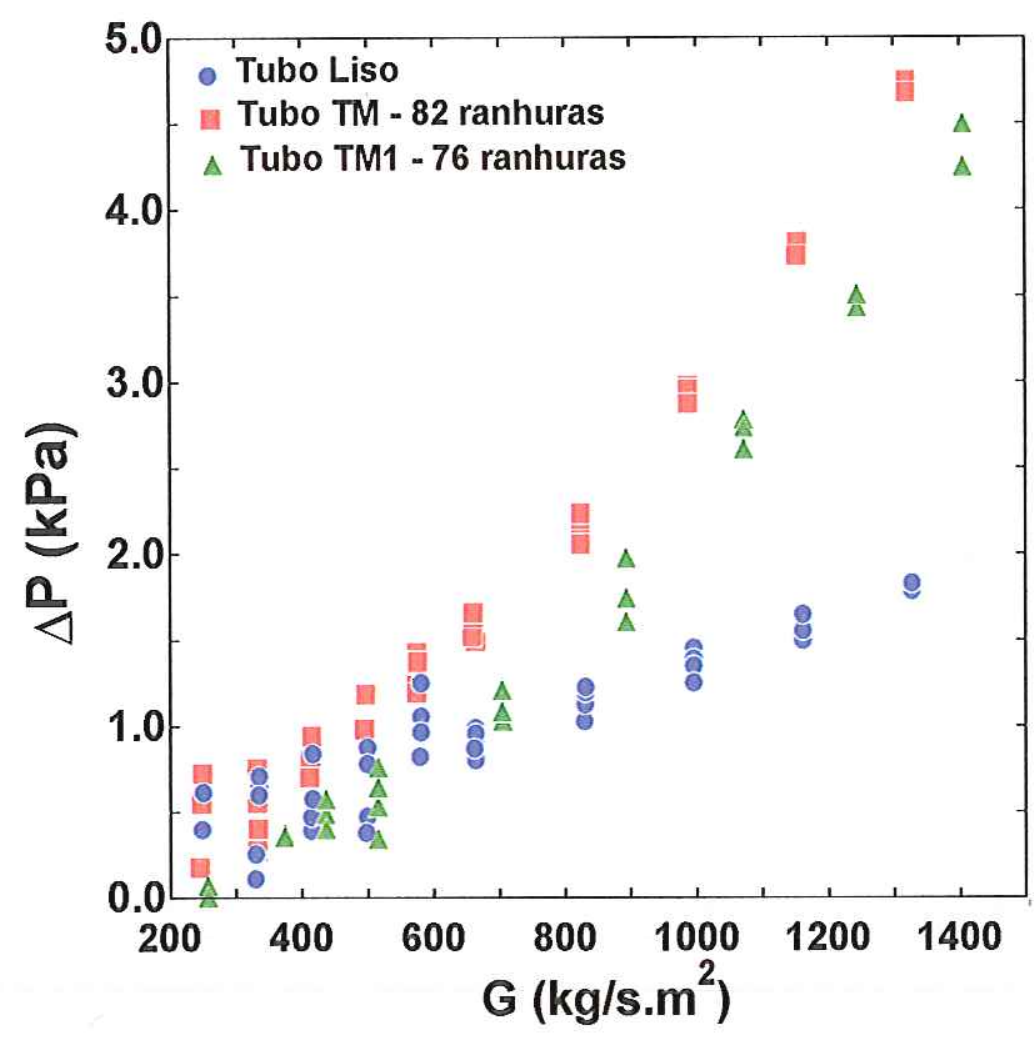

Figura 4.13 Comparação da perda de carga para os tubos: liso, microaletado (TM) 82 ranhuras e microaletado (TM1) 76 ranhuras. $\mathrm{R}-134 \mathrm{a}$. $\mathrm{D}=9,52 \mathrm{~mm} \mathrm{e} \mathrm{T}_{\mathrm{en}}=-2,5^{\circ} \mathrm{C}$.

A Fig. 4.14 ilustra uma comparação da perda de carga, $\Delta \mathrm{P}$, entre os tubos ensaiados para distintas velocidades mássicas, G. A perda de carga foi avaliada utilizando um transdutor diferencial de pressão com precisão de leitura de $0,25 \%$ do fundo de escala, como mencionado anteriormente. Nota-se que a perda de carga para vazões reduzidas $(G<400$ $\mathrm{kg} / \mathrm{s} \cdot \mathrm{m}^{2}$ ) apresenta, praticamente, valores semelhantes para os três tubos ensaiados, pois, nessas condições, o escoamento se encontra na região de transição entre os regimes laminar e turbulento, e os resultados tendem a um mesmo valor, pois, de acordo com o exposto anteriormente, a espessura da subcamada laminar tende a superar a altura da microaleta. Já para vazões superiores a $400 \mathrm{~kg} / \mathrm{s}^{2} \mathrm{~m}^{2}$, a tendência dos resultados para os tubos com intensifícação [Duplo-V e microaletado (TM)] apresentarem valores superiores aos do tubo liso é claramente observada, já que as microaletas funcionam como rugosidades. Vale destacar que o tubo denominado Duplo-V foi o que apresentou os maiores valores da perda de carga seguido do tubo microaletado e, finalmente, do tubo liso. 


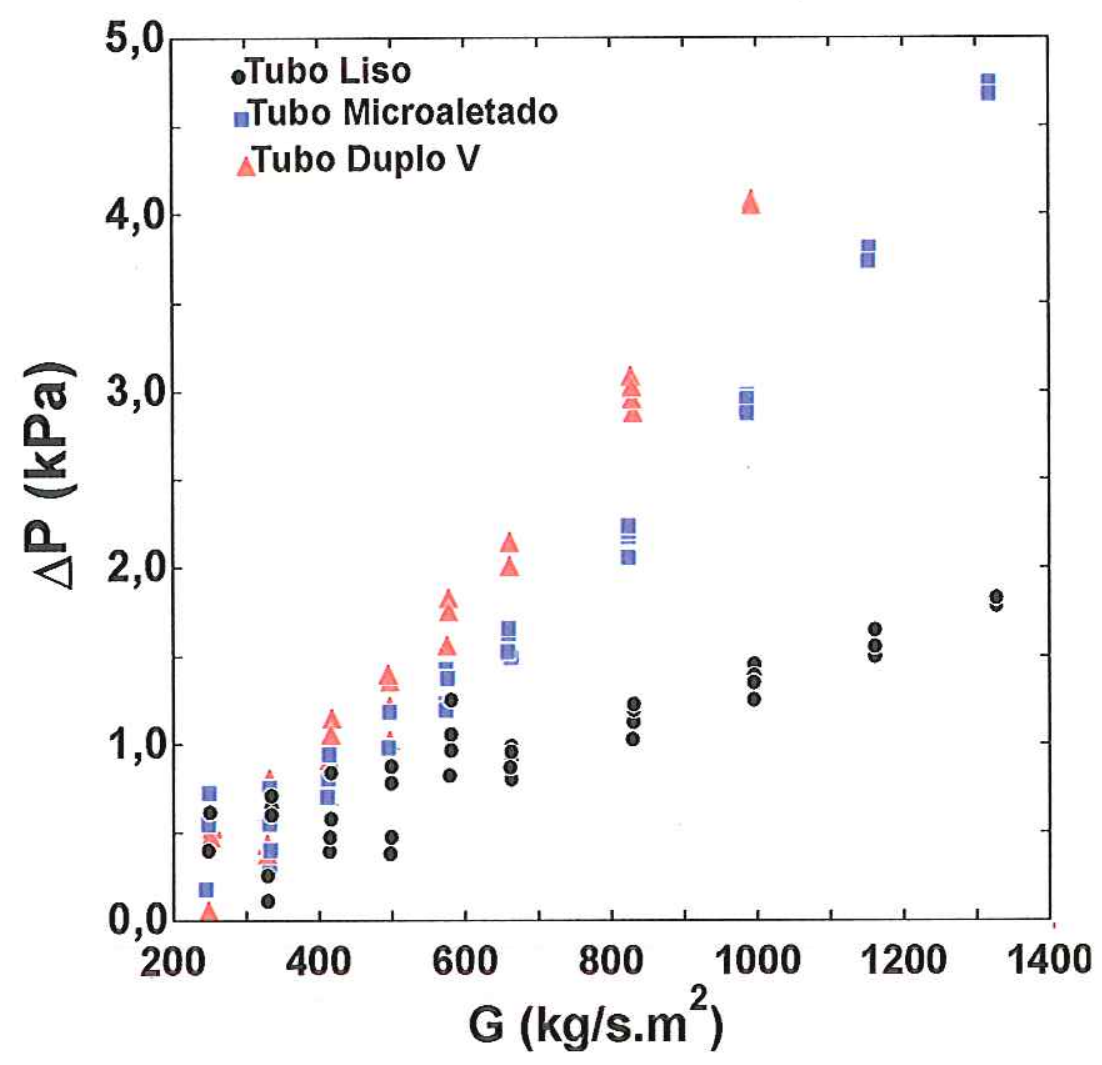

Figura 4.14 Comparação da perda de carga em função da velocidade mássica, G, para os tubos: liso, microaletado (TM) e Duplo-V. R-134a, $\mathrm{T}_{\mathrm{en}}=-2,5^{\circ} \mathrm{C}$ e $\mathrm{D}=9,52 \mathrm{~mm}$.

As principais conclusões relativas ao escoamento monofásico podem ser assim resumidas:

O coeficiente de transferência de calor para escoamento monofásico varia consideravelmente com a vazão, pois o coeficiente aumenta com o incremento desta. Por outro lado, a perda de carga é incrementada, de maneira indesejável, à medida que a vazão é elevada.

$\checkmark$ Foi verificado que para valores de Reynolds abaixo de 8000 , para tubos liso e microaletado com diâmetro de $9,52 \mathrm{~mm}$, os resultados para o grupo adimensional $\mathrm{Nu} / \mathrm{Pr}^{0,4}$, foram semelhantes. Isso evidencia que na região de transição dos regimes laminar-turbulento, a espessura da subcamada laminar é superior a altura da microaleta, não afetando, portanto, a transferência de calor.

$\circledast \mathrm{O}$ coeficiente de transferência de calor para o tubo microaletado (TM) apresentou uma intensificação da ordem de $70 \%$ em relação ao tubo liso, já o tubo Duplo-V a intensificação alcançou $130 \%$. 
$\checkmark$ A perda de carga para o tubo microaletado (TM) foi superior ao tubo liso, apresentando um incremento de $76 \%$ para $\mathrm{G}=820 \mathrm{~kg} / \mathrm{s} . \mathrm{m}^{2}, 90 \%$ para $\mathrm{G}=1000$ $\mathrm{kg} / \mathrm{s} \cdot \mathrm{m}^{2}, 135 \%$ para $1150 \mathrm{~kg} / \mathrm{s}^{2} \mathrm{~m}^{2}$ e $170 \%$ para $\mathrm{G}=1300 \mathrm{~kg} / \mathrm{s} . \mathrm{m}^{2}$.

O tubo Duplo-V, por sua vez, apresentou valores da perda de carga maiores que o tubo microaletado, onde para $\mathrm{G}=820 \mathrm{~kg} / \mathrm{s}^{\mathrm{m}} \mathrm{m}^{2}$ o aumento do $\Delta \mathrm{P}$ em relação ao tubo liso foi de $130 \%$ e para $\mathrm{G}=1000 \mathrm{~kg} / \mathrm{s} \cdot \mathrm{m}^{2}$ foi de $170 \%$.

O tubo microaletado com menor número de ranhuras (76) apresentou menor coeficiente de transferência de calor e perda de carga que o tubo com 82 ranhuras. Entretanto, o fator de intensificação global (relação entre o aumento na transferência de calor e o de perda de carga) para o tubo com 76 microaletas resultou superior ao de 82 ranhuras.

$\varpi$ O fluido refrigerante R-134a se caracterizou por apresentar valores superiores do coeficiente de transferência de calor em comparação àqueles obtidos para o R-22, escoando no tubo microaletado da empresa Furukawa, divergindo daqueles obtidos para o tubo liso. 


\subsection{Escoamento com Mudança de Fase (Ebulição Convectiva)}

\subsubsection{Considerą̧ões Preliminares}

Esta seção apresenta os resultados experimentais levantados para escoamento com mudança de fase (líquido-vapor), ou ebulição convectiva de refrigerantes no interior de tubos lisos e microaletados. A princípio será apresentada uma breve descrição do procedimento utilizado para o levantamento dos pontos experimentais. Em seguida, serão apresentados os resultados experimentais e sua relação com os padrões de escoamento através de mapas e fotografias dos principais padrões observados durante a pesquisa. A seção traz, também, a sugestão de um mapa de padrão de escoamento válido para tubos microaletados. Serão mostrados e analisados os resultados experimentais obtidos para tubos lisos com transferência de calor, abordando efeitos tais como: temperatura, diâmetro, velocidade mássica, fluxo de calor, fluido refrigerante e perda de carga. Neste caso, serão abordados os resultados para escoamento adiabático e com troca de calor, evidenciando alguns efeitos como velocidade mássica e tipo de refrigerante. Posteriormente, os resultados levantados envolvendo tubos microaletados serão apresentados, evidenciando comparações com tubos lisos e introduzindo uma análise em termos do fator de intensificação. Finalmente, serão analisados resultados envolvendo secagem de parede, abordando, principalmente, seu efeito sobre a temperatura da superficie do tubo e o coeficiente de transferência de calor associado a essa região.

\subsubsection{Procedimento Experimental - Mudança de Fase}

Após o término dos ensaios com escoamento monofásico de líquido, recolhia-se uma certa quantidade de refrigerante no depósito de líquido (garrafa de refrigerante do circuito de ensaios) para possibilitar os ensaios em ebulição convectiva. $\mathrm{O}$ variador de freqüência era programado e, automaticamente, acionada a bomba de circulação. Com o escoamento do fluido refrigerante, o "chiller" era acionado simultaneamente com a bomba de circulação da mistura anti-congelante. Com a diminuição da temperatura da solıção, as resistências elétricas do pré-aquecedor e da seção de testes eram acionadas, incrementando sua potência com objetivo de se atingir as condições pré-determinadas para os ensaios. Como observado no capítulo 3, as condições de ensaio eram estabelecidas pela Matriz de Experimentos e, inicialmente, eram mantidos constantes os valores para o fluxo de calor específico, $\phi$, aplicado na seção de testes, e velocidade mássica, G. Posteriormente, era 
ajustado o valor da potência elétrica aplicada na seção de pré-aquecimento, com o objetivo de se alcançar o valor desejado para o título de entrada da seção de testes. Finalmente, a válvula reguladora da vazão da solução anti-congelante era, cuidadosamente, ajustada permitindo, assim, o controle da temperatura de entrada na seção de testes. Se todos parâmetros se mantivessem constantes durante um período de 10 a 15 minutos, assumia-se o regime permanente e efetuava-se a aquisição. 0 procedimento experimental, desde o acionamento do variador de freqüência até a aquisição do primeiro ponto, durava cerca de 2,5 horas. É interessante ressaltar que o inventário de refrigerante no circuito principal era alterado algumas vezes no período. Por exemplo, para ensaios com vazões e títulos elevados era necessário um menor inventário de refrigerante no circuito, sob pena de não se atingir a temperatura de evaporação desejada. Para vazões e títulos reduzidos, a quantidade de refrigerante requerida pelo sistema era maior.

\subsubsection{Resultados Experimentais}

Os resultados experimentais obtidos ao longo da campanha de ensaios compõem um universo de mais de 4500 pontos, envolvendo diversos refrigerantes e distintas condições operacionais, correspondendo àquelas verificadas na maioria das aplicações frigoríficas. Com o objetivo de melhor organizar o material disponivel, optou-se por analisar os resultados experimentais em ebulição convectiva de acordo com a seguinte classificação:

Padrões de Escoamento: investigação dos distintos padrões através de mapas disponiveis na literatura e alguns registros fotográficos dos principais padrões de escoamento observados na seção de visualização, além da proposição de um mapa para tubos microaletados.

$>$ Transferência de Calor em Tubos Lisos: análise do efeito dos principais parâmetros (Velocidade Mássica, Fluido Refrigerante, Fluxo de Calor, Temperatura de Evaporação e Diâmetro).

Perda de Carga em Tubos Lisos: abordando a perda de carga em escoamento adiabático e com trora de calor, apresentando, ainda comparações em termos adimensionais.

Tubos Microaletados: análise e comparações com tubos lisos, fator de intensificação e tubos com distintas geometrias. 
Perda de Carga em Tubos Microaletados: investigação da perda de carga no interior de tubos microaletados, além de comparações em termos adimensionais.

$>$ Secagem de Parede: verificação deste efeito através da medida da temperatura superficial do tubo, analisando simultaneamente o coeficiente de transferência de calor.

A análise dos resultados experimentais será realizada através dos efeitos dos principais parâmetros mencionados anteriormente sobre, principalmente, o coeficiente de transferência de calor. Tal procedimento permitirá o desenvolvimento de uma análise sistemática dos resultados, permitindo avaliar sua consistência face ao comportamento físico esperado e a resultados obtidos em outros trabalhos.

\subsubsection{Padrões de Escoamento em Tubos Horizontais}

A maioria dos padrões de escoamento que ocorre em escoamento com mudança de fase (líquido/vapor) foi observada na seção de visualização, localizada na saída da seção de testes. Nesta seção, serão apresentados os registros fotográficos, Figs. 4.15 a 4.22, que foram obtidos, ilustrando o padrão em bolhas, pistonado, intermitente (slug), anular, estratificado liso, estratificado ondulado e em névoa, além de uma fotografia ilustrando a secagem de parede. No apêndice II, serão incluídas algumas fotografias que mostram outras características que foram observadas. Vale destacar que os padrões em bolhas e pistonado foram obtidos com líquido subresfriado na entrada da seção de testes, condição em que não há equilíbrio termodinâmico, apenas para efeito de ilustração.

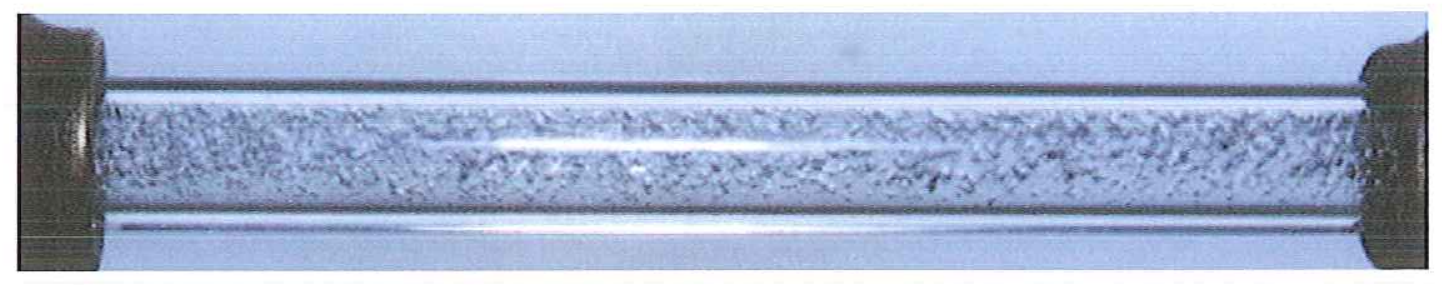

Figura 4.15 Padrão de escoamento em Bolhas, obtido para as condições: R134a, $\mathrm{T}_{\text {Evap }}=5^{\circ} \mathrm{C}, \phi=5 \mathrm{~kW} / \mathrm{m}^{2}, \mathrm{G}=300 \mathrm{~kg} / \mathrm{s} \cdot \mathrm{m}^{2}$ e $\mathrm{D}=7,93 \mathrm{~mm}$. 


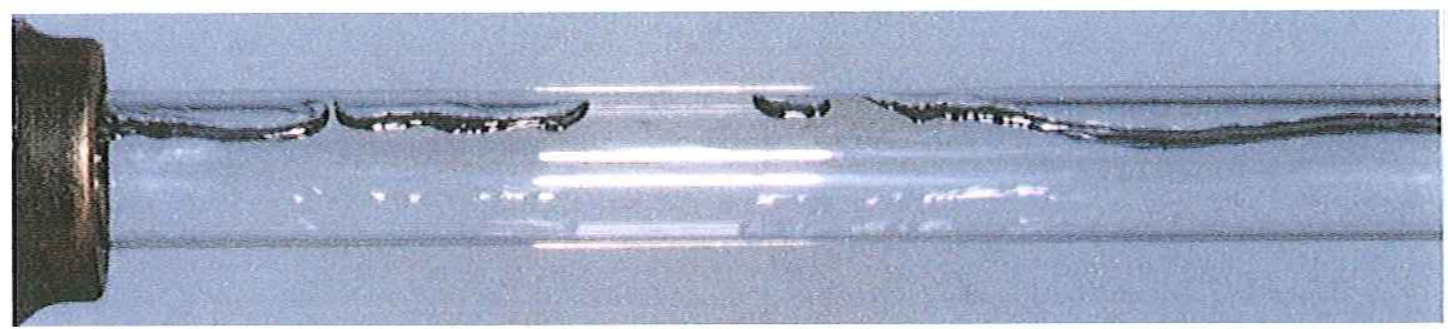

Figura 4.16 Padrão de escoamento Pistonado, obtido para as condições: R134a, $\mathrm{T}_{\mathrm{Evap}}=5^{\circ} \mathrm{C}, \phi=5 \mathrm{~kW} / \mathrm{m}^{2}, \mathrm{G}=100 \mathrm{~kg} / \mathrm{s} \cdot \mathrm{m}^{2}$ e $\mathrm{D}=9,52 \mathrm{~mm}$.

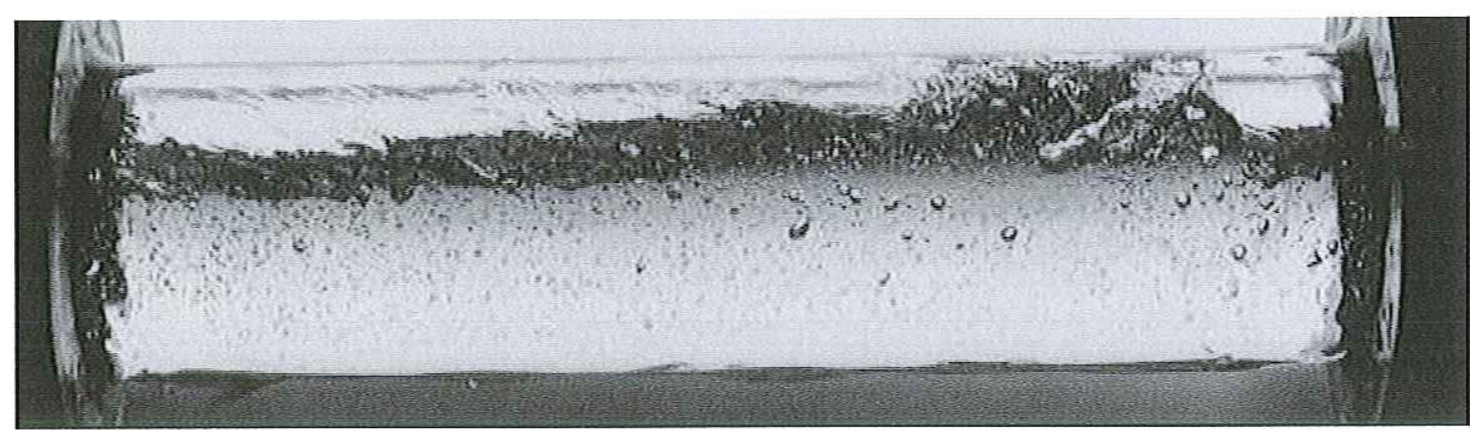

Figura 4.17 Padrão de escoamento Intermitente (Slug), obtido para as condições: R134a, $\mathrm{T}_{\text {Evap }}=5^{\circ} \mathrm{C}, \phi=5 \mathrm{~kW} / \mathrm{m}^{2}, \mathrm{G}=200 \mathrm{~kg} / \mathrm{s} \cdot \mathrm{m}^{2}$ e $\mathrm{D}=17,4 \mathrm{~mm}$.

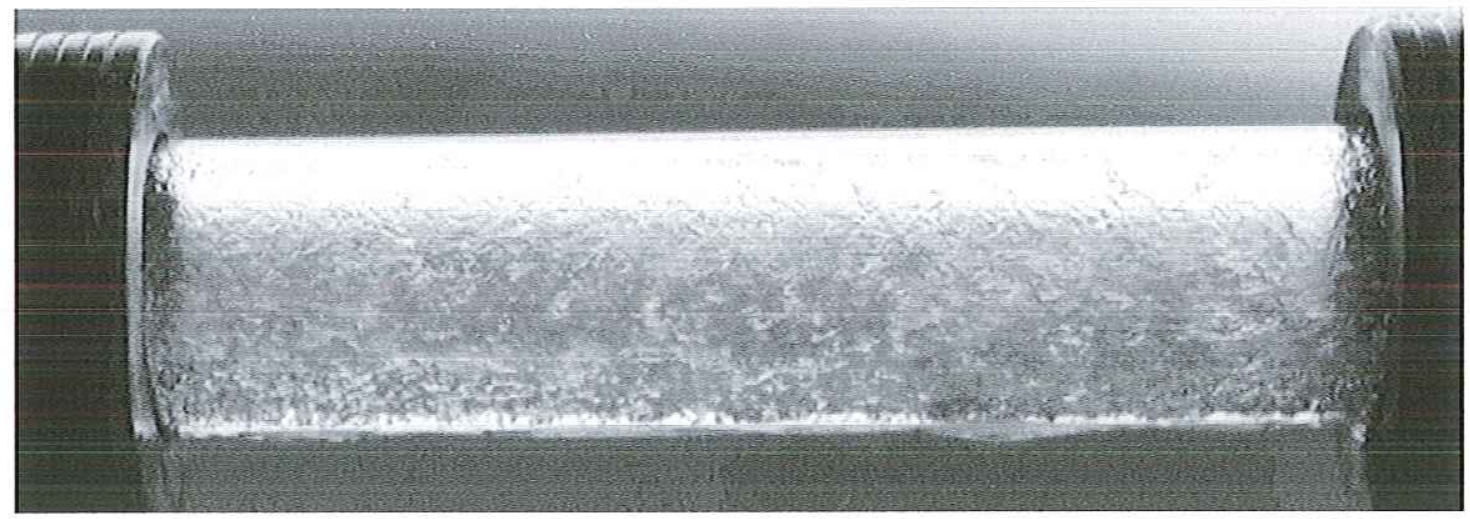

Figura 4.18 Padrão de escoamento Anular, obtido para as condições: $\mathrm{R} 134 \mathrm{a}, \mathrm{T}_{\text {Evap }}=8^{\circ} \mathrm{C}$, $\phi=5 \mathrm{~kW} / \mathrm{m}^{2}, \mathrm{G}=300 \mathrm{~kg} / \mathrm{s} . \mathrm{m}^{2}$ e $\mathrm{D}=17,4 \mathrm{~mm}$.

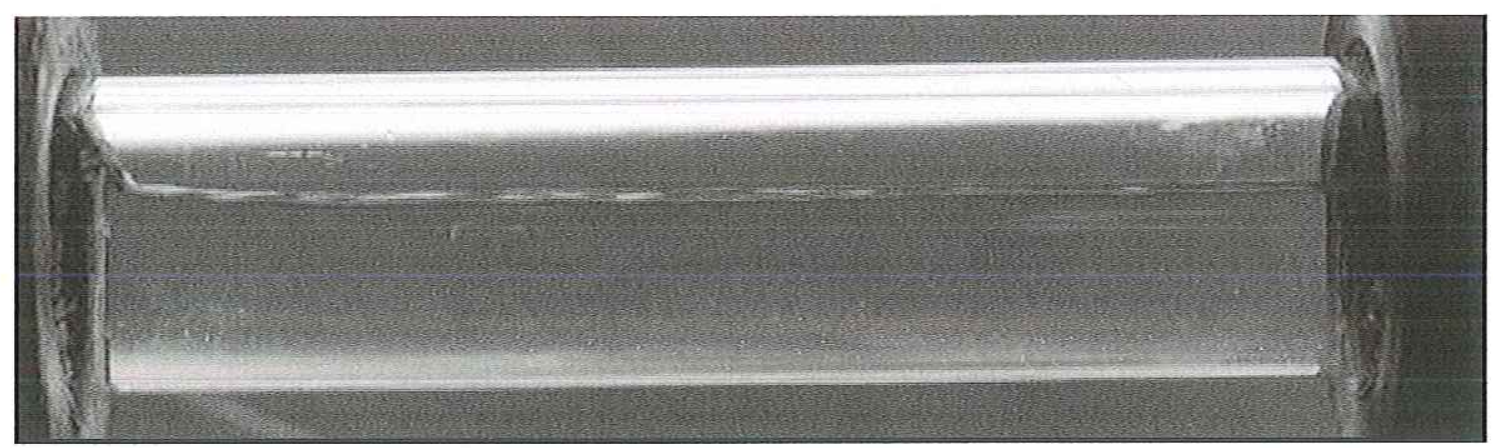

Figura 4.19 Padrão de escoamento Estratificado Liso, obtido para as condições: R134a, $\mathrm{T}_{\text {Evap }}=5^{\circ} \mathrm{C}, \phi=5 \mathrm{~kW} / \mathrm{m}^{2}, \mathrm{G}=50 \mathrm{~kg} / \mathrm{s} . \mathrm{m}^{2}$ e $\mathrm{D}=17,4 \mathrm{~mm}$. 


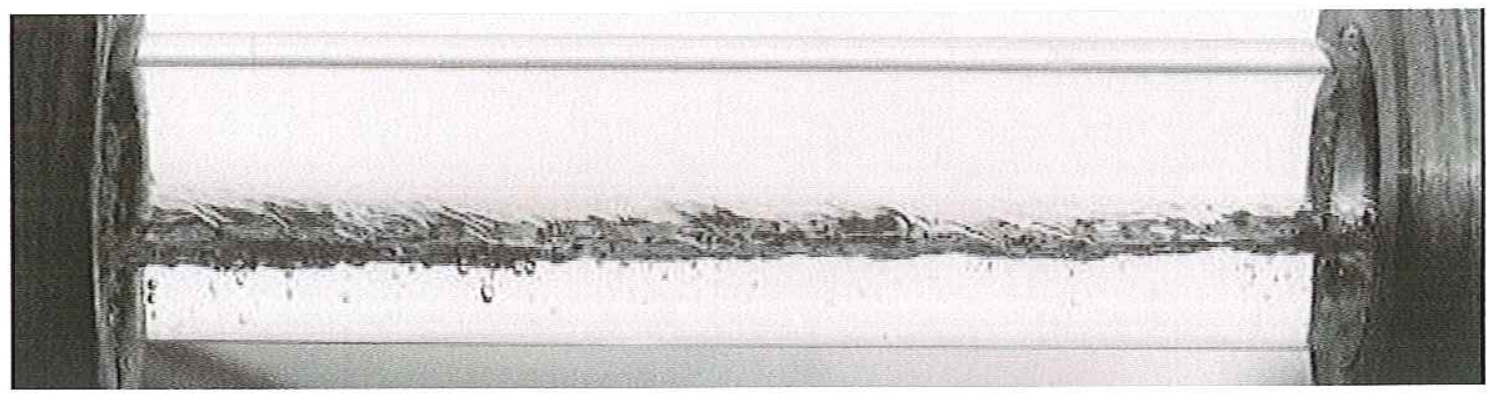

Figura 4.20 Padrão de escoamento Estratificado Ondulado, obtido para as condições: R134a, $\mathrm{T}_{\text {Evap }}=5^{\circ} \mathrm{C}, \phi=5 \mathrm{~kW} / \mathrm{m}^{2}, \mathrm{G}=100 \mathrm{~kg} / \mathrm{s} \cdot \mathrm{m}^{2}$ e $\mathrm{D}=17,4 \mathrm{~mm}$.

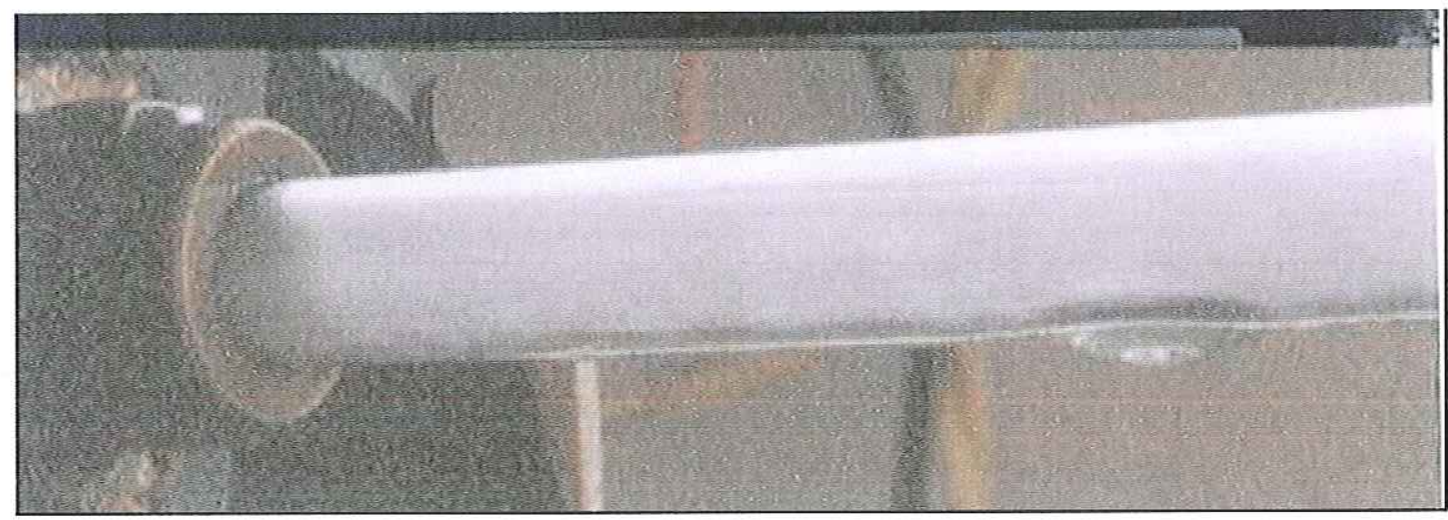

Figura 4.21 Padrão de escoamento em Névoa, obtido para as condições: R134a, $\mathrm{T}_{\text {Evap }}=5^{\circ} \mathrm{C}, \phi=5 \mathrm{~kW} / \mathrm{m}^{2}, \mathrm{G}=500 \mathrm{~kg} / \mathrm{s} \cdot \mathrm{m}^{2}$ e $\mathrm{D}=9,52 \mathrm{~mm}$.

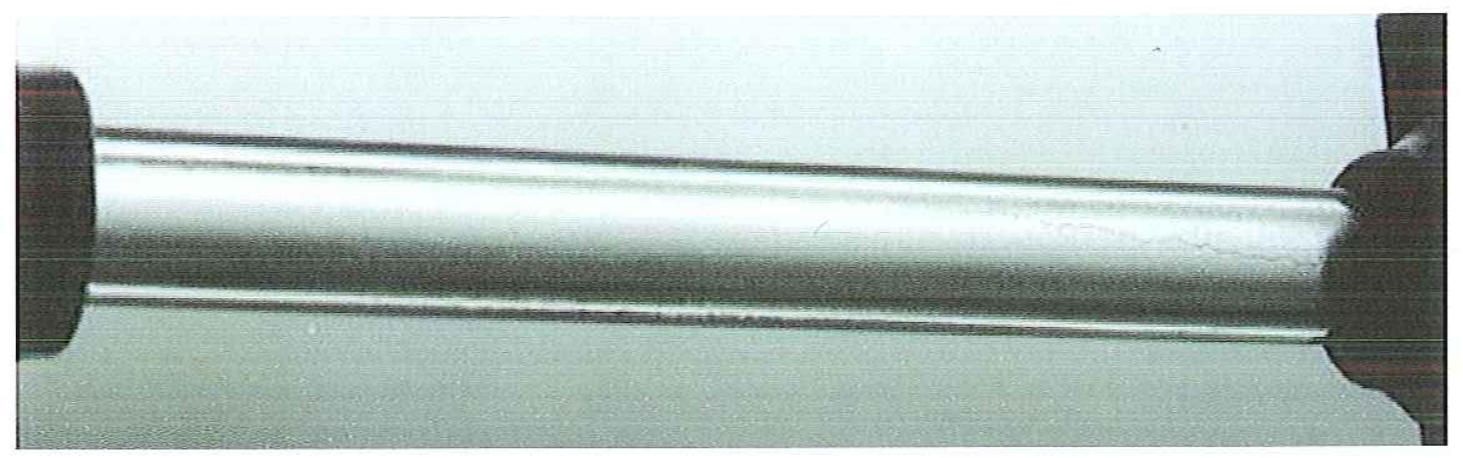

Figura 4.22 Figura ilustrado a Secagem da Parede, obtida para as condições: R134a, $\mathrm{T}_{\text {Evap }}=5^{\circ} \mathrm{C}, \phi=10 \mathrm{~kW} / \mathrm{m}^{2}, \mathrm{G}=100 \mathrm{~kg} / \mathrm{s} \cdot \mathrm{m}^{2}$ e $\mathrm{D}=9,52 \mathrm{~mm}$.

Seria interessante, a esta altura, incorporar os resultados experimentais, obtidos sob certas condições operacionais, num mapa de padrão de escoamento proposto na literatura. Nesse sentido, o mapa desenvolvido por KATTAN et al (1998) foi escolhido pela sua simplicidade e por ter sido desenvolvido sob condições semelhantes à da presente pesquisa, envolvendo o refrigerante R-134a, a velocidade mássica e título.

A Fig. 4.23 ilustra os resultados experimentais obtidos para o refrigerante R-134a escoando tubo liso de $9,52 \mathrm{~mm}$ de diâmetro, com fluxo de calor de $5 \mathrm{~kW} / \mathrm{m}^{2}$, temperatura de 
evaporação de $5^{\circ} \mathrm{C}$ e velocidades mássicas variando entre 100 e $500 \mathrm{~kg} / \mathrm{s}^{2} \mathrm{~m}^{2}$. É interessante observar que, segundo o mapa, a transição do escoamento intermitente para o anular, para valores de G superiores a $200 \mathrm{~kg} / \mathrm{s} \mathrm{m}^{2}$, se dá para títulos da ordem de $34 \%$. Efetivamente, na seção de visualização e através da análise destes resultados, apresentada mais adiante, foi observado que a transição do padrão intermitente para o anular ocorre para títulos inferiores aos sugeridos no mapa da Fig. 4.23. Outra característica deste mapa é relativa à linha de transição do padrão intermitente para o anular que é caracterizada por uma linha vertical, ou seja, para velocidades mássicas distintas, a transição ocorre para títulos constantes da ordem de $34 \%$. Entretanto, os resultados obtidos na presente pesquisa indicam que o título de transição do padrão intermitente para o anular varia com a velocidade mássica, diminuindo com esta.

Algumas características desse mapa são interessantes e merecem ser destacadas. As curvas que envolvem os padrões estratificado liso e ondulado são fisicamente consistentes, de acordo com as observações feitas, pois a interface líquido/vapor se apresentou ondulada para valores de $\mathrm{G}$ da ordem de $100 \mathrm{~kg} / \mathrm{s} . \mathrm{m}^{2}$. Nota-se que a transição do padrão estratificado liso para o ondulado varia com o título e a velocidade mássica, como seria de esperar. À medida que o título é incrementado a transição do liso para o ondulado ocorre para velocidades mássicas menores, em virtude da maior velocidade do vapor, que tende a promover a formação de ondas.

Resultados para o tubo de $17,4 \mathrm{~mm}$ de diâmetro interno foram inseridos no mapa da Fig. 4.24, para ilustrar, principalmente, os padrões associados a velocidades mássicas inferiores a $100 \mathrm{~kg} / \mathrm{s} \cdot \mathrm{m}^{2}$. O mapa revela que os resultados para $\mathrm{G}=50 \mathrm{~kg} / \mathrm{s} . \mathrm{m}^{2}$, a transição do padrão estratificado liso para o ondulado se dá para títulos da ordem de $55 \%$, o que efetivamente se observou na seção de visualização. Já para velocidades mássicas ainda menores, $G=25 \mathrm{~kg} / \mathrm{s} \cdot \mathrm{m}^{2}$, essa transição parece ocorrer para títulos superiores a $90 \%$. É importante esclarecer que um dos aspectos negativos desse mapa é que não inclui o efeito do diâmetro do tubo que, como será observado mais adiante, afeta o padrão de escoamento. 


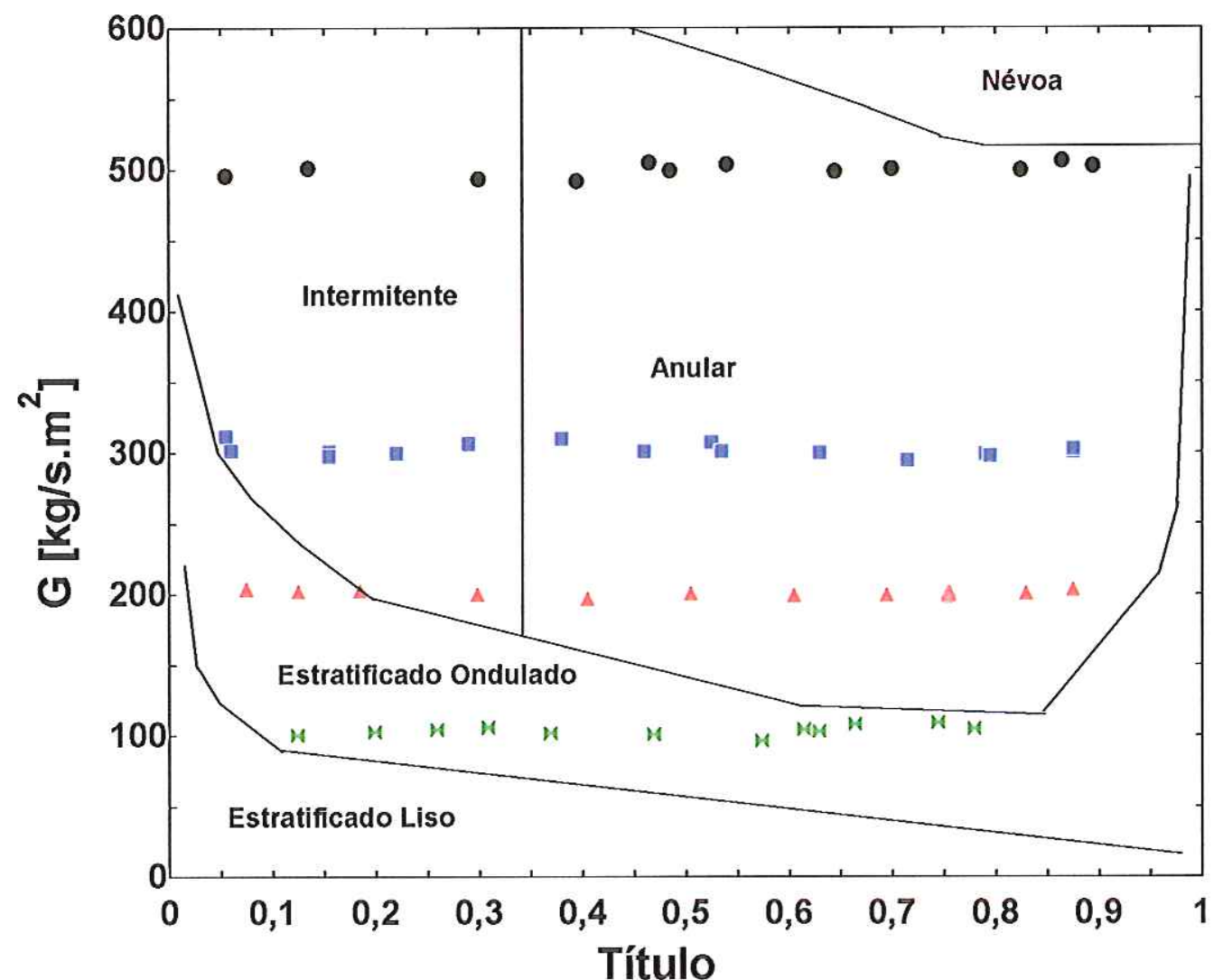

Figura 4.23 Resultados experimentais inseridos no mapa de KATTAN et al (1998), obtidos para as condições: $\mathrm{R} 134 \mathrm{a}, \mathrm{T}_{\text {Evap }}=5^{\circ} \mathrm{C}, \phi=5 \mathrm{~kW} / \mathrm{m}^{2}$ e D=9,52mm.

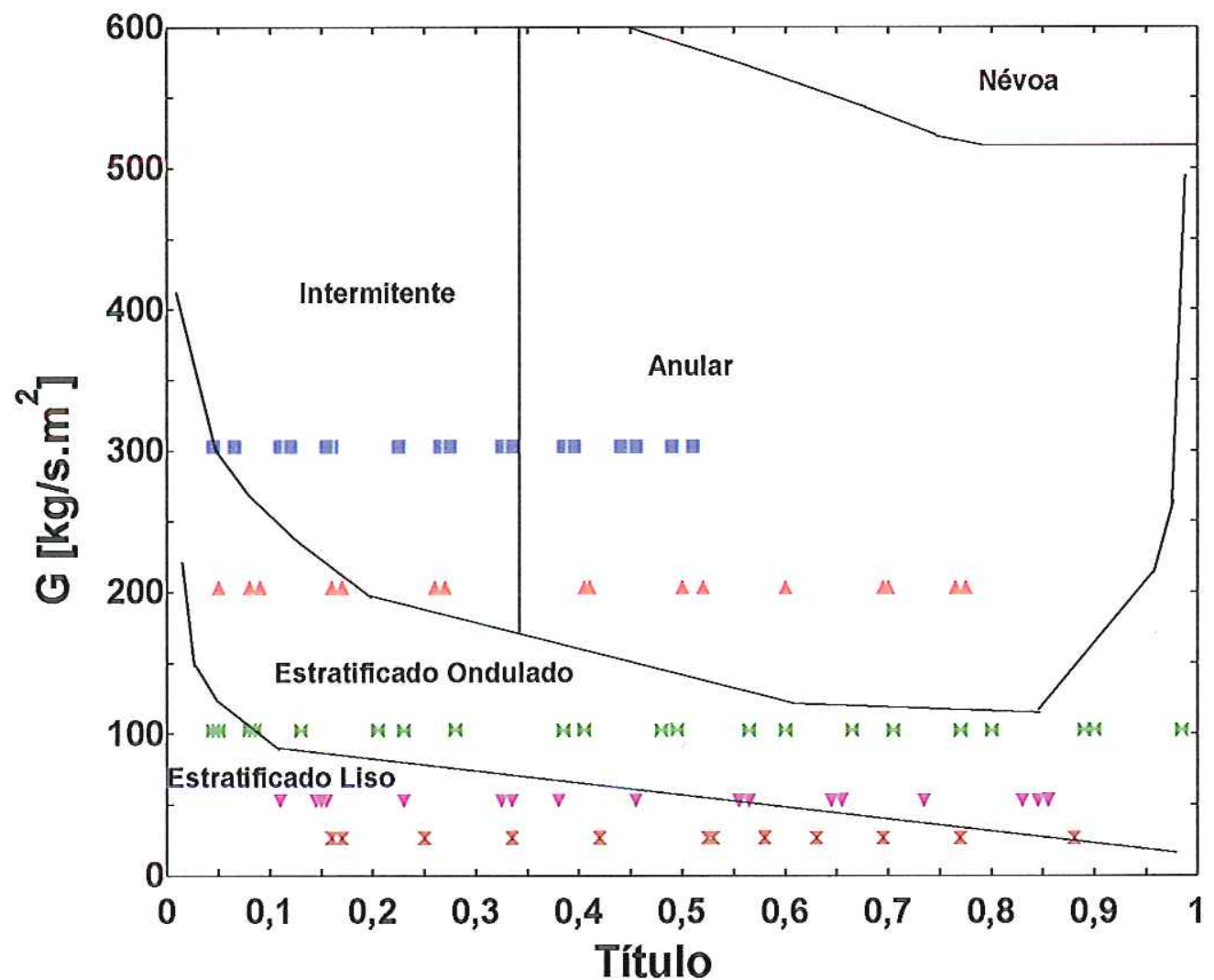

Figura 4.24 Resultados experimentais inseridos no mapa de KATTAN et al (1998), obtidos para as condições: R-134a, $\mathrm{T}_{\text {Evap }}=5^{\circ} \mathrm{C}, \phi=5$ e $10 \mathrm{~kW} / \mathrm{m}^{2}$ e D=17,4mm. 
Em relação aos tubos microaletados, não foram encontrados na literatura mapas que identifiquem os padrões para escoamento no interior desses tubos. A sugestão de um mapa de padrão de escoamento simplificado para tubos microaletados horizontais, surgiu devido a dois motivos principais: a inexistência de um mapa para identificação do padrão de escoamento em tubos microaletados e a extensa gama de pontos experimentais levantados para esses tubos no presente trabalho. Nessas condições, fundamentado em observações visuais, através de registros fotográficos, do comportamento do coeficiente de transferência de calor e da perda de carga, foi possível levantar um mapa, com base num certo subjetivismo e naquele apresentado anteriormente, proposto por KATTAN et al (1998), que é função apenas da velocidade mássica, $\mathrm{G}$, título, $\mathrm{x}$, e fluido refrigerante.

Inicialmente, foram definidos os padrões de escoamento observados em tubos microaletados. Na região de títulos reduzidos o padrão dominante foi o intermitente. Para títulos intermediários, ficou claro o domínio do padrão anular, salvo para velocidades mássicas elevadas. Já, para títulos elevados, o padrão em névoa predominou, principalmente para velocidades mássicas superiores a $300 \mathrm{~kg} / \mathrm{s} \cdot \mathrm{m}^{2}$.

Com a definição dos padrões de escoamento, o passo seguinte consistiu em avaliar a transição entre os padrões mencionados anteriormente. Nesse sentido, os dados experimentais, que se encontravam na faixa de transição, foram analisados cuidadosamente com o objetivo de se definir as linhas de transição. Nessa etapa, a análise minuciosa do comportamento do coeficiente de transferência de calor e da perda de carga foi determinante para se definir a faixa de transição entre os padrões de escoamento. Finalmente, definidas as linhas de transição, os resultados experimentais foram incorporados ao mapa com a finalidade de verificar, principalmente, a região onde ocorre a mudança do padrão de escoamento.

A Fig. 4.25 ilustra o mapa de padrão de escoamento proposto para tubos microaletados. É interessante observar que, nesse mapa, o padrão de escoamento estratificado não aparece, mesmo com vazões reduzidas, $\mathrm{G}<100 \mathrm{~kg} / \mathrm{s} . \mathrm{m}^{2}$. Isso se deve, principalmente, ao líquido que se desloca para a região superior do tubo, através dos canais, configurando, dessa maneira, o padrão anular de escoamento. Como observado anteriormente, para velocidades mássicas da ordem de $500 \mathrm{~kg} / \mathrm{s} . \mathrm{m}^{2}$, em tubos microaletados, o padrão em névoa verificou-se para títulos superiores a $50 \%$. Já para tubos lisos, esse padrão ocorre para títulos acima de $90 \%$. Esse mapa de escoamento ilustra, ainda, que o padrão anular de escoamento predomina, o que representa, em termos da transferência de calor, a melhor configuração. 
Os resultados experimentais levantados para tubos microaletados, excetuando-se os dados para o tubo Duplo-V, foram inseridos neste mapa, como mostra a Fig. 4.26. É possível observar que a maioria dos pontos, cerca de $78 \%$, se enquadraram na região de padrão anular, $8 \%$ na região de domínio do padrão intermitente e $14 \%$ da totalidade de pontos na região do padrão em névoa.

Esse mapa retrata, ainda, que, em termos de transferência de calor, o ideal seria operar com velocidades mássicas inferiores a $\mathrm{G}=200 \mathrm{~kg} / \mathrm{s} \cdot \mathrm{m}^{2}$, já que os padrões encontrados durante a evaporação do refrigerante seriam o intermitente $\mathrm{e}$, principalmente, o anular para toda a faixa de títulos. Vale destacar que, para essa faixa de vazões, os pontos estão localizados fora da região de predomínio do padrão em névoa, pois, nesse caso, a perda de carga se eleva consideravelmente e o coeficiente de transferência de calor tem seu valor reduzido.

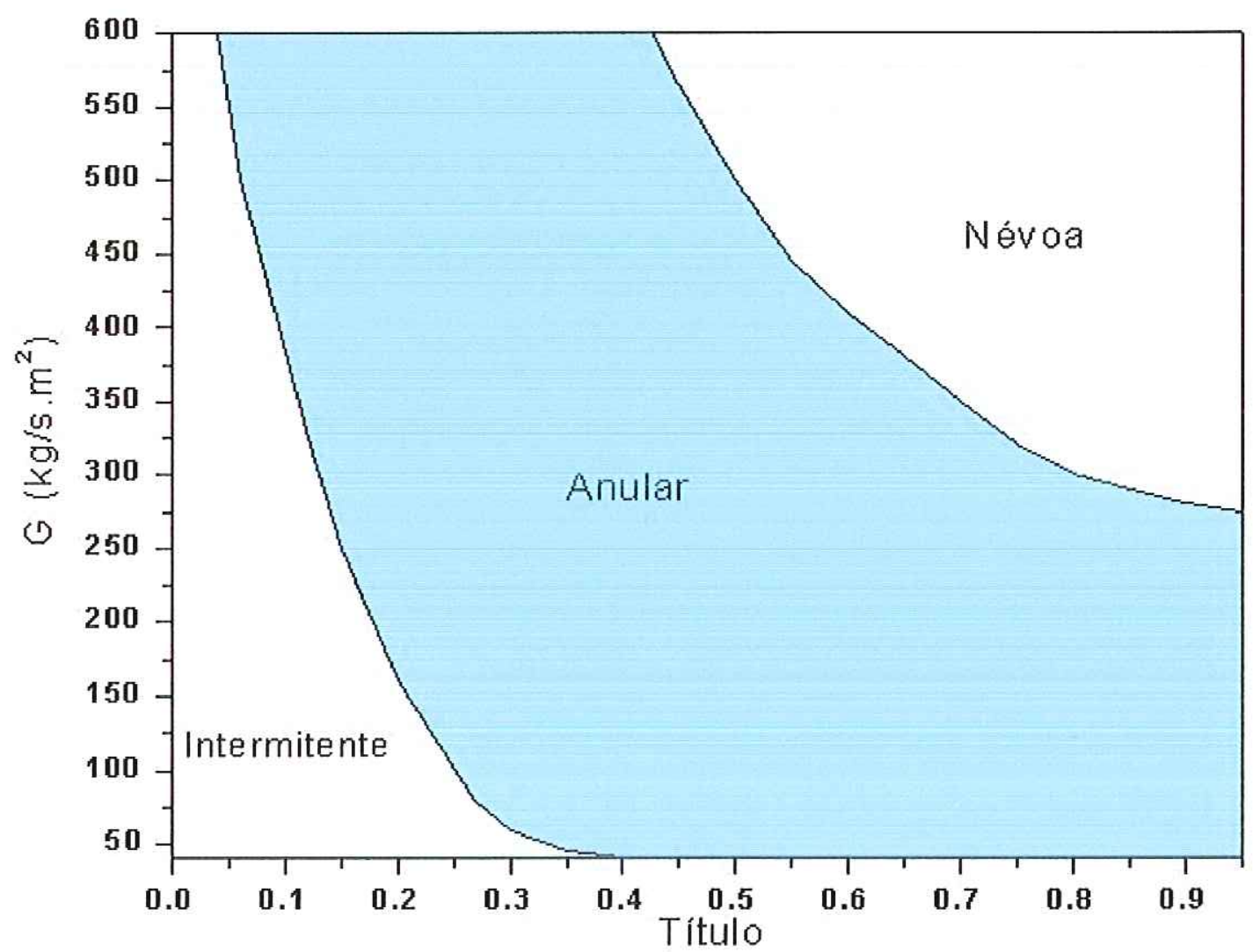

Figura 4.25 Mapa de padrão de escoamento válido para tubos microaletados. 


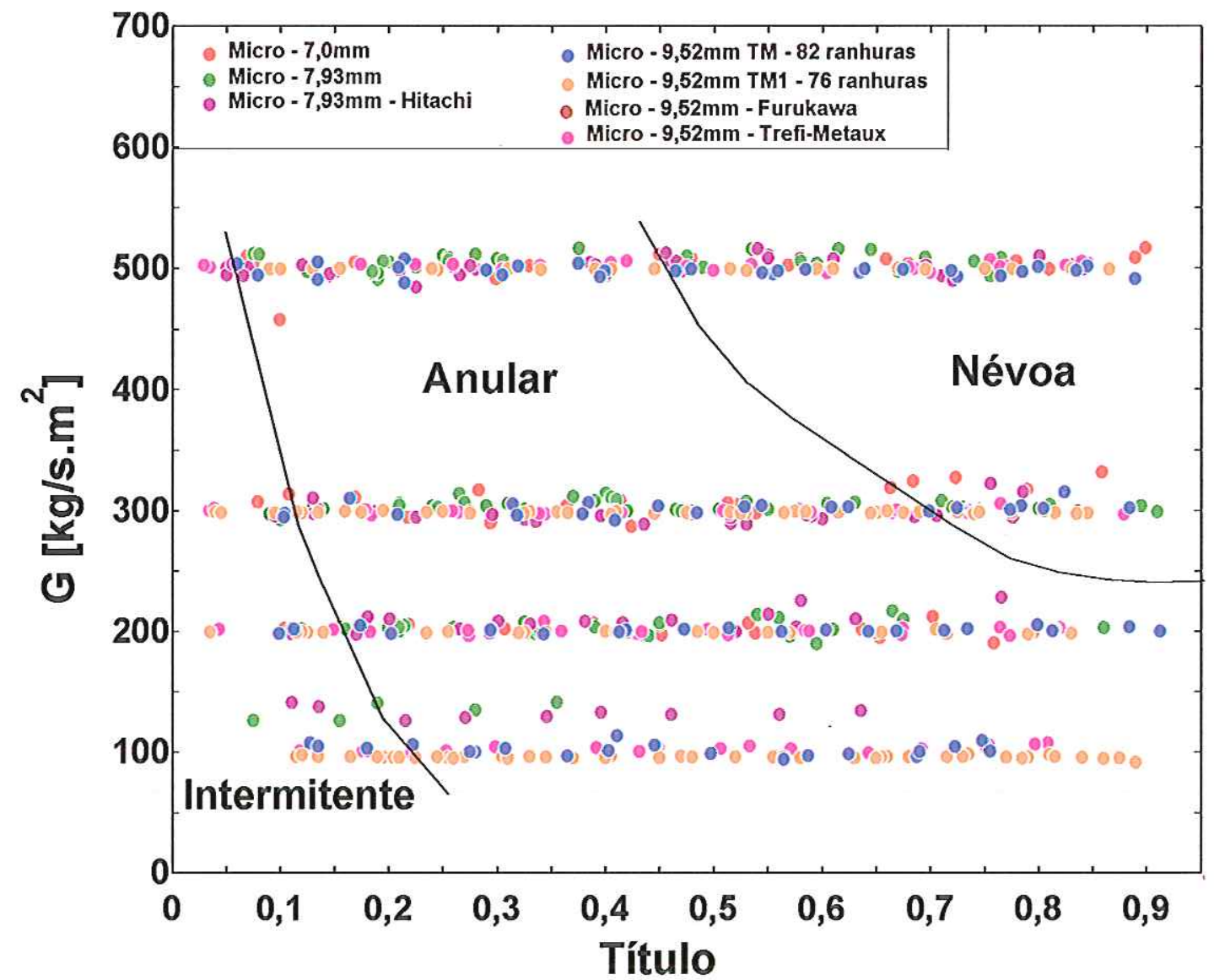

Figura 4.26 Mapa de padrão de escoamento para tubos microaletados, incluindo os pontos experimentais obtidos no presente trabalho. 


\subsubsection{Transferência de Calor em Tubos Lisos}

A seguir serão analisados e discutidos os principais parâmetros fisicos que intervêm na transferência de calor no interior de tubos.

\subsection{Efeito da Velocidade Mássica}

A velocidade mássica, $G$, é um dos parâmetros que mais afetam o coeficiente de transferência de calor, além de ser determinante no estabelecimento dos padrões de escoamento em mudança de fase. Como mencionado no capítulo anterior, a velocidade mássica nos ensaios variou entre 25 e $500 \mathrm{~kg} / \mathrm{s}^{\mathrm{m}} \mathrm{m}^{2}$, para escoamento com mudança de fase. Entretanto, para escoamento adiabático, foram atingidos valores de G da ordem de 1100 $\mathrm{kg} / \mathrm{s} . \mathrm{m}^{2}$. A faixa de velocidades mássicas ensaiadas para escoamento com mudança de fase, além de representar as condições típicas daquelas encontradas em instalações frigoríficas, permitiu inferir o efeito deste parâmetro na transição entre alguns padrões de escoamento. A janela de visualização do escoamento possibilitou, ainda, a observação de padrões de escoamento e sua relação com a velocidade mássica.

A Fig. 4.27 ilustra o comportamento típico do coeficiente de transferência de calor em função do título, para velocidades mássicas extensivas à faixa de valores ensaiada para o tubo de $12,7 \mathrm{~mm}$ de diâmetro interno, uma temperatura de evaporação de $15^{\circ} \mathrm{C}$ e fluxo de calor específico de $5 \mathrm{~kW} / \mathrm{m}^{2}$. De uma maneira geral, os resultados podem ser agrupados em duas faixas de velocidades mássicas:

$\varangle$ Inferiores a $200 \mathrm{~kg} / \mathrm{s} \cdot \mathrm{m}^{2}$, onde o padrão estratificado prevalece em toda a faixa de títulos considerada.

G Superiores a $200 \mathrm{~kg} / \mathrm{s} \cdot \mathrm{m}^{2}$, em que predomina o padrão anular de escoamento para títulos, geralmente, acima de $20 \%$, e o intermitente para títulos inferiores a esse valor.

\section{Faixa de Velocidades Mássicas Fieduzidas $\left(\mathrm{G}<20 \wp \mathrm{kg} / \mathrm{s} . \mathrm{m}^{2}\right)$}

Para a faixa de velocidades mássicas reduzidas o coeficiente de transferência de calor apresenta uma leve queda à medida que o título aumenta. Esse comportamento está intimamente relacionado aos padrões de escoamento verificados para essa faixa de vazões, padrão estratificado e ondulado, Figs. 4.19 e 4.20, respectivamente. Nesse caso, conforme o título é incrementado, a espessura do filme de líquido diminui, resultando num aumento da 
área interna do tubo exposta ao vapor. Isso pode ser confirmado, observando as Figs. 4.28 (a) e (b), pois, à medida que o título aumenta, as temperaturas da parede, principalmente a superior e lateral, se elevam gradualmente, fazendo com que o coeficiente de transferência de calor diminua. Estas figuras mostram a distribuição da temperatura da parede nas seções 2 e 4 (distantes 0,8 e $1,6 \mathrm{~m}$ da entrada da seção de testes) em escoamento com padrão estratificado, para as condições especificadas na legenda, com fluxo de calor de 5 e 20 $\mathrm{kW} / \mathrm{m}^{2}$. Observa-se que a temperatura medida na geratriz superior do tubo é maior que aquela observada na geratriz inferior, como seria de esperar, pois a região superior do tubo está em contato com o vapor. É importante notar que as diferenças entre as temperaturas da parede nas regiões inferior e superior aumentam com o fluxo de calor. Assim, para $5 \mathrm{~kW} / \mathrm{m}^{2}$ (Fig. 4.28 a) a diferença é da ordem de $1^{\circ} \mathrm{C}$, e para $20 \mathrm{~kW} / \mathrm{m}^{2}$ (Fig. $4.28 \mathrm{~b}$ ) alcança $4^{\circ} \mathrm{C}$. Deve-se observar, ainda, na Fig. 4.28 b, que, para títulos da ordem de $90 \%$, a temperatura da parede na seção 4 apresenta uma elevação da ordem de $2^{\circ} \mathrm{C}$. Isso é uma clara indicação de secagem de parede, ao passo que na seção 2 a superfície do tubo ainda está em contato com o líquido, pois não se observam alterações.

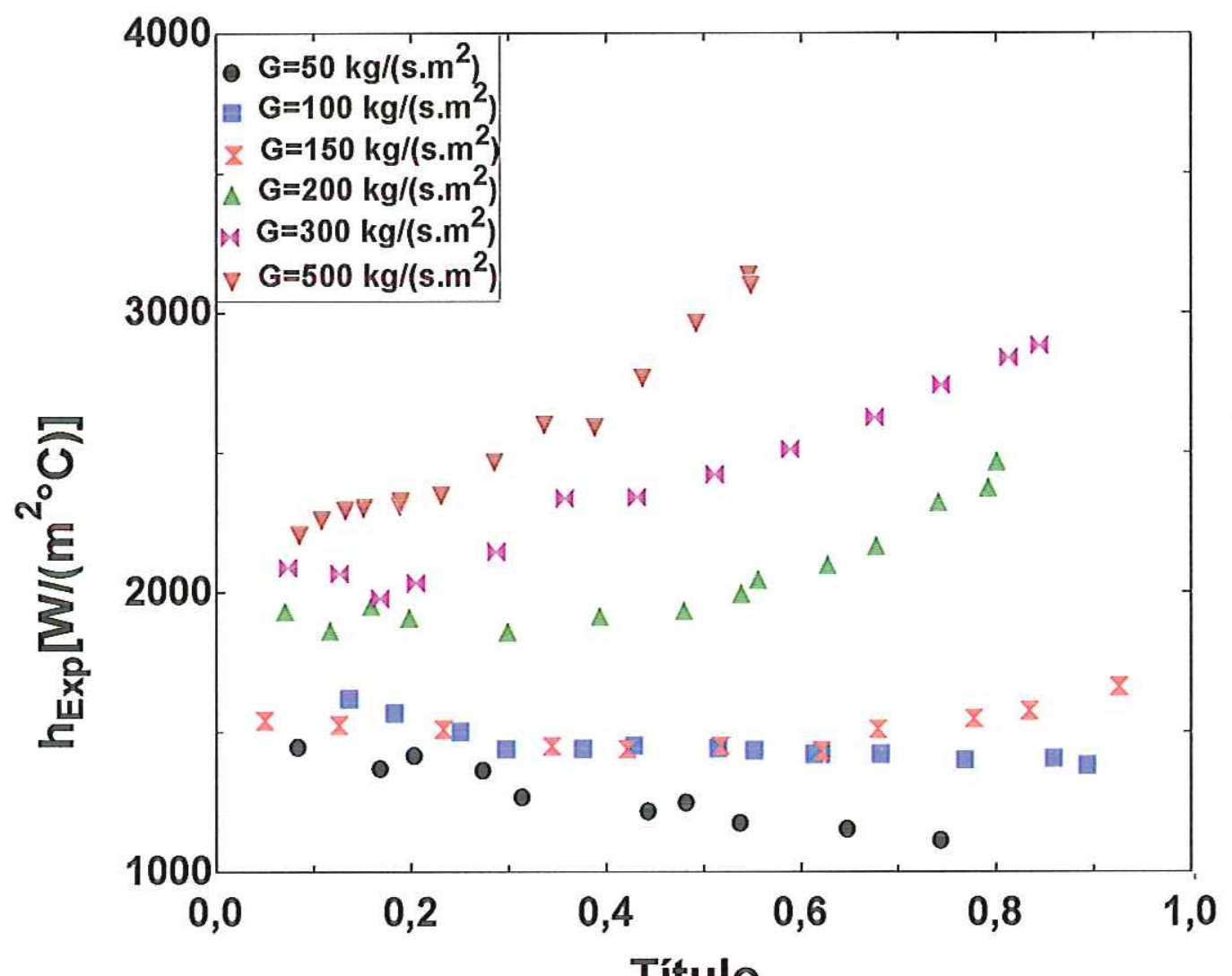

Figura 4.27 Resultados experimentais para o R-22 nas condições: $\mathrm{T}_{\text {Evap }}=15^{\circ} \mathrm{C}$, $\phi=5 \mathrm{~kW} / \mathrm{m}^{2}$ e $\mathrm{D}=12,7 \mathrm{~mm}$. 


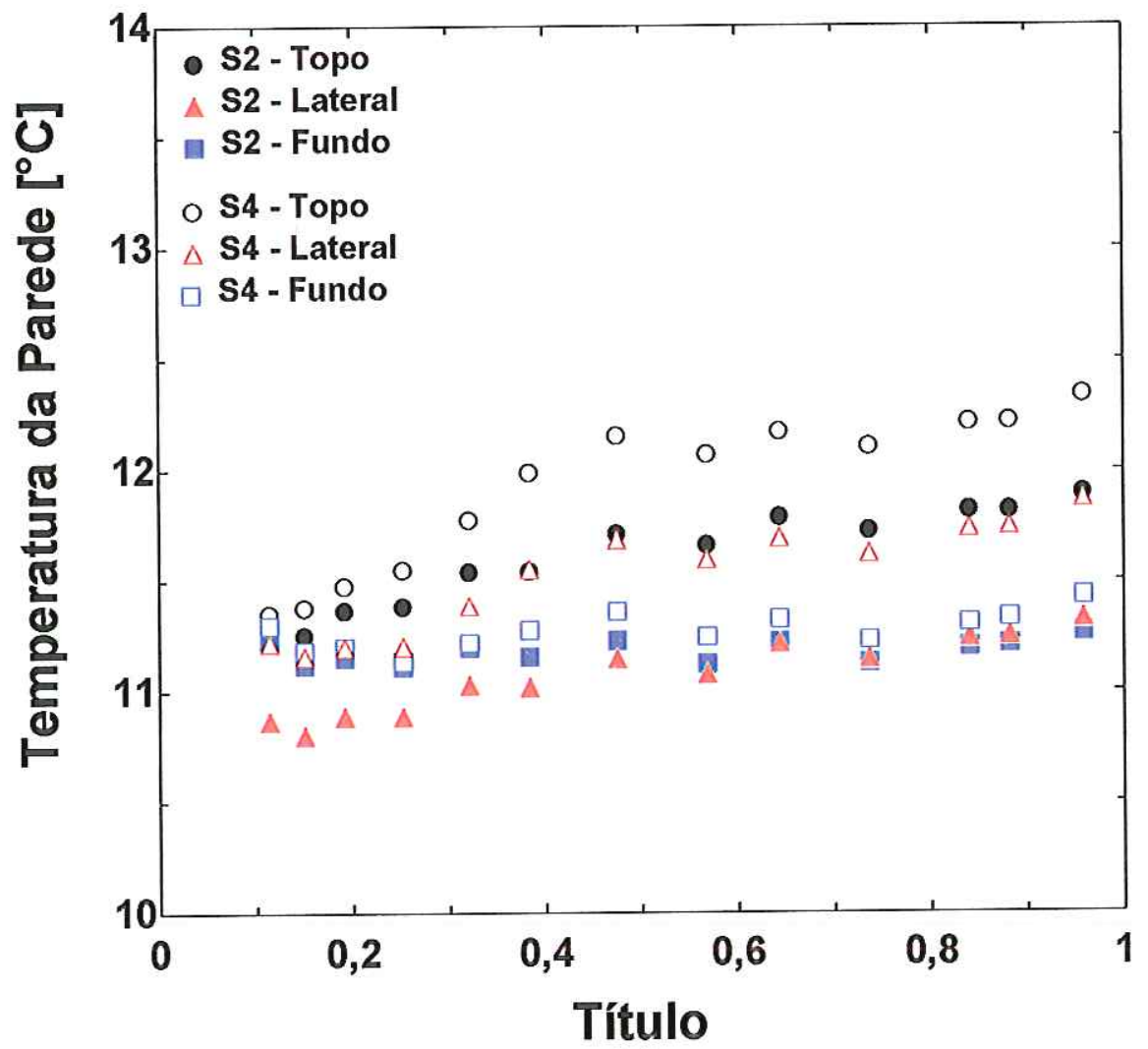

(a)

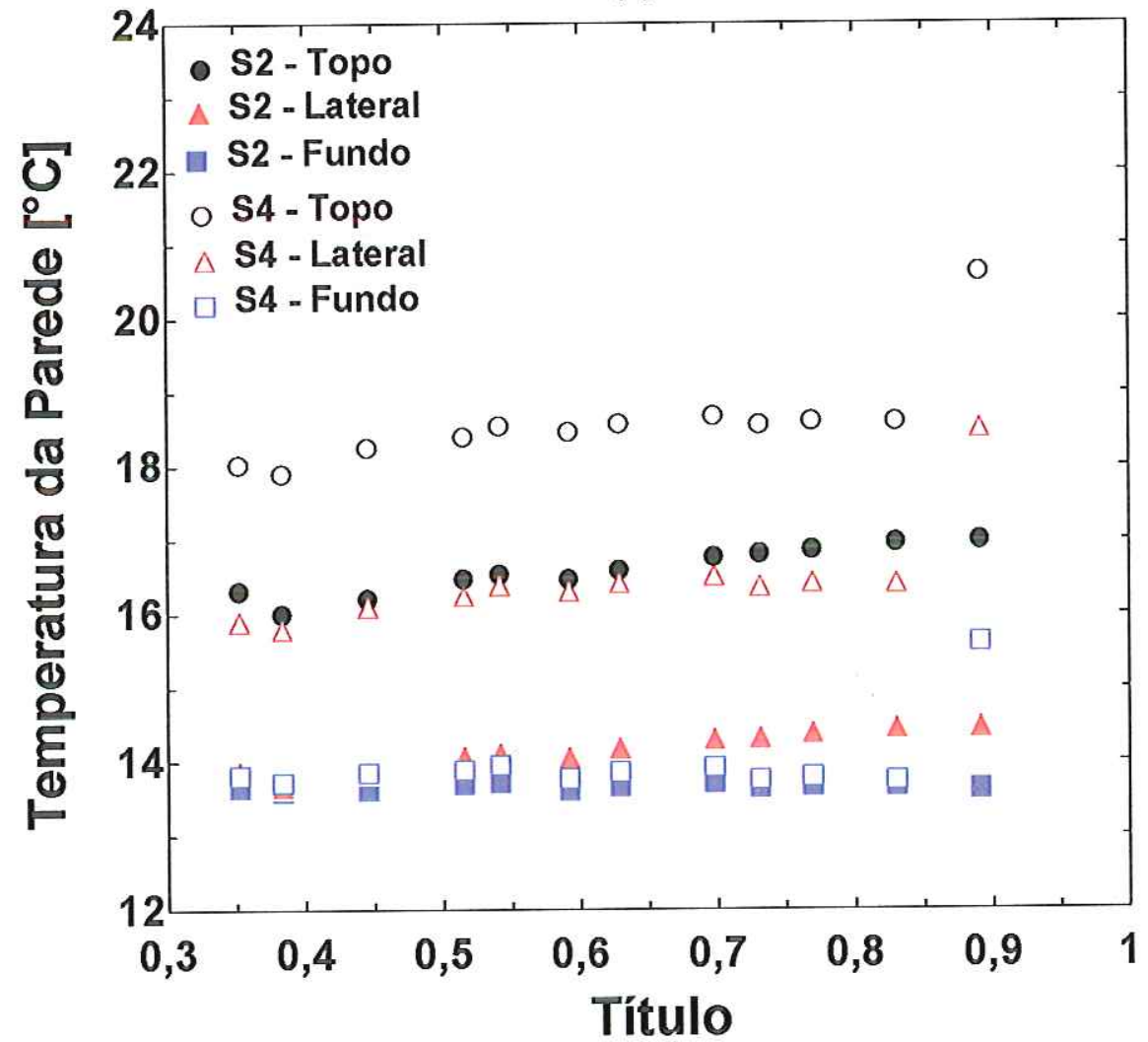

(b)

Figura 4.28 Resultados experimentais para o R-22 nas condições: $T_{\text {Evap }}=8^{\circ} \mathrm{C}, \mathrm{D}=12,7 \mathrm{~mm} \mathrm{e}$ $\mathrm{G}=100 \mathrm{~kg} / \mathrm{s} \cdot \mathrm{m}^{2}$. (a) $\phi=5 \mathrm{~kW} / \mathrm{m}^{2}$ e (b) $\phi=20 \mathrm{~kW} / \mathrm{m}^{2}$. 


\section{Faixa de Velocidades Mássicas Elevadas (G $>200 \mathrm{~kg} / \mathrm{s.m}^{2}$ )}

Para velocidades mássicas elevadas o coeficiente de transferência de calor apresenta um comportamento distinto, dependendo do título. Verifica-se, na Fig. 4.27, um mínimo local para o coeficiente, geralmente para títulos da ordem de $20 \%$, porém variando com a velocidade mássica e fluido refrigerante. Isso, possivelmente, está relacionado à transição do padrão intermitente, associado à ebulição nucleada, para o anular, característico da ebulição estritamente convectiva. Como pode ser observado, ainda na Fig. 4.27, para títulos superiores a $20 \%$, especialmente para $\mathrm{G}=300$ e $500 \mathrm{~kg} / \mathrm{s} \cdot \mathrm{m}^{2}$, percebe-se que o coeficiente de transferência de calor apresenta um crescimento com o título, correspondendo ao estabelecimento do padrão anular, que se caracteriza pela presença de um filme de líquido assimétrico ao longo da superficie interior do tubo, com a maior espessura na região inferior, com o vapor escoando na região central, como ilustra a fotografia da Fig. 4.18. A evaporação na interface líquido/vapor reduz a espessura da película de líquido aderida à parede, o que causa uma elevação do coeficiente de transferência de calor, pois, a resistência térmica $\left(\delta / \mathrm{k}_{\mathrm{L}}\right)$ associada ao filme de líquido é o fator determinante da taxa de transferência de calor na parede do tubo.

A Fig. 4.29 foi incluída neste contexto com o objetivo de ilustrar os resultados experimentais obtidos para o refrigerante R-134a, incorporando as barras de incerteza associadas aos pontos experimentais. Os resultados foram levantados para o tubo liso de 9,52mm de diâmetro, temperatura de evaporação na entrada da seção de testes de $5^{\circ} \mathrm{C}$ e fluxo de calor específico de $5 \mathrm{~kW} / \mathrm{m}^{2}$. O efeito da velocidade mássica, discutido nos parágrafos precedentes, é confirmado pelos resultados apresentados nessa figura. Nota-se que, para $\mathrm{G}=100 \mathrm{~kg} / \mathrm{s} \cdot \mathrm{m}^{2}$ e títulos superiores a $60 \%$, o coeficiente de transferência de calor apresenta um comportamento distinto daquele observado anteriormente. Isso se deve, possivelmente, à mudança de padrão de escoamento, que será discutido mais adiante no efeito do diâmetro do tubo. É interessante observar, ainda, que as maiores incertezas estão relacionadas aos coeficientes mais elevados, uma vez que tais coeficientes estão associados a menores diferenças entre a temperatura da parede e de evaporação. Por outro lado, os coeficientes de transferência de calor relativos à velocidade mássica de $100 \mathrm{~kg} / \mathrm{s} . \mathrm{m}^{2}$, apresentam incertezas absolutas inferiores àqueles obtidos para velocidades mássicas superiores, como seria de esperar, já que as diferenças entre as temperaturas são maiores. 


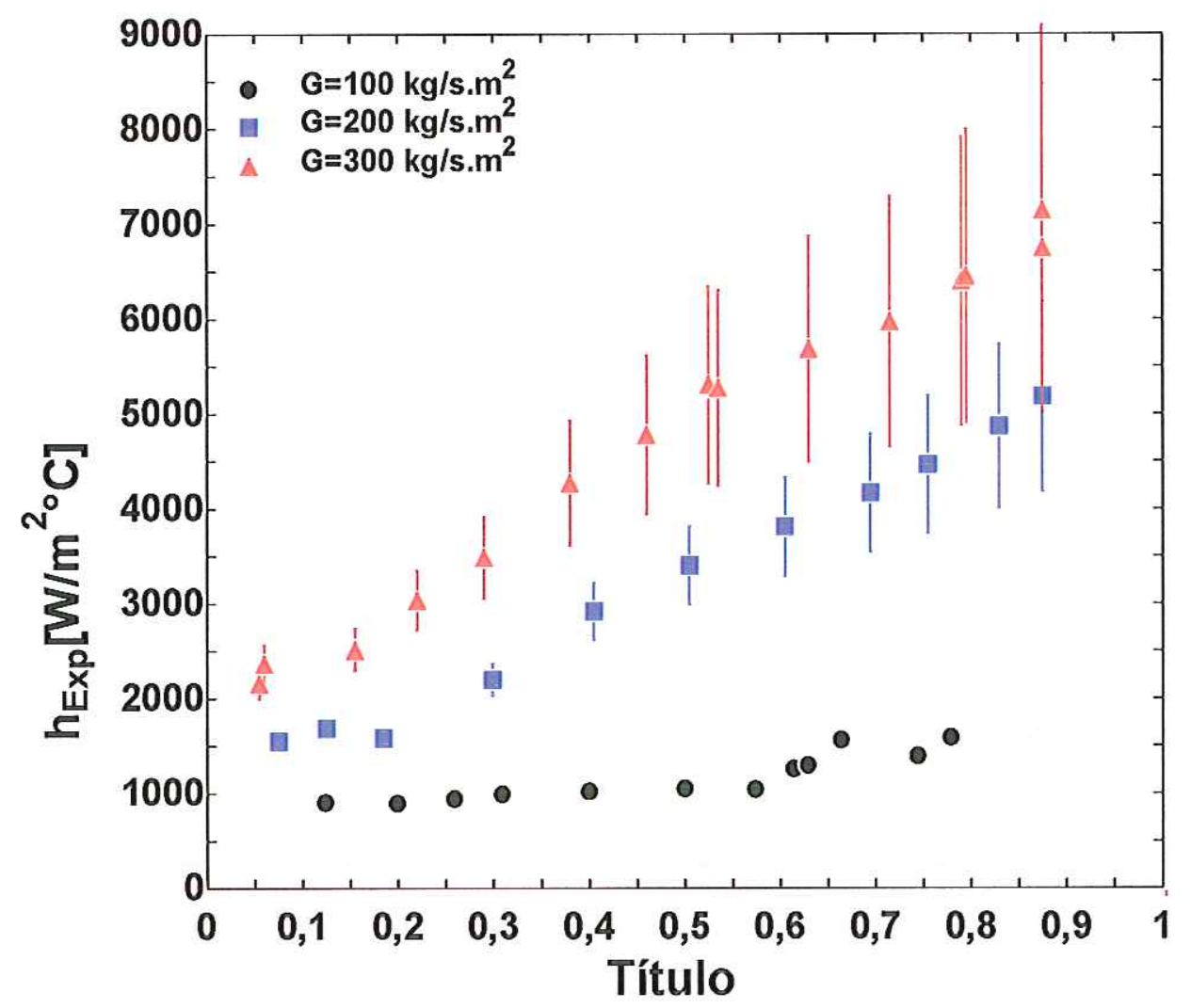

Figura 4.29 Resultados experimentais para o R-134a nas condições: $\mathrm{T}_{\text {Evap }}=5^{\circ} \mathrm{C}$, $\phi=5 \mathrm{~kW} / \mathrm{m}^{2}$ e $\mathrm{D}=9,52 \mathrm{~mm}$.

\subsection{Efeito do Refrigerante}

Apesar dos fluidos refrigerantes ensaiados no presente trabalho pertencerem à categoria dos derivados halogenados de hidrocarbonetos, os mesmos apresentam propriedades de transporte dissimilares, o que deve, possivelmente, afetar as características de transferência de calor. A Tabela 4.4 ilustra uma comparação entre as principais propriedades de transporte dos fluidos refrigerantes (R-22, R-134a, R-404A, R-407C e R417A) para temperatura de saturação de $5^{\circ} \mathrm{C}$. É possível observar que há diferenças significativas, destacando-se a viscosidade, a qual para o R-134a é $90 \%$ superior a do R404A. Outra propriedade que merece ser destacada é o número de Prandtl, $\operatorname{Pr}_{\mathrm{L}}$, para o R134a, que apresenta um incremento de $92 \%$ em relação ao do R-22. 
Tabela 4.4 Propriedades de transporte dos refrigerantes à temperatura de saturação de $5^{\circ} \mathrm{C}$.

\begin{tabular}{|c|c|c|c|c|c|c|}
\hline Fluido / Propriedade & $\mu_{\mathrm{L} \text { (Pa.s) } .10^{6}}$ & $\rho_{L}\left(\mathrm{~kg} / \mathrm{m}^{3}\right)$ & $\mathrm{k}_{\mathrm{L}}\left(\mathrm{W} / \mathrm{m}^{\circ} \mathrm{C}\right)$ & $\mathrm{cp}_{\mathrm{L}}\left(\mathrm{J} / \mathrm{kg} \mathrm{g}^{\circ} \mathrm{C}\right)$ & $\operatorname{Pr}_{L}$ & $\sigma(\mathrm{N} / \mathrm{m})$ \\
\hline $\mathrm{R}-22$ & 185,0 & 1268 & 0,0976 & 1173 & 2,22 & 0,011 \\
\hline R-134a & 311,9 & 1279 & 0,0971 & 1327 & 4,26 & 0,0109 \\
\hline $\mathrm{R}-404 \mathrm{~A}$ & 164,1 & 1129 & 0,0748 & 1397 & 3,07 & 0,0063 \\
\hline $\mathrm{R}-407 \mathrm{C}$ & 192,8 & 1215 & 0,0926 & 1449 & 3,02 & 0,0099 \\
\hline $\mathrm{R}-417 \mathrm{~A}$ & 213,9 & 1233 & 0,0799 & 1349 & 3,61 & 0,0094 \\
\hline
\end{tabular}

As características de transferência de calor são afetadas pelo gradiente de temperatura na parede, que, por sua vez, depende do padrão de escoamento. Estes efeitos são ilustrados nas Figs. 4.30 e 4.31. A primeira, apresenta a variação do coeficiente de transferência de calor em função do título para os refrigerantes R-22, R-134a, R-404A e R$407 \mathrm{C}$, para as condições especificadas na legenda. Observa-se que o padrão anular predomina em toda a faixa de títulos $(0,2$ a 0,9$)$ e, para títulos inferiores, o padrão intermitente, onde prevalecem os efeitos de ebulição nucleada.

De acordo com o exposto nos parágrafos precedentes, na Fig. 4.30, é possível afirmar que os refrigerantes ensaiados apresentam o mesmo padrão de escoamento, no caso o anular. A diferença que se observa nos coefícientes de transferência de calor está relacionada às propriedades de transporte destes refrigerantes, que determinam a espessura do filme de líquido e, conseqüentemente, a resistência térmica. Nota-se que o R-134a apresenta o coeficiente de transferência de calor mais elevado, ao passo que o R-404A se caracteriza por apresentar o menor, para títulos superiores a $35 \%$. Este comportamento pode ser justificado analisando a resistência térmica do filme de líquido, $\delta / \mathrm{k}_{\mathrm{L}}$, que é o fator determinante na transferência de calor no padrão anular. De acordo com a Tabela 4.5, para uma temperatura de evaporação de $5{ }^{\circ} \mathrm{C}$ e título de $20 \%$, percebe-se que o refrigerante $\mathrm{R}-134 \mathrm{a}$ apresenta a razão entre as densidades do líquido e vapor $\left(\rho_{\mathrm{L}} / \rho_{\mathrm{V}}\right)$ e fração de vazio superiores aos demais, o que resulta num valor de $\delta$ inferior e, conseqüentemente, menor resistência térmica da película de líquido. Assim, como seria de esperar, o coeficiente de transferência de calor para o R-134a deve apresentar os maiores valores, ao passo que para o R-404A os menores.

Tabela 4.5 Resistència térmica do filme de líquido de refrigerantes para o padrão anular.

\begin{tabular}{|c|c|c|c|c|}
\hline Fluido / Propriedade & $\rho_{\mathrm{L}} / \rho_{\mathrm{V}}$ & $\alpha$ & $\delta(\mathbf{m m})$ & $\delta / \mathbf{k}_{\mathbf{L}}\left(\mathbf{m}^{2} \cdot{ }^{\circ} \mathbf{C} / \mathrm{W}\right)$ \\
\hline $\mathrm{R}-134 \mathrm{a}\left(\mathrm{T}_{\text {Evap }}=5^{\circ} \mathrm{C}\right)$ & 74,1 & 0,815 & 0,617 & 6,35 \\
\hline $\mathrm{R}-22\left(\mathrm{~T}_{\text {Evap }}=5^{\circ} \mathrm{C}\right)$ & 51,2 & 0,775 & 0,760 & 7,78 \\
\hline $\mathrm{R}-407 \mathrm{C}\left(\mathrm{T}_{\text {Evap }}=5^{\circ} \mathrm{C}\right)$ & 54,3 & 0,714 & 0,735 & 7,94 \\
\hline $\mathrm{R}-404 \mathrm{~A}\left(\mathrm{~T}_{\text {Evap }}=5^{\circ} \mathrm{C}\right)$ & 31,6 & 0,782 & 0,983 & 13,14 \\
\hline
\end{tabular}




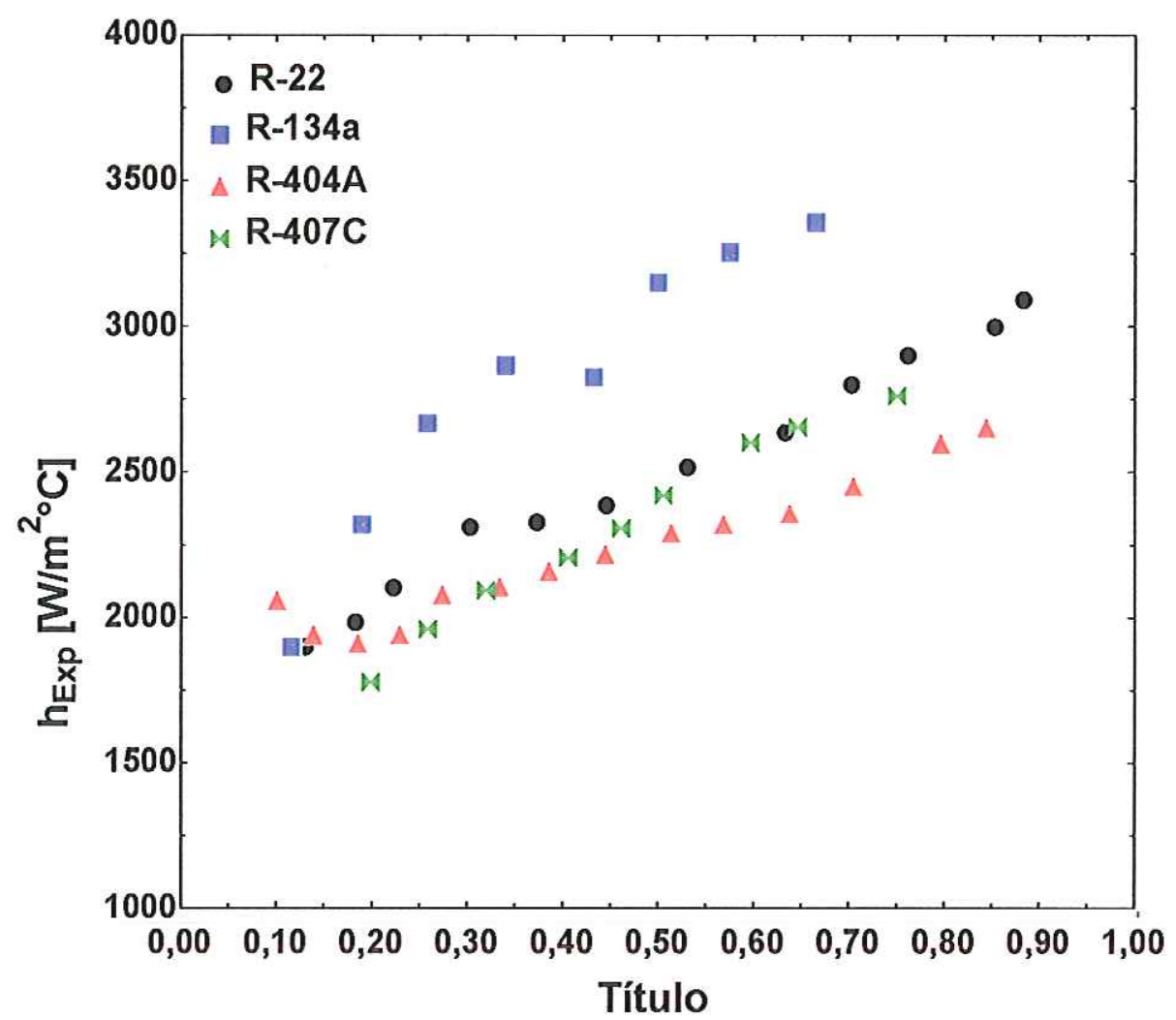

Figura 4.30 Resultados experimentais para os fluidos R-22, R-134a, R-404A e R-407C para as condições: $\mathrm{T}_{\text {Evap }}=8^{\circ} \mathrm{C}, \phi=5 \mathrm{~kW} / \mathrm{m}^{2}, \mathrm{G}=300 \mathrm{~kg} / \mathrm{s} \cdot \mathrm{m}^{2}$ e $\mathrm{D}=12,7 \mathrm{~mm}$.

A Fig. 4.31, correspondendo a $\mathrm{G}=200 \mathrm{~kg} / \mathrm{s} . \mathrm{m}^{2}$, ilustra claramente o efeito do refrigerante na transição entre os padrões de escoamento. Pode-se afirmar que tal velocidade mássica corresponde a uma condição limite para a mudança do regime intermitente para o padrão anular de escoamento. Vale salientar, ainda, que para o refrigerante R-134a, a transição para o padrão anular ocorre para títulos da ordem de $15 \%$, enquanto para o R-407C se dá somente para $25 \%$. Para o refrigerante R-22 o padrão anular se estabelece em títulos da ordem de $30 \%$, ao passo que para o R-404A apenas a partir de títulos superiores a $55 \%$. Relacionando os resultados apresentados na Fig. $4.31 \mathrm{com}$ as propriedades de transporte dos refrigerantes da Tab. 4.4, percebe-se uma relação entre a transição para o padrão anular e a viscosidade dos refrigerantes. Nesse caso, quanto maior a viscosidade do refrigerante a transição para o padrão anular se dá com títulos menores. Entretanto, novos estudos deverão ser realizados com o objetivo de relacionar a viscosidade, $\mu$, além da fração de vazio, $\alpha$, com a transição do padrão intermitente para o anular para distintos refrigerantes. 


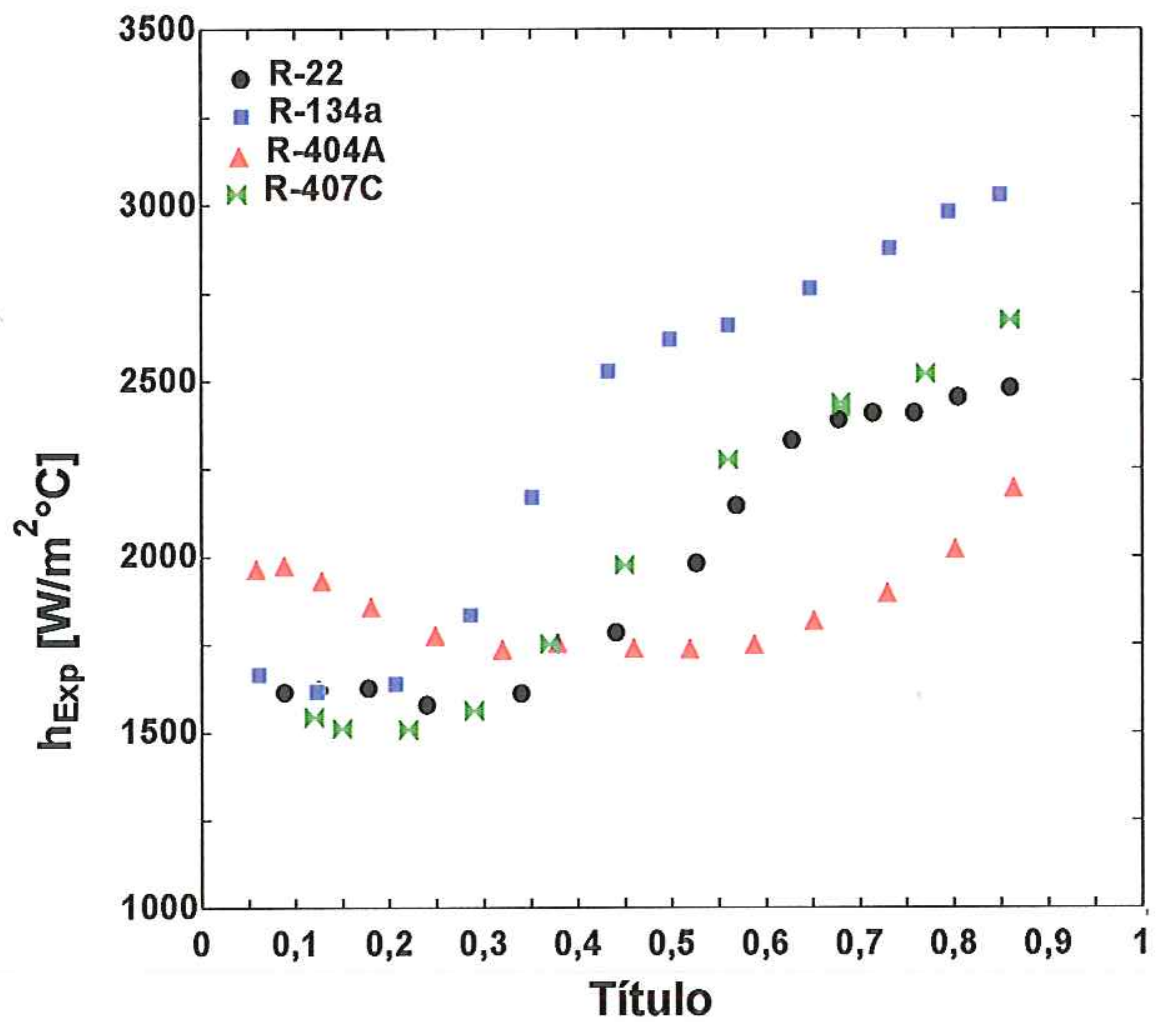

Figura 4.31 Resultados experimentais para os fluidos R-22, R-134a, R-404A e R-407C para as condições: $\mathrm{T}_{\text {Evap }}=8^{\circ} \mathrm{C}, \phi=5 \mathrm{~kW} / \mathrm{m}^{2}, \mathrm{G}=200 \mathrm{~kg} / \mathrm{s} \cdot \mathrm{m}^{2}$ e $\mathrm{D}=12,7 \mathrm{~mm}$.

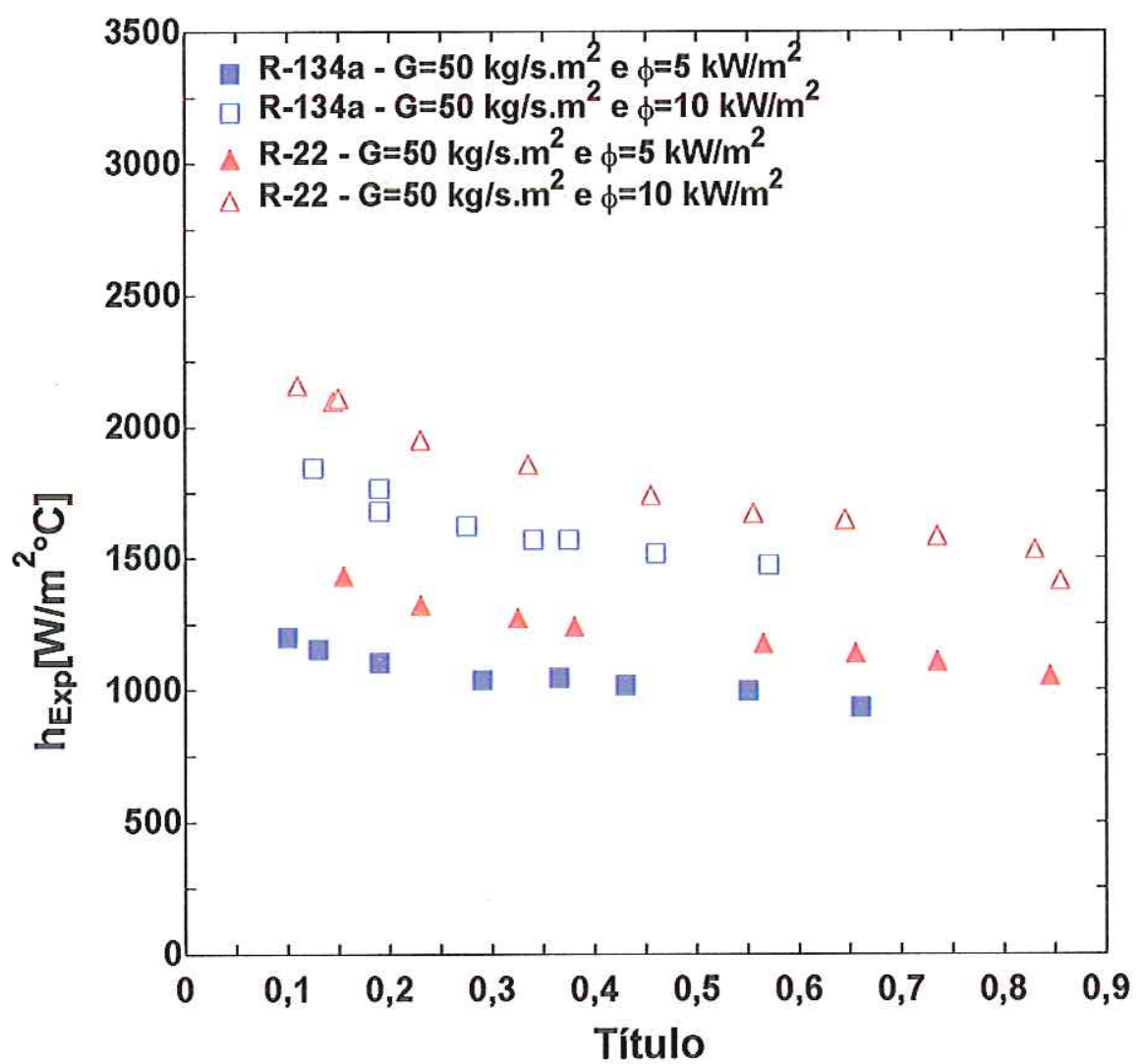

Figura 4.32 Resultados experimentais para os fluidos R-22 e R-134a para as condições: $\mathrm{T}_{\text {Evap }}=5^{\circ} \mathrm{C}, \phi$ entre 5 e $10 \mathrm{~kW} / \mathrm{m}^{2}, \mathrm{G}=50 \mathrm{~kg} / \mathrm{s} . \mathrm{m}^{2}$ e $\mathrm{D}=17,4 \mathrm{~mm}$. 
A Fig. 4.32 apresenta resultados para os refrigerantes R-134a e R-22 escoando em tubo de $17,4 \mathrm{~mm}$ de diâmetro interno, para uma velocidade mássica de $50 \mathrm{~kg} / \mathrm{s} \cdot \mathrm{m}^{2}$ e fluxos de calor de 5 e $10 \mathrm{~kW} / \mathrm{m}^{2}$, respectivamente. Deve-se esclarecer que o comportamento do coeficiente de transferência de calor é o característico do padrão estratificado, onde a fase líquida se encontra segregada na parte inferior do tubo. $\mathrm{O}$ coeficiente de transferência de calor para o R-22 foi superior ao R-134a para toda a faixa de títulos ensaiada e apresentou o mesmo comportamento para fluxos de calor distintos. Nota-se, ainda, que mesmo com a elevação do fluxo de calor, a tendência do coeficiente diminuir com o aumento do título permaneceu inalterada.

\subsection{Efeito do Fluxo de Calor Especifico}

O fluxo de calor específico afeta o coeficiente de transferência de calor nas duas faixas de velocidades mássicas apresentadas anteriormente. No caso de velocidades elevadas $\left(\mathrm{G}>200 \mathrm{~kg} / \mathrm{s} \cdot \mathrm{m}^{2}\right)$, o fluxo de calor afeta o coeficiente especialmente na região de títulos reduzidos, através de mecanismos associados à ebulição nucleada. Neste caso, o coeficiente de transferência de calor aumenta com o fluxo de calor, evidenciando a formação de bolhas. À medida que o título aumenta, as curvas associadas a distintos fluxos tendem a colapsar devido à supressão de bolhas pela, relativamente, baixa temperatura do filme de líquido que cobre toda a superfície do tubo, típico do padrão anular, como observado na Fig. 4.33. Esta figura, ilustra, ainda, um exemplo clássico, obtido a partir dos resultados de ensaios com o refrigerante R-407C para as seguintes condições: temperatura de evaporação da ordem de $8^{\circ} \mathrm{C}$, velocidade mássica de $200 \mathrm{~kg} / \mathrm{s} \mathrm{m}^{2}$, tubo de diâmetro interno de $12,7 \mathrm{~mm}$ e fluxo de calor específico de 5,10 e $20 \mathrm{~kW} / \mathrm{m}^{2}$. De acordo com o exposto anteriormente, na região de títulos reduzidos predominam os efeitos de ebulição nucleada, uma vez que o coeficiente de transferência de calor depende explicitamente do fluxo de calor. À medida que o título aumenta, o padrão anular de escoamento se estabelece, e, como seria de esperar, o resfriamento do líquido da película aderida à parede do tubo inibe a formação de bolhas, fazendo com que o coeficiente de transferência de calor não seja afetado pelo fluxo de calor. Dessa maneira, o coeficiente seria independente do fluxo de calor, passando a depender, exclusivamente, da velocidade mássica, o que caracteriza a região onde ocorre a ebulição estritamente convectiva. No caso da Fig. 4.33, o coeficiente de transferência de calor não é afetado pelo fluxo de calor para títulos acima de $35 \%$, para valores de $\phi$ de 5 e $10 \mathrm{~kW} / \mathrm{m}^{2}$. Já para fluxos de calor mais elevados, $\phi=20 \mathrm{~kW} / \mathrm{m}^{2}$, o coeficiente não é mais afetado para títulos superiores a $65 \%$. 


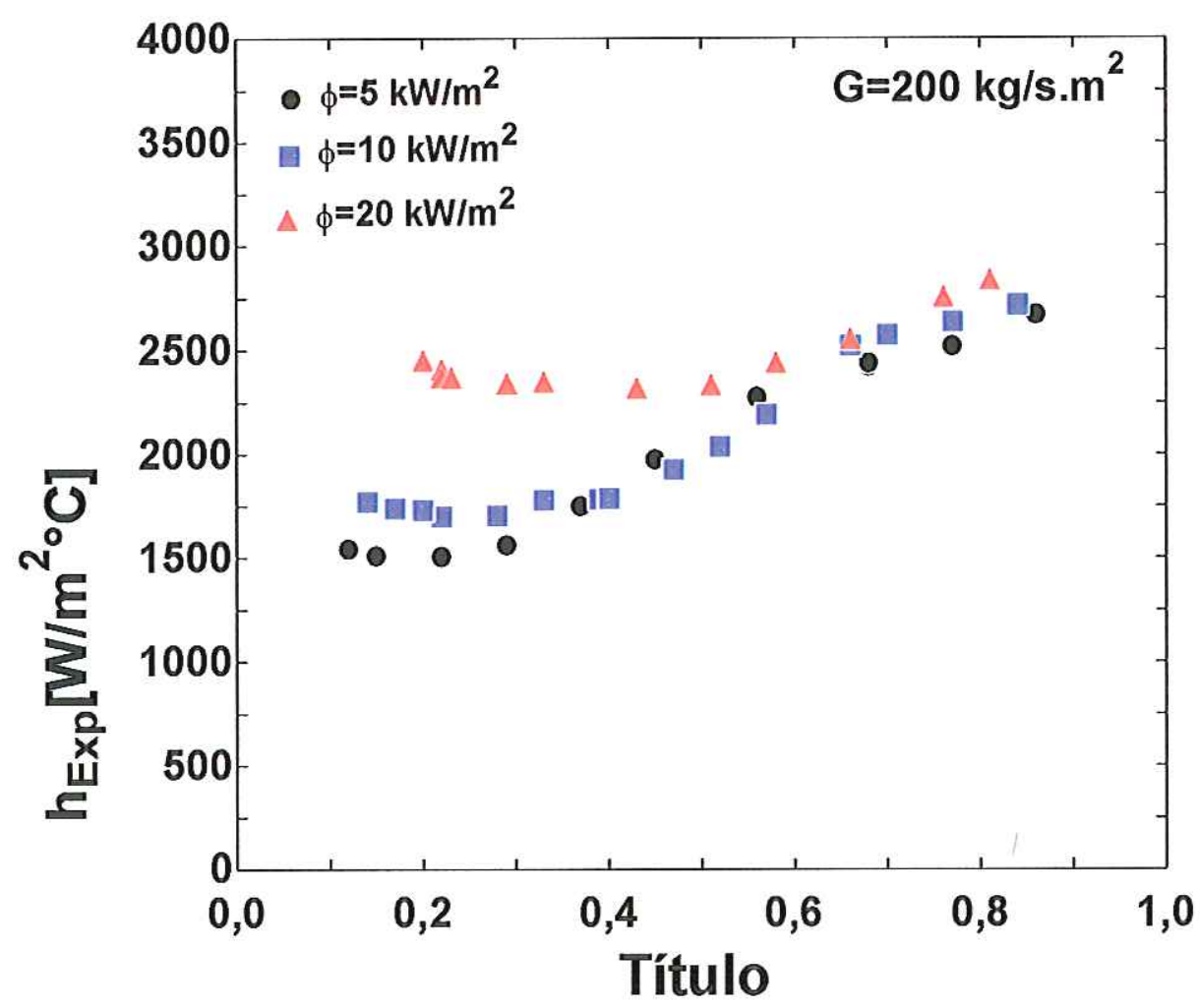

Figura 4.33 Resultados experimentais para o R-407C nas condições: $\mathrm{T}_{\text {Evap }}=8^{\circ} \mathrm{C}$, $\mathrm{G}=200 \mathrm{~kg} / \mathrm{s} \cdot \mathrm{m}^{2}$ e $\mathrm{D}=12,7 \mathrm{~mm}$.

A Fig. 4.34 apresenta os resultados para o R-134a com temperatura de evaporação de $8^{\circ} \mathrm{C}, \mathrm{G}=300 \mathrm{~kg} / \mathrm{s}^{\mathrm{m}} \mathrm{m}^{2}, \phi$ variando entre 5 e $20 \mathrm{~kW} / \mathrm{m}^{2}$ e D=12,7mm. Esta figura ilustra um comportamento semelhante ao da Fig. 4.33, porém, nota-se que, para $\mathrm{G}=300 \mathrm{~kg} / \mathrm{s} . \mathrm{m}^{2}$, o fluxo de calor deixa de afetar o coefíciente de transferência de calor para títulos da ordem de $20 \%$, para os fluxos de calor de $5 \mathrm{e} 10 \mathrm{~kW} / \mathrm{m}^{2}$. Nesse sentido, é possível afirmar que, à medida que a velocidade mássica é elevada, a região em que o fluxo de calor afeta o coefíciente de transferência de calor fica restrita a títulos reduzidos. Para fluxos da ordem de $20 \mathrm{~kW} / \mathrm{m}^{2}$, nota-se que o coeficiente apresenta maior dependência de $\phi$ até títulos próximos a $60 \%$. A partir daí, os efeitos convectivos predominam, suprimindo os efeitos do fluxo de calor. Foram incorporadas, nessa figura, barras de incerteza associadas aos resultados para o coeficiente de transferência de calor. Como pode ser observado, as maiores incertezas estão relacionadas a títulos elevados e fluxo de calor reduzido, pois, como mencionado anteriormente, estão associados as menores diferenças entre as temperaturas da parede e do fluido. 


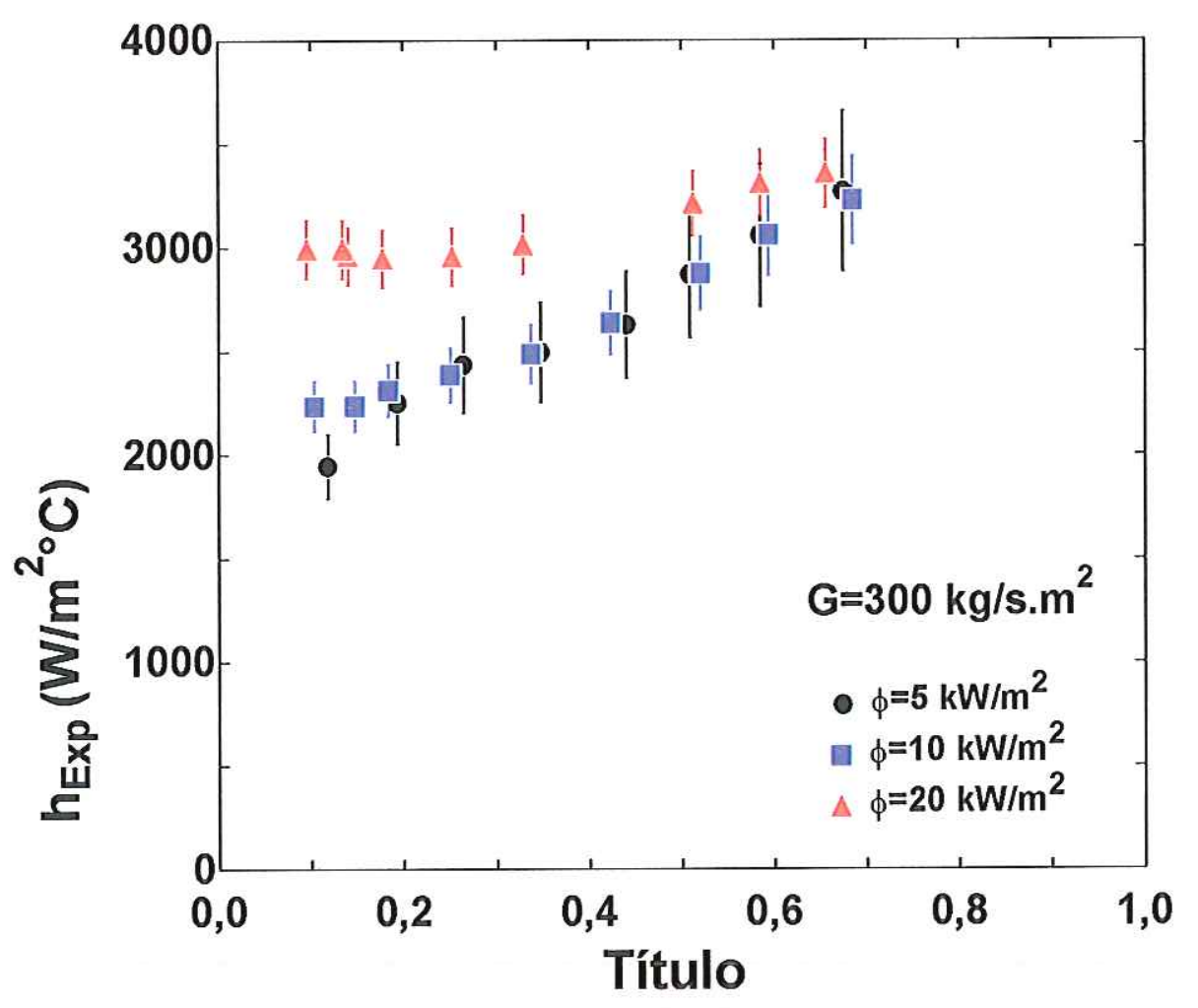

Figura 4.34 Resultados experimentais para o R-134a nas condições: $\mathrm{T}_{\text {Evap }}=8^{\circ} \mathrm{C}$, $\mathrm{G}=300 \mathrm{~kg} / \mathrm{s} . \mathrm{m}^{2}$ e $\mathrm{D}=12,7 \mathrm{~mm}$.

Ensaios foram realizados, ilustrando o efeito do fluxo de calor específico no coeficiente de transferência de calor para velocidades mássicas reduzidas. Conforme mencionado anteriormente, o fluxo de calor afeta o coeficiente de transferência de calor em toda a faixa de títulos considerada, para valores de $\mathrm{G}$ inferiores a $100 \mathrm{~kg} / \mathrm{s} . \mathrm{m}^{2}$, padrão estratificado. A Fig. 4.35 apresenta os resultados experimentais obtidos para o R-22 escoando num tubo de $17,4 \mathrm{~mm}$ de diâmetro interno, temperatura de evaporação da ordem de $5^{\circ} \mathrm{C}$, velocidade mássica de $50 \mathrm{~kg} / \mathrm{s} \cdot \mathrm{m}^{2}$ e fluxo de calor de 5 e $10 \mathrm{~kW} / \mathrm{m}^{2}$. Vale destacar que o coeficiente de transferência de calor é dependente do fluxo de calor específico em toda a faixa de títulos, ilustrando que esse comportamento está relacionado a efeitos de ebulição nucleada no filme de líquido. Observa-se, ainda, uma leve queda do coefíciente à medida que o título é incrementado, conforme discutido na seção de análise do efeito da velocidade mássica. 


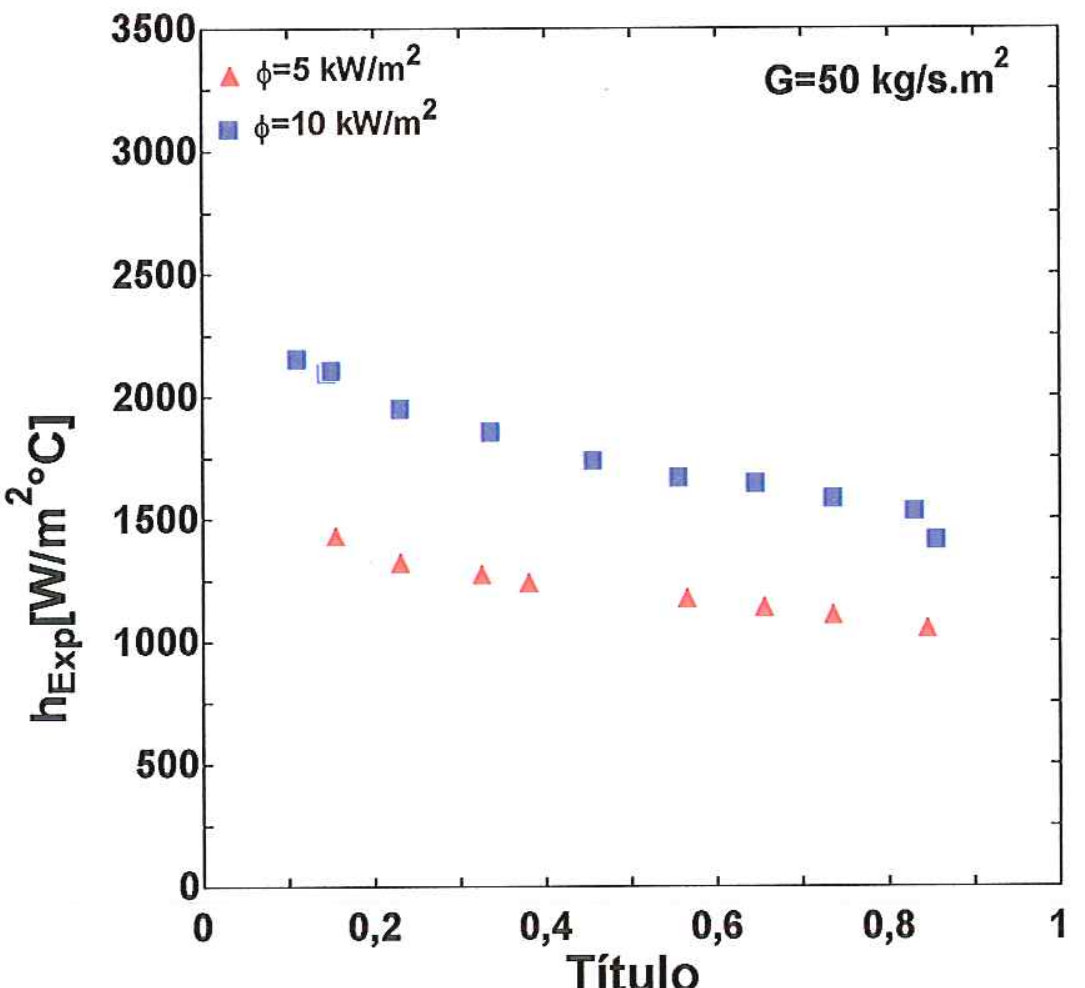

Figura 4.35 Resultados experimentais para o R-22 nas condições: $\mathrm{T}_{\text {Evap }}=5^{\circ} \mathrm{C}$, $\mathrm{G}=50 \mathrm{~kg} / \mathrm{s} \cdot \mathrm{m}^{2}$ e $\mathrm{D}=17,4 \mathrm{~mm}$.

\subsection{Efeito da Temperatura de Evaporação}

A campanha de ensaios do presente trabalho permitiu o levantamento de resultados experimentais envolvendo três temperaturas distintas de evaporação na seção de testes: 5, 8 e $15^{\circ} \mathrm{C}$. Os efeitos relacionados à temperatura de evaporação no coeficiente de transferência de calor foram mais perceptíveis para temperaturas de 8 e $15^{\circ} \mathrm{C}$, mesmo porque os ensaios foram realizados em tubo de mesmo diâmetro. A Fig. 4.36 apresenta os resultados experimentais para o coefíciente de transferência de calor, ilustrando o efeito da temperatura de evaporação do R-22 escoando num tubo de $12,7 \mathrm{~mm}$ de diâmetro interno, velocidade mássica de $100 \mathrm{~kg} / \mathrm{s} \cdot \mathrm{m}^{2}$ e fluxo de calor variando entre 5 e $20 \mathrm{~kW} / \mathrm{m}^{2}$. Percebe-se, claramente, que a temperatura de evaporação afeta o coeficiente de transferência de calor. É importante esclarecer que relação entre as densidades do líquido e vapor é inversamente proporcional à temperatura de saturação. A relação entre densidades é diretamente proporcional à fração de vazio. Assim, para temperaturas mais baixas, no caso $\mathrm{T}=8^{\circ} \mathrm{C}$, resulta numa relação entre densidades e fração de vazio mais elevadas, incrementando a área do tubo exposta ao vapor, o que justificaria, em parte, o comportamento observado na Fig. 4.36. Outro mecanismo que pode justificar o comportamento observado, está relacionado a 
efeitos de ebulição nucleada. À medida que a temperatura de evaporação se eleva, as condições para a formação de bolhas são "facilitadas", proporcionando uma população de bolhas maior, o que determina o incremento do coeficiente de transferência de calor. Isso foi comprovado através da utilização da correlação de Bergles \& Rosehnow apud SAIZ JABARDO (1988), para avaliação do fluxo de calor mínimo necessário para formação de bolhas:

$$
\phi=\left(\frac{h_{L V} \cdot k_{L} \cdot \rho_{V}}{8 \cdot T_{s a t} \cdot \sigma}\right) \cdot\left(T_{p}-T_{s a t}\right)
$$

Os resultados mostraram que, para as mesmas condições $\left(\phi=5 \mathrm{~kW} / \mathrm{m}^{2}\right.$, $\mathrm{G}=100 \mathrm{~kg} / \mathrm{s} \cdot \mathrm{m}^{2}$ e $\mathrm{D}=12,7 \mathrm{~mm}$ ), o superaquecimento necessário para formação de bolhas é menor para temperaturas de evaporação maiores.

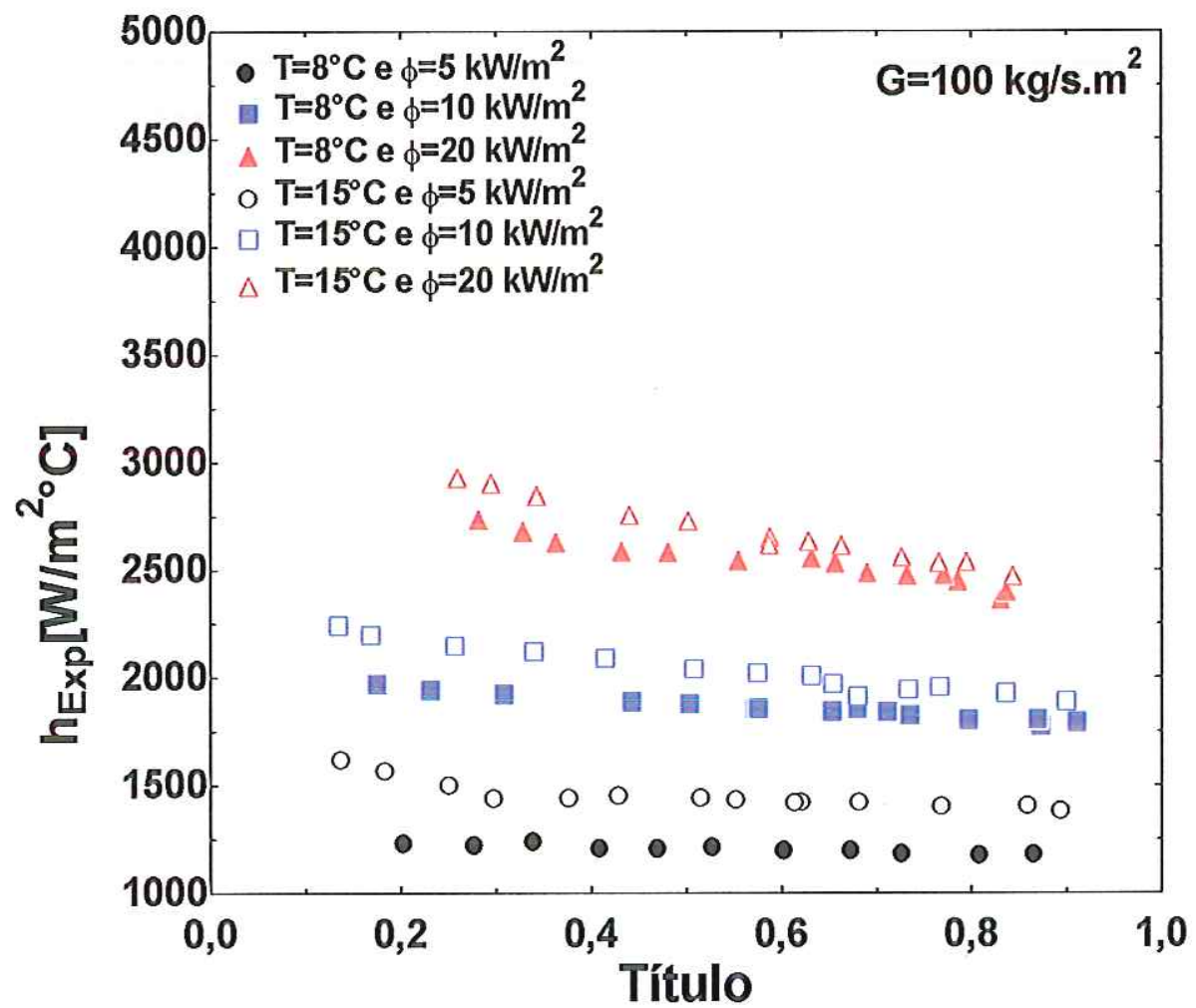

Figura 4.36 Resultados experimentais para o R-22 nas condições: $\phi=5,10$ e $20 \mathrm{~kW} / \mathrm{m}^{2}$, $\mathrm{G}=100 \mathrm{~kg} / \mathrm{s} . \mathrm{m}^{2}$ e $\mathrm{D}=12,7 \mathrm{~mm}$.

No caso da Fig. 4.37, para o refrigerante R-404A, velocidade mássica de 300 $\mathrm{kg} / \mathrm{s} \cdot \mathrm{m}^{2}$, fluxo de calor de $5 \mathrm{~kW} / \mathrm{m}^{2}$ e diâmetro interno do tubo de $12,7 \mathrm{~mm}$, percebe-se que o efeito da temperatura é mais significativo na região de títulos reduzidos, onde há o predomínio da ebulição nucleada, valendo como justificativa para esse comportamento os 
mesmos argumentos dos parágrafos anteriores. Observa-se, nesta figura, que, uma vez estabelecido o padrão anular, para títulos superiores a $35 \%$, o coeficiente de transferência de calor, associado à temperatura de evaporação de $8^{\circ} \mathrm{C}$ tende a superar, gradualmente, o de $15^{\circ} \mathrm{C}$. Foi realizada uma estimativa da espessura do filme de líquido, $\delta$, para as temperaturas de evaporação observadas na Fig. 4.37 . No caso, para $8^{\circ} \mathrm{C}, \delta$ resultou cerca de $13 \%$ inferior àquele verificado para $15^{\circ} \mathrm{C}$. Já a condutividade térmica foi $3 \%$ maior para $8^{\circ} \mathrm{C}$ em relação a de $15^{\circ} \mathrm{C}$. A resistência térmica do filme de líquido, $\delta / \mathrm{k}_{\mathrm{L}}$, para $8^{\circ} \mathrm{C}$ superou $\mathrm{em} 18 \%$ àquela observada para $15^{\circ} \mathrm{C}$ para títulos da ordem de $40 \%$ e, a medida que o título é incrementado, essa diferença se acentua gradualmente, alcançando cerca de $21 \%$. Nessas condições, como o coeficiente de transferência de calor, para esse padrão, é inversamente proporcional à resistência térmica da película de líquido, o coefíciente obtido para $8^{\circ} \mathrm{C}$ deve superar àquele verificado para $15^{\circ} \mathrm{C}$, o que efetivamente se observa.

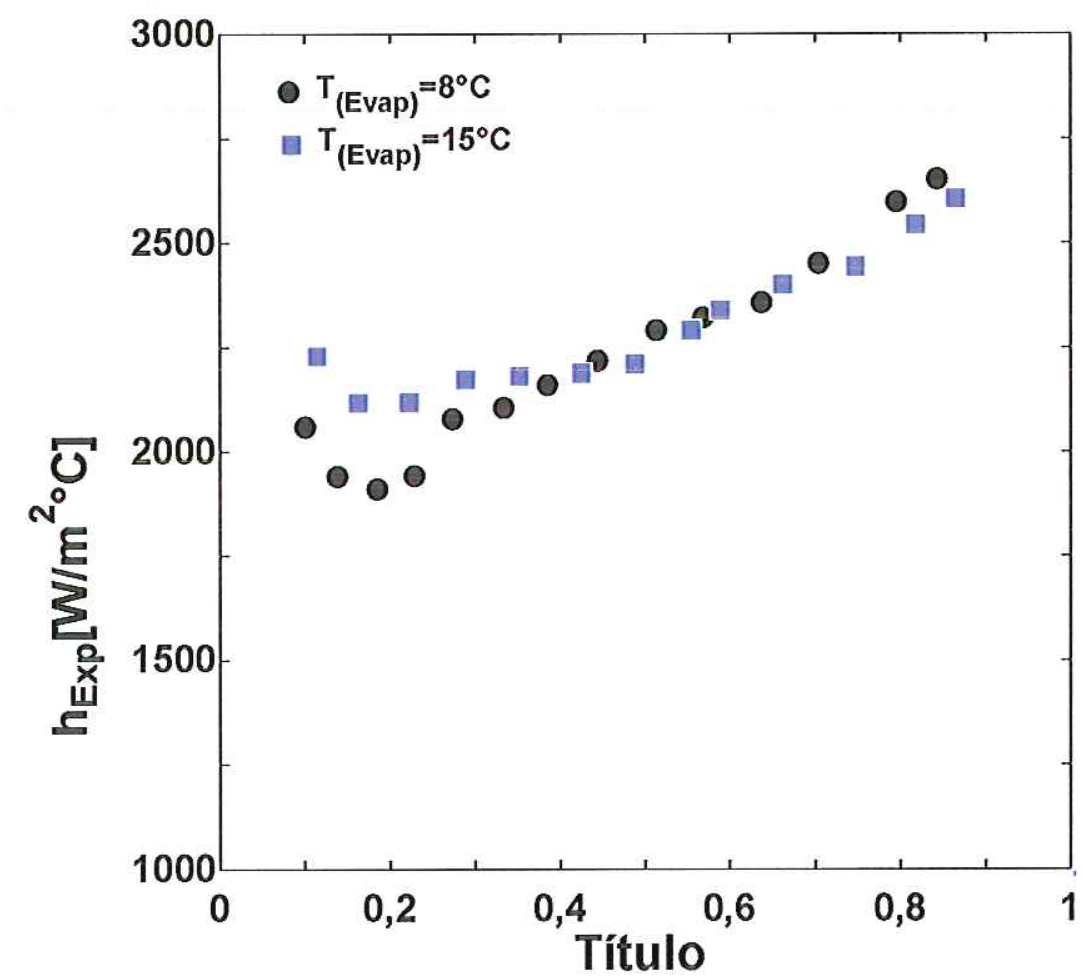

Figura 4.37 Resultados experimentais para o R-404A nas condições: $\phi=5 \mathrm{~kW} / \mathrm{m}^{2}$, $\mathrm{G}=300 \mathrm{~kg} / \mathrm{s} \cdot \mathrm{m}^{2}$ e $\mathrm{D}=12,7 \mathrm{~mm}$.

\subsection{Efeito do Diâmetro do Tubo}

Um dos parâmetros poucos explorados por pesquisadores em ebulição convectiva é aquele relativo ao diâmetro do tubo. BANDARRA FILHO (1997) analisou os resultados experimentais obtidos por WATTELET (1994) e concluiu que, para a faixa de diâmetros 
ensaiada, 7,$04 ; 7,75$ e $10,92 \mathrm{~mm}$, o efeito do diâmetro no coeficiente foi de pequena magnitude.

$\mathrm{O}$ estudo do efeito do diâmetro foi investigado na presente pesquisa, tendo sido ensaiados tubos com distintos diâmetros, Tab. 4.1. A Fig. 4.38 apresenta os resultados experimentais para o coeficiente de transferência de calor em função do título para três diâmetros de tubo distintos, 8,76;10,92 e 12,7mm, velocidade mássica de $300 \mathrm{~kg} / \mathrm{s} . \mathrm{m}^{2}$, fluxo de calor de $5 \mathrm{~kW} / \mathrm{m}^{2}$ e fluido refrigerante R-134a. Percebe-se que há um efeito flagrante do diâmetro no coeficiente de transferência de calor. Os maiores coeficientes estão associados ao tubo com menor diâmetro, no caso $8,76 \mathrm{~mm}$. Esses resultados indicam que, conforme o diâmetro é reduzido, a transição do padrão intermitente para o anular ocorre para títulos menores. No caso, para o tubo de $8,76 \mathrm{~mm}$, a transição se dá para títulos da ordem de $15 \%$, para $10,92 \mathrm{~mm}$ em $25 \%$ e para o de $12,7 \mathrm{~mm}$, a mudança no padrão se verifica para títulos da ordem de $35 \%$. Os resultados para o coeficiente de transferência de calor envolvendo o tubo com diâmetro interno de 10,92mm foram extraídos de WATTELET (1994).

A Fig. 4.39 ilustra os resultados experimentais obtidos para o refrigerante R-134a com velocidade mássica de $100 \mathrm{~kg} / \mathrm{s} \cdot \mathrm{m}^{2}$, fluxo de calor de $5 \mathrm{~kW} / \mathrm{m}^{2}$, escoando em tubos de 7,2 e $17,4 \mathrm{~mm}$ de diâmetro interno. Nota-se que o diâmetro do tubo afeta de maneira significativa o coeficiente de transferência de calor, especialmente para títulos superiores a $40 \%$. Como pode ser observado nessa figura, o coeficiente de transferência de calor apresenta um incremento para títulos superiores a $40 \%$, para o tubo de menor diâmetro, ao passo que para o tubo de $17,4 \mathrm{~mm}$ de diâmetro, o coeficiente apresenta um leve decréscimo com o título. Esse comportamento, do tubo de 7,2mm de diâmetro, está associado à mudança de padrão de escoamento, do estratificado ondulado para o anular. Com o objetivo de verificar tal afirmação, utilizou-se o mapa de TAITEL \& DUKLER (1976), que leva em consideração o efeito do diâmetro, para as mesmas condições da Fig. $4.39\left(\mathrm{G}=100 \mathrm{~kg} / \mathrm{s} . \mathrm{m}^{2}\right.$, $\phi=5 \mathrm{~kW} / \mathrm{m}^{2}$ e $\mathrm{T}_{\text {Evap }}=5^{\circ} \mathrm{C}$ ). $\mathrm{O}$ mapa revelou que, para o tubo com menor diâmetro, o padrão de escoamento é o anular, e para o de $17,4 \mathrm{~mm}$ resultou o estratificado ondulado, confirmando a mudança do padrão de escoamento.

No entanto, novos ensaios envolvendo as mesmas condições operacionais e distintos diâmetros devem ser realizados com o objetivo de ampliar o banco de dados e extrair conclusões sobre uma faixa mais ampla de diâmetros. É importante que seja realizado um estudo sistemático do efeito do diâmetro, principalmente, com tubos de características construtivas semelhantes (mesmo material, fixação de termopares, entre outras), para que este efeito seja analisado isoladamente. 


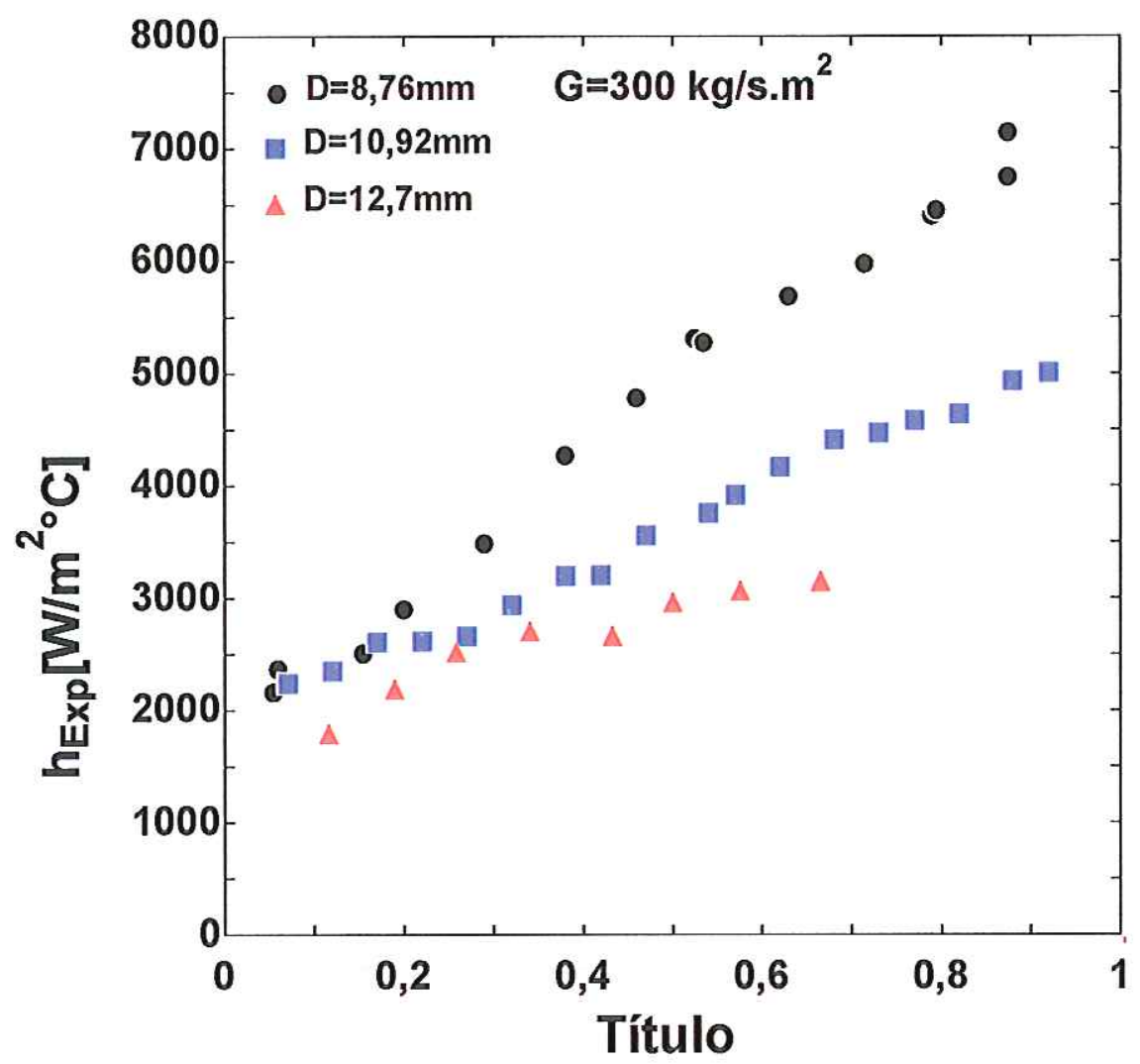

Figura 4.38 Resultados experimentais para o R-134a nas condições: $\phi=5 \mathrm{~kW} / \mathrm{m}^{2}$, $\mathrm{G}=300 \mathrm{~kg} / \mathrm{s} \cdot \mathrm{m}^{2}$ e Diâmetro de $8,76,10,92$ e $12,7 \mathrm{~mm}$.

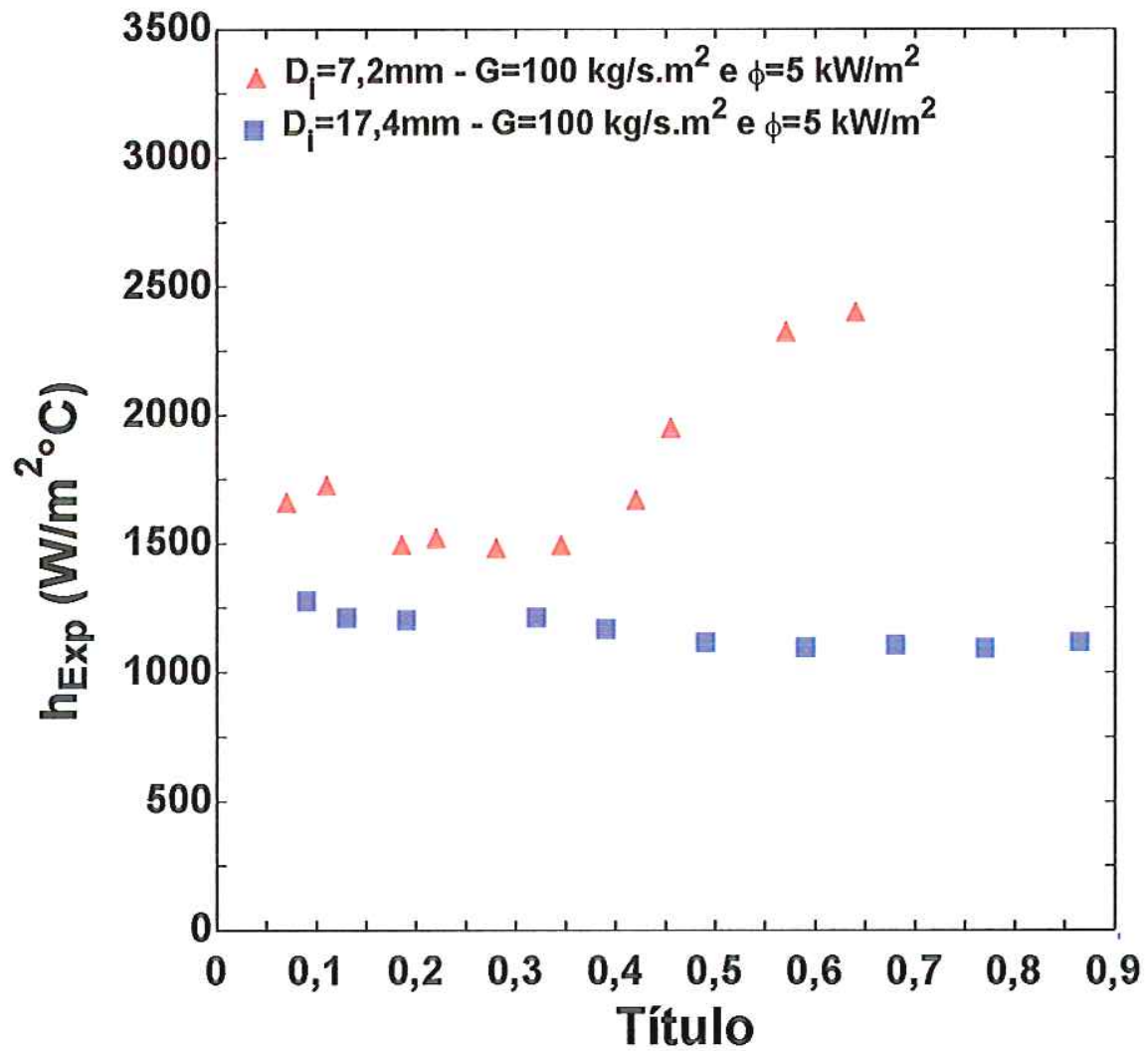

Figura 4.39 Resultados experimentais para o R-134a nas condições: $\phi=5 \mathrm{~kW} / \mathrm{m}^{2}$, $\mathrm{G}=100 \mathrm{~kg} / \mathrm{s} . \mathrm{m}^{2}$ e Diâmetro de 7,2 e $17,4 \mathrm{~mm}$. 


\subsubsection{Perda de Carga em Tubos Lisos}

A perda de carga em escoamentos com mudança de fase (Ebulição Convectiva) tende a ser elevada, razão pela qual sua correta avaliação é importante no projeto de trocadores de calor, principalmente aqueles dedicados à indústria frigorífica. Nestes, especialmente nos evaporadores, a perda de carga pode afetar de forma significativa o desempenho térmico do ciclo termodinâmico. Tendo esse aspecto como parâmetro de orientação, o presente trabalho abordou a avaliação da perda de carga em tubos com superficie interna lisa e aqueles dotados de microaletas.

Inicialmente, a variação da pressão na seção de testes foi determinada nos mesmos ensaios de avaliação do coeficiente de transferência de calor. Estes envolviam transferência de calor e, portanto, mudança de fase, que, por sua vez, redundava na aceleração da mistura bifásica, afetando a queda da pressão do refrigerante na seção de testes. No presente trabalho, com o objetivo de avaliar os efeitos exclusivos do atrito, foram levantados os efeitos de aceleração e removidos, por intermédio da seguinte equação:

$$
\Delta P_{a c e l}=G^{2} \cdot\left[\frac{1}{\rho_{L}} \cdot\left(\frac{\left(1-x_{s a}\right)^{2}}{1-\alpha_{s a}}\right)+\frac{1}{\rho_{V}} \cdot\left(\frac{\left(x_{s a}\right)^{2}}{\alpha_{s a}}\right)-\frac{1}{\rho_{L}} \cdot\left(\frac{\left(1-x_{e n}\right)^{2}}{1-\alpha_{e n}}\right)+\frac{1}{\rho_{V}} \cdot\left(\frac{\left(x_{e n}\right)^{2}}{\alpha_{e n}}\right)\right]
$$

onde $\alpha_{\mathrm{en}}$ e $\alpha_{\mathrm{sa}}$ são avaliadas pela correlação de Zivi, apud SAIZ JABARDO (1995):

$$
\alpha=\frac{1}{1+\left(\frac{\rho_{V}}{\rho_{L}}\right)^{2 / 3} \cdot\left(\frac{1}{x}-1\right)}
$$

Foram, também, realizados ensaios com escoamento adiabático do refrigerante na seção de testes, tendo por objetivo reduzir os efeitos de aceleração. Estes, a rigor, não podem ser eliminados, uma vez que restam efeitos marginais resultantes da mudança de fase por redução da pressão ("flashing").

Com o objetivo de simplificar a análise, os resultados experimentais para a perda de carga serão convertidos em parâmetros adimensionais de uso generalizado na literatura como o multiplicador bifásico, $\phi_{\mathrm{L}}$, e o parâmetro de Martinelli, $\mathrm{X}_{\mathrm{tt}}$. $\mathrm{O}$ primeiro, relaciona a perda de carga no escoamento bifásico àquela do escoamento monofásico. No caso, 


$$
\phi_{\mathrm{L}}^{2}=\frac{(\mathrm{dp} / \mathrm{dx})_{\mathrm{B}}}{(\mathrm{dp} / \mathrm{dx})_{\mathrm{L}}}
$$

onde, os índices B e L do segundo membro referem-se, respectivamente, ao escoamento bifásico e ao escoamento do líquido da mistura no mesmo tubo. A perda de carga do escoamento do líquido da mistura no tubo pode ser avaliada por intermédio de uma das correlações clássicas da literatura, como a de Blasius, por exemplo, utilizada no presente trabalho. $\mathrm{O}$ numerador resulta diretamente dos ensaios.

A Fig. 4.40, envolvendo resultados obtidos para o refrigerante R-404A, escoando num tubo de $12,7 \mathrm{~mm}$ de diâmetro interno, é característica do efeito da velocidade mássica na perda de carga. Percebe-se que $\phi_{\mathrm{L}}$ não é significativamente afetado pela velocidade mássica na faixa entre 200 e $500 \mathrm{~kg} / \mathrm{m}^{2} . \mathrm{s}$, para valores do parâmetro de Martinelli, $X_{\mathrm{tt}}$, inferiores a 1 . Os resultados da Fig. 4.40 estão de acordo com o modelo de Martinelli e são correlacionados adequadamente pelo modelo de JUNG \& RADERMACHER (1989), obtido a partir de um significativo banco de dados experimentais envolvendo diversos refrigerantes, segundo o qual,

$$
\phi_{\mathrm{L}}=3,58 \mathrm{X}_{\mathrm{tt}}^{-0,735} \quad \text { para } \mathrm{X}_{\mathrm{tt}} \leq 1
$$

Para efeito de comparação, a curva resultante da correlação de JUNG \& RADERMACHER (1989) foi superposta aos resultados experimentais da Fig. 4.40.

Deve-se observar que, para vazões reduzidas $\left(\mathrm{G} \leq 100 \mathrm{~kg} / \mathrm{s} \cdot \mathrm{m}^{2}\right)$, os resultados tendem a se afastar dos anteriores, denotando um certo efeito da velocidade mássica na perda de carga. Tal resultado está relacionado à transição do padrão anular para o estratificado (ondulado), observado em condições operacionais correspondentes às baixas velocidades mássicas. Efeitos de interface e gravitacionais passam a afetar o mecanismo de transferência de quantidade de movimento junto à parede, além dos efeitos convectivos caracterizados pelo parâmetro de Martinelli.

A Fig. 4.41, obtida a partir de levantamentos experimentais envolvendo o refrigerante R-22 em escoamento adiabático na seção de testes, para temperaturas de evaporação variando entre 8 e $15^{\circ} \mathrm{C}$ e tubo de $12,7 \mathrm{~mm}$ de diâmetro interno, ilustra o fato do parâmetro $X_{\mathrm{tt}}$ incorporar efeitos relativos à temperatura de saturação, uma vez que não se observam variações significativas do multiplicador bifásico quando a temperatura de saturação varia de $8^{\circ} \mathrm{C}$ para $15^{\circ} \mathrm{C}$. Nessa figura, como na Fig. 4.40 , foi superposta a correlação de JUNG \& RADERMACHER (1989) para efeito de comparação com os resultados experimentais obtidos. 


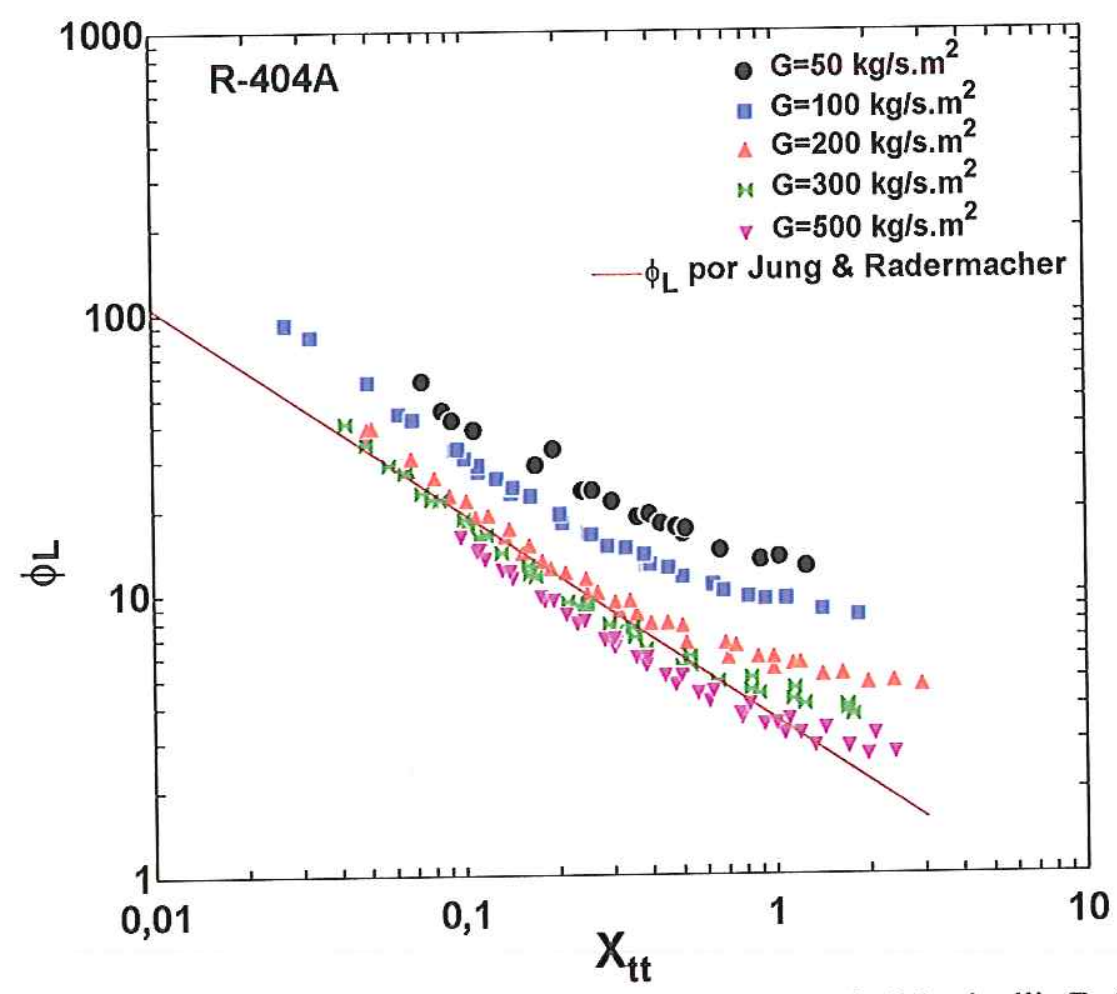

Figura 4.40 Multiplicador bifásico em função do parâmetro de Martinelli. Refrigerante: 404A. Temperatura de evaporação: $15^{\circ} \mathrm{C}$, diâmetro do tubo: $12,7 \mathrm{~mm}$.

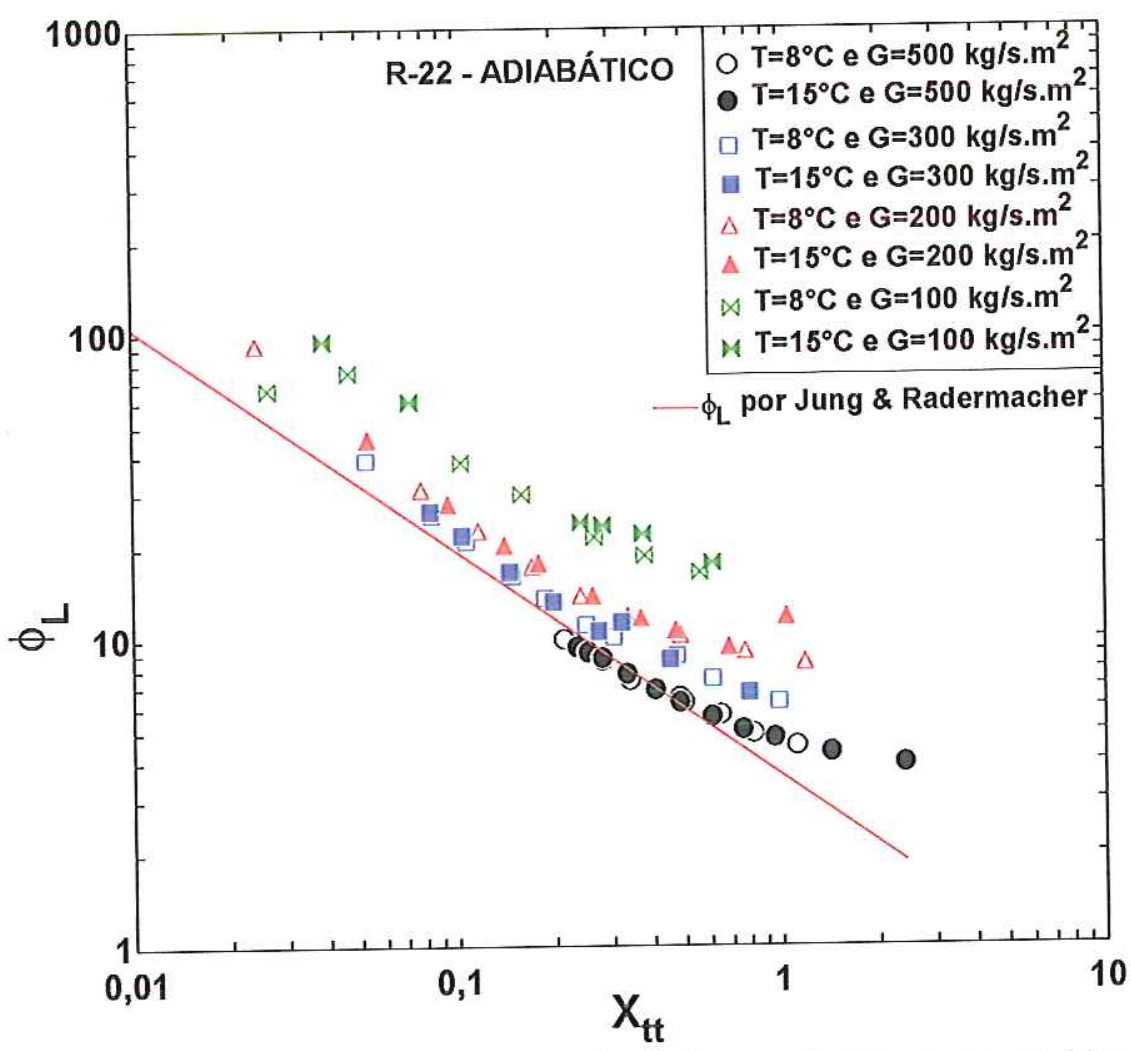

Figura 4.41 Multiplicador bifásico em função do parâmetro de Martinelli. Refrigerante R22. Escoamento adiabático na seção de testes, diâmetro interno de $12,7 \mathrm{~mm}$. 
Seria interessante especular sobre a conveniência da correlação de resultados em termos do modelo de Martinelli ( $\phi_{\mathrm{L}}$ vs. $\mathrm{X}_{\mathrm{t}}$ ), superpondo os resultados experimentais relativos a 3 fluidos refrigerantes. As Figs. 4.42 e 4.43 apresentam os resultados agrupados em duas faixas de velocidades mássicas: superiores a $100 \mathrm{~kg} / \mathrm{s} . \mathrm{m}^{2}$, na Fig. 4.42, e inferiores a 100 $\mathrm{kg} / \mathrm{s}^{\mathrm{m}} \mathrm{m}^{2}$, na Fig. 4.43. Observa-se que o parâmetro de Martinelli correlaciona adequadamente o efeito do refrigerante para velocidades mássicas superiores a $100 \mathrm{~kg} / \mathrm{s} . \mathrm{m}^{2}$, uma vez que os pontos tendem a se agrupar de forma a não se perceber distinções significativas do tipo de refrigerante. Como observado anteriormente, a velocidade mássica tende a afetar os resultados, especialmente na faixa de valores inferiores, Fig. 4.43. Tal comportamento pode estar relacionado à mudança de padrão de escoamento que se verifica quando as velocidades mássicas passam dos valores mais elevados, como regra geral, superiores a $100 \mathrm{~kg} / \mathrm{s} . \mathrm{m}^{2}$, aos inferiores. Nestes, verifica-se o padrão estratificado, ao passo que para velocidades acima de $200 \mathrm{~kg} / \mathrm{s} \cdot \mathrm{m}^{2}$, o padrão anular predomina, o que justifica a correlação do multiplicador bifásico pelo parâmetro de Martinelli. Observa-se, ainda, que a Eq. (4.6) correlaciona adequadamente os resultados experimentais correspondentes a velocidades mássicas superiores a $100 \mathrm{~kg} / \mathrm{s} \cdot \mathrm{m}^{2}$, especialmente para valores de $X_{\mathrm{tt}}$ inferiores a 1 , faixa para a qual a correlação foi levantada.

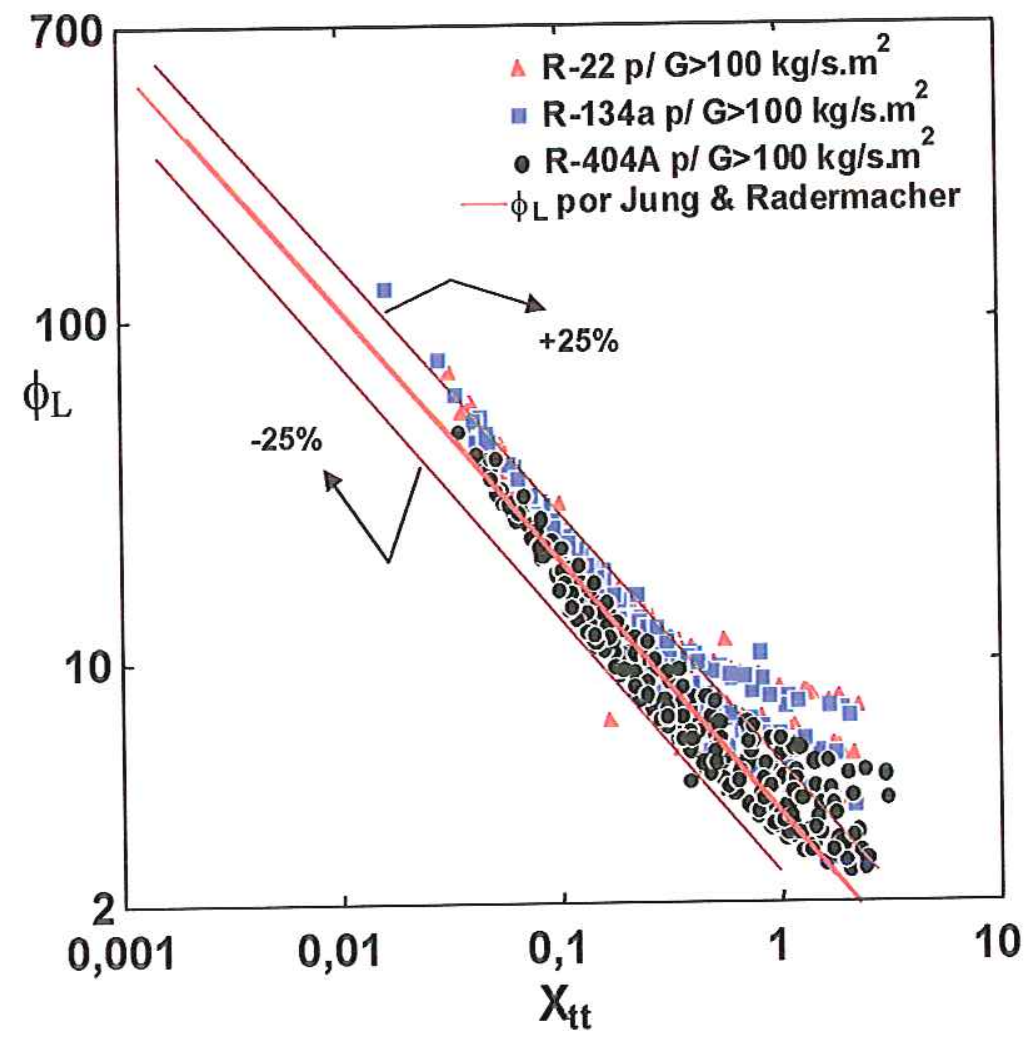

Figura 4.42 Multiplicador bifásico em função do parâmetro de Martinelli, para velocidades mássicas superiores a $100 \mathrm{~kg} / \mathrm{s} . \mathrm{m}^{2}$, diâmetro do tubo de $12,7 \mathrm{~mm}$. 


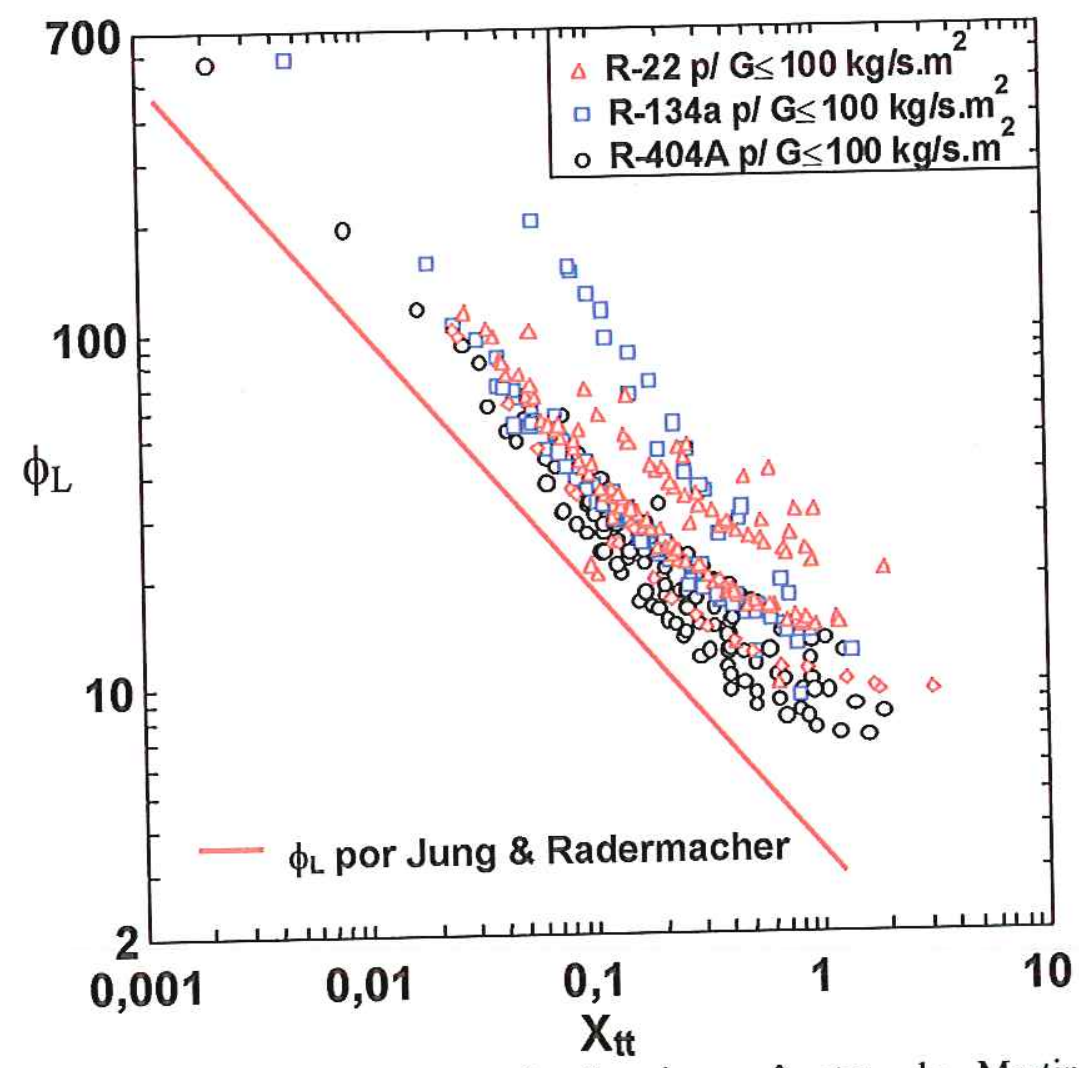

Figura 4.43 Multiplicador bifásico em função do parâmetro de Martinelli, para velocidades mássicas inferiores a $100 \mathrm{~kg} / \mathrm{s} \cdot \mathrm{m}^{2}$, diâmetro do tubo de $12,7 \mathrm{~mm}$.

Outra campanha de ensaios foi realizada para o levantamento de resultados envolvendo a perda de carga em tubos de diâmetro, $D_{i}=8,76 \mathrm{~mm}$. Os resultados, obtidos com o refrigerante R-134a escoando em tubos de dimensões e condições físicas típicas das aplicações frigoríficas, têm revelado efeitos pouco significativos da velocidade mássica sobre o multiplicador bifásico, $\phi_{\mathrm{L}}$. É interessante observar que, nos resultados obtidos no presente trabalho, tanto para velocidades mássicas reduzidas (da ordem de $100 \mathrm{~kg} / \mathrm{s} \cdot \mathrm{m}^{2}$ ) como para elevadas (da ordem de $1100 \mathrm{~kg} / \mathrm{s} \cdot \mathrm{m}^{2}$ ), para tubos com $\mathrm{D}_{\mathrm{i}}=8,76 \mathrm{~mm}$, o valor do multiplicador bifásico, $\phi_{\mathrm{L}}$, não é significativamente afetado.

A Figura 4.44 ilustra a perda de carga, $\Delta \mathrm{P} / \mathrm{L}(\mathrm{kPa} / \mathrm{m})$, em função do título para o tubo liso com diâmetro interno de $8,76 \mathrm{~mm}$, fluxo de calor da ordem de $5 \mathrm{~kW} / \mathrm{m}^{2}$ e refrigerante R-134a. Observa-se que a perda de carga aumenta consideravelmente com o incremento da vazão e do título. Para velocidades mássicas da ordem de 200 e $300 \mathrm{~kg} / \mathrm{s} \cdot \mathrm{m}^{2}$, a perda de carga apresenta um crescimento até títulos da ordem de $80 \%$ permanecendo, praticamente, nos mesmos níveis para títulos superiores. 


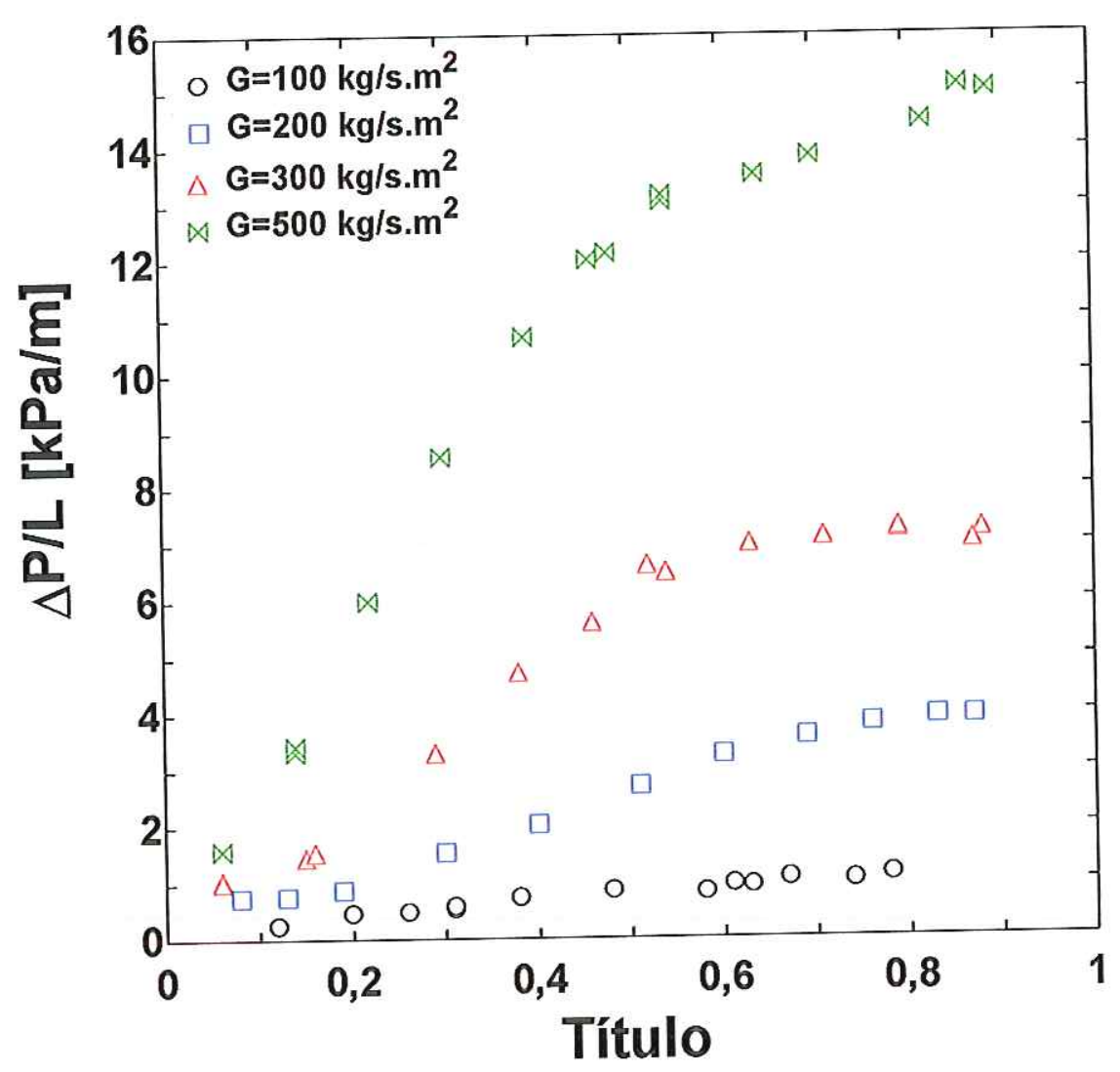

Figura 4.44 Perda de carga em função do título para diversas velocidades mássicas para escoamento em tubo liso de 8,76 de diâmetro interno.

A Fig. 4.45 ilustra a variação do multiplicador bifásico para diversas velocidades mássicas e condições especificadas na legenda. $O$ comportamento mencionado anteriormente, relativo ao efeito da velocidade mássica, fica explicito nos resultados da Fig. 4.45. Com efeito, o multiplicador bifásico mostra-se pouco sensível à velocidade mássica na faixa entre 100 e $500 \mathrm{~kg} / \mathrm{s} . \mathrm{m}^{2}$, principalmente para valores do parâmetro de Martinelli inferiores a 1. Os resultados experimentais foram confrontados com a correlação de JUNG \& RADERMACHER (1989), mostrando boa concordância, especialmente para as velocidades mássicas da ordem entre 200 e 300 kg/s.m² típicas dos ensaios que deram origem à Eq. 4.6. 


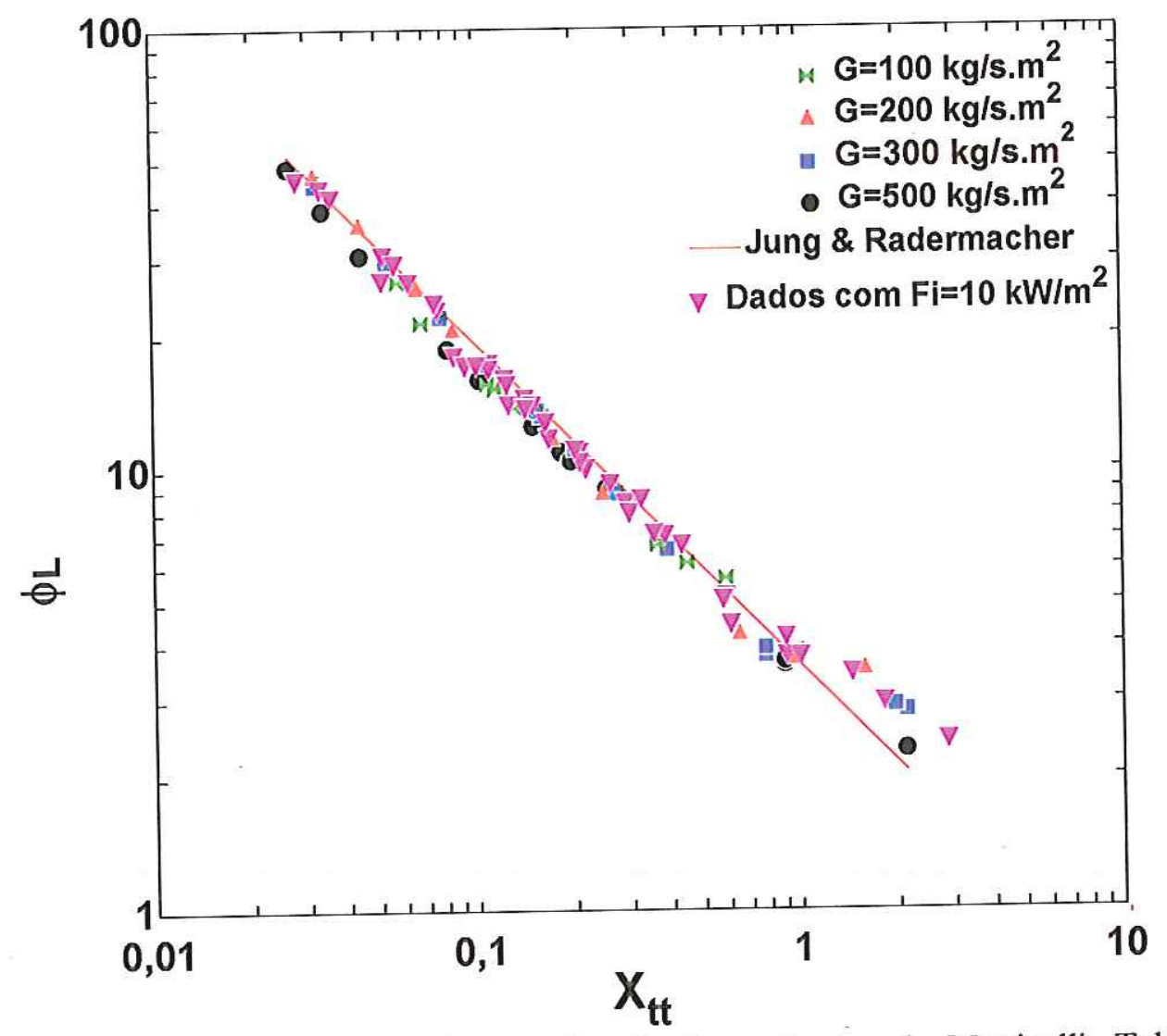

Figura 4.45 Multiplicador bifásico em função do parâmetro de Martinelli. Tubo liso, refrigerante R-134a, temperatura de saturação: $5^{\circ} \mathrm{C}$; fluxo de calor variando entre 5 e $10 \mathrm{~kW} / \mathrm{m}^{2}$.

Uma terceira bateria de ensaios foi realizada sem troca de calor na seção de testes, escoamento adiabático, para o tubo liso com $\mathrm{D}_{\mathrm{i}}=8,76 \mathrm{~mm}$, variando a velocidade mássica entre 70 e $1100 \mathrm{~kg} / \mathrm{s} . \mathrm{m}^{2}$ e o título entre 10 e $95 \%$, cujos resultados são ilustrados na Fig. 4.46 apresenta os resultados obtidos para uma larga faixa de valores de G (entre 70 e 1100 $\mathrm{kg} / \mathrm{s} \cdot \mathrm{m}^{2}$ ). É possível verificar que o multiplicador bifásico não é afetado de forma significativa pela velocidade mássica, como descrito anteriormente. Observa-se, ainda, que a correlação de JUNG \& RADERMACHER (1989), correlaciona de forma satisfatória os resultados experimentais. 


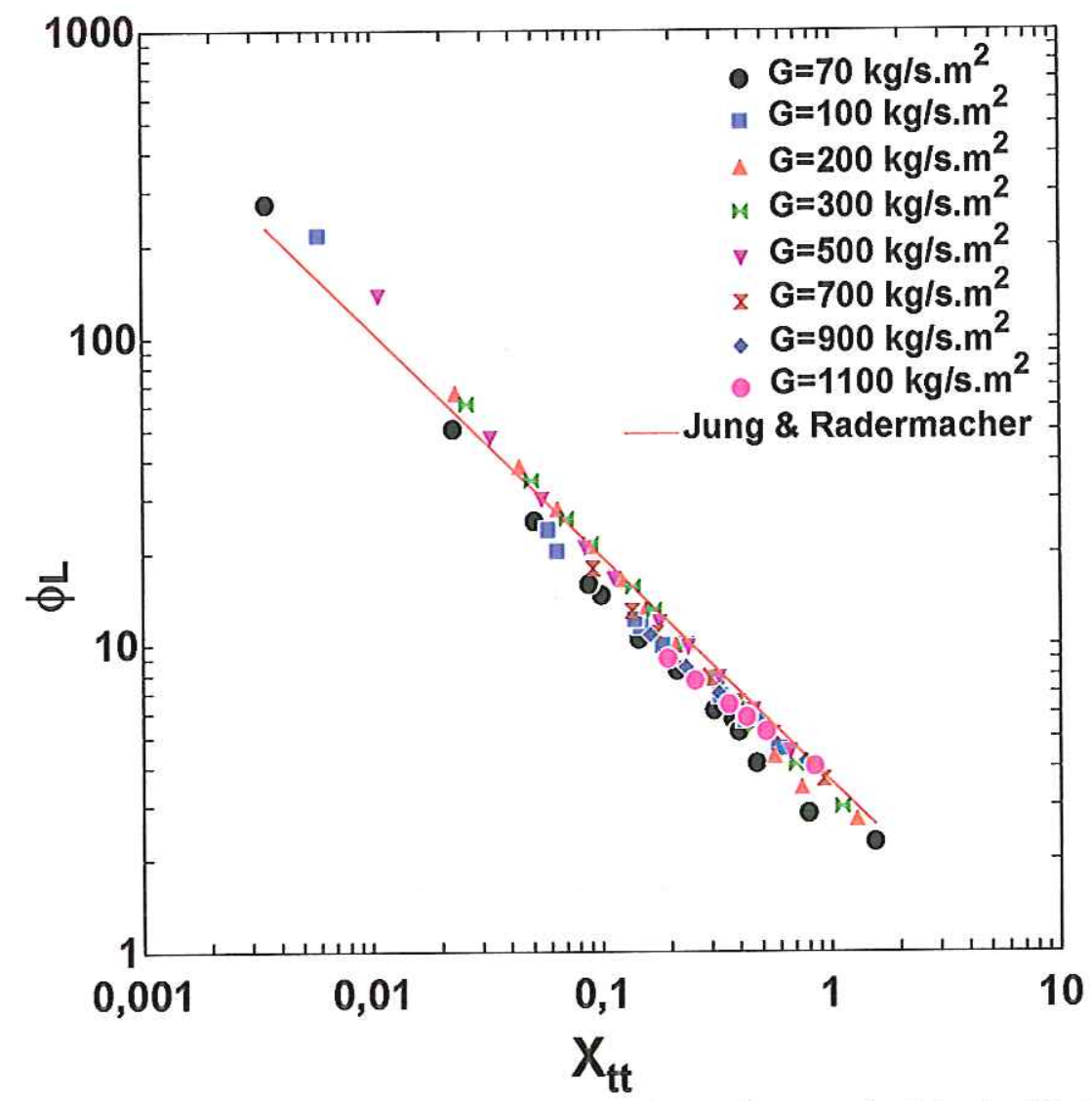

Figura 4.46 Multiplicador bifásico em função do parâmetro de Martinelli. Tubo liso, refrigerante $\mathrm{R}-134 \mathrm{a}, \mathrm{D}_{\mathrm{i}}=8,76 \mathrm{~mm}$, escoamento adiabático.

As Figs. 4.47 e 4.48 ilustram comparações do multiplicador bifásico em função do Parâmetro de Martinelli para escoamento com fluxo de calor aplicado na seção de testes (troca de calor) e escoamento adiabático, para uma dada velocidade mássica. Como pode ser observado, os resultados experimentais indicam que tais efeitos não afetam de forma significativa a perda de carga total, onde os efeitos do atrito respondem pela quase totalidade da perda de carga. Foi realizada, ainda, uma estimativa dos efeitos de aceleração. Constatouse, assim, que a parcela relativa a esses efeitos assumia valores entre 1 e $10 \%$, para fluxos de calor da ordem de $5 \mathrm{~kW} / \mathrm{m}^{2}$, da variação total de pressão ao longo da seção de testes para o tubo liso. A maior contribuição dos efeitos de aceleração ocorre no caso dos escoamentos com vazões reduzidas, mormente para valores de $\mathrm{G}=100 \mathrm{~kg} / \mathrm{s} \cdot \mathrm{m}^{2}$, pois para o mesmo fluxo de calor, quanto menor a vazão, maior será a variação do título, aumentando, desta forma, os efeitos de aceleração. Apesar de reduzidos, como observado anteriormente, tais efeitos foram eliminados, de forma a correlacionar somente os efeitos devidos ao atrito sobre a variação da pressão no caso dos ensaios com troca de calor. 


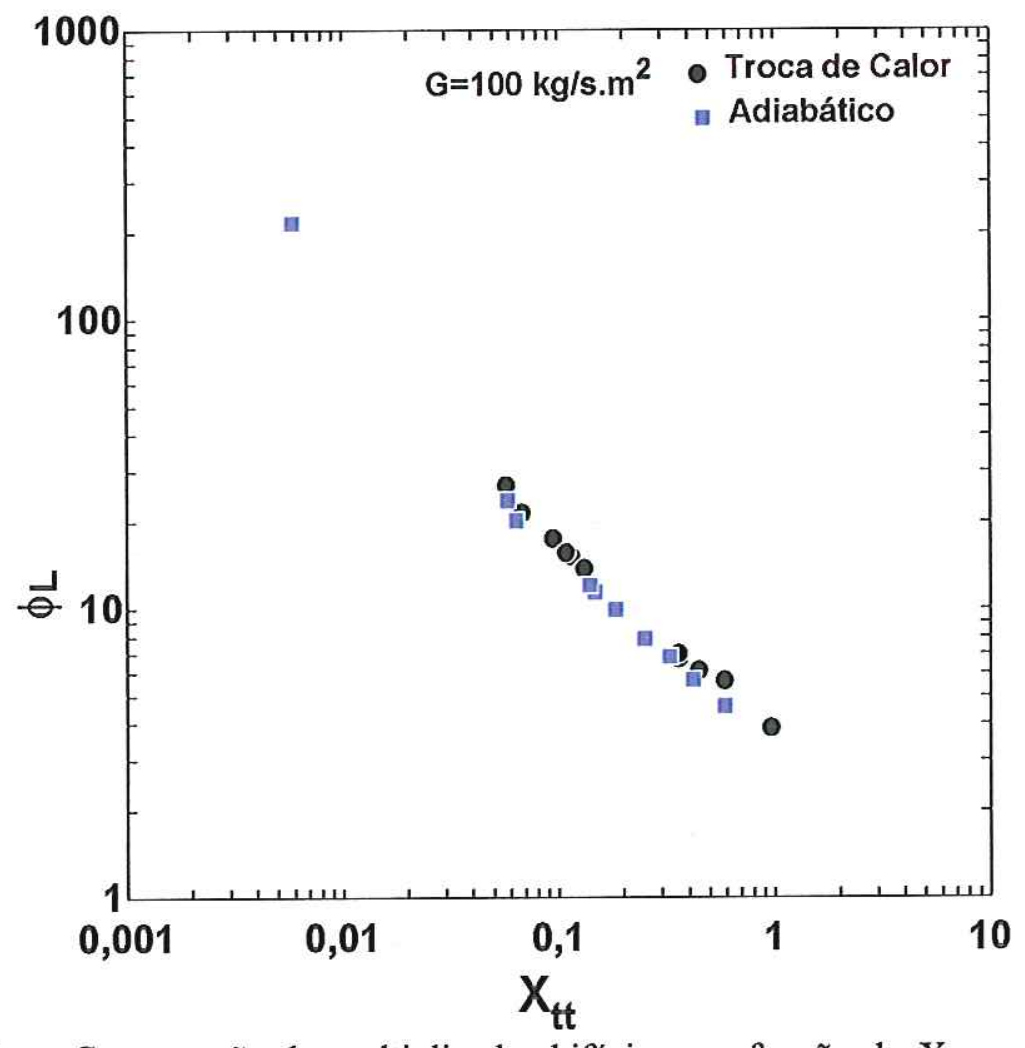

Figura 4.47 Comparação do multiplicador bifásico em função do $X_{\text {tt }}$ para escoamento com troca de calor e adiabático. $\mathrm{G}=100 \mathrm{~kg} / \mathrm{s} \cdot \mathrm{m}^{2}$ c $\mathrm{D}_{\mathrm{i}}=8,76 \mathrm{~mm}$.

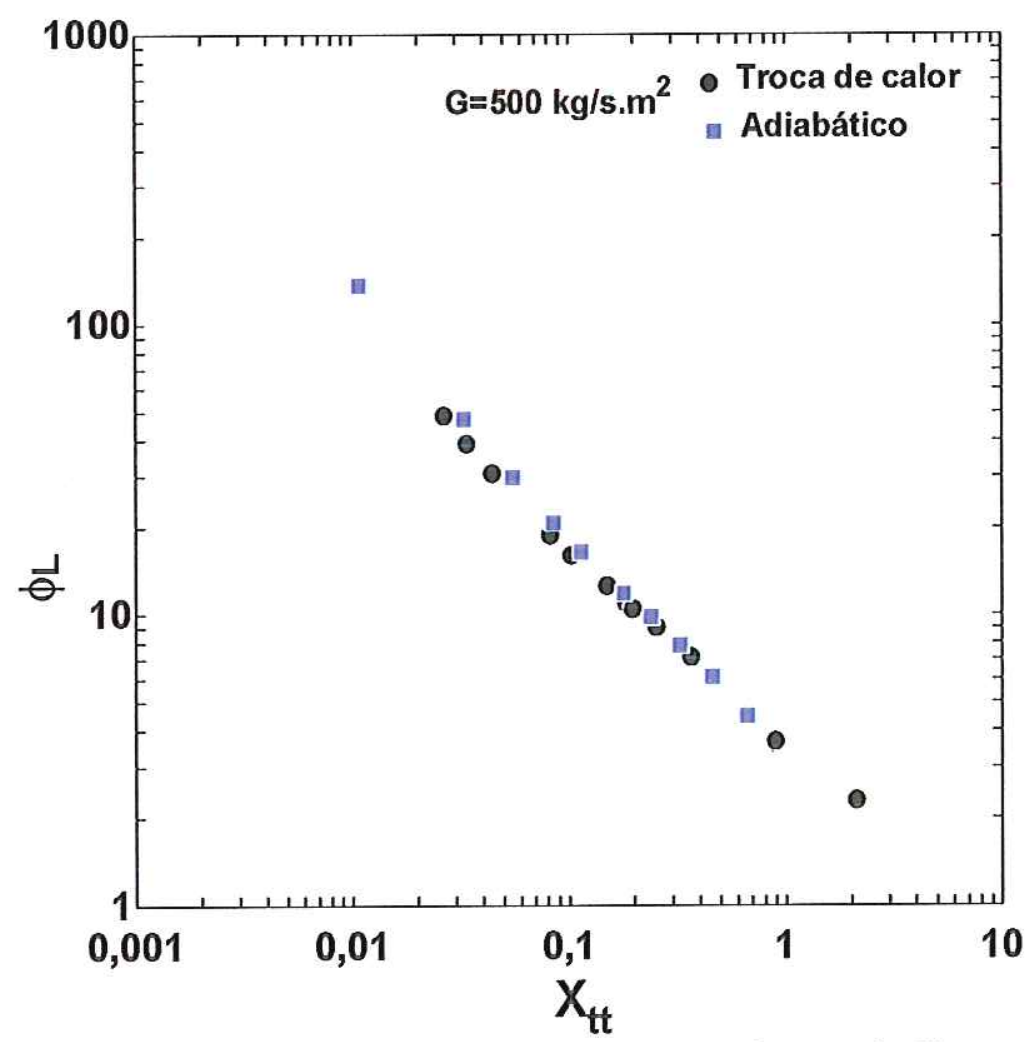

Figura 4.48 Comparação do multiplicador bifásico em função do $X_{\mathrm{tt}}$ para escoamento com troca de calor e adiabático. $\mathrm{G}=500 \mathrm{~kg} / \mathrm{s} \cdot \mathrm{m}^{2}$ e $\mathrm{D}_{\mathrm{i}}=8,76 \mathrm{~mm}$. 


\subsubsection{Tubos Microaletados}

Uma tendência relativamente recente na indústria frigorífica nacional é a utilização de tubos de cobre dotados de microaletas (ranhuras) no seu interior, anteriormente referidos. Os fabricantes alegam que o desempenho termo-hidráulico (termo relativo ao efeito combinado da transferência de calor e da perda de carga) dos refrigerantes halogenados é sensivelmente melhorado quando mudam de fase no interior desses tubos. Pesquisas levadas a cabo em outros países, especialmente Japão e Estados Unidos, têm confirmado essa tendência. No presente trabalho serão apresentados e discutidos resultados obtidos envolvendo a evaporação do refrigerante R-134a e R-22 no interior de tubos internamente ranhurados, fabricados pela empresa TERMOMECÂNICA SÃO PAULO S/A, além de outros com geometrias distintas. Os referidos tubos incluindo suas características geométricas foram apresentados na Tab. 4.1.

A Fig. 4.49 ilustra os resultados experimentais para o coeficiente de transferência de calor em função do título, para os tubos: liso, microaletado (TM) e microaletado (Hitachi) com 7,93mm de diâmetro externo. O fluido refrigerante utilizado foi o R-134a para temperatura de evaporação na entrada da seção de testes de $5^{\circ} \mathrm{C}$, fluxo de calor de $5 \mathrm{~kW} / \mathrm{m}^{2} \mathrm{e}$ velocidade mássica da ordem de $130 \mathrm{~kg} / \mathrm{s} . \mathrm{m}^{2}$. De acordo com o exposto anteriormente, o padrão de escoamento associado a essa velocidade mássica é o estratificado para tubos lisos, o que realmente se observa na Fig. 4.49. Já, para os tubos microaletados, o coeficiente de transferência de calor experimenta valores crescentes com o título, resultado típico do padrão anular de escoamento. Isso pode ser justificado levando-se em consideração que o líquido é deslocado, através dos canais das ranhuras, para a região superior do tubo. Nesse sentido, essa região, que no tubo liso se encontrava em contato com o vapor, no microaletado passa a ser ocupada por um filme de líquido com espessura bastante reduzida, da ordem da altura da microaleta. Isso explica o elevado valor do coeficiente de transferência de calor, pois, além do fato do líquido estar em contato com toda a superfície interior do tubo, o coeficiente é inversamente proporcional a espessura do filme de líquido, ou seja, quanto menor a espessura, maior é o valor do coeficiente de transferência de calor.

O mesmo comportament 3 é observado na Fig. 4.50, para um. tubo de $9,52 \mathrm{~mm}$ de diâmetro externo, temperatura de evaporação de $5^{\circ} \mathrm{C}, \phi=5 \mathrm{~kW} / \mathrm{m}^{2}$ e G=100 kg/s.m $\mathrm{m}^{2}$. Nessa figura, o coeficiente de transferência de calor para o tubo microaletado experimenta intensificação da ordem de $450 \%$, para títulos elevados, evidenciando seu excelente desempenho. 


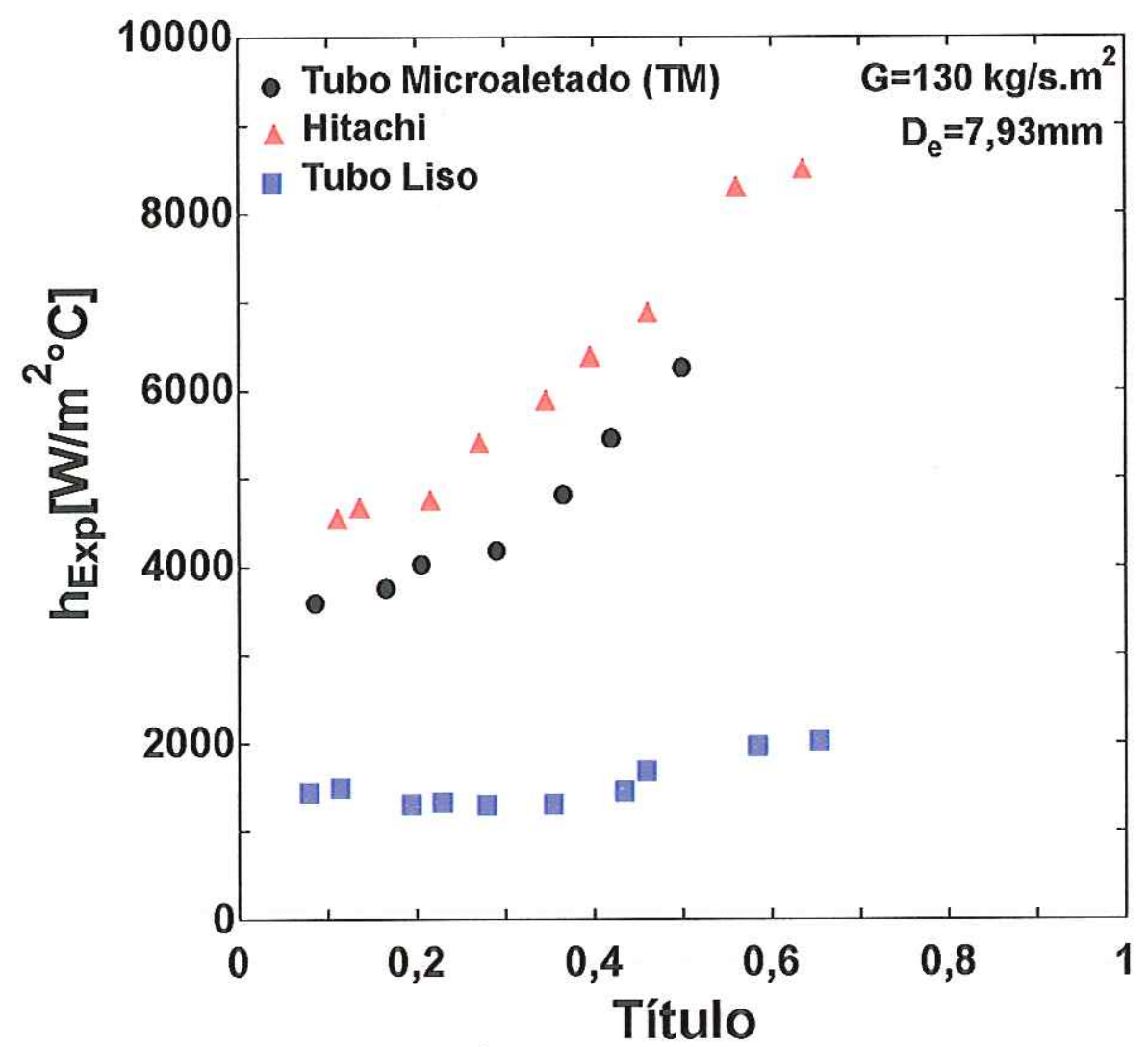

Figura 4.49 Variação do coefíciente de transferência de calor em função do título para tubos liso e ranhurado. $D_{\mathrm{e}}=7,93 \mathrm{~mm}, \mathrm{~T}_{\text {Evap }}=5^{\circ} \mathrm{C}, \phi=5 \mathrm{~kW} / \mathrm{m}^{2}$ e G=130 kg/s.m .

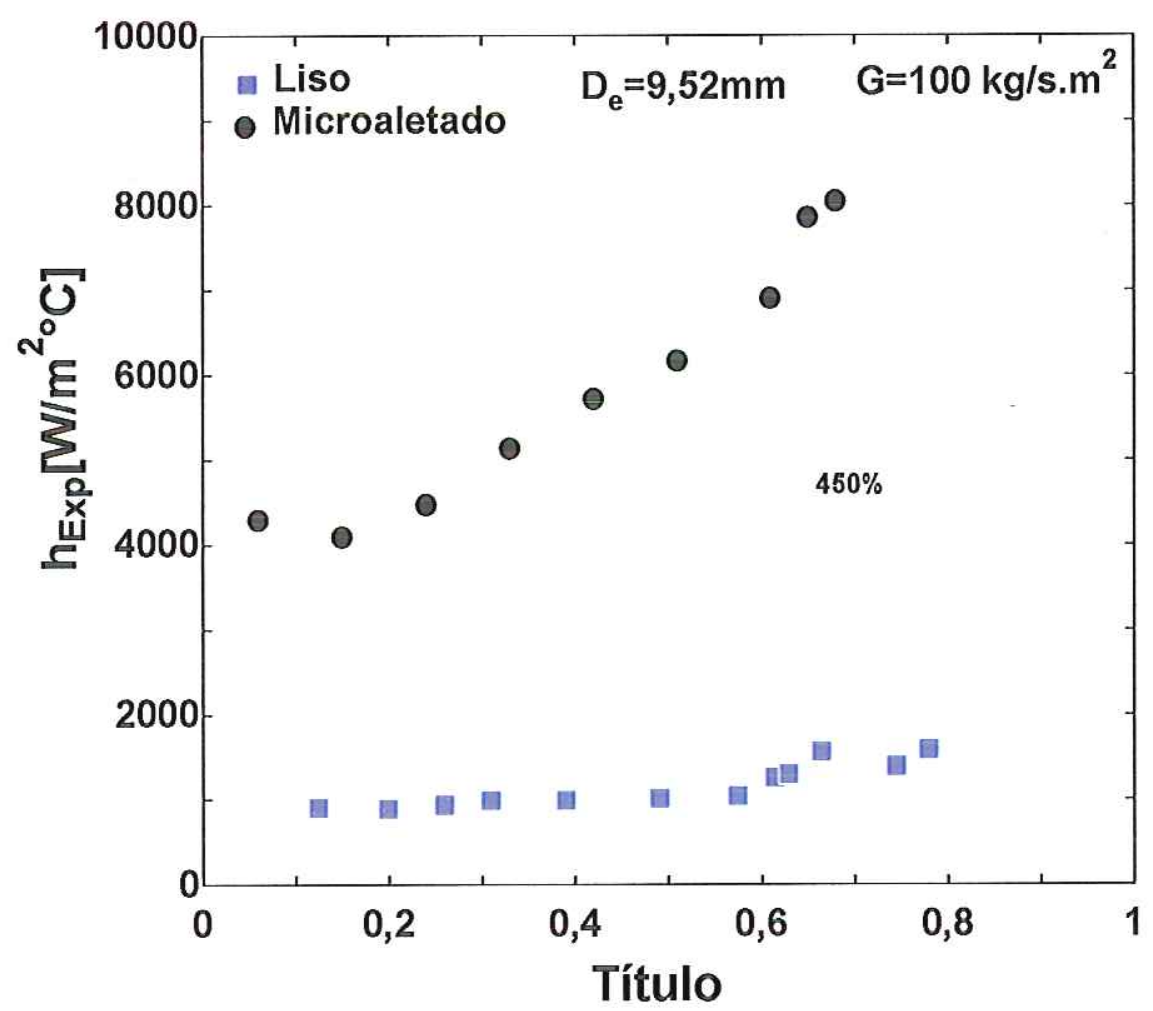

Figura 4.50 Variação do coeficiente de transferência de calor em função do título para tubos liso e ranhurado. $\mathrm{D}_{\mathrm{e}}=9,52 \mathrm{~mm}, \mathrm{~T}_{\text {Evap }}=5^{\circ} \mathrm{C}, \phi=5 \mathrm{~kW} / \mathrm{m}^{2}$ e G=100 kg/s.m . 
A intensificação da transferência de calor tende a diminuir com a vazão. Esse comportamento é explicado levando-se em consideração o padrão de escoamento, pois, como observado anteriormente, o padrão que predomina para velocidades mássicas superiores a $\mathrm{G}=200 \mathrm{~kg} / \mathrm{s} \cdot \mathrm{m}^{2}$ em tubos lisos, é o anular. Nessas condições, o principal mecanismo de intensificação está associado, basicamente, ao aumento da área interna de troca de calor.

A Fig. 4.51 apresenta os resultados experimentais para o coeficiente de transferência de calor em função do título para o R-134a com temperatura de evaporação de $5^{\circ} \mathrm{C}$, fluxo de calor de $5 \mathrm{~kW} / \mathrm{m}^{2}$ e velocidade mássica da ordem de $200 \mathrm{~kg} / \mathrm{s} . \mathrm{m}^{2}$. É interessante destacar, nessa figura, que o maior valor para intensificação da transferência de calor ocorreu para a faixa de títulos reduzida, relativa à região de ebulição nucleada. Já, para a região de domínio da ebulição estritamente convectiva, padrão anular, a intensificação da transferência de calor alcança valores da ordem de $80 \%$ para o tubo microaletado em relação ao liso.

Para velocidade mássica da ordem de $300 \mathrm{~kg} / \mathrm{s} . \mathrm{m}^{2}$, Fig. 4.52, observa-se um comportamento semelhante àquele apresentado na Fig. 4.51. Entretanto, a intensificação da transferência de calor apresenta valores da ordem de $85 \%$ na região de títulos reduzidos, e para títulos próximos a $80 \%$, o valor cai para $15 \%$. Para títulos elevados, verificou-se na seção de visualização que, nos tubos microaletados, o padrão de escoamento em névoa se estabelecia. Isso pode explicar o comportamento apresentado pelo coeficiente de transferência de calor nessa região, que permanece, praticamente, constante com o título.

Para o caso de $\mathrm{G}=500 \mathrm{~kg} / \mathrm{s} \cdot \mathrm{m}^{2}$, os resultados experimentais levantados para o coeficiente de transferência de calor em tubos microaletados revelaram uma tendência que até o presente momento não havia sido encontrada em trabalhos da literatura. Essa tendência pode ser observada nas Figs. 4.53 e 4.54, obtidas para os tubos microaletado (com 82 e 76 ranhuras internas, respectivamente) e liso com G=500 kg/s.m $\mathrm{m}^{2}, \phi=5 \mathrm{~kW} / \mathrm{m}^{2}$ e $\mathrm{T}_{\text {Evap }}=5^{\circ} \mathrm{C}$. O que se destaca nessas figuras é o comportamento do coefíciente de transferência de calor para tubos microaletados para títulos superiores a $45 \%$, que apresenta uma inversão na tendência de crescimento com o título. Isso se deve a transição do padrão de escoamento anular para o padrão em névoa. A justificativa para essa transição está relacionada à elevada velocidade da fase vapor que remove o líquido dos canais das ranhuras para o centro do tubo. Esse fenômeno, de escoamento em névoa no centro do tubo, é denominado na literatura em inglês de "Entrainment", tendo sido confirmado através da janela de visualização, para títulos superiores a $45 \%$. 


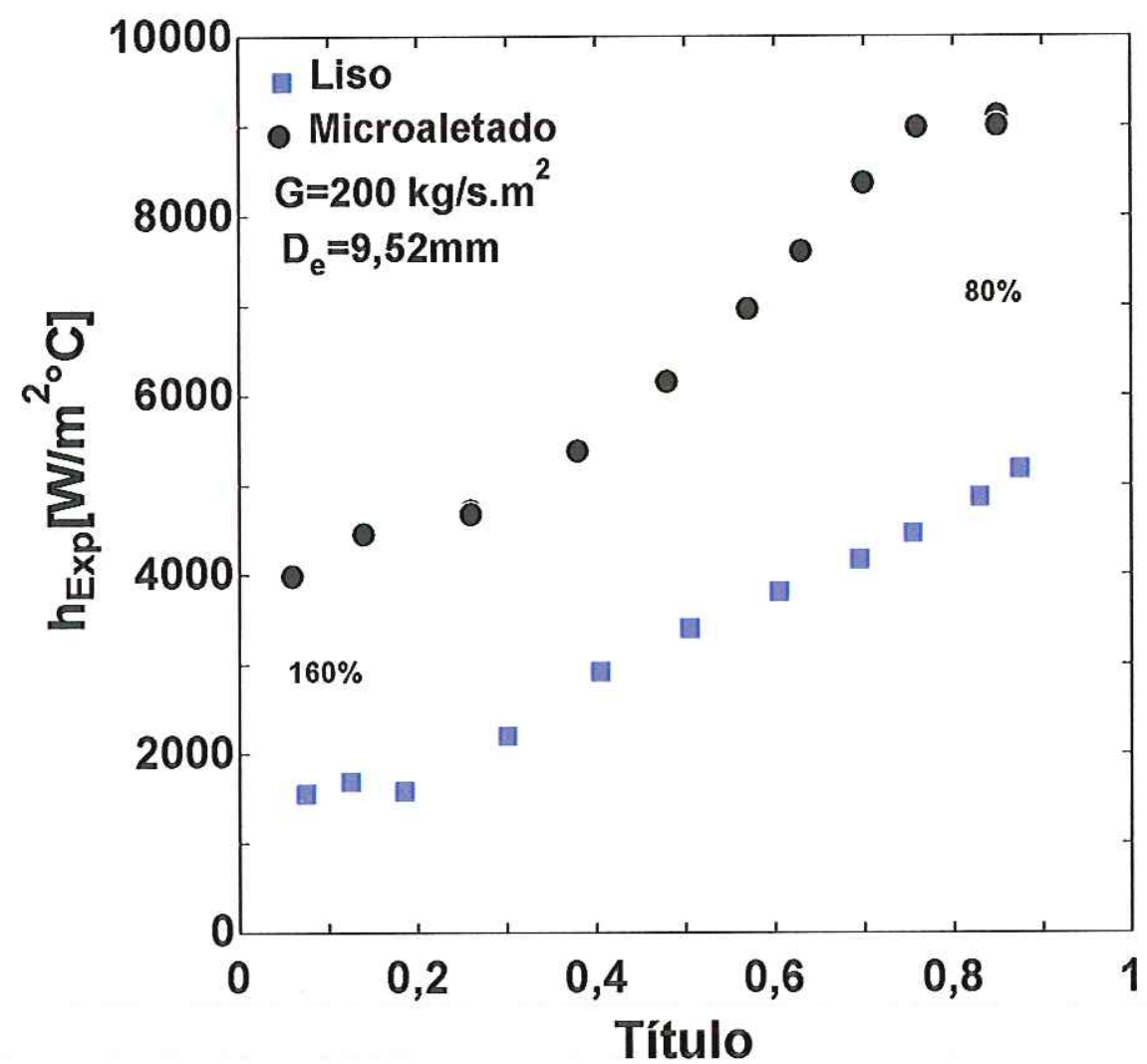

Figura 4.51 Variação do coeficiente de transferência de calor em função do título para tubos liso e ranhurado. $\mathrm{D}_{\mathrm{e}}=9,52 \mathrm{~mm}, \mathrm{~T}_{\text {Evap }}=5^{\circ} \mathrm{C}, \phi=5 \mathrm{~kW} / \mathrm{m}^{2}$ e G=200 kg/s.m .

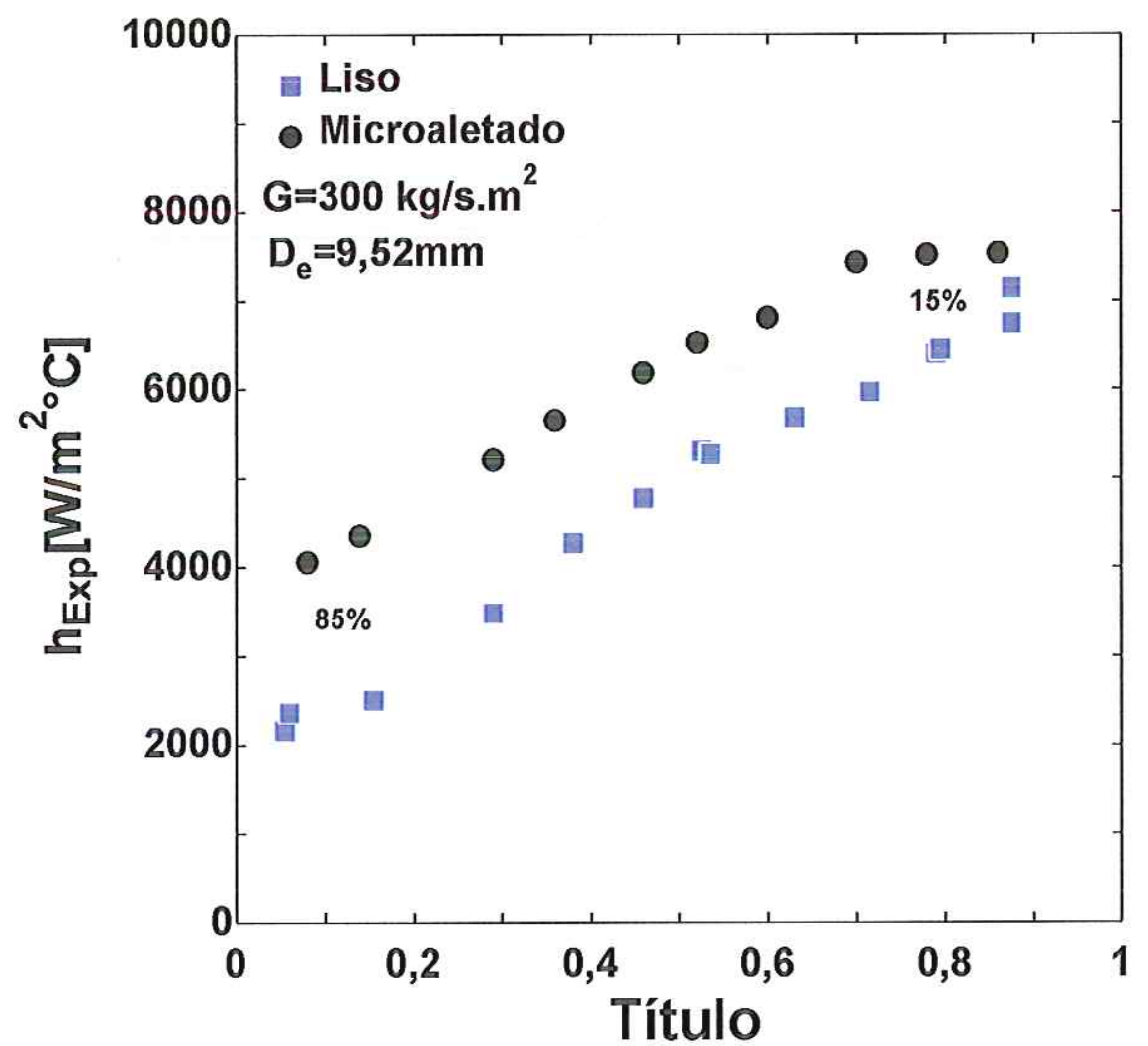

Figura 4.52 Variação do coeficiente de transferência de calor em função do título para tubos liso e ranhurado. $\mathrm{D}_{\mathrm{e}}=9,52 \mathrm{~mm}, \mathrm{~T}_{\text {Evap }}=5^{\circ} \mathrm{C}, \phi=5 \mathrm{~kW} / \mathrm{m}^{2}$ e G=300 kg/s.m ${ }^{2}$. 


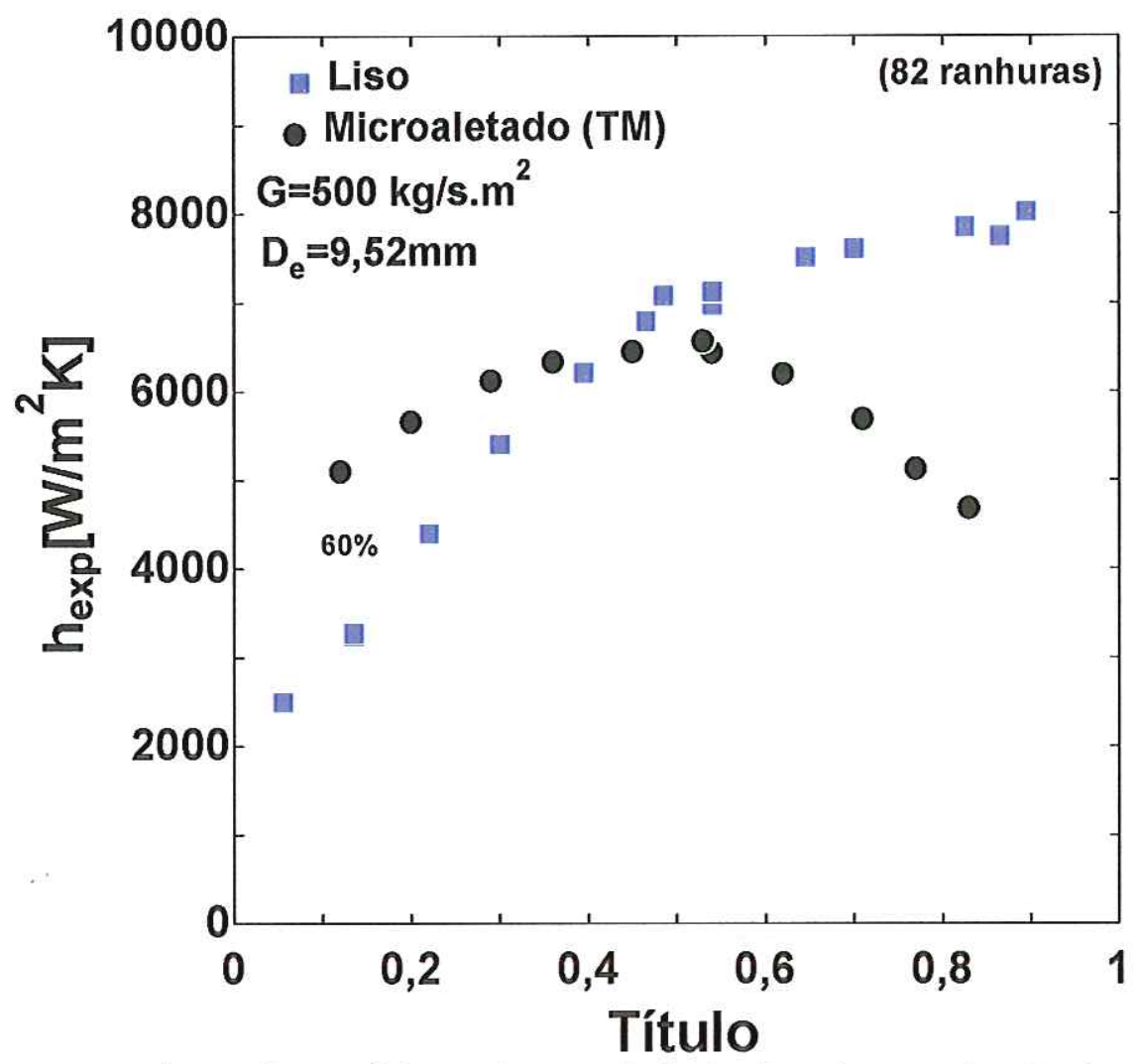

Figura 4.53 Variação do coefíciente de transferência de calor em função do título para tubos liso e ranhurado (82 ranhuras), $\mathrm{T}_{\text {Evap }}=5^{\circ} \mathrm{C}, \phi=5 \mathrm{~kW} / \mathrm{m}^{2}$ e G=500 kg/s.m ${ }^{2}$.

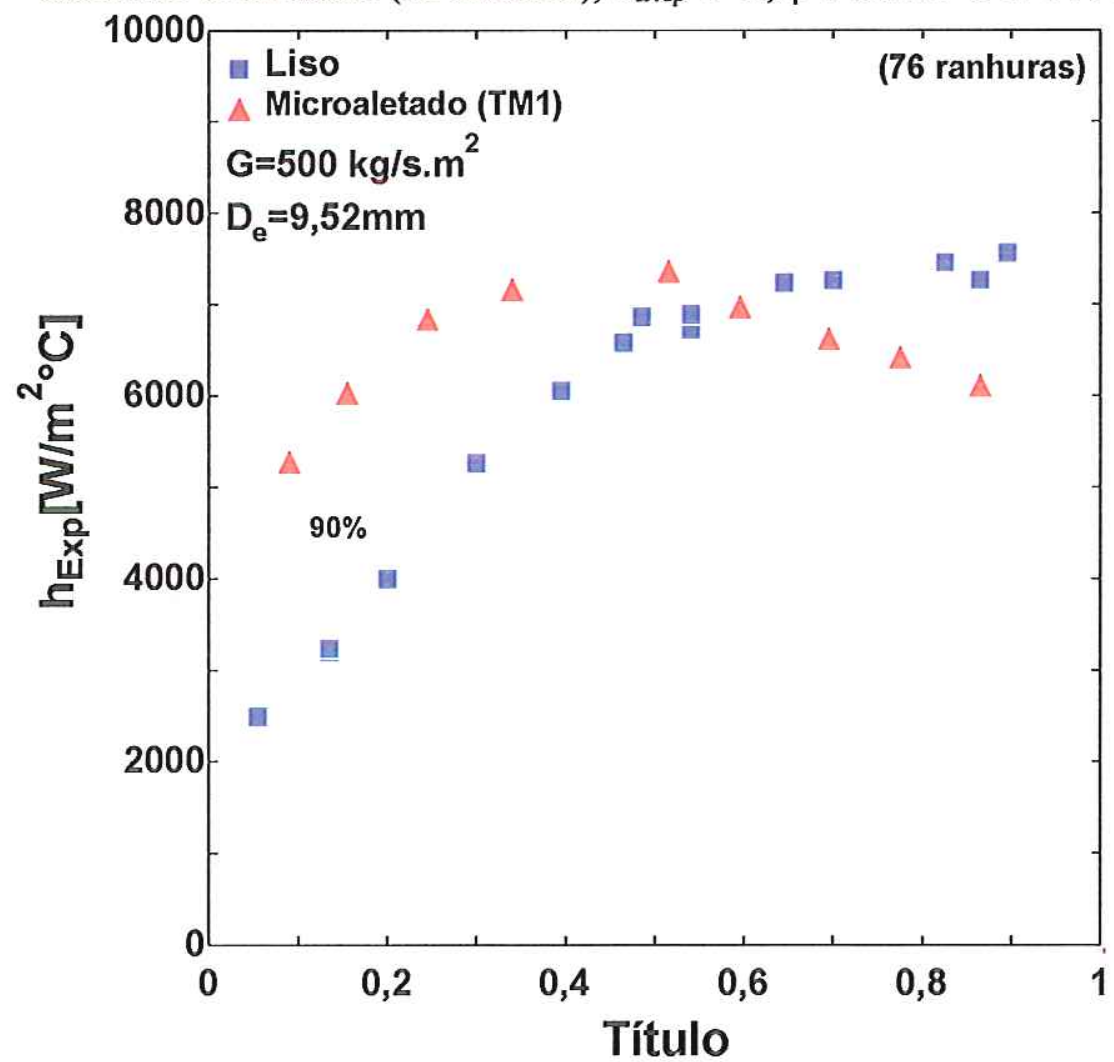

Figura 4.54 Variação do coeficiente de transferência de calor em função do título para tubos liso e ranhurado (76 ranhuras), $\mathrm{T}_{\text {Evap }}=5^{\circ} \mathrm{C}, \phi=5 \mathrm{~kW} / \mathrm{m}^{2}$ e G=500 kg/s. $\mathrm{m}^{2}$. 
Como observado nas figuras precedentes, os tubos microaletados melhoram a transferência de calor em maior ou menor grau, dependendo, quase que exclusivamente, da vazão de refrigerante e da geometria das microaletas. Pode-se definir um Fator de Intensificação da Transferência de Calor, $\mathrm{FI}_{\mathrm{h}}$, por uma relação do tipo:

$$
\mathbf{F I}_{\mathbf{h}}=\frac{\mathbf{h}_{\text {Microalctado }}}{\mathbf{h}_{\text {Liso }}}
$$

A Fig. 4.55 ilustra os resultados obtidos para o fator de intensificação da transferência de calor em função do título para o tubo microaletado de $9,52 \mathrm{~mm}$ de diâmetro externo e 82 ranhuras. Os dados foram levantados para o refrigerante R-134a, velocidades mássicas de 100,200, 300 e $500 \mathrm{~kg} / \mathrm{s} . \mathrm{m}^{2}$, fluxo de calor de $5 \mathrm{~kW} / \mathrm{m}^{2}$ e temperatura de evaporação da ordem de $5^{\circ} \mathrm{C}$. Vale ressaltar que os valores de $\mathrm{FI}_{\mathrm{h}}$ maiores que 1 , indicam que o tubo microaletado, em termos da transferência de calor, é superior ao tubo liso. Isso se verifica para os valores da velocidade mássica de 100,200 e $300 \mathrm{~kg} / \mathrm{s} . \mathrm{m}^{2}$, merecendo destaque os resultados para $\mathrm{G}=100 \mathrm{~kg} / \mathrm{s} . \mathrm{m}^{2}$, pois, neste caso, valores de $\mathrm{FI}_{\mathrm{h}}$ superiores a 4 são observados. O tubo microaletado passa a ser inviável para $\mathrm{G}=500 \mathrm{~kg} / \mathrm{s} \cdot \mathrm{m}^{2}$ e títulos superiores a $40 \%$, já que o valor de $\mathrm{FI}_{\mathrm{h}}$ experimenta valores inferiores a 1 , ou seja, o tubo liso apresenta um coeficiente de transferência de calor superior ao microaletado, como ilustrado nas Figs. 4.53 e 4.54.

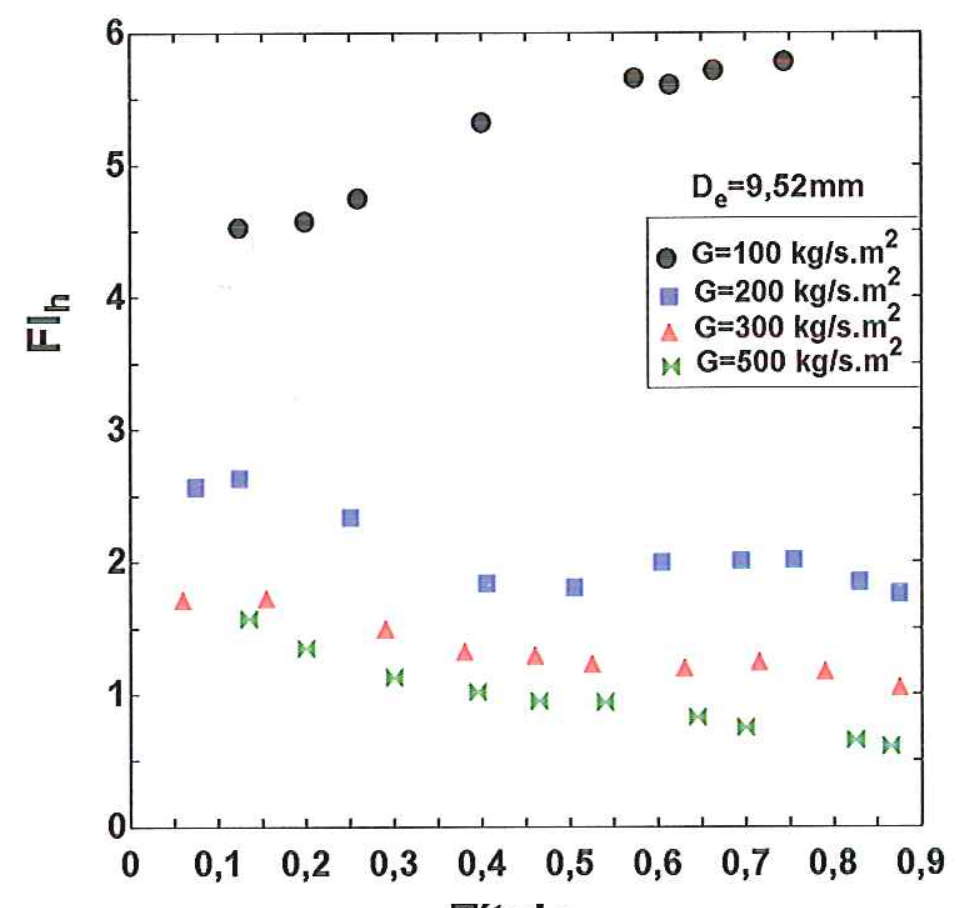

\section{Título}

Figura 4.55 Variação do Fator de Intensificação de transferência de calor, $\mathrm{FI}_{\mathrm{h}}$, em função do título para tubos liso e microaletado (TM) (82 ranhuras). 
Ensaios com tubos microaletados de geometria distinta, tubo Duplo-V ilustrado pela Fig. 4.2, foram realizados e produziram resultados interessantes. A Fig. 4.56 apresenta os resultados do coeficiente de transferência de calor em função do título para o tubo Duplo-V em comparação com aqueles obtidos para o liso e o microaletado (TM) de 82 ranhuras. A temperatura de evaporação permaneceu constante e igual a $5^{\circ} \mathrm{C}$, o fluxo de calor de $5 \mathrm{~kW} / \mathrm{m}^{2}$ e a velocidade mássica de $100 \mathrm{~kg} / \mathrm{s}^{\mathrm{m}} \mathrm{m}^{2}$, tendo sido obtidos resultados para o refrigerante R134a. O comportamento apresentado pelo coeficiente de transferência de calor do tubo Duplo-V é semelhante àquele observado para o tubo microaletado (TM) para títulos de até $50 \%$ e superiores, a partir dos quais, o coeficiente associado ao tubo Duplo-V começa a diminuir, apresentando uma tendência distinta daquela observada para o tubo microaletado. Esse comportamento está intimamente relacionado com o padrão de escoamento e à geometria do tubo. Como mencionado anteriormente, para essa vazão, o escoamento é tipicamente estratificado em tubos lisos. Já nos tubos ranhurados o líquido tende a ser transportado para a região superior por efeito de arrasto promovido pelo vapor ao longo dos canais das ranhuras. Para o tubo Duplo- $\mathrm{V}$, devido à configuração de ranhuras invertidas a cada $90^{\circ}$, o líquido é carregado para a região superior do tubo para títulos inferiores a $50 \%$. Isso se deve ao fato da espessura do filme de líquido se encontrar acima da metade do tubo e, de acordo com a geometria desse tubo, que apresenta as ranhuras ascendentes na metade superior do tubo, o líquido é deslocado para o topo do tubo, fazendo com que toda a superficie interior do tubo esteja em contato com o líquido. À medida que o título aumenta, o nível de líquido no tubo diminui e, para títulos da ordem de $50 \%$, o filme de líquido não alcança as ranhuras ascendentes, permanecendo segregado na parte inferior do tubo. Esse comportamento é claramente observado na Fig. 4.56 para o tubo Duplo-V e títulos superiores a $50 \%$, onde o coeficiente de transferência de calor começa a diminuir drasticamente em conseqüência da exposição ao vapor da região superior do tubo.

A Fig. 4.57 ilustra a variação do coeficiente de transferência de calor em função do título para o tubo Duplo- $\mathrm{V}$, superpostos os resultados para o tubo liso e microaletado, nas mesmas condições mencionadas anteriormente, porém alterando a velocidade mássica para $\mathrm{G}=200 \mathrm{~kg} / \mathrm{s} \cdot \mathrm{m}^{2}$. Essa figura mostra que à medida que o padrão anular é estabelecido, o que é verificado para vazões dessa ordem, o tubo Duplo-V tende a intensificar sobremaneira o coeficiente de transferência de calor em relação aos outros tubos. Entretanto, como poderá ser observado mais adiante, a perda de caga se eleva do mesmo modo, revelando que esse tubo é interessante comercialmente quando não há maiores preocupações com o aumento da potência de bombeamento, ou seja, com o consumo de energia. 


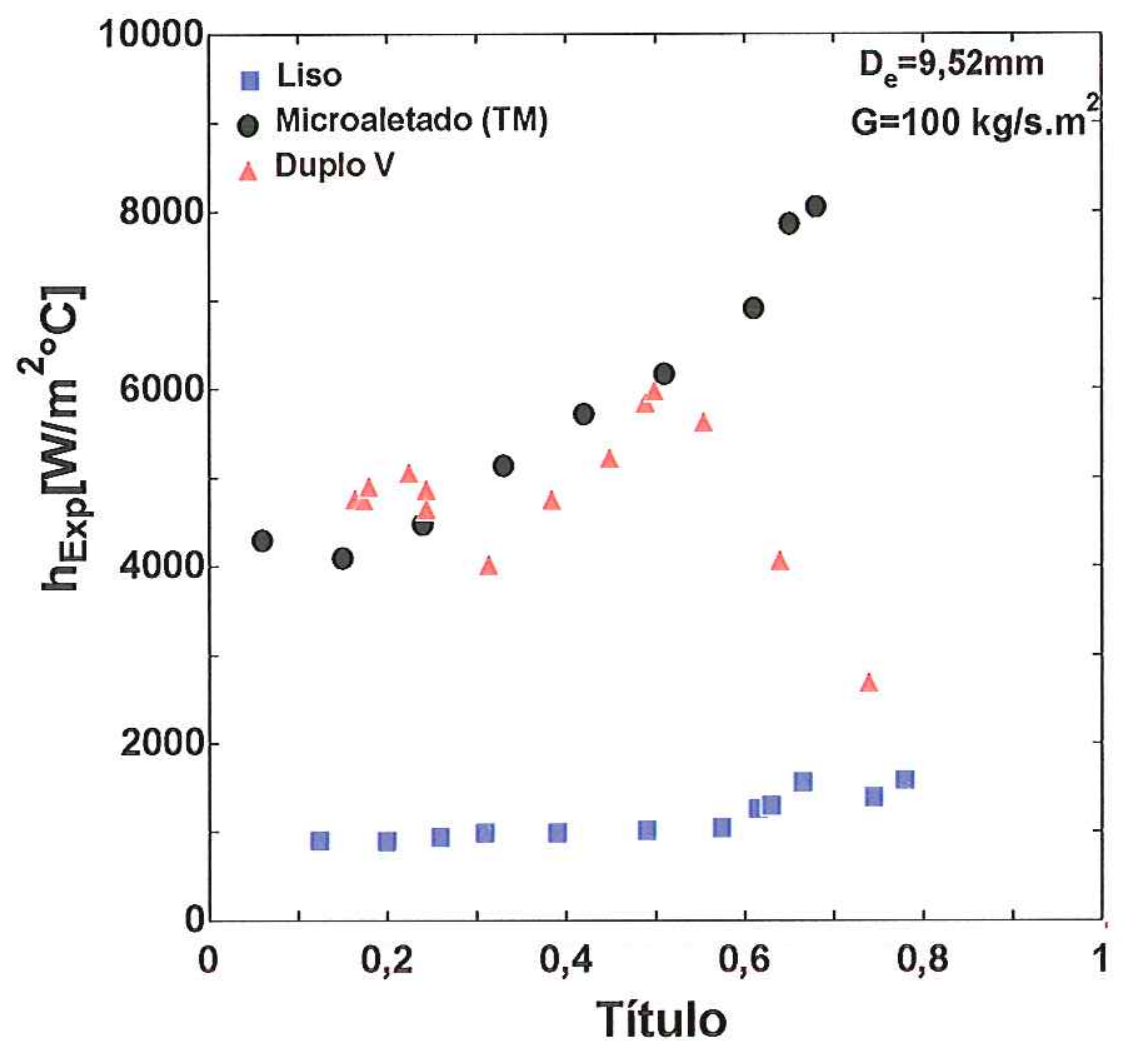

Figura 4.56 Variação do coefíciente de transferência de calor em função do título para tubos liso, microaletado e Duplo- $\mathrm{V}, \mathrm{T}_{\text {Evap }}=5^{\circ} \mathrm{C}, \phi=5 \mathrm{~kW} / \mathrm{m}^{2}$ e G=100 kg/s.m ${ }^{2}$.

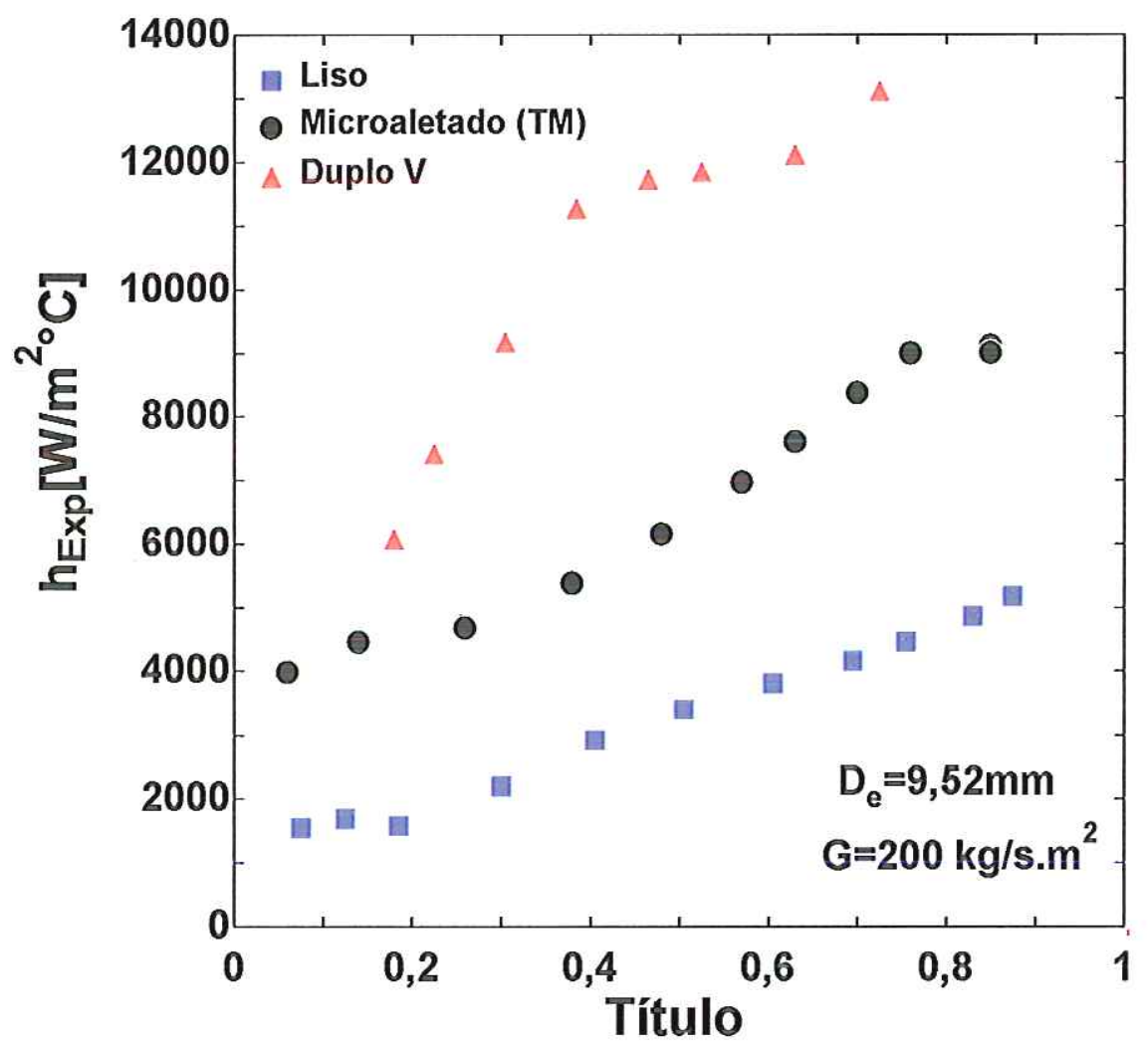

Figura 4.57 Variação do coeficiente de transferência de calor em função do título para tubos liso, microaletado e Duplo-V, $\mathrm{T}_{\text {Evap }}=5^{\circ} \mathrm{C}, \phi=5 \mathrm{~kW} / \mathrm{m}^{2}$ e G=200 kg/s.m ${ }^{2}$. 


\subsubsection{Perda de Carga em Tubos Microaletados}

A avaliação da perda de carga em tubos microaletados é de suma importância em projetos de trocadores de calor. Nessas condições, no presente trabalho, foram realizados ensaios visando à determinação da perda de carga no interior de tubos dotados de ranhuras internas em ebulição convectiva. A Fig. 4.58 apresenta uma comparação da perda de carga entre os tubos liso e microaletado para velocidades mássicas variando entre 100 e 500 $\mathrm{kg} / \mathrm{s} \cdot \mathrm{m}^{2}$, título entre 5 e $90 \%$ e fluxo de calor da ordem de $5 \mathrm{~kW} / \mathrm{m}^{2}$. Observa-se que o tubo microaletado apresenta valores, de perda de carga superiores aos do tubo liso, como seria de esperar. Este efeito é tanto mais pronunciado quanto maior a velocidade mássica e o título. Nota-se claramente que, para as velocidades mássicas superiores, 300 e $500 \mathrm{~kg} / \mathrm{s} \cdot \mathrm{m}^{2}$, as diferenças entre os gradientes de pressão, $\triangle \mathrm{P} / \mathrm{L}$, para tubos lisos e ranhurados tendem a se acentuar, especialmente, para títulos superiores a $50 \%$. Essa tendência está relacionada ao comportamento peculiar do gradiente de pressão em tubos internamente ranhurados, BANDARRA FILHO et al (2001). Para as condições operacionais em questão, caracterizadas pela velocidade mássica e o título, o padrão estritamente anular se estabelece no escoamento. À medida que o título se eleva e a película de líquido aderida à superfície do tubo se afina, o gradiente de pressão tende ao valor típico do escoamento monofásico (vapor) no caso dos tubos lisos. Tal comportamento está associado ao nivelamento que se observa nas curvas do gradiente para os títulos superiores. No caso dos tubos ranhurados, o mecanismo que parece contribuir para a elevação progressiva de $\Delta \mathrm{P}$ com o título, está relacionado ao confinamento da película de líquido a uma região de espessura da ordem das microaletas (ranhuras). Nessas condições, as aletas operam como rugosidades superficiais para o vapor. Este, ao escoar rente às aletas, promove um efeito de remoção do liquido dos canais, dispersando-o pela região central do tubo. Tal estado de coisas resulta em dois efeitos: incremento do gradiente de pressão e transição para o escoamento em névoa, observado através da janela de visualização na saída da seção de testes. 


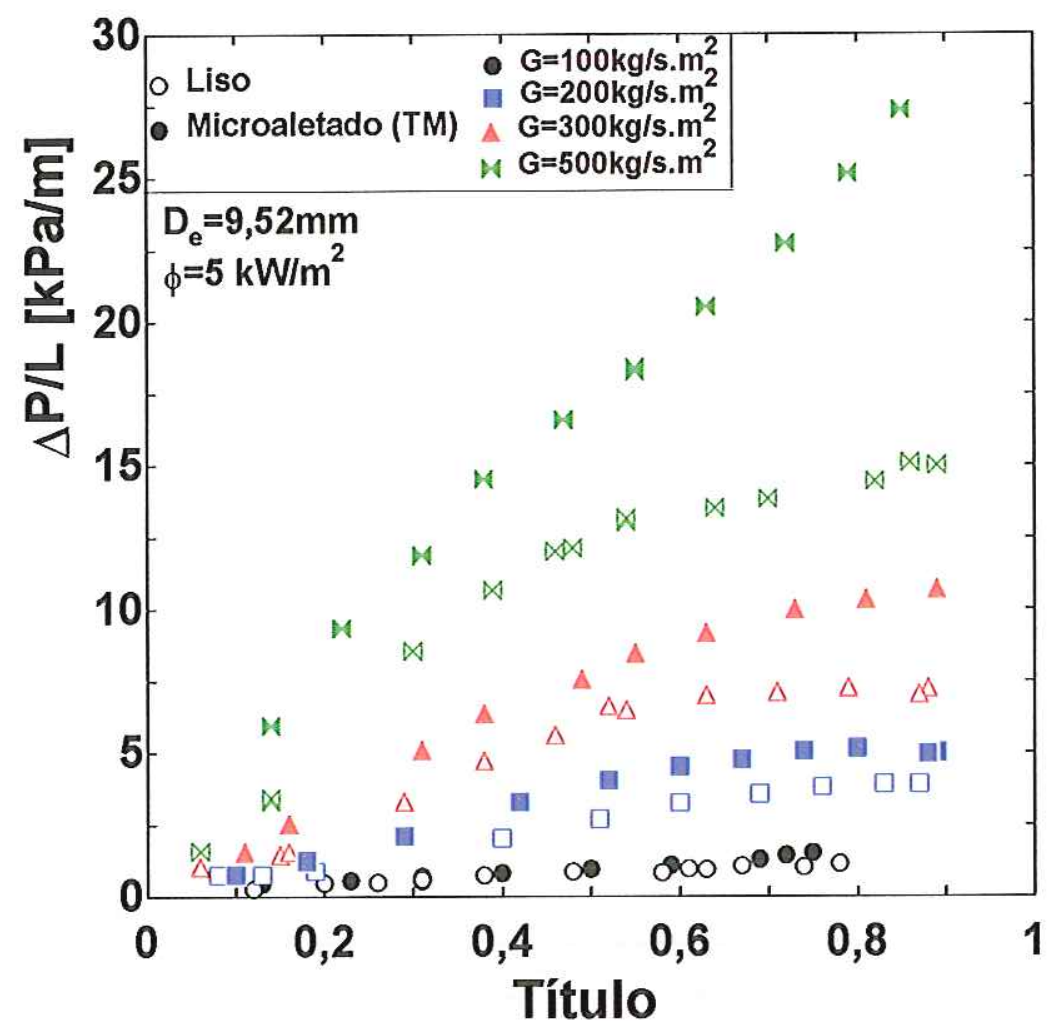

Figura 4.58 Comparação da perda de carga em função do título entre os tubos: liso e microaletado (TM), com $\mathrm{T}_{\text {Evap }}=5^{\circ} \mathrm{C}, \phi=5 \mathrm{~kW} / \mathrm{m}^{2}$ e $\mathrm{D}_{\mathrm{e}}=9,52 \mathrm{~mm}$.

Como os tubos dotados de microaletas apresentam características geométricas distintas, seria interessante verificar se a perda de carga é sensível a esse parâmetro. Nesse sentido, a Fig. 4.59 apresenta os resultados para a perda de carga em função do título para os seguintes tubos: liso; microaletado (TM) de 82 ranhuras; microaletado (TM1) de 76 ranhuras; microaletado (Trefi-Metaux) e o Duplo-V. É importante lembrar que os tubos apresentam mesmo diâmetro externo $(9,52 \mathrm{~mm})$ e os resultados foram obtidos para as mesmas condições de ensaio. Percebe-se claramente que o tubo Duplo-V apresenta o maior gradiente de pressão entre os tubos ensaiados. Isso se deve, principalmente, a sua configuração interna que apresenta as microaletas com sentido invertido a cada $90^{\circ}$. Esse comportamento (maior perda de carga para o tubo Duplo-V) foi verificado em todos ensaios com distintas velocidades mássicas. Em relação aos outros tubos ranhurados, pode-se afirmar que a perda de carga é, aproximadamente, da mesma ordem, onde o tubo microaletado (TM1) de 76 ranhuras apresenta valores levemente superiores. É importante destacar, ainda, o comportamento da perda de carga dos tubos microaletados em relação ao liso, para títulos acima de $45 \%$. Como mencionado anteriormente, o padrão de escoamento em névoa é predominante para títulos dessa ordem. 


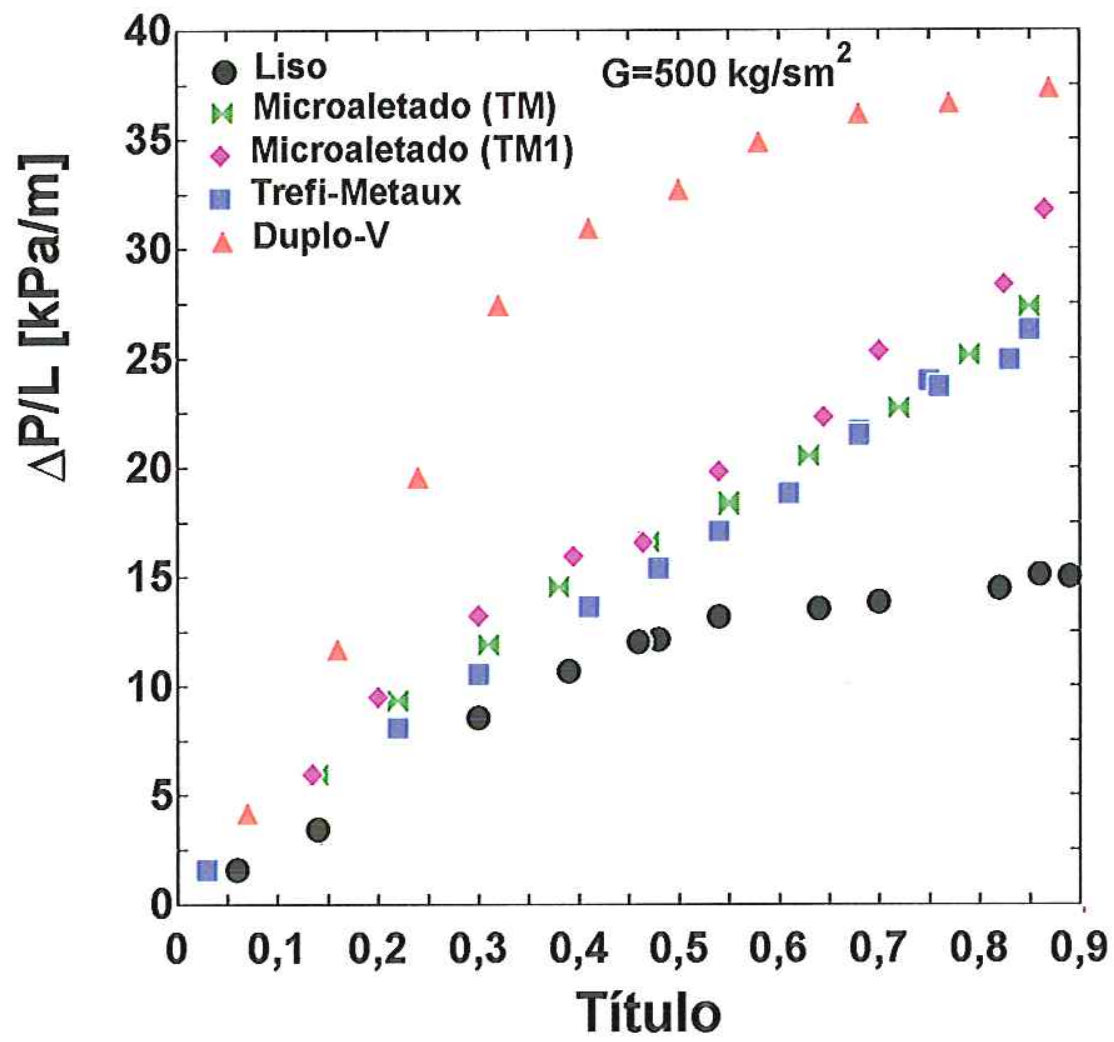

Figura 4.59 Variação da perda de carga em função do título para os seguintes tubos: liso, microaletado (TM) 82 ranhuras, microaletado (TM1) 76 ranhuras, microaletado (Trefi-Metaux.) e Duplo-V. Diâmetro externo dos tubos de $9,52 \mathrm{~mm}$, fluxo de calor de $5 \mathrm{~kW} / \mathrm{m}^{2}$ e G=500 kg/s.m².

Em relação aos tubos microaletados, é interessante observar que o multiplicador bifásico apresenta a mesma tendência que aquela encontrada para o tubo liso, porém verifica-se um incremento em seu valor, conforme ilustrado pelas Figs. 4.60 (a) e (b), como seria de esperar. Tais figuras apresentam a comparação entre os tubos liso e microaletado para velocidades mássicas de 200 e $300 \mathrm{~kg} / \mathrm{s} . \mathrm{m}^{2}$, respectivamente, e fluxo de calor específico de $5 \mathrm{~kW} / \mathrm{m}^{2}$. A correlação de JUNG \& RADERMACHER (1989) foi superposta aos resultados experimentais para efeito de ilustração do comportamento relativo dos resultados experimentais. 


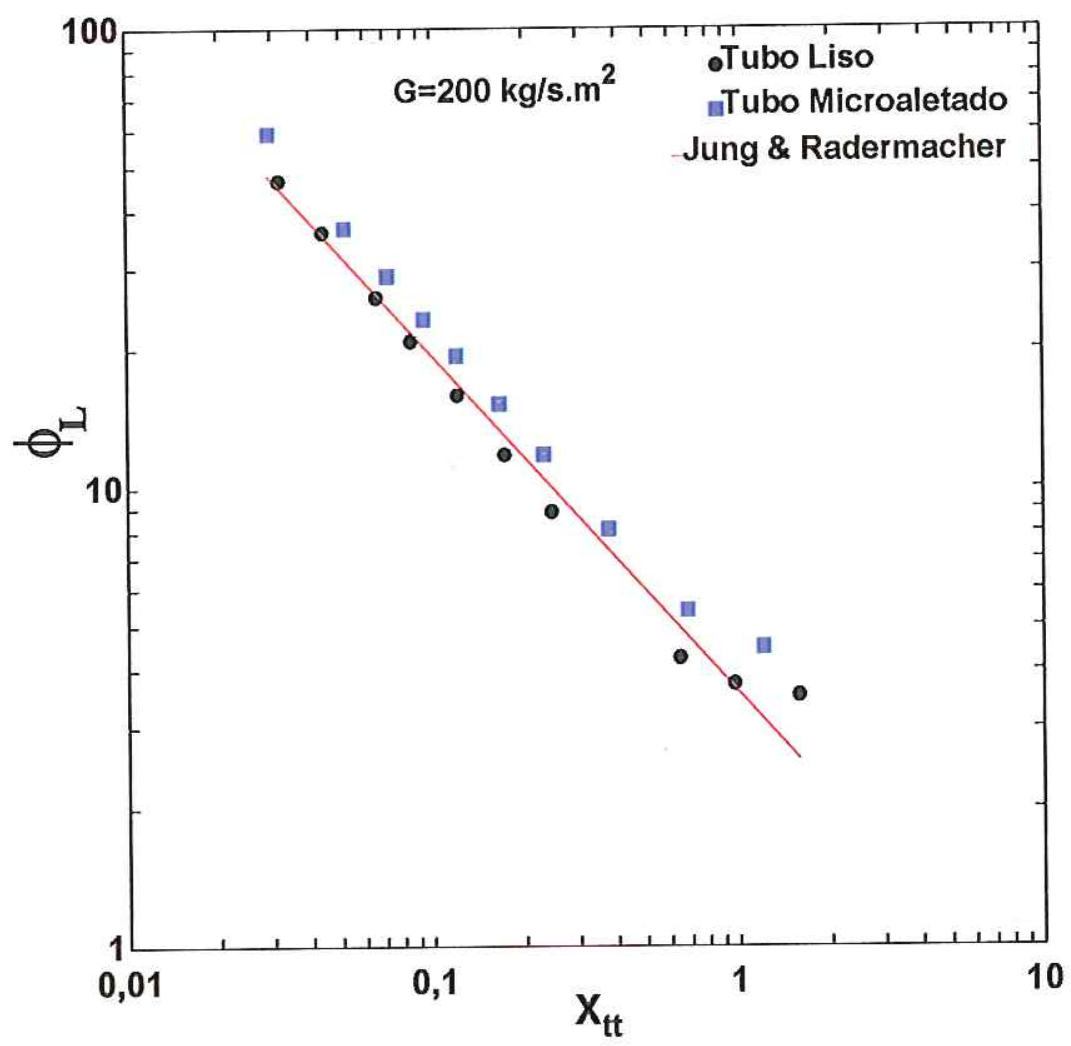

(a)

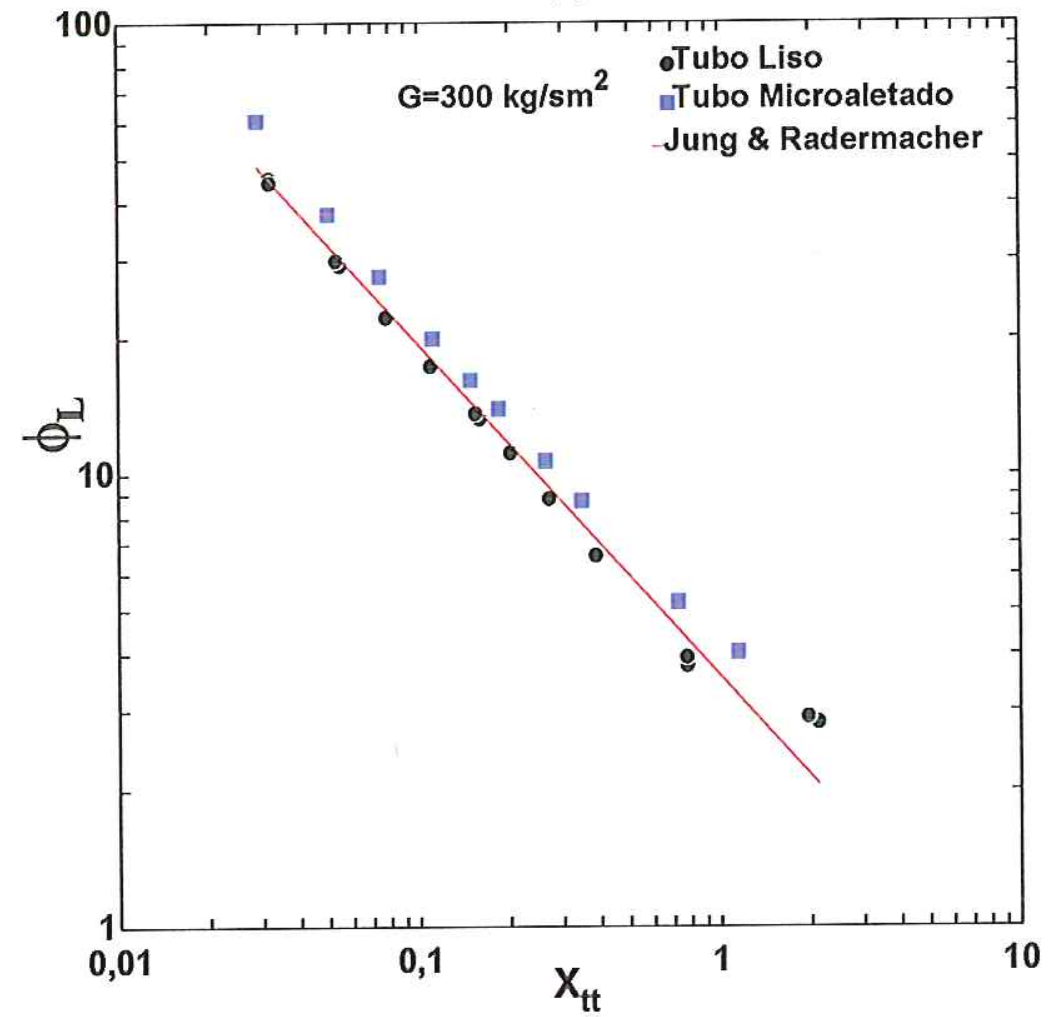

(b)

Figura 4.60 Comparação do multiplicador bifásico em função do $X_{\mathrm{tt}}$ para os tubos: liso e microaletado. (a) $\mathrm{G}=200 \mathrm{~kg} / \mathrm{s} \cdot \mathrm{m}^{2}$ e (b) $\mathrm{G}=300 \mathrm{~kg} / \mathrm{s} \cdot \mathrm{m}^{2}$. $\mathrm{D}=9,52 \mathrm{~mm}$. 
De acordo com o exposto nos parágrafos precedentes, o efeito das microaletas nos tubos ranhurados se expressa tanto através do incremento da transferência de calor quanto no da perda de carga. Se por um lado, a transferência de calor afeta o aspecto térmico do trocador de calor (no caso o evaporador) no sentido positivo, a perda de carga afeta negativamente, tanto o desempenho do próprio trocador (pois impõe uma redução na temperatura do fluido refrigerante) quanto o do circuito frigorífico, resultante da pressão de aspiração do compressor, SAIZ JABARDO et al (2000). Nesse sentido, seria importante avaliar o desempenho termo-hidráulico, ou seja, o aumento da transferência de calor em relação ao incremento indesejável da perda de carga para as mesmas condições. Assim, a relação da intensificação da transferência de calor e da perda de carga é definida, neste trabalho, de acordo com SAIZ JABARDO et al (2000), como Fator de Intensificação Global, $\mathrm{FI}_{\text {Global}}$, dado pela seguinte relação:

$$
\mathbf{F I}_{\text {Global }}=\frac{\mathbf{h}_{\text {Microaletado }} / \mathbf{h}_{\text {Liso }}}{\Delta \mathbf{P}_{\text {Microaletado }} / \Delta \mathbf{P}_{\text {Liso }}}
$$

Percebe-se, assim, que valores do Fator de Intensificação Global, $\mathrm{FI}_{\text {Global, }}$, superiores a 1, estão relacionados a uma intensificação da transferência de calor superior à da perda de carga.

A Fig. 4.61 apresenta a variação do Fator de Intensificação Global em função do título para o tubo microaletado (TM) de 82 ranhuras, para velocidades mássicas variando entre 100 e $500 \mathrm{~kg} / \mathrm{s} \cdot \mathrm{m}^{2}$. Os ensaios foram realizados para temperatura de evaporação da ordem de $5^{\circ} \mathrm{C}$, fluxo de calor de $5 \mathrm{~kW} / \mathrm{m}^{2}$ e fluido de trabalho utilizado foi o R-134a. Nota-se que o $\mathrm{FI}_{\mathrm{Global}}$ praticamente assume valores maiores que 1 para todas velocidades mássicas consideradas, exceto a de $\mathrm{G}=500 \mathrm{~kg} / \mathrm{s} . \mathrm{m}^{2}$, que apresenta valores de $\mathrm{FI}_{\text {Global }}$ inferiores a $1 \mathrm{em}$ toda a faixa de títulos ensaiada. Em suma, pode-se afirmar que, para $\mathrm{G}=100 \mathrm{~kg} / \mathrm{s} . \mathrm{m}^{2}$, o Fator de Intensificação Global se eleva com o título, em virtude da expressiva elevação da transferência de calor em relação àquela observada para a perda de carga. À medida que se eleva a vazão, $G=200$ e $300 \mathrm{~kg} / \mathrm{s} \cdot \mathrm{m}^{2}$, a intensificação da transferência de calor não é tão significativa. Entretanto, se verifica um incremento considerável na perda de carga. Nessas ccndições, o $\mathrm{FI}_{\mathrm{Global}}$ assume valores mais modestos.

A Fig. 4.62 ilustra a variação do $\mathrm{FI}_{\mathrm{Global}}$ com o título para o tubo Duplo-V e as mesmas condições mencionadas anteriormente. Observa-se que o aumento da perda de carga exerce um papel importante no valor de $\mathrm{FI}_{\text {Global }}$. Assim, mesmo apresentando uma transferência de calor elevada, o incremento da perda de carga reduz significativamente $o$ $\mathrm{FI}_{\mathrm{Global}}$. Deve-se destacar, ainda, que, para $\mathrm{G}=100 \mathrm{~kg} / \mathrm{s} \cdot \mathrm{m}^{2}$ e títulos superiores a $50 \%$, o tubo 
Duplo- $\mathrm{V}$, em virtude de suas características geométricas, apresenta um $\mathrm{FI}_{\mathrm{Global}}$ que diminui com o título, ao passo que, no tubo microaletado, esse fator se mantém superior a 4 .

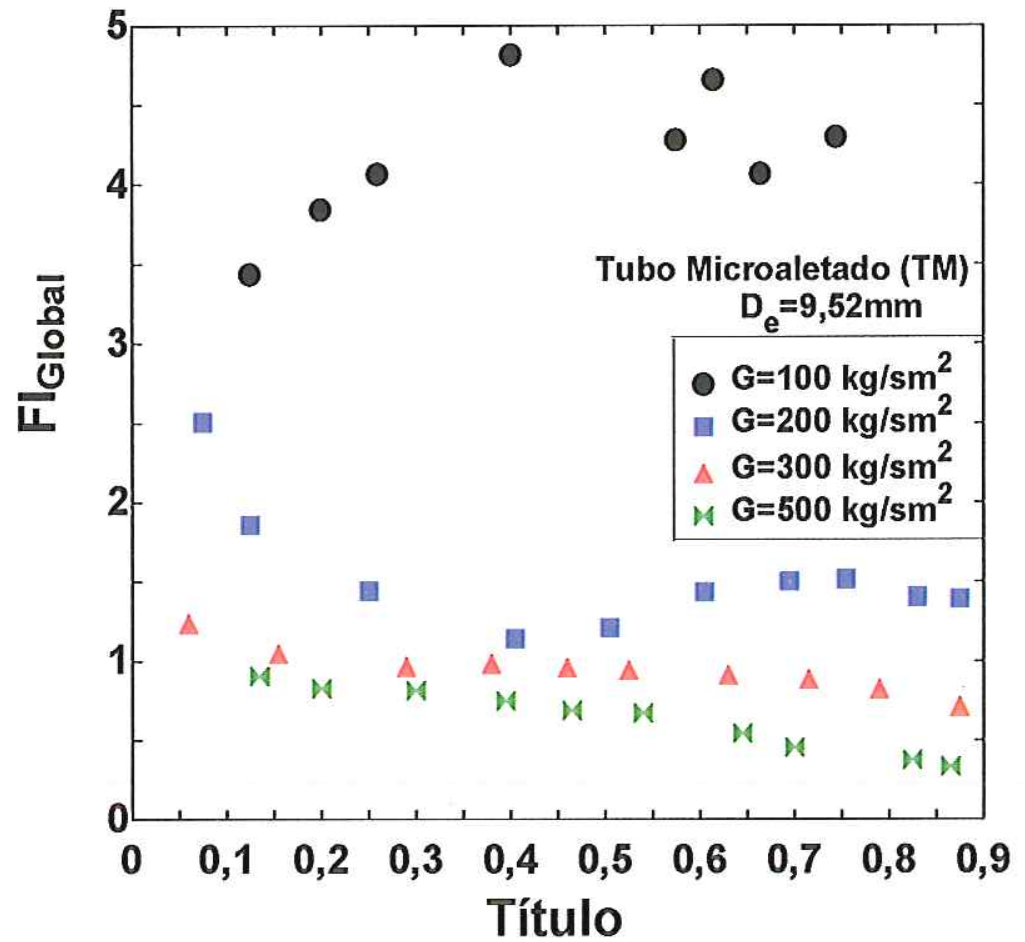

Figura 4.61 Variação do Fator de Intensificação Global, $\mathrm{FI}_{\text {Global, }}$ em função do título para o tubo microaletado (TM) (82 ranhuras).

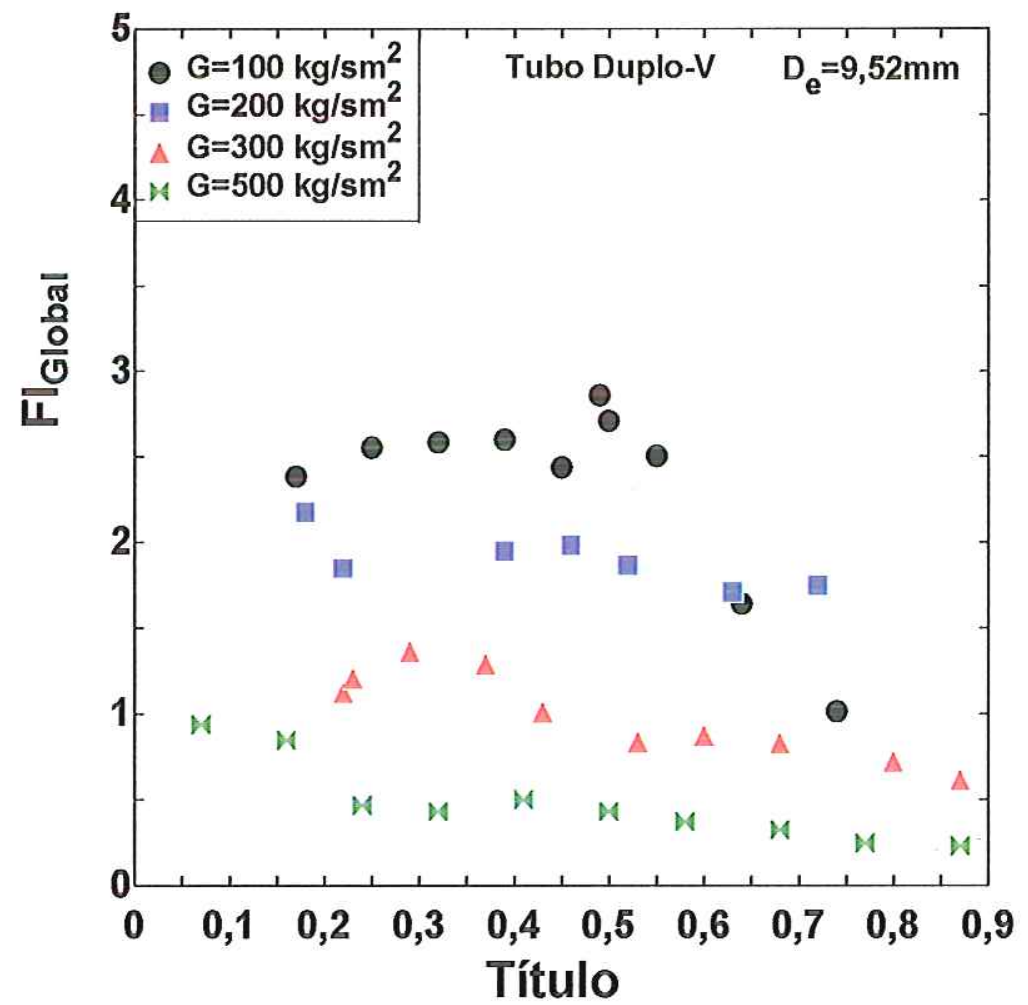

Figura 4.62 Variação do Fator de Intensificação Global, $\mathrm{FI}_{\text {Global, }}$ em função do título para o tubo Duplo-V. 


\subsubsection{Secagem de Parede}

A região de secagem de parede tem sido pouco estudada no passado, especialmente em aplicações fora do âmbito das nucleares. Nestas, o estudo e análise dos mecanismos de secagem de parede assume significativa importância em virtude dos elevados fluxos específicos de calor com que se opera nos reatores. O potencial para a ocorrência de secagem de parede, mesmo em condições de ebulição local, com o líquido ainda subresfriado, justifica as preocupações com o fenômeno na área nuclear. A secagem de parede, mesmo que local, implica em elevadas temperaturas superficiais, o que pode comprometer a integridade dos materiais envolvidos. Nas aplicações em que os fluxos de calor específico são relativamente reduzidos, a secagem de parede ocorre de forma mais amena, envolvendo elevações da temperatura superficial muito inferiores, como resultado de uma redução progressiva na camada de líquido em contato com a superfície aquecida. A secagem sob estas condições é denominada de "dryout" na literatura em inglês.

Na mudança de fase convectiva para aplicações industriais, os fluxos de calor são inferiores ao fluxo crítico, podendo atingir valores máximos da ordem de $50 \mathrm{~kW} / \mathrm{m}^{2}$ no caso da refrigeração. $\mathrm{Na}$ região que antecede a secagem de parede, para velocidades mássicas elevadas, $\mathrm{G} \geq 200 \mathrm{~kg} / \mathrm{s} . \mathrm{m}^{2}$, verifica-se o padrão anular de escoamento, caracterizado por elevados valores do coeficiente de transferência de calor devido à reduzida resistência térmica da película de líquido junto à superficie, associada à sua espessura. Como esta diminui no sentido do escoamento em virtude da evaporação do líquido, o coefíciente de transferência de calor se incrementa na mesma proporção, atingindo seu valor máximo na região que antecede a seção de secagem da parede. Nessa seção, a superfície aquecida sofre uma elevação de temperatura como resultado do contato direto com o vapor, condição em que o coeficiente de transferência de calor é, caracteristicamente, muito inferior ao da região anterior, assumindo valores típicos do escoamento monofásico de vapor. No caso de velocidades mássicas reduzidas, $\mathrm{G}<200 \mathrm{~kg} / \mathrm{s} \cdot \mathrm{m}^{2}$, o padrão estratificado prepondera ao longo do evaporador, conferindo ao coeficiente de transferência de calor um valor relativamente constante até a completa secagem da parede, seção em que se verifica um leve aumento da temperatura superficial, sem, entretanto, atingir os níveis observados no caso do padrão anular.

A secagem de parede (“dryout") está associada a uma significativa elevação da temperatura da superficie aquecida, como observado anteriormente, comportamento que permite o acompanhamento do referido fenômeno. A Fig. 4.63 ilustra a variação da temperatura superficial média nas quatro seções de medida da seção de testes em função do 
tempo. É interessante observar o comportamento da temperatura média na seção 4, distante $1,6 \mathrm{~m}$ da entrada, distinguido daquele das seções precedentes em que permanece constante. De fato, a partir do instante 40 segundos observa-se uma significativa elevação da temperatura, que atinge um máximo da ordem de $60^{\circ} \mathrm{C}$, voltando posteriormente aos níveis originais a partir do instante 70 segundos. 0 comportamento da seção 4 ilustra a ocorrência da secagem na região onde a mesma está localizada. Entretanto, logo após a secagem, a superficie é novamente molhada pelo líquido, o que determina a rápida redução da temperatura superficial. Durante os ensaios realizados, observou-se que o mecanismo de alternação entre os períodos de superfície seca e molhada se prolongava indefinidamente, com origem supostamente $\mathrm{cm}$ interações hidrodinâmicas a montante da seção de testes.

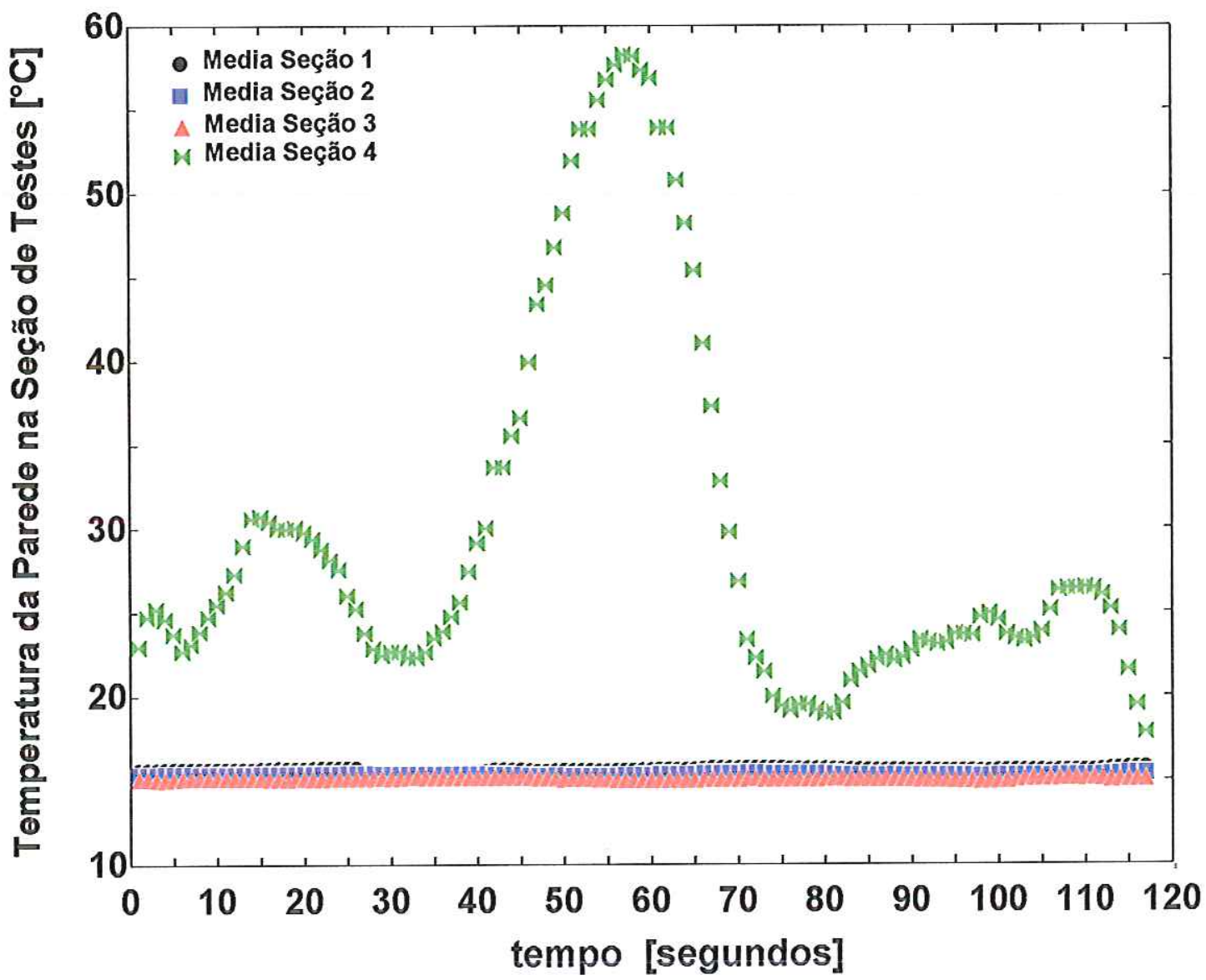

Figura 4.63 Distribuição de temperatura superficial na seção de testes em função do tempo. Refrigerante R-134a; $\mathrm{T}_{\text {Evap }}=6,2^{\circ} \mathrm{C} ; \mathrm{G}=175 \mathrm{~kg} / \mathrm{s} \cdot \mathrm{m}^{2} ; \phi=25 \mathrm{~kW} / \mathrm{m}^{2}$.

O acompanhamento da temperatura superficial de forma detalhada, através de medidas realizadas na geratriz superior, lateral e inferior da seção 4 do tubo de testes é ilustrado na Fig. 4.64 para as mesmas condições da Fig. 4.63. É interessante destacar que a temperatura 
da geratriz superior é a maior na seção nos instantes inicias, prévios à secagem completa da parede. Tal comportamento está associado à ocorrência de um padrão de escoamento estratificado, com a região inferior permanecendo efetivamente molhada e a superior parcialmente seca, mas submetida ao efeito de resfriamento das regiões inferiores, por efeito de condução pela parede do tubo. Uma vez estabelecida à completa secagem do tubo, as temperaturas nos três pontos de medida se elevam rapidamente, tendendo a apresentar um valor uniforme, como se observa no intervalo de tempo em torno do máximo de temperatura. A seguir, uma vez restabelecida a condição original, as temperaturas reassumem o comportamento anterior.

A Fig. 4.65 apresenta resultados de secagem para fluxo de calor superior ao das figuras anteriores. No caso, operou-se com o máximo disponível na seção de testes. Como pode se observar, o comportamento da temperatura superficial na seção em que ocorre a secagem (a 4, como no caso anterior) é qualitativamente distinto do caso anterior. Não mais se observa a oscilação, mas a temperatura média da superfície permanece razoavelmente constante em níveis significativamente elevados (ordem de $95^{\circ} \mathrm{C}$ ). Nas seções a montante, a temperatura média superficial permanece sem alterações em níveis inferiores (da ordem de $15^{\circ} \mathrm{C}$ ). No passado, pesquisadores como WEDEKIND \& STOECKER (1968) e SAIZ JABARDO (1976), trabalhando com a evaporação completa, sugeriram uma região de instabilidades da temperatura superficial associada à secagem da parede do tubo, como observado anteriormente. $\mathrm{O}$ comportamento observado nas Figs. 4.63 e 4.64 parece satisfazer aquele modelo. Entretanto, o aumento do fluxo de calor a níveis elevados para as aplicações frigoríficas, como é o caso da Fig. 4.65, parece limitar a extensão da região de instabilidades. Nesse caso, a seção 4 estaria na região de vapor superaquecido e a de instabilidades se localizaria entre as seções 3 e 4 , indicando que sua extensão depende explicitamente do fluxo de calor e, possivelmente, da velocidade mássica, cujo efeito não foi reproduzido neste contexto. 


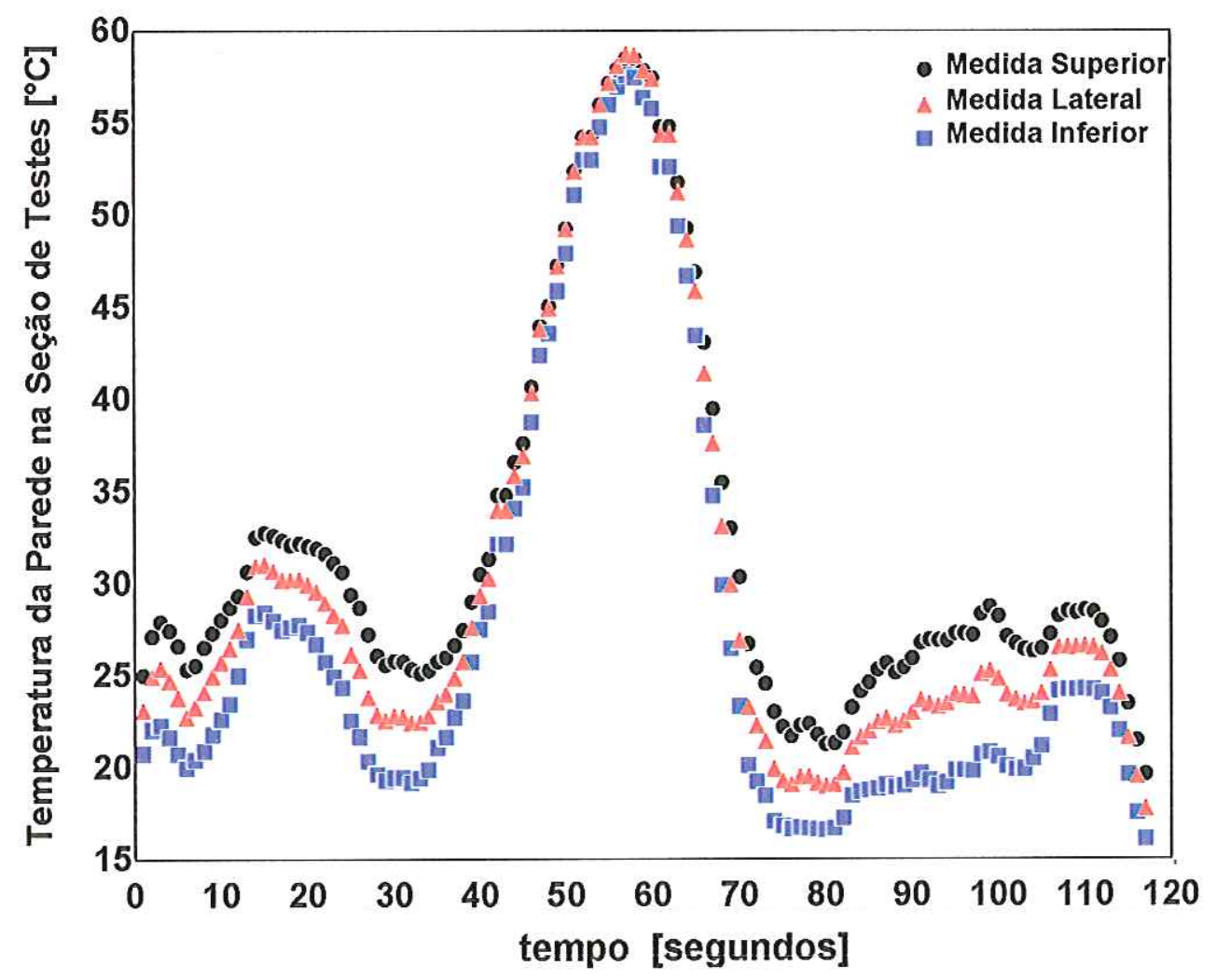

Figura 4.64 Variação temporal da temperatura superficial nas geratrizes superior, lateral e inferior da seção 4 para as condições da Fig. 4.63.

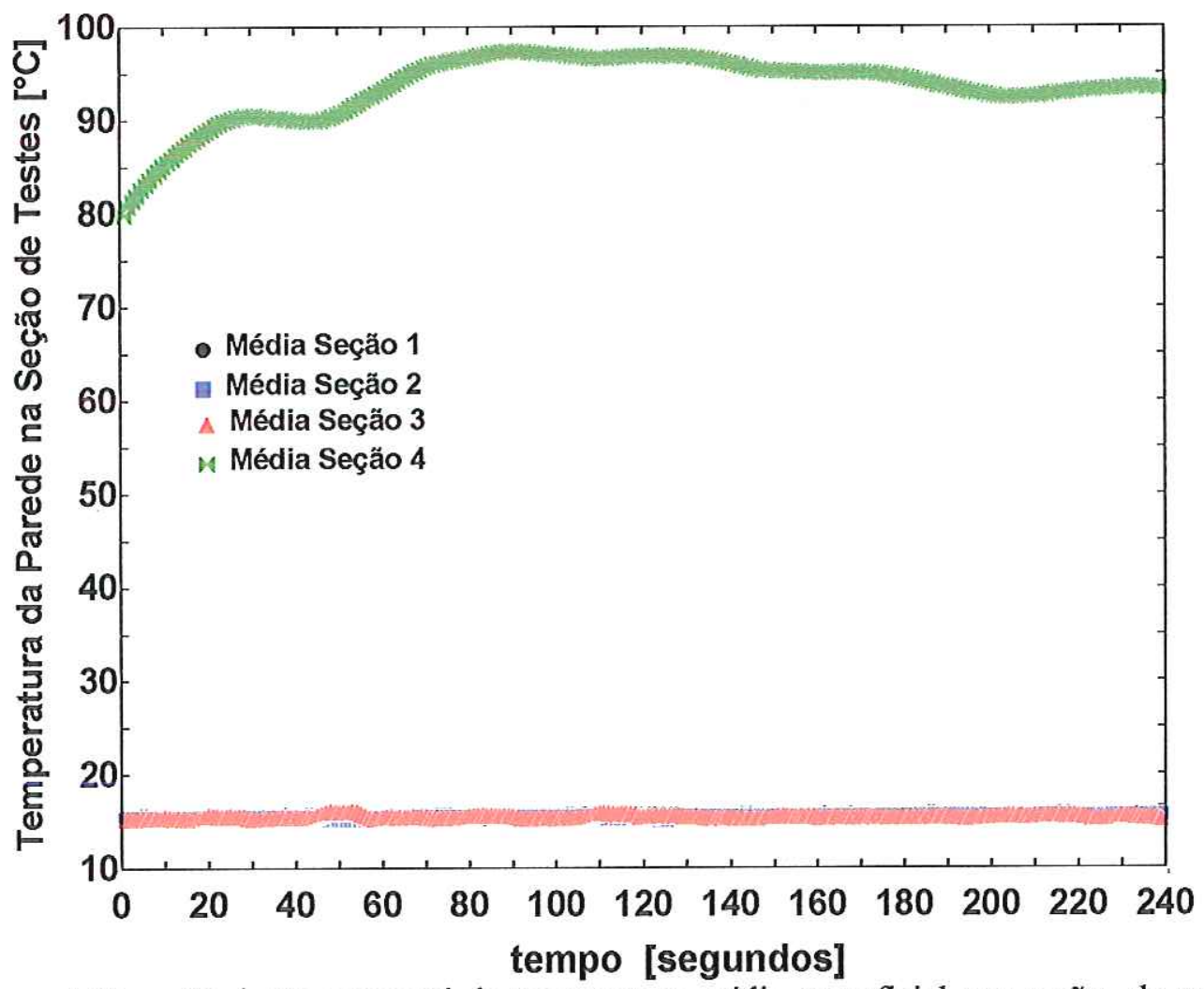

Figura 4.65 Variação temporal da temperatura média superficial nas seções de medida do tubo de testes. R-134a; $\mathrm{T}_{\text {Evap }}=6,5^{\circ} \mathrm{C} ; \mathrm{G}=170 \mathrm{~kg} / \mathrm{s} \cdot \mathrm{m}^{2} ; \phi=35 \mathrm{~kW} / \mathrm{m}^{2}$. 
A Fig. 4.66 apresenta a evolução da temperatura superficial média relativa às seções de medida ao longo da seção de testes, para títulos do refrigerante na entrada relativamente elevados. Nas duas primeiras seções, a temperatura superficial se mantém praticamente inalterada. Na terceira seção, distante $1,2 \mathrm{~m}$ da entrada da seção de testes, percebe-se um leve aumento, indício da secagem de parede parcial. Na última seção, distante $0,4 \mathrm{~m}$ da terceira, ocorre a secagem completa da parede, onde a temperatura superficial média experimentou valores da ordem de $35^{\circ} \mathrm{C}$.

Uma análise do coefíciente de transferência de calor na região de secagem de parede, apresentado pela Fig. 4.67, permitiu verificar seu comportamento para as mesmas condições especificadas na Fig. 4.66. Nessa figura, foram incorporados os coeficientes de transferência de calor para secagem de parede para a mesma vazão, obtido a partir das correlações de DITTUS \& BOELTER (1930), Eq. (2.15), LAVIN (1963), Eq. (2.86), e RHEE (1972), Eq. (2.91). Nota-se, claramente, que o escoamento que precede a região de secagem de parede é o anular, nas duas primeiras seções. Nessas ( $\mathrm{S} 1$ e S2), como deve ter ficado claro, o coeficiente de transferência de calor se eleva no sentido do escoamento. Na terceira seção, o coeficiente sofre uma significativa redução, da ordem de $50 \%$, a qual se acentua na última, em que o coeficiente assume o mesmo valor daquele correspondente ao escoamento monofásico de vapor. Nesta seção, para todos os efeitos, não há mais mudança de fase. As correlações proporcionaram resultados distintos para o coeficiente de transferência de calor, Dittus-Boelter: $220 \mathrm{~W} / \mathrm{m}^{2 \circ} \mathrm{C}$, Lavin: $157 \mathrm{~W} / \mathrm{m}^{2 \circ} \mathrm{C}$ e Rhee: $367 \mathrm{~W} / \mathrm{m}^{2 \circ} \mathrm{C}$. Em comparação àquele obtido experimentalmente, $235 \mathrm{~W} / \mathrm{m}^{2 \circ} \mathrm{C}$, na seção de secagem de parede, a correlação de Dittus-Boelter apresentou o menor desvio médio absoluto, 7\%, as de Lavin e Rhee resultaram $33 \%$ e $56 \%$, respectivamente. 


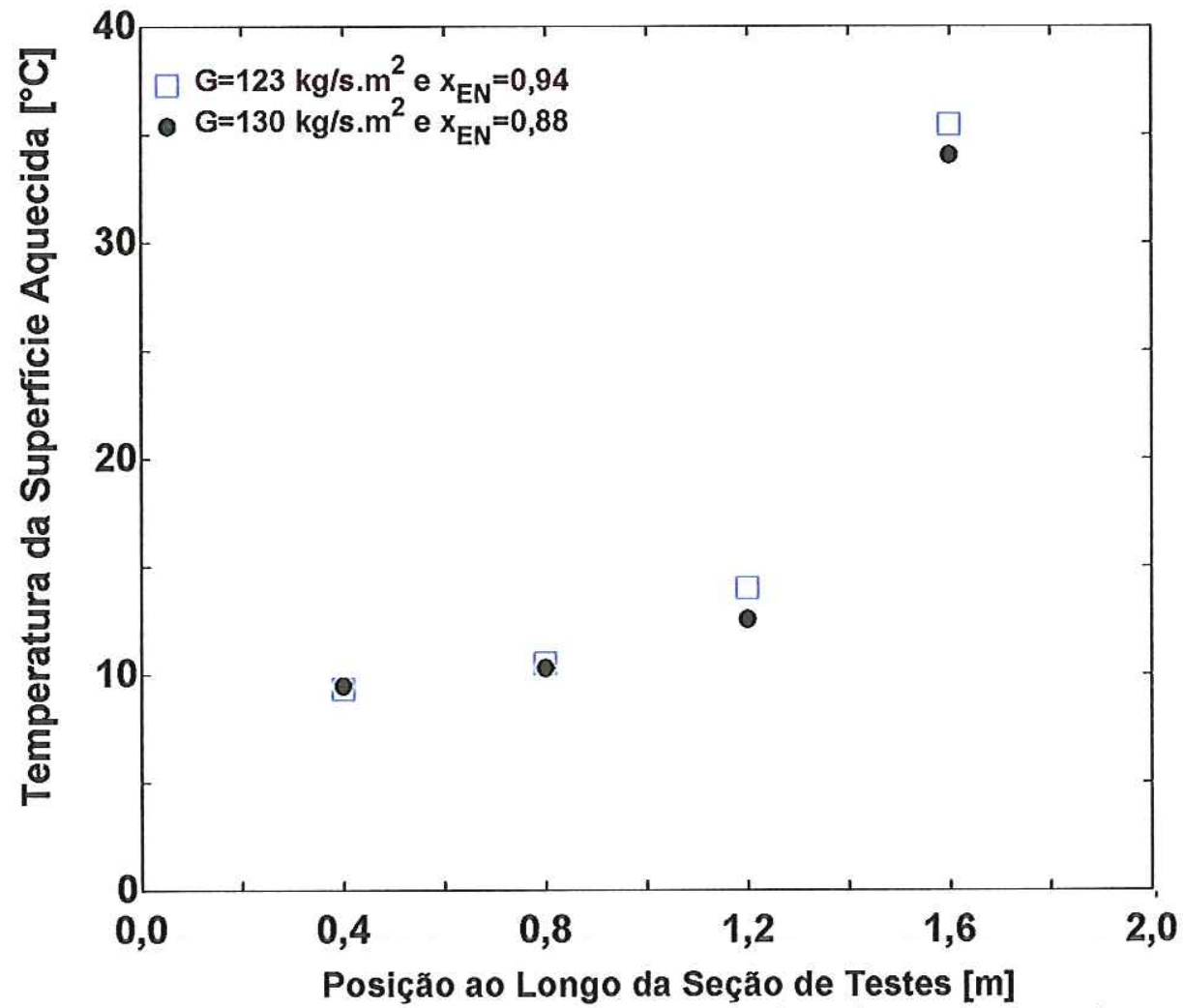

Figura 4.66 Distribuição da temperatura média da parede ao longo da seção de testes. R$22, \mathrm{~T}_{\text {Evap }}=10^{\circ} \mathrm{C}$ e $\phi=5 \mathrm{~kW} / \mathrm{m}^{2}$.

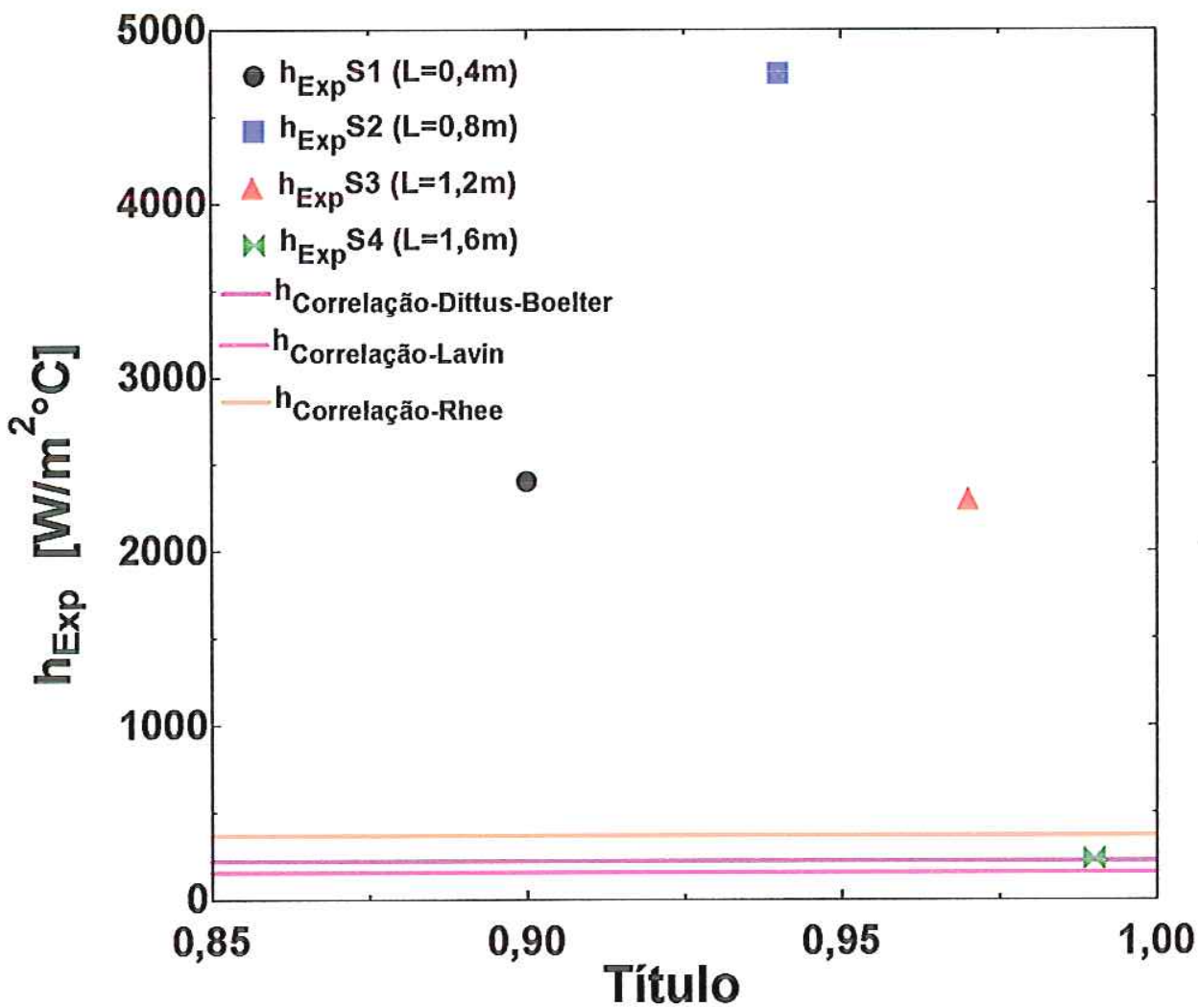

Figura 4.67 Distribuição do coeficiente de transferência de calor ao longo da seção de testes. R-22, $\mathrm{T}_{\text {Evap }}=10^{\circ} \mathrm{C}, \mathrm{G}=130 \mathrm{~kg} / \mathrm{s}^{\mathrm{m}} \mathrm{m}^{2}$ e $\phi=5 \mathrm{~kW} / \mathrm{m}^{2}$. 
Uma comparação em termos do coeficiente de transferência de calor em função do fluxo específico de calor, $\phi$, permite extrair informações interessantes, como aquelas da Fig. 4.68. É importante esclarecer que as condições de ensaio permaneceram constantes, variando somente o fluxo específico de calor. Deve-se observar que o comportamento do coeficiente de transferência de calor na seção 1 permanece constante mesmo com o aumento do fluxo de calor. Pode-se afirmar que, nesta seção, o padrão de escoamento é o anular pois, como mencionado anteriormente, nesse padrão, o coefíciente de transferência de calor não é afetado pelo fluxo de calor. Já nas seções 2, 3 e 4 percebe-se um decréscimo do coefíciente com o fluxo específico de calor. Esse comportamento é um sinal evidente que se caminha para a secagem de parede, onde, inicialmente, ocorre a secagem parcial da parede, ou seja, não há líquido em contato com a região superior do tubo e, posteriormente, ocorre a evaporação completa, o que, efetivamente, se observa na seção 4 para fluxos de calor elevados. Vale ressaltar, ainda, que o coeficiente de transferência de calor, para um mesmo fluxo de calor, diminui à medida que se avança pela seção de testes. Por exemplo, para um fluxo de calor de $11500 \mathrm{~W} / \mathrm{m}^{2}$, a diferença entre os valores dos coefícientes das seções 1 e 4 (distantes $0,9 \mathrm{~m}$ entre si) é da ordem de 10 vezes, ilustrando que a superfície da seção 4 está seca.

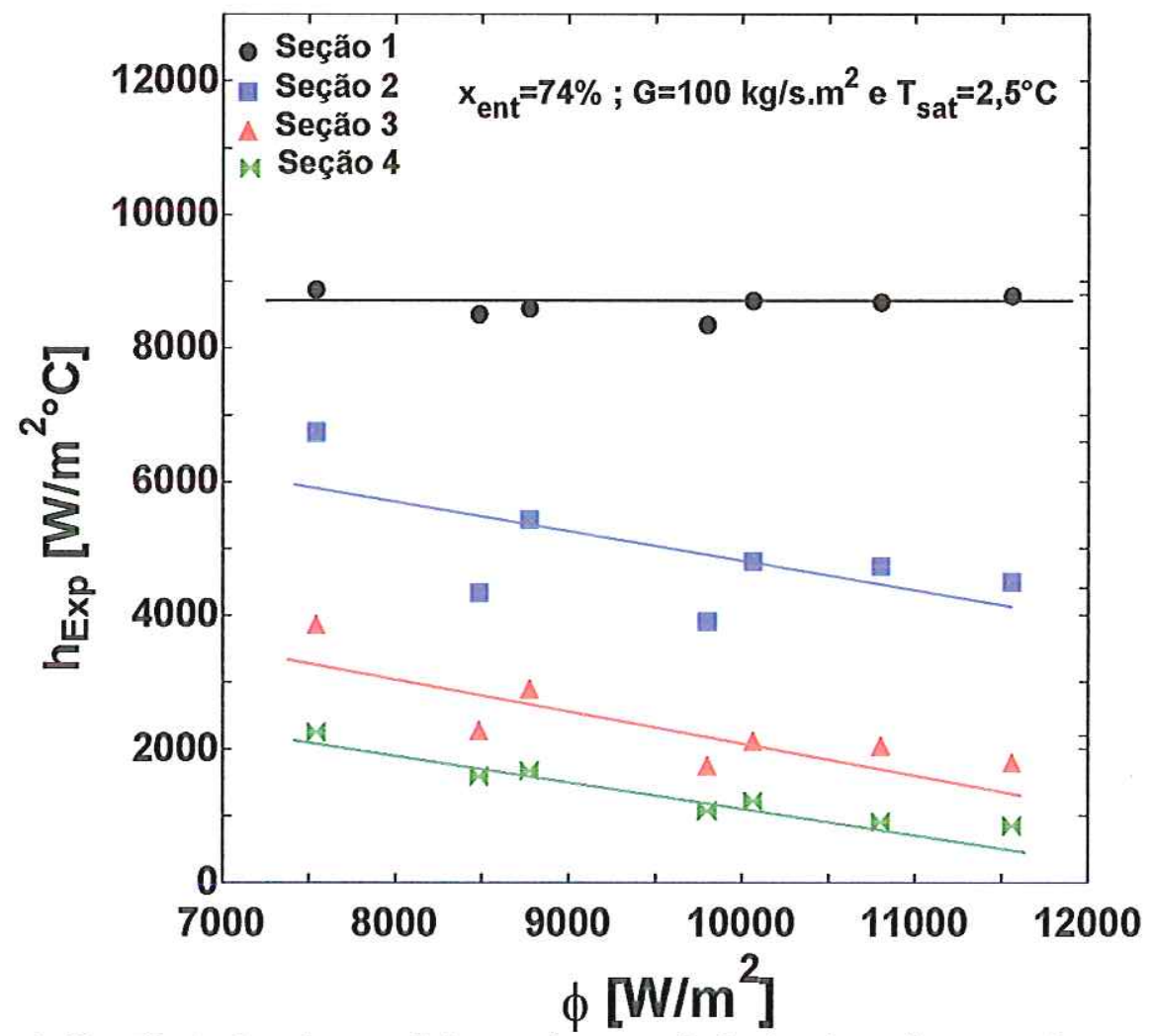

Figura 4.68 Variação do coeficiente de transferência de calor em função do fluxo específico de calor para o tubo microaletado TM de 9,52mm. Refrigerante R$134 \mathrm{a} ; \mathrm{T}_{\mathrm{sat}}=2,5^{\circ} \mathrm{C} ; \mathrm{G}=100 \mathrm{~kg} / \mathrm{s} \cdot \mathrm{m}^{2}$ e $\mathrm{x}_{\mathrm{cnt}}=74 \%$. 


\section{CAPÍTULO 5 - CORRELAÇÃO DE RESULTADOS}

\subsection{Introdução}

$\mathrm{E}$

ste capítulo é dedicado à correlação de resultados experimentais para a perda de carga devido ao atrito e o coeficiente de transferência de calor. Para o desenvolvimento dos modelos é necessário definir o tipo de padrão de escoamento predominante. Conhecida a topologia da interface líquido/vapor do escoamento é possivel identificar os principais mecanismos fisicos inerentes à transferência de calor e quantidade de movimento. Assim, de acordo com o exposto no capítulo anterior, os modelos para a perda de carga e transferência de calor em tubos lisos serão desenvolvidos com base nas duas faixas de velocidades mássicas definidas: elevadas $\left(\mathrm{G} \geq 200 \mathrm{~kg} / \mathrm{s} \cdot \mathrm{m}^{2}\right)$ e reduzidas $\left(\mathrm{G}<200 \mathrm{~kg} / \mathrm{s} \cdot \mathrm{m}^{2}\right)$. A faixa de velocidades elevadas assume implicitamente o padrão anular de escoamento e, como observado anteriormente, o parâmetro físico que correlaciona satisfatoriamente os resultados é o parâmetro de Martinelli, $X_{\mathrm{tt}}$. Nessas condições, as correlações para a perda de carga e coeficiente de transferência de calor devem incorporar este parâmetro na sua forma final. Já, para faixa de velocidades reduzidas, o padrão de escoamento predominante em, praticamente, todos os ensaios foi o estratificado ondulado. A topologia da interface desse padrão sugere a utilização de um parâmetro que leve em consideração os efeitos de superficie livre, como o número de Froude. Nesse sentido, é de se esperar que este parâmetro deve estar presente nos modelos de perda de carga e transferência de calor para vazões reduzidas.

Em : clação aos tutos ricroaletados, os modelos devem incorporar o parâmetro de Martinelli na sua forma final para as duas faixas de velocidades mássicas. A justificativa para essa afirmação se deve, justamente, ao tipo de padrão de escoamento verificado para baixas vazões em tubos microaletados, nesse caso, o anular, como observado anteriormente. 
Comparações das principais correlações de transferência de calor e perda de carga disponiveis da literatura em relação aos resultados experimentais foram incorporadas ao capítulo, confrontando os desvios com aqueles obtidos dos modelos propostos.

\subsection{Correlação para Perda de Carga em Tubos Lisos}

A perda de carga em escoamento com mudança de fase no interior de tubos horizontais é composta por duas parcelas: a perda de carga devido ao atrito e outra de aceleração.

Existem, basicamente, dois tipos de modelos para caracterizar o efeito do atrito em escoamento bifásico: o modelo homogêneo e o modelo denominado de fases separadas, ilustrados na Fig. 5.1. No modelo homogêneo tudo se passa como se a mistura bifásica (líquido+vapor) escoasse como um fluido homogêneo de propriedades médias entre as fases líquido e vapor, dependentes somente do título. Nessas condições, o modelo homogêneo assume que ambas as fases escoam com a mesma velocidade. É interessante destacar que esse modelo é melhor aplicado quando se opera com vazões significativamente elevadas, onde o deslizamento entre as fases é menor.

$\mathrm{O}$ modelo de fases separadas considera que, fisicamente, as fases liquido/vapor escoam separadamente no interior de um tubo e com velocidades distintas. COLLIER \& THOME (1996) sugeriram que o modelo de fases separadas, para perda de carga, é mais preciso para velocidades mássicas inferiores a $1300 \mathrm{~kg} / \mathrm{s} . \mathrm{m}^{2}$. Os resultados experimentais obtidos neste trabalho tiveram como limite valores de $\mathrm{G}$ da ordem de $1100 \mathrm{~kg} / \mathrm{s} . \mathrm{m}^{2}$, dentro da faixa proposta por esses autores.

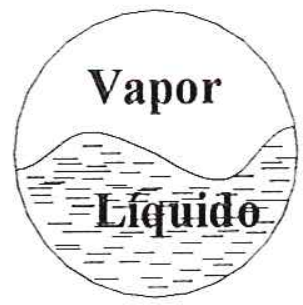

Modelo Homogêneo

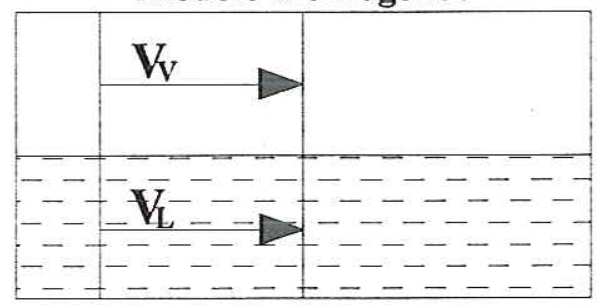

Modelo de Fases Separadas

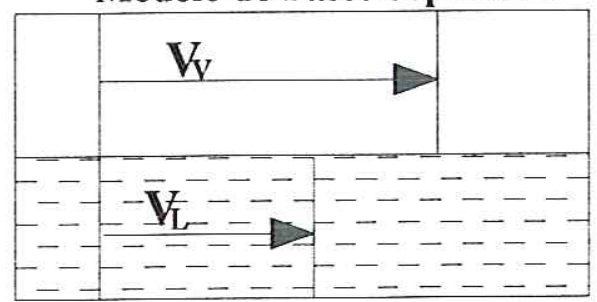

Figura 5.1 Ilustração dos modelos Homogêneo e de Fases Separadas. 
O presente trabalho procurou desenvolver uma correlação baseada no modelo de fases separadas, utilizando o modelo desenvolvido por Martinelli e colaboradores, que propõe correlacionar o multiplicador bifásico em termos do parâmetro de Martinelli, como ilustrado pela Eq. (5.1).

$$
\phi_{\mathrm{L}}=\mathbf{C} \cdot \mathbf{X}_{\mathbf{t t}}^{\mathbf{m}}
$$

Vale ressaltar que esse modelo deve ser aplicado, preferencialmente, onde o padrão de escoamento predominante é o anular, pois, para a faixa de velocidades mássicas elevadas, $\mathrm{G} \geq 200 \mathrm{~kg} / \mathrm{s} \cdot \mathrm{m}^{2}$, verificou-se que esse modelo correlaciona de forma adequada os resultados experimentais. Para a faixa de velocidades reduzidas, $\mathrm{G}<200 \mathrm{~kg} / \mathrm{s} . \mathrm{m}^{2}$, como será observado mais adiante, o parâmetro de Martinelli não correlaciona adequadamente os resultados, devendo ser incorporados outros parâmetros, como, por exemplo, o número de Froude.

A Fig. 5.2 ilustra os resultados experimentais para o multiplicador bifásico em função do parâmetro de Martinelli para o R-134a, temperatura de evaporação de $5^{\circ} \mathrm{C}$, velocidade mássica variando entre 25 e $500 \mathrm{~kg} / \mathrm{s} \cdot \mathrm{m}^{2}$, para tubos lisos de diâmetros 7,0; 7,93; 9,52 e $17,4 \mathrm{~mm}$. Nota-se que os resultados para tubo com $17,4 \mathrm{~mm}$ de diâmetro interno apresentaram um comportamento distinto daqueles observados para os tubos de menor diâmetro. Isso pode estar relacionado ao tipo de padrão de escoamento predominante em praticamente todos os ensaios para o tubo de $17,4 \mathrm{~mm}$ de diâmetro, o estratificado ondulado, verificado para velocidades mássicas inferiores a $200 \mathrm{~kg} / \mathrm{s} . \mathrm{m}^{2}$. Nesse caso, como observado anteriormente, a utilização exclusiva do parâmetro de Martinelli no modelo não correlaciona de forma adequada os resultados experimentais. As incertezas associadas ao tubo de $17,4 \mathrm{~mm}$ de diâmetro foram, consideravelmente, superiores àquelas dos demais tubos, devido, principalmente, aos valores reduzidos da perda de carga. Enquanto que a perda de carga para os tubos de 7,0; 7,93 e 9,52mm apresentou valores na faixa entre 1,5 e $52 \mathrm{kPa}$, o tubo de diâmetro maior experimentou valores entre 0,1 e 1,5 kPa. 


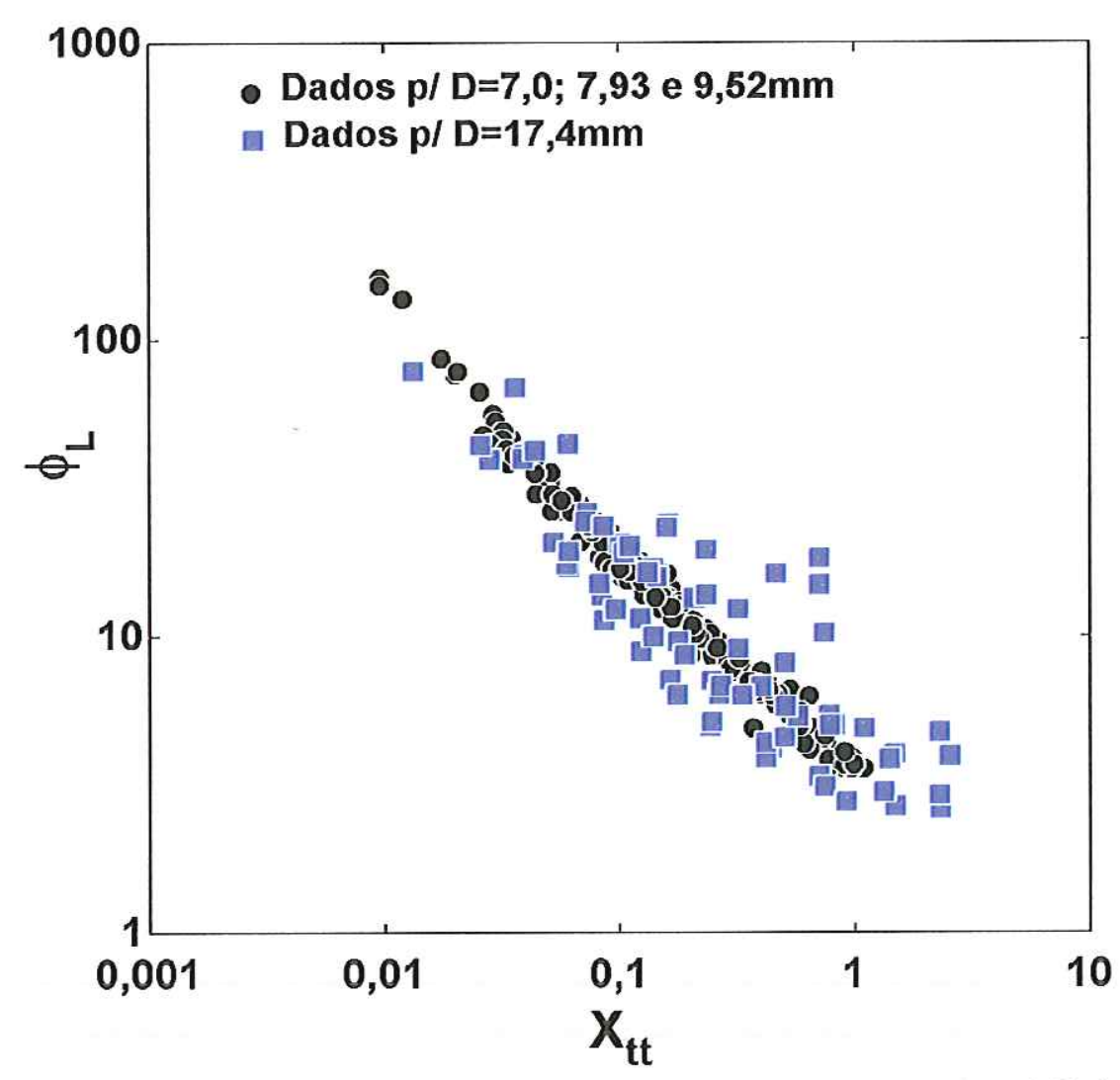

Figura 5.2 Resultados experimentais para tubos lisos do multiplicador bifásico em função do Parâmetro de Martinelli. R-134a, $\mathrm{T}_{\text {Evap }}=5^{\circ} \mathrm{C}$ e $\mathrm{G}$ entre 25 e 500 $\mathrm{kg} / \mathrm{s} . \mathrm{m}^{2}$.

Assim, fica evidente a necessidade de se correlacionar os resultados experimentais para as duas faixas características de velocidades mássicas.

\subsubsection{Correlação para Perda de Carga em Tubos Lisos para Vazões Elevadas}

Com o objetivo de correlacionar os resultados experimentais para a perda de carga devido ao atrito no interior de tubos lisos para velocidades mássicas elevadas, os dados foram selecionados de acordo com a faixa de vazão pré-determinada. Assim, a Fig. 5.3 apresenta os resultados em termos do multiplicador bifásico, $\phi_{\mathrm{L}}$, para os tubos de 7,0; 7,93 e 9,52mm de diâmetro, utilizando o R-134a como fluido de trabalho, temperatura de evaporação de $5^{\circ} \mathrm{C}$ e velocidade mássica variando entre 200 e $500 \mathrm{~kg} / \mathrm{s} . \mathrm{m}^{2}$, onde o padrão de escoamento predominante é o anular. Deve-se salientar que, os dados referentes a esses tubos, foram selecionados por terem sido obtidos através do transdutor diferencial de pressão. De acordo com o exposto anteriormente, a correlação proposta apresenta o mesmo 
formato da correlação de Martinelli e colaboradores, Eq. (5.1). Porém, com o objetivo de apresentar uma configuração mais adequada, propôs-se um formato fisicamente consistente, pois leva em consideração a condição assintótica correspondente a $X_{\mathrm{tt}}$ tendendo a infinito, que está relacionada ao escoamento de título nulo, ou seja, líquido. Para tal condição, a perda de carga no escoamento bifásico deveria assumir o valor daquela do escoamento monofásico de líquido, o que é satisfeito pela forma expressa na Eq. (5.2). Nessas condições, ajustando os resultados experimentais por uma correlação desse tipo, obteve-se a seguinte expressão, que apresentou um coeficiente de correlação de $99 \%$ :

$$
\phi_{\mathrm{L}}=1+2,6 . X_{\mathrm{tt}}^{-0,85} \text { para } X_{\mathrm{tt}} \leq 1 \text { e } G \geq 200 \mathrm{~kg} / \mathrm{s} \cdot \mathrm{m}^{2}
$$

Como pode ser observado na Fig. 5.3, o desvio médio absoluto, cuja definição é apresentada a seguir, encontrado para essa correlação foi de $6,4 \%$.

$$
\begin{array}{rlrl} 
& \overline{\mathrm{E}} & =\frac{1}{n} \sum_{i=1}^{n} \mathrm{E}_{i} \quad \text { (Desvio médio relativo) } \\
& |\overline{\mathrm{E}}|=\frac{1}{n} \sum_{i=1}^{n}\left|\mathrm{E}_{i}\right| \quad \text { (Desvio médio absoluto) } \\
\text { onde, } & \mathrm{E}_{i}=\frac{\left(h_{\text {correl }}-h_{\text {Exp }}\right)}{h_{\text {Exp }}}
\end{array}
$$

Os resultados experimentais foram, ainda, comparados com a correlação de JUNG \& RADERMACHER (1989), Eq. (4.6), tendo sido verificado um desvio médio absoluto de $7,7 \%$. Como pode ser notado, a correlação de Jung-Radermacher apresentou um desvio muito próximo àquele da correlação proposta nesse trabalho. Deve-se ressaltar que a correlação proposta é válida para a faixa de vazões elevadas $\left(G \geq 200 \mathrm{~kg} / \mathrm{s} \cdot \mathrm{m}^{2}\right)$, associadas ao padrão anular de escoamento, e para valores de $X_{\mathrm{tt}}$ inferiores a 1 . Valores de $X_{\mathrm{tt}}$ superiores a 1 estão associados a títulos reduzidos, condição em que predomina o padrão intermitente, como mencionado anteriormente. A consistência dos resultados em relação à correlação proposta e à de Jung-Radermacher sugere a solidez desta abordagem, aliada à sua simplicidade.

Deve-se salientar que os resultados experimentais envolvendo a perda de carga para os refrigerantes R-404A e R-407C não puderam ser aproveitados no desenvolvimento da correlação, pois o transdutor diferencial de pressão ainda não estava instalado. 


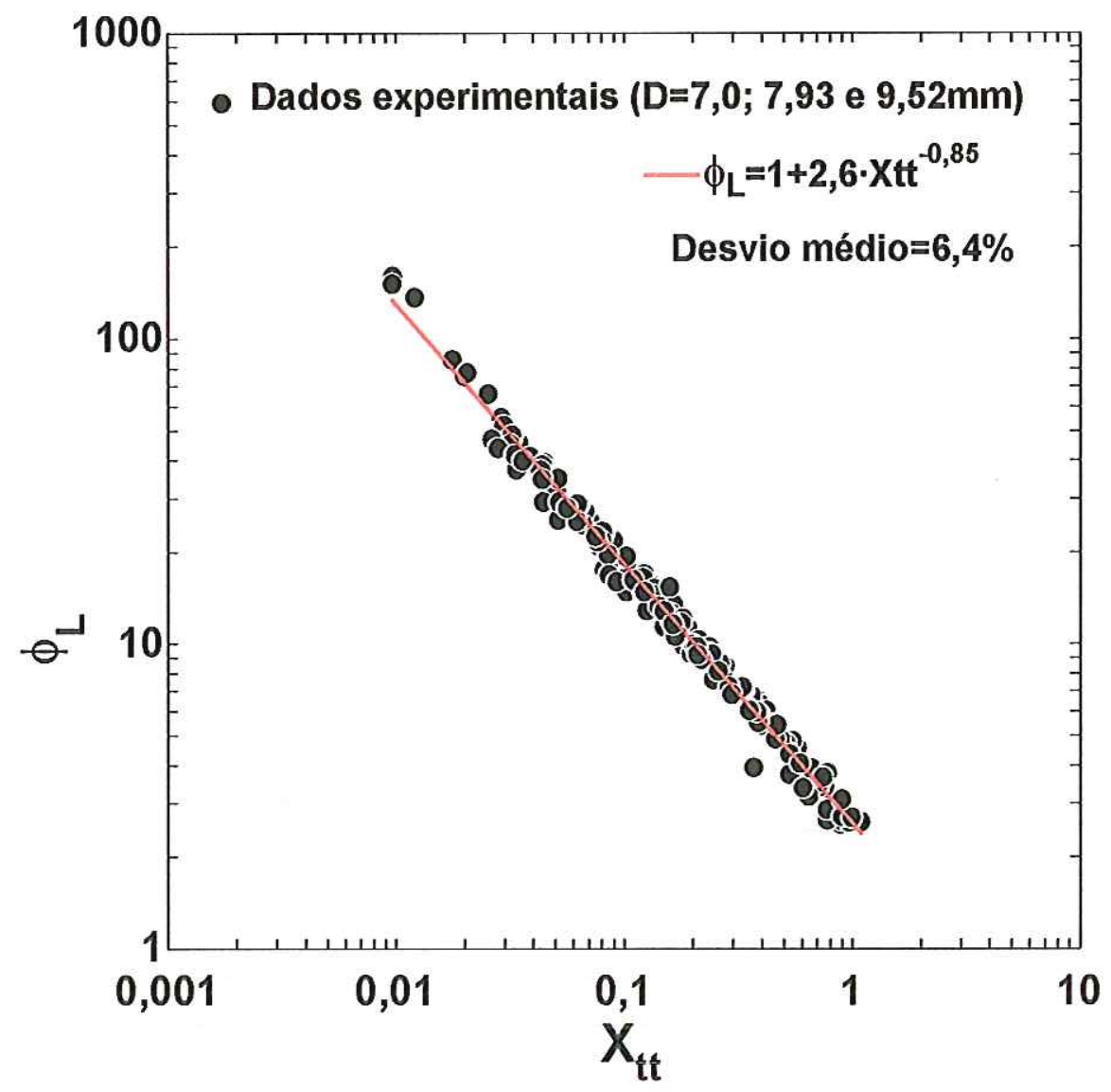

Figura 5.3 Correlação dos resultados experimentais para tubos lisos. $\mathrm{R}-134 \mathrm{a}, \mathrm{T}_{\mathrm{Evap}}=5^{\circ} \mathrm{C}$ e $\mathrm{G}$ variando entre 200 e $500 \mathrm{~kg} / \mathrm{s} . \mathrm{m}^{2}$.

\subsubsection{Correlação para Perda de Carga em Tubos Lisos para Vazões Reduzidas}

O desenvolvimento de uma correlação para perda de carga em tubos lisos com vazões reduzidas foi necessário, pois, como observado anteriormente, os mecanismos físicos que intervêm no escoamento estratificado são distintos daqueles verificados no padrão anular. Nessas condições, sabe-se que o parâmetro de Martinelli, $X_{\mathrm{tt}}$, não correlaciona, de maneira satisfatória, os resultados experimentais. Um parâmetro que deve ser levado em consideração na modelagem do escoamento estratificado é o número de Froude, Fr, pois incorpora os efeitos relativos de inércia e de gravidade. O escoamento estratificado é caracterizado pela fase líquida segregada no fundo do duto e a interface líquido/vapor (podendo ser ondulada) exemplifica a configuração onde os efeitos de gravidade e inércia interagem, conferindo ao número de Froude significativa importância na correlação de 
resultados que envolvem balanços de energia e quantidade de movimento. As instabilidades da interface líquido/vapor, como formação de ondas, algumas de razoável dimensão, estão relacionadas a Fr elevados, sendo que estas podem atingir a região superior do tubo, configurando o padrão intermitente. Se o número de Froude for suficientemente elevado, tais instabilidades podem levar ao escoamento anular. Já o inverso, em que Fr assume valores reduzidos, deve estar relacionado ao padrão estratificado com a interface lisa. Seguindo essa linha de raciocínio, é possível afirmar que o multiplicador bifásico deve guardar alguma relação com o número de Froude para valores de $\mathrm{G}<200 \mathrm{~kg} / \mathrm{s} . \mathrm{m}^{2}$.

Dessa forma, seria interessante utilizar um número de Froude local, $\mathrm{Fr}_{\mathrm{L}}$, definido a seguir, variando com o título, com o objetivo de corrigir o multiplicador bifásico em toda a faixa de títulos. Assim, resultou a seguinte expressão, que proporcionou um coeficiente de correlação de $87 \%$.

$$
\phi_{\mathrm{L}}=0,8 . \mathrm{Fr}_{\mathrm{L}}^{-0,45} \text { para } \mathrm{X}_{\mathrm{tt}} \leq 1 \text { e } \mathrm{G}<200 \mathrm{~kg} / \mathrm{s} . \mathrm{m}^{2}
$$

onde,

$$
F r_{L}=\frac{G^{2} \cdot(1-x)^{2}}{\rho_{L}^{2} \cdot D \cdot g}
$$

A Fig. 5.4 apresenta os resultados experimentais da perda de carga, em termos do multiplicador bifásico, em função do número de Froude local, $\mathrm{Fr}_{\mathrm{L}}$, para o R-134a escoando num tubo de $17,4 \mathrm{~mm}$ de diâmetro, temperatura de evaporação da ordem de $5^{\circ} \mathrm{C}$, fluxo de calor específico variando entre 5 e $10 \mathrm{~kW} / \mathrm{m}^{2}$ e velocidade mássica entre 25 e $100 \mathrm{~kg} / \mathrm{s} \cdot \mathrm{m}^{2}$. Os efeitos de aceleração foram avaliados e removidos, através da Eq. (4.4), sendo que, os valores relativos a esse efeito, variaram entre 3 e $27 \%$ da parcela total da perda de carga Deve-se destacar que a maior contribuição dos efeitos de aceleração ocorre no caso dos escoamentos com vazões reduzidas, mormente para valores de $\mathrm{G} \leq 100 \mathrm{~kg} / \mathrm{s} \cdot \mathrm{m}^{2}$, pois, para o mesmo fluxo de calor, quanto menor a vazão, maior será a variação do título, aumentando, desta forma, os efeitos de aceleração.

Nota-se que a correlação é válida para valores do parâmetro de Martinelli inferiores a 1 , similarmente à corrulação para vazões elevadas. $\mathrm{O}$ desvio médio absoluto em relação aos resultados experimentais resultou em $18,9 \%$. Comparando os resultados experimentais para vazões reduzidas com outras correlações da literatura, como a de JUNG \& RADERMACHER (1989), Eq. (4.6), e a de SOUZA \& PIMENTA (1995), proposta, especialmente, para vazões reduzidas, Eq. (5.4), a seguir, resultaram em desvios absolutos da ordem de $30 \%$ e $62 \%$, respectivamente. 


$$
\phi_{L}=\sqrt{1,376 \cdot\left(\frac{C_{1}}{X_{t t}^{C_{2}}}\right) \cdot(1-x)^{1,75}}
$$

onde,

$$
\begin{aligned}
& C_{1}=4,172+5,48 \cdot F r-1,564 \cdot F r^{2} \\
& e \\
& C_{2}=1,773-0,169 \cdot F r
\end{aligned}
$$

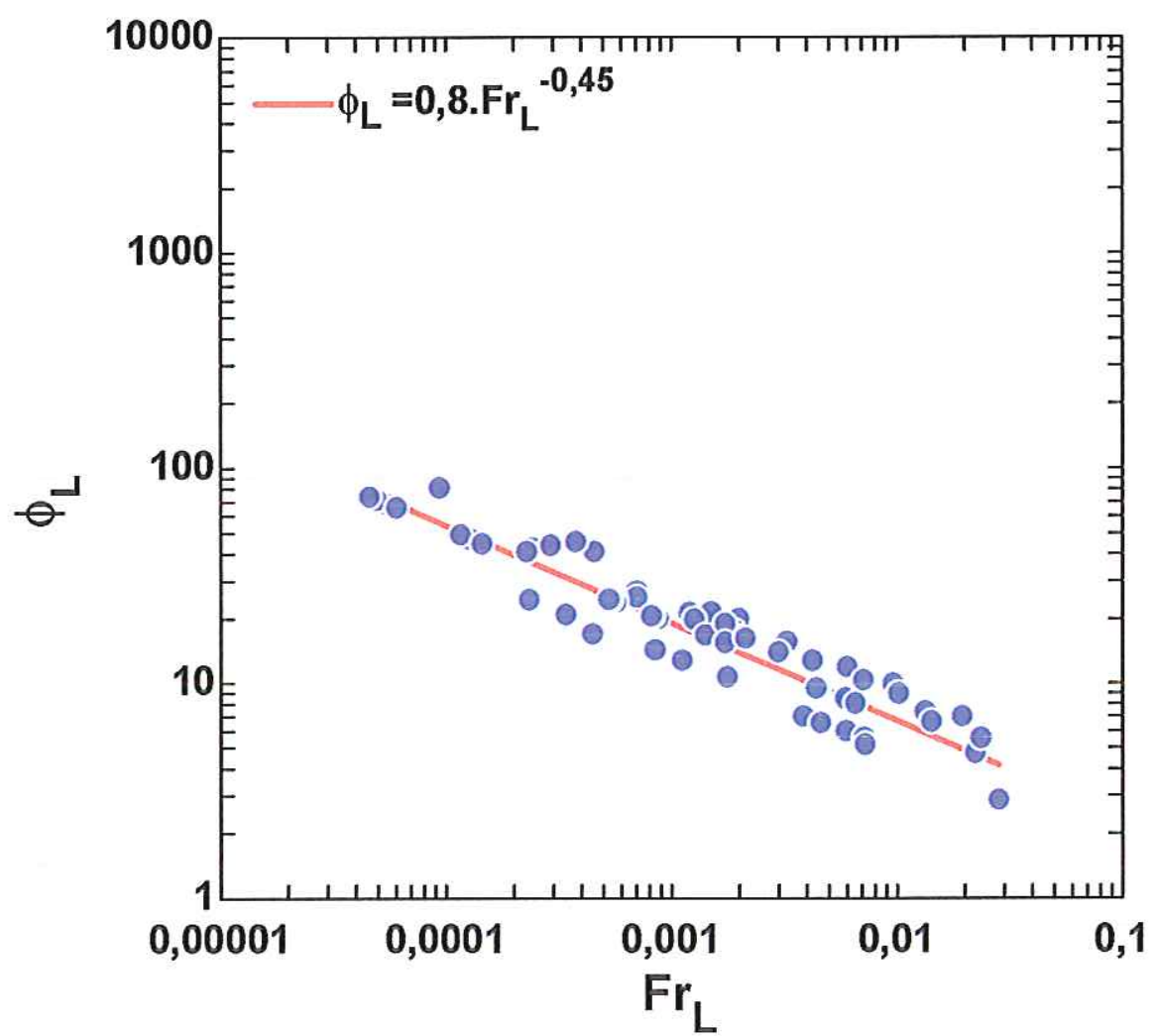

Figura 5.4 Correlação dos resultados experimentais para tubos lisos para vazões reduzidas. R-134a, $\mathrm{T}_{\text {Evap }}=5^{\circ} \mathrm{C}$ e G variando entre $25 \mathrm{e} 100 \mathrm{~kg} / \mathrm{s} . \mathrm{m}^{2}$.

\subsection{Correlação para Perda de Carga em Tubos Microaletados}

De maneira similar à perda de carga em tubos lisos, os resultados experimentais para tubos microaletados foram correlacionados em termos do multiplicador bifásico. Como mencionado anteriormente, é de suma importância o conhecimento do padrão de escoamento predominante no desenvolvimento do modelo. Nessas condições, utilizando o mapa de padrão de escoamento proposto no capítulo anterior, pode-se considerar a ocorrência do padrão anular para a faixa de velocidade mássica ensaiada, que variou entre 100 e 500 $\mathrm{kg} / \mathrm{s} . \mathrm{m}^{2}$. Deve-se esclarecer que os resultados para $\mathrm{G}=100 \mathrm{~kg} / \mathrm{s} . \mathrm{m}^{2}$ foram mantidos para o desenvolvimento da correlação pois, em tubos microaletados, o líquido é deslocado, através 
dos canais das ranhuras, para a região superior do tubo. Nesse sentido, essa região, que no tubo liso se encontrava em contato com o vapor, no microaletado passa a ser ocupada por um filme de líquido com espessura bastante reduzida, da ordem da altura da microaleta, configurando o padrão anular.

A parcela devido aos efeitos de aceleração foi avaliada, representando entre 1 e $5 \%$ da variação total da pressão na seção de testes, tendo sido removida, utilizando a Eq. (4.4). Na Fig. 5.5 são apresentados os resultados experimentais para o tubo microaletado TM de 9,52mm de diâmetro externo e 82 ranhuras, para as seguintes condições operacionais: R$134 \mathrm{a}$, velocidade mássica variando entre 100 e $500 \mathrm{~kg} / \mathrm{s} \cdot \mathrm{m}^{2}$ e fluxo de calor da ordem de 5 $\mathrm{kW} / \mathrm{m}^{2}$. Ajustando tais resultados em termos de uma equação do tipo da Eq. (5.1) e mantendo o mesmo valor do expoente da correlação de JUNG \& RADERMACHER (1989), Eq. (4.6), resultou a seguinte correlação, válida, especificamente, para esse tubo microaletado, apresentando um coeficiente de correlação de $99,1 \%$ :

$$
\phi_{L}=4,13 \cdot X_{t t}^{-0,735} \quad \text { para } \quad X_{t t} \leq 1
$$

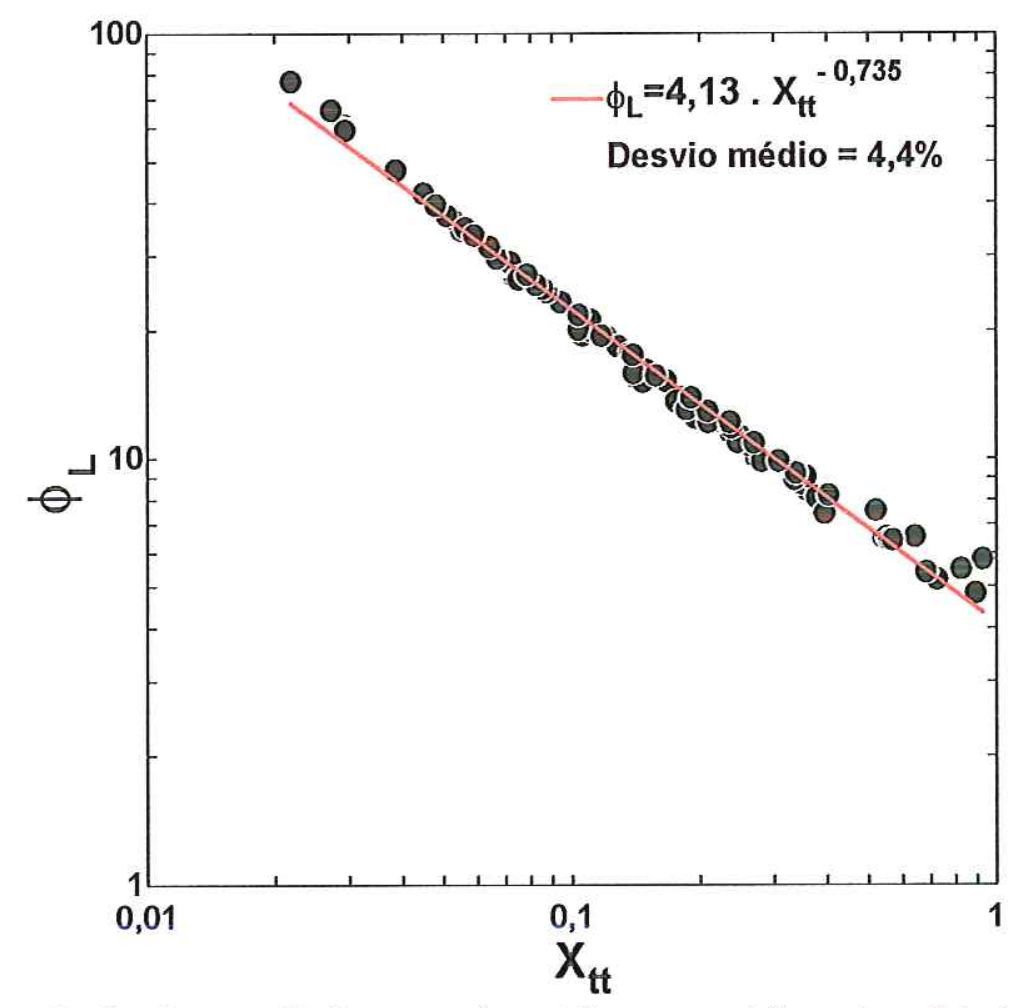

Figura 5.5 Correlação dos resultados experimentais para o tubo microaletado (TM) de $9,52 \mathrm{~mm}$ diâmetro, $\mathrm{T}_{\text {Evap }}=5^{\circ} \mathrm{C} \mathrm{c} \mathrm{G}$ variando entre 100 e $500 \mathrm{~kg} / \mathrm{s} \cdot \mathrm{m}^{2}$. 
Com o objetivo de verificar a adequação da correlação proposta, os resultados experimentais disponíveis para os tubos de diâmetros iguais a $7,0 \mathrm{~mm} ; 7,93 \mathrm{~mm} ; 9,52 \mathrm{~mm}$ (Trefi-Metaux); 9,52mm (Furukawa) e 9,52 mm (Duplo V) foram analisados e comparados com a correlação sugerida. Deve-se destacar que a Eq. (5.5), correlaciona de forma satisfatória os resultados experimentais, resultando num desvio médio absoluto de $6,5 \% \mathrm{em}$ relação aos resultados experimentais para o tubo de $7,0 \mathrm{~mm}, 4,3 \%$ para o de $7,93 \mathrm{~mm}, 3,37 \%$ (Trefi-Metaux) e 4,8\% (Furukawa).

O tubo denominado Duplo-V, que apresenta características distintas dos microaletados convencionais (suas ranhuras são alternadas a cada $90^{\circ}$ da circunferência do tubo), foi ensaiado e seus resultados comparados com a correlação sugerida. Como seria de esperar, os resultados para o multiplicador bifásico, $\phi_{\mathrm{L}}$, foram superiores aos da correlação proposta, pois a perda de carga apresentou valores mais elevados que para os tubos microaletados. A Fig. 5.6 ilustra a comparação dos resultados experimentais para o tubo Duplo-V com a correlação proposta. Como pode ser observado, a maioria dos resultados experimentais se encontra acima da curva que representa a correlação sugerida, resultando num desvio médio absoluto de $15,6 \%$.

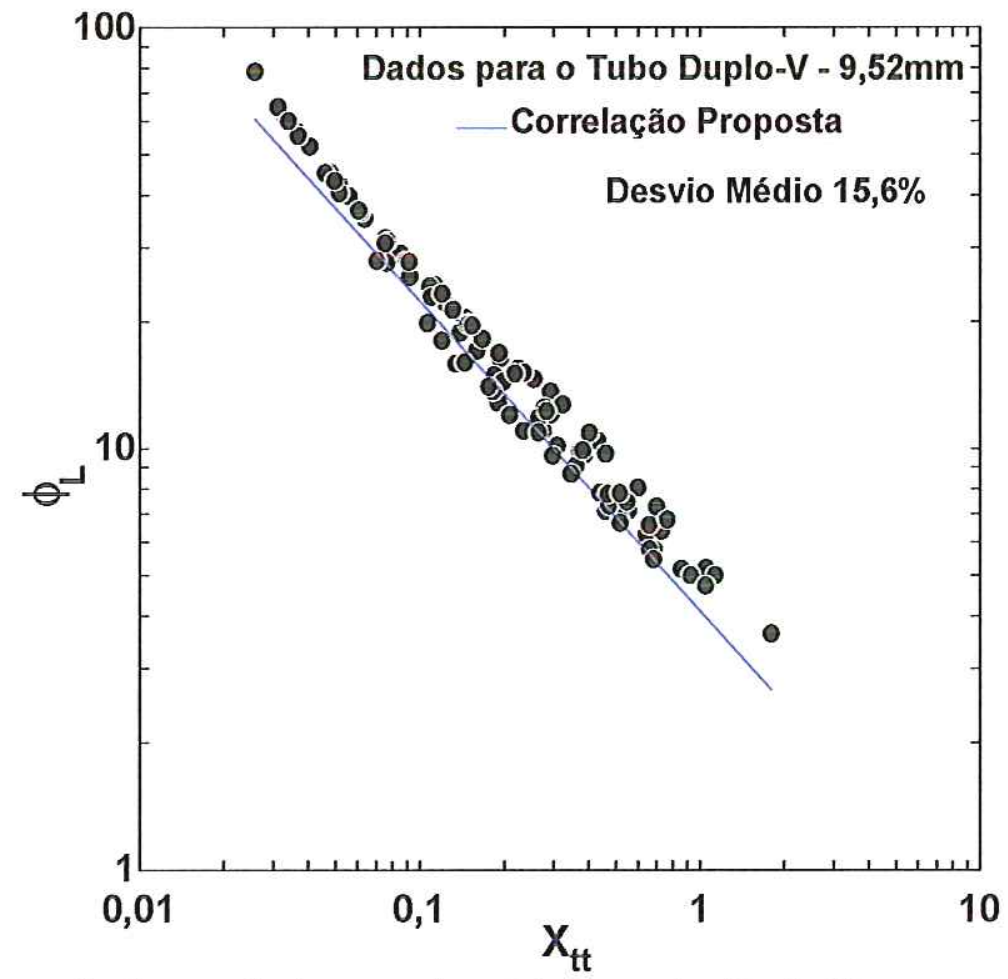

Figura 5.6 Comparação dos resultados experimentais para tubo Duplo-V com a correlação proposta, Eq. 5.5. D=9,52mm, R-134a, $\mathrm{T}_{\text {Evap }}=5^{\circ} \mathrm{C}$ e G entre 100 e $500 \mathrm{~kg} / \mathrm{s} . \mathrm{m}^{2}$.

Como os resultados proporcionados pela correlação proposta para o tubo TM de 9,52mm de diâmetro com 82 ranhuras se mostraram promissores, decidiu-se agrupar os 
resultados experimentais disponíveis para a perda de carga, cerca de 700 pontos experimentais, e correlacioná-los da mesma forma, porém, deixando livre o expoente da correlação e utilizando um formato similar ao da Eq. (5.2). Nessas condições, a correlação resultante apresenta a seguinte forma:

$$
\phi_{\mathrm{L}}=1+3,0 . \mathbf{X}_{\mathrm{tt}}^{-0,83}
$$

A Fig. 5.7 ilustra os resultados experimentais da perda de carga, em termos do multiplicador bifásico, $\phi_{\mathrm{L}}$, função do parâmetro de Martinelli, $\mathrm{X}_{\mathrm{tt}}$, incorporando a correlação sugerida pela Eq. (5.6). O desvio médio absoluto encontrado para a correlação proposta em relação aos resultados experimentais foi de 6,3\%. Observa-se que o desvio médio, excluindo os resultados com velocidade mássica reduzida, $\mathrm{G}<100 \mathrm{~kg} / \mathrm{s} \cdot \mathrm{m}^{2}$, praticamente não sofreu alteração. Isso, possivelmente, está relacionado ao fato do padrão de escoamento para vazões reduzidas em tubos microaletados apresentar as características do anular. Portanto, a correlação pode ser aplicada sem restrições quanto à velocidade mássica, título, fluido refrigerante e geometria do tubo.

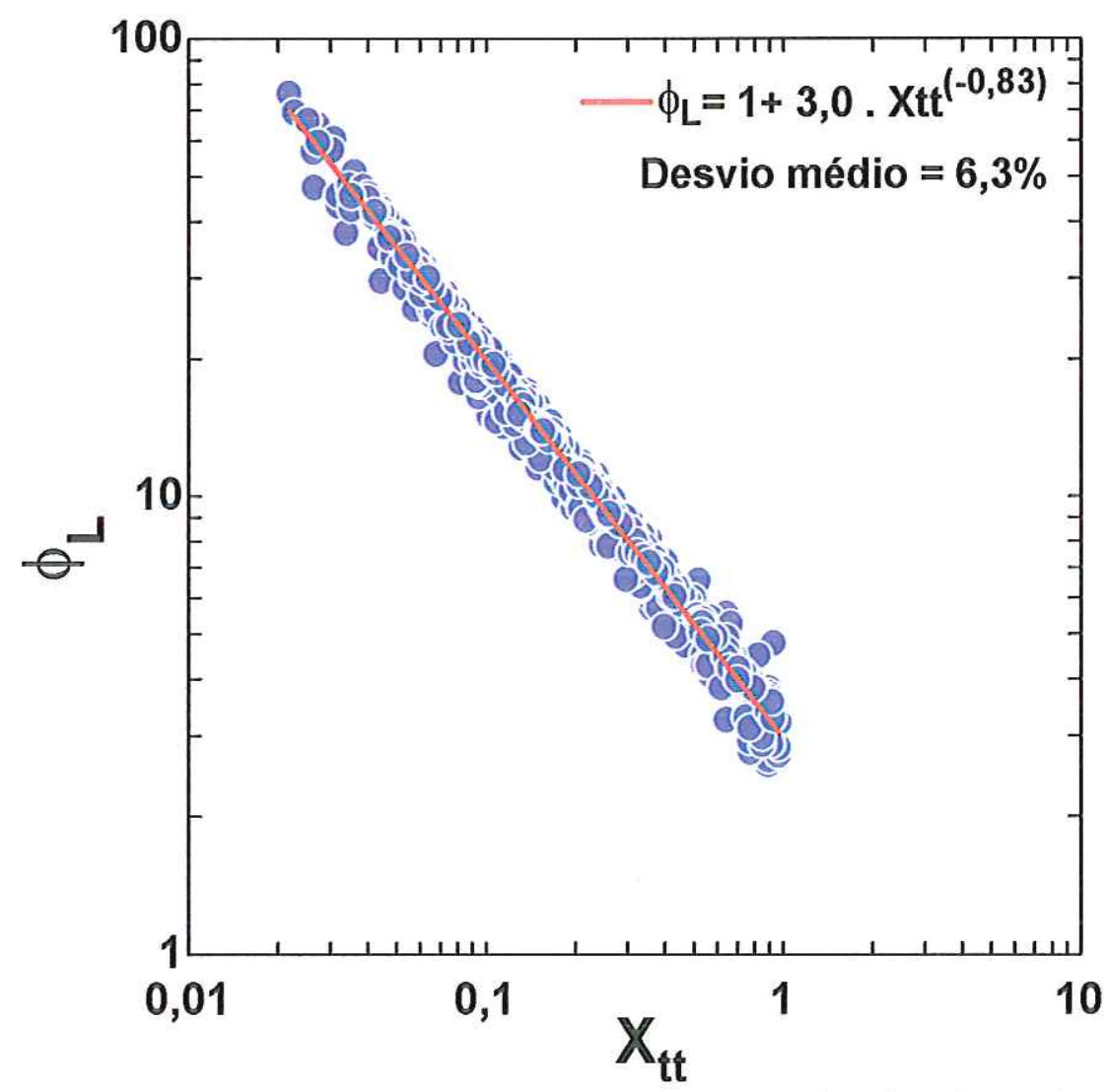

Figura 5.7 Comparação dos resultados experimentais envolvendo tubos microaletados de distintos diâmetros e geometrias com a correlação proposta, Eq. (5.6). R-

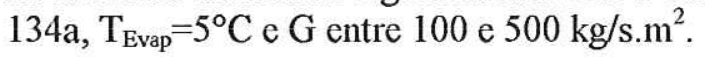


Foi possível realizar a validação da correlação proposta somente com os resultados experimentais levantados por KATTAN (1996) em sua tese de doutoramento, e um banco de dados extraído de um relatório do NIST*, de autoria de CHOI et al (1999), já que não foram encontradas correlações na literatura para a avaliação da perda de carga em tubos microaletados.

O tubo microaletado utilizado por KATTAN (1996) media 3,0m de comprimento e $11,9 \mathrm{~mm}$ de diâmetro interno, com ângulo de hélice da ordem de $18^{\circ} \mathrm{e}$ altura da microaleta de 0,25mm. Como observado na Fig. 5.8, os resultados são bem correlacionados pelo modelo proposto, Eq. (5.6), apresentando um desvio médio absoluto de 7,1\%, o que corrobora a afirmação de que a correlação pode ser aplicada independente da geometria do tubo. Vale lembrar que esses resultados foram obtidos para o R-134a, com $T_{\text {Evap }}=3,8^{\circ} \mathrm{C}$, fluxo de calor variando entre 4 e $14 \mathrm{~kW} / \mathrm{m}^{2}$ e três velocidades mássicas distintas, $\mathrm{G}=100,200$ e 300 $\mathrm{kg} / \mathrm{s} \cdot \mathrm{m}^{2}$.

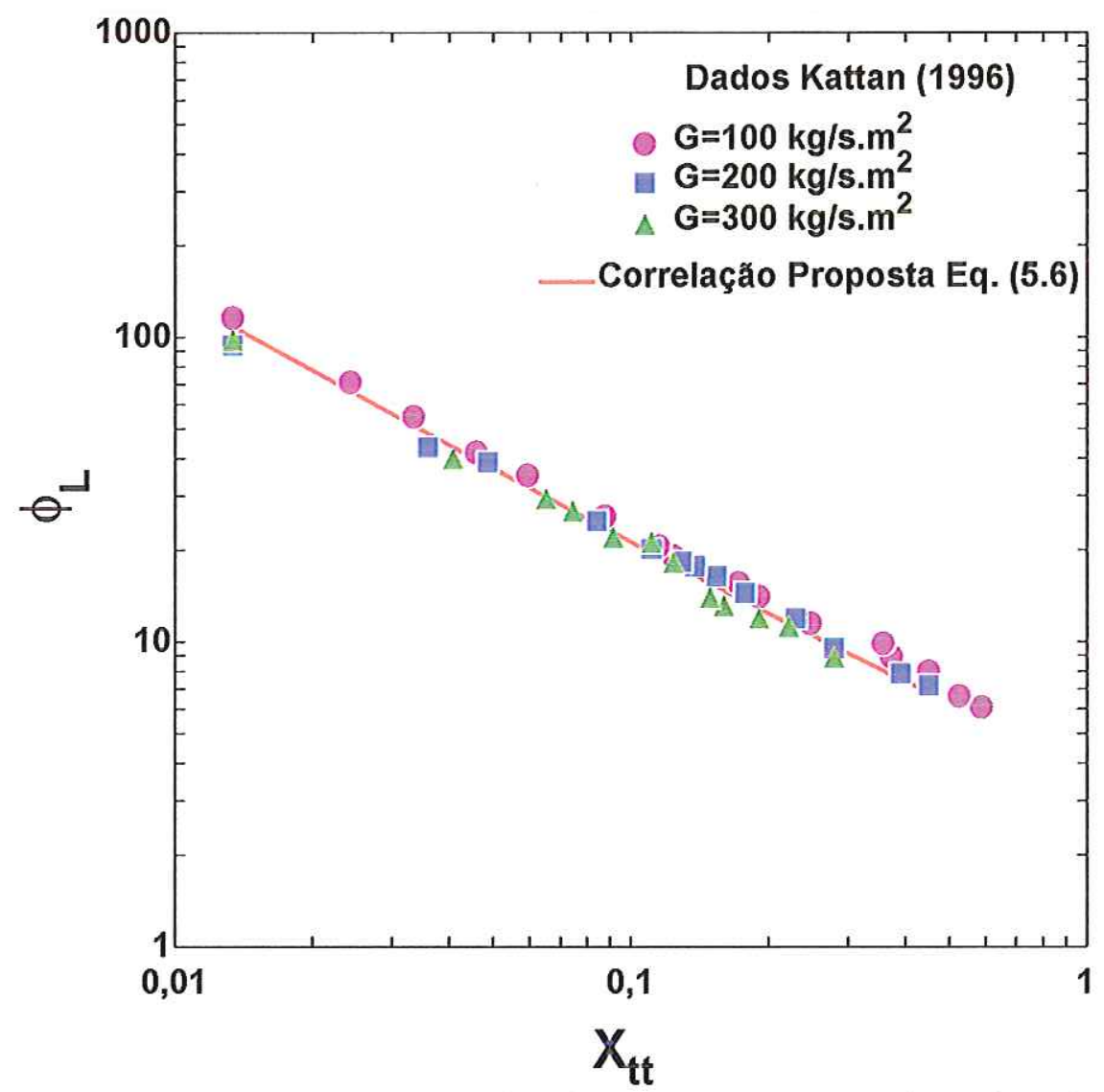

Figura 5.8 Comparação dos resultados de KATTAN (1996) para tubos microaletados com o modelo proposto, R-134a, $\mathrm{D}_{\mathrm{i}}=11,9 \mathrm{~mm}, \mathrm{~T}_{\text {Evap }}=3,8^{\circ} \mathrm{C}$ e $\phi$ entre 4 e $14 \mathrm{~kW} / \mathrm{m}^{2}$.

\footnotetext{
* NIST: National Institute of Standards and Technology do Departamento de Comércio dos Estados Unidos da América.
} 
CHOI et al (1999) publicaram cerca de 200 pontos experimentais para a perda de carga em escoamento com ebulição convectiva. A seção de testes era composta por um tubo microaletado de $1,58 \mathrm{~m}$ de comprimento por $9,52 \mathrm{~mm}$ de diâmetro externo, apresentando uma espessura de parede de $0,3 \mathrm{~mm}$, altura da microaleta de $0,2 \mathrm{~mm}$, ângulo de hélice de $18^{\circ} \mathrm{e}$ ângulo de cunha de $50^{\circ}$. Os ensaios foram realizados com os refrigerantes R-134a e o R-22, para uma temperatura de evaporação da ordem de $5^{\circ} \mathrm{C}$ e velocidade mássica variando entre 300 e $370 \mathrm{~kg} / \mathrm{s} \cdot \mathrm{m}^{2}$. Como se observa nas Figs. 5.9 e 5.10, os resultados experimentais são bem correlacionados pelo modelo proposto no presente trabalho. Os desvios máximos proporcionados pela correlação (5.6) foram incorporados à figura e o desvio médio absoluto resultou em 3,3\% para o R-134a e 2,8\% para o R-22. Esses resultados demonstram que a correlação proposta pode ser utilizada com razoável precisão, inclusive para outros fluidos refrigerantes.

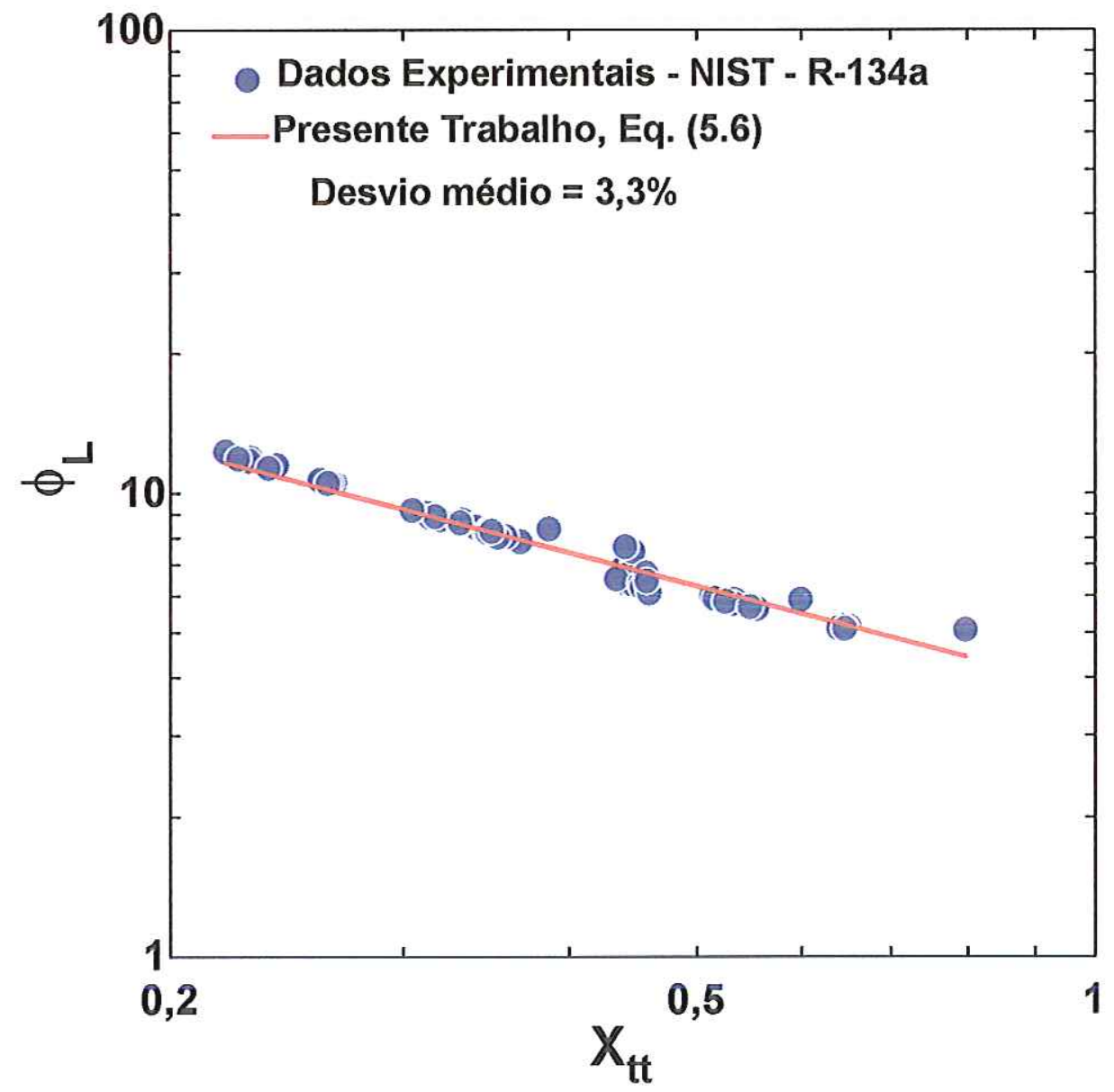

Figura 5.9 Comparação dos resultados de CHOI et al (1999) para tubos microaletados com a correlação proposta, $\mathrm{R}-134 \mathrm{a}, \mathrm{D}_{\mathrm{i}}=8,9 \mathrm{~mm}, \mathrm{~T}_{\mathrm{Evap}}=5^{\circ} \mathrm{C} \mathrm{c} \mathrm{P}_{\mathrm{sat}}=350 \mathrm{kPa}$. 


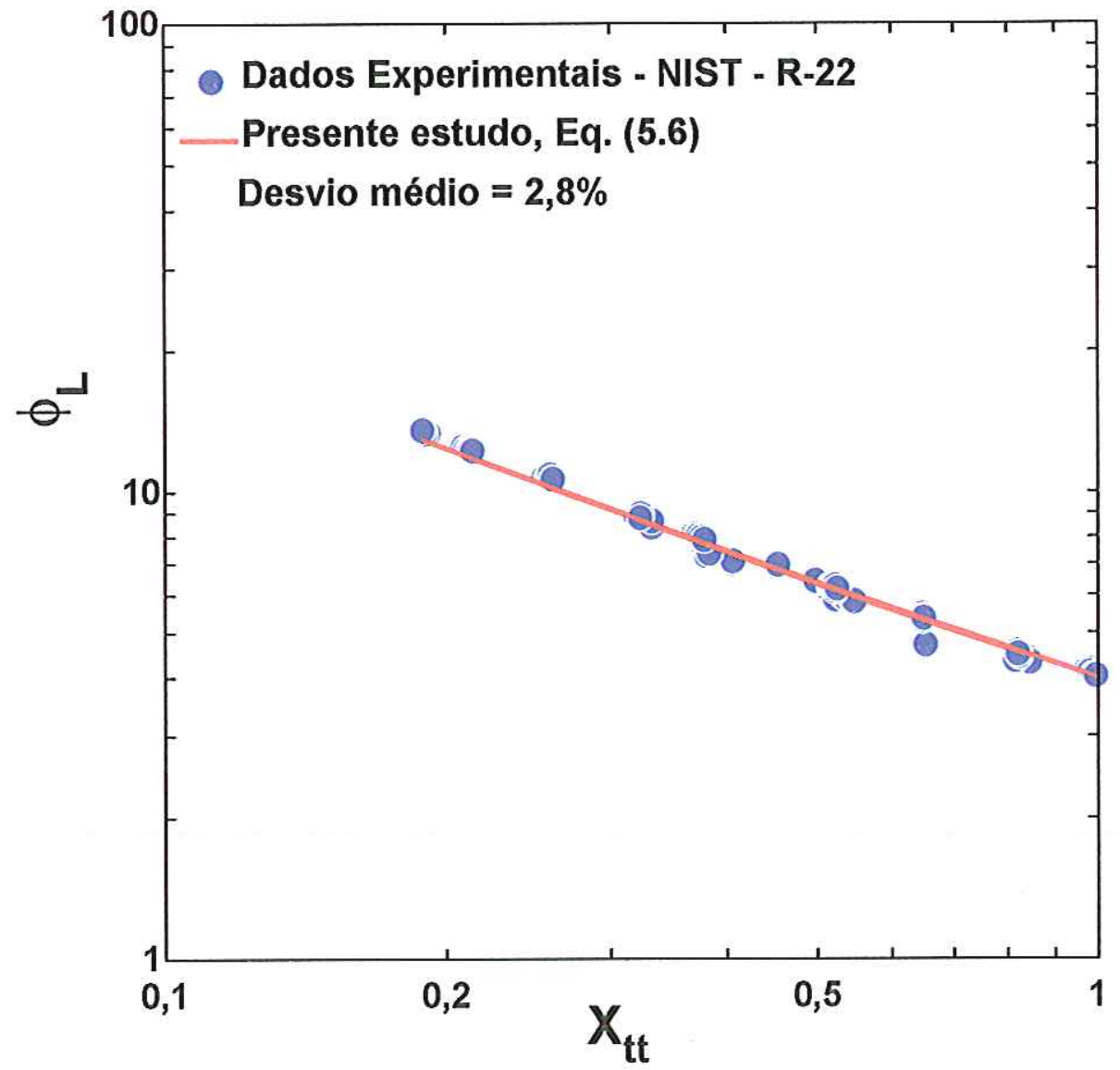

Figura 5.10 Comparação dos resultados de CHOI et al (1999) para tubos microaletados com a correlação proposta, $\mathrm{R}-22, \mathrm{D}_{\mathrm{i}}=8,9 \mathrm{~mm}, \mathrm{~T}_{\mathrm{Evap}}=5^{\circ} \mathrm{C}$ e $\mathrm{P}_{\text {sal }}=585 \mathrm{kPa}$. 


\subsection{Correlação para o Coeficiente de Transferência de Calor para Tubos Lisos}

Nesta seção, será apresentado o procedimento utilizado no desenvolvimento de uma correlação para a avaliação do coeficiente de transferência de calor que caracterize os resultados experimentais obtidos no presente trabalho.

Seguindo o mesmo princípio adotado para o desenvolvimento de correlações para a perda de carga em tubos lisos, serão propostas correlações para as duas faixas pré-definidas de velocidade mássica. Inicialmente, serão apresentados os principais mecanismos físicos associados à faixa de velocidades mássicas elevadas, $\mathrm{G} \geq 200 \mathrm{~kg} / \mathrm{s} \cdot \mathrm{m}^{2}$, incorporando, no desenvolvimento da correlação, os parâmetros adimensionais que levam em consideração tais mecanismos. De maneira similar ao procedimento adotado para velocidades mássicas elevadas, o desenvolvimento de uma correlação para a faixa de velocidades mássicas reduzidas, $\mathrm{G}<200 \mathrm{~kg} / \mathrm{s} \cdot \mathrm{m}^{2}$, consistiu na definição do padrão de escoamento predominante e elencou os principais parâmetros relacionados à interface líquido/vapor.

\subsubsection{Comparação dos Resultados Experimentais para o Coeficiente de Transferência de Calor com as Principais Correlações}

A presente pesquisa comparou os resultados experimentais para o coeficiente de transferência de calor, obtidos para as duas faixas de velocidades mássicas, com as principais correlações apresentadas na pesquisa bibliográfica. Nesse sentido, foram escolhidas as correlações propostas para o coeficiente, válidas para velocidades mássicas elevadas, em que o padrão de escoamento predominante é o anular e comparadas aos resultados experimentais obtidos para tais condições.

Para a faixa de velocidades mássicas reduzidas, foram realizadas diversas comparações entre as correlações para a avaliação do coeficiente de transferência de calor e os resultados experimentais. Inicialmente, foram descartadas comparações com as correlações pertencentes ao primeiro grupo, segundo a classificação realizada no presente trabalho, denominadas de correlações estritamente convectivas, já que assumem implicitamente o padrão anular. Nessas condições, foram realizadas comparações com as correlações do $2^{\circ}$ e $3^{\circ}$ grupo, baseadas na superposição de efeitos e estritamente empíricas, respectivamente. Com o objetivo de organizar as comparações, foram utilizadas correlações que incorporam o número de Froude, Fr. O mesmo procedimento foi adotado para selecionar as correlações pertencentes ao terceiro grupo. 
A Tabela 5.1 apresenta os desvios médios relativos e médios absolutos, proporcionados pelas distintas correlações em relação aos resultados experimentais para as duas faixas de velocidades mássicas.

Em relação à faixa de velocidades mássicas reduzidas, observa-se que as correlações que apresentaram os menores desvios absolutos são as de Jung-Radermacher, Kandlikar e Wattelet. Já as correlações de Lima, Liu-Winterton e Bandarra Filho resultaram em desvios absolutos consideravelmente elevados. Esse comportamento foi resultado, principalmente, dos dados obtidos para valores da velocidade mássica inferiores a $\mathrm{G}=50 \mathrm{~kg} / \mathrm{s} . \mathrm{m}^{2}$, onde as correlações dos referidos autores subestimam o valor do coeficiente de transferência de calor, indicando um desvio médio relativo negativo, como pode ser observado na Tabela 5.1. Já para a faixa de vazões elevadas, as correlações experimentaram desvios médios absolutos semelhantes, entretanto as de Murata-Hashizume e Schrock-Grossman se destacaram negativamente.

Tabela 5.1 Desvio médio absoluto e relativo proporcionados pelas correlações em relação aos resultados experimentais. R-134a, R-22, $\mathrm{T}_{\text {Evap }}$ variando entre 5 e $15^{\circ} \mathrm{C}, \mathrm{G}$ entre 25 e $500 \mathrm{~kg} / \mathrm{s} . \mathrm{m}^{2}, \phi$ entre 5 e $20 \mathrm{~kW} / \mathrm{m}^{2}$ e $\mathrm{D}_{\mathrm{i}}$ entre 6,24 e $17,4 \mathrm{~mm}$.

\begin{tabular}{|c|c|c|c|c|}
\hline Correlação & Grupo & Desvio Médio & $\begin{array}{l}\mathrm{G} \geq 200 \\
\mathrm{~kg} / \mathrm{s} \cdot \mathrm{m}^{2}\end{array}$ & $\begin{array}{l}\mathrm{G}<200 \\
\mathrm{~kg} / \mathrm{s} \cdot \mathrm{m}^{2}\end{array}$ \\
\hline \multirow{2}{*}{$\begin{array}{c}\text { Gungor-Winterton (1986) } \\
\text { Eq. (2.34) }\end{array}$} & \multirow{2}{*}{ Grupo 2} & Absoluto, $|\overline{\mathrm{E}}|$ & $16,5 \%$ & $41,6 \%$ \\
\hline & & Relativo, $\overline{\mathrm{E}}$ & $-11,1 \%$ & $-40,2 \%$ \\
\hline \multirow{2}{*}{$\begin{array}{c}\text { Jung-Radermacher (1989) } \\
\text { Eq. }(2.40)\end{array}$} & \multirow{2}{*}{ Grupo 2} & Absoluto, $|\overline{\mathrm{E}}|$ & $25,0 \%$ & $22,6 \%$ \\
\hline & & Relativo, $\overline{\mathrm{E}}$ & $-19,5 \%$ & $1,4 \%$ \\
\hline \multirow{2}{*}{$\begin{array}{c}\text { Liu-Winterton (1991) } \\
\text { Eq. (2.45) }\end{array}$} & \multirow{2}{*}{ Grupo 2} & Absoluto, $|\overline{\mathrm{E}}|$ & $18,5 \%$ & $57,0 \%$ \\
\hline & & Relativo, $\overline{\mathrm{E}}$ & $12,3 \%$ & $-54,6 \%$ \\
\hline \multirow{2}{*}{$\begin{array}{c}\text { Murata-Hashizume (1993) } \\
\text { Eq. }(2.51)\end{array}$} & \multirow{2}{*}{ Grupo 2} & Absoluto, $|\overline{\mathrm{E}}|$ & $32,0 \%$ & $38,2 \%$ \\
\hline & & Relativo, $\overline{\mathrm{E}}$ & $22,0 \%$ & $-10,5 \%$ \\
\hline \multirow{2}{*}{$\begin{array}{c}\text { Wattelet (1994) } \\
\text { Eq. }(2.59)\end{array}$} & \multirow{2}{*}{ Grupo 2} & Absoluto, $|\overline{\mathrm{E}}|$ & $23,0 \%$ & $21,9 \%$ \\
\hline & & Relativo, $\overline{\mathrm{E}}$ & $15,4 \%$ & $20,4 \%$ \\
\hline \multirow{2}{*}{$\begin{array}{l}\text { Lima (2000) } \\
\text { Eq. }(2.61)\end{array}$} & \multirow{2}{*}{ Grupo 2} & Absoluto, $|\overline{\mathrm{E}}|$ & $16,7 \%$ & $80,2 \%$ \\
\hline & & Relativo, $\overline{\mathrm{E}}$ & $2,1 \%$ & $-80,2 \%$ \\
\hline \multirow{2}{*}{$\begin{array}{l}\text { Shah (1982) } \\
\text { Eq. }(2.68)\end{array}$} & \multirow{2}{*}{ Grupo 3} & Absoluto, $|\overline{\mathrm{E}}|$ & $17,4 \%$ & $37,1 \%$ \\
\hline & & Relativo, $\overline{\mathrm{E}}$ & $-2,5 \%$ & $-32,6 \%$ \\
\hline
\end{tabular}




\begin{tabular}{|c|c|c|c|c|}
\hline \multirow{2}{*}{$\begin{array}{c}\text { Kandlikar (1990) } \\
\text { Eq. }(2.78)\end{array}$} & \multirow{2}{*}{ Grupo 3} & Absoluto, $|\overline{\mathrm{E}}|$ & $18,5 \%$ & $17,9 \%$ \\
\hline & & Relativo, $\overline{\mathrm{E}}$ & $8,4 \%$ & $-2,6 \%$ \\
\hline \multirow{2}{*}{$\begin{array}{c}\text { Schrock \& Grossman (1962) } \\
\text { Eq. (2.67) }\end{array}$} & \multirow{2}{*}{ Grupo 3} & Absoluto, $|\overline{\mathrm{E}}|$ & $52,5 \%$ & $50,5 \%$ \\
\hline & & Relativo, $\overline{\mathrm{E}}$ & $-52,5 \%$ & $-50,5 \%$ \\
\hline \multirow{2}{*}{$\begin{array}{l}\text { Bandarra Filho (1997) } \\
\text { Eq. }(2.80 \text { e } 2.81)\end{array}$} & \multirow{2}{*}{ Grupo 3} & Absoluto, $|\overline{\mathrm{E}}|$ & $17,0 \%$ & $60,4 \%$ \\
\hline & & Relativo, $\overline{\mathrm{E}}$ & $2,3 \%$ & $-60,4 \%$ \\
\hline
\end{tabular}

\subsubsection{Desenvolvimento de um Modelo para o Coeficiente de Transferência de Calor em Tubos Lisos para Vazões Elevadas $\left(G \geq 200 \mathrm{~kg} / \mathrm{s.m}^{2}\right)$}

BANDARRA FILHO (1997) sugeriu uma correlação, Eq. (2.81), para avaliação do coeficiente de transferência de calor, classificada, neste trabalho, de estritamente empírica. Como ressaltado no capítulo 2, essa correlação conciliou, ao mesmo tempo, simplicidade e precisão nos resultados, principalmente, aqueles associados a vazões elevadas, onde o padrão de escoamento é o anular.

Nessas condições, desenvolveu-se uma correlação nos mesmos moldes daquela apresentada por BANDARRA FILHO (1997), caracterizada por corrigir a forma geral das correlações estritamente convectivas, $\frac{h_{b}}{h_{L}}=f\left(X_{t t}\right)$. Nesse caso, seria interessante incorporar um parâmetro adimensional que leva em consideração os efeitos relativos à ebulição nucleada, com o objetivo de correlacionar os resultados experimentais na região de títulos reduzidos. Assim, o parâmetro escolhido foi o número de ebulição, Bo, que relaciona, explicitamente, o fluxo de calor específico com a velocidade mássica. Esse parâmetro adimensional é definido pela seguinte expressão:

$$
B o=\frac{\phi}{G \cdot i_{L V}}
$$

Assim, a correlação proposta para a avaliação do coeficiente de transferência de calor em tubos lisos para faixa de velocidades mássicas elevadas, $\mathrm{G} \geq 200 \mathrm{~kg} / \mathrm{s} . \mathrm{m}^{2}$, apresenta a seguinte forma geral: 


$$
\frac{h_{b}}{h_{L}}=1+C_{1} \cdot X_{t t}^{C_{2}} \cdot B o^{C_{3}}
$$

Nessas condições, verificou-se que a correlação proporcionava os menores desvios para os seguintes valores do coeficiente $C_{1}$ e os expoentes $C_{2}$ e $C_{3}$ : $C_{1}=20, C_{2}=-0,66$ e $C_{3}=$ 0,23 , tendo sido verificado um coeficiente de correlação de $92 \%$. A forma final da correlação para o coeficiente de transferência de calor para a faixa de velocidades mássicas elevadas é expressa pela seguinte equação:

$$
\frac{h_{b}}{h_{L}}=1+20 \cdot X_{t t}^{-0,66} \cdot B o^{0,23} \quad \text { para } \mathrm{G} \geq 200 \mathrm{~kg} / \mathrm{s} \cdot \mathrm{m}^{2}
$$

Os parâmetros adimensionais $X_{\mathrm{tt}}$ e Bo correlacionam, satisfatoriamente, os resultados experimentais, como ilustrado na Fig. 5.11. O parâmetro de Martinelli, $X_{t t}$, como mencionado anteriormente, correlaciona adequadamente os resultados onde o padrão de escoamento anular prepondera. Já o número de ebulição, Bo, foi incorporado ao modelo a fim de representar os efeitos da ebulição nucleada, ou seja, a presença de bolhas no escoamento, que estão associados, em geral, a altos fluxos de calor na parede do tubo e a títulos reduzidos.

A Fig. 5.11 ilustra uma comparação entre o coeficiente de transferência de calor obtido experimentalmente com aquele avaliado pela correlação (5.9). O desvio médio absoluto encontrado foi de $15 \%$ e o relativo de $-3,6 \%$ em relação aos dados experimentais, como ilustrado pela Tabela 5.2. Deve-se ressaltar que os pontos estão agrupados em relação à linha média, com reduzida dispersão, indicando que a correlação proposta representa satisfatoriamente os resultados experimentais. Comparando os desvios proporcionados pela Eq. (5.9) com aqueles observados na Tabela 5.1, é possível verificar que a correlação proposta experimenta o menor desvio em relação às demais.

Tabela 5.2 Desvio médio absoluto e relativo proporcionado pela correlação (5.9) em relação aos resultados experimentais. R-134a e R-22, $T_{\text {Evap }}$ variancio entre 5 e $15^{\circ} \mathrm{C}, \widehat{\mathrm{J}}$

\begin{tabular}{|c|c|c|c|}
\hline Correlação & Grupo & Desvio Médio & Valor \\
\hline Presente Trabalho (2002) & \multirow{2}{*}{ Grupo 3} & Absoluto, $|\overline{\mathrm{E}}|$ & $15,0 \%$ \\
\hline Eq. (5.9) & & Relativo, $\overline{\mathrm{E}}$ & $-3,6 \%$ \\
\hline
\end{tabular}
entre 25 e $500 \mathrm{~kg} / \mathrm{s} \cdot \mathrm{m}^{2}, \phi$ entre 5 e $20 \mathrm{~kW} / \mathrm{m}^{2}$ e $\mathrm{D}_{\mathrm{i}}$ entre 6,24 e $17,4 \mathrm{~mm}$. 


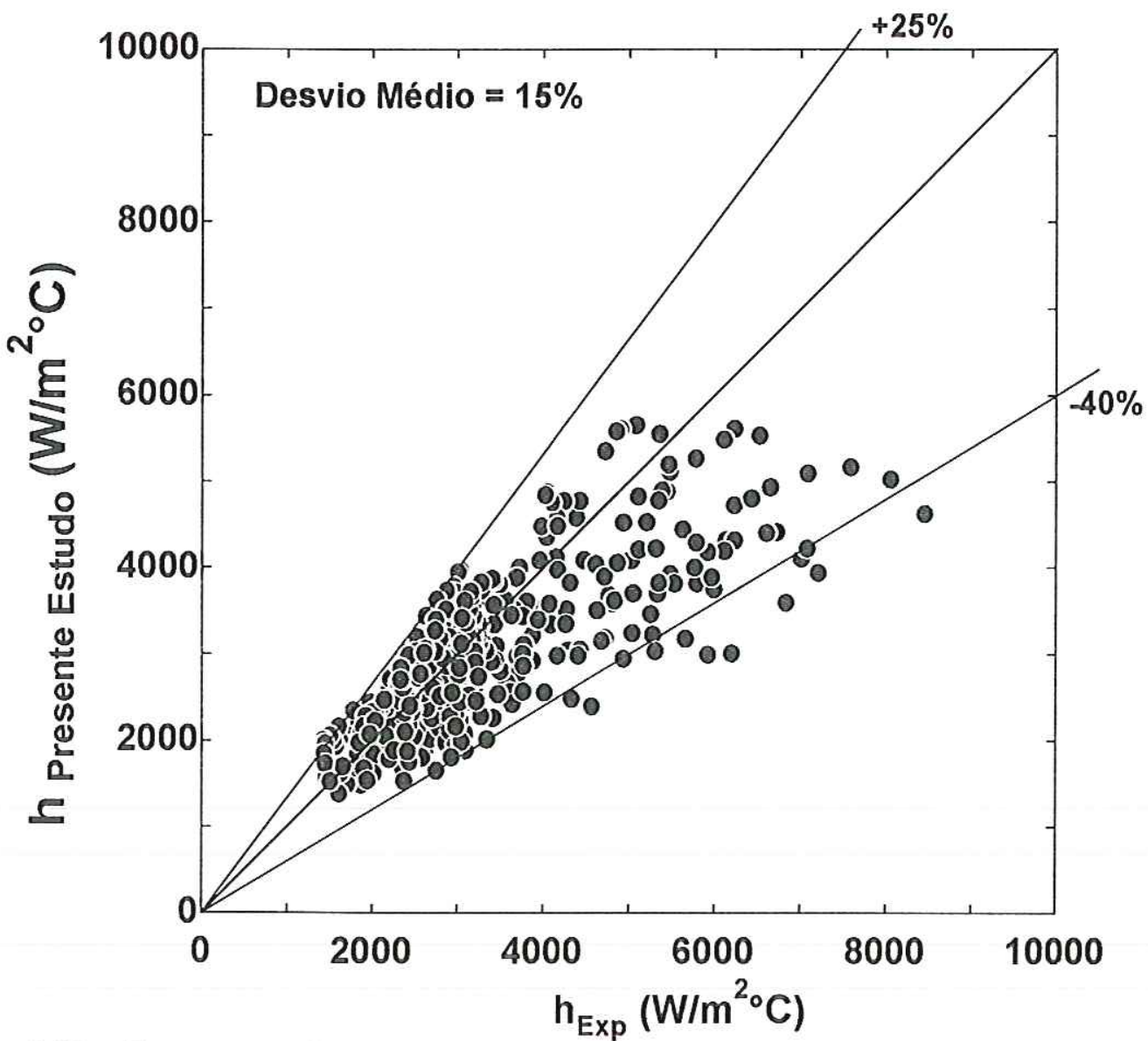

Figura 5.11 Comparação da correlação proposta, Eq. (5.9) com resultados experimentais.

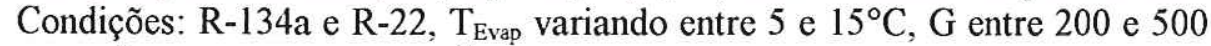
$\mathrm{kg} / \mathrm{s} \cdot \mathrm{m}^{2}, \phi$ entre 5 e $20 \mathrm{~kW} / \mathrm{m}^{2}$ e $\mathrm{D}_{\mathrm{i}}$ entre 6,24 e $17,4 \mathrm{~mm}$.

\subsubsection{Desenvolvimento de uma Correlação para o Coeficiente de Transferência de Calor em Tubos Lisos para Vazões Reduzidas $\left(G<200 \mathrm{~kg} / \mathrm{s.m}{ }^{2}\right)$}

Os elevados desvios absolutos apresentados pelas principais correlações para avaliação do coeficiente de transferência de calor para vazões reduzidas, como observado na Tabela 5.1, motivaram o desenvolvimento de um modelo para o coefíciente de transferência de calor para escoamento estratificado.

Nesta seção, será apresentado o procedimento adotado para o desenvolvimento de uma correlação para o coeficiente de transferência de calor que represente, de forma satisfatória, os resultados experimentais para faixa de velocidades mássicas reduzidas $\left(\mathrm{G}<200 \mathrm{~kg} / \mathrm{s} \cdot \mathrm{m}^{2}\right)$. Optou-se por desenvolver um modelo baseado em parâmetros adimensionais, incluindo, principalmente, os grupos convencionalmente utilizados em ebulição convectiva, seguindo o mesmo princípio adotado para vazões elevadas. Nessas condições, é comum a utilização dos grupos adimensionais, que supostamente incorporam 
alguns dos principais mecanismos ou efeitos, como por exemplo: o parâmetro de Martinelli, $X_{\mathrm{tt}}$, o número de ebulição, Bo, o número de Froude, entre outros.

De acordo com o exposto anteriormente, o desenvolvimento da correlação partiu da forma básica das correlações estritamente convectivas, levando-se em consideração a consistência fisica, ou seja, o coeficiente de transferência de calor bifásico tem que ser igual ao monofásico de líquido quando o título for nulo. Assim, os resultados experimentais foram correlacionados em termos adimensionais, utilizando a relação entre os coeficientes bifásico e monofásico como função do parâmetro de Martinelli, $\mathrm{X}_{\mathrm{tt}}$.Como seria de esperar os desvios médios foram elevados. Posteriormente, o número de ebulição, Bo, foi incorporado à correlação, pois o coeficiente de transferência de calor para baixas vazões mostrou forte dependência do fluxo de calor, como observado no capítulo anterior. Entretanto os desvios encontrados permaneceram elevados. Finalmente, o número de Froude, Fr, que correlaciona muito bem os resultados para escoamento estratificado, foi introduzido, porém o desvio médio apresentou pouca melhora, da ordem de $52 \%$

Nessas condições, ficou claro que o parâmetro de Martinelli não correlaciona de forma satisfatória os resultados experimentais para escoamento com baixas vazões, padrão estratificado, devendo ser aplicado, principalmente, onde o padrão anular predomina. Evidentemente, o coeficiente de transferência de calor mostrou forte dependência do fluxo de calor, bem como da velocidade mássica no padrão estratificado. Porém, foi observado que mesmo excluindo o parâmetro de Martinelli da correlação, mantendo o número de ebulição e o número de Froude, os desvios permaneceram elevados, apresentando pouca alteração. A incorporação do número de ebulição ao modelo, para escoamento estratificado, foi descartada, pois, para baixas vazões, $\mathrm{G}<200 \mathrm{~kg} / \mathrm{s} \cdot \mathrm{m}^{2}$, como observado na análise dos resultados, os efeitos de ebulição nucleada, embora significativos, não são afetados pela velocidade mássica, de forma que o número de ebulição, Bo, não é representativo, devendo tais efeitos ser representados por outro adimensional que incorpore o fluxo de calor, como poderá ser observado mais adiante. Por outro lado, para vazões elevadas, $\mathrm{G} \geq 200 \mathrm{~kg} / \mathrm{s} . \mathrm{m}^{2}$, de acordo com o exposto anteriormente, a região de títulos reduzidos se caracteriza por apresentar efeitos de ebulição nucleada. A extensão dessa região, em termos da faixa de títulos, depende da velocidade mássira. Com efeito, verificou-se que, com o incremento da velocidade mássica, a região associada a efeitos de ebulição nucleada ficava limitada a uma faixa de títulos progressivamente mais reduzida. Assim, no desenvolvimento de uma correlação generalizada, extensiva à faixa de títulos considerados na presente pesquisa, o referido efeito deve ser contemplado, o que implica na incorporação do número de ebulição, dado que este associa efeitos de ebulição nucleada aos efeitos de vazão. 
Nesse sentido, uma análise dimensional, envolvendo variáveis e propriedades físicas que caracterizem o processo de transferência de calor em escoamento bifásico, foi realizada com o objetivo de levantar os principais grupos adimensionais, focalizando aquele que, explicitamente, leva em consideração o fluxo de calor. As principais variáveis associadas ao processo são: $\phi, h, T_{p}, T_{\text {sat, }} g, D, G$, entre outras. As propriedades de transporte: $\rho_{L}, \rho_{V}, c_{L}$, $\mathrm{i}_{\mathrm{LV}}, \mathrm{k}_{\mathrm{L}}, \mathrm{k}_{\mathrm{V}}, \mu_{\mathrm{L}}, \mu_{\mathrm{V}}, \sigma$, entre outras. Estas variáveis e propriedades podem ser combinadas $\mathrm{e}$ agrupadas para a formação de grupos adimensionais. Nessas condições, apenas para exemplificação, alguns números adimensionais resultantes dessa análise podem ser destacados:

$$
\begin{aligned}
& \Pi_{1}=\frac{G \cdot D}{\mu_{L}}=\mathrm{Re} \rightarrow \text { Número de Reynolds, relativo à fase líquida. } \\
& \Pi_{3}=\frac{\phi}{G \cdot i_{L V}}=\mathrm{Bo} \rightarrow \text { Número de Ebulição } \\
& \Pi_{4}=\frac{G^{2}}{\rho_{L}^{2} \cdot g \cdot D}=\mathrm{Fr} \rightarrow \text { Número de Froude, relativo à fase líquida. } \\
& \Pi_{5}=\frac{G^{2} \cdot D}{\sigma \cdot \rho}=\mathrm{We} \rightarrow \text { Número de Weber } \\
& \Pi_{6}=\frac{\phi \cdot D}{k_{L} \cdot T_{s a t}}=\mathrm{Bj} \rightarrow \text { Número Adimensional }
\end{aligned}
$$

$\mathrm{O}$ número adimensional encontrado, denominado neste trabalho de $\mathrm{B} j$, pode ser considerado uma relação entre o fluxo de calor aplicado à parede do tubo e os efeitos de condução no filme de líquido segregado na parte inferior do tubo. Este parâmetro deve representar adequadamente os resultados experimentais para o padrão estratificado, já que este é afetado significativamente pelo fluxo de calor. Vale ressaltar que Tsat deve ser fornecido em Kelvin.

Similarmente ao procedimento adotado para vazões elevadas, optou-se por correlacionar os resultados experimentais do grupo $h_{b} / h_{L}$ em função do número adimensional encontrado, $\mathrm{B} j$, e do número de Froude local, $\mathrm{Fr}_{\mathrm{L}}$, relativo à fase liquida, já que este parâmetro varia localmente com o título.

Assim, a correlação proposta apresenta a seguinte forma geral: 


$$
\frac{h_{b}}{h_{L}}=1+C_{1} \cdot \mathrm{Bj}^{C_{2}} \cdot \mathrm{Fr}_{L}^{C_{3}}
$$

Com o objetivo de proporcionar um desvio médio absoluto reduzido e, principalmente, simplificar a expressão final, o coeficiente e os expoentes foram verificados e assumiram os seguintes valores: $C_{1}=0,74, C_{2}=2 / 3$ e $C_{3}=-1 / 3$. Desse modo, foi possível encontrar um coeficiente de correlação da ordem de $98,9 \%$ em relação aos resultados experimentais. Deve-se ressaltar que o parâmetro de Martinelli, $X_{\mathfrak{t}}$, não aparece na correlação, diferenciando-a da maioria dos modelos encontrados na literatura para o coeficiente de transferência de calor, que incorporam este parâmetro na correlação geral. A forma final da correlação proposta é apresentada pela seguinte relação:

$$
\frac{h_{b}}{h_{L}}=1+0,74 \cdot \mathrm{Bj}^{2 / 3} \cdot F r_{L}^{-1 / 3} \quad \text { para } \mathrm{G}<200 \mathrm{~kg} / \mathrm{s} \cdot \mathrm{m}^{2}
$$

A correlação apresentada, Eq. (5.10), é de fácil e rápida aplicação, além de aliar simplicidade na sua forma e precisão dos seus resultados. $O$ desvio médio absoluto encontrado em relação aos resultados experimentais foi de $5,9 \%$ e o desvio médio relativo foi de $-2,4 \%$, como mostra a Tabela 5.3. Em comparação com os desvios médios absolutos apresentados na Tabela 5.1, para a faixa de vazões reduzidas, percebe-se que houve uma redução considerável. Assim, apesar do limitado banco de dados disponível para a faixa de vazões reduzidas, a correlação proposta apresentou resultados encorajadores.

Tabela 5.3 Desvio médio absoluto e relativo proporcionado pela correlação (5.10) em

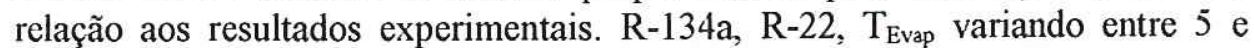
$15^{\circ} \mathrm{C}, \mathrm{G}$ entre 25 e $100 \mathrm{~kg} / \mathrm{s} \cdot \mathrm{m}^{2}$, $\phi$ entre 5 e $20 \mathrm{~kW} / \mathrm{m}^{2}$ e $\mathrm{D}_{\mathrm{i}}$ entre 8,76 e $17,4 \mathrm{~mm}$.

\begin{tabular}{|c|c|c|c|}
\hline Correlação & Grupo & Desvio Médio & Valor \\
\hline Presente Trabalho (2002) & \multirow{2}{*}{ Grupo 3 } & Absoluto, $|\overline{\mathrm{E}}|$ & $5,9 \%$ \\
\cline { 3 - 4 } Eq. (5.10) & & Relativo, $\overline{\mathrm{E}}$ & $-2,4 \%$ \\
\hline
\end{tabular}

A Fig. 5.12 ilustra a comparação da correlação proposta, Eq. (5.10), com os resultados experimentais. Como pode ser notado, o desvio máximo apresentado foi da ordem de $14 \%$. 


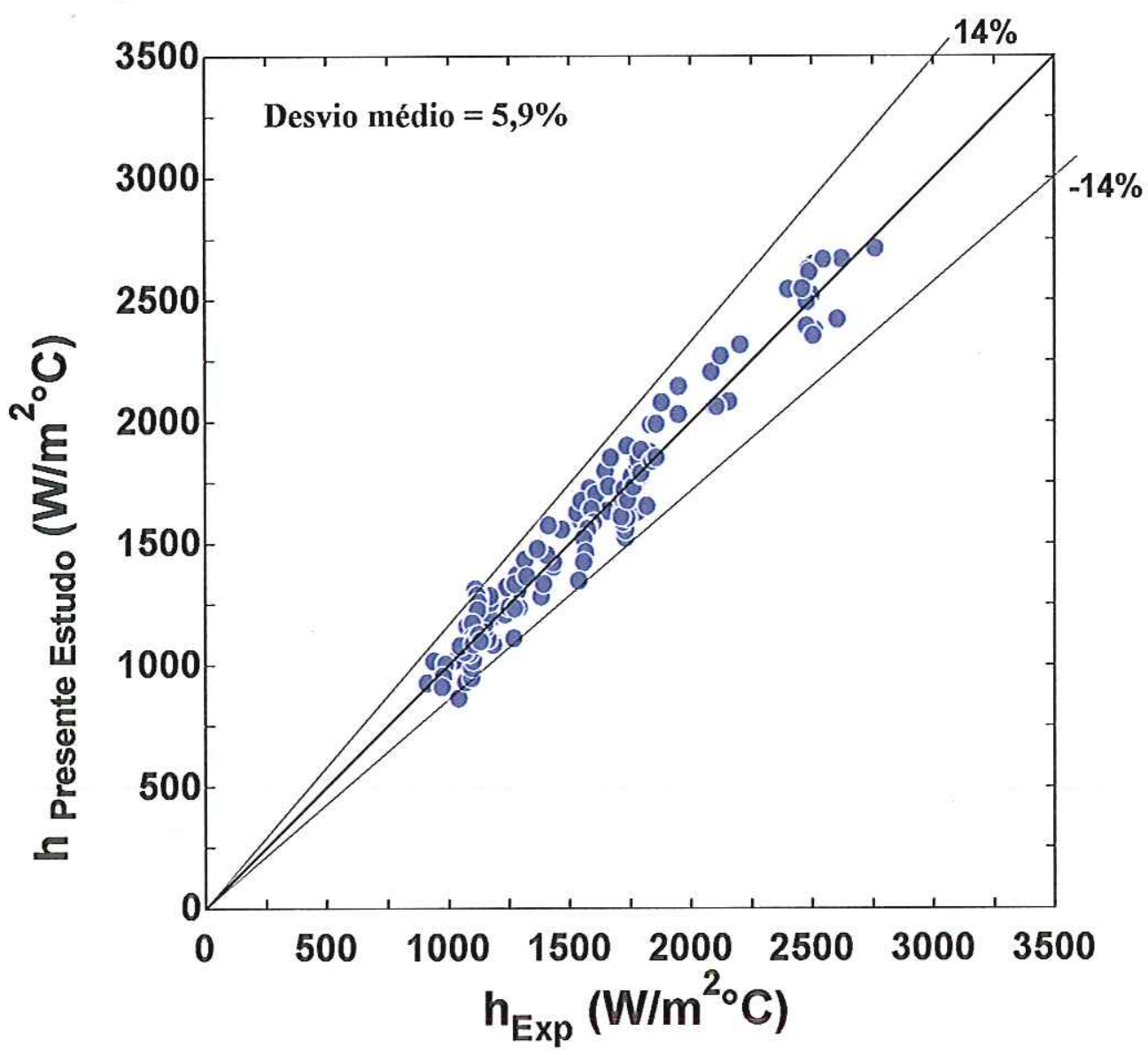

Figura 5.12 Comparação da correlação proposta, Eq. (5.10) com resultados experimentais. Condições: R-134a, R-22, $\mathrm{T}_{\text {Evap }}$ variando entre 5 e $15^{\circ} \mathrm{C}, \mathrm{G}$ entre 25 e 100 $\mathrm{kg} / \mathrm{s} . \mathrm{m}^{2}, \phi$ entre 5 e $20 \mathrm{~kW} / \mathrm{m}^{2}$ e $\mathrm{D}_{\mathrm{i}}$ entre 8,76 e $17,4 \mathrm{~mm}$.

As Figs. 5.13, 5.14, 5.15 e 5.16 ilustram comparações de resultados experimentais, válidos para as condições especificadas na legenda, com as correlações que apresentaram os menores desvios, no caso, a correlação de Jung-Radermacher, Wattelet e Kandlikar. A correlação proposta foi superposta nestas figuras para efeito de comparação. Como pode ser observado, o modelo proposto é o que melhor correlaciona os resultados experimentais, representando, inclusive, a tendência do coeficiente de transferência de calor diminuir com o aumento do título para escoamento estratificado. Deve-se ressaltar que as Figs. 5.13 e 5.14 foram obtidas para o refrigerante R-134a, ao passo que as Figs. 5.15 e 5.16 para o R-22. 


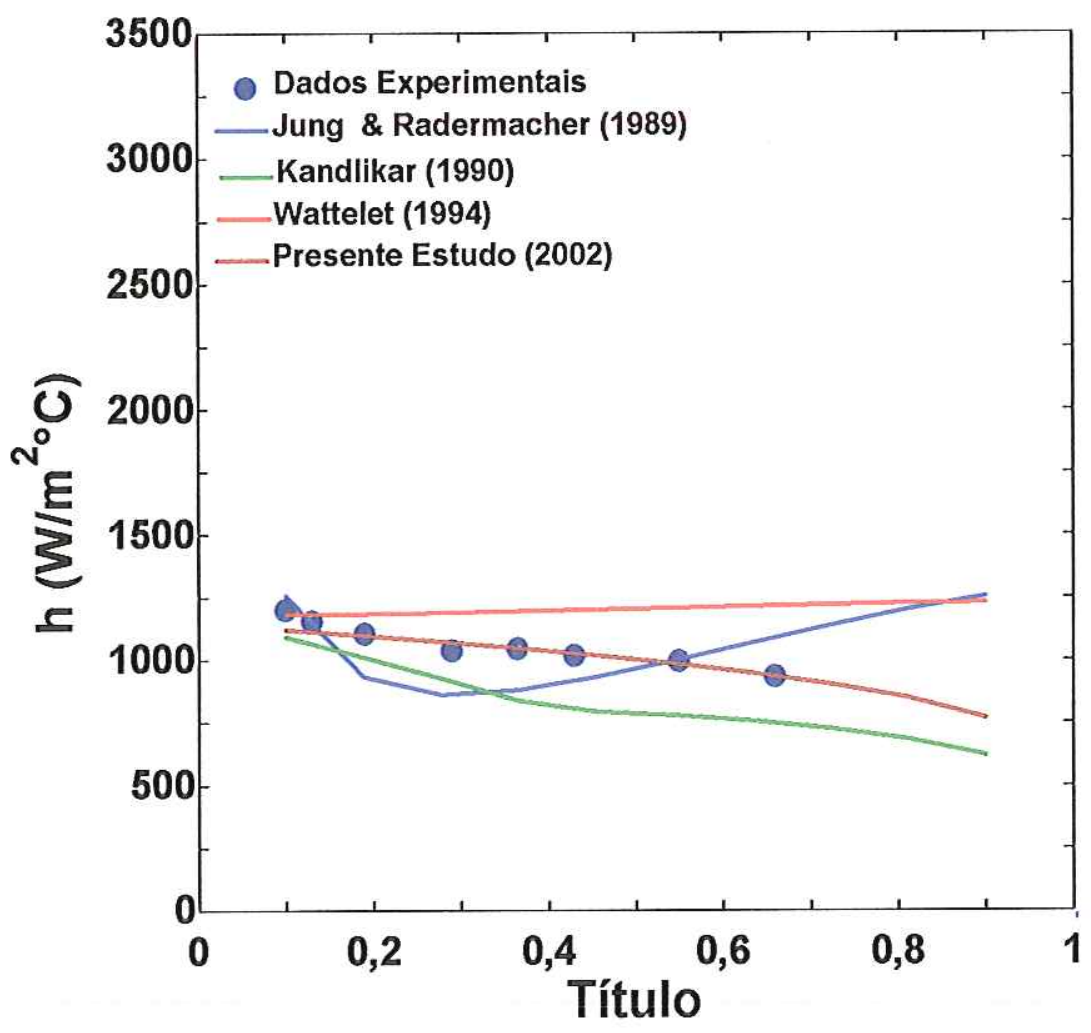

Figura 5.13 Comparação dos resultados experimentais com as correlações de JungRadermacher, Wattelet e Kandlikar, superposta a correlação proposta, Eq. (5.10). R-134a com $\mathrm{T}_{\text {Evap }}=5^{\circ} \mathrm{C}, \mathrm{G}=50 \mathrm{~kg} / \mathrm{s} \cdot \mathrm{m}^{2}, \phi=5 \mathrm{~kW} / \mathrm{m}^{2}$ e $\mathrm{D}_{\mathrm{i}}=17,4 \mathrm{~mm}$.

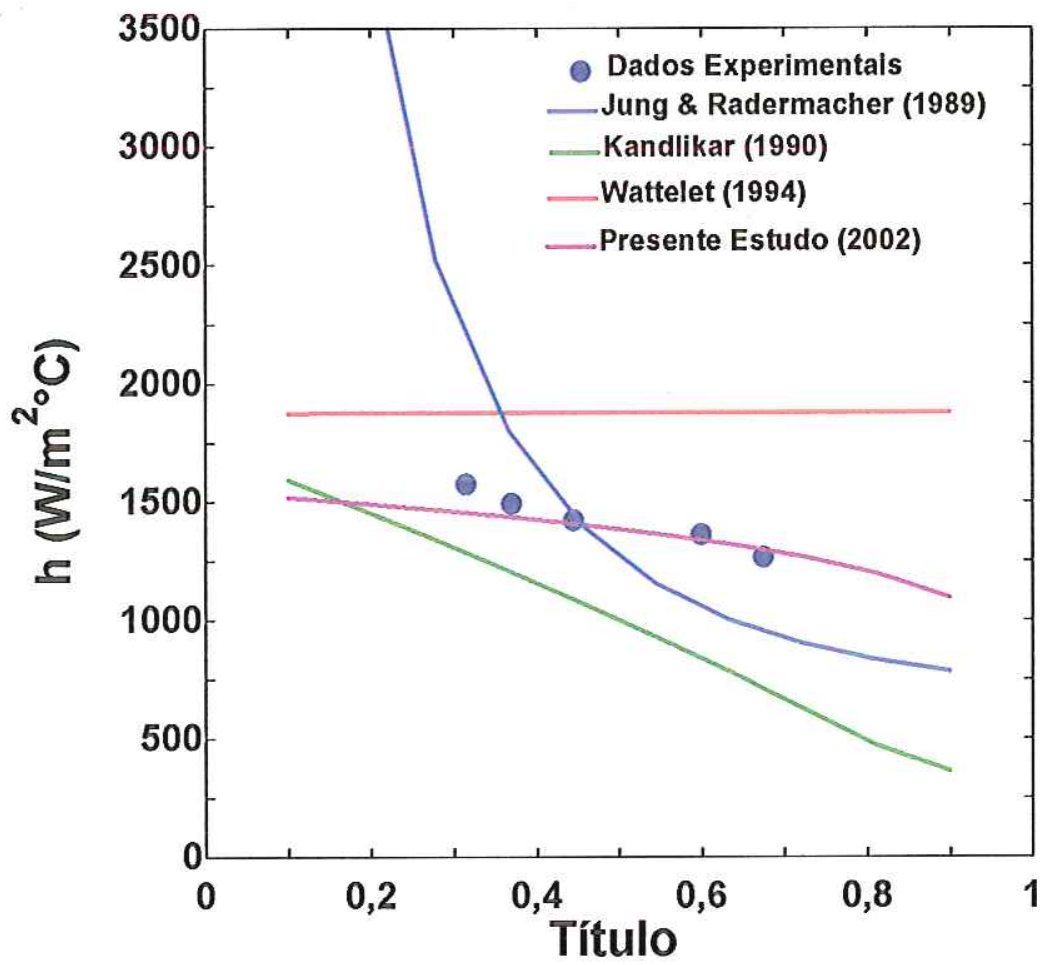

Figura 5.14 Comparação dos resultados experimentais com as correlações de JungRadermacher, Wattelet e Kandlikar, superposta a correlação proposta, Eq. (5.10). R-134a com $\mathrm{T}_{\text {Evap }}=5^{\circ} \mathrm{C}, \mathrm{G}=25 \mathrm{~kg} / \mathrm{s} \cdot \mathrm{m}^{2}, \phi=10 \mathrm{~kW} / \mathrm{m}^{2}$ e $\mathrm{D}_{\mathrm{i}}=17,4 \mathrm{~mm}$. 


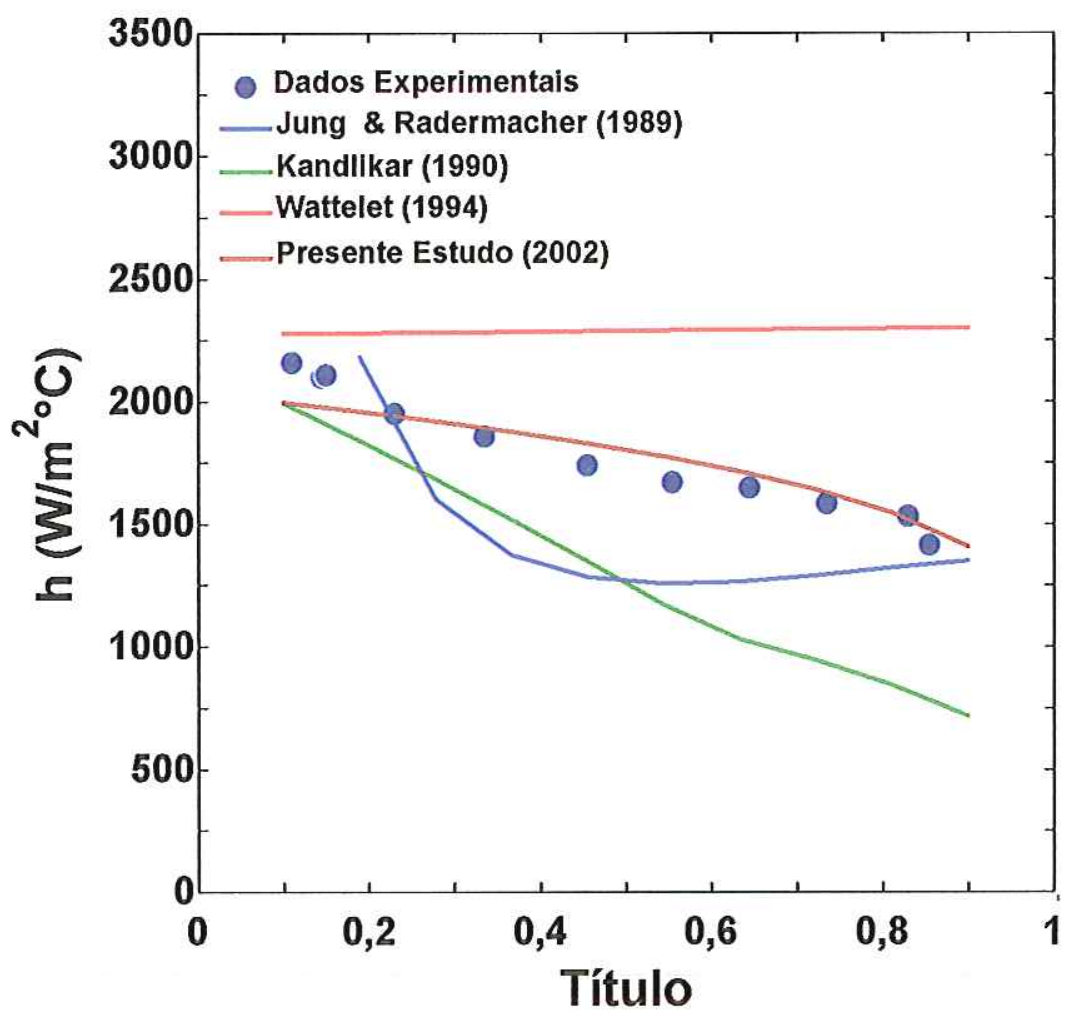

Figura 5.15 Comparação dos resultados experimentais com as correlações de JungRadermacher, Wattelet e Kandlikar, superposta a correlação proposta, Eq. (5.10). R-22 com $\mathrm{T}_{\text {Evap }}=5^{\circ} \mathrm{C}, \mathrm{G}=50 \mathrm{~kg} / \mathrm{s} \cdot \mathrm{m}^{2}, \phi=10 \mathrm{~kW} / \mathrm{m}^{2}$ e $\mathrm{D}_{\mathrm{i}}=17,4 \mathrm{~mm}$.

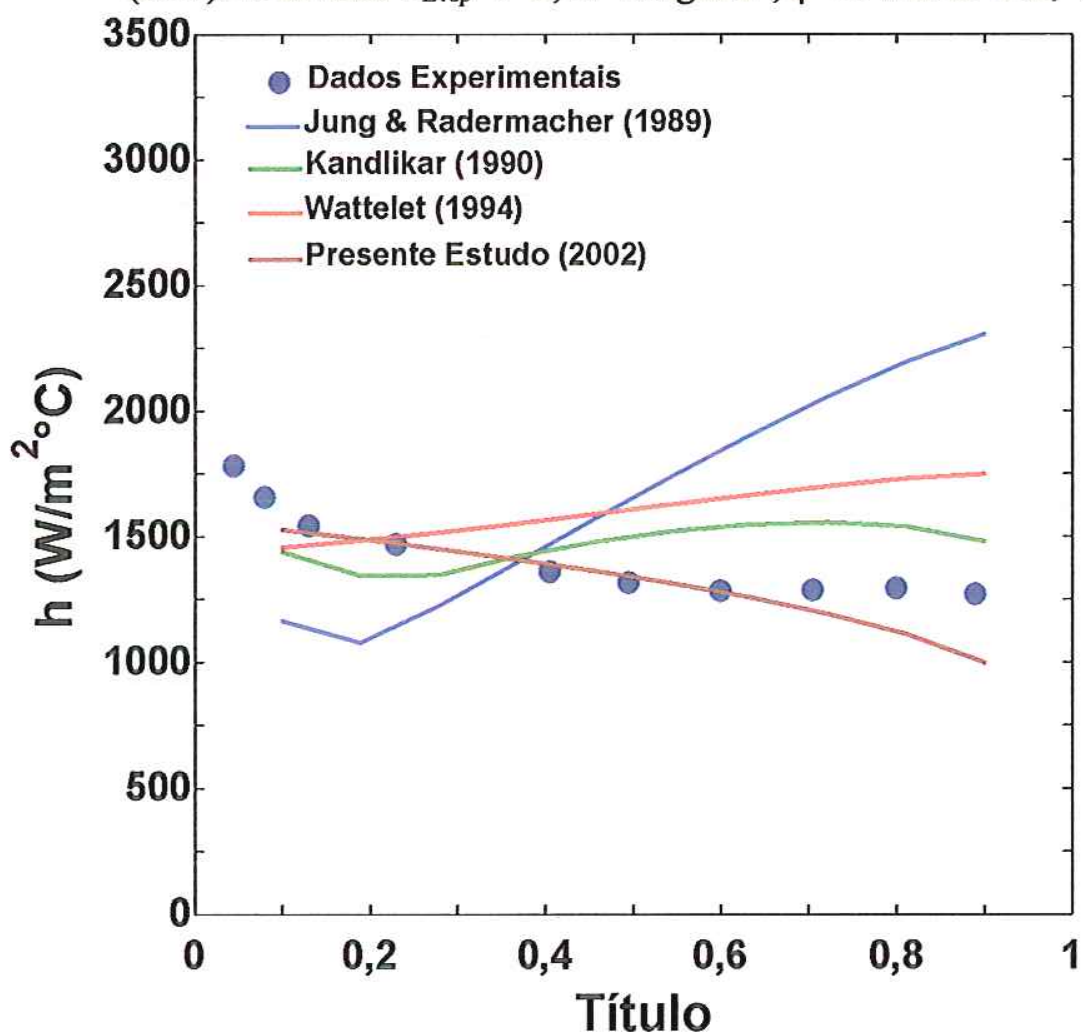

Figura 5.16 Comparação dos resultados experimentais com as correlações de JungRadermacher, Wattelet e Kandlikar, superposta a correlação proposta, Eq. (5.10). R-22 com $\mathrm{T}_{\text {Evap }}=5^{\circ} \mathrm{C}, \mathrm{G}=100 \mathrm{~kg} / \mathrm{s} \cdot \mathrm{m}^{2}, \phi=5 \mathrm{~kW} / \mathrm{m}^{2}$ e $\mathrm{D}_{\mathrm{i}}=17,4 \mathrm{~mm}$. 
Com o objetivo de validar a correlação proposta, buscou-se, na literatura aberta, resultados experimentais com vazões reduzidas, $\mathrm{G}<200 \mathrm{~kg} / \mathrm{s} . \mathrm{m}^{2}$, padrão estratificado, para que fosse possível realizar a verificação. Na tese de doutoramento de KATTAN (1996), foram selecionados alguns resultados para o R-134a escoando num tubo de $10,9 \mathrm{~mm}$ de diâmetro interno com $\mathrm{G}=100 \mathrm{~kg} / \mathrm{s}^{\mathrm{m}} \mathrm{m}^{2}$ e $\phi$ variando entre 4 e $8 \mathrm{~kW} / \mathrm{m}^{2}$. Como pode ser observado nas Figs. 5.17 e 5.18, o modelo proposto é o que melhor representa os resultados experimentais de KATTAN (1996). Os desvios médios absolutos proporcionados pelas correlações de Jung-Radermacher, Kandlikar, Wattelet e a do presente estudo em relação aos resultados experimentais de KATTAN (1996) foram inseridos nessa figura, para efeito de comparação.

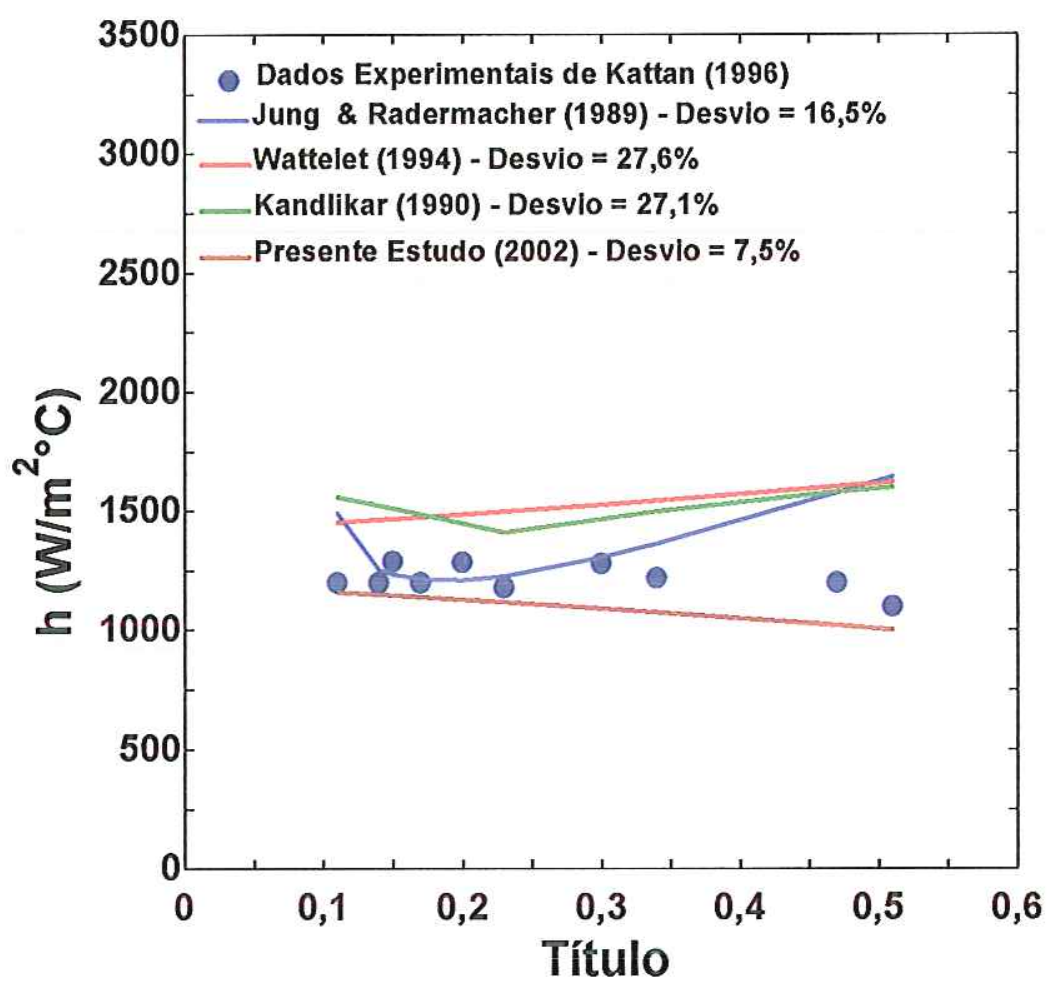

Figura 5.17 Comparação dos resultados experimentais de KATTAN (1996) com a correlação proposta e as correlações de Jung-Radermacher, Wattelet e Kandlikar, Eq. (5.10). Condições: R-134a com $\mathrm{T}_{\text {Evap }}=10^{\circ} \mathrm{C}, \mathrm{G}=100 \mathrm{~kg} / \mathrm{s} \cdot \mathrm{m}^{2}, \phi$ entre 4 e $6 \mathrm{~kW} / \mathrm{m}^{2}$ e $\mathrm{D}_{\mathrm{i}}=10,9 \mathrm{~mm}$. 


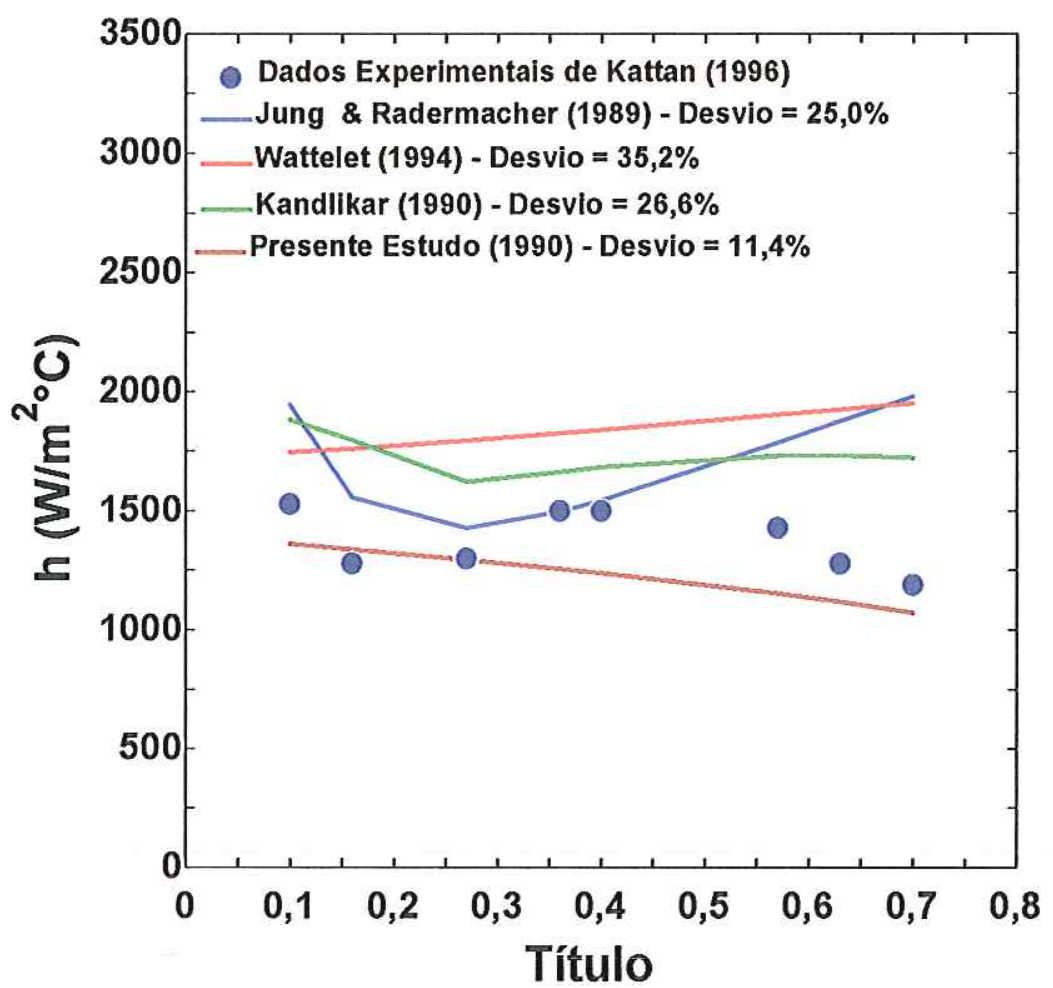

Figura 5.18 Comparação dos resultados experimentais de KATTAN (1996) com a correlação proposta e as correlações de Jung-Radermacher, Wattelet e Kandlikar, Eq. (5.10). Condições: R-134a com $T_{\text {Evap }}=10^{\circ} \mathrm{C}, \mathrm{G}=100 \mathrm{~kg} / \mathrm{s} \cdot \mathrm{m}^{2}, \phi$ entre 6 e $8 \mathrm{~kW} / \mathrm{m}^{2}$ e $\mathrm{D}_{\mathrm{i}}=10,9 \mathrm{~mm}$. 


\subsection{Correlação para o Coeficiente de Transferência de Calor em Tubos Microaletados}

Seguindo o mesmo procedimento utilizado no desenvolvimento da correlação para a avaliação da transferência de calor em tubos lisos, especialmente, para vazões elevadas, onde predomina o padrão anular, os resultados experimentais para tubos microaletados foram correlacionados em termos adimensionais. De acordo com o mapa proposto para tubos microaletados no capítulo anterior, o padrão anular prepondera em toda a faixa de títulos e velocidades mássicas. Nessas condições, é de se esperar que a relação $h_{b} / h_{L}$ seja função do parâmetro de Martinelli, $X_{\mathrm{tt}}$, e do número de ebulição, Bo. A introdução do parâmetro de Martinelli se deve, principalmente, ao predomínio do padrão anular e, como observado anteriormente, o $\mathrm{X}_{\mathrm{tt}}$ correlaciona, muito bem, os resultados experimentais. Já o número de ebulição foi incorporado à correlação, pois, na região de títulos reduzidos, verificou-se um pequeno efeito da ebulição nucleada no coeficiente de transferência de calor. Esse parâmetro tende a diminuir à medida que a velocidade mássica é incrementada, o que, efetivamente, se observa nos resultados experimentais.

Nessas condições, a correlação proposta deve apresentar uma forma similar à Eq. (5.9). Otimizando o coeficiente e os expoentes para obter o menor desvio, a configuração final da correlação para avaliação do coeficiente de transferência de calor resultou na seguinte expressão:

$$
\frac{h_{b}}{h_{L}}=1+345 \cdot X_{t t}^{-0,68} \cdot B o^{0,44}
$$

Deve-se destacar que não houve maiores preocupações em correlacionar a geometria dos tubos, o que, evidentemente, tornaria a correlação mais complexa. A Fig. 5.19 ilustra umà comparação entre o coeficiente de transferência de calor obtido experimentalmente com aquele proporcionado pela correlação (5.11). O desvio médio absoluto em relação aos dados experimentais foi de $18 \%$ e o relativo foi de $0,35 \%$.

As correlações de KANDLIKAR \& RAYKOFF (1997) e de MURATA \& HASHIZUME (1993) propostas para o cálculo do coeficiente de transferência de calor em tubos microaletados, apresentadas no capítulo 2, foram comparadas com os resultados experimentais, tendo proporcionado os desvios ilustrados pela Tabela 5.4. Observa-se que a correlação proposta apresenta os menores desvios. 
Tabela 5.4 Desvio médio absoluto e relativo proporcionados pelas correlações em relação aos resultados experimentais. R-134a, $\mathrm{T}_{\text {Evap }}=5^{\circ} \mathrm{C}, \mathrm{G}$ variando entre 100 e 500 $\mathrm{kg} / \mathrm{s} . \mathrm{m}^{2}, \phi$ entre 5 e $10 \mathrm{~kW} / \mathrm{m}^{2}$ e $\mathrm{D}_{\mathrm{i}}$ entre 6,4 e $8,96 \mathrm{~mm}$.

\begin{tabular}{|c|c|c|}
\hline Correlação & Desvio Médio & Valor \\
\hline $\begin{array}{c}\text { Murata \& Hashizume (1993) } \\
\text { Eq. (2.51) }\end{array}$ & Absoluto, $|\overline{\mathrm{E}}|$ & $32,5 \%$ \\
\cline { 2 - 3 } & Relativo, $\overline{\mathrm{E}}$ & $-40,2 \%$ \\
\hline $\begin{array}{c}\text { Kandlikar \& Raykoff (1997) } \\
\text { Eq. (2.82) }\end{array}$ & Absoluto, $|\overline{\mathrm{E}}|$ & $28,0 \%$ \\
\cline { 2 - 3 } & Relativo, $\overline{\mathrm{E}}$ & $-25,4 \%$ \\
\hline $\begin{array}{c}\text { Presente Estudo (2002) } \\
\text { Eq. (5.11) }\end{array}$ & Absoluto, $|\overline{\mathrm{E}}|$ & $18,0 \%$ \\
\cline { 2 - 3 } & Relativo, $\overline{\mathrm{E}}$ & $0,35 \%$ \\
\hline
\end{tabular}

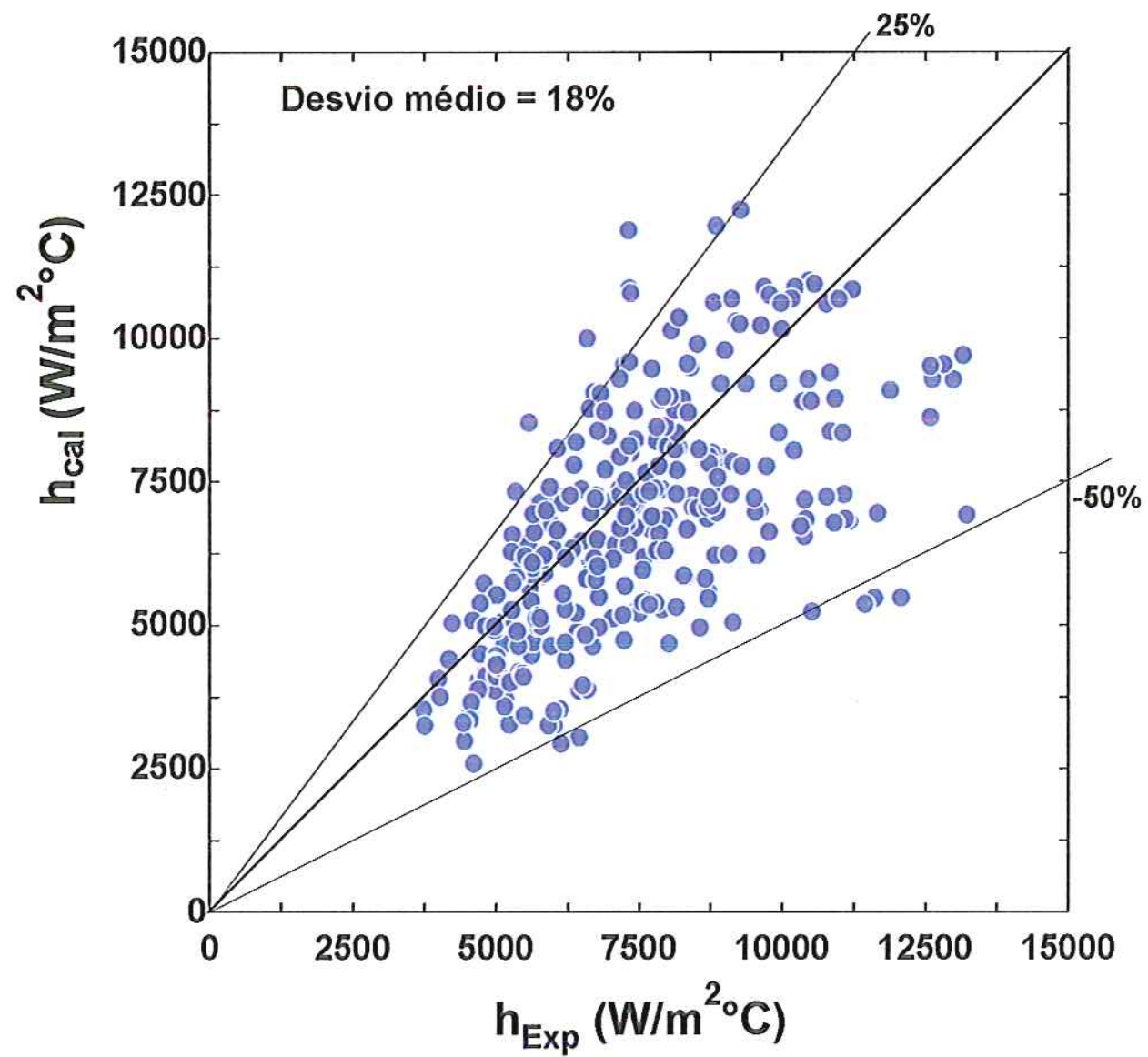

Figura 5.19 Comparação dos resultados experimentais obtidos experimentalmente com o calculado pela correlação proposta no presente estudo. Condições: R-134a, $\mathrm{T}_{\text {Evap }}=5^{\circ} \mathrm{C}, \mathrm{G}$ variando entre 100 e $500 \mathrm{~kg} / \mathrm{s} . \mathrm{m}^{2}, \phi$ entre 5 e $10 \mathrm{~kW} / \mathrm{m}^{2}$ e $\mathrm{D}_{\mathrm{i}}$ entre 6,4 e $8,96 \mathrm{~mm}$. 
Deve-se esclarecer que a correlação de KANDLIKAR \& RAYKOFF (1997) incorpora dois fatores dependentes da geometria do tubo. Esses fatores foram definidos de acordo com os dados experimentais obtidos de 6 fontes distintas. Para efeito de comparação, foram utilizados os fatores definidos para o tubo de KHANPARA et al (1987), utilizando o $\mathrm{R}-22$ como fluido de trabalho, $\mathrm{F}_{\mathrm{EC}}=1,04$ e $\mathrm{F}_{\mathrm{EN}}=1,8$, pois resultaram nos menores desvios. $\mathrm{O}$ presente trabalho procurou ajustar os fatores dependentes da geometria do tubo da correlação de KANDLIKAR \& RAYKOFF (1997) aos resultados experimentais obtidos na campanha de ensaios. Os ajustes dos fatores resultaram $\mathrm{F}_{\mathrm{EC}}=1,55$ e $\mathrm{F}_{\mathrm{EN}}=2,0$, proporcionando um desvio médio absoluto de $16,5 \%$, o que representa uma redução significativa em relação ao anterior.

Vale ressaltar que a correlação apresentada no presente trabalho é de rápida e fácil aplicação, ao passo que o mesmo não se verifica para as correlações de KANDLIKAR \& RAYKOFF (1997) e de MURATA \& HASHIZUME (1993).

\subsection{Sumário das Correlações Propostas}

A Tabela 5.5 ilustra, de forma seqüencial, as correlações propostas no presente capítulo.

Tabela 5.4 Sumário das correlações propostas no presente trabalho.

\begin{tabular}{|c|c|c|c|}
\hline $\begin{array}{c}\text { Tipo } \\
\text { Perda de Carga }\end{array}$ & $\begin{array}{c}\text { Correlação } \\
\phi_{\mathrm{L}}=1+2,6 . \mathrm{X}_{\mathrm{tt}}{ }^{-0,85}\end{array}$ & \begin{tabular}{|c} 
Tipo de Tubo \\
Liso
\end{tabular} & $\begin{array}{l}\text { Faixa de Validade } \\
X_{\mathrm{tt}} \leq 1 \mathrm{e} \\
\mathrm{G} \geq 200 \mathrm{~kg} / \mathrm{s} \cdot \mathrm{m}^{2}\end{array}$ \\
\hline Perda de Carga & $\phi_{\mathrm{L}}=0,8 \cdot \mathrm{Fr}_{\mathrm{L}}^{-0,45}$ & Liso & $\begin{array}{c}X_{\mathrm{tt}} \leq 1 \mathrm{e} \\
\mathrm{G}<200 \mathrm{~kg} / \mathrm{s} \cdot \mathrm{m}^{2}\end{array}$ \\
\hline Perda de Carga & $\phi_{\mathrm{L}}=1+3,0 \cdot \mathrm{X}_{\mathrm{tt}}^{-0,83}$ & Microaletado & $X_{\mathrm{tt}} \leq 1$ \\
\hline Transferên cia de Calor & $\frac{h_{b}}{h_{L}}=1+20 \cdot X_{t}^{-0,66} \cdot B o^{0,23}$ & Liso & $\mathrm{G} \geq 200 \mathrm{~kg} / \mathrm{s} \cdot \mathrm{m}^{2}$ \\
\hline Transferência de Calor & $\frac{h_{b}}{h_{L}}=1+0,74 \cdot \mathrm{Bj}^{2 / 3} \cdot F r_{L}^{-1 / 3}$ & Liso & $\mathrm{G}<200 \mathrm{~kg} / \mathrm{s} \cdot \mathrm{m}^{2}$ \\
\hline Transferência de Calor & $\frac{h_{b}}{h_{L}}=1+345 \cdot X_{t t}^{-0,68} \cdot B o^{0,44}$ & Microaletado & - \\
\hline
\end{tabular}




\section{CAPÍTULO 6 - CONCLUSÕES E RECOMENDAÇÕES}

\subsection{Introdução}

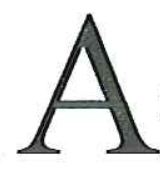

pesquisa em ebulição convectiva, levada a cabo no presente trabalho, contribuiu para um melhor conhecimento dos mecanismos físicos associados à mudança de fase no interior de tubos. A pesquisa bibliográfica, que abrangeu a transferência de calor no interior de tubos lisos, tubos microaletados e na região de defíciência de líquido, serviu de base para a análise dos resultados experimentais e também para o desenvolvimento de correlações. O equipamento experimental sofreu algumas alterações ao longo da pesquisa, com o objetivo de propiciar maior agilidade, melhorando sensivelmente a aquisição dos pontos experimentais, além de proporcionar maior versatilidade à bancada, o que permitiu ampliar, de certo modo, a faixa de operação.

Os objetivos propostos para este trabalho foram alcançados de maneira satisfatória, com destaque para análise dos resultados experimentais e as correlações para a transferência de calor em escoamento estratificado e para a perda de carga em tubos microaletados, pois proporcionaram resultados encorajadores. Um extenso banco de dados foi levantado, envolvendo diversas condições operacionais e distintos fluidos refrigerantes. Aproximadamente 500 registros fotográficos foram obtidos com razoável qualidade, auxiliando no entendimento do fenômeno físico.Uma seleção das fotos foi adicionada ao Apêndice II.

A seguir serão apresentadas as principais conclusões relativas à presente pesquisa e, posteriormente, recomendaŗ̃ões e sugestões para pesquisas futuras ou os próximos passos para a continuidade deste trabalho. 


\subsection{Conclusões Finais}

As principais conclusões relativas ao presente trabalho podem ser resumidas nos seguintes tópicos:

( A pesquisa bibliográfica resumiu e agrupou os principais trabalhos sobre a ebulição convectiva, intensificação da transferência de calor e as principais pesquisas sobre a região de deficiência de líquido ou secagem de parede.

$\sigma$ Verificou-se que, para escoamento monofásico de líquido e números de Reynolds abaixo de 8000 , os resultados para o grupo adimensional $\mathrm{Nu} / \mathrm{Pr}^{0,4}$, foram semelhantes para tubos: liso e microaletado com diâmetro de 9,52mm. Esse comportamento evidenciou que, na região de transição entre os regimes laminarturbulento, a espessura da subcamada laminar é superior a altura da microaleta, não afetando, portanto, a transferência de calor.

$\varpi \quad$ Os principais padrões de escoamento encontrados na mudança de fase de refrigerantes no interior de tubos horizontais foram observados e registrados. Essas fotografias contribuíram para o estudo do fenômeno físico, assim como auxiliaram na confecção de um mapa de padrão de escoamento para tubos microaletados.

$\sigma$ Um mapa de padrão de escoamento para tubos microaletados foi proposto, baseado em observações visuais, registros fotográficos e análise do coeficiente de transferência de calor e perda de carga, aliando simplicidade, pois é função apenas da velocidade mássica e título, e precisão, representando de forma satisfatória os resultados experimentais.

$\sigma \quad$ A velocidade mássica afeta de forma significativa o coeficiente de transferência de calor. Uma análise minuciosa permitiu identificar duas faixas típicas de velocidade mássica que alteram o coeficiente. Valores de G superiores a $200 \mathrm{~kg} / \mathrm{s} . \mathrm{m}^{2}$, que correspondem faixa de vazões elevadas, onde o escoamento predominante é o anular, com elevação do coeficiente no sentido do escoamento. Valores de $\mathrm{G}$ inferiores a 200 $\mathrm{kg} / \mathrm{s} \cdot \mathrm{m}^{2}$, associadas a vazões reduzidas, com predomínio do padrão estratificado de escoamento, onde a característica principal é o coeficiente apresentar uma leve queda ao longo do evaporador.

$\sigma \quad$ Os resultados experimentais mostraram que o tipo de fluido refrigerante afeta 0 coeficiente de transferência de calor. Em escoamento anular, altas vazões, o coeficiente associado ao R-134a apresentou valores superiores ao R-22. Já em escoamento 
estratificado, baixas vazões, o coeficiente de transferência de calor para o R-22 foi superior.

$\odot$ Observou-se que o fluxo de calor afeta o coeficiente nas duas faixas de vazões, mencionadas anteriormente. Em vazões elevadas, o coeficiente de transferência de calor apresentou forte dependência do fluxo de calor na região de títulos reduzidos, evidenciando que, na região de domínio da ebulição nucleada, esse parâmetro deve ser levado em consideração. Para a região de títulos superiores a 30 ou $40 \%$, o fluxo de calor não mais afeta o coefíciente de transferência de calor. Já para vazões reduzidas, o coeficiente mostrou-se afetado pelo fluxo de calor em toda a região de evaporação.

$\sigma$ Apesar da faixa estreita de temperaturas ensaiadas, percebeu-se que há um certo efeito da temperatura de evaporação sobre o coefíciente de transferência de calor, principalmente na região de títulos reduzidos para vazões elevadas e em toda a faixa de títulos para vazões reduzidas. Isso está intrinsecamente relacionado à condição para formação de bolhas e a fração de vazio.

(6) Como seria de esperar, a perda de carga aumentou consideravelmente com a vazão e o título. A parcela da perda de carga, associada ao atrito, avaliada por intermédio do multiplicador bifásico, foi adequadamente correlacionada em termos do parâmetro de Martinelli, para uma ampla faixa de velocidades mássicas.

$\sigma$ Os tubos microaletados ensaiados mostraram excelente desempenho para vazões reduzidas, típicas do padrão estratificado para tubos lisos. Esse comportamento se deve às configurações das ranhuras, que promovem o deslocamento do líquido para região superior do tubo, favorecendo, substancialmente, a transferência de calor. Para vazões muito elevadas, $\mathrm{G}=500 \mathrm{~kg} / \mathrm{s} \cdot \mathrm{m}^{2}$, o coeficiente de transferência de calor, para o tubo microaletado, apresentou um comportamento atípico para títulos superiores a $40 \%$, diminuindo com este. Isso está relacionado à formação do padrão em névoa promovido pelo arrasto do vapor como resultado da "expulsão" do líquido dos canais formados pelas ranhuras. Assim, a parede do tubo seca e o coeficiente de transferência de calor diminui drasticamente.

$\varangle$ A perda de carga para os tubos microaletados apresentou valores superiores em re'ação aos tubos lisos. Esse efeito é tanto mais pronunciado quanto maior a vazão e c título. Para vazões elevadas, G>300 kg/s.m², as diferenças entre os gradientes de pressão para tubos lisos e microaletados tendem a se elevar, principalmente, para títulos superiores a $50 \%$.

๑ O efeito combinado da intensificação da transferência de calor e perda de carga, denominado de Fator de Intensificação Global, revelou que, para vazões reduzidas, 
$\mathrm{G}<100 \mathrm{~kg} / \mathrm{s} . \mathrm{m}^{2}$, o desempenho do tubo microaletado é, consideravelmente, superior às demais vazões, apresentando um $\mathrm{FI}_{\mathrm{Global}}$ da ordem de 5 .

A análise dos resultados para secagem de parede mostrou sua significativa importância em termos da transferência de calor. Observou-se que a temperatura superficial oscilou significativamente, obedecendo a um mecanismo físico de exposição alternada do vapor e líquido, cuja origem está relacionada a aspectos hidrodinâmicos prévios à entrada da seção de testes.

$\sigma$ Uma correlação para o cálculo da perda de carga no interior de tubos lisos para vazões elevadas, em termos adimensionais, foi proposta, apresentando um desvio médio absoluto de $6,4 \%$ em relação aos resultados experimentais.

$\Phi$ Para a faixa de vazões reduzidas, a correlação proposta para a perda de carga incorporou o número de Froude local, $\mathrm{Fr}_{\mathrm{L}}$, proporcionando um desvio médio de 18,9\%.

Seguindo o mesmo princípio adotado para o tubo liso, propôs-se uma correlação para a avaliação da perda de carga em tubos microaletados. Este modelo correlacionou de forma satisfatória os resultados experimentais do presente trabalho, apresentando um desvio médio absoluto de $6,3 \%$. Como validação, o modelo proposto correlacionou os resultados de KATTAN (1996) para perda de carga, resultando num desvio médio absoluto de 7,1\%. Já em relação aos dados de CHOI et al (1999), o desvio absoluto foi da ordem de 3,3\% para o R-134a e 2,8\% para o R-22, mostrando o potencial para sua utilização.

๑ A correlação proposta para o coeficiente de transferência de calor para a faixa de vazões elevadas apresentou um formato semelhante à correlação de BANDARRA FILHO (1997), conciliando simplicidade e precisão. O desvio médio absoluto encontrado em relação aos resultados experimentais foi de $15 \%$.

G $\mathrm{O}$ modelo desenvolvido para o cálculo do coefíciente de transferência de calor para vazões reduzidas, típicas do padrão estratificado de escoamento, apresentou excelentes resultados, quando comparado às demais correlações, como ilustrado nas Tabelas 5.1 e 5.3 .

G Em relação aos tubos microaletados, uma correlação foi sugerida, semelhante àruela proposta para tubos lisos, proporcionando um desvio médio absoluto de $18 \%$. Já as correlações de KANDLIKAR \& RAYKOFF (1997) e MURATA \& HASHIZUME (1993) apresentaram um desvio, em relação aos resultados experimentais, de $28 \%$ e $32,5 \%$, respectivamente. 


\subsection{Recomendações a Trabalhos Futuros}

A seguir serão relacionadas algumas sugestões e recomendações para futuros trabalhos, para que haja possibilidade de se concluir os principais tópicos em ebulição convectiva de refrigerantes.

$\hookrightarrow \quad$ Avaliar a transferência de calor em ebulição convectiva de refrigerantes halogenados puros (outras condições de ensaios), misturas não azeotrópicas e refrigerantes naturais (por exemplo o $\mathrm{CO} 2$ ).

$\hookrightarrow \quad$ Levantar o desempenho termo-hidráulico (transferência de calor e perda de carga) desses refrigerantes em tubos lisos, microaletados, ovais (liso e microaletado), achatados, de distintos diâmetros.

$\hookrightarrow \quad$ Investigar os padrões de escoamento característicos da ebulição convectiva de refrigerantes no interior de tubos horizontais e suas transições, através da análise de sinais das pressões, filmagens em câmera de vídeo tape rápido e de observações visuais.

$\hookrightarrow \quad$ Pesquisar o mecanismo fisico responsável pela intensificação da transferência de calor na ebulição convectiva em tubos microaletados, incluindo os efeitos que as ranhuras causam no escoamento da mistura líquido/vapor e como esses efeitos alteram os padrões de escoamento.

$\hookrightarrow \quad$ Modelar o escoamento no interior de tubos microaletados.

$\hookrightarrow \quad$ Analisar, através de uma abordagem teórico-experimental os padrões anular e estratificado caracterizados pelo mecanismo de ebulição estritamente convectiva.

$\hookrightarrow \quad$ Investigar experimentalmente os tubos de diâmetros com dimensão da ordem de $1 \mathrm{~mm}$, denominados de microcanais, em ebulição convectiva.

$\hookrightarrow \quad$ Realizar ensaios com misturas refrigerante/ólęo de lubrificação, com o objetivo de se avaliar o efeito do óleo no coeficiente de transferência de calor e na perda de carga. 


\subsection{Considerações Finais}

A comunidade cientifica há muito tem se empenhado na tentativa de esclarecer os mecanismos físicos associados à mudança de fase em ebulição convectiva. A presente pesquisa se insere neste esforço, objetivando colaborar no desenvolvimento e aperfeiçoamento de novas tecnologias.

Particularmente, este trabalho teve a pretensão de contribuir para um melhor entendimento físico do fenômeno que rege a ebulição convectiva. A carência de investigações cientificas no campo da ebulição convectiva, área de fundamental importância para o desenvolvimento tecnológico do país, que se ressente de grupos de pesquisa nacionais, corrobora a motivação suficiente para a continuação dessa linha de pesquisa. 


\section{REFERÊNCIAS BIBLIOGRÁFICAS}

\section{Trabalhos Citados}

AL-FAHED, S.; CHAMRA, L.M.; CHAKROUN, W. (1999). Pressure Drop and Heat Transfer Comparison for Both Microfin Tube and Twisted-Tape Inserts in Laminar Flow. Experimental Thermal and Fluid Science, v. 18 p. 323-333.

ALTMAN, M.; NORRIS, R.H.; STAUB, F.W. (1960). Local an Average Heat Transfer and Pressure Drop for Refrigerants Evaporating in Horizontal Tubes. Journal of Heat Transfer, p. 189-198.

ANDERSON, S. W.; RICH, D.G.; GEARY, D.F. (1966). Evaporation of R22 in a Horizontal 3/4-in OD tube; ASHRAE Semiannual Meeting,Texas, January 24-27.

BAKER, O. (1954). Simultaneous Flow of Oil and Gas; Oil and Gas Journal, v.53, p.185195.

BANDARRA FILHO, E.P.; SAIZ JABARDO, J.M.; LIMA, C.U.S. (1997). Estudo da Transferência de Calor em Ebulição Convectiva de Refrigerantes em Tubos Horizontais. III Congreso Iberoamericano de Ingeniería Mecánica. La Habana, Cuba. 23-26/09.

BANDARRA FILHO, E.P. (1997). Estudo da Transferência de Calor em Ebulição Convectiva de Refrigerantes Halogenados em Tubos Horizontais. São Carlos, 1997. 139p. Dissertação (Mestrado)- Escola de Engenharia de São Carlos, Universidade de São Paulo.

BANDARRA FILHO, E.P.; SAIZ JABARDO, J.M.; LIMA, C.U.S. (2000). Heat Transfer Under Convective Boiling of Refrigerants R-404A and R-407C In a Horizontal Copper Tube Electrically Heated. VIII International Refrigeration Conference. July 25-28/2000, Purdue - USA.

BANDARRA FILHO, E.P.; SAIZ JABARDO, J.M.; MACEDO, R. (2001). Estudo Experimental do Desempenho Termo-Hidráulico do Refrigerante HFC-134a em Escoamento Monofásico no Interior de Tubos Horizontais - Liso, Microaletado e DuploV, Ibero-American Conference of Air Conditioning and Refrigeration - CIAR 2001. Agosto/2001, Buenos Aires - Argentina.

BENSLER, H. (1984). Flow Boiling of Refrigrants Inside a Twisted Tape Inserts Tube. Master of Science Thesis, Milwaukee- USA.

BERTHOUD, G.; JAYANTI, S. (1990). Characterization of Dryout in Helical Coils. International Journal of Heat and Mass Transfer, v. 33, N. 7, p. 1451-1463. 
BROGNAUX, L.J.; WEBB, R.L.; CHAMRA, L.M. (1997). Single Phase Heat Transfer in Micro-fin Tubes. International Journal of Heat and Mass Transfer - v. 40, N. 18, p. 4345-4357.

CAVAlLINI, A.; DEL COL, D.; DORETTI, L.; LONGO, G.A. and ROSSETO, L. (2000). "Heat Transfer and Pressure Drop During Condensation of Refrigerants Inside Horizontal Enhanced Tubes. "International Journal of Refrigeration - N. 23 p. 4-25.

CHADDOCK, J.B.;NOERAGER, J.A. (1966). Evaporation of R12 in Horizontal Tube with Constant Wall Heat Flux. ASHRAE Transactions, v. 72, part I, p. 90-103.

CHADDOCK, P.E.; BUZARD, G. (1986) Film Coefficients for In-Tube Evaporation of Ammonia and R502 with and without Small Percentages of Mineral Oil. ASHRAE Transactions, N. 2935 (RP-224), p. 22-40.

CHAMRA, L.M.; WEBB, R.L.; RANDLETT, M.R. (1996). Advanced Micro-fin Tubes For Evaporation. International Journal of Heat and Mass Transfer, v. 39, N. 9, p. 18271838.

CHEN, J.C. (1966). Correlation for Boiling Heat Transfer to Saturated Fluids in Convective Flow. I\&EC Process Design and Development, p. 322-329.

CHIOU, C.B.; WANG, C.C.; LU, C.D.C. (1995). "Single-Phase Heat Transfer and Pressure Drop Characteristics of Micro-Fin Tubes." ASHRAE Transactions - v. 101, Part. 2, p. 1041-1048.

CHOI, J.Y.; KEDZIERSKI, M.A.; DOMANSKI, P.A. (1999). "A Generalized Pressure Drop Correlation for Evaporating and Condensation of Alternative Refrigerants in Smooth and Micro-Fin Tubes." NIST - IR - 633. Gaithersburg, MD 20899.

COLLIER, J.G. (1981). Convective Boiling and Condensation, 2nd Edition, McGraw-Will, New York.

COLLIER, J.G.; THOME, J.R. (1996). Convective Boiling and Condensation, 3th Edition, Oxford Science Publications, New York.

COOPER, M. G. (1989). Flow Boiling-The Apparently Nucleate Regime._International Journal of Heat and Mass Transfer, v. 32, N. 3, p.459-464.

DARABI, J.; SALEHI, M.; SAEEDI, M.H.; OHADI, M.M. (1995). Review of Available Correlation for Prediction of Flow Boiling Heat Transfer in Smooth and Augmented Tubes. ASHRAE Transactions, v. 101, part 1, p. 965-975.

DENGLER, C.E.; ADDOMS, J.N. (1956). Heat Transfer Mechanism for Vaporization of Water Tube. Chemical Engineering Progress Symp jsium Series, v. 52, N. 18, p. 95-103.

DITTUS, F.W.; BOELTER, L.M.K. (1930). University of California Publications on Engineering, v. 2, N. 13, p. 443.

ECKELS, S.J.; PATE, M.B. (1990). A Comparison of R-134a and R12 in Tube Heat Transfer Coefficient Based on Existing Correlations. ASHRAE Transactions, v. 96, Part I, p. 256-265. 
ECKELS, S.J.; PATE, M.B.; BEMISDERFER, C.H. (1992). Evaporation Heat Transfer Coefficients for R22 in Micro-fin Tubes of Different Configurations., Enhanced Heat Transfer, ASME, HTD- v. 202, p. 117-125.

FOSTER, H.K.; ZUBER, N. (1955). Dynamics of Vapor Bubbles and Boiling Heat Transfer. American Institute Chemical Engineering Journal, v. 1, N. 4, p. 531-535.

GNIELINSKI, V. (1976). New Equations for Heat and Mass Transfer in Turbulent Pipe and Channel Flow. International Chemical Engineering, v. 16, N. 2, p. 359-368.

GROOTHUIS, H.; HENDAL, W.P. (1959). Heat Transfer in Two-Phase Flow. Chemical Engineering Science. v. 11, N 3, p. 212-220.

GUERRIERI, S.A.; TALTY, R.D. (1956). A Study of Heat Transfer Organic Liquids in Single Tube, Natural Circulation, Vertical Tube Boilers. Chemical Engineering Progress Symposium Series, v. 52, N.18, p. 69-77.

GUNGOR, K. E.; WINTERTON, R.H.S. (1986). A General Correlation for Flow Boiling in Tubes and Annuli. International Journal Heat Mass Transfer, v. 9, N. 1, p. 351-358.

HA, S.; BERGLES, A.E. (1993). The Influence of the Oil on Local Evaporation Heat Transfer Inside a Horizontal Microfin Tube. ASHRAE Transactions, v. 99, p. 1244-1255.

HAMBRAEUS, K. (1991). Two Phase Flow Boiling of Oil-HFC134a Mixture . XVIII $I^{\text {th }}$ International Congress of Refrigeration. Paper 91.

HAMBRAEUS, K. (1993). Flow Boiling of Pure and Oil Contaminated Refrigrants. Doctoral Thesis, The Royal Institute of Technology at Stockholm.

HAMBRAEUS, K. (1995). Heat Transfer of Oil-contaminated HCFC134a in a Horizontal Evaporator. International journal of Refrigeration, v. 18, N. 02, p. 87-99.

HOYER, N. (1998). Calculation of Dryout and Post-Dryout Heat Transfer for Tube Geometry. International Journal of Multiphase Flow. v. 24, N. 2, p. 319-334.

INCROPERA, F.P.; DE WITT, D.P. (1990). Fundamentos de Transferência de Calor e de Massa. $3^{\mathrm{a}}$ Edição, Guanabara Koogan, Capítulo 8, Escoamento Interno. p. 213-231.

INCROPERA, F.P.; DE WITT, D.P. (1994). Fundamentos de Transferência de Calor e de Massa. $4^{\text {a }}$ Edição, Livros Técnicos e Científicos Editora, Capítulo 8, Escoamento Interno. p. 213-231.

ITO, R; KIMURA, W. (1979). Boiling Heat Transfer and Pressure Drop in Internal SpiralGrooved Tubes. Bulletin of the JSME, v.22, N. 171, p. 1251-1257.

JOHNSTON, J.R.; CHADDOCK, J.B. (1966). Heat Transfer and Pressure Drop of Refrigerants Evaporating in Horizontal Tubes. ASHRAE $71^{\text {st }}$. Annual Meeting, Cleveland, Ohio.

JUNG, D.S.; RADERMACHER, R. (1989). "Prediction of Pressure Drop During Horizontal Annular Flow Boiling of Pure and Mixed Refrigerants," International Journal of Heat and Mass Transfer, Vol. 32, No. 12, pp. 2435-2446. 
JUNG, D.S.; RADERMAKER, R. (1991). Prediction of Heat Transfer Coefficient of Various Refrigerants During Evaporation. ASHRAE Transactions - v. 97, p. 3492-3497.

KAJI, M., MORI, K., NAKANISHI, S., HIRABAYASHI, K, OHISHI, M. (1995). Dryout and Wall-Temperature Fluctuations in Helically Coiled Evaporating Tubes. Heat Transfer-Japanese Research. v. 24, N. 3, p. 239-254.

KAKAÇ, .S.; BHATTI, M.; SHAH, R. (1986). Handbook of Single Phase Convective Heat Transfer. John Wiley \& Sons.

KANDLIKAR, S.G. (1990). A General Correlation for Saturated Two-Phase Flow Boiling Heat Transfer Inside Horizontal and Vertical Tubes. Journal of Heat Transfer. Transaction of the ASME, v. 112, p. 219-228.

KANDLIKAR, S.G.; RAYKOFF, T. (1997). Predicting Flow Boiling Heat Transfer of Refrigerants in Microfin Tubes. Journal of Enhanced Heat Transfer, v. 4, p. 257-268.

KATTAN, N. (1996). Contribuition to the Heat Transfer Analysis of Substitute Refrigerants in Evaporator Tube with Smooth or Enhanced Tube Surfaces. Doctoral Thesis, École Polytechnique Fédérale de Lausanne.

KATTAN, N.; THOME, J.R.; FAVRAT, D. (1998). Flow Boiling in Horizontal Tubes: Part 1- Development of a Diabatic Two-Phase Flow Pattern Map. Journal of Heat Transfer. Transaction of the ASME, v. 120, N. 1, p. 140-147.

KATAN, N.; THOME, J.R.; FAVRAT, D. (1998). Flow Boiling in Horizontal Tubes: Part 2New Heat Transfer Data for Five Refrigerants. Journal of Heat Transfer. Transaction of the ASME, v. 120, N. 1, p. 148-155.

KATTAN, N.; THOME, J.R.; FAVRAT, D. (1998). Flow Boiling in Horizontal Tubes: Part 3- Development of a New Heat Transfer Model Based on Flow Pattern. Journal of Heat Transfer. Transaction of the ASME, v. 120, N. 1, p. 156-165.

KHANPARA, J.C., BERGLES, A. E.; PATE, M.B. (1986). Augmentation of R113 in-Tube Evaporation with Micro-fin Tubes. ASHRAE Transactions Part 2B, p. 506-524.

KHANPARA , J.C., BERGLES, A. E.; PATE, M.B. (1987). A Comparison of In-Tube Evaporation of Refrigerant R-113 in Electrically Heated and Fluid Heated Smooth and Microfin Tubes. Advances in Enhanced Heat Transfer. ASME HTD. v.68, p. 35-46.

KOYAMA, S.; YU, J.; MOMOKI, S.; FUJII, T.; HONDA, H. (1995). Forced Convective Flow Boiling Heat Transfer of Pure Refrigerants Inside a Horizontal Microfin Tube. Proceedings of Convective Flow Boiling, An International Conference Held at the Banff Center for Conferences, Banff, Alberta, Canada, p. 137-142.

KUO, C.S.; WANG, C.C. (1996). Horizontal Flow Boiling of R22 and R407C in a $9.52 \mathrm{~mm}$ Micro-fin Tube. Applied Thermal Engineering, v. 16, Nos. 8/9, p. 719-731.

KUO, C.S.; WANG, C.C.; CHENG, W.Y.; LU, D.C. (1995). Evaporation of R22 in a $7 \mathrm{~mm}$ Micro-fin Tube. ASHRAE Transactions, v. 101, Part 2, p. 1055-1061.

KUTATELADZE, S. S. (1961). Boiling Heat Transfer. International Journal of Heat and Mass Transfer, v. 4, N. 1, p. 31-45. 
LAVIN, J.G. (1963). Heat Transfer to Refrigerants Boiling Inside Plain Tubes and Tubes with Internal Turbulators. Doctoral Thesis, University of Michigan.

LIMA, C.U.S. (2000). "Ebulição Convectiva de Refrigerantes Halogenados Escoando no Interior de Tubos Horizontais de Cobre". Tese (Doutorado) - Escola de Engenharia de São Carlos, Universidade de São Paulo. 167 p.

LIU, Z.; WINTERTON, H.S. (1991). A General Correlation for Saturated and Subcooled Flow Boiling in Tubes and Annuli, Based on a Nucleate Pool Boiling Equation. Journal of Heat and Mass Transfer, v. 34, N. 11, p. 2759-2766.

LOMBARDI, G. (1983). Sistema de Confecção, Aferição e Implantação de Pares Termoelétricos. Anais do VII Congresso Brasileiro de Engenharia Mecânica Uberlândia $-M G$. A-7, p. 63-74.

LOCKHART, R.W.; MARTINELLI, R.C. (1949). Proposed Correlation of Data for Isothermal Two Phase, Two Component Flow in Pipes. Chemical Engineering Process, v. 45, N. 1, p. $39-48$.

McADAMS, W.H. (1954). Heat Transmission, 3rd Edition, Editora McGraw-Hill, New York.

MACBAIN, S.M.; BERGLES, A.E. (1995). Heat Transfer and Pressure Drop Characteristics of Forced Convective Evaporation in Deep Spirally Fluted Tubing. Proceedings of Convective Flow Boiling, An International Conference Held at the Banff Center for Conferences, Banff, Alberta, Canada, p. 143-148.

MACBAIN, S.M.; BERGLES, A.E.; RAINA, S. (1997). Heat Transfer and Pressure Drop Characteristics of Flow Boiling in Horizontal Deep Spirally Fluted Tube. International Journal of Refrigeration, v. 3, N. 1, p. 65-80.

MOFFAT, R J. (1988). Describing the Uncertainties in Experimental Results. Experimental Thermal and Fluid Science, v. 1, p. 3-17.

MURATA, K.; HASHIZUME, K. (1993). Forced Convective Boiling of Nonazeotropic Refrigerant Mixtures Inside Tubes. Journal of Heat Transfer, v. 115, p. 680-688.

MUZZIO, A, NIRO, A.; AROSIO, S. (1997). Heat Transfer and Pressure Drop During Evaporation and Condensation of R-22 Inside 9,52-mm O.D. Microfin Tubes of Different Geometries. Journal of Enhanced Heat Transfer, v. 5, p. 39-52.

NIDEGGER, E.; THOME. J.R.; FAVRAT, D. (1997). Flow Boiling and Pressure Drop Measurements for R-134a/Oil Mixtures - Part 1: Evaporation in Microfin Tube. International Journal of Refrigiration, v. 3, N. 1, p. 38-53.

NISHIKAWA, K.; FUJITA, Y.; OHTA, H.; HIDAKA, S. (1982). Effect of the Surface Roughness on the Nucleate Boiling Heat Transfer Over the Wide Range of Pressure. Proc. $7^{\text {th }}$ International Heat Transfer Conf., v. 4, p. 61-66.

PALM, B. (1991). Enhancement of Boiling Heat Transfer by Aid of Perforated Metal Foils. Doctoral Thesis, The Royal Institute of Technology at Stockholm. 
PANEK, J. (1992). Evaporation Heat Transfer and Pressure Drop in Ozone-Safe Refrigerants and Refrigerantt-Oil Mixtures. M.S. Thesis, University of Illinois at UrbanaChampaign.

PETUKHOV, B.S. (1970). Heat Transfer and Friction in Turbulent Pipe Flow with Variable Physical Properties. Advances in Heat Transfer, Irvine, T.F. et al, v. 6, p. 503-564.

PIERRE, B. (1956). Coefficient of Heat Transfer for Boiling Freon-12 in Horizontal Tubes. Heating and Air Treatment Engineer, v. 19, p. 302-310.

REID, R.S.; PATE, M.B.; BERGLES, A.E. (1991). A Comparison of Augumentation Techniques During In-Tube Evaporation of R-113. Journal of Heat Transfer, Transaction of the ASME, v. 113, p. 451-458.

RHEE, B.W. (1972). Heat-Transfer to Boiling Refrigerants R-12 and R-22 Flowing Inside a Plain Copper Tube. Doctoral Thesis, University of Michigan.

ROSS, H.; RADERMACHER, R; MARZO, M.D.; DIDION, D. (1987). Horizontal Flow Boiling of Pure and Mixed Refrigerants . International Journal of Heat and Mass Transfer, v. 30, N. 5, p. 979-992.

SAIZ JABARDO, J.M. (1976). Dinâmica de Evaporadores Resfriadores de ar. São Paulo, 1976. 124p. Dissertação (Mestrado) - Escola Politécnica, Universidade de São Paulo.

SAIZ JABARDO, J.M. (1988). Transferência de Calor em Escoamentos Bifásicos. Apostila da Escola Politécnica da Universidade de São Paulo.

SAIZ JABARDO, J.M. (1995). Transferência de Calor em Escoamentos Bifásicos. Notas de Aula.

SAIZ JABARDO, J.M.; BANDARRA FILHO, E. P.;LIMA, C. U. S. (1999). A New Correlation for Convective Boiling of Pure Halocarbon Refrigerants Flowing in Horizontal Tubes. RBCM, The Brazilian Journal of Mechanical Sciences. 21(2), 245 258 .

SAIZ JABARDO, J.M.; BANDARRA FILHO, E.P. (2000). Convective Boiling of Halocarbon Refrigerants Flowing in a Horizontal Copper Tube - An Experimental Study. Experimental Thermal and Fluid Science, Vol. 23, pp. 93-104.

SAIZ JABARDO, J.M.; BANDARRA FILHO, E.P; MACEDO, R. (2000). Desempenho do Refrigerante R-134a no Interior de Tubos de Cobre Internamente Ranhurados.; Revista Tecnologia da Refrigeração, RPA Editora, Vol. 1, No. 2, Outubro 2000, p. 22-37.

SAIZ JABARDO, J.M. (2001). Apostila sobre Fluidos Refrigerantes. Laboratório de Fefrigeração - Escola de Engenharia de São Carlos - USP.

SCHLAGER, L.M.; PATE, M.B.; BERGLES, A.E. (1988). Evaporation and Condensation of Refrigerant-Oil Mixtures in a Smooth Tube and a Micro-fin Tube. ASHRAE transactions, v. 94, p. 149-168.

SCHROCK, V.E.; GROSSMAN, L.M. (1962). Forced Convection Boiling in Tubes. Nuclear Science and Engineering, v. 12, p. 474-481. 
SEO, K.; KIM, Y. (2000). Evaporation heat transfer and pressure drop of R-22 in 7 and $9.52 \mathrm{~mm}$ smooth/micro-fin tubes. International Journal of Heat and Mass Transfer. v. 43, N. 16, p. $2869-2882$.

SHAH, M.M. (1976). A New Correlation for Heat Transfer During Boiling Flow Through Pipes. ASHRAE Transactions, v. 82, p. 66-86.

SHAH, M.M., (1982). Chart Correlation for Saturated Boiling Heat Transfer: Equations and Further Study. ASHRAE Transactions, v. 88, N. 1, p. 185-196.

SINGH, A.; OHADI, M.M.; DESSIATOUN, S. (1996). Flow Boiling Heat Transfer Coefficients of R-134a in a Microfin Tube. Journal of Heat Transfer, Transaction of the $A S M E$, v. 118 , p. 497-499.

SOUZA, A.M.; PIMENTA, M.M. (1995). Prediction of Pressure Drop During Horizontal Two-Phase Flow of Pure and Mixed Refrigerants ASME - Symposium on Cavitation and Multiphase Flow, v. 210, p. 167-171.

STEINER, D.; TABOREK, J. (1992). Flow Boiling Heat Transfer in Vertical Tubes Correlated by an Asymptotic Model. Heat Transfer Engineering, v. 13, N. 2, p. 43-69.

STEPHAN, K.; ABDELSALAM, M., (1980). Heat-Transfer Correlation for Natural Convection Boiling. International Journal of Heat and Mass Transfer. v. 23, p. 73-87.

STHAPAK, B.K.; VARMA, H.K.; GUPTA, C.P. (1976). Heat Transfer Coefficient in DryOut Region of Horizontal Tube Water Heated R-12 Evaporator. ASHRAE Transactions, v. 82, N. 2 , p. $47-55$.

TAITEL, Y.; DUKLER, A. E. (1976). A Model for Predicting Flow Regime Transitions in Horizontal and Near Horizontal Gas-Liquid Flow. American Institute Chemical Engineering Journal, v. 22, N. 1, p. 47-55.

TAKAMATSU, H.; MIYARA, A.; KOIAMA, S; FUJII, T; YONEMOTO, K. (1988). Forced Convective Boiling Heat Transfer of Nonazeotropic Refrigerant Mixture of R22/R-114 Inside a Horizontal Tube. Transactions of the JSME, B, 54(505), p. 25232528 .

TAKAMATSU, H.; MOMOKI, S.; FUJII, T. (1991). A Comparison of Evaporation Heat Transfer Coefficients and Pressure Drop in a Horizontal Smooth Tube for HFC134a and CFC12; XVII International Congress of Refrigeration - Montreal.

TATSUMI, A.; OIZUMI, K.; HAYASHI, M. and ITO, M. (1982). "Application of Inner Groove Tubes to Air Conditioning". Hitachi Review. v. 32. N.1, p. 55-60.

TOJO, S.; HOSOKAWA, K.; AR'MOTO, T.; YAMADA, H. and OHTA, Y. (1984). "Performance Characteristics of Multigrooved Tubes For Air Conditioning." Australian Refrigeration Air Conditioning and Heating. August, 1984, p. 45-51.

TORIKOSHI, K.; EBISU, T. (1994). Heat Transfer and Pressure Drop Characteristics of R134a, R-32 and Mixture of R-32/R-134a Inside a Horizontal Tube, ASHRAE Transactions, v. 99, p. 90-96. 
VARMA, H.K. (1970). Experimental investigation of Dry-Out in Forced Convection Evaporation. Doctoral Thesis, Duke University.

WATTELET, J.P.; CHATO, J.C.; JABARDO, J.M.S.; PANEK, J.S.; RENIE, J.P. (1991). An Experimental Comparison of Evaporation Characteristics of HFC-134a and CFC-12. Proceedings, XVIII International Congress of Refrigeration.

WATTELET, J.P. (1994). Heat Transfer Flow Regimes of Refrigerants in a Horizontal-Tube Evaporator. Doctoral Thesis, University of Illinois at Urbana-Champaign.

WEBB, R.L. (1994). Principles of Enhanced Heat Transfer. New York, John Wiley \& Sons.

WEDEKIND, G.L. and STOECKER, W.F. (1968). Transient Response of the MixtureVapor Transition Point in Horizontal Evaporating Flow. Transactions of ASHRAE, v.72, p. IV 2.1-2.6.

ZAHN, W.R. (1964). A Visual Study of Two Phase Flow While Evaporating in Horizontal Tubes Transactions of the ASME, Journal of Heat Transfer, p. 417-429.

\section{Trabalhos Não Citados}

ALVES, G.E. (1954). Cocurrent Liquid-Gas Flow in a Pipe-Line Contactor. Chemical Engineering Progress. V. 50, N. 9, p. 449-456.

ANDRITSOS, N.; WILLIAMS, L.; HANRATTY, T.J. (1989). Effect of Liquid Viscosity on the Stratified-Slug Transition in Horizontal Pipe Flow. International Journal of Multiphase Flow, v. 15, N. 6, p. 877-892.

BANDARRA FILHO, E.P.; SAIZ JABARDO, J.M. e LIMA, C.U.S. (1998). Proposta de uma Nova Correlação para a Avaliação do Coeficiente de Transferência de Calor Bifásico em Tubos Horizontais. Congresso de Ar Condicionado, Refrigeração, Aquecimento e Ventilação do Mercosul - MERCOFRIO'98. 28-01 de Outubro, Porto Alegre - RS - Brasil.

BANDARRA FILHO, E.P.; SAIZ JABARDO, J.M. e LIMA, C.U.S. (1999). Estado da Arte das Correlações para a Determinação do Coeficiente de Transferência de Calor no Escoamento com Mudança de Fase de Refrigerantes, $I V$ - Congreso Iberoamericano de Ingeniería Mecánica - CIDIM'99, Novembro/1999, Santiago - Chile.

BANDARRA FILHO, E.P.; SAIZ JABARDO, I.M. e LIMA, C.U.S. (1999). Avaliação Experimental do Coeficiente de Transferência de Calor na Evaporação do HFC-134a em Tubos Horizontais, $I V$ - Congreso Iberoamericano de Ingeniería Mecánica - CIDIM'99, Novembro/1999, Santiago - Chile.

BANDARRA FILHO, E.P. e SAIZ JABARDO, J.M. (2000). Avaliação Experimental da Região de Secagem de Parede na Evaporação do Refrigerante R-134a em Tubos Horizontais. Congresso Nacional de Engenharia Mecânica - CONEM - Agosto/2000, Natal-RN. 
BANDARRA FILHO, E.P.; SAIZ JABARDO, J.M. e MACEDO, R. (2000). Avaliação do Desempenho Termo-Hidráulico do Refrigerante HFC-134a em Escoamento Monofásico no Interior de Tubos Microaletados., Congresso de Ar Condicionado, Refrigeração, Aquecimento e Ventilação do Mercosul - MERCOFRIO'2000. Outubro/2000, Porto Alegre - RS - Brasil.

BEJAN, A. (1996). Transferência de Calor. Edgard Blücher, Capítulo 8, Conveç̧ão com Mudança de Fase, p. 325-353.

BENNETT, G. L.; CHEN, J.C. (1980). Forced Convective Boiling in Vertical Tubes for Saturated Pure Components and Binary Mixtures. American Institute Chemical Engineering Journal, v. 26, N. 3, p. 454-461.

BERENSON, P.J.; STONE, R.A. (1965). A Photographic Study of the Mechanism of Forced Convection Vaporization. Chemical Engineering Progress Symposium Series. N. 57, p. 213-219.

BERGLES, A.E.; ROHSENOW, W.M. (1964). The Determination of Forced-Convection Surface-Boiling Heat Transfer. Journal of Heat Transfer - Transactions of the ASME, p. 365-372.

BERGLES, A.E.; FULLER; W.D.; HYNEK, S.J. (1971). Dispersed Flow Boiling of Nitrogen with Swirl Flow. International Journal of Heat and Mass Transfer, v. 14, N. 5, p. 1343-1354.

BERGLES, A.E. (1988). Some Perspectives on Enhanced Heat Transfer: Second Generation Heat Transfer Technology. ASME - Journal of Heat Transfer, v.110, N.4, p.1082-1096.

BJORGE, R. W.; HALL, G.R.; ROHSENOW, W.M. (1982). Correlation of Forced Boiling Heat Transfer Data. International Journal of Heat and Mass Transfer, v. 25, N. 6, p. 753-757.

BOYD, R.D.; SMITH, A.; MENG, X.; TURKNETT, J. (1994). Measurements of Local Heat Transfer for Forced Convection and Flow Boiling in Horizontal, Uniformly Heated Smooth Tubes. Experimental Heat Transfer, v. 7, p. 19-29.

BREVI, R.; CUMO, M. (1971). Quality Influence in Post-Burnout Heat Transfer. International Journal of Heat and Mass Transfer, v. 14, N. 2, p. 483-489.

CHAN, A.M.C. (1995). Stratified Flow Film Boiling Inside Horizontal Tubes. _Journal of Heat Transfer, v. 117, p. 179-184.

COLLIER, J.G.; WIKHAMMER, G.A.; MOECK, E.O.; MACDONALD, I.P.L. (1965). The Effect of Certain Geometrical Factors On Dryout for High Quality Stiam/Water Mixtures Flowing in a Vertical Internally Heated Annulus at $1000 \mathrm{lb} / \mathrm{sq}$. in. abs. Chemical Engineering Progress Symposium Series. N. 57, p. 192-204.

COOPER, M.G. (1992). Correlation for Nucleate Boiling-formulation Using Reduced Properties. PCH Physico Chemical Hydrodynamics, v. 3, N. 02, p. 89-111. 
D'YCHKOV, F.N. (1978). Investigation of Heat Transfer and Hydraulics for Boiling of Freon-22 in internally-Finned Tubes. Heat Transfer-Soviet Research, v.10, N.2, p. 1019.

ECKELS, S. J.; DOER, T. M.; PATE, M. B. (1994). In Tube Heat Transfer and Pressure Drop of R134a and Ester Lubricant Mixtures in Smooth Tube and a Micro-fin Tube: Part I - Evaporation. ASHRAE Transaction, v. 100, p. 265-282.

ECKELS, S.J.; PATE, M.B. (1991). In Tube Evaporation and Condensation of RefrigerantLubricant Mixtures of HFC-134a and CFC-12. ASHRAE Transactions, v. 97, N. 2, p. $62-71$.

GOUSE JR, S.W.; COUMOU, K.G. (1965). Heat Transfer and Fluid Flow Inside a Horizontal Tube Evaporator: Phase I. ASHRAE $72^{\text {nd }}$ Annual Meeting, Portland, Ore.

GOUSE JR, S.W.; DICKSON, A.J. (1966). Heat Transfer and Fluid Flow Inside a Horizontal Tube Evaporator: Phase II. ASHRAE Semiannual Meeting in Houston, Tex.

GRANRYD, E. (1991). Heat Transfer in Flow Evaporation of Azeotropic Refrigerant Mixtures - A Theatrical. Aproach XVIII International Congress of Refrigeration. Paper 251.

HIHARA, E.; TANIDA, K.; SAITO, T. (1989). Forced Convective Boiling Experiments of Binary Mixtures. JSME International Journal, Series II, v. 32, N. 1, p. 98-106.

HIHARA, E.; SAITO, T. (1995). Forced Convective Boiling Heat Transfer of Binary Mixtures in a Horizontal Tube. ASHRAE Transactions, v. 101.

HOOGENDOORN, C.J. (1959). Gas-Liquid Flow in Horizontal Pipes. Chemical Engineering Science. v. 9, N. 4, p. 205-217.

HSIEH, S.S.; WEN, M.Y. (1995). An Experimental Study of Flow Boiling Heat Transfer in Rib-Roughened Tube Annuli. Journal of Heat Transfer. Transaction of the ASME, v. 117, p. 185-194.

HUGHMARK, G.A. (1965). Heat Transfer in Horizontal Annular Gas-Liquid Flow. Chemical Engineering Progress Symposium Series. N. 57, p. 176-178.

JONES, J.H.; ALTMAN, M. (1965). Two-Phase Flow and Heat Transfer for Boiling Liquid Nitrogen in Horizontal Tubes. Chemical Engineering Progress Symposium Series. N. 57, p. 205-212.

JUNG, D.S.; McLINDEN, M.; RADERMACHER, R.; DIDION, D. (1989). A Study of Flow Boiling Heat Transfer with Refrigerant Mixtures. International Journal of Heat and Mass Transfer. v. 32, N. @, p. i751-1764.

JUNG,D.S.; McLINDEN, M.; RADERMACHER, R.; DIDION, D. (1989). Horizontal Flow Boiling Heat Transfer Experiments with Mixture of R22/R114. International Journal of Heat and Mass Transfer. v. 32, N. 1, p. 131-145.

KANDLIKAR, S.G. (1986). Flow Boiling Maps for Water, R22 and R134a in the Saturated Region. International Congress of Heat and Mass Transfer, Israel. 
KANDLIKAR, S.G. (1991). Development of a Flow Boiling Map for Subcooled and Saturated Flow Boiling of Different Fluids Inside Circular Tubes. Transactions of the $A S M E$, v. 113. p. $190-200$.

KANDLIKAR, S.G. (1998). Boiling Heat Transfer With Binary Mixtures: Part I - A Theoretical Model for Pool Boiling. Journal of Heat Transfer. Transaction of the $A S M E$, v. 120 , p. $380-387$.

KANDLIKAR, S.G. (1998). Boiling Heat Transfer With Binary Mixtures: Part II - Flow Boiling in Plain Tubes. Journal of Heat Transfer. Transaction of the ASME, v. 120, p. 388-394.

KANDLIKAR, S.G. (1998). Heat Transfer Characteristics in Partial Boiling, Fully Developed Boiling, and Significant Void Flow Regions of Subcooled Flow Boiling. Journal of Heat Transfer. Transaction of the ASME, v. 120, p. 395-401.

KANDLIKAR, S.G. (1998). Artwork - A Review of Research Work Done by Professor Arthur (Art) E. Bergles. Heat Transfer Engineering, v. 19, N. 3, p. 13-42.

KATTAN, N.; THOME, J.R.; FAVRAT, D. (1995). R502 and Two Near-Azeotropic Alternatives: Part I - In Tube Flow Boiling Tests. ASHRAE Transactions, v. 101.

KATTAN, N.; THOME, J.R.; FAVRAT, D. (1995). R502 and Two Near-Azeotropic Alternatives: Part II - Two Phase Flow Patterns ASHRAE Transactions, v. 101.

KENNING, D.B.R.; COOPER, M .G., (1989). Saturated Flow Boiling of Water in Vertical Tubes. International Journal of Heat and Mass Transfer, v. 32, N. 3, p. 445-458.

KLAUSNER, J.F.; MEI,R.; BERNHARD, D. M.; ZENG, L.Z., (1993). Vapor Bubble in Forced Convection Boiling. International Journal of Heat and Mass Transfer, v. 36, N. 3, p.651-662.

KLIMENKO, V.V. (1988). A Generalizes Correlation for Two-Phase Forced Flow Heat Transfer. International Journal of Heat and Mass Transfer, v. 31, N. 3, p. 541-552.

LAVERTY, W.F.; ROHSENOW, W.M. (1967). Film Boiling of Saturated Nitrogen Flowing in a Vertical Tube. Journal of Heat Transfer, Transaction of the ASME, p. 90-98.

LAVIN, J.G.; YOUNG, E.H. (1965). Heat Transfer to Evaporating Refrigerants in Two Phase Flow. American Institute Chemical Engineering Journal, v. 11, p. 1124-1132.

LIMA, C.U.S.; BANDARRA FILHO, E.P. e SAIZ JABARDO, J.M. (1999). Estudo Experimental do Coeficiente de Transferência de Calor na Evaporação do R-22 em Tubos Horizontais Aquecidos Eletricamente, $X V$ - Congresso Brasileiro de Engenharia Mes:ânica - COBEM'97, Novembro/1999, Águas de Lindóia - SP - Brasil.

LIN, P.Y.; HANRATTY, T.J., (1986). Prediction of Initiation of Slugs with Linear Stability Theory. International Journal of Multiphase Flow, v. 12, N.1, p. 79-98.

MELIN, P.; VAMLING, L. (1995). Flow Boiling Heat Transfer and Pressure Drop for HFC134a in a Horizontal Tube. International Journal of Refrigeration, v. 1, N. 3, p. 575-582. 
PIERRE, B. (1964). Flow Resistance with Boiling Refrigerants - Part I - ASHRAE Journal, v. 6, p. $58-65$.

PIERRE, B. (1964). Flow Resistance with Boiling Refrigerants - Part II - ASHRAE Journal, v. 6, p. $73-77$.

POLOMIK, E.E.; SAWOCHKA, S.G. (1964). Film Boiling of Steam-Water Mixtures in Annular Flow at 800, 1100, and 1400 Psi. Journal of Heat Transfer, Transaction of the ASME, p. 451-458.

QUANDT, E. (1965). Analysis of Gas-Liquid Flow Patterns. Chemical Engineering Progress Symposium Series. N. 57, p. 128-135.

ROHSENOW, W.M. (1952). A Method of Correlating Heat Transfer Dada for Surface Boiling of Liquids. ASME Transactions, v. 74, p. 969-976.

ROHLIN, P. (1995). Heat Transfer Coefficients in Horizontal Flow Boiling of Some Pure Refrigerants and Their Zeotropic Mixtures: Experimental and Theorical Results. p. 583590 .

RUDER, Z.; HARANTTY, P.J.; HARANTTY, T.J. (1989). Necessary Conditions for the Existence of Stable Slugs. International Journal Multiphase Flow, v. 15, N. 2, p. 209226.

SAIZ JABARDO, J.M.; BANDARRA FILHO, E. P. and LIMA, C. U. S. (1999) Bancada para Avaliação do Desempenho Térmico de Refrigerantes Halogenados em Ebulição Convectiva no Interior de Tubos Horizontais - Discussão de Resultados Envolvendo a Perda de Carga, $V$ - Congresso Ibero Americano de Ar Condicionado e Refrigeração CIAR'99, Outubro/1999, Lisboa - Portugal.

SCHLAGER, L.M.; PATE, M.B.; BERGLES, A.E. (1989). Performance of Micro-Fin Tubes with Refrigerant-22 and Oil Mixtures. ASHRAE Journal, p. 17-28.

STEPHAN, K. (1995). Two Phase Heat Exchange for New Refrigerants and Their Mixtures. International journal of Refrigeration, v. 18, N. 03, p. 198-209.

STYUSHIN, N.G. (1981). Forced-Convection Heat Transfer to Boiling Liquids . Heat Transfer-Soviet Research, v. 13, N. 1, p. 84-92.

TAKAMATSU, H.; MOMOKI, S.; FUJII, T. (1993). A Correlation for Forced Convective Boiling Heat Transfer of Pure Refrigerants in a Horizontal Smooth Tube. International Journal of Heat and Mass Transfer, v. 36, N. 13. p. 3351-3360.

TAKAMATSU, H.; MOMOKI, S.; FUJII, T. (1993). A Correlation for Forced Convective Boiling Heat Tratsfer of Nonazeotiopic Refrigerant Nixture of HCFC22/CFC114 in a Horizontal Smooth Tube. International Journal of Heat and Mass Transfer, v. 36, N. 14. p. 3355-3363.

THOME, J.R. (1995). Flow Boiling of Refrigerant-Oil Mixtures: A Current Review. Proceedings of Convective Flow Boiling, An International Conference held at Banff Center for Conferences, Banff, Alberta, Canada. p. 285-290. 
THOME, J.R.; KATTAN, N.; FAVRAT, D. (1995). Boiling of Two Zeotrope Mixtures and R-502 Inside a Plain Horizontal Tube. p. 565-575.

THONON, B.; FELDMAN, A.; MARGAT, L.; MARVILLET, C. (1997). Transition From Nucleate Boiling to Convective Boiling in Compact Heat Exchangers. International Journal of Refrigeration, v. 20, N. 8, p. 592-597.

TICHY, J.A.; DUVAL, W.M.B.; MACKEN, N.A. (1985). An Experimental Investigation of Heat Transfer in Forced-Convection Evaporation of Oil-Refrigerant Mixtures. p. 450460.

YOSHIDA, S.; MATSUNAGA, T.; HONG, H.P.; MIYAZAKI, M. (1991). An a Experimental Investigation of Oil Influence on Heat Transfer to a Refrigerant Inside Horizontal Evaporator Tubes. p. 112-129.

WADEKAR, V.V. (1986). Flow Boiling - A Simple Correlation for Convective Heat Transfer Component. Thermal Hydraulics Division, Harwell Laboratory, Oxifordshire, $U K$. Israel.

WADEKAR, V.V. (1991). Vertical Slug Flow Heat Transfer with Nucleate Boiling. Phase Change Heat Transfer, ASME, HTD, v. 159, p. 157-161.

WANG, C.C.; CHIANG, C.S. (1997). Two-Phase Heat Transfer Characteristics for R-22/R407C in a $6.5-\mathrm{mm}$ Smooth Tube. International Journal of Heat and Fluid Flow, v. 18, p. 550-558.

WATTELET, J.P.; CHATO, J.C.; SOUZA, A.L.; CHRISTOFFERSEN, B.R. (1992). Evaporative Characteristics of R12, R134a, and Mixture at Low Mass Fluxes. ASHRAE Transitions Symposia, N.94-2-1, p.603-615.

ZURCHER, O.; THOME, J.R.; FAVRAT, D. (1997). Flow Boiling and Pressure Drop Measurements for R-134a / Oil Mixtures Part 2: Evaporation in Plain Tube. Heating, Ventilating, Air Condictioning and Refrigeration Research, v. 3, N. 1, p. 54-64. 


\section{APÊNDICE - I $\rightarrow$ CALIBRAÇÃO DOS INSTRUMENTOS}

\section{Termopares}

Os termopares foram calibrados utilizando como referência um conjunto de termômetros de precisão e um banho termostático. $\mathrm{O}$ processo de calibração consistiu na inserção dos termopares e do termômetro de precisão em um banho termostático. Desse modo, levantou-se a faixa de temperatura utilizada nos ensaios, no caso, foram utilizados cinco termopares e a faixa de temperatura variou entre -10 e $50^{\circ} \mathrm{C}$. A temperatura fornecida pelo termômetro de precisão foi considerada a real, $\mathrm{T}_{\text {Real }}$.

Adotou-se, para as incertezas associadas às medições, um valor baseado no desvio padrão apresentado pela regressão linear da referida relação de temperaturas. A curva e os dados de calibração, bem como a descrição dos equipamentos utilizados neste procedimento são apresentadas a seguir.

A regressão linear da curva apresentada na Fig. AI.1 proporcionou a seguinte relação:

$$
\mathrm{T}_{\text {Termopar }}=0,0358+0,9989 . \mathrm{T}_{\text {Real }}
$$

Ou simplificando, resulta:

$$
\mathrm{T}_{\text {Termopar }}=0,014+1,0 . T_{\text {Real }}
$$

Considerando uma distribuição normal para os desvios, as incertezas nas medidas de temperaturas serão assumidas como duas vezes o desvio padrão e considerando um intervalo de confiança de $95 \%$. Assim,

Desvio Padrão: $\sigma=0,096^{\circ} \mathrm{C}$

$$
\delta \mathrm{T}: 2 \cdot \sigma=0,192^{\circ} \mathrm{C} \cong 0,2^{\circ} \mathrm{C}
$$

Nessas condições, pode-se considerar a seguinte relação para a medida de temperatura: 
$\mathbf{T}_{\text {Real }}=\mathbf{T}_{\text {Termopar }} \pm \mathbf{0 , 2 ^ { \circ } \mathrm { C }}$

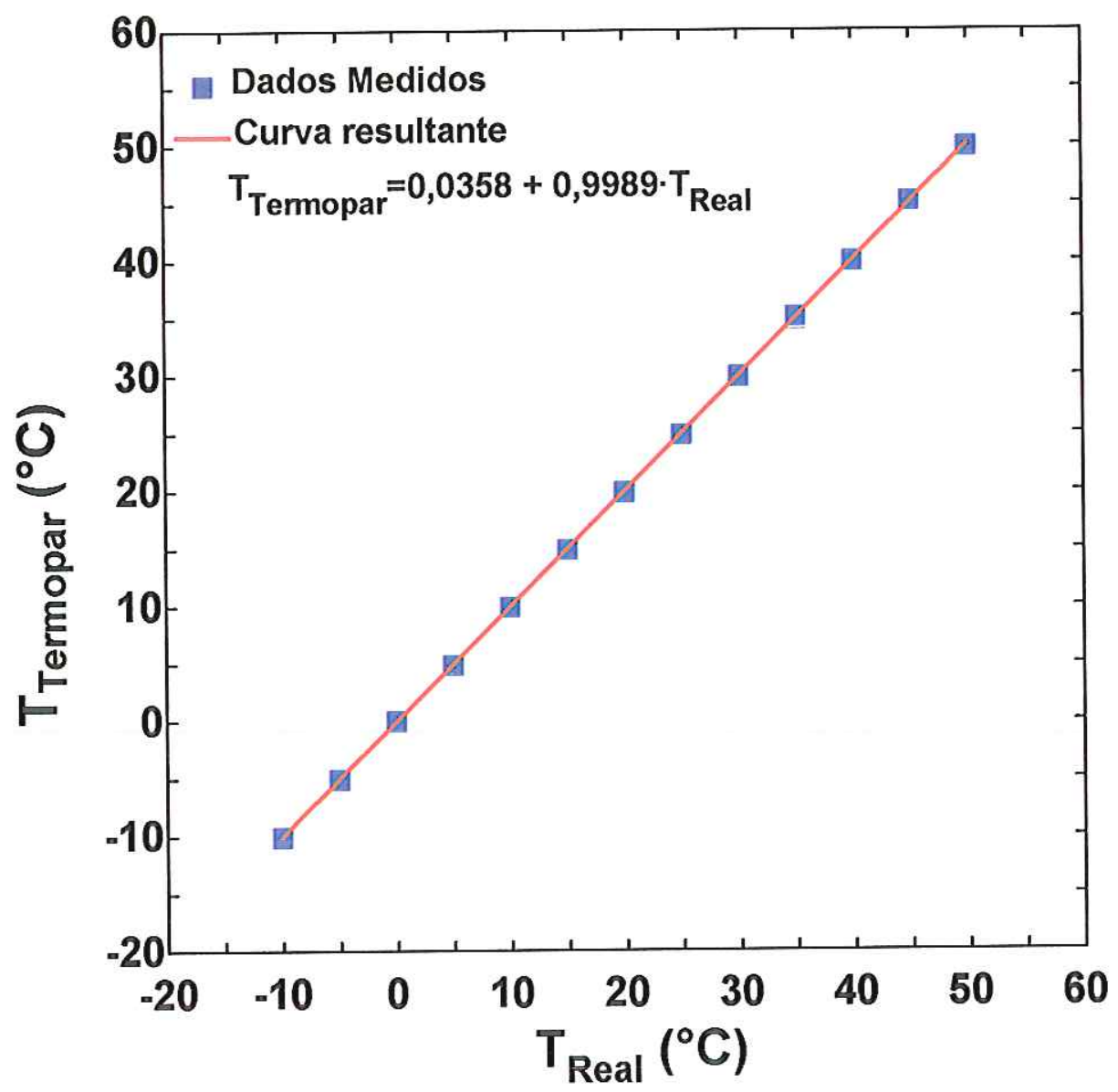

Figura AI.1 Curva de calibração dos termopares.

Tabela AI.1 Dados medidos pelos termopares e termômetro de precisão.

\begin{tabular}{|c|c|c|c|c|c|}
\hline $\mathbf{T}_{\text {Real }}$ & Termopar 1 & Termopar 2 & Termopar 3 & Termopar 4 & Termopar 5 \\
\hline $\mathbf{- 1 0 ^ { \circ } \mathbf { C }}$ & $-9,9$ & $-9,95$ & $-9,87$ & $-9,91$ & $-10,03$ \\
\hline $\mathbf{- 5}^{\circ} \mathbf{C}$ & $-5,01$ & $-4,93$ & $-4,92$ & $-4,99$ & $-5,02$ \\
\hline $\mathbf{0}^{\circ} \mathbf{C}$ & 0,05 & 0,12 & 0,19 & $-0,02$ & 0,07 \\
\hline $\mathbf{5}^{\circ} \mathbf{C}$ & 5,04 & 5,08 & 5,02 & 4,98 & 4,92 \\
\hline $\mathbf{1 0}^{\circ} \mathbf{C}$ & 10,05 & 10,12 & 10,15 & 10,01 & 9,96 \\
\hline $\mathbf{1 5}^{\circ} \mathbf{C}$ & 14,98 & 15,05 & 15,1 & 14,82 & 14,92 \\
\hline $\mathbf{2 0}^{\circ} \mathbf{C}$ & 19,96 & 19,94 & 20,05 & 20,1 & 19,89 \\
\hline $\mathbf{2 5}^{\circ} \mathbf{C}$ & 24,93 & 24,87 & 25,06 & 25,11 & 24,9 \\
\hline $\mathbf{3 0}^{\circ} \mathbf{C}$ & 30,09 & 30,08 & 29,9 & 29,88 & 29,93 \\
\hline $\mathbf{3 5}^{\circ} \mathbf{C}$ & 35,08 & 35,04 & 34,99 & 34,87 & 35,15 \\
\hline $\mathbf{4 0}^{\circ} \mathbf{C}$ & 40,18 & 40,13 & 39,91 & 39,82 & 39,93 \\
\hline $\mathbf{4 5}^{\circ} \mathbf{C}$ & 44,96 & 45,06 & 45,16 & 44,89 & 45,13 \\
\hline $\mathbf{5 0}^{\circ} \mathbf{C}$ & 50,09 & 50,14 & 49,86 & 49,92 & 49,83 \\
\hline
\end{tabular}




\section{Termômetros de Referência}

Foram utilizados três termômetros de bulbo de mercúrio com rastreabilidade NIST, um para cada faixa de temperatura:

- Faixa de -35 a $25^{\circ} \mathrm{C}$

- Fabricante: OMEGA; Modelo: 3543Y

- Resolução: $0,1^{\circ} \mathrm{C}$

- Faixa de 20 a $60^{\circ} \mathrm{C}$

- Fabricante: OMEGA; Modelo: 3570Y

- Resolução: $0,1^{\circ} \mathrm{C}$

- Banho Termostático

- Fabricante: HAAKE; Modelo: F6-C35

- Resolução: $0,01^{\circ} \mathrm{C}$

- Faixa de utilização: -60 a $250^{\circ} \mathrm{C}$

\section{Transdutores de Pressão}

No início da operação, os transdutores foram calibrados no Laboratório de Fenômeno de Transporte do Departamento de Hidráulica e Saneamento da EESC, utilizando um calibrador de peso morto e um multímetro digital. Tais resultados podem ser encontrados em LIMA (2000). Posteriormente, os transdutores de pressão foram calibrados no Laboratório de Refrigeração da EESC, utilizando um manômetro de coluna de mercúrio e um multímetro digital de precisão. Na fig. AI.2, são mostrados os resultados da calibração, incorporando as curvas resultantes da regressão dos pontos.

A Tabela AI.2 apresenta os valores obtidos na calibração dos transdutores 1 e 2, entrada e saída da seção de testes, respectivamente.

$$
\begin{aligned}
& P_{\text {Transdutor-1 }}=616,21 . \mathrm{i}-2444,9 \\
& P_{\text {Transdutor-2 }}=616,56 . \mathrm{i}-2467,5
\end{aligned}
$$




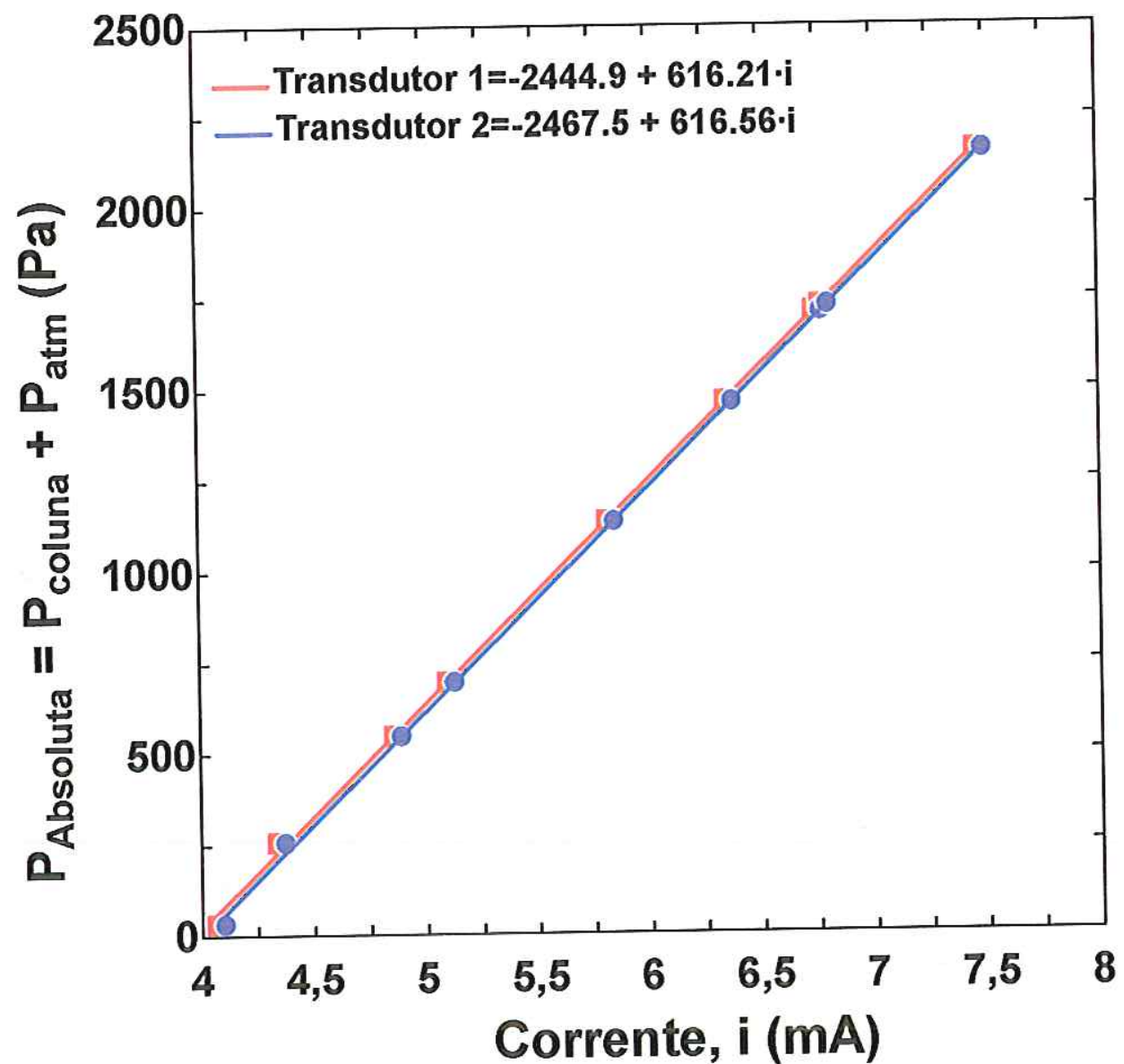

Figura AI.2 Curva de calibração dos transdutores de pressão.

Tabela AI.2 Dados medidos pelos transdutores de pressão e multímetro.

\begin{tabular}{|c|c|c|}
\hline Pressão Absoluta (kPa) & Transdutor 1 (mA) & Transdutor 2 (mA) \\
\hline $\mathbf{6 9 8}$ & 5,133 & 5,1 \\
\hline $\mathbf{2 1 5 5}$ & $\mathbf{7 , 5 0 2}$ & 7,469 \\
\hline $\mathbf{1 7 1 2}$ & 6,775 & 6,742 \\
\hline $\mathbf{1 4 6 6}$ & 6,379 & 6,346 \\
\hline $\mathbf{1 1 4 0}$ & 5,851 & 5,818 \\
\hline $\mathbf{6 9 8}$ & 5,132 & 5,099 \\
\hline $\mathbf{1 1 3 8}$ & 5,847 & 5,814 \\
\hline $\mathbf{1 4 6 5}$ & 6,378 & 6,345 \\
\hline $\mathbf{1 7 2 9}$ & 6,805 & 6,773 \\
\hline $\mathbf{2 1 5 5}$ & 7,502 & 7,469 \\
\hline $\mathbf{3 5 , 0 5}$ & 4,105 & 4,07 \\
\hline $\mathbf{2 5 8 , 1}$ & 4,376 & 4,341 \\
\hline
\end{tabular}

As especificações dos transdutores de pressão utilizados no presente trabalho foram apresentadas no capítulo 3 . 


\section{Transdutor Diferencial de Pressão}

O procedimento utilizado para a calibração do transdutor diferencial de pressão foi similar àquele verificado para o transdutor de pressão. Assim, a Fig. AI.3 ilustra os dados e a curva resultante da calibração do transdutor diferencial de pressão. Tais resultados podem ser encontrados na Tabela AI.3.

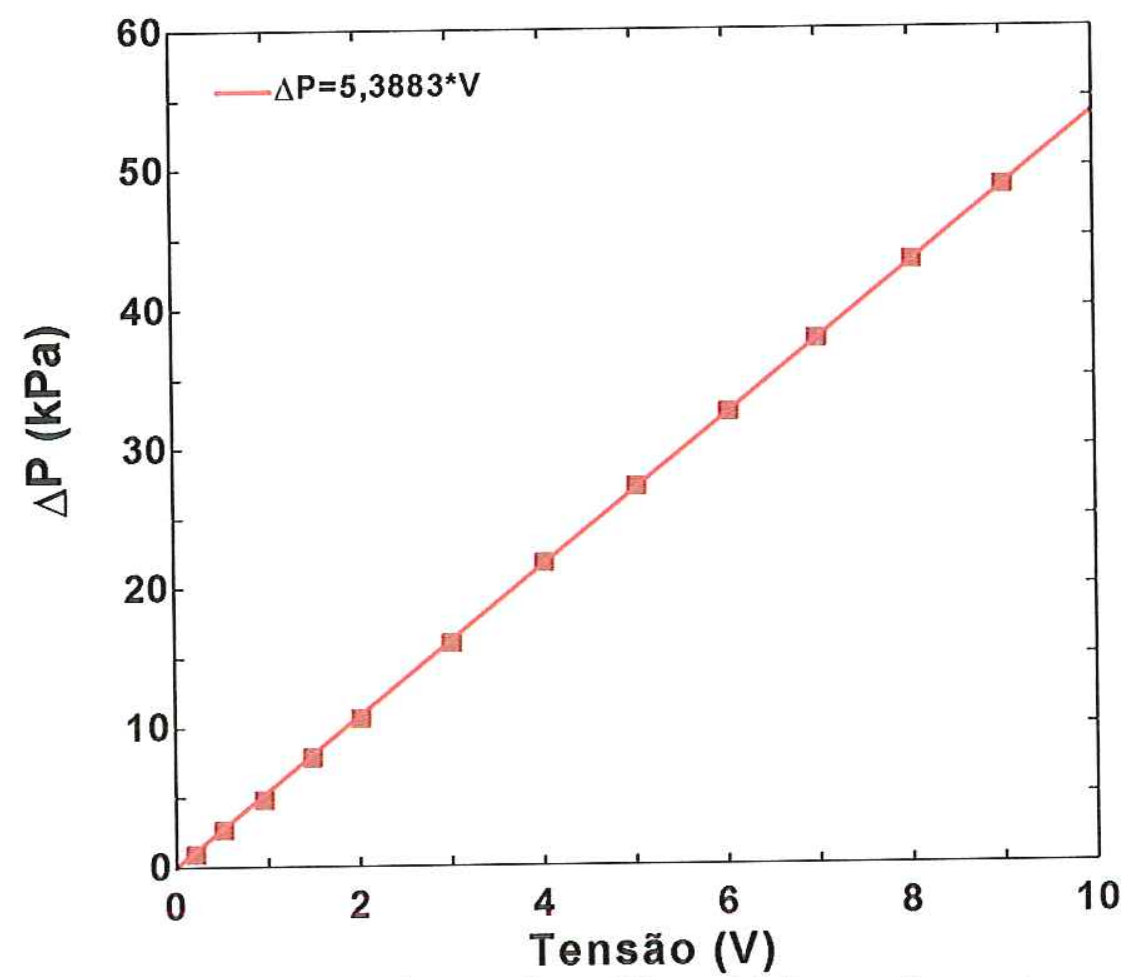

Figura AI.3 Curva de calibração do transdutor diferencial de pressão.

Tabela AI.3 Dados medidos pelo transdutor diferencial de pressão e multímetro.

\begin{tabular}{|c|c|}
\hline Diferença de Pressão $\mathbf{( k P a )}$ & Tensão (V) \\
\hline 0 & 0 \\
\hline 0,2167 & 0,9333 \\
\hline 0,5227 & 2,6665 \\
\hline 0,9598 & 4,7996 \\
\hline 1,496 & 7,866 \\
\hline 2,025 & 10,6658 \\
\hline 3,009 & 15,9987 \\
\hline 4,026 & 21,7316 \\
\hline 5,036 & 27,1978 \\
\hline 6,036 & 32,5307 \\
\hline 6,998 & 37,7302 \\
\hline 8,038 & 43,3298 \\
\hline 9,033 & 48,6627 \\
\hline 10 & 53,9956 \\
\hline
\end{tabular}




\section{Medidor de Vazão}

O medidor de vazão utilizado na medição é do tipo Coriolis e foi calibrado no Laboratório de Vazão do Instituto de Pesquisas Tecnológicas da Universidade de São Paulo, cuja folha de calibração é dada a seguir. Assim, a incerteza adotada foi de $0,15 \%$ do valor medido, correspondente ao valor indicado no catálogo do fabricante.

\section{Erros em função da vazão}

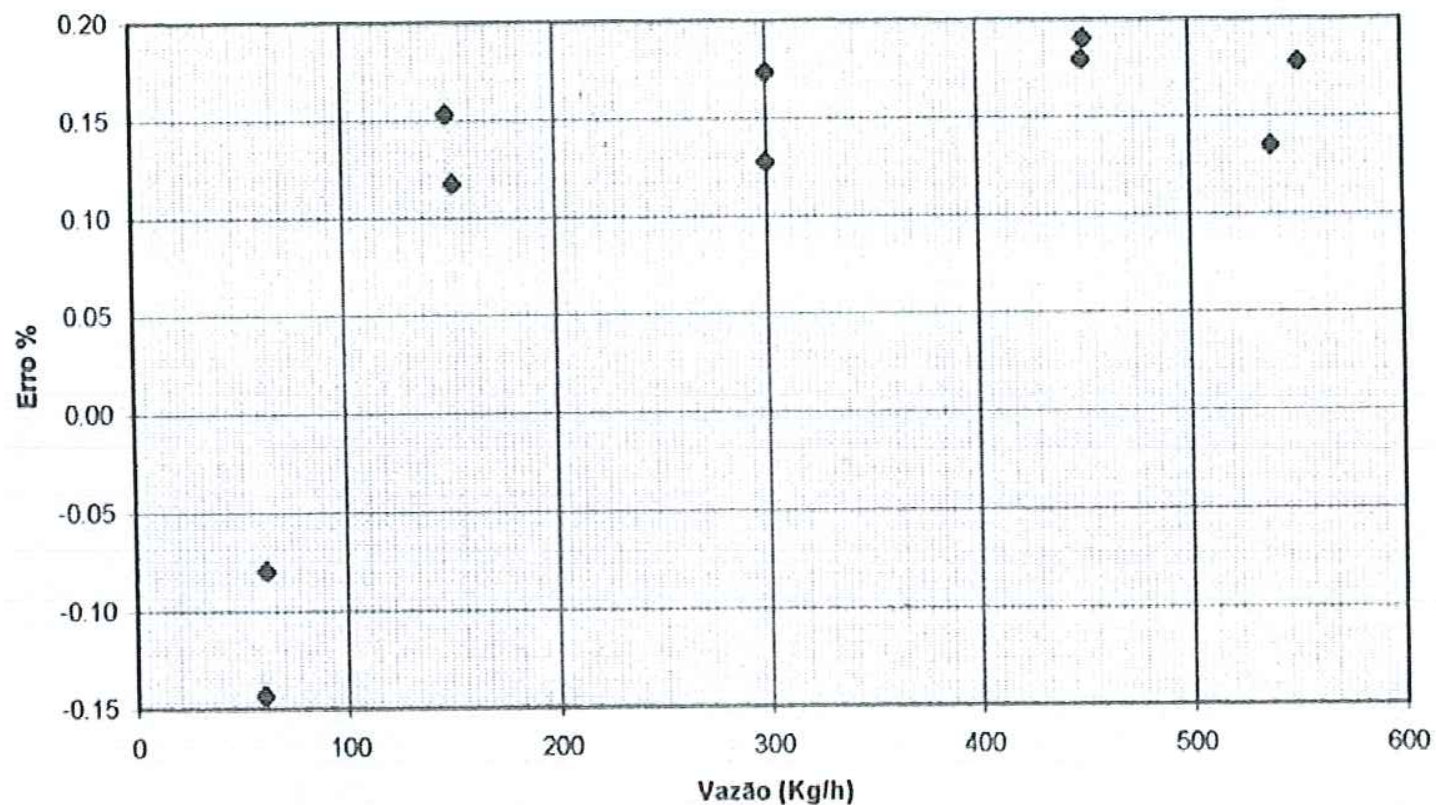

Figura AI.4 Curva de calibração do medidor de vazão.

Tabela AI.4 Dados medidos pelo medidor de Vazão e o erro proporcionado.

\begin{tabular}{|c|c|c|c|}
\hline \multicolumn{2}{|c|}{ Resultados Ordenados } & \multicolumn{2}{|l|}{ Mádias } \\
\hline $\begin{array}{l}\text { Vazăo } \\
(\mathrm{kg} / \mathrm{h})\end{array}$ & $\begin{array}{l}\text { Érro } \\
(\%)\end{array}$ & $\begin{array}{c}\text { Vazảo } \\
\text { ind. } \\
\text { (kg/h) }\end{array}$ & $\begin{array}{l}\text { Êrro } \\
(\%)\end{array}$ \\
\hline 59.89 & -0.14 & & \\
\hline 61.53 & $=0.08$ & 60.71 & -0.11 \\
\hline 149.05 & 0.15 & & \\
\hline 151.77 & 0.12 & 150.41 & 0.14 \\
\hline 299.60 & 0.13 & & \\
\hline 300.45 & 0.17 & 300.02 & 0.15 \\
\hline 449.27 & 0.18 & & \\
\hline 450.19 & 0.19 & 449.73 & 0.18 \\
\hline 537.96 & 0.13 & & \\
\hline 551.37 & 0.18 & 544.66 & 0.16 \\
\hline
\end{tabular}




\section{APÊNDICE - II $\rightarrow$ FOTOS DOS PADRÕES DE ESCOAMENTO}

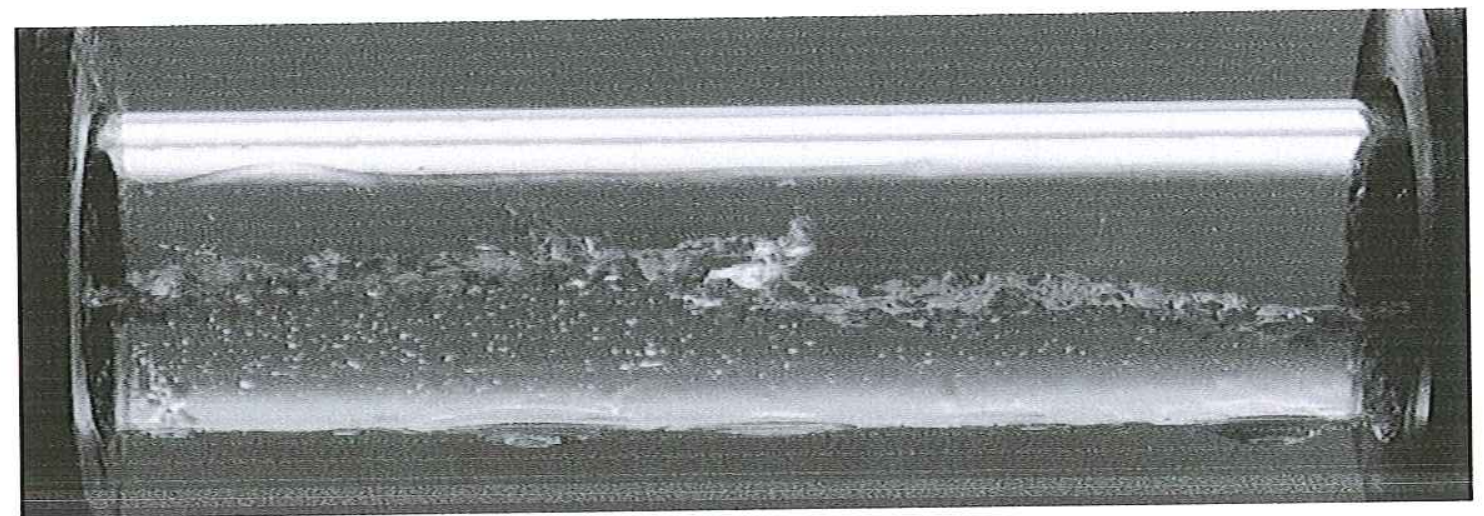

Figura AII.1 Padrão de escoamento em Ondulado. Detalhe de uma onda sendo rompida pelo vapor. $\mathrm{R}-134 \mathrm{a}$ e $\mathrm{D}_{\mathrm{i}}=17,4 \mathrm{~mm}$.

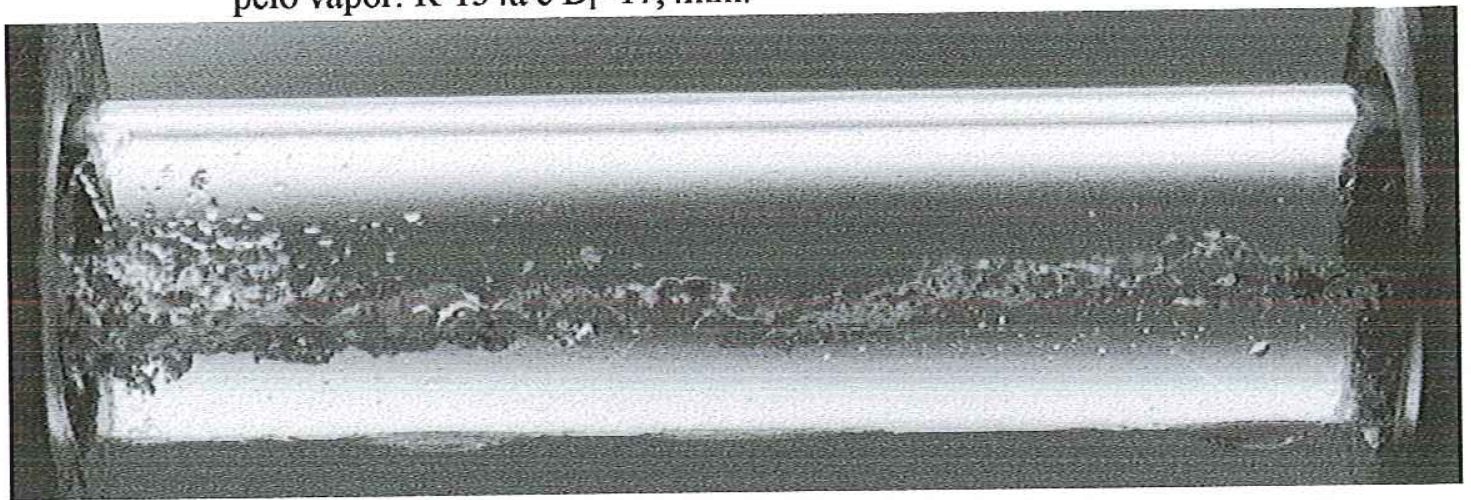

Figura A.II.2 Padrão de escoamento Ondulado. Detalhe de uma onda sendo rompida pelo vapor na entrada do visor. $R-134 a$ e $D_{i}=17,4 \mathrm{~mm}$.

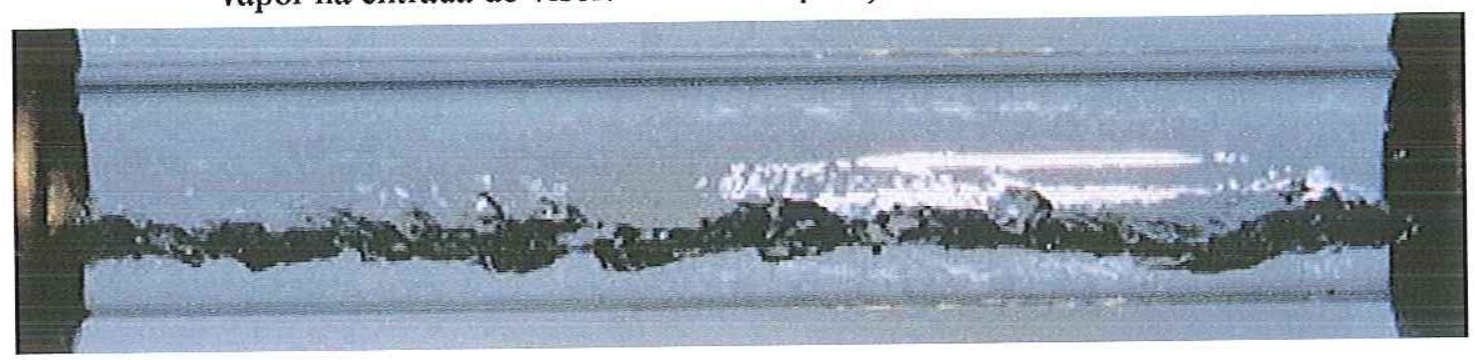

Figura AII.3 Padrão de escoamento Ondulado. R134a e $\mathrm{D}_{\mathrm{i}}=12,7 \mathrm{~mm}$. 


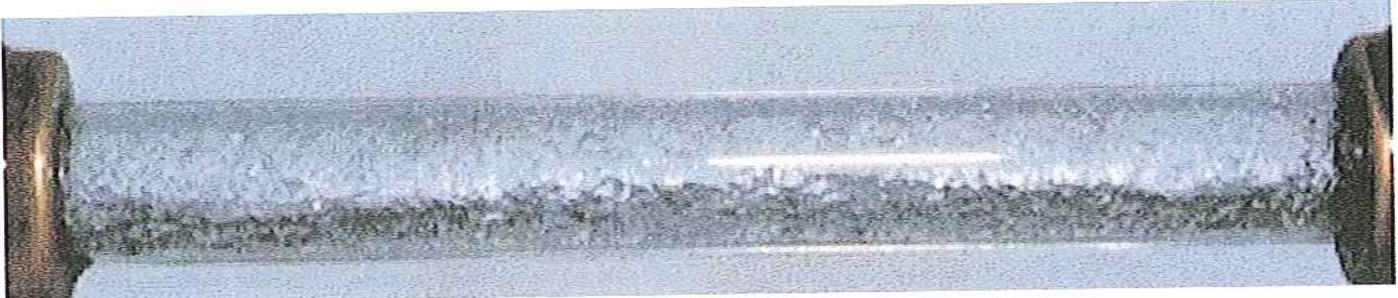

Figura AII.4 Padrão de escoamento Anular. R134a e $D_{\mathrm{i}}=8,76 \mathrm{~mm}$.

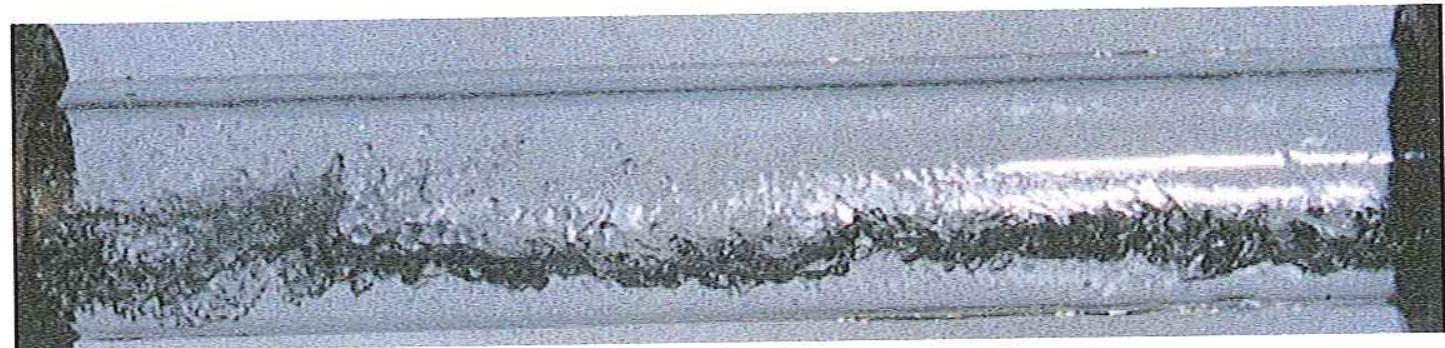

Figura AII.5 Padrão de escoamento Intermitente. Detalhe do rompimento de uma onda de grande amplitude. R134a e $\mathrm{D}_{\mathrm{i}}=12,7 \mathrm{~mm}$.

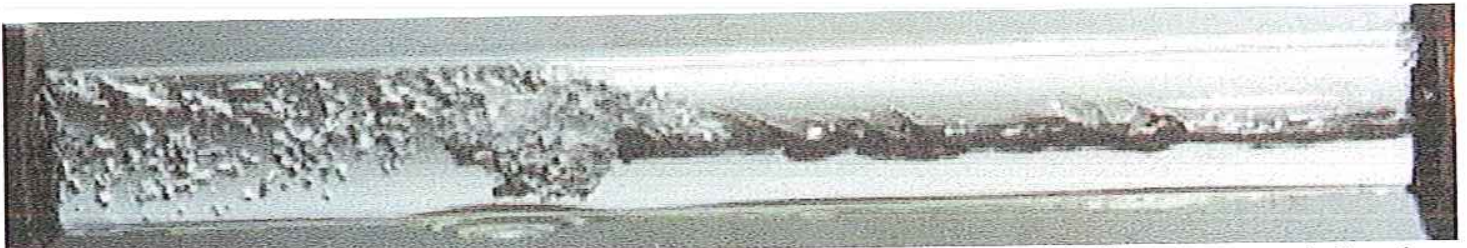

Figura AII.6 Padrão de escoamento Estratificado Ondulado. Detalhe de um pistão de líquido: R134a e $\mathrm{D}_{\mathrm{i}}=8,76 \mathrm{~mm}$.

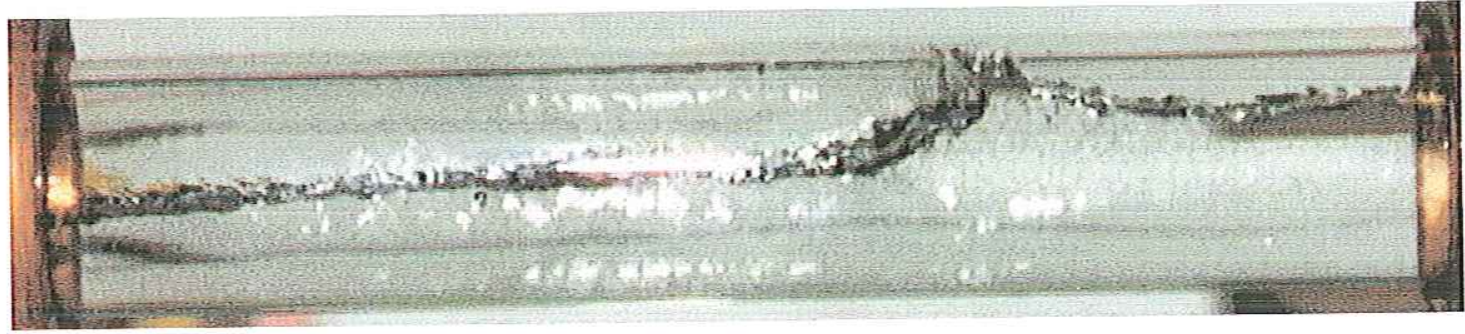

Figura AII.7 Padrão de escoamento Intermitente, ilustrando uma onda de grande amplitude. R134a e $D_{i}=12,7 \mathrm{~mm}$.

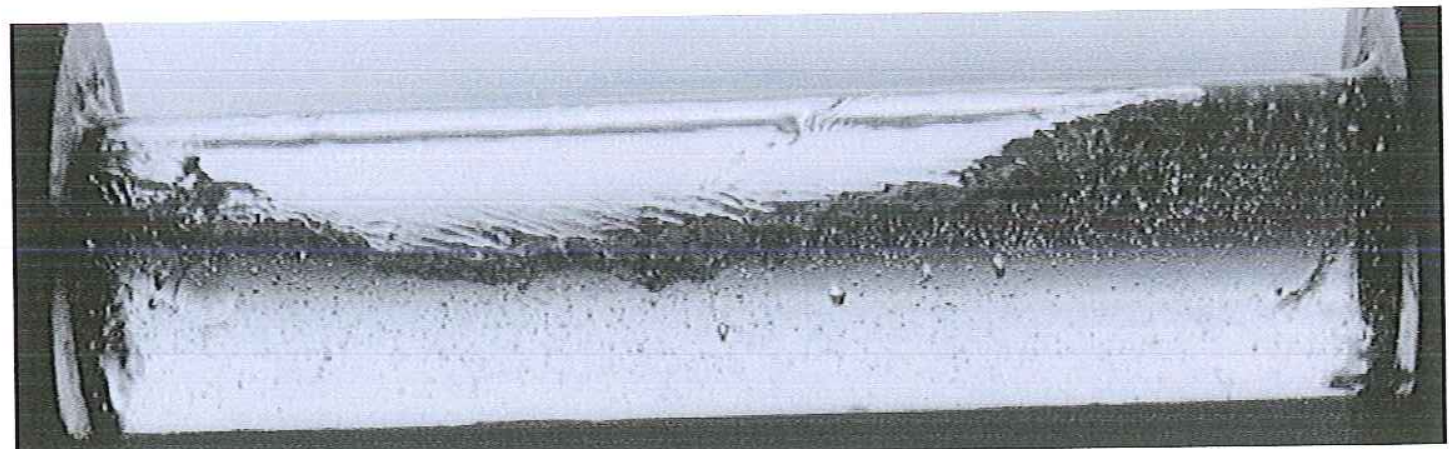

Figura AII.8 Padrão de escoamento Intermitente, ilustrando uma onda de grande amplitude. R134a e $\mathrm{D}_{\mathrm{i}}=17,4 \mathrm{~mm}$. 


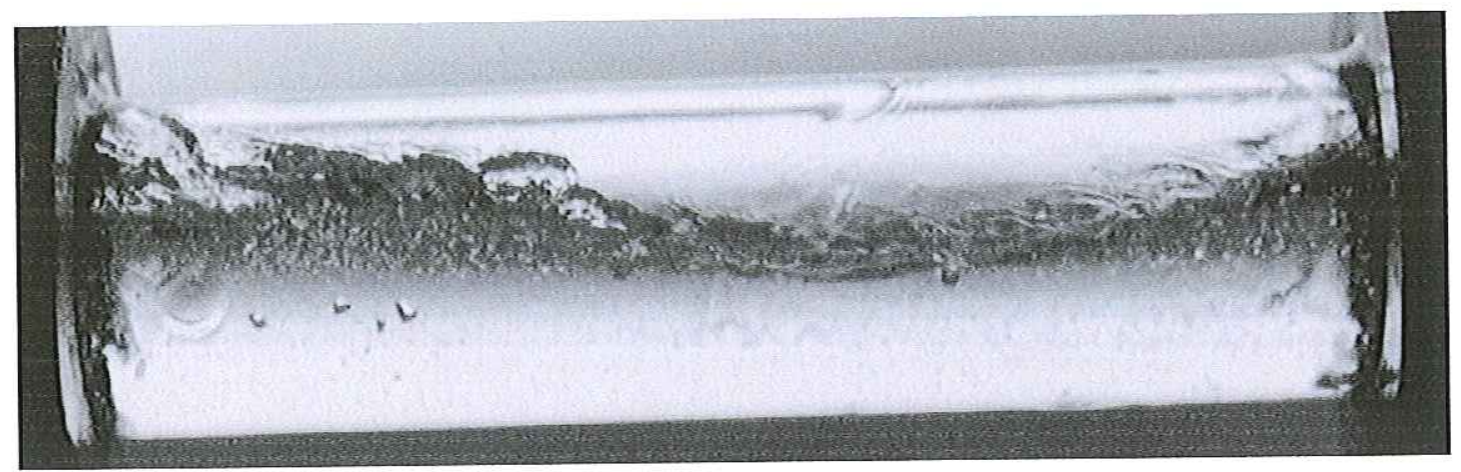

Figura AII.9 Padrão de escoamento Intermitente, ilustrando uma onda de grande amplitude na entrada do visor. $\mathrm{R} 134 \mathrm{a}$ e $\mathrm{D}_{\mathrm{i}}=17,4 \mathrm{~mm}$.

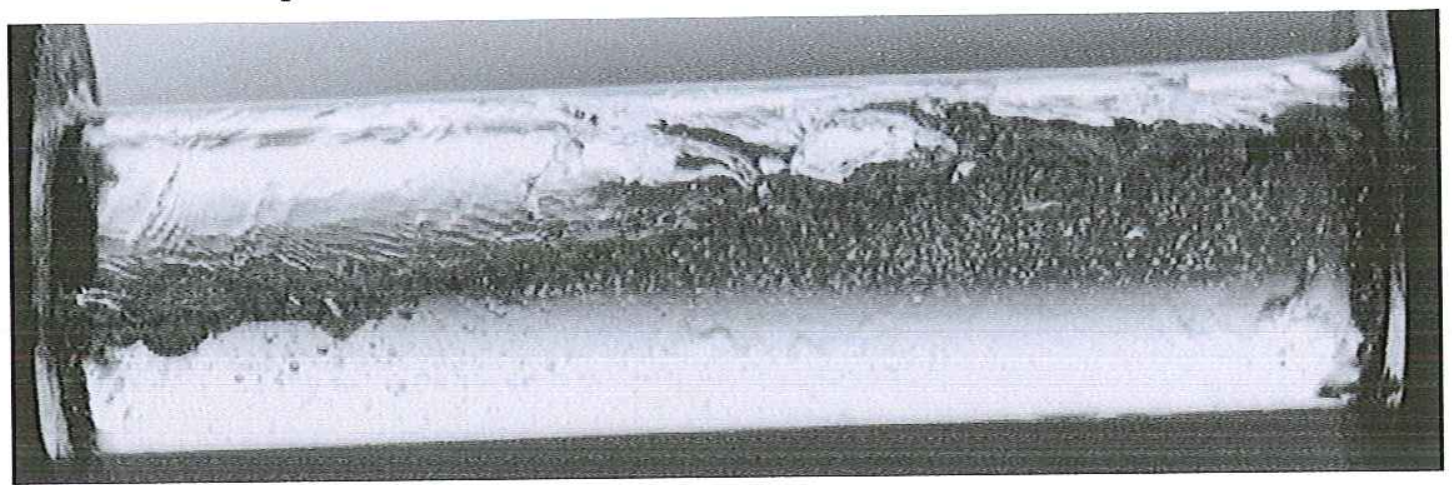

Figura AII.10Padrão de escoamento Intermitente, ilustrando o momento que uma onda de grande amplitude atinge a região superior do tubo. $\mathrm{R} 134 \mathrm{a}$ e $\mathrm{D}_{\mathrm{i}}=17,4 \mathrm{~mm}$.

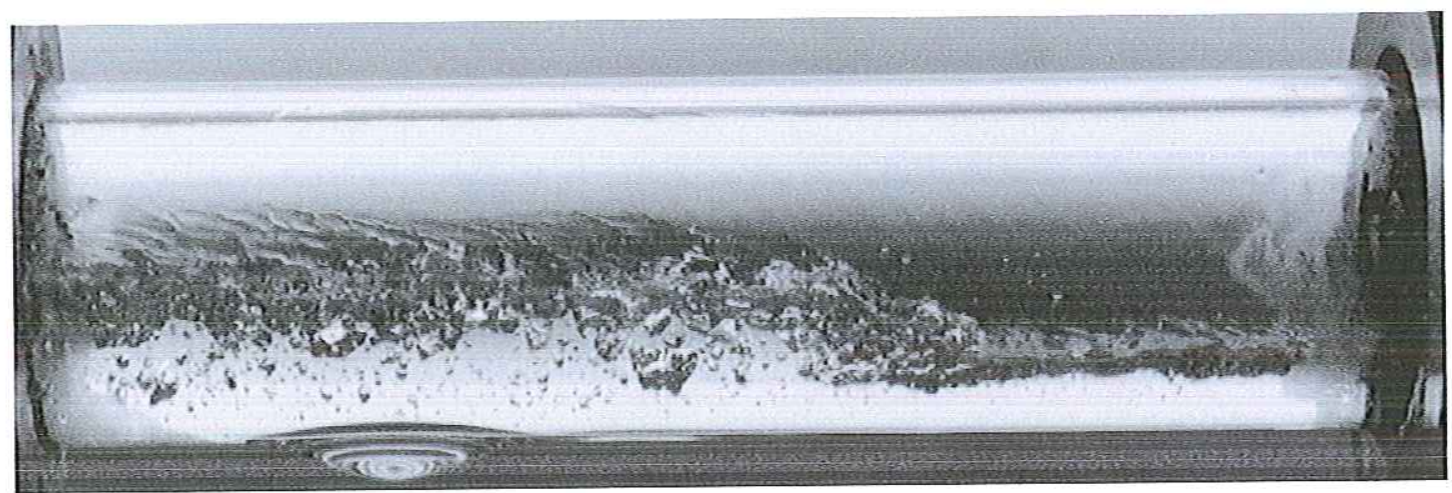

Figura AII.11 Padrão de escoamento Ondulado, ilustrando as instabilidades hidrodinâmicas do escoamento. R134a e $\mathrm{D}_{\mathrm{i}}=17,4 \mathrm{~mm}$. 


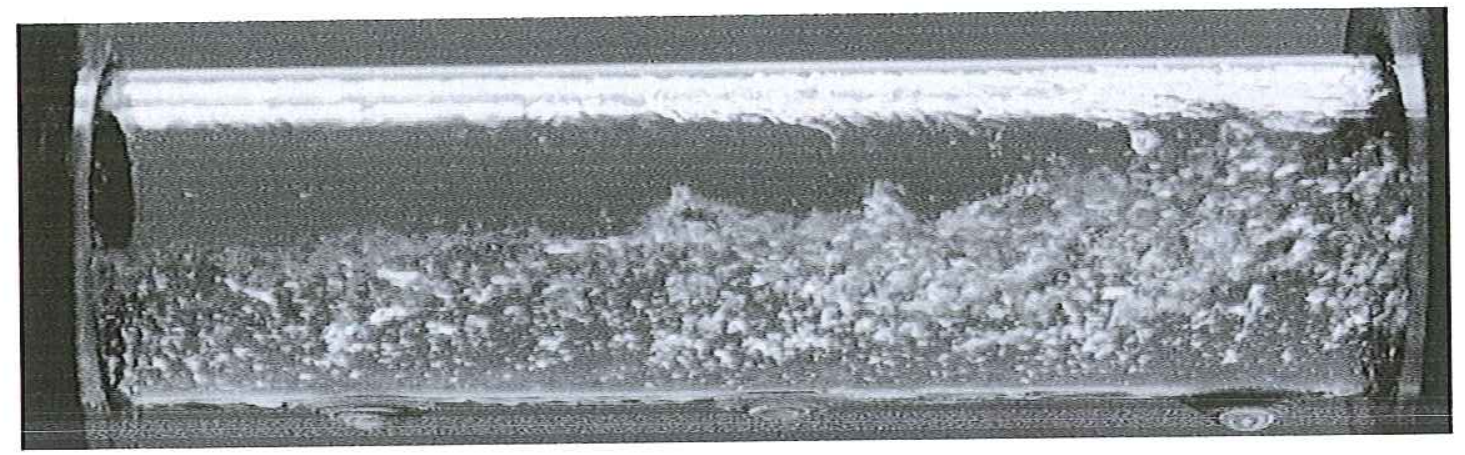

Figura AII.12 Padrão de escoamento Ondulado, ilustrando o momento da passagem de um pistão de líquido. R134a e $\mathrm{D}_{\mathrm{i}}=17,4 \mathrm{~mm}$.

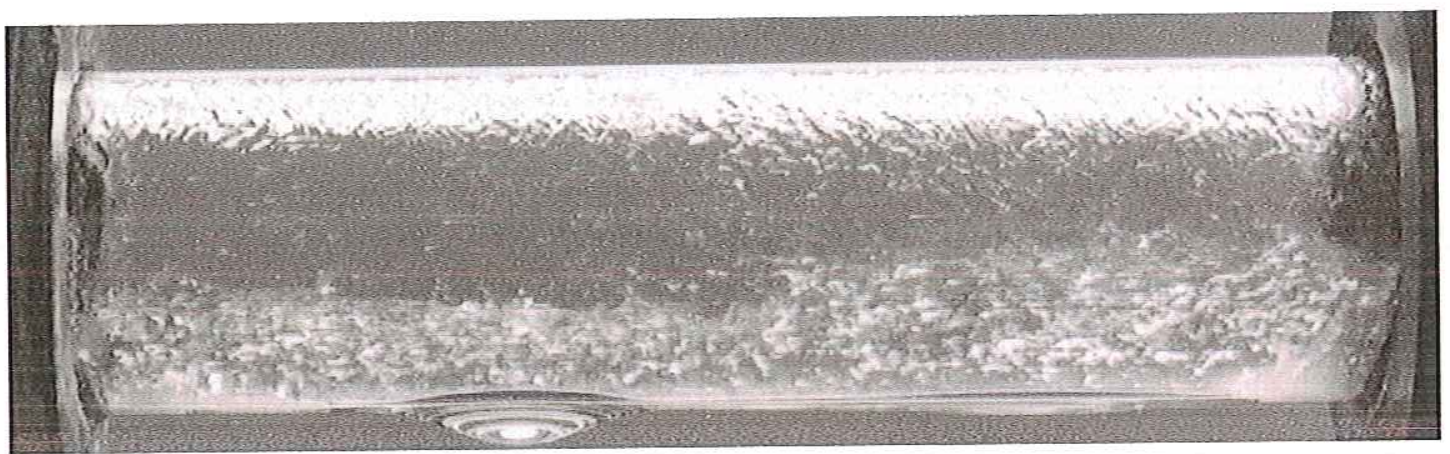

Figura AII.13 Padrão de escoamento Anular, com a espessura do filme de líquido maior na região inferior do tubo. $\mathrm{R} 134 \mathrm{a}$ e $\mathrm{D}_{\mathrm{i}}=17,4 \mathrm{~mm}$.

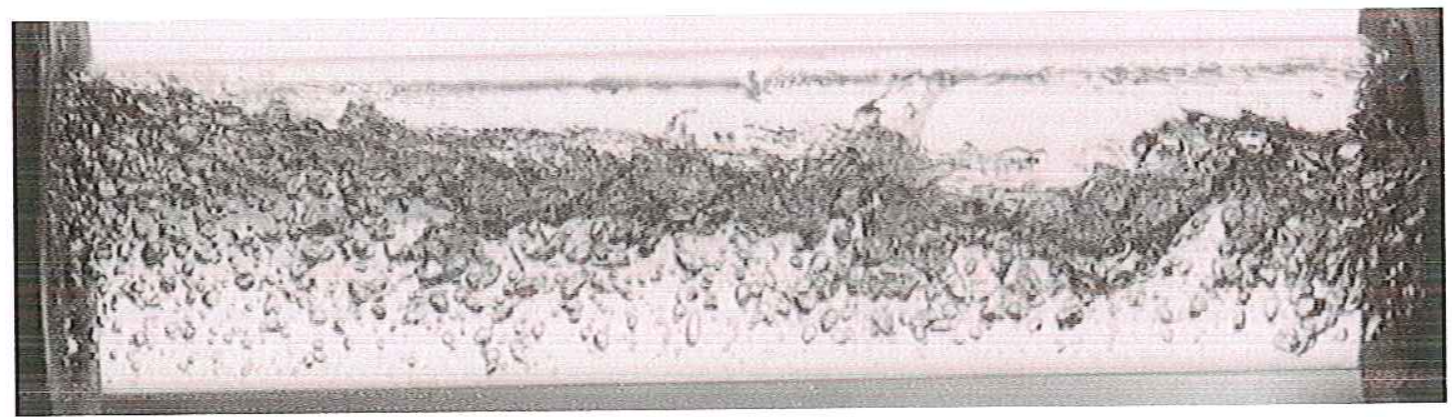

Figura AII.14 Padrão de escoamento Intermitente, ilustrando as instabilidades hidrodinâmicas do escoamento. R134a e $\mathrm{D}_{\mathrm{i}}=17,4 \mathrm{~mm}$.

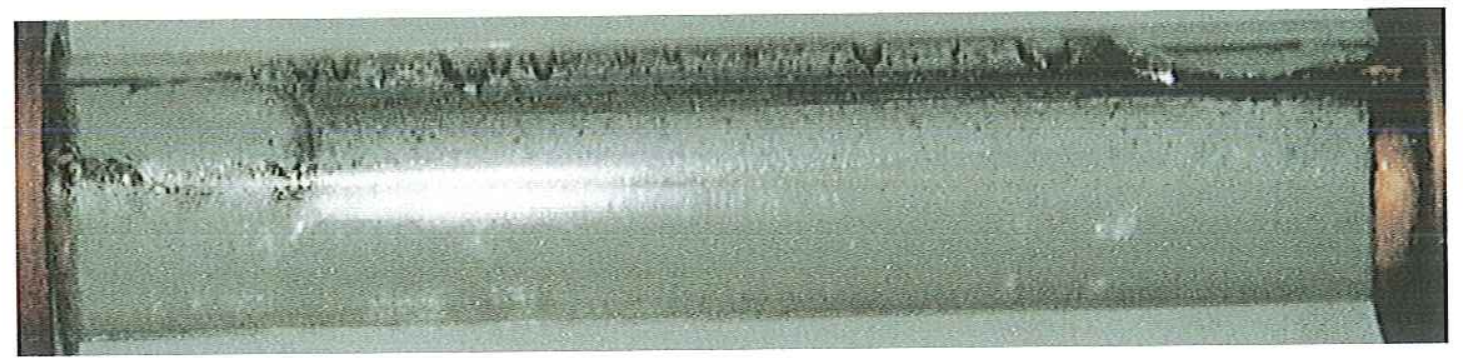

Figura AII.15 Transição do padrão $\mathrm{cm}$ Bolhas para o Pistonado. R134a e $\mathrm{D}_{\mathrm{i}}=12,7 \mathrm{~mm}$. 


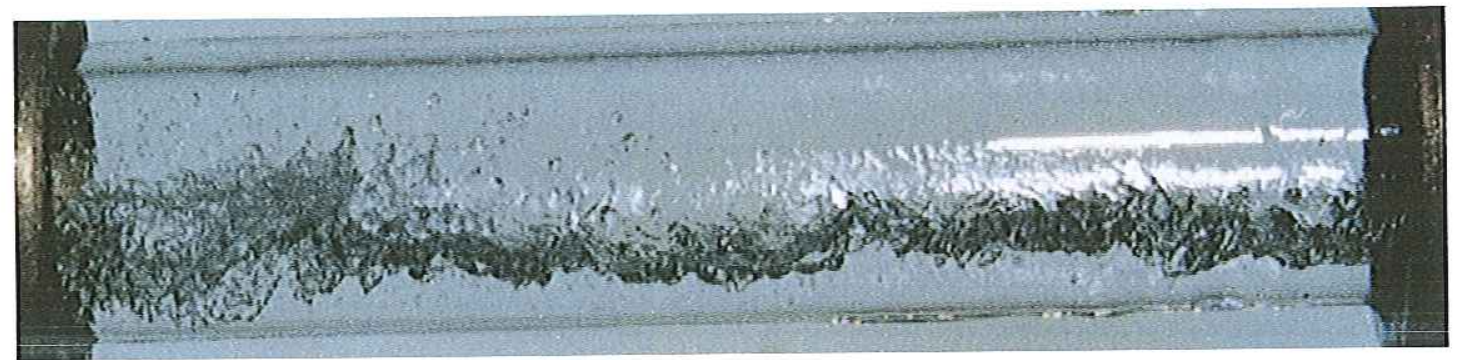

Figura AII.16 Padrão de escoamento Ondulado, Detalhe do rompimento de uma onda de grande amplitude. $\mathrm{R} 134 \mathrm{a}$ e $\mathrm{D}_{\mathrm{i}}=12,7 \mathrm{~mm}$.

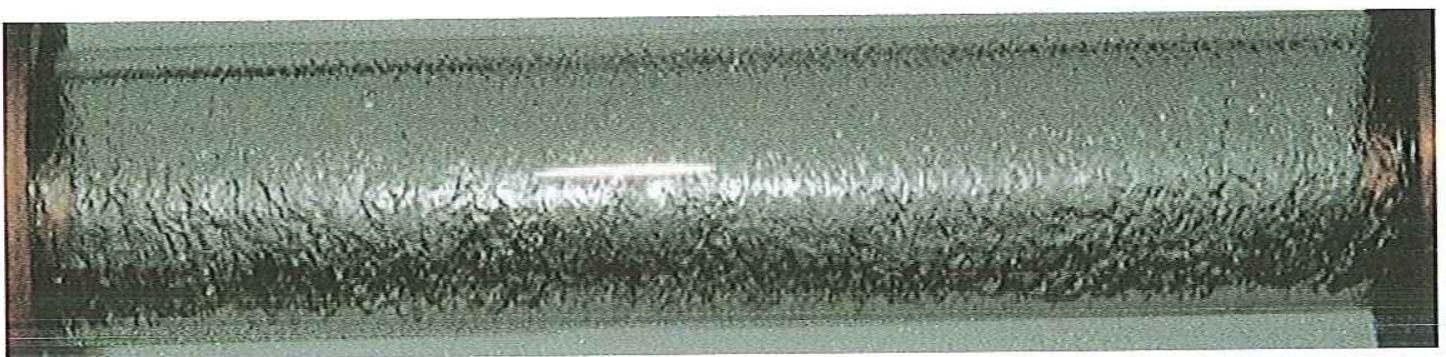

Figura AII.17Padrão de escoamento Anular, com a espessura do filme de líquido maior na região inferior do tubo. $\mathrm{R} 134 \mathrm{a}$ e $\mathrm{D}_{\mathrm{i}}=12,7 \mathrm{~mm}$.

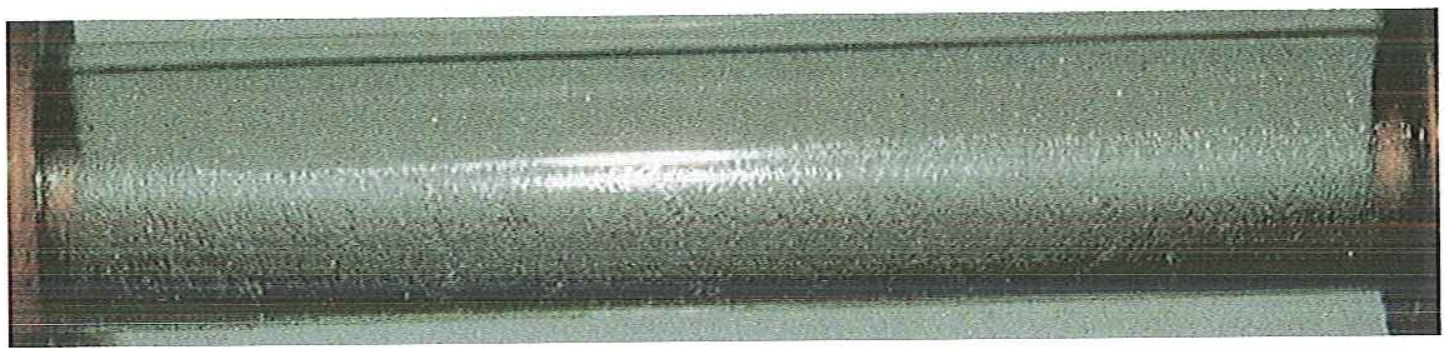

Figura AII.18 Padrão de escoamento Anular, com menor espessura do filme de líquido que a Fig. AII.17. R134a e $D_{i}=12,7 \mathrm{~mm}$.

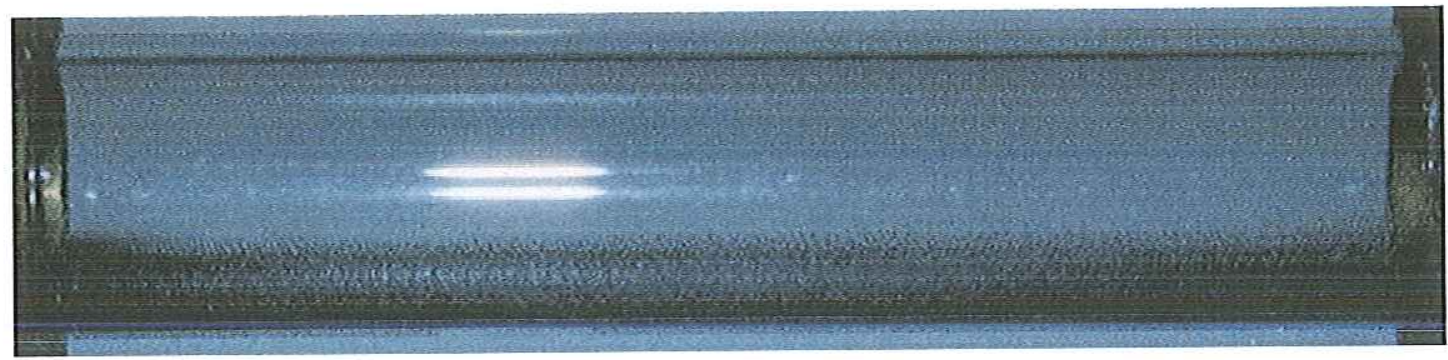

Figura AII.19Transição do padrão de escoamento Anular para Névoa. Detalhe da espessura do filme de líquido na região inferior do tubo. R134a e $\mathrm{D}_{\mathrm{i}}=12,7 \mathrm{~mm}$. 